Christoph Chlosta und Matthias Jung (Hg.)

\title{
DaF integriert
}

\section{Literatur - Medien - Ausbildung}

36. Jahrestagung des Fachverbands Deutsch als Fremdsprache an der Heinrich-Heine-Universität Düsseldorf 2008

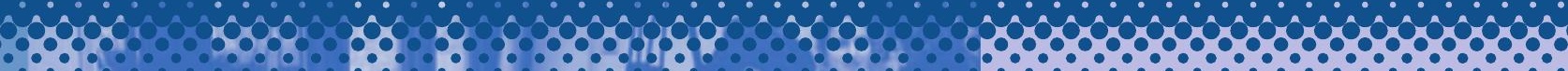

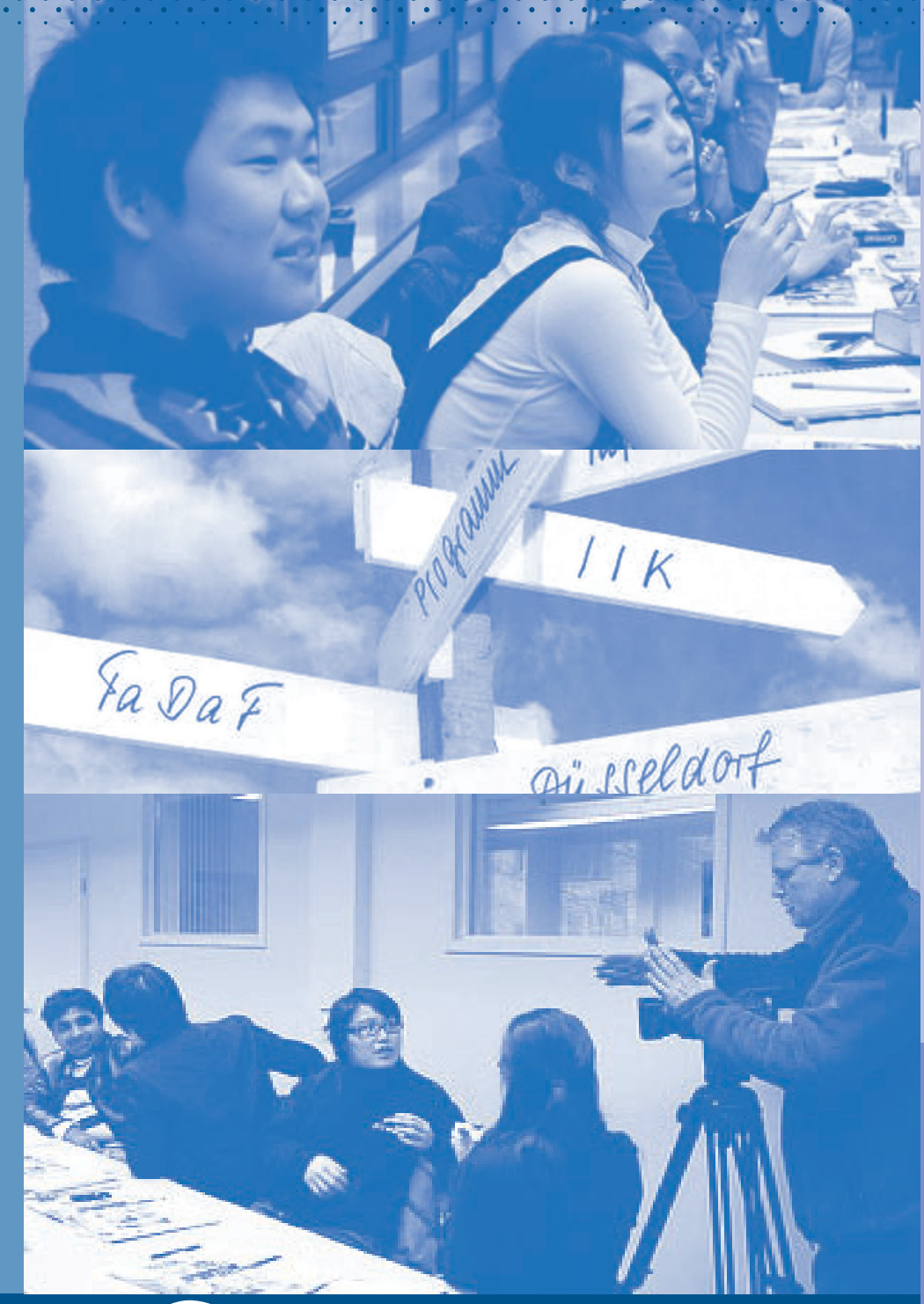

Band 81

Materialien

Deutsch als Fremdsprache

\section{fadaf}



Christoph Chlosta, Matthias Jung (Hg.)

$\mathrm{DaF}$ integriert

This work is licensed under the

Creative Commons License 3.0 "by-nd", allowing you to download, distribute and print the document in a few copies for private or educational use, given that the document stays unchanged and the creator is mentioned.

You are not allowed to sell copies of the free version.

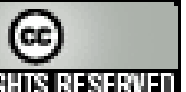

SORERIGHISRESERVED 
erschienen als Band 81 in der Reihe „Materialien Deutsch als Fremdsprache“ in den Universitätsdrucken im Universitätsverlag Göttingen 2010 
Christoph Chlosta und

Matthias Jung (Hg.)

\section{DaF integriert}

Literatur - Medien - Ausbildung

36. Jahrestagung des Fachverbandes

Deutsch als Fremdsprache 2008

an der Heinrich-Heine-Universität

Düsseldorf

Materialien

Deutsch als Fremdsprache

Band 81

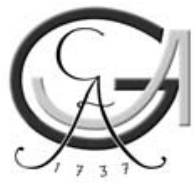

Universitätsverlag Göttingen 2010 


\section{Bibliographische Information der Deutschen Nationalbibliothek}

Die Deutsche Nationalbibliothek verzeichnet diese Publikation in der Deutschen Nationalbibliographie; detaillierte bibliographische Daten sind im Internet über $<$ http://dnb.ddb.de $>$ abrufbar.

Die „Materialien Deutsch als Fremdsprache“ sind eine Reihe des Fachverbands Deutsch als Fremdsprache e.V. $(\mathrm{FaDaF})$, in der Tagungsergebnisse, Dissertationen und andere wichtige Einzeldarstellungen aus dem Bereich Deutsch als Fremdsprache veröffentlicht werden.

http://www.fadaf.de/de/Publikationen/mat_daf/

\section{fadaf}

Schriftleitung: Annett Eichstaedt; Annegret Middeke

Dieses Buch ist nach einer Schutzfrist auch als freie Onlineversion über die Homepage des Verlags sowie über den OPAC der Niedersächsischen Staats- und Universitätsbibliothek (http://www.sub.uni-goettingen.de) erreichbar und darf gelesen, heruntergeladen sowie als Privatkopie ausgedruckt werden. Es gelten die

Lizenzbestimmungen der Onlineversion. Es ist nicht gestattet, Kopien oder gedruckte Fassungen der freien Onlineversion zu veräußern.

Satz und Layout: Beate Gorny, Anne Wessner

Korrektorat: Beate Gorny, Neli Chakarova

Umschlaggestaltung: Jutta Pabst

Fotos: http://www.flickr.com/photos/iik-duesseldorf/

(C) 2010 Universitätsverlag Göttingen

http:/ / univerlag.uni-goettingen.de

ISBN: 978-3-941875-05-0

ISSN: $1866-8283$ 


\section{Inhalt}

9RZRWW IX IX

向

Literatur, Theater und Film im DaF-Unterricht

Peter Dammeier \& Wolf-Dirk Skiba 1

Einführender Bericht

Simone Schiedermair

Texte zur Fremde - Ein Projekt zum Sprachenlernen mit literarischem

Übungsmaterial

Amina Arfaoui

Arbeit mit dramatischen Texten im Fremdsprachenunterricht Deutsch am Beispiel von Friedrich Dürrenmatts „Der Besuch der alten Dame“ und „Die Physiker“"

Karl Esselborn

Lust auf Literatur. Zugänge zur deutschsprachigen Gegenwartsliteratur für DaF-Lerner

Anke Stöver-Blahak

Die Entwicklung von Sprech- und Vortragskompetenzen bei der Arbeit mit Gedichten im DaF-Unterricht. Ein Beitrag aus der Praxis und der Forschung

Susanne Horstmann

Förderung von interkultureller Kompetenz durch Auseinandersetzung mit Filmen?

Sebastian Chudak

Arbeit mit Filmen im DaF-Unterricht als eine Möglichkeit der Förderung der interkulturellen Kompetenz auf der Fortgeschrittenenstufe

Oliver Eß

Aschenputtel in China - eine Theaterinszenierung im DaF-Unterricht

Nils Bernstein

Phraseologismen im Fremdsprachenunterricht. Didaktisierungsvorschläge für den Umgang mit festen Mehrwortverbindungen in literarischen Texten 


\section{Mediengestütztes Lernen}

Uwe Koreik \& Martin Lange \& Timo van Treeck

Einführender Bericht

Dietmar Rösler

Deutsch als Fremdsprache mit digitalen Medien - Versuch einer Zwischenbilanz im Jahr 2008

Carola Strobl

Blended Learning im universitären Fachsprachenunterricht: eine Fallstudie im Fach Wirtschaftsdeutsch an der Universität Gent

Karin Madlener

Computergestützte Anwendungen in Spracherwerb und Spracherwerbsforschung: Die „Multimedia-Chunks für Deutsch als Fremdsprache“

Sylwia Adamczak-Krysztofowicz \& Antje Stork

Podcastgestützte integrative Hörverstehensentwicklung in universitären Sommerdeutschkursen

Rüdiger Schreiber

Aktionsforschung zum Einsatz von Podcasts und MP3 als Interaktionsmedium zwischen Dozenten und Lernenden

Jörg Roche

Klinisch getestet: Zur Erforschung und Evaluation von e-Mehrwerten

\section{Lehreraus- und -fortbildung}

Ernst Apeltauer \& Susanne Duxa \& Andreas Westhofen

Einführender Bericht

Magdalena Michalak

Sprachförderung Deutsch als Zweitsprache - Ja, aber von wem?

Rupprecht S. Baur

Mehrsprachige Schüler - einsprachige Lehrer?

Bettina Seipp

Sprachförderkompetenz Deutsch als Zweitsprache im Unterricht aller Fächer - Übertragung des Projekts „Förderunterricht für Kinder und Jugendliche mit Migrationshintergrund“ der Stiftung Mercator in die neue Lehrerbildung in Nordrhein-Westfalen

Udo Ohm

Fachliche Schwierigkeiten sind sprachliche Schwierigkeiten. Müssen

Fachlehrer und Ausbilder auch Sprachlehrer sein? 
Joachim Schlabach \& Sabine Grasz \& Edeltraud Sormunen

QualiDaF - Qualitätssicherung im fachbezogenen Deutsch als Fremdsprache-Unterricht mündliche Kommunikation

Carmen Schier

„Alle anders, alle gleich?“ - Herausforderungen und Gestaltungsmög-

lichkeiten germanistischer Studiengänge nach Bologna

Thesen zur Podiumsdiskussion

Magdalena Michalak

Udo Ohm

Bettina Seipp

Edwin Stiller

\section{Integrationskurse}

Silvia Demmig \& Susan Kaufmann

Einführender Bericht

Silvia Demmig \& Susan Kaufmann

Das Rahmencurriculum für die Integrationskurse

Anja Ucharim

„In meiner Heimat war ich Jurist [...] und jetzt fahre ich Taxi.“ Die

diskursive Konstruktion der Arbeitswelt in Lehrwerken für Integrationskurse

Magdalena Michalak

„Deutsch kann ich nur mit einem Lehrbuch lernen.“ Wege zum informellen Spracherwerb

Petra Szablewski-Çavuş

Qualität im berufsbezogenen Deutsch als Zweitsprache-Unterricht.

Kriterien und Umsetzungsstrategien

Andrea Daase

Integrationskurse - Was kommt danach?

Silke Ghobeyshi

SprachBarriere. Eine Untersuchung unter Teilnehmern der Sprachprüfung nach $\int 30$, Abs. I, Nr. 2 AufenthaltG. 


\section{Forum „Unterrichtspraxis“}

Christian Krekeler \& Rolf Rodenbeck

Einführender Bericht

Rolf Rodenbeck

Deutsch als Wirtschafts- und Geschäftssprache: Lehrforschung und Curriculumentwicklung

Stanka Murdsheva

„Mit Witzen Deutsch lernen?“ - „Mach doch keine Witze!“ Humor im interkulturellen DaF-Unterricht aller sprachlichen Stufen

Renata Rozalowska-Żądło

Projektarbeit im landeskundlichen Deutsch als Fremdsprache-Unterricht am Beispiel des Projekts „Österreich in Polen“

\section{Forum „Beruf und Qualifikation“}

Matthias Jung \& Annegret Middeke

Einführender Bericht

Claudia Riemer

Erste Schritte empirischer Forschung: Themenfindung, Forschungsplanung, forschungsmethodische Entscheidungen

\section{Matthias Jung}

DaF-Ausbildung am Arbeitsmarkt vorbei? Bestandsaufnahme und Vorschläge 


\section{Vorwort}

Vom 22. bis 24. Mai 2008 fand an der Heinrich-Heine-Universität Düsseldorf die 36. Jahrestagung des Fachverbandes Deutsch als Fremdsprache statt, organisiert vom Institut für Internationale Kommunikation (IIK Düsseldorf e.V.). Unter dem Motto „daf integriert. literatur : medien : ausbildung“ wurden vier Themenschwerpunkte - (1) Literatur, Theater und Film im DaF-Unterricht, (2) Mediengestütztes Lernen, (3) Lehreraus- und -fortbildung, (4) Integrationskurse - sowie das Forum „Unterrichtspraxis“ und das Forum „Beruf und Qualifizierung“ angeboten. Der Sammelband enthält neben Beiträgen aus den Themenschwerpunkten und Foren auch den Plenarvortrag von Prof. Dr. Dietmar Rösler „DaF mit digitalen Medien - wo stehen wir 2008?““, der dem Themenschwerpunkt 2 zugeordnet ist. Der Plenarvortrag von Werner Wnendt, Leiter der Abteilung Kultur und Kommunikation im Auswärtigen Amt, zum Thema „Auswärtige Kultur- und Bildungspolitik und die deutsche Sprache“, wurde bereits in Info DaF 5 (2008) veröffentlicht. Dr. Werner Roggausch zog die Bewahrung der Mündlichkeit seines Plenarvortrages zum Thema „Deutsch als Fremdsprache: Berufsbezug, Sprachenpolitik, Forschung - Perspektiven für ein internationales Fach“ vor, so dass dieser weder hier noch an anderer Stelle publiziert werden konnte.

Im Themenschwerpunkt 1 ging es darum, über den Einsatz von Film, Theater, Literatur Materialien im DaF- und DaZ-Unterricht nicht nur die Sprachkompetenz, sondern auch die Sensibilität für ästhetische Formen, die Interpretationsfähigkeit und die Medienkompetenz der Lerner zu fördern. Mit „,mediengestütztem Lernen“ beschäftigte sich der Themenschwerpunkt 2, in dem Möglichkeiten und Gefahren, Fortschritt und Grenzen virtueller Lernangebote ausgelotet wurden. Der Themenschwerpunkt 3 „Lehreraus- und -fortbildung" umfasst Beiträge aus den Bereichen: (a) Erstausbildung im Rahmen von Studiengängen $\mathrm{DaF} / \mathrm{DaZ}$ in deutschsprachigen Ländern bzw. der Schullehrerausbildung in den übrigen Ländern, (b) zertifizierte, nachträgliche, im Vergleich 
zu einem grundständigen DaF-Studium verkürzte Fortbildung nicht einschlägig ausgebildeter Lehrkräfte zu DaF- oder DaZ-Lehrern, (c) Erweiterung der Kompetenzen von Fachlehrern um DaF-/DaZ-Kenntnisse, (d) permanente Weiterbildung bereits qualifizierter DaF-/DaZ-Lehrkräfte zur Aktualisierung ihrer Kompetenzen. Die Beiträge des Themenschwerpunkts 4 sind sowohl Forschungsprojekte als auch wissenschaftlich begleitete Beispiele aus der Praxis der „Integrationskurse“. Das Forum „Unterrichtspraxis“ versteht sich traditionell als eine von den Themenschwerpunkten unabhängige Plattform „,aus der Praxis für die Praxis“. Es werden neue Kurserfahrungen und eigene, unveröffentlichte Unterrichtsmaterialien vorgestellt. Das relativ junge Forum „Beruf und Qualifizierung“، das in Düsseldorf erstmals durchgehend besetzt war, hingegen bietet Kolleginnen und Kollegen, die bereits in DaF-bezogenen Berufsfeldern tätig sind oder dort demnächst arbeiten wollen, Informationen und Weiterbildungsveranstaltungen zur Reflexion und Verbesserung ihrer beruflichen Situation.

Wie die Evaluation der Jahrestagung zeigt, wurde diese Vielfalt der thematischen Angebote von den Tagungsteilnehmern durchweg mit mindestens ,gut“ bewertet, auch wenn sich nicht jeder durch alles angesprochen fühlte, geschweige denn an allem teilnehmen konnte und wollte. Gelobt wurden insbesondere die Freundlichkeit und Hilfsbereitschaft der Tagungsorganisatoren, und so sei an dieser Stelle den Themenschwerpunktbetreuern und dem Team des IIK Düsseldorf, vor allem dem Tagungsmanager Stephan Semmler, herzlich gedankt. Auch die Aussteller und darunter vor allem die Verlage haben durch ihre Präsenz und ihr Sponsoring wesentlich zum Gelingen und zur Finanzierbarkeit der Tagung beigetragen. Ein besonderer Dank gilt natürlich auch dem DAAD für die großzügige finanzielle Unterstützung der Veranstaltung.

\begin{tabular}{|l|l|}
\hline Themenschwerpunkt/Forum & TSP-Betreuer \\
\hline TSP 1 Literatur, Medien, Theater und Film & $\begin{array}{l}\text { Peter Dammeier, Dr. Dirk-Wolf Skiba } \\
\text { Prof. Dr. Uwe Koreik, Martin Lange, } \\
\text { Timo van Treeck }\end{array}$ \\
TSP 3 Lehreraus- und -fortbildung & $\begin{array}{l}\text { Prof. Dr. Ernst Apeltauer, Dr. Susanne } \\
\text { Duxa, Andreas Westhofen } \\
\text { PD Dr. Petra Buchwald, Dr. Silvia }\end{array}$ \\
TSP 4 Integrationskurse & $\begin{array}{l}\text { Demmig, Susan Kaufmann } \\
\text { Prof. Dr. Christian Krekeler, Rolf } \\
\text { Rodenbeck }\end{array}$ \\
Forum A „Unterricht“ & $\begin{array}{l}\text { Dr. Matthias Jung, Dr. Annegret } \\
\text { Middeke }\end{array}$ \\
\hline
\end{tabular}

Die FaDaF-Vertreter aus den Betreuerteams der Themenschwerpunkte und Foren haben die Beiträge gesammelt und die Auswahl für die Veröffentlichung getroffen, sie haben die Korrespondenzen mit den Autoren geführt und ihre Texte redigiert. Christoph Chlosta und Beate Gorny (beide Universität Duisburg-Essen) haben nach weiteren 
Korrekturdurchgängen und Formatierungsarbeiten zügig die Druckvorlage für das Buch vorgelegt. Die Endfassung, die einige verspätete Änderungswünsche von Auto-

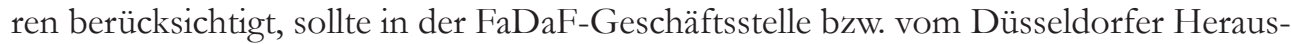
geber angefertigt werden. Dass die Druckvorlage mit dem Profi-DesktoppublishingProgramm InDesign erstellt worden war, führte bei dieser Übergabe zu einer Reihe von Kompatibilitätsfragen. Die Zeit, in der die technischen Probleme behoben wurden, diente gleichzeitig zur erneuten Überarbeitung und Ergänzung der Druckvorlage, die diesmal Anne Wessner M.A. (Leipzig) durchgeführt hat.

Vor allem Christoph Chlosta, Beate Gorny und Anne Wessner bin ich zu großem Dank verpflichtet, aber auch Neli Chakarova M.A. (Göttingen), die sämtliche Quellenangaben überprüft und gegebenenfalls korrigiert hat. Dr. Annegret Middeke (Göttingen), die den Band von Anfang an begleitet hat, war so etwas wie der gute Geist in dessen komplizierter Entstehungsgeschichte und hat viel zur hohen Qualität der Druckvorlage beigetragen.

Matthias Jung für das Herausgeberteam

Düsseldorf im November 2010 



\section{Peter Dammeier \& Wolf-Dirk Skiba}

\section{Themenschwerpunkt Literatur, Theater und Film im DaF-Unterricht - Bericht}

Der Themenschwerpunkt „Literatur, Theater und Film im DaF-Unterricht“ beschäftigte sich mit den Chancen und Grenzen eines DaF-Unterrichts, der von literarischem Übungsmaterial ausgeht und die Weiterentwicklung von Medienkompetenz und Interpretationsfähigkeit zum Ziel hat. Zu unterscheiden war hierbei die Vermittlung von literaturwissenschaftlicher Fachsprache und textanalytischer Fertigkeiten von dem Einsatz von Spielfilmen, Theaterszenen und literarischen Texten als Rede- und Schreibanlässen. Außerdem wurde die Verwendung von Textbeispielen aus den Bereichen Literatur, Theater und Film zur Übung des Lese- oder Hörverstehens oder als Basis für landeskundlich orientierten Sprachunterricht betrachtet. Literarische Medien öffnen Zugänge zur deutschen Kultur und Gesellschaft. In diesem Themenschwerpunkt wurden daher anschauliche Praxisbeispiele, die didaktische Reflexion über die Verwendung fiktionaler Textvorlagen und ästhetischer Medien im DaF-Unterricht sowie Berichte über den Erfolg eines literarisch ausgerichteten Sprachunterrichts vorgestellt. Vorträge zum Einsatz von lyrischen und dramatischen Texten und vor allem von Filmen im DaF-Unterricht standen dabei im Mittelpunkt.

Den Auftakt bildete ein grundlegender Vortrag von Uwe Koreik (Universität Bielefeld) über „Die Bedeutung der Rezeptionsästhetik in Literaturwissenschaft und DaF mit Blick auf Film- und Textrezeption“.

Es folgte die Vorstellung eines Pilotprojekts zum Sprachenlernen mit literarischem Übungsmaterial unter dem Titel „,Texte zur Fremde“ durch Simone Schiedermair (Institut für Deutsch als Fremdsprache/Transnationale Germanistik der LMU München). Im Zentrum ihres Vortrags standen Erläuterungen zum STIBET-Programm des DAAD. Ausgangspunkt ihrer Darstellung waren Beispiele für die Bewältigung von Fremdheitserfahrungen verschiedener ausländischer Besucher Deutschlands (u.a. der japanischen Schriftstellerin Yoko Tawada). Im Weiteren stellte Frau Schiedermair das Konzept dieses Projekts vor und vermittelte anhand konkreter Beispiele aus der Unterrichtspraxis, was ein solcher von literarischen Texten (überwiegend Gedichten) und von Filmen zum Thema „Fremde“ ausgehender Sprachkurs für das Gelingen des Auslandsstudiums in Deutschland leisten kann.

Amina Arfaoui (Faculté Des Lettres, des Arts et des Humanités der Universitãt La Manouba, Tunis) berichtete über ihre Arbeit mit dramatischen Texten in Tunesien im Fremdsprachenunterricht Deutsch am Beispiel von F. Dürrenmatts „Der Besuch der alten Dame“ und „Die Physiker“. Zunächst stellte sie die Verständnisprobleme vor, die aus dem Erfahrungshintergrund und Kenntnisstand Studierender aus einem arabischislamischen Land Nordafrikas entstehen; sie verwies dabei auf die Fülle von Anspie- 
lungen in Dürrenmatts Werken auf Motive der jüdisch-christlichen Tradition wie auch der antiken Mythologie, die den Studierenden in Tunesien nicht ohne Weiteres verständlich seien, ohne die aber ein Textverständnis nicht erfolgreich sein könne. Davon ausgehend erläuterte die Referentin, wie sie vorgegangen ist, um das Interesse der Studierenden für die literarischen Texte zu wecken und es rege zu erhalten.

Karl Esselborn (München) bot unter dem Titel „Lust auf Literatur? Zugänge zur deutschsprachigen Gegenwartsliteratur für DaF-Lerner“ einen Beitrag zu einem eigenen Projekt für eine angeleitete Lektüre literarischer Texte (Lyrik, Kurzprosa). Ausländischen Studierenden wurde über die Instituts-Computer ein selbst gesteuerter Zugang zu einer nach Themenschwerpunkten angeordneten Textsammlung zeitgenössischer Autorinnen und Autoren (mit literaturdidaktischen Einführungen, Lese- und ErschlieBungshilfen) ermöglicht. Dieses Konzept wurde mehrmals erfolgreich den an deutschsprachiger Literatur interessierten Studenten vorgestellt. Der Referent verglich die Arbeit mit seinem Computer-Programm mit der Nutzung von Printmedien und stellte vor allem die Vorzüge der selbstgesteuerten Computer-Arbeit heraus. Er berichtete auch über die Reaktion von Studierenden, die auf diesem Weg einen offenen, individuellen Einstieg in die deutsche Literatur fanden, der auch ihrem landeskundlichen Interesse entgegenkam.

Im Anschluss daran zeigte Anke Stoever-Blahak (Fachsprachenzentrum der Universität Hannover) „Eine Methode zur Entwicklung von Sprech- und Vortragskompetenzen bei der Arbeit mit Gedichten im Fremdsprachenunterricht". Sie stellte erste Ergebnisse aus einem 2007/2008 durchgeführten Forschungsdurchlauf ihres Sprechkundeprojektes dar, in dessen Mittelpunkt die Erarbeitung einer Vortragsfassung für ein vom Studierenden ausgewähltes Gedicht stand. Die Entwicklung der Sprech- und Redekompetenz der kleinen Gruppe von Probanden wurde an Videobeispielen veranschaulicht.

Susanne Horstmann (Universität Bielefeld) begann ihren Vortrag „Förderung von Interkultureller Kompetenz durch Auseinandersetzung mit Filmen“" mit einem Literaturüberblick zum Thema. Eine kritische Neueinschätzung der Verwendung des Einsatzes von Filmen im DaF-Unterricht eröffnet - ihren Erläuterungen nach - differenziertere Ideen der Förderung von interkultureller Kompetenz.

Auch Sebastian Chudak (Abt. Methodik und Didaktik DaF der Adam-MickiewiczUniversität Poznań, Polen) sprach über die Arbeit mit Filmen im DaF-Unterricht als eine der Möglichkeiten der Förderung der interkulturellen Kompetenz auf der Fortgeschrittenenstufe. Zunächst formulierte er sein Unbehagen gegenüber einem interkulturell ausgerichteten, auch landeskundlichen Themen verpflichteten DaF-Unterricht, der sich ausschließlich auf vorhandene Lehrwerke stützt. Dagegen stellte er das Modell, durch Filme zur Förderung ,,interkultureller Kompetenz“ fortgeschrittener Lerner beizutragen. Gerade Filme seien geeignet, die „Fremdperspektive“ zu zeigen und dadurch zur kognitiven und affektiven Auseinandersetzung mit den Phänomenen anzuregen, die die Kultur des Landes der Zielsprache besonders kennzeichnen. Am Ende des Vortrags 
ging Herr Chudak auch auf Ergebnisse einer Umfrage sowie Unterrichtsstunden mit fortgeschrittenen DaF-Lernenden in Polen ein.

Mit dem Werkstattbericht von einer Theaterinszenierung im DaF-Unterricht (Aschenputtel in China) kam Oliver Eß (Oldenburg, Ostfriesland) auf den Themenbereich „kreative Literaturarbeit“ zurück. Der Vortrag beschrieb zunächst, wie mit Studentinnen und Studenten der Zhejiang Universität für Wissenschaft und Technik in Hangzhou (China) ein Theaterprojekt im DaF-Unterricht in die Praxis des Spielens und der Aufführung umgesetzt wurde. Anhand dieses Beispiels wurde reflektiert, welche didaktischen Möglichkeiten ein Theaterprojekt für sprachliche und interkulturelle Lernprozesse eröffnet. Schließlich wurde das Theaterspiel in den Kontext des handlungsorientierten interkulturellen Literaturunterrichts gestellt.

Der Themenschwerpunkt wurde abgeschlossen durch den Vortrag von Nils Bernstein (Lüneburg) zum Thema „Phraseologismen im Fremdsprachenunterricht“. Der Referent klärte zunächst zentrale Begriffe, wie „Festigkeit“, „Polylexikalität“, „Idiomatizität" und unterschied zwischen verschiedenen Klassen von Phraseologismen. Im Anschluss daran wurden Didaktisierungsvorschläge für den Umgang mit Mehrwortverbindungen in der Literatur des 20. Jahrhunderts gemacht. Ausgehend von Textauszügen aus Werken von Grass („Blechtrommel“), Mon (Gedichte) u.a. stellte Bernstein Entwürfe von Aufgabenstellungen für DaF-Lerner verschiedener Niveau-Stufen vor. Abschließend diskutierte er die Frage, welches phraseologische Optimum bzw. Minimum für den Fremdsprachenunterricht erstrebenswert ist. 

Christoph Chlosta, Matthias Jung (Hrsg.) (2010):

DaF intergriert: Literatur - Medien - Ausbildung. Tagungsband der

36. Jahrestagung des Fachverbandes Deutsch als Fremdsprache 2008.

Göttingen: Universitätsverlag, 5-19.

\section{Simone Schiedermair (München)}

\section{Texte zur Fremde - Ein Projekt zum Sprachenlernen mit literarischem Übungsmaterial}

\section{Einleitung}

„Ich erinnerte mich an eine japanische Sage von dem sogenannten Fuchsfenster: Wenn man allein im tiefen Gebirge unterwegs war, bekam man manchmal das Gefühl, als würde man unversehens eine seelische Grenze überschreiten und somit nie wieder als zivilisierter, vernünftiger Mensch in die Stadt zurückkehren können. In dem Fall sollte man schnell mit beiden Händen einen Kreis bilden und durch diese Öffnung die Naturlandschaft noch einmal betrachten. Dadurch konnte man es vermeiden, die gefährliche Grenze zu überschreiten und verrückt zu werden. Den Kreis, den man mit den Händen bildete, nannte man das Fuchsfenster." (Tawada 2000: 32)

In ihrem Essay beschreibt die japanische Schriftstellerin Yoko Tawada eine alte japanische Umgangsweise mit der Fremdbegegnung. Es ist die Begegnung zwischen Zivilisation und ungebändigter Natur: Jemand ist allein „im tiefen Gebirge“ unterwegs. Was er sieht, stellt seine Kategorien in Frage. Er droht, verrückt zu werden, die Vernunft zu verlieren, seine bisherigen Kategorien und damit die Möglichkeit zu verlieren, in die Stadt zurückzukehren. Der alten Sage nach hilft da ein „Fuchsfenster“; mit den Händen bildet man einen Kreis, hält ihn vor die Augen. Man schränkt das Blickfeld ein, man reduziert die Eindrücke. Man setzt einen Rahmen, der aus dem potentiell Möglichen ein erträgliches Maß ausschneidet. Einen Rahmen setzen - ein zivilisatorischer Akt, der einordnet, verfügbar macht, strukturiert, interpretiert, der eingrenzt und ausgrenzt, der die Wahrnehmungsmöglichkeiten dem eigenen Horizont anpasst. Und der Distanz 
schafft, der einen herausnimmt aus seiner Umgebung und zum Betrachter macht. Das, was überwältigt und die eigene Auffassungskapazität übersteigt, wird eingeschränkt.

Das Fuchsfenster als optisches Phänomen schafft Distanz. Wenn man den Blickwinkel einengt, durch diese Linse oder Röhre aus Händen blickt, rückt das Angeblickte in weitere Ferne und wird klein, so klein, dass es zwischen die eigenen Hände passt - und verliert auch dadurch seine Bedrohlichkeit.

Diese Wirkung überträgt Tawada im nächsten Satz selbst auf einen typischen Gegenstand, der in unserer Zeit zum Einsatz kommt, wenn man der Fremde begegnet:

„Mit dem Fotoapparat verhielt es sich ähnlich: Der Fotoapparat ist das Fuchsfenster für die Reisenden im Ausland.“ (Tawada 2000: 32f.)

Wie das Fuchsfenster der alten japanischen Sage den zivilisierten Menschen vor dem Verrücktwerden im Gebirge bewahrt, so schützt der Fotoapparat den Touristen vor dem Verrücktwerden auf seinen Reisen.

Konkret in dem vorliegenden Text schützt er das Ich vor dem Verrücktwerden beim Anblick einer kleinen mittelalterlichen Stadt im Süden Deutschlands. Die Zitate stammen aus dem kurzen Prosatext „Rothenburg ob der Tauber: Ein deutsches Rätsel“", der erstmals 1996 in dem Band „Talisman“ erschienen ist. Geschildert wird, wie eine Touristengruppe - vermutlich eine Gruppe aus Japan - eine Führung durch die Kleinstadt macht. Der Text ist eine Wiedergabe der Hinweise der Stadtführerin; nicht direkt, sondern gebrochen durch das Bewusstsein einer Ich-Erzählerin. Alle Hinweise der Führerin erscheinen nur in dieser durch Assoziationen der japanischen Teilnehmerin modifizierten Form.

Sowohl vor Bombardierungen im Zweiten Weltkrieg als auch vor Modernisierungsmaßnahmen danach verschont, konnte Rothenburg seine mittelalterliche Gestalt bewahren. Mit japanischen Augen gesehen ist der Anblick dieser kleinen Stadt, sie zählt heute 11.000 Einwohner, in der mittelfränkischen Provinz so bedrohlich, Kategorien sprengend, wild und urwüchsig wie der Anblick einer wilden japanischen Gebirgslandschaft für einen Städter, einen zivilisierten Menschen, einen, der aus Tokyo kommt.
„In Tokyo bezeichnet man ein Haus als ,alt‘, wenn es über dreißig Jahre als ist. Viele Häu- ser werden abgerissen, bevor sie zwanzig Jahre alt werden. Die Architektur ist in Japan eine der vergänglichsten Formen der Kunst. Vielleicht war das der Grund, warum es mir so schwerfiel zu glauben, daß [sic] diese alten Fachwerkhäuser tatsächlich dort standen. Mir kam es vor, als würden sie schwanken, verschwimmen, und meinem Blickfeld ent- gleiten. Erst durch die Linse meines Fotoapparates konnte ich die Stadt richtig betrach- ten, die auf einmal klein wie die Bühne eines Puppentheaters aussah. Sie war eingerahmt und wirkte weiter entfernt von mir als vorher." (Tawada 2000: 32)

Weitere Stellen in Tawadas kleinem Text sind interessant im Hinblick auf ihren Umgang mit Fremde. Ich zitiere drei weitere Textpassagen:

„In den ersten zwanzig Minuten waren unsere Augen nur von den verschiedenen Schaufenstern gefesselt. Keiner blickte auf die Dächer, Wände und Fenster der alten Häuser. Die Waren im Schaufenster wirkten zugänglicher als die alten Häuser, weil wir sie kaufen und mitnehmen konnten." (Tawada 2000: 31) 
Für diesen Umgang mit der Fremde lassen sich die Stichwörter „Kaufen“ bzw. „Konsum" finden.

„,Fränkisches Früchtebrot ${ }^{6}$ stand auf dem kleinen Schild. Sie ähnelten den Steinen aus einem Vulkan. Wir kauften gemeinsam ein Stück und probierten es. Einer sagte, es schmecke nach Mittelalter. Ein anderer sagte, es schmecke überhaupt nicht, Brot müsse leicht sein wie Wolken und nicht schwer wie ein Stein." (Tawada 2000: 30)

Hier wird das Fremde „gegessen“ und auf diese Weise sozusagen ins Eigene integriert.

„Wir waren von dem Kriminalmuseum fasziniert, nicht etwa wegen der heißgeliebten mittelalterlichen Grausamkeit, sondern weil dort eine Reihe von sympathischen Kriminellen dargestellt war: schlechte Musikanten, streitsüchtige Frauen, Hausdrachen und so weiter. Die Kriminellen bekamen interessante Masken, die mich an die mittelasiatischen Theatermasken erinnerten, und wurden auf der Straße zur Schau gestellt. Diese Masken hießen Schandmasken, aber für mich wäre es eher eine Ehre als eine Schande, mit diesen ausdrucksvollen Masken vom Publikum betrachtet zu werden.“ (Tawada 2000: 35)

Es findet eine Interpretation unabhängig von dem ursprünglichen Kontext der Objekte statt. Das Fremde wird vor dem eignen kulturellen Hintergrund „umgewertet“ und für positive Zusammenhänge verfügbar gemacht.

Aus diesem kurzen Text von Tawada lassen sich also verschiedene Modi des Umgangs mit dem Fremden extrapolieren. Erstens der Versuch, dem Fremden die Bedrohlichkeit zu nehmen, indem man es in den eigenen Horizont einpasst, auf die GröBe dessen reduziert, was man durch einen mit den eigenen Händen gebildeten Kreis sehen kann bzw. indem man es in ein Bild, in eine Fotografie verwandelt und damit der eigenen Verfügung unterstellt. Oder zweitens, indem man Gegenstände kauft, die man mitnehmen kann, um von den ungeheueren Gebäuden abgelenkt zu sein, die dort fest und unverrückbar stehen, indem man also das vertraute Umgehen mit Dingen, den Konsum, wählt, um die Fremdheit abzuschwächen. Oder drittens, indem man das fremdartige Gebäck isst, um es sich buchstäblich „einzuverleiben“. Oder viertens, indem man die Objekte der fremden Kultur in die eigene Kultur einordnet und sie damit in einen neuen Wertezusammenhang stellt.

Die soeben an dem Text von Tawada exemplifizierte Auseinandersetzung mit den verschiedenen Möglichkeiten der Fremdbegegnung war das inhaltliche Ziel für den Kurs, den ich im Folgenden vorstellen möchte. Es war der Versuch, das Thema „Fremde“ als Grundlage zu nehmen für einen Sprachkurs. Die Konzeption geschah vor dem Hintergrund der Frage, wie sich die Erkenntnisse der interkulturellen Germanistik in die konkrete Unterrichtspraxis umsetzen lassen. Wie lassen sich insbesondere die im Zusammenhang mit dem Rahmenbegriff „Fremdheit“ formulierten Erkenntnisse vermitteln bzw. reflektieren und diskutieren. Ich greife drei Aspekte heraus, die in der Fremdheitsforschung immer wieder formuliert werden. Erstens „die Einschätzung kultureller Vielfalt als Reichtum, Anregung und Fülle, nicht als Chaos, Unordnung und Vielerlei““ (Albrecht 2003: 233). Zweitens die Notwendigkeit, den automatisierten 
Umgang mit Fremde ${ }^{1}$ ins Bewusstsein zu heben und zu reflektieren. Und drittens die Beobachtung, dass die „Fremderfahrung Studierender zur Möglichkeit erkenntnisfördernder Selbstreflexion wird“ (Wierlacher 2003: 13). Es galt, diese Punkte in ein Programm für einen Sprachkurs mit Studierenden aus unterschiedlichen Herkunftsländern und unterschiedlichen Fachstudiengängen umzusetzen. Nicht in einen Literaturkurs für Germanisten oder Landeskundekurs, nicht in einen Kurs zum interkulturellen Lernen oder ein Proseminar für DaF-Studierende.

Wie kann man solchen Studierenden, die eigentlich in Deutschland sind, um ein Fachstudium zu absolvieren, dabei helfen, auf das Fuchsfenster zu verzichten, etwa die Einschränkung auf die Zusammenhänge des eigenen Studiums; wie kann man sie dazu anregen, die Fremdbegegnung nicht durch Konsum abzumildern, sie nicht auf die Auseinandersetzung mit Schweinshaxe und Schwarzwälderkirschtorte zu beschränken, kulturelle Muster in ihrer vielleicht auch monströsen Fremdheit nicht durch die Interpretation mit Hilfe eigener kultureller Muster zu entschärfen. Wie kann man Studierende, die Deutschland mit russischen, afrikanischen, chinesischen, ukrainischen, belgischen, polnischen Augen sehen - so wie Tawada Rothenburg ob der Tauber mit japanischen Augen sieht - , wie kann man sie dazu anregen, ihre konkrete tägliche Erfahrung in den Diskurs über Fremde, den es in Deutschland gibt, einzuflechten.

\section{Institutioneller Rahmen}

Ziel ist es im Folgenden, die Kurskonzeption genauer vorzustellen mit konkreten Textbeispielen und Hinweisen auf die Mittel zum sprachlichen Training, die ich verwendet habe. Zunächst zum Hintergrund des Kurses. Das Stipendien- und Betreuungsprogramm des DAAD, kurz STIBET-Programm, ermöglicht es Hochschulen, spezielle Angebote für ausländische Studierende und Doktorandinnen zu entwickeln, um deren Studienaufenthalt an einer deutschen Universität so effektiv wie möglich zu gestalten. Seit dem Wintersemester 2006/2007 gibt es auch an der Ludwig-Maximilians-Universität in München verschiedene Angebote im Rahmen dieses STIBET-Programms, mit dem allgemein formulierten Ziel „,der interdisziplinären Betreuung junger WissenschaftlerInnen über ihre Einbindung in die jeweiligen Fachinstitute hinaus" (Programmbroschüre) zu dienen. Im ersten Semester gab es Angebote zu drei Schwerpunkten. Je ein Sprachkurs auf den Niveaus B1, C1, C2. Während es in dem Kurs auf Niveau B1 darum ging, die sprachliche Handlungsfähigkeit im universitären Forschungs- und Wissenschaftsalltag zu verbessern, waren die beiden C-Kurse auf das wissenschaftliche Schreiben ausgerichtet. Der zweite Schwerpunkt war ein semesterbegleitender sogenannter Orientierungskurs. Dabei ging es um Orientierung etwa in den wissenschaftlichen Bibliotheken. Es ging ums Recherchieren, um Zeitmanagement, um die Gestaltung eines Posters oder Vortrags und Ähnliches. Der dritte Bereich war mit den Stichwörtern „Wissenschaft und Kultur in München " überschrieben und umfasste Besuche in verschiedenen wissenschaftlichen und kulturellen Einrichtungen, etwa im Institut für Zeitgeschichte, im

Vgl. Albrecht (2003: 233): „Menschen erwerben eine fremde Sprache und sehen eine fremde Kultur immer durch den Filter ihrer eigenkulturellen Vorverständnisse und Vorbilder.“ 
Institut für Rechtsmedizin, bei der Fraunhofergesellschaft, im Beschleunigerlabor, in der Musikhochschule sowie Stadtführungen und Exkursionen, etwa nach Ingolstadt und Landshut, um der Geschichte der Münchner Universität nachzugehen. Da die Evaluationen nach dem ersten Semester ergaben, dass die Promovierenden vor allem Interesse an Sprachkursen hatten, wurde in den folgenden Semestern insbesondere dieser Bereich ausgebaut: Sprachkurse auf den Niveaus A1-C2 mit dem Fokus auf Uni und Alltag bzw. wissenschaftlichem Schreiben wurden ergänzt durch Spezialangebote wie mündliche Wissenschaftskommunikation, eine Schreibwerkstatt, Aussprachetraining für Asiaten, Deutsch für Juristen und individuelle Sprachlernberatung.

In diesem Zusammenhang steht auch der Sprachkurs, den ich im vorliegenden Beitrag vorstellen möchte: „Texte zur Fremde - Lektüre und Diskussion“ - so der Titel. Der Kurs umfasste elf Sitzungen à 90 Minuten, die semesterbegleitend angeboten wurden. Zielgruppe waren DoktorandInnen und PostdoktorandInnen aller Disziplinen auf dem sprachlichen Niveau C1/C2:

„Der Kurs richtet sich an WissenschaftlerInnen, die sich unabhängig von ihren Fachstudien mit Aspekten von Leben und Kultur in Deutschland auseinandersetzen und dabei ihre sprachlichen Fähigkeiten erweitern und vertiefen wollen. Im Wintersemester steht das Thema ,Fremde“ im Zentrum. Auf der Basis von kurzen literarischen Texten, Essays und aktuellen Zeitungsartikeln soll nachvollzogen werden, wie Fremdsein und Fremde in Deutschland erlebt, diskutiert und dargestellt werden." (Kursbeschreibung im Internet)

Der Kurs hatte also eine doppelte Ausrichtung: Erstens die inhaltliche Auseinandersetzung mit dem Thema „Fremde“ in Deutschland und zweitens das sprachliche Training für die mündliche Diskussion. Zunächst in einem groben Überblick, wie sich das Konzept des Kurses an dieser zweifachen Zielvorgabe orientiert hat. Als Grundlage für die Bearbeitung des Themas „Fremde“ wurde folgendes Material ${ }^{2}$ verwendet:

1. Zeitungsartikel aus der SZ-Serie von 2005 - Fremde Heimat. 50 Jahre Gastarbeiter in München,

2. Statistiken - vom Statistischen Bundesamt zur ausländischen Bevölkerung,

3. Theorietexte - u. a. ein Text aus der Literaturwissenschaft von Michael Hofmann und ein Text aus der Soziologie von Ulrich Beck und Elisabeth Beck-Gernsheim,

4. literarische Texte von

a) deutschsprachigen Autoren - Karoline von Günderode, Franz Kafka, Rainer Maria Rilke, Reinhard Lettau,

b) deutsch-türkischen AutorInnen - Feridun Zaimoglu, Zafer Şenocak, Emine Sevgi Özdamar,

c) AutorInnen verschiedener Muttersprachen - Yoko Tawada, Herta Müller, Zé do Rock,

5. Essay - von Axel Hacke über die erste Pizzeria in Deutschland,

6. Film - „Solino“ von Fatih Akin.

2 Die genauen Angaben zu den einzelnen Materialien finden sich im Literaturverzeichnis. 
Folgendes Material wurde für das sprachliche Training verwendet:

1. Kopien mit Redemitteln - „Seine eigene Meinung ausdrücken“ - „Bewertungen von Vor- und Nachteilen“ - Redemittel zur „Beteiligung in Lehrveranstaltungen“ aus dem Materialband zur Studienbeleitung von Grit Mehlhorn,

2. Wortschatzarbeit anhand der Texte - einzelne Ausdrücke klären, wichtige und insbesondere wissenschaftssprachliche Formulierungen markieren,

3. lautes Vorlesen der Texte in Gruppen und im Plenum,

4. die einzelnen Gruppen lesen verschiedene Teile des Gesamttextes, fassen ihren Teil zusammen und stellen ihn im Plenum vor,

5. Zusammenfassungen und Essays als Hausaufgabe - Kopie mit „Sprachlichen Mitteln für das Schreiben einer Zusammenfassung“".

Mit dem angebotenen Material zum sprachlichen Training sollte das gezielt unterstützt werden, was in der wissenschaftlichen Literatur als Beitrag literarischer Texte im Fremdsprachenunterricht genannt wird:

„Schulung des mündlichen Ausdrucksvermögens und zur Erweiterung der Kenntnisse in der Zielsprache. Diese Chance wird jedoch nur dann voll genutzt, wenn die Lernenden angehalten werden, sich die für die Interpretation erforderlichen Wörter; Kollokationen und Strukturen systematisch anzueignen [...] [und wenn die] mündliche[...] Ausdrucksschulung [...] [mit] eine[r] ebensolche[n] im schriftlichen Bereich einhergeh[t].“ (Glaap; Rück 2003: 137)

In den Antworten der Studierenden in der abschließenden Evaluation bestätigt sich die doppelte Ausrichtung des Kurses, auch wenn die sprachliche Komponente für die Studierenden eindeutig im Vordergrund stand. Alle haben als Begründung für die Wahl des Kurses angegeben, dass sie „das Angebot zur [...] Diskussion nutzen wollte[n], um [ihre] [...] mündliche Ausdrucksfähigkeit zu trainieren“" (Evaluationsbogen). Die Hälfte gab an, dass sie „die Auseinandersetzung mit dem Thema ,Fremde in Deutschland“ interessant fand" (Evaluationsbogen). An zwei weiteren Stellen des Evaluationsbogens wird dieser Fokus der Studierenden deutlich. So haben bei der Frage nach den Sozialformen des Unterrichts alle angekreuzt, dass Sie die Diskussionen im Plenum sehr gut bzw. am besten fanden. Dagegen wurden die Lektüre in Kleingruppen und die Zusammenfassungen im Plenum nur von der Hälfte der Teilnehmer als positiv hervorgehoben. Auch in der abschließenden allgemeinen, nicht auf den Kurs bezogenen Frage nach gewünschten Sprachkursangeboten, bestätigt sich dieses Interesse am Diskutieren.

Nach diesen allgemeinen Informationen zur Kurskonzeption werde ich im Folgenden Unterrichtsbeispiele aus zwei Bereichen vorstellen: Theorie zur Fremde und Gastarbeiter in Deutschland. 


\section{2 Überblick - Relationalität und Komplementarität}

In den ersten beiden Sitzungen ging es zunächst darum, einen Einblick in das Thema „Fremde“ zu gewinnen. Ein erster zentraler Aspekt ist hier die grundlegende Feststellung der Fremdheitsforschung, „, dass ,fremd' nicht die objektive Eigenschaft eines Menschen oder Gegenstandes ist, dass es sich vielmehr um einen relationalen Begriff handelt" (Hofmann 2006: 14). Eingeführt wurde dieser Aspekt mit einer Reihe von kurzen literarischen Texten deutschsprachiger Autoren. Das Rilke-Gedicht „Eingang“ setzt mit der Aufforderung ein, aus der eigenen Stube hinauszutreten, aus dem eigenen Bereich hinauszutreten, in dem man alles weiß, in dem einem alles vertraut ist, sozusagen den Schritt in die Ferne, ins Fremde zu wagen. Denn ,als letztes vor der Ferne liegt dein Haus" (Rilke 1990: 317); es ist immer das letzte vor der Ferne, vor dem Fremden; wo diese Ferne oder Fremde beginnt, ist aber unklar, vor der Schwelle, in einer Entfernung von zehn Metern, von hundert Metern, von Kilometern? Fest steht nur, sie beginnt immer da, wo das Eigene endet. In Kafkas Text „Heimkehr“ wird die Relationalität direkt thematisiert. Er beginnt mit der Rückkehr eines Ich-Erzählers in sein Elternhaus. Als der Heimkehrer über den Hof geht, kommen ihm die Einzelheiten vertraut vor, die Pfütze, die Katze, der Flur und die Treppe. Vor der Küchentür hält er inne und während er darüber nachdenkt, was wohl in der Küche vorgeht, werden ihm die soeben noch so vertraut erschienenen Zusammenhänge immer fremder. „Je länger man vor der Tür zögert, desto fremder wird man" (Kafka 1992: 321).

Ausführlicher wurde ein Ausschnitt aus Reinhard Lettaus Band „Zur Frage der Himmelsrichtungen" von 1988 besprochen. Anhand einer Spielerei reflektiert Lettau, wie die geographischen und kulturellen Einteilungen jeweils abhängig sind von dem Standpunkt, den man einnimmt. Im Eingangstext geht es zunächst darum, wie die Bezeichnungen der Himmelsrichtungen „Osten“ und „Westen“ mit den Bezeichnungen für den östlichen und westlichen Kulturraum kollidieren. Beispielsweise, wenn sich ein Besucher in San Francisco mit seinem dortigen Freund über die westliche Welt unterhält, der dabei nach Westen zeigt, also auf den Pazifik bzw. nach China und Russland:

„Gilt es [...] nicht als ausgemacht, dass jene Länder zum Osten gehören? Wenn Du in den Westen zeigst, zeigst Du dann nicht in den Osten? Den Osten, rief er, haben wir schon im Osten! Ist es dann nicht ungünstig für Euch, entgegnete ich, an beiden Küsten von Osten umgeben zu sein? Der wirkliche Osten, wenn ihr ihn sucht, ist im Westen, während der Westen, von dem ihr sprecht, weit im Osten entfernt ist!“ (Lettau 1988: 7)

Nach weiteren Überlegungen kommt Lettau zu dem - selbstverständlich ironisch zu verstehenden - Schluss, dass man sich nach Europa, genauer nach Erfurt in Thüringen begeben müsse, ,um die Himmelsrichtungen, wie sie uns überliefert sind, zu bezeichnen, ohne hierbei den jeweiligen geographischen Standort zu leugnen [...]. Von hier aus ist es nun möglich, Paris oder Fulda als westlich, was zutrifft, Nordhausen, Oslo als nördlich zu erkennen, wobei über die Himmelsrichtung von Gera lange Gespräche nicht nötig sind“ (Lettau 1988: 8). 
Schon, wenn man diesen Orientierungspunkt ein bisschen verschiebt, etwa $25 \mathrm{~km}$ nach Osten, sprich nach Weimar, treffen die Himmelsrichtungen nicht mehr zu:

„Wo doch in Weimar schon gar nichts mehr stimmt? Dortselbst erbetene Auskünfte über die Himmelsrichtung von Erfurt: es liege im Westen, gelten selbstverständlich für Weimar, aber nicht für die Welt, die doch zuhört.“ (Lettau 1988: 11)

Die Suche nach dem geeigneten bzw. absoluten Mittelpunkt bzw. Orientierungsnullpunkt, ,jenes vielleicht festen, vielleicht auch sich ein wenig bewegenden Fleckens, an welchem lokaler und universaler Standpunkt versöhnt wären“ (Lettau 1988: 12) wird endgültig ad absurdum geführt mit dem Vorschlag, der Punkt sei als eine bestimmte Stelle auf einem Teppich im Wohnzimmer eines Erfurter Bürgers namens Nippold auszumachen (Lettau 1988: 12).

Der Text von Lettau stellte sich für die Studierenden als wenig zugänglich heraus; sicherlich stellte er auch sprachlich die größte Herausforderung aller verwendeten Texte dar. Vielleicht wäre der Gedanke leichter nachzuvollziehen gewesen in Kombination mit einem anderen Text, der weniger abstrakt den gleichen Aspekt durchspielt, die Abhängigkeit der Himmelsrichtungen vom eigenen Standpunkt. In dem Text „Der Kompass“, erschienen 2006 in dem Band „Das Land hinter den Buchstaben: Deutschland und der Islam im Umbruch" schildert der deutsch-türkische Autor Zafer Şenocak, wie der Kompass seines Vaters auf Reisen dazu diente, die Gebetsrichtung, Mekka, zu bestimmen. Der Aspekt der eigenen kulturellen Prägung, des eigenen religiösen Zusammenhangs, der eigenen religiösen Ausrichtung, wird auch hier mit der geographischen Fragestellung verknüpft. Şenocak reflektiert die Frage, ob ein Reisen in die Fremde eigentlich ein Umkreisen der eigenen - kulturellen - Herkunft ist:
„Zu Hause brauchte man keinen Kompass, da kennt man schon die Gebetsrichtung. Wer keinen Kompass besitzt, muss zu Hause bleiben. Manchmal auf großen Reisen, die uns durch Länder führten, deren Namen ich noch nie gehört hatte, beschlich mich das Gefühl, dass wir Mekka umkreisten. Denn mein Vater änderte von Ort zu Ort seine Gebetsrichtung wie im Kreis.“ (Şenocak 2006: 20)

In den ersten beiden Sitzungen des Kurses ging es außerdem darum, einen theoretischen Überblick über die verschiedenen Modi des Umgangs mit einer Fremderfahrung als gemeinsame Diskussionsgrundlage zu erarbeiten. Dies geschah anhand eines theoretischen Textes, nämlich anhand von zwei längeren Ausschnitten aus dem ersten Kapitel der „Einführung in die interkulturelle Literaturwissenschaft“ von Michael Hofmann, in dem er die Begriffe „Interkulturalität, Fremdheit, Differenz" vorstellt und diskutiert. Ausgewählt habe ich die Stelle über die drei grundlegenden Bedeutungszusammenhänge des deutschen Ausdrucks „fremd“, erstens in Bezug auf die Topographie, also „fern“. Damit verbinden sich Fremdheitserfahrungen wie die der Reise, aber auch der Eroberung, Kolonisierung und von Kriegszügen. Zweitens „fremd“ in der Bedeutung, „jemand anderem gehören“ und drittens „fremd“ im Sinne von „fremder Art", also „fremdartig“, „unvertraut“, in unterschiedlicher Hinsicht verschieden, etwa im Aussehen, im Verhalten oder Ähnlichem. Dazu Hoffmanns Zusammenfassung von Ortrud Gutjahrs „Facetten der Fremdheit“ - Der Tod als das radikal Fremde, Das Fremde als 
das noch Unbekannte, Das Fremde als das unbekannte Drinnen und Das Fremde als das verdrängte Eigene (Hofmann 2006: 15-19). Und als zweiten Textabschnitt seinen Überblick über Ortfried Schäffters „Modi des Fremderlebens“ - Fremde als Resonanzboden des Eigenen, Fremdheit als Gegenbild, Fremdheit als Ergänzung, Fremdheit als Komplementarität (Hofmann 2006: 20-25).

Diese zwei Teile wurden in zwei verschiedenen Gruppen gelesen. Die Studierenden hatten die Aufgabe, ihren jeweiligen Text in der Gruppe laut zu lesen, sprachliche Unklarheiten untereinander oder mit meiner Hilfe zu klären, den Inhalt kurz zu diskutieren und zusammenzufassen. Es galt dann, die wichtigsten Punkte des eigenen Textes im Plenum so vorzustellen, dass allen Kursteilnehmern der gesamte Theorieüberblick aus der Hofmannschen Einführung als Grundlage für die Diskussionen in den folgenden Sitzungen zur Verfügung stand. In der Wahl ihrer Präsentationsweise waren die Gruppen frei. Die einen gaben eine mündliche Zusammenfassung, die anderen hatten ein Schaubild entwickelt, das sie an der Tafel vorstellten. Bereits während der Vorstellungen gab es die Gelegenheit zum Nachfragen und Diskutieren.

Die Diskussion setzte vor allem bei Schäffters viertem Modus des Fremderlebens ein, Fremdheit als Komplementarität, ein Modus, der das Fremde nicht aufzulösen versucht, in ein „Es ist eben doch wie das Eigene“, der die Differenz als Differenz wahrnimmt und anerkennt, der nicht auf Konsens und Verständigung aus ist. Das Eingeständnis oder die Erkenntnis, dass es gilt, eine „Realität aus vielen autonomen Einzelzentren [zu] rekonstruieren. Aus der nicht mehr zu leugnenden Vielfalt eigenständiger Perspektiven und gleichermaßen ,möglicher ${ }^{6}$ Interpretationen der Welt wird erkennbar, daß [sic] im Aufeinandertreffen unterschiedlicher Bezugssysteme kein unbestreitbares Fundament und kein allem übergeordneter Bezugspunkt zur Verfügung steht, um über sie zu entscheiden“" (Schäffter 1991: 25).

Selbst das Ausgehen von anthropologischen Universalien, von einer gemeinsamen Basis für so grundlegende menschliche Tätigkeiten wie Essen, Schlafen und Lieben wird problematisiert; auch diese werden ,in verschiedenen kulturellen Konstellationen ganz unterschiedlichen Sinnzuweisungen zugeordnet“ (Hofmann 2006: 25). Um zu verdeutlichen, welche Herausforderungen mit diesem Erfahrungsmodus verbunden sein können, verweist Hofmann auf die indische Tradition der Witwenverbrennung, die heute offiziell verboten ist, und stellt zu Recht die Frage, ob wir als Europäer diese kulturelle Praxis verstehen können. Diese Frage stellte sich auch im Kurs: Inwieweit können wir, die wir im konkreten Fall dieses internationalen Kurses alle vor unterschiedlichen kulturellen Hintergründen argumentieren, diese Tradition im Modus der Komplementarität verstehen; inwieweit kann man tatsächlich eine solche Tradition akzeptieren ohne jegliche emotionale und humanitäre Einwände.

Da es sich um eine kulturelle Praxis handelt, die in Europa seit langem bekannt ist, habe ich den Studierenden eine Interpretation dazu vom Anfang des 19. Jahrhunderts vorgelegt und ihnen damit einen Ausblick auf eine Fremdbegegnung ermöglicht, die vor zweihundert Jahren stattgefunden und sich in einem kleinen literarischen Text niedergeschlagen hat, in dem Gedicht „Die malabarischen Witwen“ von Karoline von Günderode, entstanden 1806: 
Die malabarischen Witwen.

Zum Flammentode gehn an Indusstranden

Mit dem Gemahl, in Jugendherrlichkeit,

Die Frauen, ohne Zagen, ohne Leid,

Geschmücket festlich, wie in Brautgewanden.

Die Sitte hat der Liebe Sinn verstanden,

Sie von der Trennung harter Schmach befreit,

Zu ihrem Priester selbst den Tod geweiht,

Unsterblichkeit gegeben ihren Banden.

Nicht Trennung ferner solchem Bunde droht,

Denn die vorhin entzweiten Liebesflammen

In Einer schlagen brünstig sie zusammen.

Zur süßen Liebesfeyer wird der Tod,

Vereinet die getrennten Elemente,

Zum Lebensgipfel wird das [sic] Daseins Ende.

Bei der anschließenden Arbeit mit dem Gedicht ging es zunächst darum, zu analysieren, wie die junge Dichterin mit dieser Tradition aus einer fremden Kultur umgeht. Sie nimmt die „Fremdheit als Resonanzboden des Eigenen“ (Schäffter 1991: 16ff), verbindet die indische Tradition mit dem romantischen Konzept des ewigen Liebesbundes (siehe besonders Strophe II) und projiziert damit das eigene Liebesideal in das fremdkulturelle Verhalten, die malabarische Tradition wird zur erlösenden Metapher des romantischen Konzepts Sehnsucht nach der unsterblichen Liebe. In einem zweiten Schritt galt es, diese europäische Sicht der idealisierten Witwenverbrennung ${ }^{3}$ durch eine Sicht aus Indien zu konterkarieren. In der Malabarischen Korresponden $z^{4}$ finden sich im zweiten Brief u. a. zwei Fragen zur Witwenverbrennung. Bei der malabarischen Korrespondenz, die in den Jahren 1714 bis 1717 - also fast hundert Jahre vor Günderrodes Gedicht - von Johann Ernst Gründler und Bartholomäus Ziegenbalg herausgegeben wurde, handelt es sich u. a. um eine Sammlung von 99 Briefen von Südindern an die bei-

3 Gerhard Anton von Halem hat in seinem Gedichtband „Blüthen aus Trümmern“ (1798) ebenfalls ein Gedicht mit dem Thema der idealisierten Witwenverbrennung geschrieben. Günderode kannte dieses Gedicht wohl, da es sich nachweislich in ihrem Besitz befand. Die Witwenverbrennung firmierte in Europa jedoch nicht nur in dieser romantischen Idealisierung, sondern war vor allem Gegenstand heftiger Kritik. Günderodes positive Deutung war eher ein Ausstieg aus der üblichen Interpretation. Allgemein galt die Witwenverbrennung den Europäern ,als besonders problematisch empfundener Brauch [...], die schon Herder in seinen ,Ideen' [(1784-1791), Erg. S. Sch.] als inhuman kritisiert hatte und die auch in Goethes Ballade „Der Gott und die Bajadere“ [(1798), Erg. S. Sch.] eine zweideutige Rolle gespielt hat.“ (Hofmann 2006: 91).

4 „Dies [= Die malabarische Korrespondenz, S. Sch.] war wohl die erste Publikation, aus der sich europäische Leser zumindestens [sic] bruchstückhaft mit Auffassungen indischer Zeitgenossen anhand deren eigener Darstellung vertraut machen konnten. Bis zu diesem Zeitpunkt waren sie auf Berichte von europäischen Reisenden, Händlern, Soldaten und Missionaren angewiesen, in denen je nach Intention und Bildung vom Verfasser eigene Schwerpunkte gesetzt und vielfach eigenes Erleben und Hörensagen vermengt wurden.“ (Liebau 1998: 9) 
den Missionare, die diese dann übersetzt und kommentiert im Rahmen der „Halleschen Berichte" herausgegeben haben (Liebau 1998: 7).

Die Antworten der Inder auf die beiden Fragen zur Witwenverbrennung zeigen, dass diese Tradition auch in der Ausgangskultur durchaus keine einheitliche Interpretation erfuhr. Als Gründe für die Witwenverbrennung werden angegeben: Erstens, dass durch den zeitgleichen Tod ausgeschlossen ist, dass die Witwen durch ihr späteres Verhalten Schande über die Familie des Mannes bringen können (Gründler; Ziegenbalg 1998: 82f.); zweitens, dass die Frauen dadurch selig werden (ebda.: 84f.), drittens, dass sie dadurch ihrem Ehemann die Erlösung sichern (ebda.: 267, Anmerkung 39) und, dass sie dadurch einem Leben entgehen, ,in dem sie als unrein angesehen“" werden (ebda.).

Auch die Einstellung der Witwen wird in den Briefen durchaus nicht als eine durch kulturelle Prägung homogene dargestellt. Es gibt Witwen, die vor Angst vorher sterben (Gründler; Ziegenbalg 1998: 83); andere, die zu dem Schritt gezwungen werden (ebda.); solche, die sich gleichzeitig mit dem verstorbenen Mann verbrennen lassen (ebda.) und solche, die sich der Sitte fügen und in einer feierlichen Zeremonie, unter den Augen von tausenden von Zuschauern, an einem eigens dafür festgesetzten Tag begehen (Gründler; Ziegelbalg 1998: 84). ${ }^{5}$

Vor diesem Hintergrund verschärft sich noch einmal die Frage nach dem Umgang mit dem Fremden am Beispiel der Witwenverbrennung, findet sich doch bereits in der Ausgangskultur eine „Vielzahl eigenständiger Perspektiven und gleichermaßen ,möglicher' Interpretationen der Welt“" (Schäffter 1991: 25).

Nach dieser inhaltlichen Diskussion der von Hofmann präsentierten Konzepte zur Fremde und der intensiven Auseinandersetzung mit dem Modus Komplementarität folgte die sprachliche Arbeit mit dem Text von Hofmann. Dabei ging es vor allem darum, auf für das Deutsche als Wissenschaftssprache typische Formulierungen im Text aufmerksam zu machen; sie bewusst zu machen und damit für die Verwendung in eigenen wissenschaftlichen Texten - in diesem Kurs konkret beim Verfassen der Doktorarbeit - verfügbar zu machen. Dafür wurde der Text noch einmal gemeinsam durchgegangen. Dabei wurden wichtige sprachliche Mittel markiert. Zur Verdeutlichung hier einige Beispiele:

a) Fremdheitsforschung, Interkulturalitätsdiskussion, Problemkonstellation, Problemstellung,

b) es handelt sich um, im Hinblick auf, hier ist der Aspekt XXX wichtig, der Aspekt der XXX spielt eine wichtige Rolle,

c) erste und grundlegende Bedeutung, in einer zweiten Bedeutung, die dritte und ganz wichtige Bedeutung,

d) es lässt sich herausstellen als, man kann formulieren, es lässt sich wie folgt erläutern. ${ }^{6}$

Sowohl die inhaltliche als auch die sprachliche Komponente dieser Sitzung sollten in der dazugehörigen Hausaufgabe noch einmal vertieft werden, die wie folgt lautete: Schrei-

5 Siehe zur genaueren Beschreibung auch die Anmerkung d. auf derselben Seite.

6 Die Beispiele finden sich auf den Seiten 14 und 15 in Hofmann 2006. 
ben Sie eine Zusammenfassung zu einem Ausschnitt aus dem Theorietext von Hofmann. Als Hilfe bekamen die Studierenden eine Kopie mit Hinweisen und sprachlichen Mitteln zur Textart „Zusammenfassung“.

Im Fall dieses ersten Theorietextes wurden die wichtigen Formulierungen lediglich markiert. Für den Text von Beck; Gernsheim erhielten die Studierenden eine zusätzliche Kopie mit einer Liste hilfreicher Formulierungen aus dem Text.

\section{Einblick - Türken und Italiener}

Neben der Auseinandersetzung mit der Theorie zur Fremde bildeten die konkreten Erfahrungen mit Fremde in Deutschland einen wichtigen inhaltlichen Schwerpunkt, besonders die Frage nach der Integration der ehemaligen Gastarbeiter, insbesondere der Türken und Italiener. Für die Türken, deren Situation anhand von Zeitungsartikeln und literarischen Texten deutsch-türkischer Autoren und Autorinnen bearbeitet wurde, stellte sich als besonders interessant der Aspekt des Umgangs mit der Sprache heraus. Mit dem Türkendeutschen bzw. Kanakischen scheinen sie eine spezifische Lösung für die Problematik ihrer sprachlichen Integration gefunden zu haben, für dieses Dazwischensein zwischen dem Türkischen und dem Deutschen. Prominentester Text in diesem Zusammenhang ist sicher Feridun Zaimoglus „Kanak Sprak“. Hier stellt sich natürlich die Frage, inwieweit es sinnvoll ist, solche Texte im Unterricht Deutsch als Fremdsprache einzusetzen. Joachim Gerdes, der sich in einem Artikel in der Zeitschrift „Zielsprache Deutsch"ausführlich damit auseinandersetzt, kommt zu dem Schluss, dass vor einem Einsatz gewarnt werden muss, da diese Texte einerseits als nur sehr begrenzt authentisch gelten können, andererseits ,,den Adressaten selbst, nämlich den ausländischen Deutschlerner“ diskriminieren (Gerdes 2006: 40). In meinem Kurs mit den internationalen Promovierenden jedoch - der zugegebenermaßen auf sehr hohem Sprach- und Reflexionsniveau stattfand - war das Interesse gerade daran groß, wie andere mit der deutschen Sprache umgehen; sei es nun die perfekte Essayistik Şenocaks, die naiv anmutenden Reflexionen Tawadas, die Sprachspielereien Zé do Rocks, die an der Grenze der Verständlichkeit sich bewegende Prosa Özdamars oder Hänsel und Gretel auf Kanakisch ${ }^{7}$, was die Studierenden mit großem Vergnügen mit verteilten Rollen vorgelesen haben.

Bleibenden Eindruck hat auf die Studierenden aber vor allem die Thematik der italienischen Gastarbeiter gemacht, die ebenfalls anhand von Zeitungsartikeln bearbeitet wurde sowie mit dem Essay von Axel Hacke über die erste Pizzeria in Deutschland. Höhepunkt dieses Themenbereichs war jedoch das gemeinsame Ansehen und die anschlieBende Diskussion des Films „Solino“ von Fatih Akın aus dem Jahr 2002, die Geschichte der süditalienischen Familie Amato, die ins Ruhrgebiet auswandert. „Solino“ wurde im Evaluationsbogen am häufigsten genannt bei der Frage danach, welcher Text oder Film ihnen spontan als erstes einfalle, wenn Sie an den Kurs dächten. Bei der genaueren Nachfrage, was ihnen dabei einfalle, wurden die verschiedensten Aspekte genannt. Interessant war der Film wegen der vielen Angebote, eigene Erfahrungen mit dem Dargestellten zu vergleichen. Interessant fanden die Studierenden dabei die Darstellung der

\footnotetext{
Der Text findet sich in dem Artikel von Joachim Gerdes auf den Seiten 22-23.
} 
verschiedenen Phasen der Integration. Beschäftigt hat sie auch, wie unterschiedlich das Leben der italienischen Familie in Deutschland und Italien war. Außerdem kamen wir in der Diskussion auf verschiedene Unterschiede zwischen Italien und Deutschland zu sprechen und welche Rolle das Erkennen der kulturellen Muster für eine erfolgreiche Integration spielt. In dieser Hinsicht reflektiert der Film, wie - und hier zitiere ich eine Kursteilnehmerin - ,jede Kultur zum Zentrum eines Universums wird. So wurde der

deutsche Film [von Gigi] in Deutschland mit [einem] Preis ausgezeichnet, während in Italien [seine] italienische Komödie bejubelt worden ist." Gigi, der selbst Filme dreht, ist eine der beiden Hauptfiguren des Films.

\section{Ausblick}

Was ist nun aus dem eingangs erwähnten Fuchsfenster geworden? Haben die Studierenden neue Einblicke in das Thema „Fremde“ bzw. „Fremde in Deutschland“ bekommen? Die Antworten der Studierenden auf diese Frage im Evaluationsbogen weisen alle in dieselbe Richtung. Das Interessante an diesem Kurs war ihrer Meinung nach, zu sehen, wie andere mit ihrer Fremderfahrung in Deutschland umgehen, einerseits die Autoren und Autorinnen mit Migrationshintergrund, andererseits, und das schien fast noch wichtiger zu sein, die Kommilitonen und Kommilitoninnen im Kurs - oder wie es ein Teilnehmer ausgedrückt hat:

„Es war sehr interessant, in einer internationalen Gruppe zu arbeiten und zu beobachten, wie die Menschen aus verschiedenen Staaten die deutsche Kultur wahrnehmen und [das] dann mit eigenen Gedanken vergleichen."

\section{Literatur}

Albrecht, Corinna (2003): Fremdheit. In: Wierlacher, Alois; Bogner, Andrea (Hrsg.): Handbuch interkulturelle Germanistik. Stuttgart, Weimar: Metzler, 232-238.

Beck, Ulrich; Beck-Gernsheim, Elisabeth (2007): Generation Global. In: Beck, Ulrich (Hrsg.): Generation Global. Ein Crashkurs. Frankfurt a.M.: Suhrkamp, 236-265.

Glaap, Albert-Reiner; Rück, Heribert (2003): Literarisches Curriculum. In: Bausch, Karl-Richard; Christ, Herbert; Krumm, Hans-Jürgen (Hrsg.): Handbuch Fremdsprachenunterricht. Tübingen, Basel: Francke, 133-138.

Gerdes, Joachim (2006): Jugendsprache im DaF-Unterricht - Reflexion zu Struktur, Authentizität und didaktischer Eignung des jugendsprachlichen Modephänomens „Türkendeutsch/Kanakisch“. In: Zielsprache Deutsch 3/2006, 19-43.

Goebel, Anne (2005): Gleis 11, Ankunft im neuen Leben. Der Münchner Hauptbahnhof war Umschlagplatz für Gastarbeiter aus vielen Ländern. In: SZ, 14.12.2005, 45.

Gründler, Johann Ernst; Ziegenbalg, Bartholomäus (1998): Die malabarische Korrespondenz. Tamilische Briefe an deutsche Missionare. Eine Auswabl. Eingeleitet und erläutert von Kurt Liebau. Sigmaringen: Thorbecke. 
Günderrode, Karoline von (1990): Die malabarischen Witwen. In: Morgenthaler, Walter (Hrsg.): Sämtliche Werke und ausgewählte Studien. Band I. Texte. Basel u.a.: Stroemfeld, Roter Stern, 325.

Hacke, Axel (2005): Nick di Camillo. In: Ders.: Deutschlandalbum. Reinbek bei Hamburg: Rowohlt, 108-118.

Häuser, Hans (2005): Ein Koffer voll Hoffnung. Feier zum 50. Jubiläum des Anwerbevertrags mit Italien. In: SZ, 15.12.2005, 45.

Hofmann, Michael (2006): Interkulturelle Literaturwissenschaft. Eine Einführung. Paderborn: Finck, 14-25.

Kafka, Franz (1992): Heimkehr. In: Raabe, Paul (Hrsg.): Sämtliche Eræählungen. Frankfurt a.M.: Fischer, $320 f$.

Lettau, Reinhard (1988): Zur Frage der Himmelsrichtungen. München: Hanser.

Liebau, Kurt (1998): Einleitung. In: Gründler, Johann Ernst; Ziegenbalg, Bartholomäus: Die malabarische Korrespondenz. Tamilische Briefe an deutsche Missionare. Eine Auswabl. Eingeleitet und erläutert von Kurt Liebau. Sigmaringen: Thorbecke, 7-36.

Lutz-Temsch, Birgit (2005): Die Gastarbeiter machten München zur Weltstadt. Spaghetti, Latin Lovers: Der Historiker Martin Baumeister über den Einfluss von Ausländern und deren Kultur auf die Stadt. In: SZ, 17.12.2005, 53.

Mehlhorn, Grit u. a. (2005): Studienbegleitung für ausländische Studierende an deutschen Hochschulen. München: Iudicium.

Müller, Herta (1995a): Der Überfall des Glücks auf die Gedanken. In: Dies.: Der Teufel sitzt im Spiegel. Wie Wahrnehmung sich erfindet. Berlin: Rotbuch, 107-111.

Müller, Herta (1995b): Das Land am Nebentisch. In: Dies.: Der Teufel sitzt im Spiegel. Wie Wahrnehmung sich erfindet. Berlin: Rotbuch, 121-124.

Näger, Doris (2005): „Wir wissen einfach zu wenig voneinander.“ Drei junge Türken aus der dritten Gastarbeiter-Generation über Heimat, Sprache, Freunde und ihre Lebenswünsche in Deutschland. In: SZ, 10.12.2005, 49.

Nicklas, Hans; Müller, Burkhard; Hagen, Kordes (2006): Einleitung. Interkultureller Wandel - Probleme, Handlungsfelder, Methoden. In: Dies. (Hrsg.): Interkulturell denken und handeln. Theoretische Grundlagen und gesellschaftliche Praxis. Bonn, Frankfurt a.M.: Lizenzausgabe für die Bundeszentrale für politische Bildung, 15-24.

Özdamar, Emine Sevgi (1998): Mutterzunge. In: Dies.: Mutteræunge. Eræählungen. Köln: Kiepenheuer und Witsch, 9-14.

Rilke, Rainer Maria ( $\left.{ }^{4} 1990\right)$ : Eingang. In: Zinn, Ernst (Hrsg.): Die Gedichte. Frankfurt a.M.: Insel, 317.

Şenocak, Zafer (2001): Sprache, die Kundschafterin. In: Ders.: Zungenentfernung: Bericht aus der Quarantänestation. München: Babel, $91 \mathrm{f}$.

Şenocak, Zafer (2006): Der Kompass. In: Ders.: Das Land hinter den Buchstaben: Deutschland und der Islam im Umbruch. München: Babel, $19 \mathrm{f}$.

Schäffter, Ortfried (1991): Modi des Fremderlebens. Deutungsmuster im Umgang mit Fremdheit. In: Ders. (Hrsg.): Das Fremde. Erfahrungsmöglichkeiten zwischen Fasquination und Bedrohung. Opladen: Westdeutscher Verlag, 11-42. 
Tawada, Yoko (2000): Talisman. Literarische Essays. Tübingen: Konkursbuch.

Wierlacher, Alois (2003): Interkulturelle Germanistik. Zur ihrer Geschichte und Theorie. Mit einer Forschungsbibliographie. In: Ders.; Bogner, Andrea (Hrsg.): Handbuch interkulturelle Germanistik. Stuttgart, Weimar: Metzler, 1-45.

Zaimoglu, Feridun ('2004): Kanak Sprak. 24 Mißtöne vom Rande der Gesellschaft. Hamburg: Rotbuch.

Zé do Rock ( $\left.{ }^{3} 1997\right)$ : fom winde ferfeelt. Weltstrolch macht links-shreibreform. Neuausgabe light. München: Piper. 

Christoph Chlosta, Matthias Jung (Hrsg.) (2010): DaF intergriert: Literatur - Medien - Ausbildung. Tagungsband der 36. Jahrestagung des Fachverbandes Deutsch als Fremdsprache 2008. Göttingen: Universitätsverlag, 21-31.

\section{Amina Arfaoui (La Manouba, Tunesien) \\ Arbeit mit dramatischen Texten im \\ Fremdsprachenunterricht Deutsch am Beispiel von Friedrich Dürrenmatts „Der Besuch der alten Dame“ und „Die Physiker“}

\section{Vorbemerkung}

Als Dozentin an der Deutschabteilung der Faculté des Lettres der Universität La Manouba (Tunesien), wo ich seit mehreren Jahren im zweiten und im vierten Studienjahr sowie im Masterstudiengang Literatur unterrichte (hauptsächlich Drama und Lyrik), möchte ich im vorliegenden Beitrag einige aus der Praxis entwickelte Überlegungen zu meinem Umgang mit dramatischen Texten mitteilen. Zwar ist mir bekannt, dass zum Thema Literatur im DaF eine umfangreiche Bibliographie ${ }^{1}$ existiert, aber einerseits ist es den tunesischen Lehrenden kaum möglich, sich diese Literatur zu beschaffen und andererseits mögen manche Untersuchungen sowieso zu abstrakt erscheinen, weil sie eine Situation beschreiben, die anders als diejenige ist, mit der die Lehrenden in Tunesien, einem arabisch-islamischen Land, konfrontiert sind. Bevor ich auf mein Thema eingehe, sei deshalb erst ein Bild von den tunesischen Zuständen sehr kurz skizziert, damit die folgenden Ausführungen richtig bewertet werden.

1 Vgl. die vom DAAD regelmäßig veröffentlichte Auswahlbibliographie Für Sie gelesen, die „Kommentare und Rezensionen zu über hundert Neuerscheinungen für das Fach Deutsch als Fremdsprache" bietet. 
Zu berücksichtigen ist vor allem die Tatsache, dass die Studenten sich zum ersten Mal in ihrem Leben mit einem deutschen dramatischen Text beschäftigen, da das Drama seit einigen Jahren im ersten Jahr nicht mehr unterrichtet wird, obwohl es ,als die grundlegende literarische Form, der Poesie, Prosa usw. als Spezialisierungen unterstellt sind“, (Tselikas 2002: 58) gilt. Begrüßenswert ist daher im Universitätsjahr 2006/2007 die Existenz eines Theaterkurses im ersten Studienjahr, bei dem allerdings „,besonders die Pragmatik und nonverbale Kommunikation eine Rolle spielen" (Seyferth ${ }^{2}$ ). Im ersten Jahr werden also derzeit nur Lyrik und Kurzgeschichte unterrichtet. Noch zu erwähnen sind das schwache sprachliche Niveau der Studenten, das den Unterricht und die Kommunikation erschwert, und die schlechten Arbeitsbedingungen in der (allerdings an neuen deutschen Büchern sehr armen) Bibliothek, aus der sie nur ein Buch entleihen dürfen. ${ }^{3}$

\section{2}

Eine solche Situation stellt eine große Herausforderung für die Lehrenden dar, die alles Mögliche tun, um ihren Aufgaben trotz dieser Schwierigkeiten nachzugehen. Dabei müssen sie freilich eine eigene Unterrichtsstrategie entwickeln. Im vorliegenden Beitrag habe ich vor, zu beschreiben, wie ich meinerseits verfahre, um das Interesse der Studierenden des zweiten Jahres für den dramatischen Text zu wecken und es rege zu halten, in der Hoffnung, dass diese Erfahrungen den jüngeren Kollegen und Kolleginnen in Tunesien (und vielleicht auch woanders) nützlich sein könnten, die sich oft fragen, wie sie die Studenten in die literarische Analyse einweihen können (dieses Studienjahr ist deswegen gewählt worden, weil Seminare des „Premier Cycle“ besonders wichtig für die Studierenden sind, die sich in den folgenden Jahren gründlicher mit literarischen Texten befassen). Anschließend wird auch gezeigt, was den tunesischen Studenten den Zugang zum literarischen Text besonders erschwert, und wie dieser Situation abzuhelfen ist. Dabei werde ich mich hauptsächlich auf Friedrich Dürrenmatts „Der Besuch der alten Dame“ und „Die Physiker“ beziehen.

\section{3}

Bei den angeführten Schwierigkeiten mag es wenig überraschen, dass die große Mehrheit der Studenten eigentlich nichts über den Autor und den programmatischen Text weiß. Aber auch wenn einige von ihnen über die Hauptproblematik des Dramas „Die Physiker“ - die Verantwortung des Wissenschaftlers und den Hinweis auf die Atomkriegsgefahr - im Bilde sind, sind sie meistens nicht fähig, ohne die Hilfe des Dozenten die sich darauf beziehenden Stellen in Texte zu erkennen bzw. herauszufinden. Wie kann dieses Problem beseitigt werden?

2 Sybille Seyferth war 2006-2007 Sprachassistentin des DAAD an der Faculté des Lettres La Manouba.

3 Ob der Mangel an Büchern durch den Einsatz des Internets verbessert werden wird, bleibt dahingestellt, da sowieso nur wenige über einen Computer und eine Internet-Verbindung verfügen. 


\section{4}

Die von mir im Unterricht verwendete Methode, um den Studenten einen Zugang zum Text zu verschaffen, besteht darin, sie in kleinen Dosen mit dem Werk bekannt zu machen, damit sie mit dem Drama vertraut werden, ohne in Panik zu geraten. So ist davon abzuraten, bei der Vorbereitung des Semesterprogramms gleich mit theoretischen Fragen anzufangen. Als erste Etappe gilt es, die Studierenden mit dem Autor selbst bekannt zu machen. Gleich auf den Text einzugehen, als ob er anonym wäre, finde ich wenig glücklich, weil das ihr Interesse daran vermindern kann, während eine kleine Vorstellung des Schriftstellers einen Kontakt zu ihm und dessen Werk herstellt und ihre Neugierde erweckt. Es sei gleich präzisiert, dass es selbstverständlich nicht darum geht, sich ausführlich mit dem Leben des Autors zu beschäftigen, sondern darum, in der einleitenden Lehrveranstaltung die Informationen auszusuchen, die bei der Analyse des im Unterricht zu analysierenden Textes helfen können und relevant sind. Es sei hier auf ein kleines konkretes Beispiel hingewiesen. Die Tatsache, dass Dürrenmatt ein moderner Schweizer Autor ist, ist zu erwähnen - wie wären sonst die vielen, meistens ironischen, Anspielungen auf die Schweiz, deren Landschaft, deren Gesellschaft und Wirtschaft zu verstehen? - und auch, dass er Pfarrerssohn ist; darauf wird später eingegangen.

\section{5}

Darüber hinaus hat der Lehrende bei der Beschäftigung mit dem dramatischen Text den Studenten nicht nur das dazugehörende Vokabular beizubringen, sondern er hat ihnen auch dabei zu helfen, zwischen den verschiedenen Textsorten, den Regieanweisungen und dem Beginn der Handlung, zu unterscheiden, da die Studenten anfangs weder die Funktion der informationsreichen Regieanweisungen noch der Requisiten verstehen. Empfehlenswert ist auch, dass Studenten ab und zu und der Reihe nach den Text vorlesen, damit sie mit den Figuren und der Handlung vertraut werden. Das zwingt sie zu folgen und sich zu konzentrieren. Dabei wird von ihnen erwartet, dass sie sich einigermaßen in die „dramatis personae“ hineinversetzen, sie sollen die Rolle spielen und die richtige Intonation einnehmen (wenn es sich z.B. um eine Frage, um einen Befehl, um den Ausdruck eines Gefühls handelt). Diese an sich nicht komplizierte Übung ist nicht einfach zu realisieren, so fällt zu Semesterbeginn auf, dass das Vorlesen den Studenten große Schwierigkeiten bereitet: Wenn sie lesen, sind sie nicht imstande, die richtige Seite oder den richtigen Passus zu finden, denn sie sind wahrscheinlich aus Schüchternheit - wie blind. Aber zu Semesterschluss können sie das ohne weiteres tun und sind in der Lage, bei Dürrenmatt oft vorkommende kleine, manchmal aus einem einzigen Wort bestehende oder subjektlose Sätze zu verstehen. ${ }^{4}$

4 Wie im Gespräch zwischen dem Inspektor und der Oberschwester am Anfang des Dramas „Der Besuch der alten Dame“ z.B.:

Der Dritte: Ruiniert.

Der Vierte: Die Wagnerwerke zusammengekracht.

Der Erste: Bockmann bankrott. 


\section{6}

Nach dieser kurzen Vorstellung der Arbeitsweise fragt sich jetzt, wie man auf den dramatischen Text eingehen kann, damit der Verstehensprozess gefördert wird. Mit dieser Frage komme ich zum eigentlichen Kernpunkt meines Beitrags, der sich mit der Schwierigkeit befasst, von der die tunesischen - und eigentlich bestimmt auch die in einem anderen arabisch-islamischen Land lebenden - Studenten betroffen sind, wenn sie sich mit einem deutschsprachigen Text befassen.

\section{7}

Meines Erachtens besteht diese Schwierigkeit zum großen Teil in ihrer Unfähigkeit, im literarischen Texte religiöse, bzw. biblische und mythologische Bezüge zu erkennen und zu verstehen. Europäische Studierende brauchen keine Erklärungen für solche Bezüge, weil die griechisch-römische Mythologie und die jüdisch-christliche Religion zu den Grundlagen der Kultur gehören, ${ }^{5}$ in der sie aufgewachsen sind und von der ihr Geist und derjenige der europäischen Autoren tief geprägt sind, die sich davon inspirieren lassen und sich damit auseinandersetzen.

\section{8}

Damit wird freilich nicht behauptet, dass christliche Religion und griechisch-römische Mythologie den ganzen Inhalt eines literarischen Textes ausmachen, dessen Facettenreichtum vielleicht sogar unerschöpflich ist: Wie könnten sonst Kommentare zu schon sehr oft interpretierten Werken noch regelmäßig veröffentlicht werden (vgl. Jäger 2008)? Aber da diese mythologischen und religiösen Anspielungen den tunesischen Studierenden nicht auffallen, weil sie es nicht erwarten und sie in ihrem Kopf naiv Literatur und Religion als getrennte Bereiche betrachten und vermutlich Mythologie nur bei den Autoren der Antike zu finden denken, soll im Unterricht gleich zu Beginn des Semesters darauf hingewiesen werden, vor allem in einem Land arabisch-islamischer Kultur. Das im Voraus zu wissen, wird den Studierenden den Zugang zum Text erleichtern und ihnen ermöglichen, auf weitere Aspekte des Dramas einzugehen.

\section{$[\ldots]$}

Der Dritte: Leben von der Arbeitslosenunterstützung.

Der Vierte: Von der Suppenanstalt.

Der Erste: Leben?

Der Zweite: Vegetieren.

Der Dritte: Krepieren.

Der Vierte: Das ganze Städtchen.

5 Deswegen kommen uns alle Manifestationen des Antisemitismus, der bekanntlich ein europäisches Phänomen war (und noch ist?) und in der Barbarei des Holocausts gipfelte, als unverständliches und widersprüchliches Phänomen vor, weil die Antisemiten die Wurzeln ihrer eigenen Kultur angegriffen haben, waren doch Maria, Jesus und die Apostel Juden! 


\section{9}

Zwar ist eine solche Feststellung schon erkannt worden:

„Für die westeuropäischen Kulturen sind vor allem zwei Mythologien wichtig: die antike Mythologie und die christliche Mythologie (die sich teilweise mit der jüdischen deckt). Bestimmte antike und christliche Mythen (z.B. Sisyphos, Ödipus, Herakles usw., Paradies, Judith, Magdalena, Verlorener Sohn usw.) sind von den westeuropäischen Literaturen häufig wieder aufgegriffen oder konnotiert worden. Ohne Kenntnis dieser Mythologien sind viele Konnotationen nicht als solche erkennbar",

schreibt z.B. Jürgen Link (1990: 86), und mag deswegen an kompliziertere Thesen gewohnten Geistern als Evidenz oder sogar als Binsenweisheit vorkommen, aber ich bin der Meinung, dass sie nicht genug Widerhall findet und dass ihr hier mehr Aufmerksamkeit gewidmet werden sollte.

\section{0}

Wie wichtig die Zusammenhänge mit biblischen Motiven und Figuren und der griechisch-römischen Mythologie bei Dürrenmatt sind, dem allerdings der Vater die Bibel und die Mutter die griechisch-römische Mythologie beigebracht haben, kann schon aus der Liste seiner Werke ersehen werden (Auswahl): „Ein Engel kommt nach Babylon“, „Romulus der Große“, „Herkules und der Stall des Augias“, „Die Wiedertäufer" usw.

\section{1}

Viele Punkte des literarischen bzw. dramatischen Textes sind also den in einem arabischislamischen Land lebenden Studierenden dunkel, weil diese in Kontakt mit einer ihnen fremden Kultur und Religion gebracht werden, so fremd, wie es der Islam in Europa ist (was sicherlich auf eine Lücke in der Allgemeinbildung hinweist ${ }^{\dagger}$ ). Hier ein Beispiel: Als im Unterricht darauf hingewiesen wurde, dass Dürrenmatt als Pfarrerssohn in einer besonders religiösen bzw. frommen Umgebung aufgewachsen ist, wurde festgestellt, dass die Studenten nicht zwischen Priester und Pfarrer bzw. zwischen Katholizismus und Protestantismus unterscheiden konnten. Zwar haben sie im Landeskundeunterricht von Martin Luther und der Reformation gehört, aber die Unterschiede zwischen diesen zwei Richtungen des Christentums kennen sie kaum, denn es gibt keine Lehrveranstaltung, in der auf das Christentum eingegangen wird. Obwohl ihre Unkenntnis darüber sogar erstaunlich ist (so hat ein Student das Kreuz der von ihm selbst zu Semesteranfang erwähnten Schweizerischen Flagge als ein Pluszeichen interpretiert), die sich auch u.a. in ihrer Unfähigkeit zeigt, in der Malerei eine Szene aus dem Leben der Jungfrau Maria oder einen Christus darstellendes Gemälde zu verstehen, fällt im Unterricht auf, dass die tunesischen Studenten mehr vom Katholizismus als vom Protestantismus gehört

6 Es sei hier auf die von der Zeitschrift „Qantara“ erwähnte Veröffentlichung des ersten deutschen IslamSchulbuches verwiesen, das „Saphir“ heißt und von den drei profilierten islamischen Religionspädagogen Lamya Kaddor, Rabeya Müller und Harry Harun Behr herausgegeben wird (Mende 2008). 
haben, vielleicht wegen der Nähe Italiens zu Tunesien oder wegen der weltbekannten Person des derzeitigen Papstes.

\section{2}

Das bedeutet praktisch, dass die im Drama vorkommenden Anspielungen auf das Christentum und auf die Bibel - sowohl auf das Alte als auf das Neue Testament - ihnen vollkommen entgehen, ganz zu schweigen von den damit verbundenen Bildern und Metaphern. Diese Feststellung steht allerdings im Widerspruch zu der Meinung Lothar Bredellas (2002: 307), der schreibt:

„Da literarische Texte Erfahrungen und Handlungen darstellen, bedürfen ihre Leser keines speziellen Sachwissens, um sie zu verstehen, sondern können sich auf ihr lebensweltliches Vorwissen über Handlungen und Wertvorstellungen wie Gut und Böse, Gerechtigkeit und Ungerechtigkeit, Schönheit und Hässlichkeit verlassen. “

\section{3}

Um diese angeführte Schwierigkeit zu umgehen und damit der Text leichter zugänglich wird, soll der Dozent die Studierenden auf diese religiösen Bezüge aufmerksam machen und ihren Geist für solche Informationen zu öffnen, indem er ihnen erklärt, wie wichtig der religiöse Hintergrund ist. Er soll sie von vornherein auf die Bibel als eine wichtige Quelle verweisen, aus der der Dramatiker manche Anregungen geschöpft hat - auch wenn dieser sich davon distanziert bzw. selbst nicht gläubig ist -, und ihnen zu empfehlen, eventuell sich selbst darauf zu beziehen, um sich zu informieren, wenn sie den literarischen Text richtig verstehen wollen. Denn in manchen literarischen Werken wimmelt es von religiösen Anspielungen (selbst beim Marxisten Bertolt Brecht). Ich bin der Ansicht, dass im Drama „Die Physiker“ hauptsächlich Hinweise auf das Alte Testament vorkommen, während im „Besuch der Alten Dame“ eher Hinweise auf das Neue Testament zu finden sind, eine Behauptung, die allerdings noch gründlicher zu belegen ist.

\section{4}

Hier seien ein paar kleine Beispiele aus den „Physikern“ angeführt. So hat Missionar Rose viele Kinder, weil er als protestantischer Geistlicher eine Familie gründen darf. Möbius singt Psalmen. Wichtiger und auffallender sind die leitmotivisch wiederkehrenden Anspielungen auf König Salomo. Um die Teilnahme der Studenten zu fördern, lässt man sie zum Beispiel alle Passagen heraussuchen und markieren, in denen diese Figur erwähnt wird, sodass sie dann mit einigen Stellen vertraut werden und ihnen das Verständnis der Szene(n) erleichtert wird. Dabei gewinnt der Unterricht einen spielerischen Charakter, weil selbst die wenig begabten Studenten gerne mitmachen und sie nachher allein weitere Belege finden können. Da bei der von mir verwendeten Unterrichtsmethode die Textanalyse nicht geradlinig, sondern flexibel verläuft, kann im Drama „Die Physiker“ schon in den ersten Lehrveranstaltungen gleich auf das Ende des Dramas eingegangen werden, dessen letzte Worte lauten: „ich bin Salomo, ich bin 
Salomo, ich bin der arme König Salomo“, was eben die Wichtigkeit dieser allerdings nie auftretenden, nur erwähnten biblischen Figur im Drama belegt. Im „Besuch der alten Dame“, in der die Verführbarkeit und die Käuflichkeit der Gemeinde auch an der Figur des Pfarrers demonstriert werden, sagt dieser im zweiten Akt zu Ill: „Führe uns nicht in Versuchung, indem du bleibst.“ (76). Das Wort „Versuchung“ bzw. dessen religiöse Bedeutung ist zu erklären, damit die Erscheinung der Claire Zachanassian als „Teufelin“, die die Güllener mit ihrem Geld verführt, verstanden wird.

\section{5}

$\mathrm{Zu}$ betonen ist auch, wie Dürrenmatt durch Symbolik und Metaphorik - Namen-, Farben- und Tiersymbolik sowie Tiermetaphorik - diese religiösen Anspielungen ausdrückt und illustriert. Denn Dürrenmatt bedient sich oft der Symbolik, und da Symbole universell sind, kann die Aufmerksamkeit der Studierenden, die sich die Erklärungen gerne anhören, leicht darauf gelenkt werden. Die Namensymbolik erscheint deutlich im Namen der Stadt Güllen und der Protagonistin Claire Wäscher, während die Nebenfiguren - außer Ill - keinen Namen, sondern eine Nummer oder den Namen ihres Berufs tragen (der Lehrer, der Bürgermeister, usw.). Die Farbensymbolik zeigt sich in der gelben Farbe der Schuhe, der Farbe des Verrats: auch hier kann im Text verfolgt werden, wer diese gelben Schuhe trägt. Diese Symbolik dient bekanntlich dazu, die Heuchelei und die Käuflichkeit der christlichen Güllener Gemeinde hervorzuheben.

\section{6}

Um Dürrenmatts Werke verstehen zu können, ist nicht nur die Lektüre der Bibel bzw. von Fachbüchern zu biblischen Figuren und Themen zu empfehlen ${ }^{7}$, sondern auch eine präzise Kenntnis der griechisch-römischen Mythologie, für die die obigen Äußerungen auch gelten. Denn im Gegensatz zu den europäischen Studenten, die durch Literatur, bildende Kunst (man denke an die Malerei und an die Bildhauerei der Antike und der Renaissance) und Musik damit vertraut sind, haben die tunesischen Studenten kaum eine Ahnung davon, obwohl sich praktisch jeder europäische Autor darauf bezieht und die verschiedenen Sprachen Europas davon geprägt sind - was unseren Studenten auch entgeht.

\section{7}

Positiv ist aber, dass diese sich die verschiedenen Erklärungen gerne anhören, genau wie sie die religiösen Bezüge mit Aufmerksamkeit verfolgen, zumal manchmal Ähnlichkeiten mit dem Islam vorkommen - eine Tatsache, die ihnen besonders gefällt -, wie es der Fall für den König Salomo in den „Physikern“ ist, der im Islam ein wichtiger Pro-

In diesem Zusammenhang gestehe ich ein, dass ich zum Thema christliche Religion keine zugänglichen, von Literaturwissenschaftlern (d.h. nicht von Theologen) verfassten Bücher gefunden habe, die ausführlich und klar die religiösen Themen und Motive vorstellen. Bei dem in Tunesien vorherrschenden Mangel an Büchern ist das kein Wunder, es gibt aber sicherlich welche in den europäischen Universitätsbibliotheken. 
phet ist, der Prophet Sulaymen. Die Anspielungen auf die griechisch-römische Mythologie werden in den „Physikern“ vom Lehrer, das heißt vom Gebildeten der Güllener Gemeinde, gemacht, der sich als „ein Humanist, ein Freund der alten Griechen, ein Bewunderer Platos" (99) bezeichnet und Claire Zachanassian mit einer Parze vergleicht: „Kommt mir vor wie eine Parze“ (34). „Sie ist aus dem Orkus gekommen“, sagt er noch. Seine sich auf Claire Zachanassian als Parze beziehenden Anspielungen helfen dazu, die Funktion der facettenreichen Heldin auch als Todesengel zu verstehen.

\section{8}

Freilich wird im Unterricht noch auf weitere Punkte eingegangen: auf die Frage der literarischen Gattung - Tragikomödie oder Komödie - und auf die von Dürrenmatt verwendeten Begriffe und Stilmittel des Paradoxen und des Grotesken, die die Sprache des Dramatikers charakterisieren, und deswegen auch zu erklären sind. In diesem $\mathrm{Zu}$ sammenhang kann auf die Theorie des Aristoteles eingegangen werden, falls das nicht bei der Präsentation des Dramas gemacht wurde, um zu erklären, wie Dürrenmatt als Vertreter der Moderne die Theorie des Aristoteles nur zitiert, um sich darüber lustig zu machen, wie z.B. in den einleitenden Regieanweisungen zu den „Physikern“, wo er über die drei Einheiten schreibt:

„Auch den Salon werden wir nie verlassen, haben wir uns vorgenommen, die Einheit von Raum, Zeit und Handlung streng einzuhalten; einer Handlung, die unter Verrückten spielt, kommt nur die klassische Form bei.“ (10)

\section{9}

Ich bin der Meinung, dass unsere Studenten, die sich verunsichert fühlen, weil sie sich zum ersten Mal mit einem deutschsprachigen dramatischen Text befassen, durch einen solchen Ansatz Anhaltspunkte gewinnen und bereit werden, weitere Aspekte des inhaltlich reichen Textes zu verstehen. Außerdem eröffnet ein solcher Ansatz den tunesischen Studierenden, für die es nicht so einfach ist, Forschungsthemen zu finden, da die Germanisten der ganzen Welt sich mit allen möglichen Themen beschäftigen, eine neue Forschungsperspektive und ermöglicht ihnen von diesem Standpunkt aus deutschsprachige Texte mit ihrer Lesart und einer eigenen Fragestellung zu behandeln.

\section{0}

Erwähnenswert ist auch, dass die von mir verwendete Arbeitsmethode zu positiven Ergebnissen geführt hat. So haben im Jahre 2004-2005 tunesische Studierende der Deutschabteilung der Faculté La Manouba die Initiative ergriffen, das im Literaturunterricht des zweiten Studienjahres analysierte Drama „Der Besuch der alten Dame“ zu inszenieren, und es ist ihnen gelungen, trotz der verschiedenen Schwierigkeiten, die ihnen begegnet sind, zwei interessante, lebendige Aufführungen durchzuführen. ${ }^{8}$ Obwohl diese Studierenden auf sich selbst angewiesen waren und über keine finanzielle Un-

\footnotetext{
8 Verantwortlich für Inszenierung, Regie, Beleuchtung usw. war der Student Ali Ouatouti.
} 
terstützung verfügten, haben sie weder Zeit noch Energie gescheut, um ihr Projekt zu verwirklichen. Zwei Jahre später haben weitere Studierende - diesmal mit meiner Unterstützung - anlässlich der Tuniser Faust-Tagung ${ }^{9}$ Szenen der Gretchen-Tragödie (aus dem „Urfaust“) aufgeführt, bei denen sie mit großem Talent Faust, Mephistopheles, Gretchen, Frau Marthe und Lieschen gespielt haben. ${ }^{10}$ Wie die Dom- und Zwingerszenen aufgeführt und interpretiert wurden, ist erstaunlich - von der Kerker-Szene ganz zu schweigen! Diese Aufführungen, mit deren Analyse sich noch niemand beschäftigt hat, stellen auch ein eventuelles Forschungsthema dar.

\section{1}

Die vorliegenden Äußerungen haben hoffentlich auch gezeigt, dass es mit einem solchen Ansatz möglich ist, bestimmte dramatische Texte, deren Lektüre DaF-Studierenden schwierig vorkommen könnten, - was sie nicht daran hindert, sie im Programm haben zu wollen - in das Curriculum der folgenden Studienjahre zu integrieren. Gedacht ist hier beispielsweise an den „Urfaust“, an „Faust I“ und auch an Schillers Drama „Maria Stuart“, deren Protagonistin die schöne katholische, königliche „Sünderin“ ist. „Maria Stuart“ ist ein Thema im Seminar „Literatur des 18. Jahrhunderts“ des vierten Studienjahres. Dafür spricht auch die Tatsache, dass die mit dem Literaturnobelpreis ausgezeichnete österreichische Schriftstellerin und Vertreterin des postdramatischen Theaters Elfriede Jelinek sich in ihrem Schauspiel „Ulrike Maria Stuart“ (vgl. Gutjahr 2007) damit befasst, auch wenn es ihr darum geht, es zu dekonstruieren. Ob Elfriede Jelinek in ihrer Bearbeitung von Schillers Tragödie die Mortimer-Figur und die BeichtSzene (u.a.) beibehalten hat oder nicht, ist mir nicht bekannt, da sie den Text ihres Dramas leider nicht veröffentlichen will.

\section{2}

Abschließend möchte ich Folgendes hinzufügen: Obwohl ich von der Voraussetzung ausgegangen bin, dass die europäischen Studenten über religiöse und mythologische Grundkenntnisse verfügen, darf gefragt werden, ob sie tatsächlich noch imstande sind, in einem literarischen Text alle mythologischen und religiösen Konnotationen zu erkennen bzw. zu verstehen. Bei zunehmendem Desinteresse an der Religion, über das sich die westeuropäischen Kirchen beklagen, ist diese Frage berechtigt, zumal es unter diesen Studenten Migranten-Kinder gibt. Da die muslimische Bevölkerung Deutschlands hauptsächlich türkischen Ursprungs ist, wäre es in diesem Zusammenhang interessant $\mathrm{zu}$ wissen, ob und wie deutsche Studierende türkischer Abstammung diese religiösen und mythologischen Bezüge wahrnehmen.

\footnotetext{
Unter der Leitung der Studentin Yamina Abidi, die sich um viele weitere Aufgaben gekümmert hat.

10 Aus Anlass des 200. Jahres der Veröffentlichung von Goethes „Faust. Der Tragödie Erster Teil“ haben die Deutschabteilung der Faculté des Lettres, des Arts et des Humanités der Universität La Manouba, Tunesien, und die Goethe-Gesellschaft in Weimar ein Kolloquium in Tunis veranstaltet (1.-3. November 2007), dessen Thema lautete: „Goethes „Faust“ und das Faustische“ (Organisationskomitee: Amina Arfaoui, Peter-Anton von Arnim, Jochen Golz und Hédi Ouanès).
} 


\section{3}

Aus den obigen Reflexionen ergeben sich noch weitere Fragen, die z.B. lauten: Welche weiteren Themen oder Anspielungen können die tunesischen Studierenden in einem deutschsprachigen Werk nicht erkennen? Und: Bei welchen Autorinnen, bei welchen Autoren stimmt der hier vorgestellte Ansatz nicht? Oder noch: „Gibt es in der Literatur länderübergreifende Themen? Gibt es den europäischen Autor? Und allgemeiner: Was ist Europa aus Sicht der Literatur- und Kulturwissenschaft, aus Sicht europäischer und außereuropäischer Schriftsteller?“"11 Die zuletzt zitierten Fragen, die von der Zeitschrift „Kritische Ausgabe“ für deren Themenheft „Europa“ aufgeworfen werden, scheinen mir einen Zusammenhang mit den im vorliegenden Beitrag ausgedrückten Reflexionen zu haben, die vielleicht auch im Internationalen Promotionskolleg „Gründungsmythen Europas“ (Bonn - Paris IV Sorbonne - Florenz) oder auf dem XII. Kongress der Internationalen Vereinigung für Germanistik (Warschau 30. Juli bis 7. August 2010), in der Sektion „Nationale und Transnationale Identitäten“ oder in der Sektion „Einheit in der Vielfalt? Der Europadiskurs der SchriftstellerInnen seit der Klassik“ ergänzt oder widerlegt werden könnten. ${ }^{12}$

\section{Literatur}

Dürrenmatt, Friedrich (1956): Der Besuch der alten Dame. Eine tragische Komödie. Zürich: Arche.

Dürrenmatt, Friedrich (1962): Die Physiker. Eine Komödie in zwei Akten. Zürich: Arche.

Bredella, Lothar (2002): Fremdverstehen mit literarischen Texten. In: Ders.: Literarisches und interkulturelles Verstehen. Tübingen: Narr, 306-330.

Gutjahr, Ortrud (Hrsg.) (2007): „Ulrike Maria Stuart“ von Elfriede Jelinek. In: Theater und Universität im Gespräch 5, Würzburg.

Jaeger, Michael (2008): Global Player Faust oder Das Verschwinden der Gegenwart. Zur Aktualität Goethes. Berlin: wjs.

Link, Jürgen (1990): Literaturwissenschaftliche Grundbegriffe. Eine programmierte Einführung auf strukturalistischer Basis. München: Fink.

Mende, Claudia (2008): Erstes deutsches Islam-Schulbuch. Edelstein als Lehrmaterial. http:/ / de.qantara.de/webcom/show_article.php/_c-469/_nr-935/i.html (15.12.2008).

Seyferth, Sybille: Erfahrungsbericht: Szenisches Theater mit Lernenden der Niveaustufen A2/B1 GER, unveröffentlichter Bericht.

Tselikas, Elektra (2002): Dramapädagogischer Literaturunterricht als ein Prozess von interkulturellen Identifikationen und Grenzverschiebungen. In: Krumm, Hans Jürgen; Portmann-Tselikas, Paul R. (Hrsg.): Literatur im DaF-Unterricht. Theorie und Praxis (Österreichische Beiträge zu Deutsch als Fremdsprache 6). Innsbruck; Wien: Studienverlag, 57-74.

11 Call for Papers der Zeitschrift „Kritische Ausgabe“.

12 Die Informationen zu der Zeitschrift „Kritische Ausgabe“, dem Bonner Kolleg und dem Warschauer Kongress der IVG verdanken wir H-GERMANISTIK, „dem Netzwerk für literaturwissenschaftlichen Wissenstransfer, Humanities-Network for German Literature and Philology“. 


\section{Informationen aus dem Internet}

Call for Papers: Themenheft „Europa“ der Zeitschrift „Kritische Ausgabe“. http:// hsozkult.geschichte.hu-berlin.de/termine/id=9687 (01.08.2008).

H-Germanistik, Netzwerk für literaturwissenschaftlichen Transfer: http://www.hgermanistik.de (15.09.2008)

From: Prof. Dr. Michael Bernsen

Subject: ANK: Trinationales Promotionskolleg: Gründungsmythen Europas in Literatur, Kunst und Musik

Date: Friday, May 16, 2008 14:09 PM

From: Marcel Diel < diel@kritische-ausgabe.de>

Subject: CFP: Themenheft „Europa“ der Zeitschrift „Kritische Ausgabe“ (15.09.2008)

Date: Friday, August 01, 2008 18:59 PM

From: Prof. Laura Auteri

Subject: CFP: IVG-Sektion 27: Nationale und Transnationale Identitäten, Warschau (30.11.2008)

Date: Wednesday, September 24, 2008 21:51 PM

From: Peter Hanenberg

Subject: CFP: IVG-Sektion 34: Einheit in der Vielfalt? Der Europadiskurs der SchriftstellerInnen seit der Klassik, Warschau (30.11.2008)

Date: Friday, September 19, 2008 19:25 PM 

Christoph Chlosta, Matthias Jung (Hrsg.) (2010): DaF intergriert: Literatur - Medien - Ausbildung. Tagungsband der 36. Jahrestagung des Fachverbandes Deutsch als Fremdsprache 2008. Göttingen: Universitätsverlag, 33-48.

\section{Karl Esselborn (München)}

\section{Lust auf Literatur. Zugänge zur deutschsprachigen Gegenwartsliteratur für DaF-Lerner}

\section{Einleitung}

Literarische Texte waren in den 1990er Jahren im FSU DaF noch selbstverständlich präsent. Der Sprachkurs „Die Suche“ (1993ff.) - nach zeitweiliger Begeisterung wieder aus der Mode - baute sogar im Sinne eines ganzheitlichen „narrativen Ansatzes“ (Schwerdtfeger 2000, Hunfeld 1990) ganz auf eigens dafür geschriebenen literarischen Texten auf, das Lehrbuch „Elemente“ (1996) setzte mit zunehmendem Niveau fast ausschließlich auf Literatur, sein anspruchsvolles kulturhermeneutisches Programm scheint allerdings eher für spezielle Interessenten geeignet. Bei der Zunahme der Fachsprachenkurse und der stärkeren Ausrichtung des immer unter Zeitdruck stehenden Deutschunterrichts auf (standardisierte) Sprachprüfungen (bei welchen wie bei der Zertifikatsprüfung DaF Literatur keine Rolle spielt) bzw. bei der zunehmenden Orientierung der neuesten Sprachlehrwerke am eher quantifizierenden Referenzrahmen des Europarates - der erst auf der Niveaustufe 4 (B2) nach 700-800 Unterrichtsstunden unter „Lesen“ auch das Verstehen zeitgenössischer literarischer Prosatexte vorsieht (vgl. Kuri 2001) - rücken literarische Texte gegenwärtig offenbar immer weiter aus dem Blickfeld. 2002 wurde im österreichischen DaF-Jahrbuch „Theorie und Praxis“ (6/2002) mit Schwerpunkt „Literatur im DaF-Unterricht“ konstatiert, dass sich Literatur im FSU auf dem Rückzug befinde und der Einsatz literarischer Kurztexte im Unterricht nur lohne, wenn auf den „zu hastigen Transfer“ von Konzepten der Literaturwissenschaft verzichtet und „ihr 
Einsatz dem zentralen Anliegen des Fremdsprachenunterrichts, nämlich dem Erlernen der Fremdsprache, untergeordnet wird“ (Krenn 2002: 20, 17). Die Konsequenz sind Vorschläge zum Einsatz kleiner Texte der Jugend- und Kinderliteratur, deren Inhalte dann hinter einem ausführlichen Sprach-Lernprogramm vollständig verschwinden. ${ }^{1}$

Ähnlich definierten Altmayer und Forster 2003 das wissenschaftliche Fach Deutsch als Fremdsprache (im Rückgriff auf die Strukturdebatte von 1992-96) als „einheitliches Fach mit unterschiedlichen Aufgaben und Schwerpunkten, in dessen Mittelpunkt die Theorie und Praxis des Erwerbs/Lernens und Lehrens der Fremdsprache Deutsch steht" (Götze; Suchsland 1996: 67, zitiert nach Altmayer; Forster 2003), ohne aber eine genauere Definition dessen zu geben, was letztlich mit „Sprache“ gemeint ist. Zu ihr gehören aber neben der pragmatischen Dimension (Kulturstandards) auch die Literatur und der öffentliche Diskurs als wichtige Teilbereiche und ihr entscheidender Beitrag zur eng miteinander verbundenen Sprach- und Kulturgeschichte, weshalb Harald Weinrich und die Thesen des GI noch 1992 Deutsch als Fremdsprache als „Kultursprache“ propagierten (Beirat Deutsch als Fremdsprache 1992: 34-35). ${ }^{2}$ Erst neuerdings betont der neugewählte Präsident des Goethe-Instituts Lehmann wieder: „Die deutsche Sprache ist nicht nur ein Instrument, sie ist Kulturträger.“ Deshalb sollen Spracharbeit (speziell für Schulen) und Programmarbeit stärker auf einander bezogen werden. ${ }^{3}$ Allerdings kamen vom Goethe-Institut, das seit den 1980er Jahren zahlreiche Materialien zur (nicht nur schulischen) Literaturdidaktik veröffentlichte, wie die Reihe „Werkhefte Literatur“ oder didaktische Ausgaben von Kinder- und Jugendliteratur usw., seit der unvermittelten Auflösung der Abteilung für Forschung und Entwicklung keine systematischen Beiträge mehr zu diesem Bereich. ${ }^{4}$

$\mathrm{Zu}$ dominieren scheint eher wieder die verengte linguistische Sicht und das traditionelle vorwissenschaftliche Konzept des Sprachunterrichts für Anfänger im Inland, die oft kaum Ansätze von Textgrammatik oder Stilistik kennen, ${ }^{5}$ keine literarische Lektüre usw., und die von einer minimalen fremdsprachlichen Verstehens- und Ausdrucksfähigkeit der Lerner ohne Rücksicht auf ihre muttersprachlichen (literarischen) Kompetenzen ausgehen. Die fremdsprachendidaktischen Methodendiskussionen der letzten Jahrzehnte um eine Differenzierung der fremdsprachlichen Fertigkeiten (speziell was Lesen und Argumentieren betrifft) und ihre Fundierung durch ein Fremdverstehen scheinen für die Praxis kaum Bedeutung zu haben.

1 Deutlich offener sind die Beiträge zum Schwerpunkt „Die Vielperspektivität in Literatur und Literaturvermittlung“ der Münchner FaDaF-Tagung 2002 (Materialien DaF Bd. 70, Regensburg 2003), da meist aus der Perspektive der Auslandsgermanistik argumentiert wird.

21998 erwähnt er allerdings den fremdsprachigen Literatur- und Landeskundeunterricht nur noch als förderlich für Sprachkenntnisse und Kommunikationsfähigkeit, weil statt der Sprache selbst der Handlungs- und Inhaltsaspekt im Vordergrund stehe (Beirat Deutsch als Fremdsprache 1998).

3 In: Goethe-Institut aktuell, April 2008: 1.

4 Zurzeit wird Literatur nur an Schulen im Ausland unterhalb des Niveaus der deutschen Auslandsschulen vermittelt und erscheint dort auch eher in Projekten. Literatur für den FSU (oder die Landeskunde) ist kein Thema mehr für die Lehrerfortbildung, da offenbar „Integration“ das neue Konzept ist.

5 Obwohl auch die in Lehrwerken jetzt üblichen Zeitungstexte eine gewisse literarisch-rhetorische Stilisierung aufweisen. 
Vergessen wird auch, dass im Deutschunterricht an Schulen und Hochschulen im Ausland deutschsprachige Literatur stets zugleich eine pädagogische und literarische Bildungsfunktion zu erfüllen hat, wie immer diese auch entsprechend den nationalen Traditionen definiert wird. Denn eine systematische Bestandsaufnahme der Rolle von Literatur in den unterschiedlichen nationalen Bildungskonzepten - vor allem im Vergleich mit den idealistischen deutschen Traditionen - ist noch ein dringendes Desiderat. ${ }^{6}$ Die (schon früher einsetzende) Didaktik der Neueren Fremdsprachen Englisch und Französisch für die Schule, die die pädagogische und anthropologische Dimension der literarischen Lektüre konsequent mit einbezieht, hat inzwischen von der interkulturellen Germanistik auch die xenologische Perspektive für eine „Didaktik des Fremdverstehens" (Bredella 1996, Bredella; Christ 1995) übernommen.

\section{Rückblick und aktuelle Diskussion}

Tatsächlich war der Fremdsprachenunterricht in Deutschland zu Anfang einmal ganz auf die Lektüre literarischer Klassiker ausgerichtet, deren Bildungswert in vielen Ländern noch immer unumstritten scheint. Das Interesse an der Literatur verschwand mit der zunehmenden Orientierung an der pragmatischen Alltagskommunikation. Erst der kommunikative Ansatz seit den 1960er Jahren und alternative ganzheitliche Konzepte, die zunehmend auf authentische Kommunikationsanlässe setzten, auf die Aktivierung des Lerners durch Berücksichtigung seiner Interessen und Bedürfnisse, seiner Phantasie, Kreativität und Emotionalität, und auf pädagogische Aspekte, entdeckten zuletzt auch wieder die besonderen Möglichkeiten der Literatur. Die in den 80er Jahren entwickelte fremdsprachliche deutsche Literaturdidaktik (Kast 1984, Heid 1985, Projekte des Goethe-Instituts ${ }^{\top}$ ), die zum Teil auch für den Deutschunterricht an Auslandsschulen gedacht war, erkannte die besonderen didaktischen Vorteile, was Motivation, ganzheitliche Perspektive, landeskundliche Thematik usw. betrifft. Im Gegensatz zum Trend zur Fachsprachenvermittlung entwarf eine weiterentwickelte kommunikative und alternative Fremdsprachendidaktik längst auch Konzepte, die das Interesse der Lerner am Erzählen, die Neugier auf „Geschichten“ über Menschen für einen ganzheitlichen „,narrativen“ oder „hermeneutischen“ Ansatz (Schwerdtfeger 2000, Hunfeld 1990) nutzen. Auch im schulischen Bereich von Deutsch als Zweitsprache spielt die Literatur, speziell die Migrationsliteratur für das Konzept einer ,interkulturellen Erziehung“ seit langem eine selbstverständliche Rolle, was auch von einem muttersprachlichen „interkulturellen Literaturunterricht" inzwischen aufgenommen wird (Rösch 2001, HonnefBecker 2007, Dawidowski; Wrobel 2006).

Es wäre anzuschließen an das fortzusetzende Projekt von Hans-Christoph Graf von Nayhauss (1993): Dokumentation zur Rezeption und Didaktik deutschsprachiger Literaturen in nichtdeutschsprachigen Ländern. Zu den idealistischen Traditionen des Literaturunterrichts vgl. man Kopp; Wegmann (1988). In außereuropäischen literarischen Kulturen (Fernost, Afrika u.a.) leitet sich aus einem viel weiteren Literaturbegriff (jenseits der modernen westlichen Autonomieästhetik) oft ein ganz anderer Bildungswert von Literatur ab (s. Peterson 2006).

7 Vgl. dazu Esselborn (2003). 
Größere Bedeutung könnten auch Anthologien literarischer Texte für Deutschkurse der Studienanwärter an deutschen Universitäten (z.T. auch Germanistikstudenten) haben, wie die umfangreiche und außerordentlich gelungene Sammlung von Texten der Gegenwartsliteratur „Prisma“ von Gisela Tütken $(2002)^{8}$ (und ihre Vorgänger), die mit dem Literatur-Angebot (über die Anforderungen der Sprachprüfung hinaus) ,intellektuell anregen, ästhetisches Vergnügen bereiten sowie affektives Empfinden ansprechen“ und den Blick für die deutsche Lebenswirklichkeit schärfen will, und das „Miteinanderins-Gespräch-Kommen“ als „eine Dimension interkulturellen Lernens“ versteht.

An ausländischen Universitäten (und in Studiengängen für ausländische Studenten) verbinden sich die Erfordernisse und Interessen einer pädagogischen und fremdsprachendidaktischen Literaturvermittlung allerdings mit Traditionen einer Germanistik, die Studieninhalte oder literarische Leselisten aus rein wissenschaftlicher Perspektive festlegte und für den akademischen Bereich eine Didaktik bisher nicht für nötig hielt. Die ungünstigen Lernervoraussetzungen und die institutionellen Beschränkungen erforderten aber eine Literaturdidaktik, die Ansätze der fremdsprachlichen (und muttersprachlichen) deutschen Literaturdidaktik aufgriff, ohne die germanistische Sicht - und die Erkenntnisse der interkulturellen Germanistik - aus den Augen zu verlieren, auch wenn sie aus der Praxis für die Praxis entwickelt wurde wie zuletzt etwa Jürgen Koppensteiners „Literatur im DaF-Unterricht“ (2001).

\section{Aktuelle Probleme der Literaturdidaktik Deutsch}

Problematisch ist es gegenwärtig allerdings, systematische Begründungen für die Beschäftigung mit (fremdsprachlicher) Literatur zu finden, seien sie anthropologischer, pädagogischer oder literaturwissenschaftlicher Art bzw. aus dem bildungspolitischen Diskurs übernommen - was besonders an der zuletzt wieder aufgekommenen Diskussion über den Begriff einer , literarischen Bildung“ deutlich wird. Besonders da die Literatur in den letzten Jahrzehnten, vor allem in der Konkurrenz mit den neuen audiovisuellen Medien, an gesellschaftlicher Bedeutung und sozialem Prestige, an kulturellem und pädagogischem Gebrauchswert enorm verloren hat. Genau genommen ist davon vor allem der Bereich der sogenannten „hohen“ Literatur betroffen (den die traditionelle bürgerliche Autonomie-Ästhetik ohnehin als Nischen-Phänomen definiert und teilweise zugleich als „die Literatur“ ontologisiert hat, was schon im Blick auf die Jahrtausende alte weltweite Vielfalt von Literatur eine sehr willkürliche Verengung bedeutet). Vor allem traditionelle Lyrik wird kaum mehr gelesen und lässt sich kaum noch verkaufen, erfreut sich aber zugleich in multimedialen Präsentationen bei literarischen events erstaunlicher Beliebtheit. So nutzt auch die Lyrikplattform „Lyrikline.org“ den

\footnotetext{
Dazu eine Rezension des Vf. im Jahrbuch Deutsch als Fremdsprache (2004: 471-475). Man vgl. die Anthologie zur konkreten Poesie von Krusche; Krechel (1984) oder von Hartmann; Leroy „Nirgend ein Ort“ (1987) oder das Bändchen der Studienreihe DaF „Moderne Literatur verstehen“ (Beuers; Schneider 1981).
} 
multimedialen Erlebnischarakter des Internets, um eine multilinguale Bibliothek für Lyrik im Netz mithilfe diverser nationaler Literatur-Institutionen aufzubauen. ${ }^{?}$

Tatsächlich hat Literatur heute in Gestalt von Film und Fernsehen und der Trivialliteratur einen nie dagewesenen Einfluss auf die Wahrnehmung und Einschätzung (Konstruktion) von gesellschaftlicher „Wirklichkeit“ und auf den öffentlichen Diskurs - was von einer historischen Germanistik weder akzeptiert noch beeinflusst wird.

Nur schwer zu klären ist jedoch, was literarische Texte überhaupt zu leisten vermögen, welche soziale Funktion, welcher Bildungswert ihnen zukommt, oder wieweit speziell fremdsprachige Literatur fremde Kultur repräsentieren und zugänglich machen kann, inwiefern sich eigen- und fremdkulturelle literarische Lektüre unterscheiden, was denn die leitende Idee bei der Beschäftigung mit fremdsprachlicher und fremdkultureller Literatur sein könnte, welche institutionellen Lernziele damit vereinbar sind, welche didaktischen Auswahlkriterien für Leselisten bzw. für einen speziellen literarischen Kanon sich daraus ergeben, wie schließlich eine methodisch-didaktische Umsetzung aussehen könnte usw.

\section{Muttersprachliche deutsche Literaturdidaktik}

Die gegenwärtige muttersprachliche deutsche Literaturdidaktik gibt inzwischen einen ganz anderen didaktischen Rahmen für die Vermittlung und den Umgang mit Literatur vor (vgl. Abraham; Kepser 2006, Dawidowski; Wrobel 2006). Sie versteht sich als eine eigene Disziplin im Spannungsfeld von Fachwissenschaft, Schule, Bildungs- und Lerntheorien. Ihr Ziel ist die wissenschaftliche Erschließung des gesamten „kulturellen Handlungsfeldes ,Literatur‘ in Bezug auf vergangene, gegenwärtige und zukünftige Lehr- und Lernkontakte“ (Abraham; Kepser 2006: 9). Die Germanistik stellt für sie keine Mutterwissenschaft mehr dar, es geht ihr nicht um die Vermittlung germanistischen Fachwissens und sie lässt sich erst recht nicht auf den vermeintlichen Zentralbereich „Poetizität“ der Texte und eine literaturwissenschaftliche, strukturalistisch-linguistische Textanalyse unter Ausblendung von Autor und Adressaten/Rezeption(sgeschichte) und der Inhalte beschränken - im Sinne einer unreflektierten vormodernen AutonomieÄsthetik. Literarische Lektüre ist über die ästhetische Erfahrung (und entsprechende Gratifikationen) hinaus immer auch „Selbst-Bildung“.

„Schülerinnen und Schüler an eine lustvolle, unterstützende und bereichernde Rezeption von Literatur heranzuführen (Individuation), sie zu einem medienbezogenen Dialog mit anderen einzuladen und sie dazu befähigen (Sozialisation) sowie sie am Prozess gesellschaftlicher Selbstverständigung über Literatur teilhaben zu lassen (Enkulturation), ist das gegenwärtige Kernanliegen literarischer Bildung.“ (Abraham; Kepser 2006: 55) ${ }^{10}$

9 Bezeichend allerdings die unterschiedenen Zeitebenen des Angebots: „Das hörbare Erbe“ mit moderner Klassik und „Gegenwartslyrik“ bereits bekannter Autoren. Nicht zufällig taucht übrigens im Magazin der Deutsch-Arabischen Jugendwebseite li-lak. (www.goethe.de/li-lak) nur Poetry Slam als literarisches Thema auf.

10 „Wir glauben generell nicht, dass es überhaupt möglich ist aus literarischer Lektüre nur zu lernen, was die Literatur selbst betrifft.“ (Abraham; Kepser 2006: 83) 
Es geht um Literatur als Ausdrucks- und Verständigungsmedium, um den Transfer menschlicher Grunderfahrungen, die nur über Literatur zugänglich sind, um eine Ethnologie der eigenen Kultur bzw. eine „Poetik der Kultur“ (M. Baßler). Als kulturelle Praxis trägt Literatur wesentlich zu Wahrnehmungs- und Deutungskonzepten, zur Norm- und Wertediskussion der Gesellschaft, zur kollektiven Identität und zum kollektivem Gedächtnis bei. Grundlegende Aufgaben des Literaturunterrichts sind neben der Unterstützung von Individuation, Sozialisation und Enkulturation die Leseförderung, literarische Bildung (gegenstandsorientiert), literarisches Lernen (subjektorientiert), Sprach- und Medienreflexion. Lernziele sind eine literarische Kompetenz, eine emotive, eine kreative, eine emanzipatorische, eine Projektkompetenz, eine ästhetische und eine kritische Wertungskompetenz. Es sollen Imaginationsfähigkeit, Empathie, Fremdverstehen, intersubjektive Verständigung und Anschlusskommunikation (im literarischen Schulgespräch) gefördert und Ordnungsbegriffe wie Gattungen oder Epochen und diverse Interpretationsmethoden vermittelt werden. Ein weiter Literaturbegriff schließt Kinder- und Jugendliteratur, Trivialliteratur und Medien und vor allem auch Gegenwartsliteratur mit ein. Methodische Zugänge könnten Lernen am Modell, inneres Probehandeln, ein offenes Unterrichtsgespräch und allgemein kreative, produktionsorientierte Verfahren sein. Diese neuen Positionen der muttersprachlichen Literaturdidaktik sind entsprechend auch auf eine fremdsprachliche Literaturdidaktik Deutsch zu übertragen.

\section{Lust an Literatur}

Die offene Textsammlung, die hier vorgestellt wird, entstand im Laufe der Zeit aus Deutschkursen mit Studenten, speziell aus literarischen Lesekursen, und vor allem aus Seminaren zu verschiedenen literarischen Gattungen und landeskundlichen Themen für DaF-Studenten oder aus Fortbildungskursen für Deutschlehrer. Ein für die Studienreihe DaF zusammengestelltes Bändchen wurde vom Hueber Verlag als zu wenig aussichtreich dann doch nicht veröffentlicht. Um die Texte für interessierte Teilnehmer von studentischen Sprachkursen zugänglich zu machen, schienen freiwillige literarische Lesekurse neben dem Sprachunterricht (etwa der Mittelstufe) bzw. wenigstens ein frei zugängliches Computer-Programm im Medienraum für eine selbst zu organisierende Privatlektüre die beste Möglichkeit zu bieten. Tatsächlich konnte in den entsprechenden Kursen (und bei den Lehrkräften) dafür geworben und in mehreren Einführungsstunden erfolgreich in das Angebot eingeführt werden. Das Interesse ist aber längerfristig nur zu erhalten, wenn regelmäßig von Dozenten und Mediatoren mit eigener Überzeugung für diese besondere Möglichkeit geworben wird.

Natürlich wären einzelne Texte auch zur Unterstützung des Unterrichts - thematisch oder z.B. als Lese- oder Hörvorlage - geeignet, oder - in Themeneinheiten - für Landeskunde-Kurse oder literarische Einführungen zur Gegenwartsliteratur im DaF- 
Studium einzusetzen, die deutlich über das traditionelle germanistische Angebot hinausgehen. ${ }^{11}$

Das Programm ist (ähnlich wie bei „Prisma“) nach acht Themeneinheiten zusammengestellt, die für ausländische Jugendliche von Interesse schienen: Junge Leute, Frauen, Liebe, Fremd hier, Reisen, Natur, Zeitgeschichte, Merkwürdige und komische Geschichten. Und zwar so, dass in den verwandten Texten einfach ,geblättert“ und ausgesucht werden kann, was für eine Lektüre (im ausgedruckten Text) interessiert. Die Vorlagen können auch Informationen zum Autor (Fotos, Bio- und Bibliographien, auch z.B. über Google, Wikipedia usw.), sprachliche Hilfen und zum Nachdenken anregende Fragen bereitstellen. Manche Online-Angebote von großen Zeitungen enthalten bereits die Möglichkeit, zu beliebigen Wörtern und Begriffen sprachliche Erklärungen abzurufen, was mit einigem Aufwand sicher auch für diese Texte zu realisieren wäre. Für Themeneinheiten wie Naturgedichte, Migrantenliteratur, Wendegedichte sind für die Leser zudem kurze Einführungen auf einfachem sprachlichen Niveau vorhanden, wie sie in zwei thematischen Aufsätzen zu aktuellen deutschsprachigen Liebesgedichten und Reisetexten im InfoDaF (Esselborn 2005a, 2005b) ausführlicher entwickelt wurden. Die vorhandenen Hörfassungen stammen von einer Veröffentlichung der Bosch Stiftung zum Chamisso-Preis oder sind von der Kollegin Dr. Ingrid Plank eingesprochen. Die Comicszenen von Loriot, die auch als Vorlagen zum szenischen Spiel gedacht sind, können zum privaten Gebrauch aus den gesammelten Werken auf DVD entnommen werden. Im Internet wäre - etwa über Google oder literarische Programme wie „Perlentaucher.de“ oder „Litrix.de“ - sicher noch einiges mehr zu finden, so der Song „Fremd im eigenen Land“ der bekannten Hip Hop Gruppe „Advanced Chemistry“ von 1992, der inzwischen bei Youtube auch in Videoversion zu finden ist. Einen besonderen Zugang bieten Interviews mit den Autoren, manchmal aus einer Fernsehshow oder aus einer der literarischen Sendungen des deutschen Fernsehens zu zeitgenössischen Autoren und aktuellen Büchern, auf die - wie auch auf die Feuilletons der Zeitungen in Online-Ausgaben - nachdrücklich hinzuweisen ist.

Der direkte Zugang vom Computerprogramm zum Internet ist sicher ein unschätzbarer Vorteil für die (private) Suche nach mehr Informationen zu Autoren und Texten. Allerdings sollten einfache Hilfen verhindern, dass der Sprachlerner sich im oft unüberschaubaren Angebot von zufälligen Anmerkungen oder reiner Werbung völlig verliert. Die Rückmeldung, das literarische Gespräch über das Gelesene, Gehörte und Gesehene, das auch zu den Teilfertigkeiten einer „literarischen Bildung“ gehört, ist nur möglich, wenn nachträglich ein Austausch mit anderen Lesern oder in einer (Lerner-) Gruppe stattfinden kann. Rezensionen aus dem Internet, wie sie schon die Verkaufsangebote des Buchversands häufig enthalten, bieten zumindest einen Vergleich mit den Eindrücken und Urteilen anderer Leser. Dozenten oder einzelne Leser könnten leicht ein weit umfangreicheres Dossier zu einem Text allein aus dem Internet zusammenstellen, falls das persönliche Interesse entsprechend groß ist.

11 Auch germanistische Angebote im Internet, etwa von gesprochenen literarischen Texten wie bei www.sprechbude.de enden meist bei den „modernen Klassikern“ der 20/30er Jahre. 


\section{Perspektive}

Zum Schluss ist noch einmal an das (literaturdidaktische) Fernziel zu erinnern, den FSU Deutsch nicht etwa um ein zusätzliches Pensum (historischer) Bildung zu erweitern, sondern dem fremdsprachigen Leser (und dann auch den späteren Adressaten der Deutschlehrer in der Schule oder Hochschule) einen aktuellen Zugang zum ,gesamten kulturellen Handlungsfeld Literatur" in den deutschsprachigen Ländern, zur literarischen Szene und zu ihren Autoren und Texten zu eröffnen, der dann jeweils nach eigenen Interessen weiter ausgebaut werden kann. Dazu gehören vor Ort im Zielsprachenland übrigens auch der Besuch literarischer Veranstaltungen, Lesungen und Auftritte wie Slam-Poetry-Wettbewerbe usw.

Abschließend soll dringend an alle Zuständigen appelliert werden, die Fremdsprachenvermittlung im Bereich DaF nicht weiter auf Sach- und Fachkommunikation zu reduzieren, sondern dem unübersehbaren unverzichtbaren Anteil der Literatur an Sprache und Kultur der deutschsprachigen Länder den notwendigen Raum zu geben - zumindest über fakultative private Lese-, Hör- und Sehangebote.

\section{Literatur}

Abraham, Ulf; Kepser, Matthis (2006): Literaturdidaktik Deutsch. Eine Einführung. 2.Aufl. (Grundlagen der Germanistik 42). Berlin: E. Schmidt.

Altmayer, Claus; Forster, Roland (Hrsg.) (2003): Deutsch als Fremdsprache: Wissenschaftsanspruch - Teilbereiche - Bezugsdisziplinen (Werkstattreihe DaF 73). Frankfurt a.M. u.a.: Lang.

Beirat Deutsch als Fremdsprache des Goethe-Instituts (1992): 25 Thesen zur Sprachund Kulturvermittlung im Ausland. In: Fremdsprache Deutsch 6, 34-35.

Beirat Deutsch als Fremdsprache des Goethe-Instituts (1998): 24 vermittlungsmethodische Thesen und Empfehlungen in: „Deutsch als Fremdsprache“. In: Info DaF 25/1, 85-96.

Beuers, Aloys; Schneider, Sigrid (1981): Moderne Literatur verstehen. Texte und Anregungen zur Interpretation deutschsprachiger Literatur seit 1945 (Studienreihe Deutsch als Fremdsprache 6/7). Dortmund: Lensing.

Bredella, Lothar (1996): The Anthropological and Pedagogical Significance of Aesthetic Reading in the Foreign Language Classroom. In: Ders.; Delanoy, Werner (Hrsg.): Giessener Beiträge zur Fremdsprachendidaktik: Challenges of literary text in the foreign language classroom. Tübingen: Narr, 1-29.

Bredella, Lothar; Christ, Herbert (Hrsg.) (1995): Didaktik des Fremdverstehens (Giessener Beiträge zur Fremdsprachendidaktik). Tübingen: Narr.

Dawidowski, Christian; Wrobel, Dieter (Hrsg.) (2006): Interkultureller Literaturunterricht. Konzepte - Modelle - Perspektiven. Diskussionsforum Deutsch 22. Baltmannsweiler: Schneider.

Esselborn, Karl (2003): Interkulturelle Literaturdidaktik. In: Wierlacher, Alois; Bogner, Andrea (Hrsg.): Handbuch interkulturelle Germanistik. Stuttgart, Weimar: Metzler, 480487. 
Esselborn, Karl (2005a): Themenorientierte fremdsprachliche Literaturdidaktik am Beispiel neuerer deutscher Liebeslyrik. In: Info DaF 32, 583-596.

Esselborn, Karl (2005b): Vom Auszug in die Fremde zur interkulturellen Mobilität. Das Reisethema in aktuellen deutschsprachigen Prosatexten für den Bereich interkulturelle Germanistik/DaF. In: Info DaF 32, 3-13.

Grub, Frank Thomas (2003): Deutsch als Fremdsprache und Literaturwissenschaft. In: Altmayer, Claus; Forster, Roland (Hrsg.) (2003): Deutsch als Fremdsprache: Wissenschaftsanspruch - Teilbereiche - Bezugsdisziplinen (Werkstattreihe DaF 73). Frankfurt a.M. u.a.: Lang, 135-156.

Hartmann, Anneli; Leroy, Robert (Hrsg.) (1987): Nirgend ein Ort. Deutschsprachige Kuraprosa seit 1968. Ismaning: Hueber.

Honnef-Becker, Irmgard (Hrsg.) (2007): Dialoge zwischen den Kulturen. Interkulturelle Literatur und Ibre Didaktik (Diskussionsforum Deutsch 24). Baltmannsweiler: Schneider.

Hunfeld, Hans (1990): Literatur als Sprachlehre. Ansätze eines hermeneutisch orientierten Fremdsprachenunterrichts. Berlin u.a.: Langenscheidt.

Kopp, Detlev; Wegmann, Nikolaus (1988): Das Lesetempo als Bildungsfaktor? Ein Kapitel aus der Geschichte des Topos „Lesen bildet“. In: Der Deutschunterricht 40/4, 45-58.

Krenn, Wilfried (2002): Garnierung oder Hauptgericht? Überlegungen zum Einsatz literarischer Kurztexte im Unterricht Deutsch als Fremdsprache. In: Theorie und Praxis. Österreichische Beiträge zu Deutsch als Fremdsprache 6/2002, 15-40.

Krusche, Dietrich; Krechel, Rüdiger (1984): Anspiel. Konkrete Poesie im Unterricht Deutsch als Fremdsprache. Bonn: Inter Nationes.

Kuri, Sonja (2001): Studiengänge mit zukunftsorientierten Fremdsprachencurricula. Zwischenbilanz der laufenden Ergebnisse. In: Dies.; Saxer, Robert (Hrsg.): Deutsch als Fremdsprache an der Schwelle zum 21. Jahrhundert. Innsbruck u.a.: Studienverlag, 106118.

Nayhauss, Hans-Christoph Graf von (Hrsg.) (1993): Dokumentation zur Rezeption und Didaktik deutschsprachiger Literaturen in nichtdeutschsprachigen Ländern. München: Iudicium.

Pettersson, Anders (Hrsg.) (2006): Literary History: Towards a Global Perspective. Vol. 1: Notions of Literature Across Times and Cultures. Berlin, New York: de Gruyter.

Tütgen, Gisela (Hrsg.) (2002): Prisma: Begegnung mit Deutschland in deutschsprachiger Gegenwartsliteratur. Literarische Texte für den DaF-Unterricht (Materialien Deutsch als Fremdsprache 60). Regensburg: FaDaF.

Rösch, Heidi (2001): Migrantenliteratur: Entwicklungen und Tendenzen. In: Helbig, Gerhard u.a. (Hrsg.): Deutsch als Fremdsprache. Ein internationales Handbuch. Bd. 2. Berlin, New York: de Gruyter, 1353-1360.

Schwerdtfeger, Inge Christine (2000): Anthropologisch-narrative Didaktik des fremdsprachlichen Lernens. In: Fremdsprachen Lebren und Lernen 29, 106-123.

Wolff, Armin; Riedner Ursula Renate (Hrsg.) (2003): Grammatikvermittlung - Literaturreflexion - Wissenschaftspropädeutik - Qualifizierung für eine transnationale Kommunikation. Regensburg: FaDaF. 


\section{Anhang}

\section{Lust auf Literatur}

\section{Themen:}

\section{Liebe}

Liebesgedichte (1 S.)

Matthias Altenburg,

Amorbahn (3,5 S.)

Doris Dörrie, Das Sofa (3,5 S.)

Ingo Schulze, Kinder (3,8 S.)

Ingo Schulze, Neues Geld (4,5 S.)

Burkhard Spinnen,

Das Ultimatum (7,2 S.)

Keto von Waberer,

Das gläserne Zimmer (10,2 S.)

\section{Junge Leute}

Doris Dörrie, Wer sind Sie? (8,5 S.)

Karen Duve, Keine Ahnung (11 S.)

Helmut Krausser, Neues vom Norbert $(8,8 \mathrm{~S}$.)

Selim Özdogan, Kein Spaß (3,3 S.)

Lorenz Schröter (0,6 S.)

Lutz Rathenow, Ohne Anfang (1,5 S.)

\section{Natur}

Naturgedichte (6,7 S.)

Marian Nakitsch, Naturgedichte (1 S.)

\section{Einführungen}

Liebesgedichte

Migrantenliteratur

Naturgedichte

Reisen und Reiseliteratur

Wendegedichte

\section{Reisen}

Thomas Bernhard, Expedition (1 S.)

Karen Duve, Der Indianer (3 S.)

Durs Grünbein, Der Kosmopolit (0,5 S.)

Robert Menasse, Starten, Neubeginnen...

(1 S.)

Christoph Ransmayr, Vor allem (0,6 S.)

Malin Schwerdtfeger, Mein erster Achttausender (5,3 S.)

Gerold Späth, Midlife Reise (4 S.)

Hannelies Taschau, Life seeing und zurück $(0,6 \mathrm{~S}$.)

Maike Wetzel, Einmal Schweden (4,6 S.)

Ror Wolf, Das Ende der fremden Verhältnisse $(0,3 \mathrm{~S}$.)

\section{Frauen}

Matthias Altenburg, Amorbahn (3,5 S.)

Renan Demirkan, Brief an Evelyn (4 S.)

Doris Dörrie, Das Sofa (3,5 S.)

Doris Dörrie, Wer sind Sie? $(8,5 \mathrm{~S}$.)

Karen Duve, Keine Ahnung (11 S.)

Christoph Hein, Die Witwe eines Maurers $(1,1 \mathrm{~S}$.

Ursula Krechel, Meine Mutter (1,5 S.)

Brigitte Kronauer, Eine erfolgreiche Bemühung um Fräulein Block (3,2 S.)

Angelika Mechtel, Katrin (2,8 S.)

Svende Merian, Mutterglück (4,5 S.)

Terézia Mora, Gier (3,1 S.)

Ingo Schulze, Neues Geld (4,5 S.)

Botho Strauß, Mädchen mit Zierkamm (3,1 S.)

Aglaia Veteranyi, Der Besuch (0,3 S.)

Keto von Waberer, Das gläserne Zimmer $(10,2$ S.)

Maike Wetzel, Einmal Schweden (4,6 S.) 


\section{Fremd hier}

Migrantengedichte (12 S.)

Advanced Chemistry, Fremd im eigenen Land (2 S.)

Zehra Çirak, Kulturidentität (1 S.)

Maxim Biller, Kleine Autobiographie (2,1 S.)

Erol Denizeri, Das verlorene Gesicht (2,1 S.)

Doris Dörrie, Neue Schuhe für Frau Hung (11 S.)

Osman Engin, Türkischer Brummschädel (1 S.)

Judith Hermann, Bali-Frau (9,2 S.)

Wladimir Kaminer, Russen in Berlin (4,6 S.)

Kadir Kurt, Trevor und Nachbar (1,5 S.)

Christoph Ransmayr, Przemyśl (4 S.)

Zafer Senocak, Gedichte, Lebenslauf (3,8 S.)

Suleman Taufiq, Die Frage (2 S.)

Eleni Torossi, Mutter-Sprache (2 S.)

Maike Wetzel, Einmal Schweden (4,6 S.)

Urs Widmer, Eine Geschichte aus New York (1,3 S.)

Abdellatif Youssafi, Ich heirate einen Hund (9,5 S.)

Feridun Zaimoglu, Kanak Sprak (1,6 S.)

\section{Zeitgeschichte}

Zeitgedichte (7 S.)

Gedichte zur Wende (16 S.)

Bas Böttcher, Dran glauben (0,8 S.)

Erich Fried, Kleintierjagd auf dem Nil (1 S.)

Reiner Kunze, Taktik (1 S.)

Lutz Rathenow, Ohne Anfang (1,5 S.)

Philipp Schiemann, Im Westen nichts Neues (1,5 S.)

Ingo Schulze, Neues Geld (4,5 S.)

\section{Merkwürdige und komische Geschichten}

Peter Bichsel, San Salvador (1,2 S.)

Franz Hohler, Der Granitblock im Kino (1 S.)

Wolfgang Hilbig, Das Ende der Nacht (0,7 S.)

Reinhard Lettau, Besuch (0,5 S.)

Guntram Vesper, Schöne freie Welt (1 S.)

Loriot: Szenen (2 S.)

\section{Kurze Informationen zu den Autoren} (über Links) 


\section{Lust auf Literatur}

\section{Nachweis der erwähnten Texte}

Advanced Chemistry (2003): Fremd im eigenen Land. In: Verlan, Sascha (Hrsg.): RapTexte. Arbeitstexte für den Unterricht. Stuttgart: Reclam, 70-74.

Altenburg, Matthias (1996): Amorbahn. In: Hielscher, Martin (Hrsg.): Wenn der Kater kommt. Neues Erä̈hlen - 38 deutschsprachige Autorinnen und Autoren. Köln: Kiepenheuer \& Witsch, 236-241.

Bernhard, Thomas (1987): Expedition. In: Ders.: Der Stimmenimitator. Frankfurt a.M.: Suhrkamp, 150-152.

Bichsel, Peter (1964): San Salvador. In: Ders.: Eigentlich möchte Frau Blum den Milchmann kennenlernen. 21 Geschichten. Olten: Walter.

Biller, Maxim (2001): Kleine Autobiographie. In: Ders.: Deutschbuch. München: dtv, 331 333.

Böttcher, Bas (2008): dran glauben. In: Anders, Petra (Hrsg.): Texte und Materialien für den Unterricht. Slam Poetry. Stuttgart: Reclam.

Brechbühl, Beat (1972): Ehepaar beim Nachtessen. In: Ders.: Der geschlagene Hund pisst an die Säulen des Tempels. Alte und neue Gedichte. Zürich: Diogenes, 63.

Burmeister, Brigitte (1995): Mohnkörner. In: Dies.: Herbstfeste. Erzählungen. Stuttgart: Klett-Cotta, 5-18.

Chiellino, Gino (1984): Bahnhof. In: Ders.: Mein fremder Alltag. Kiel: Neuer Malik Verlag, $14 f$.

Chiellino, Gino (1984): Sklavensprache. In: Ders.: Mein fremder Alltag. Kiel: Neuer Malik Verlag, 71.

Chiellino, Gino (1987): Sprachcollage. In: Ders.: Sehnsucht nach Sprache. Gedichte 19631985. Kiel: Neuer Malik Verlag, 11.

Chiellino, Gino (1987): Das wohltemperierte Haus. In: Ders.: Sehnsucht nach Sprache. Gedichte 1963-1985. Kiel: Neuer Malik Verlag, 38.

Chiellino, Gino (1992): für Rose Ausländer. In: Ders.: Sich die Fremde nehmen. Gedichte 1986-1991. Kiel: Neuer Malik Verlag.

Çırak, Zehra (1991): Kulturidentität. In: Dies.: Vogel auf dem Rücken eines Elefanten. Gedichte. Köln: Kiepenheuer \& Witsch, 94.

Ç1rak, Zehra (1991): Sich warm laufen. In: Dies.: Vogel auf dem Rücken eines Elefanten. Gedichte. Köln: Kiepenheuer \& Witsch, 93f.

Ç1rak, Zehra (1991): Istanbul. In: Dies.: Vogel auf dem Rücken eines Elefanten. Gedichte. Köln: Kiepenheuer \& Witsch, 89.

Çrak, Zehra (1994): Stadtgrenze. In: Dies.: Fremde Flügel auf eigener Schulter. Gedichte. Köln: Kiepenheuer \& Witsch, 51.

Çırak, Zehra (1994): Fremde Flügel auf eigener Schulter. In: Dies.: Fremde Flügel auf eigener Schulter. Gedichte. Köln: Kiepenheuer \& Witsch, 98. 
Çırak, Zehra (1994): Ab- und Zugezogenes. In: Dies.: Fremde Flügel auf eigener Schulter. Gedichte. Köln: Kiepenheuer \& Witsch, 32.

Çırak, Zehra (1994): Vogel auf der Rampe. In: Dies.: Fremde Flügel auf eigener Schulter. Gedichte. Köln: Kiepenheuer \& Witsch, 73.

Çırak, Zehra (2000): Lustspiel. In: Dies.: Leibesübungen. Gedichte. Köln: Kiepenheuer \& Witsch, 36.

Delius, Friedrich Christian (1981): Fünfter Gang im Grenzgebiet. In: Ders.: Die unsichtbaren Blitze. Gedichte. Berlin: Rotbuch, 27.

Demirkan, Renan (2000): Brief an Evelyn. In: Ostermeyer, Ulrike (Hrsg.): West-östliche Diven. Anthologie. München: dtv, 194-200.

Denizeri, Birol (1993): Das verlorene Gesicht. In: Ackermann, Irmgard (Hrsg.): In zwei Sprachen leben. Berichte, Erzä̈hlungen, Gedichte von Ausländern. München: dtv, 16-18.

Dörrie, Doris (1995): Neue Schuhe für Frau Hung. In: Dies.: Bin ich schön? Eræählungen. Zürich: Diogenes, 70-88.

Dörrie, Doris (1995): Wer sind Sie? In: Dies.: Bin ich schön? Erzählungen. Zürich: Diogenes, 89-103.

Dörrie, Doris (1996): Das Sofa. In: Wittstock, Uwe (Hrsg.): Kunst des Eræählens. Zwan₹ig Abenteuer aus der Gegenwart. Frankfurt a.M.: Fischer Taschenbuch, 241-245.

Duve, Karen (1999): Der Indianer. In: Dies.: Keine Abnung. Eræählungen. Frankfurt a.M.: Suhrkamp, 53-59.

Duve, Karen (1999): Keine Ahnung. In: Dies.: Keine Ahnung. Eræählungen. Frankfurt a.M.: Suhrkamp, 7-29.

Einzmann, Nadja (2003): Tod oder nicht Tod. In: Dies.; Hermann, Judith; Wetzel, Maike: Liebe, Tod und Spiel. Ausgewählte Erzählungen von Nadja Einzmann, Judith Hermann und Maike Wetzel. Hannover: Schroedel, 11-12.

Einzmann, Nadja (2003): Jeremy. In: Dies.; Hermann, Judith; Wetzel, Maike: Liebe, Tod und Spiel. Ausgewählte Erzählungen von Nadja Einzmann, Judith Hermann und Maike Wetzel. Hannover: Schroedel, 15.

Einzmann, Nadja (2003): Da kann ich nicht nein sagen. In: Dies.; Hermann, Judith; Wetzel, Maike: Liebe, Tod und Spiel. Ausgewählte Erzä̆blungen von Nadja Einzmann, Judith Hermann und Maike Wetzel. Hannover: Schroedel, 11.

Einzmann, Nadja (2003): Hochzeiten. In: Dies.; Hermann, Judith; Wetzel, Maike: Liebe, Tod und Spiel. Ausgewählte Erzählungen von Nadja Einzmann, Judith Hermann und Maike Wetzel. Hannover: Schroedel, 13.

Engin, Osman (1987): Türkischer Brummschädel. In: Esselborn, Karl (Hrsg.): Über Grenzen. Berichte, Erzählungen, Gedichte von Ausländern. München: dtv, 100-102.

Fried, Erich (1982): Kleintierjagd auf dem Nil. In: Ders.: Das Unmaß aller Dinge. 35 Erzählungen. Berlin: Wagenbach, 35.

Grünbein, Durs (1999): Kosmopolit. In: Ders.: Nach den Satiren. Gedichte. Frankfurt a.M.: Suhrkamp, 85.

Hein, Christoph (1982): Die Witwe eines Maurers. In: Ders.: Nachtfahrt und früher Morgen. Prosa. Hamburg: Hoffmann und Campe, 95-96. 
Hermann, Judith (1998): Bali-Frau. In: Dies.: Sommerhaus, später. Erzählungen. Frankfurt a.M.: Fischer 97-113.

Hilbig, Wolfgang (1992): Das Ende der Nacht. In: Ders.: Zwischen den Paradiesen. Leipzig: Reclam, 89f.

Hohler, Franz (1983): Der Granitblock im Kino. In: Ders.: Der Granitblock im Kino. Frankfurt a.M: Fischer Taschenbuch, 14f.

Huchel, Peter (1963): Winterpsalm. In: Ders.: Chausseen, Chausseen. Gedichte. Frankfurt a.M.: Fischer.

Illies, Florian (2003): Generation Gold. In: Einzmann, Nadja; Hermann, Judith; Wetzel, Maike: Liebe, Tod und Spiel. Ausgewählte Erzählungen von Nadja Einzmann, Judith Hermann und Maike Wetzel. Hannover: Schroedel, 117-119.

Kurt, Kadir (2000): Trevor und Nachbar. In: Tutschik, Jamal (Hrsg.): MorgenLand. Neueste deutsche Literatur. Frankfurt a.M.: Fischer Taschenbuch, 201-204.

Kaminer, Wladimir (2000): Russen in Berlin. In: Ders.: Russendisko. München: Goldmann, 9-18.

Kirchhoff, Bodo (1987): Tschakwau. In: Ders.: Ferne Frauen. Eræählungen. Frankfurt a.M.: Suhrkamp, 94-104.

Kirsch, Sarah (2005): Ende Mai. In: Dies.: Sämtliche Gedichte. München: DVA, 148.

Kirsch, Sarah (2005): Vögel. In: Dies.: Sämtliche Gedichte. München: DVA, 151.

Kirsch, Sarah (2005): Im Sommer. In: Dies.: Sämtliche Gedichte. München: DVA, 153.

Krausser, Helmut (1990): Neues vom Norbert. In: Ders.: Spielgeld. Erzähhlungen und andere Prosa. München: Kirchheim, 13-24.

Krechel, Ursula (1977): Meine Mutter. In: Dies.: Nach Mainz! Gedichte. Darmstadt, Neuwied: Luchterhand, $5 \mathrm{f}$.

Kronauer, Brigitte (1981): Eine erfolgreiche Bemühung um Fräulein Block. In: Dies.: Die gemusterte Nacht. Erzählungen. Stuttgart: Klett-Cotta, 57-61.

Krüger, Michael (1982): Dieser Baum. In: Ders.: Aus der Ebene. Gedichte. München, Wien: Hanser, 33f.

Krusche, Dietrich (2002): Lesen. In: Gerstberger, Günter; Albers, Frank (Hrsg.): Viele Kulturen - eine Sprache. Hommage an Harald Weinrich. Stuttgart: Robert Bosch Stiftung, 21.

Kunze, Reiner (1976): Taktik. In: Ders.: Die wunderbaren Jahre. Frankfurt a.M.: Fischer, $56 \mathrm{f}$.

Lentz, Michael (1999): zum beispiel über das abhanden kommen. In: Schrott, Raoul (Hrsg.): Jahrbuch der Lyrik 1999/2000. Über den Atlas gebengt. München: Beck, 108.

Lettau, Reinhard (1998): Besuch. In: Ders.: Alle Geschichten. München: Hanser, 108f.

Mechtel, Angelika (1976): Katrin. In: Dies.: Die Träume der Füchsin. Erzählungen. Frankfurt a.M.: Fischer Taschenbuch, 7-11.

Menasse, Robert (1996): Starten, Neubeginnen... In: Hielscher, Martin (Hrsg.): Wenn der Kater kommt. Neues Erzählen - 38 deutschsprachige Autorinnen und Autoren. Köln: Kiepenheuer \& Witsch, $11 \mathrm{f}$. 
Merian, Svende (1986): Mutterglück. In: Bauer-Kerber, Inge; Dietrich-Chérel, Karin (Hrsg.): Neue Literatur von Frauen. Literatur und Landeskunde 2. Berlin u.a.: Langenscheidt, 11-15.

Mora, Terézia (2000): Gier. In: Ostermeyer, Ulrike; Zeitz, Sophie: West-östliche Diven. Anthologie. München: dtv, 26-30.

Nakitsch, Marian (1994): Landschaft, längst vergangen. In: Ders.: Flügelapplaus. Gedichte. Frankfurt a.M.: Fischer Taschenbuch, 78.

Nakitsch, Marian (1994): In der Kindheit war ich den Vögeln am nächsten. In: Ders.: Flügelapplaus. Gedichte. Frankfurt a.M.: Fischer Taschenbuch, 10.

Nakitsch, Marian (1994): Unter Vögeln. In: Ders.: Flügelapplaus. Gedichte. Frankfurt a.M.: Fischer Taschenbuch, 72.

Özdogan, Selim (1998): Kein Spaß. In: Ders.: Ein gutes Leben ist die beste Rache: Stories. Berlin: Rütten \& Loening, 134-139.

Ransmayr, Christoph (1987): Vor allem. In: Ders.: Die Schrecken des Eises und der Finsternis. Frankfurt a.M.: Fischer Taschenbuch, 9.

Ransmayr, Christoph (1996): Przemyśl. Ein mitteleuropäisches Lehrstück. In: Wittstock, Uwe (Hrsg.): Kunst des Eræä̆hlens. Zwan₹ig Abenteuer aus der Gegenwart. Frankfurt a.M.: Fischer Taschenbuch, 214-220.

Rathenow, Lutz (1989): Ohne Anfang. In: Ders.: Ohne Anfang. München: Serie Piper (935), 9-11.

Schiemann, Philipp (2004): Im Westen nichts Neues. In: Strubel, Antje Rávic; Lentz, Michael; Hoeps, Thomas; Gülich, Martin (Hrsg.): Zeitronen. Literatur in Deutschland 2004. Wien: edition selene, 28f.

Schröter, Lorenz (o.A.). In: Lager, Sven; Naters, Elke (2001): the Buch. leben am pool. Köln: Kiepenheuer \& Witsch, 19.

Schulze, Ingo (1996): Kinder. In: Hielscher, Martin (Hrsg.): Wenn der Kater kommt. Neues Erzählen - 38 deutschsprachige Autorinnen und Autoren. Köln: Kiepenheuer \& Witsch, 214-219.

Schulze, Ingo (1999): Neues Geld. In: Ders.: Simple Storys. Ein Roman aus der ostdeutschen Provinz: München: dtv, 24-30.

Schwerdtfeger, Malin (2001): Mein erster Achttausender. In: Dies.: Leichte Mädchen. Köln: Kiepenheuer \& Witsch, 9-16.

Şenocak, Zafer (1985): ich habe meine Füße... In: Ders.: Flammentropfen. Berlin: Daggyeli, $69 \mathrm{f}$.

Şenocak, Zafer (1987): Erdufer VIII. In: Ders.: Ritual der Jugend. Berlin: Daggyeli, 40f.

Şenocak, Zafer (1994): Türsprachen. In: Ders.: Fernwehanstalten. München: Babel, 69.

Şenocak, Zafer (1995): Lebenslauf. In: Ders.: Der Mann im Unterhemd. München: Babel, 137-141.

Späth, Gerold (1980): King. In: Ders.: Commedia. Frankfurt a.M.: Fischer, $115 f$.

Späth, Gerold (1980): Lothar Ott. In: Ders.: Commedia. Frankfurt a.M.: Fischer, 184f.

Späth, Gerold (1983): Mitlife Reise. In: Ders.: Sacramento. Neun Geschichten. Frankfurt a.M.: Fischer, 131-139. 
Spinnen, Burkhard (1996): Das Ultimatum. In: Ders.: Kalte Ente. Geschichten. Frankfurt a.M.: Fischer Taschenbuch, 117-132.

Strauß, Botho (1987): Mädchen mit Zierkamm. In: Ders. (1990): Niemand anderes. München: Hanser, 9-13.

Taschau, Hannelies (1984): Life seeing und zurück. In: Dies.: Gefährdung der Leidenschaft. Gedichte. Darmstadt, Neuwied: Luchterhand, 159 f.

Taufiq, Suleman (1980): Die Frage. In: Biondi, Franco (Hrsg.): Im neuen Land. Bremen: Con, $132 \mathrm{f}$.

Tawada, Yoko (2002): Eine leere Flasche. In: Dies.: Überseezungen. Literarische Essays. Tübingen: Konkursbuch, 53-57.

Torossi, Eleni (1998): Mutter-Sprache. In: Dies.: Zauberformeln. Eræäblungen. Köln: Romiosini, 79-85.

Uslar, Moritz von (1999): Davos. In: Kracht, Christian (Hrsg.): Mesopotamia. Stuttgart: dtv, 13-29.

Vesper, Guntram (1979): Schöne freie Welt. In: Wandrey, Uwe (Hrsg.): Kein schöner Land? Deutschsprachige Autoren zur Lage der Nation. Reinbek: Rowohlt, $37 \mathrm{f}$.

Veteranyi, Aglaja (2004): Der Besuch. In: Dies.: Vom geräumten Meer, den gemieteten Socken und Frau Butter. München: DVA, 112.

Waberer, Keto von (1991): Das gläserne Zimmer. In: Ders.: Fischwinter. Eræählungen. München: dtv, 9-24.

Wetzel, Maike (2000): Einmal Schweden. In: Dies.: Hochzeiten. Eræählungen. Frankfurt a.M.: Collection S. Fischer, 9-20.

Widmer, Urs (1988): Eine Geschichte aus New York. In: Ders.: Auf, auf, ihr Hirten! Die Kub haut ab! Kolumnen. Zürich: Diogenes, 20-22.

Wolf, Ror (1992): Das Ende der fremden Verhältnisse. In: Ders.: Nachrichten aus der bewohnten Welt. Frankfurt a.M.: Frankfurter Verlagsanstalt, 15.

Youssafi, Abdellatif (2000): Ich heirate einen Hund. In: Tuschik, Jamal (Hrsg): MorgenLand. Neueste deutsche Literatur: Frankfurt a.M.: Fischer Taschenbuch, 217-231.

Zaimoglu, Feridun (1995): Ich spiel in der Liga der Verdammten. Hakan, 22, Kfz-Geselle. In: Ders.: Kanak Sprak. 14 Mißtöne vom Rande der Gesellschaft. Hamburg: Rotbuch, 84-86. 
Christoph Chlosta, Matthias Jung (Hrsg.) (2010): DaF intergriert: Literatur - Medien - Ausbildung. Tagungsband der 36. Jahrestagung des Fachverbandes Deutsch als Fremdsprache 2008. Göttingen: Universitätsverlag, 49-58.

\section{Anke Stöver-Blahak (Hannover)}

\section{Die Entwicklung von Sprech- und Vortragskompetenzen bei der Arbeit mit Gedichten im DaF-Unterricht. Ein Beitrag aus der Praxis und der Forschung}

\section{Einleitung}

Grundlage für das Projekt ist eine Beobachtung, die ich als Dozentin für Deutsch als Fremdsprache am Fachsprachenzentrum der Leibniz Universität machte: Die ausländischen Studierenden hatten im Gespräch, aber auch bei längeren Redebeiträgen manchmal große Schwierigkeiten, vollständige Sätze gebunden, in angemessener Intonation, Artikulation und Haltung zu sprechen. Dies kann zu Irritationen, zu Missverständnissen und im Extremfall auch zum völligen Misslingen von Kommunikation führen.

Im Fachsprachenzentrum gab es keinen Kurs, der diesen Aspekt der „Mündlichen Kommunikation" systematisch bearbeitete - und bei einer Überblicksrecherche an deutschen Universitäten fanden sich keine Modelle, die ich für unsere Situation als passend erachtete. Phonetikkurse (die es in Hannover im Übrigen auch gab und gibt) befassen sich mehr mit Einzellauten und Kombinationen von Lauten, führen aber selten zu längeren Vortrags- oder Redeleistungen. Kurse für Vortrags- und Präsentationstechniken trainieren das Erstellen und Halten von Präsentationen eher auf inhaltlicher und formaler Ebene - weniger auf der sprechtechnischen. Die dazwischen liegende „Lücke“ galt es zu füllen. ${ }^{1}$

1 Der vorliegende Beitrag ist auch in der Reihe „Oldenburger Forum Fremdsprachendidaktik“ erschienen (Stöver-Blahak 2010). 


\section{Grundsätzliche Überlegungen zum Lernen und Lehren}

In seinen Grundannahmen zum Menschenbild und den daraus resultierenden Annahmen zum Lehren und Lernen basiert das Projekt auf einem konstruktivistischen, postmodernen Ansatz, wie er z.B. von Horst Siebert formuliert wird:

„Lernen ist eine selbstständige, biographie- und erfahrungsbasierte Tätigkeit, die durch Lehre unterstützt, aber nicht gesteuert werden kann. Erwachsene sind so gesehen lernfähig, aber im Normalfall unbelehrbar.

Diese ,Aneignungsperspektive' wird durch die konstruktivistische Erkenntnistheorie bestätigt. Der Konstruktivismus betont auf der Grundlage neurowissenschaftlicher Forschungen die Selbsttätigkeit des Erkennens und die Selbststeuerung des Lernens.“

(2008: 7)

Dabei ist zu berücksichtigen, dass der - lernende - Mensch hier nicht nur als kognitives Wesen gesehen wird, sondern explizit auch als Wesen mit Emotionen und Sinnlichkeit. Siebert meint, dass in der Postmoderne der ästhetische Zugang zur Welt sogar aufwertet wird:

„Die Postmoderne wertet den ästhetischen Zugang zur Welt auf. Ästhetisch meint - im ursprünglichen Sinne des Wortes - die sinnliche, anschauliche Wahrnehmung von Welt." (ebd.: 13)

Konstruktivistische Ideen sind vielfach in die Fremdsprachendidaktik eingegangen und diskutiert worden. Einen besonderen Stellenwert nimmt dabei das „Autonome Lernen“ ein, z.B. bei Wolff (2002), Altmayer (2002), Legenhausen (1999), Little (1999) u.a.

Auch in der Fremdsprachlichen Literaturdidaktik wurde z.T. sehr heftig über (radikal) konstruktivistische Ideen zum Verstehensprozess von Literatur und den daraus resultierenden Folgen für den Einsatz von Literatur im Fremdsprachenunterricht gestritten, z.B. von Wendt, Bredella, Overmann u.a.

Für die Ästhetische Kommunikation, die „künstlerische Sprechgestaltung literarischer Texte für Hörer“ (nach Forster 2002) im Fremdsprachenunterricht, gibt es m.W. noch keine explizit konstruktivistische Einordnung. Die für unseren Zusammenhang relevanten Aspekte der o.g. Wissenschaften sind aber durchaus mit meiner Auffassung von Ästhetischer Kommunikation im DaF-Unterricht vereinbar.

\section{Unterrichtskonzeption}

Die Konzeption des Unterrichts folgt also konstruktivistischen Vorgaben, wie im Einzelnen noch nachgewiesen werden soll. Zunächst aber zur Orientierung drei Vorbedingungen, die das dem Forschungsprojekt zugrunde liegende Unterrichtsprojekt kurz skizzieren:

\subsection{Rahmenbedingungen}

Das Seminar „Mündliche Kommunikation“ findet zweistündig (90 Minuten) während des Semesters (14 Wochen) als Veranstaltung des Fachsprachenzentrums der Leibniz 
Universität statt. Durchgeführt wird es im „3D-Raum“ des Rechenzentrums, denn dort gibt es eine für die Zwecke nützliche technische Ausstattung:

Der Raum ist ausgestattet mit drei an der Decke hängenden Kameras, sehr guten Wiedergabemöglichkeiten durch zwei Beamer, einem abgetrennten Regieraum und mehreren Mikrofonen. Die Kameras werden von dem Regieraum aus gesteuert (das erfordert die Anwesenheit von mindestens einer Hilfskraft), das gesamte Unterrichtsgeschehen wird aufgezeichnet (zu beachten ist dabei, dass die Person im Regieraum die Kameraperspektive bestimmt), es besteht die Möglichkeit, schnell und unkompliziert Aufzeichnungen wieder einzuspielen.

Vorteile: Die Kameras und die gesamte Technik bestimmen oder beeinträchtigen das Unterrichtsgeschehen fast gar nicht. Spätestens nach der zweiten Sitzung scheinen KursteilnehmerInnen und Dozentin zu „,vergessen“, dass aufgezeichnet wird. Die KursteilnehmerInnen entwickeln in der immer angstbehafteten Vortragssituation keine zusätzliche Angst vor der Kamera. Es ist für die Dozentin entlastend, dass sie sich auf die Aktivitäten im Unterricht und auf die TeilnehmerInnen konzentrieren kann. Es ist für alle vorteilhaft, wenn Einspielungen schnell und ohne große Such- und Spularbeit geschehen können.

Nachteile: Manchmal funktioniert die Technik nicht. Der Raum ist manchmal anderweitig belegt. Es besteht ein größerer Abstimmungsbedarf. Die Nachteile fallen aber gegenüber den großen Vorteilen kaum ins Gewicht.

\subsection{Die Textsorte „Lyrik}

Bei den Überlegungen, wie den oben genannten Problemen ausländischer Studierender zu begegnen sei, hatte ich folgende Leitgedanken, die mich in den Bereich der Sprechwissenschaft/Sprecherziehung und hier besonders zu der Ästhetischen Kommunikation führten:

Um Sprech- und Vortragsverhalten, d.h. gebundene Rede, Aussprache und Intonation, HörerInnen- und Situationsbezug zu trainieren, sollte der gesamte Rede- und Vortragsprozess entlastet werden, damit auch genau diese Bereiche im Zentrum der Aufmerksamkeit stehen können.

Sprechen vor Publikum ist ein hochkomplexer Prozess (vgl. Forster 1997: 45f.), aus dem das „Produzieren“ von eigenem Inhalt herausgelöst werden kann, indem man den KursteilnehmerInnen schon fertige Texte zur Verfügung stellt. Damit entlastet man sie gleichzeitig von der in einer Fremdsprache oft so schwierigen und kraftraubenden Beachtung grammatischer Regeln und dem Finden der richtigen Wörter.

Die Texte, die zur Verfügung gestellt werden, sollten nicht zu lang sein, damit sie möglichst zügig so gesprochen werden können, dass die SprecherInnen sich auf die Sprech- und Vortragssituation konzentrieren können. Sie sollten aber andererseits auch genügend inhaltliche und sprachliche Dichte haben, damit die KursteilnehmerInnen Variationen ausprobieren und verschiedene Gestaltungsmöglichkeiten haben können. Die KursteilnehmerInnen sollen genügend Zeit haben, die Möglichkeiten des Sprechens auszuloten, sie sollen sich andererseits auch nicht mit ihrem Text langweilen. Der 
Text sollte ihnen außerdem die Möglichkeit geben, sich selbst in ihrer Persönlichkeit, d.h. auch mit Emotionen und körperlich zu erfahren und darzustellen. Alle genannten Bedingungen sind in der Textsorte „Lyrik“ erfüllt.

Die Besonderheit der sehr gestalteten und ,künstlichen“ Sprache ist in unserem Zusammenhang zu vernachlässigen, weil Aussprache, Intonation und Melodie gleich oder zumindest ähnlich wie in der gesprochenen Sprache sind (nicht zuletzt gibt es in vielen Phonetik-Lehrwerken Übungen mit Gedichten). Der Gebrauch der ,,richtigen“ Grammatik ist explizit nicht Thema des Kurses. Allerdings sollten die KursteilnehmerInnen mit Gedichten arbeiten, die ihnen gefallen, die ihren Persönlichkeiten entsprechen und die sie „herausfordern“ in dem Sinne, dass sie sich mit ihnen ein Semester lang beschäftigen können. Auf keinen Fall sollten alle mit dem gleichen Gedicht arbeiten. Das böte im Unterricht und auch für die Untersuchung zwar eine größere Vergleichbarkeit, wäre aber für alle Beteiligten vermutlich sehr schnell langweilig und entspräche v.a. nicht der Gesamtkonzeption.

\subsection{Kursverlauf}

Die KursteilnehmerInnen erhalten am Anfang eine Zusammenstellung von ca. 20 Gedichten aus unterschiedlichen Epochen, von verschiedenen Dichtern und Dichterinnen, in unterschiedlicher Länge. Sie sollen und dürfen das Gedicht aussuchen, das ihnen am besten gefällt. Dieses Gedicht ist dann ihre sprachliche Grundlage für den Kurs. Doppelte oder gar dreifache Auswahl eines Gedichtes ist kein Problem. Solche Fälle werden im Kurs genutzt, um verschiedene Vortragsmöglichkeiten zu diskutieren und zu verdeutlichen, dass es keine „richtige“ Lösung gibt, sondern nur solche, die dem Sprecher/der Sprecherin, dem Gedicht und dem HörerInnenkreis angemessen sind (siehe unten).

Die „Aufgabe“ der KursteilnehmerInnen ist es demnach, ein ganzes Semester lang eine Vortragsfassung von ,ihrem“ Gedicht zu erarbeiten. Dazu werden sie das Gedicht mehrfach vor der Gruppe vortragen. Nach jedem Vortrag werden sie selbst und die anderen ZuschauerInnen den Vortrag beurteilen, in einem zweiten Schritt werden sie ihre Beobachtungen an der Videoaufzeichnung überprüfen. Im Laufe des Kurses wird ein Kriterienkatalog „Was ist ein guter Vortrag?" entwickelt. Zu allen Teilaspekten des Kriterienkatalogs werden Übungen gemacht, z.B. zur Körperhaltung, Aussprache, Gestik, Mimik, Augenkontakt etc.

Der Kurs endet mit einer „öffentlichen“ Aufführung, die die KursteilnehmerInnen weitgehend selbständig vorbereiten und für die das Gelernte noch einmal zusammengefasst wird.

\subsection{Konstruktivistische Anteile am Unterrichtskonzept}

Manfred Overmann hat in seinem Artikel „Konstruktivistische Prinzipien und ihre didaktischen Implikationen“ (2008: 20) 18 lerntheoretische Prämissen zusammengestellt, die sich in dem beschriebenen Unterrichtskonzept wiederfinden lassen. Zusammenfassend seien besonders folgende Punkte hervorgehoben:

- Die KursteilnehmerInnen knüpfen an ihr Vorwissen an - sowohl bei dem Umgang mit Gedichten als auch bei den Erfahrungen, die sie schon mit Vortragssituationen gemacht haben. 
- Sie erfahren Perturbationen durch das Gedicht, aber auch durch die Kommentare der andern und versuchen, durch die Auseinandersetzung mit diesen ihren Organismus wieder zu equilibrieren.

- Sie viabilisieren durch die Kommunikation mit anderen immer neue Konstrukte.

- Sie sind autonom in ihren Entscheidungen darüber, was sie annehmen und was nicht.

- Sie sind in einem explorativen Prozess.

- Das Lernen erscheint ihnen lebensweltlich nützlich, es ist an realen Bedürfnissen orientiert und umfasst die ganze Persönlichkeit.

Was genau den Leser/Sprecher/die Leserin/Sprecherin bei der Erarbeitung einer Vortragsfassung lenkt und beeinflusst, werden wir dieser Theorie entsprechend nur aus der Eigenperspektive/Innenperspektive der ProbandInnen konstruieren können.

\title{
3 Forschungsdesign
}

\subsection{Qualitative Forschung}

Die Untersuchung wurde im Qualitativen Forschungsparadigma durchgeführt. Quantitative Forschung schließt sich aufgrund der kleinen ProbandInnengruppe aus. Es wird aber auch davon ausgegangen, dass das eigentliche Forschungsinteresse zunächst nur mit qualitativen Methoden im Sinne der „Grounded Theory“ behandelt werden kann. Im Sinne von Strauss und Corbin soll aus den erhobenen Daten eine Theorie entwickelt werden.

\begin{abstract}
„Eine ,Grounded'Theory ist eine gegenstandsverankerte Theorie, die induktiv aus der Untersuchung des Phänomens abgeleitet wird, welches sie abbildet. Sie wird durch systematisches Erheben und Analysieren von Daten, die sich auf das untersuchte Phänomen beziehen, entdeckt, ausgearbeitet und vorläufig bestätigt. Folglich stehen Datensammlung, Analyse und die Theorie in einer wechselseitigen Beziehung zueinander. Am Anfang steht nicht eine Theorie, die anschließend bewiesen werden soll. Am Anfang steht vielmehr ein Untersuchungsbereich - was in diesem Bereich relevant ist, wird sich erst im Forschungsprozeß herausstellen.“ (Strauss; Corbin 1996: 7-8, Hervorhebung durch die Autorin)
\end{abstract}

Dieses Forschungsformat, in dem eine Theorie quasi konstruiert wird, schließt sich auch an das oben skizzierte Menschenbild und die beschriebene Unterrichtskonzeption an.

Am Ende meiner Untersuchung könnten sich Perspektiven ergeben, die eine Fortführung eventuell auch nur von Einzelaspekten mit quantitativen Methoden sinnvoll erscheinen lassen.

\subsection{Grundlage, Forschungsgruppe, „Feld““}

Grundlage der Untersuchung - der „Untersuchungsbereich“ im o.g. Sinne - ist ein Kurs, der ungesteuert nach üblichen Anmeldekriterien des FSZ zustande kam. Von den insgesamt zehn TeilnehmerInnen wurden von sieben umfassende Daten erhoben, zwei Teilnehmer waren nach bzw. kurz vor Beendigung des Kurses nicht mehr erreichbar, eine Teilnehmerin erfüllte die sprachlichen Mindestvoraussetzungen nicht. Die schon 
erhobenen Daten wurden nicht berücksichtigt. Aus den verbliebenen sieben TeilnehmerInnen mit vier Ausgangssprachen werden nach einer ersten möglicherweise auch zweiten Auswertung der Daten nach dem „theoretical sampling“ voraussichtlich drei mit verschiedenen Ausgangssprachen einer besonders intensiven Betrachtung unterzogen. Hier sollen die in der vorangegangenen Auswertung gewonnenen Aussagen an weiteren Daten überprüft, vertieft und eventuell modifiziert werden.

Als „Fall“ der Untersuchung ist also auch unter dem Aspekt der „Zugänglichkeit“ ein zufällig entstandener Kurs zu bezeichnen, der aber in einer Reihe von Kursen steht, die nach den gleiche Kriterien entstanden - insofern ist ihm eine Repräsentativität zuzuschreiben. Das große „Feld“, in dem die Untersuchung stattfindet, sind die ausländischen Studierenden der Leibniz-Universität mit einem allgemeinen Sprachniveau C1, denn für sie ist der Kurs ausgeschrieben. Die KursteilnehmerInnen meldeten sich an, weil sie an ihrer mündlichen Kommunikation arbeiten - nicht, weil sie sich an einer Studie beteiligen wollten. Nach Vorstellung des Konzeptes blieben einige weg, bis sich die Untersuchungsgruppe formierte. Charakteristisch für sie ist ihre Heterogenität in Ausgangssprachen, Studienfächern und Stadien im Studium. Damit ist ein wichtiges Kriterium für einen „Fall“ erfüllt: Der „Facettenreichtum“ (Merkens 2007: 291). Er ermöglicht auch die Auswahl von Einzelfällen.

Das Auswahlverfahren der ProbandInnengruppe ergibt sich demnach sowohl aus der beschriebenen Zugänglichkeit, aber es rechtfertigt sich auch aus dem Ziel der Untersuchung. Durch die systematische Bearbeitung der Forschungsfragen möchte ich herausfinden, ob und ggf. warum und wie sich diese Methode für den DaF-Unterricht am Fachsprachenzentrum und möglicherweise auch darüber hinaus eignet - für Gruppen, die ähnlich „zufällig“ zusammengesetzt werden wie die hier zugrunde liegende.

\subsection{Forschungsfragen}

In der Forschungsarbeit geht es vor allem um folgende Komplexe:

- Wie ist der Weg der TeilnehmerInnen/ProbandInnen zu einer gestalteten Vortragsfassung?

- Welche Veränderungen werden von Sprechern selbst wahrgenommen?

- Welche Veränderungen sind von außen beobachtbar?

\subsection{Datenerhebung}

Die Hauptdatenerhebung fand im WiSe 2007/2008 in der Zeit vom 17.10.2007 bis zum 30.01.2008 statt. Es wurden folgende Daten erhoben:
a) Video:
Aufzeichnungen des gesamten Unterrichtsgeschehens
b) drei Fragebögen:
Am Anfang (biographische Daten, Selbsteinschätzung, Motivation)
In der Mitte (Gedicht-Verstehensprozess)
Am Ende (Selbsteinschätzung, genauere Beurteilung des Kurses) 
c) Lernertagebücher: Erhoben jeweils am Ende der Stunde, persönliche Einschätzungen der eigenen Aktvität, des Kursgeschehens

d) „Kriterienkatalog“: Beurteilung einer Sprechleistung durch die anderen KT

e) Evaluationsbögen Allgemeine Einschätzung und Bewertung des Kurses des FSZs:

f) Skype-Interview: Schwerpunkte:

Verstehensprozess des Gedichtes, nachträgliche

Wertung des Kurses, allg. Verhältnis zur deutschen Kultur/ Sprache

g) Diagnosebögen: Standardisierte Einschätzungen

Externe ExpertInnen: unabhängige Einschätzung

ProbandInnen: eigene Einschätzung

Forscherin: erweiterte Einschätzung, evtl. Begründungen

\subsection{Methoden der Auswertung:}

Kodieren: offenes, axiales, selektives Kodieren // Perspektivenvergleich

Bei der Auswertung der Fragebögen, Lernertagebücher, Interviews und der Diagnosebögen, die von den TeilnehmerInnen selbst ausgefüllt wurden, steht entsprechend dem Kursthema und der Forschungsfragen die Wahrnehmung des eigenen Vortragsverhaltens im Fokus. Im Sinne des offenen Herangehens an die Daten soll dabei auch beobachtet werden, wie die ProbandInnen dabei die Rolle des Gedichtes empfinden (Auswertungsschritte 1-3).

Am Ende soll nach der statistischen Auswertung der ExpertInnen-Diagnosebögen ein Vergleich zu den gewonnenen Daten der Eigenperspektive der ProbandInnen gezogen werden (Auswertungsschritt 4).

\subsection{Auswertungsverlauf:}

- Erster Auswertungsschritt:

Grundlagen: Schriftliche Daten im Kursverlauf

1. Lernertagebuch, 2. Fragebogen, 3. Fragebogen auswerten nach der qualitativen Inhaltsanalyse

Perspektive: Selbsteinschätzung der KursteilnehmerInnen während des Kurses Einzelfallanalysen, Vergleiche

- Zweiter Auswertungsschritt:

Überprüfen, Ergänzen der Ergebnisse durch Daten der ProbandInnen nach Kursende Interview, Diagnose der eigenen Leistungen im Kursverlauf nach Video-Ausschnitten nach mehrmonatigem Abstand zum Kurs; Grundlage: Diagnosebogen für externe ExpertInnen (s.u.)

Einzelfallanalysen, Vergleiche 
- Dritter Auswertungsschritt:

Zusammenführung, Verdichtung der Daten, evtl. Formulierung von Thesen/einer Theorie (?) als Beantwortung der Frage:

Wie vollzieht sich die Aneignung von Vortragskompetenz anhand lyrischer Texte im Kontext einer exemplarischen DaF-Lernsituation aus der Perspektive der Lernenden?

- Vierter Auswertungsschritt:

Hier wird der Ansatz der Innenperspektive aufgebrochen und erweitert um die Forschungsfrage: Was wird von ZuhörerInnen wahrgenommen?

Sieben unabhängige externe DaF-ExpertInnen aus dem In- und Ausland beurteilen das Rede- und Vortragsverhalten eines jeden Probanden/einer jeden Probandin in zwei Beiträgen freier Rede und fünf Gedichtvorträgen in verschiedenen Erarbeitungsphasen nach von mir entwickelten Diagnosebögen anhand von Videoaufnahmen. Ich zitiere hier aus dem Anschreiben an die ExpertInnen: ${ }^{2}$

„Mit diesen Diagnosebögen soll von externen ExpertInnen das Rede- und Vortragsvermögen der KursteilnehmerInnen zu verschiedenen Zeiten des Kurses beurteilt werden. Entsprechend der Grundlagen der Ästhetischen Kommunikation kommt es hierbei weniger auf bestimmte messbare Einzelphänomene an, sondern mehr auf den Gesamteindruck, der sich in die unten genannten Bereiche aufschlüsseln lässt. Ich beziehe mich hier auf Ziele der Ästhetischen Kommunikation speziell im DaF-Unterricht, die Roland Forster wie folgt formuliert hat: ,Lernende sollen, so die Zielvorstellung, das angemessene Sprechen von Texten erarbeiten. Dabei sollen sie authentisch wirken, textadäquat arbeiten, zuhörerbezogen und situationsangemessen kommunizieren. ${ }^{63}$ Die vier hier genannten sprecherzieherischen Kriterien Authentizität, Textadäquatheit, Zuhörerbezogenheit und Situationsangemessenheit wurden ergänzt um den für die mündliche Kommunikation grundlegenden Bereich der Beherrschung der Aussprache und Intonation. Betont werden soll an dieser Stelle aber noch einmal, dass es bei dem ,Diagnostizieren um den Gesamteindruck des Vortrags und des/der Vortragenden geht.“

Den Ideen des Konstruktivismus aber auch der Rezeptionsästhetik und der Ästhetischen Kommunikation folgend kann es bei diesem Verfahren nicht darum gehen, eine objektiv „richtige“ Fassung eines Vortrags zu ermitteln. Wenn wir aber das Vortragen von Gedichten als kommunikativen Akt begreifen, müssen wir auch die Perspektive eines Zuschauers/Zuhörers/einer Zuschauerin/einer Zuhörerin einnehmen, um das Gelingen von Kommunikation nachzuweisen oder zu untersuchen, was ein Gelingen stören oder misslingen lassen kann.

Ebenso erscheint es mir wichtig, den Prozess, den die ProbandInnen erleben und in den Daten nachvollziehen, auch aus einer Außenperspektive zu beobachten. Da mein Untersuchungsfokus auf der (möglichen) Entwicklung der Rede- und Vortragskompetenz liegt, sollen auch die ExpertInnen, die weder die ProbandInnen kennen noch in das Unterrichtsgeschehen eingebunden waren, nur dieses in verschiedenen Stufen beobachten.

2 Stöver-Blahak, Anke: Anschreiben an ExpertInnen vom 24.07.2008.

3 Forster (2002). 
Die Ergebnisse dieser Auswertung werden mit den Ergebnissen der Auswertung der Fragebögen der ProbandInnen verglichen. Durch dieses Verfahren erhalte ich ein facettenreiches Bild der Entwicklung der ProbandInnen aber auch Aufschlüsse über das Gelingen der Kommunikation.

\section{Fazit und Ausblick}

„Gedichte? - Sind doch total langweilig!“

„Wozu braucht ein Maschinenbauer Gedichte?“

Diese beiden Zitate aus der Professorenschaft der technisch geprägten Leibniz Universität Hannover belegen eine wohl nicht nur hier anzutreffende Haltung zu Gedichten.

Die skizzierte Unterrichtspraxis und ein Vortrag vor eben diesen Professoren (Stöver-Blahak 2007) zeigen, dass Gedichte nicht als langweilig empfunden werden müssen und auch MaschinenbauerInnen, ElektrotechnikerInnen oder BauingenieurInnen in der dargestellten Methode Gedichte „brauchen“ können.

In dem beschriebenen Forschungsprojekt geht es darum, zu untersuchen, wie sich die Rede- und Vortragskompetenz bei der Erarbeitung der Sprechfassung eines Gedichtes bei verschiedenen ProbandInnen in einer bestimmten Lernumgebung entwickelt. Die Ergebnisse dieser Forschungsarbeit sollen dann wieder für die Praxis nutzbar gemacht werden - wenn möglich nicht nur an der Leibniz Universität Hannover.

\section{Literatur}

Altmayer, Claus (2003): Konstruktivistische Fremdsprachendidaktik. http://www.babyloniati.ch/BABY3_403/PDF/altm.pdf (20.09.2008).

Bredella, Lothar: Die Verheißung von Autonomie, Kreativität und Allmacht. Zur Kritik der radikal-konstruktivistischen Fremdsprachendidaktik. ourworld.compuserve.com/homepages / michaelwendt/Seiten/Bredella (01.10.2008).

Forster, Roland (1997): Mündliche Kommunikation in Deutsch als Fremdsprache: Gespräch und Rede. St. Ingbert: Röhrig Universitätsverlag.

Forster, Roland (2002): Von der Leselehre zum Textsprechen: Ästhetische Kommunikation im DaF-Unterricht. In: Wolff, Armin; Lange, Martin (Hrsg.): Europäisches Jahr der Sprachen: Mehrsprachigkeit in Europa. Materialien DaF 65. Regensburg: Fachverband Deutsch als Fremdsprache, 234-246.

Legenhausen, Lienhard (1999): Traditional and autonomous learners compared: The impact of classroom culture on communicative attitudes and behaviour. In: Edelhoff, Christoph; Weskamp, Ralf (Hrsg.): Autonomes Fremdsprachenlernen. Ismaning: Hueber, 166-182.

Little, David (1999): Autonomy in second language learning: some theoretical pespectives and their practical implications. In: Edelhoff, Christoph; Weskamp, Ralf (Hrsg.): Autonomes Fremdsprachenlernen. Ismaning: Hueber, 22-36.

Merkens, Hans (2007): Auswahlverfahren, Sampling, Fallkonstruktion. In: Flick, Uwe; von Kardoff, Ernst; Steinke, Ines (Hrsg.): Qualitative Forschung. Ein Handbuch. Reinbek bei Hamburg: Rowohlt Taschenbuch, 286-299. 
Overmann, Manfred (2002): Konstruktivistische Prinzipien und ibre didaktischen Implikationen: I. Radikales Fragen und neue Perspektiven II. Konsequenzen für die Lerntheorie. ourworld.compuserve.com/homepages/michaelwendt/Seiten/Overman2.htm (01.10.2008).

Siebert, Horst (2008): Konstruktivistisch lehren und lernen, Augsburg: ZIEL-Verlag.

Stöver-Blahak, Anke (2007): Lernen mit Gedichten im Fremdsprachenunterricht. Ein neuer Weg zur Verbesserung der mündlichen Kommunikationsfähigkeit von ausländischen Studierenden. http://www.uni-hannover.de/imperia/md/content/elearning/vortrag_eteaching_2007_stoever.pdf (23.10.10).

Stöver-Blahak, Anke (2007): Lernen mit Gedichten im Fremdsprachenunterricht. In: Krüger, Marc; Hold, Ulrike von (Hrsg.): Neue Medien in Vorlesungen, Seminaren \& Projekten an der Leibniz. Universität Hannover, Tagungsband zu eTeaching und eScience Tagung 2007. Aachen: Shaker, 88-99.

Stöver-Blahak, Anke (2010): Die Entwicklung von Sprech- und Vortragskompetenzen bei der Arbeit mit Gedichten im DaF-Unterricht. In: Engelhardt, Maike; Gehring, Wolfgang (Hrsg.): Fremdsprachendidaktik - Neue Aspekte in Forschung und Lehre. Oldenburg: BIS-Verlag der Carl von Ossietzky Universität Oldenburg, 43-57.

Strauss, Anselm; Corbin, Juliet (1996): Grounded Theory: Grundlagen Qualitativer Sozialforschung. Weinheim: Beltz; PsychologieVerlagsUnion.

Wendt, Michael: „... warum radikale Konstruktivisten überhaupt schreiben. “Eine Antwort auf einen Beitrag von Lothar Bredella. ourworld.compuserve.com/homepages/michaelwendt/Seiten/Wendt2 (01.10.2008).

Wolff, Dieter (2002): Fremdsprachenlernen als Konstruktion: Grundlagen für eine konstruktivistische Fremdsprachendidaktik. Frankfurt a.M.: Peter Lang.

Wolff, Dieter (2002): Fremdsprachenlernen als Konstruktion. http://www.babylonia-ti.ch/ BABY402/PDF/wolff.pdf (20.09.2008). 
Christoph Chlosta, Matthias Jung (Hrsg.) (2010): DaF intergriert: Literatur - Medien - Ausbildung. Tagungsband der 36. Jahrestagung des Fachverbandes Deutsch als Fremdsprache 2008. Göttingen: Universitätsverlag, 59-71.

\section{Susanne Horstmann (Bielefeld)}

\section{Förderung von interkultureller Kompetenz durch Auseinandersetzung mit Filmen?}

\section{Einleitung}

Der folgende Artikel beschäftigt sich mit der Frage, welche Voraussetzungen von Lehrerseite gegeben sein müssen, damit durch den Einsatz des Mediums Film interkulturelle Kompetenz von Lernern gefördert werden kann. Dazu werde ich zunächst Gedanken präsentieren, die sich in aktuellerer fremdsprachendidaktischer Literatur zum Filmeinsatz - insbesondere zum interkulturellen Filmeinsatz im Unterricht - finden. Da in diesem Bereich die Literaturlage eher dünn ist, werde ich anschließend auf Anregungen aus der Literatur zur interkulturellen Filmanalyse zurückgreifen. Diese Anregungen benennen sehr konkret Vorbedingungen, die auf Lehrerseite erfüllt sein müssen, damit vermeintlich gutgemeinter interkultureller Filmeinsatz nicht Effekte entgegen der beabsichtigten erzeugt, also beispielsweise statt zum Aufbrechen von Stereotypen zur Stereotypisierung beiträgt. Auch auf Lernerseite sind sicherlich Vorbedingungen zu erfüllen, mit denen beschäftige ich mich aber in diesem Artikel explizit nicht. Meine Absicht ist nicht, Lösungen liefern, sondern lediglich anzuregen, über bestimmte Konzepte nachzudenken, um diese für eine bewusste Filmauswahl zu nutzen.

\section{Interkulturelle Filmarbeit - Sichtung didaktischer Literatur}

Welche Hilfestellungen bietet fremdsprachendidaktische Literatur zur interkulturellen Arbeit mit Filmen? 


\subsection{Anregungen aus dem Bereich Deutsch als Fremdsprache}

Bereits 1989 nannte Schwerdtfeger die heute noch immer geltenden zentralen Argumente für den Einsatz von Filmen im Fremdsprachenunterricht:

„Filme und die in ihnen verbundenen Übungen und Unterrichtsmethoden vermögen es, ein anderes Gefüge von kognitiven und emotionalen Kräften in den Schülern anzusprechen und eine andere Äußerungsbereitschaft der Schüler zu schaffen, als sie bisher im FU vorherrschte. Ich sehe eine Verknüpfung zwischen allgemeiner Neugier, Neugier am Menschen, Lust, über Menschen zu sprechen, und Filmeinsatz, und den mit ihm verbundenen Übungsformen und Methoden im FU.“ (Schwerdtfeger 1989: 20)

und weiter:

„Für den fremdsprachlichen Unterricht ist als 5. ,Fertigkeit das Seh-Verstehen zu fordern [...] In fremdsprachendidaktischen und -methodischen Entscheidungen wurde bisher vorwiegend berücksichtigt, daß Sprachverstehen erheblich von der visuellen Wahrnehmung des Sprachbenutzers abhängt. Völlig vernachlässigt wurde jedoch die Tatsache, dass die visuelle Wahrnehmung eine zentrale Bedeutung für die individuelle Sprachfähigkeit und Sprecblust hat." (ebd.: 24, Hervorhebungen im Original)

In aktueller DaF-didaktischer Literatur zum Thema, so z.B. von Sass (2007), die den Basisartikel für ein Heft zum Thema „Filme im Unterricht“ der Zeitschrift „Fremdsprache Deutsch" verfasst hat, sind darüber hinausgehende Argumente kaum zu finden. ${ }^{1}$ Es scheint sich also in den letzten 20 Jahren nicht viel getan zu haben. Zwar wird bei Sass im Unterpunkt „Vielfältige Methoden bereichern den Unterricht“ die interkulturelle Perspektive angesprochen, diese bleibt jedoch recht vage: Filme könnten auch aus landeskundlich-interkultureller Perspektive betrachtet werden und dies ermögliche zum einen einen differenzierten Blick auf deutschen Alltag, zum anderen würden interkulturelle Sprechanlässe geschaffen (vgl. ebd. 10). Theoretische Reflexionen zum Thema Interkulturalität spielen denn auch in den weiteren Artikeln des Heftes keine Rolle mehr. ${ }^{2}$ Weitere aktuelle Literatur zum Themengebiet Filmeinsatz und Interkulturalität im DaFUnterricht konnte ich nicht finden.

\subsection{Anregungen aus anderen Fremdsprachendidaktiken}

Ein Blick in neuere Texte anderer Fremdsprachendidaktiken wirft jedoch weitere Gesichtspunkte auf:

So wird in einem 2004 erschienenen entsprechenden filmdidaktischen Themenheft der Zeitschrift „Der fremdsprachliche Unterricht Englisch“ der Interkulturalität mehr Raum zugestanden: Im Basisartikel sieht Surkamp (2004) fremdsprachige Filme als authentische

Hier lauten die die entsprechenden Abschnitte einleitenden Überschriften „Schärfung des Seh-Vermögens“ (ebd.: 6) und „Filme ermöglichen mit Emotionen verknüpftes Lernen“ (ebd: 7).

2 Es finden sich allerdings im Themenschwerpunkt „Landeskunde“ zwei Didaktisierungen, die dem Bereich Interkulturalität zugeordnet werden können: Gregori et al. (2007) beschäftigen sich mit dem „Schwarzfahrer“ (1993) (Thema: Rassismus), Lundquist-Mog (2007) diskutiert den Einsatz von Vorabendserien im DaF-Unterricht und entwickelt Aufgaben zu den Bereichen Stereotypisierung, Interkulturelle Unterschiede und Missverständnisse sowie Perspektivenwechsel zur ersten Folge der ersten Staffel von „Türkisch für Anfänger“ (2006). 
Kulturprodukte und sie verweist auf (häufig) insgesamt leichtere Verständlichkeit, da unterschiedliche Kommunikationskanäle benutzt werden (Entlastung), was gleichzeitig zur Förderung pragmatischer Kompetenz in der Fremdsprache beitrage. Diehr (2004) hebt in ebendiesem Heft auf die Schlüsselfertigkeit „Dezentrierung“ ab: Kulturell bedingte Konflikte könnten aus der Distanz betrachtet werden. So erhöhe sich die Chance, dass diese Konflikte handlungsentlastet sachlich analysiert würden (vgl. insb. ebd.: 84).

Blell und Lütge (2004) konzentrieren sich in einem in „Praxis Fremdsprachenunterricht“ erschienenen Artikel auf die Anknüpfungspunkte für die Reflexion eigenund fremdkultureller Phänomene, die wegen der plurimedialen Darstellung im Film besonders reizvoll sei. Sie betonen die Relevanz der Untersuchung des eigenen kulturellen Selbstverständnisses, die Möglichkeit der Thematisierung multikultureller oder multilingualer Kontexte und das Ziel, monokulturell geprägte Bewusstseinshaltungen von Schülerinnen und Schülern aufzubrechen. Um dies zu erreichen, müssten mediale Inszenierungen zentraler Kulturthemen berücksichtigt werden, letztlich wird von den Autorinnen eine kulturwissenschaftliche Filmanalyse angestrebt (vgl. insb. ebd.: 404).

Und schließlich plädiert Linke (2006), die sich theoretisch an Hansen (2003) orientiert, - ebenfalls in der Zeitschrift „Praxis Fremdsprachenunterricht“ - dafür, im Fremdsprachenunterricht nicht nur die Kultur der „große[n] Gruppe der Nation“ (Linke 2006: 40) zu berücksichtigen, sondern auch „die Kultur kleinerer Untergruppen“ (ebd.). Sie fordert, nicht nur allgemeine Normen der Zielkultur zu vermitteln, sondern auch ,,auf subjektive Unterschiede in der Lebensweise von Individuen“ (ebd.) einzugehen und schließlich die Thematisierung der Unterschiede und Gemeinsamkeiten zwischen Herkunfts- und Zielkultur.

\subsection{Zusammenfassung und kritische Reflexion der gefundenen Ziele und Möglichkeiten}

In der folgenden Tabelle sind die bisher besprochenen Anregungen zusammengefasst:

\begin{tabular}{|l|l|l|}
\hline & DaF (Sass 2007) & $\begin{array}{l}\text { FU Englisch (Surkamp 2004, Blell; Lütge 2004, Diehr } \\
\text { 2004, Linke 2006) }\end{array}$ \\
\hline 1 & $\begin{array}{l}\text { Landeskunde, deut- } \\
\text { scher Alltag }\end{array}$ & Filme als authentische Kulturprodukte \\
\hline 2 & $\begin{array}{l}\text { Interkulturelle Sprech- } \\
\text { anlässe }\end{array}$ & $\begin{array}{l}\text { Pragmatische Kompetenz } \\
\text { nen kulturellen Selbstverständnisses }\end{array}$ \\
\hline 4 & & $\begin{array}{l}\text { Kennenlernen multikult.- und multiling. Situationen, } \\
\text { Schlüsselfertigkeit Dezentrierung }\end{array}$ \\
\hline 5 & & $\begin{array}{l}\text { Kultur v. Untergruppen und subjektive Unterschiede } \\
\text { vermitteln }\end{array}$ \\
\hline 6 & & $\begin{array}{l}\text { Mediale Inszenierungen zentraler Kulturthemen: Kul- } \\
\text { turwissenschaftliche Filmanalyse }\end{array}$ \\
\hline
\end{tabular}

Tabelle 1: Mögliche Lernziele in interkultureller Filmarbeit 
Wir haben nun also eine längere und durchaus differenziertere Liste von mit didaktischem Filmeinsatz verbundenen interkulturellen Zielen und Möglichkeiten. Kann ich als Lehrkraft damit bereits erfolgreich interkulturelle Filmarbeit durchführen?

Meines Erachtens sind einige Voraussetzungen von Lehrerseite aus notwendig, um die genannten Ziele überhaupt anstreben zu können. Die Lehrkraft muss bestimmte Konzepte für sich selber als gültig ansehen, sie auf die eigene Biographie anwenden können, und sie muss entsprechend der im Folgenden genannten Grundgedanken Filme auswählen.

a) Für die in Zeile 3 bis 6 genannten Ziele ist es unabdingbar, ein Grundverständnis der Konstruiertheit von Zugehörigkeit und Identität zu entwickeln und von der Mehrfachzugehörigkeit jedes Menschen auszugehen.

b) Um Filme unter kulturwissenschaftlichen Gesichtspunkten zu betrachten, müssen sie als kulturelle Produkte angesehen werden, nicht als Wirklichkeit.

c) Und schließlich muss man, nimmt man b) ernst, erneut überlegen, wie die Annahme von Film als ,authentisches Kulturprodukt“ zu verstehen ist.

Bei unreflektiertem Filmeinsatz besteht die Gefahr, dass trotz hehrer Ziele letztlich Unterschiede essentialisiert und Gruppen unreflektiert stereotypisiert werden.

\section{Anregungen aus der interkulturellen Filmanalyse}

Diese - zunächst recht abstrakt anmutenden - Grundgedanken möchte ich anhand einiger Anregungen aus der interkulturellen Filmanalyse erläutern und durch Filmbeispiele konkretisieren (Blumentrath 2007, Bauer 1997, Hall 2000, Welsch 1997, Knopp 2006).

\subsection{Transkulturalität und Mehrfachzugehörigkeit}

„Die Medien sind [...] stets eine reduktive Rekonstruktion von Wirklichkeit und geben darüber hinaus immer neue Definitionen von Wirklichkeit [...]“ (Bauer 1997: 58)

Bauer (1997) geht davon aus, dass unsere Gesellschaften so vielfältig sind, dass unser alltagsweltlicher, an einer homogenen Nationalkultur orientierter Kulturbegriff im Zusammenhang mit Medien obsolet geworden ist. Er reflektiert über die Rolle der Medien, insbesondere des Films, in einem kulturellen Transformationsprozess, der durch die Transkulturalität des Einzelnen vorangetrieben wird. Blumentrath et al. (2007) zitieren dazu Welsch (1997):

„Unsere Kulturen haben de facto längst nicht mehr die Form der Homogenität und Separiertheit. Sie haben vielmehr eine neuartige Form angenommen, die ich als transkulturell bezeichne, weil sie durch die traditionellen Kulturgrenzen wie selbstverständlich bindurchgeht. Die kulturellen Verhältnisse sind heute weithin durch Mischungen und Durchdringungen gekennzeichnet." (Welsch 1997: 71, zitiert nach Blumentrath 2007: 16)

„Kulturen [sind...] nach innen vielfach differenziert [...und weisen] auch nach außen zahlreiche Verbindungen mit anderen Kulturen auf.“ (Blumentrath 2007: 17) 
So haben möglicherweise Golfspieler auf der ganzen Welt mehr miteinander gemeinsam als ein kenianischer Golfspieler mit einer kenianischen Haushaltshilfe.

Jeder gehört aber auch mehreren Gruppen an, mehreren Gruppen, deren Interessen möglicherweise miteinander in Konflikt stehen und die teilweise unterschiedlichen Standardisierungen, z.B. im Umgang mit Zeit, Ansprüchen an Ordnung und Sauberkeit etc. folgen. ${ }^{3}$

Ich stelle die These auf, dass Lehrkräfte eine solche Sichtweise von Kultur nachvollziehen und für sich akzeptieren können müssen, sie müssen eigene Mehrfachzugehörigkeiten, Veränderungen eigener Zugehörigkeiten reflektieren können. Habe ich als Lehrkraft selbst einen starren Kulturbegriff, so endet jede scheinbar interkulturelle Filmarbeit doch letztlich wieder bei der Postulierung starrer nationaler Grenzen. An vielen in interkultureller Absicht erstellten didaktischen Filmen ist gerade dieser implizit vorhandene starre Kulturbegriff zu bemängeln. Er findet sich beispielsweise in dem noch immer beliebten Film „Nazmiyes Kopftuch“ (ursprünglich 1981, noch 2000 neu aufgelegt) und in „Mehmet und Maria“ (1993). Solche Filme sind erstellt worden, um Wissen über andere Kulturen zu verbreiten, haben dieses eine Schwerpunktthema und reduzieren alles auf dieses Thema. Die mitspielenden Menschen werden auf ihre national-kulturelle Zugehörigkeit reduziert.

Wichtig wäre es also, Filme auszusuchen, die dieser Falle entgehen. Leichter fündig wird man bei Spielfilmen, die eben nicht in primär didaktischer Absicht erstellt worden sind. Multikulturalität wird nicht mehr als „Pflicht“, sondern als ein Aspekt unter vielen angesehen (Blumentrath 2007: 86, 118ff.). Als Beispiel für einen Film, in dem sich transkulturelle Aspekte finden, ist „Kebab Connection“ (2005) zu nennen: In diesem Film geht es nicht nur um türkisch-deutsche Beziehungen, sondern auch um das Verhältnis von Mann und Frau, um die Entwicklung von Lebensperspektiven, um damit zusammenhängende Auseinandersetzungen und um das Aushandeln von Relationen und Einstellungen zueinander. Jeder gehört mehreren Gruppen an, Positionen/Meinungen, auch Stereotype werden formuliert und thematisiert - Meinungen und Positionen

3 Es gibt einige Kritikpunkte an diesem Kulturbegriff: Zum einen verschwinde, je konkreter man nachdenkt, die Abgrenzung zum (pädagogischen) Rollenbegriff, zum zweiten führe diese Ansicht letztlich zu einer kompletten Entdifferenzierung und damit letztlich wieder zu einer Homogenisierung und schließlich würden konkrete Machtverhältnisse ausgeblendet. Das Konzept bedenke nicht, dass Menschen aufgrund sozialer Ungleichheit keinen gleichberechtigten Zugang zu Ressourcen und kulturellem Kapital haben.

Auf die ersten beiden Kritikpunkte finden sich folgende Entgegnungen: Beim Rollenbegriff geht es um Aufgaben, nicht um Standardisierungen (Begriff nach Hansen 2003). Bei genauerem Nachdenken sind zwischen beiden Größen aber sicherlich Interrelationen zu finden. Auch führt zunehmende Differenzierung gerade nicht zu Homogenität, sondern zu verschiedenen Arten von Vielfalt.

Der Kritik an der Ausblendung konkreter Machtverhältnisse hingegen kann m.E. kein Widerspruch entgegengesetzt werden (zur Kritik und ihrer Diskussion siehe Blumentrath 2007: 17f.). Dies weist uns darauf hin, dass wir uns im Rahmen der Auseinandersetzung mit Film und Interkulturalität mit der Frage der Machtverhältnisse und ihrer Sichtbarkeit beschäftigen sollten (siehe dazu Abschnitt 2.3 des vorliegenden Artikels). 
verändern sich aber auch im Laufe des Films. Kulturelle Einheitserwartungen werden humorvoll thematisiert und teilweise sogar persifliert. ${ }^{4}$

An dieser Stelle deutet sich bereits der zweite Gesichtspunkt an, den ich anhand von Filmausschnitten thematisieren möchte: Wenn jeder mehreren Gruppen angehört, dann konstruiert er seine kulturelle Identität aus der Zugehörigkeit zu diesen verschiedenen Gruppen - und diese kulturelle Identität ist nicht statisch - sie verändert sich im Laufe der Zeit, u.a. in Verbindung mit den eigenen Lebensumgebungen und -verschiebungen.

\subsection{Kulturelle Identität und Hybridität}

„Interkulturalität ist mit den Möglichkeiten und Chancen der Selbstfindung in einer komplexen Welt verknüpft. Durch Medien werden Grenzen zu Räumen der Begegnung und der Berührung und erst durch diese Grenzen wird Identität definiert.“ (Bauer 1997: 56)

Hinter diesem Identitätskonzept stehen die Ideen des britisch-jamaikanischen Kulturwissenschaftlers Stuart Hall (2000). Er sieht zwei - einander ergänzende - Möglichkeiten, um über kulturelle Identität nachzudenken: ${ }^{5}$ Kulturelle Identität ist einerseits das, was Menschen miteinander vereinigt, was sie miteinander teilen: historische Erfahrungen, kulturelle Codes, die uns mit stabilen Referenz- und Bedeutungsrahmen versorgen (in der interkulturellen Debatte auch als Standardisierungen bezeichnet, Hansen 2003). An-

Kurze Inhaltsangabe: Tizzi, Freundin von Ibo, ist schwanger und hat sich entschieden, das Kind zu bekommen. Wegen der Schwangerschaft befindet sie sich im Konflikt mit der Mutter. Außerdem hat sie Schwierigkeiten, diese mit ihrem Berufswunsch Schauspielerin zu vereinbaren. Ibo weiß nicht, ob er schon Vater werden will, bekommt Druck von seinen Eltern, die zunächst eine nichttürkische Freundin nicht akzeptieren wollen.

Zur Illustration der o.g. Behauptungen oder möglicherweise auch zur Entwicklung eigener Didaktisierungen eignen sich beispielsweise folgende Szenen:

Die Kinderwagenszene

- 3 Minuten, 26:20-28:24: Tizzi teilt ihrer Mutter mit, dass sie schwanger ist und sich entschieden hat, das Kind zu bekommen. Ihre Mutter ist nicht erfreut und reagiert mit der Frage: „Hast du schon mal 'nen Türken 'nen Kinderwagen schieben sehen?" In der darauf folgenden Szene testet Tizzi die Kinderwagenschiebbereitschaft ihres Freundes und es ergibt sich eine teilweise slapstickartige Szene.

Drei Szenen mit Ibos Vater

- 2,5 Min., 17:44-19:16: Ibo erzählt seinen Eltern, dass seine Freundin schwanger ist und wird rausgeschmissen, weil der ein Kind mit einer „Ungläubigen“ bekommen wird.

- 2 Min., 33:20-35-14: Tizzi klingelt bei Ibos Eltern und erklärt seinem Vater in einem häufiger unterbrochenen Monolog, weshalb sie auf solch eine Schwiegerfamilie verzichten kann. Anschließend unterhalten sich die Eltern im Wohnzimmer und Ibos Mutter bringt ihren Mann durch Appelle an Ehre und Stolz dazu, das zukünftige Enkelkind zu akzeptieren.

- 1,5 Min., 1:15:15-1:16:40: Ibos Vater bringt Tizzi mit seinem Taxi zur Entbindung ins Krankenhaus.

Ein weiteres Beispiel für Transkulturalität und Mehrfachzugehörigkeit findet sich in „Kurz und Schmerzlos“. In diesem Film werden die Protagonisten anhand ihrer Nationalität eingeführt; bereits in der zweiten Szene (bei einer Hochzeit) stellt sich aber heraus, dass andere Gruppenzugehörigkeiten bedeutend wichtiger sind. Auch hier finden wir Themenvielfalt: Gabriel (Protagonist, Türke) wird nach Gefängnisaufenthalt und dem Wunsch, nun legal zu leben, wieder in ein Gangleben hineingezogen. Weitere Themen sind die Trennung seiner Schwester von ihrem Freund Costa (der Grieche), also die Bereiche Frauen/Männer und Liebe, der Versuch Bobbys (Serbe), über Mafiaverbindungen reich zu werden und die Freundschaft zwischen Gabriel, Costa und Bobby.

5 Knopp (2006) wendet dieses Denkmodell auch auf die personale Identität an. 
dererseits gibt es aber auch Punkte signifikanter Differenz, die das konstituieren, was wir geworden sind: Die türkische kulturelle Identität ist eine andere, je nachdem, ob man immer in der Türkei gewohnt hat, ob man remigriert ist oder aber inzwischen seit mehreren Generationen in Deutschland ansässig. Als gleichzeitig gemeinsame Erfahrung und Bruch ist aber auch der Nationalsozialismus in Deutschland anzusehen. Aufgrund dieser Erfahrung haben wir solch ein „gebrochenes“ Verhältnis zu Konzepten wie Nation, kulturelle Identität und Patriotismus.

Wir stellen uns unsere kulturelle Identität immer eher als kohärent vor; wir rekonstruieren unsere kulturellen Identitäten durch Erzählungen, Geschichten über uns und unsere Vergangenheit. Dadurch positionieren wir uns selber, werden aber auch durch die Erzählungen anderer positioniert (Blumentrath 2007: 23). Die Konstruktion von „Türkisch-Sein“ von Migranten in Deutschland hängt damit zusammen, wie man sich „Türkisch-Sein“ in der Türkei vorstellt und diese Auffassungen miteinander kommuniziert. „Deutsch-Sein“ hat sich nach der Weltmeisterschaft 2006 verändert, durch eigene und fremde Erzählungen, z.B. durch die Medienberichterstattung: Aus dem hässlichen Deutschen, dem Nazi, wurde ein gastfreundlicher Deutscher.

Kulturelle Identität verändert sich demnach ständig entlang verschiedener Linien, sie gehört nicht nur der Vergangenheit, sondern auch der Zukunft an. Innerhalb der Kontinuität und entlang der Kontinuitiät existiert Differenz. ${ }^{6}$ Identität ist niemals fertig.

„Kebab Connection“ inszeniert solche Veränderungen, z.B. Veränderungen der Einstellung von Ibos Vater zu Tizzis Schwangerschaft, die zumindest teilweise kommunikativ ausgehandelt wird, u.a. mit Hinweis auf kulturelle Identität. ${ }^{7}$ Der Film „Kurz und Schmerzlos“ zeigt sowohl Veränderungen von Identität ${ }^{8}$ als auch ihre kommunikative Aushandlung?.

Aus der Sichtweise der ständigen Konstruktion von Identität ergibt sich das Konzept der Hybridität. Ein wichtiger Vordenker dieses Konzepts ist Homi K. Bhaba. Er geht nicht mehr, wie frühere Rassismustheoretiker, von einer Dualität zwischen Unterdrückern und Unterdrückten aus, sondern es werden „Hybridisierungen produziert“ (Blumentrath 2007: 24), Minderheitenangehörige eignen sich Aspekte der Mehrheitskultur

\footnotetext{
Hall (2000: 709) verweist hier auf Derrida als Gedankengeber, der mit den Worten „differ“ und „defer“", „unterscheiden“ und „verzögern“, spielt.

siehe Fußnote 4.

8 Beispielsweise zeigen vier sehr kurze Szenen einen Wandel im Umgang mit Religion seitens des Protagonisten Gabriel. Zu Beginn des Films befindet er sich u.a. zusammen mit seiner Schwester auf einer Hochzeit, ein buddhistischer Furba-Dolch wird als Talisman überreicht (3:50-4:13). In einer zweiten Szene bietet der Vater dem Sohn an, gemeinsam zu beten, dieser lehnt ab (27:10-27:30). In einer dritten Szene - in der zweiten Hälfte des Films, nachdem unserem Protagonisten die Kontrolle über die Ereignisse entglitten ist - wird eine kurze Szene in einer Moschee eingeblendet, in der Gabriel zwar mitbetet, aber durch verzögertes Verhalten, fehlende Kopfbedeckung und vorzeitiges Verlassen der Moschee auffällt (1:14:30-1:15:38), und schließlich endet der Film nach der Katastrophe mit einem Betangebot des Vaters an den Sohn, das dieser diesmal annimmt (1:30:51-1:31:53).

9 Gabriel und seiner Schwester thematisieren in einem Gespräch die beiden verschiedenen Traditionen, Loyalitäten und Zugehörigkeiten, und sie handeln Gabriels Rolle als türkischer großer Bruder aus. Positionen verändern sich (27:40-28:47).
} 
an, weichen dabei aber ,vom Original ab“ (ebd.: 25). ${ }^{10}$ Hà (2004) reflektiert über die „Selbst-Kanakisierung als strategische Diskurspolitik“ (ebd.: 199): Begriffe sind in Kommunikationsgemeinschaften positiv oder negativ konnotiert. Durch die Aufnahme negativ konnotierter Kategorisierungen von Minderheitsangehörigen in ihren eigenen Diskurs geschieht eine Umwertung dieser Kategorisierungen, Bedeutungen werden geändert/modifiziert und „ein aufgezwungenes Selbstbild subversiv [...] unterlaufen“ (ebd.: 200). Auch hier ist zur Illustration wieder eine Szene aus „Kurz und Schmerzlos“ geeignet: Bobby (Serbe) und Costa (Grieche) verhandeln um einen Laptop, den Costa geklaut hat. Bobby gibt weniger als den vereinbarten Preis (40 Sekunden, 11:30-12:10). Hier die Grobtranskription der Szene:
Bobby:
Buzukimann... Laptop. Gib mir den Laptop.
Costa:
Ey du willst mich bescheißen, Alter..., Jugo Betrugo, Alter!
Bobby:
Eh kannst du machen nichts, Lebe geht weiter.
Costa:
Kannst du machen nix? ... Kannst du mir geben eine Hunderter mehr!
Bobby:
Kannst du mir geben Akku dafür!
Costa:
Akku bekommst du...
Bobby:
Ey, weißt du was, du bist richtig gut geworden.

Die Äußerungen im „Ausländerdeutsch“ werden gerahmt durch einen Auslöser („Buzukimann“) und einen Metakommentar Bobbys („Ey, weißt du was, du bist richtig gut geworden"). Innerhalb dieses Rahmens konstruieren die beiden durch ihre veränderte Sprechweise einen scheinbar prototypischen kriminellen Ausländer. Fremdstereotype werden also umgedeutet, indem sie von den potentiell Stereotypisierten selbst zitiert werden. Mit Identität wird auf diese Weise gespielt.

Nun zum grundlegendsten, aber wegen seiner Abstraktheit zumindest im konkreten Fall am schwersten zugänglichen Aspekt:

\subsection{Rekonstruktion von Wirklichkeit und Definitionsmacht ${ }^{11}$}

Mediale Darstellungen sind keine Abbilder der Wirklichkeit, sondern konstruieren Realität.

„Die Medien [...] sind stets eine reduktive Rekonstruktion von Wirklichkeit und geben darüber hinaus immer neue Definitionen von Wirklichkeit.“" (Bauer 1997: 58)

Dies geschieht auf mindestens drei Ebenen: Zum einen wählen Film-Macher aus, was sie auf welche Weise zeigen, und stellen so Wirklichkeit her. Welche Themen werden als darstellungswürdig angesehen? Wie werden diese Themen behandelt? Zum zweiten entscheiden sich Film-Macher, wie sie ihre Protagonisten konstruieren: Wer wird wie dargestellt, wer wird wie gesehen, wessen Identität wird wie konstituiert? Was wird als gut und was als problematisch angesehen? Wie viel Definitionsmacht geben die Macher den Protagonisten, wie viel Handlungsfreiheit räumen sie ihnen ein: Wer spricht, wer handelt, wer hat Handlungsspielräume - und wer ist möglicherweise nur ein Opfer der Verhältnisse? So wird in vielen Filmen der 80er und frühen 90er des letzten Jahrhunderts den Minderheitsangehörigen

10 Dieses Phänomen wird auch unter dem Namen „Mimikry“ beschrieben.

11 Die Idee zu dieser Anregung stammt von Paul Mecheril, der genau diesen Gesichtspunkt anhand des unten diskutierten Films „Schwarzfahrer“ vor mehreren Jahren auf einer Tagung präsentiert hat. 
die Opferrolle zugeschrieben. ${ }^{12}$ Beispielhaft illustrieren lässt sich das durch „Nazmiyes Kopftuch“ (1981) im Vergleich zu „Hallo Erkan“ (2002) oder „Respekt“ (2000). Während ersteres eindeutig aus der Mehrheitsperspektive gedreht ist, enthält „Hallo Erkan“ einen Wechsel der Perspektiven. ${ }^{13}$ „,Respekt" schließlich, ein Dokumentarfilm, ist ganz aus der Minderheitenperspektive gedreht. Filmemacher (re-)konstruieren also Wirklichkeit, und diese (Re-)Konstruktion hat etwas mit Macht zu tun. Aus der oben erwähnten zweifachen Auswahl lassen sich Rückschlüsse auf die Positionen der Macher ziehen: ,The practices of representation always implicate the positions from which we speak or write " (Hall 2000: 704). Und schließlich hat - drittens - auch der Rezipient seine jeweils eigene kulturelle Brille auf, setzt dadurch eigene Relevanzen und konstruiert sich daraus sein Bild dessen, was er sieht. $^{14}$

Aus der Perspektive der Rekonstruktion von Wirklichkeit betrachtet, ist der häufig didaktisierte Film „Schwarzfahrer“ (1992) kritischer zu sehen als üblicherweise angenommen: Den größten Teil des Filmes nimmt ein Bild ein, in dem eine ältere Frau weißer Hautfarbe und ein jüngerer Mann dunklerer Färbung in einem Bus nebeneinander sitzen, wobei die ältere Frau durchgängig rassistische Äußerungen ausstoßend redet, während die Kamera abwechselnd sie, den jungen Mann und die Mitfahrenden fokussiert. Die Frau agiert also: Ihr Redefluss wird, dies zeigt die Kamera, sicherlich von einigen Mitfahrern kritisch gesehen, diese greifen aber nicht ein. Der Schwarze re-agiert, zunächst durch Schweigen und später auf unkonventionelle (nicht legale) und originelle Weise, indem er ihren Fahrschein aufisst.

Welche Schlussfolgerung lassen sich daraus ziehen? Erstens: Wenn man als Minderheitenangehöriger wegen seiner Zugehörigkeit angegriffen wird, kann man nur außerhalb des legalen Rahmens (erfolgreich) reagieren. Besonders von der Umwelt positiv gesehen werden humoristische Handlungen, Handlungen, die Lacher hervorrufen. ${ }^{15}$

12 Auch in der zeitgleich verfassten interkulturellen Kinderliteratur findet sich diese Tendenz. So z.B. in: Schwarz, Annelies (1986): Hamide spielt Hamide. Ein türkisches Mädchen in Deutschland. München: dtv junior, sowie in: van Heyst, Ilse (1976): Alles für Karagöz. Stuttgart: Spectrum etc. Diese Bücher wurden übrigens allesamt bis Ende der 90er Jahre vielfach aufgelegt.

13 „Hallo Erkan“ zeigt eine Auseinandersetzung zwischen Kindern deutscher und türkischer Herkunft. Auch hier finden sich, wie in „Nazmiyes Kopftuch“, Diskriminierungsszenen, Erkan ist diesen aber nicht so ausgeliefert wie Nazmiye, sondern handelt selber, und durchaus nicht moralisch vollkommen einwandfrei. Die Kamera wechselt zwischen den Perspektiven Erkans und der ihn verfolgenden Jungen, wenn auch die Identifikation mit Erkan durch die Kameraführung in etwas stärkerem Maße nahegelegt wird. Das Ende des Films ist offen, möglicherweise wurden durch die im Film gezeigten Geschehnisse auf beiden Seiten Positions- und Meinungsänderungen bewirkt.

14 Schon 1986 hat sich Kreuzer mit dem fremden Blick beschäftigt, und zwar hinsichtlich der Frage, wie in Deutschland fiktive Filme aus anderen Ländern und über andere Länder gesehen werden, nämlich quasidokumentarisch. Die Fremdheit des Blicks ist ein meines Wissens in der DaF-Didaktik bisher nicht systematisch reflektiertes Thema.

15 Wenn Sie dies übertrieben finden, versetzen Sie sich in eine solche rassistische, aber nicht gefährliche Situation, derer Sie sicher auch schon Zeuge geworden sind: Hätte der Schwarze sich verbal-argumentativ gewehrt, wäre ihm nicht unbedingt die Solidarität der Umsitzenden sicher gewesen, ein Unwohlsein wäre aufgetreten, das durch diese originelle Reaktion vermieden wird. Solche Reaktionen schonen uns Zuhörer und wecken in uns Sympathien mit dem Minderheitsangehörigen, ohne dass wir uns als Mehrheitsrepräsentanten angegriffen fühlen müssten. 
Zweitens: Als Minderheitenangehöriger muss man immer alles „richtig“ machen, um Stereotypen nicht zu entsprechen (z.B. als Schwarzer mit Fahrschein fahren). Auch wenn man sich „richtig“ verhält: Stereotype der Mehrheitsangehörigen kann man nicht wirklich ausräumen. Man hat also in zweierlei Hinsicht fehlende Handlungsfreiheit. ${ }^{16}$

Dieses Wissen ermöglicht nun eine differenziertere Reflexion von Reaktionsmöglichkeiten auf den Film: Zeigt man ihn Mehrheitsangehörigen, so reagieren diese häufig auf das fehlende Engagement der Mitfahrenden. Zeigt man ihn Minderheitsangehörigen mit Deutschlandbezug, so erinnern sich diese - ebenfalls üblicherweise - an eigene Diskriminierungssituationen. Didaktische Situationen mit Mehrheitsangehörigen, die diesen Film diskutieren, werden oft als gelungen angesehen, didaktische Situationen mit Minderheitsangehörigen, in denen dieser Film eingesetzt wird, gelingen häufig nicht. ${ }^{17}$ Ein möglicher Grund dafür ist, dass Mehrheitsangehörige sich aufgrund ihrer Biographie eher den Mitfahrenden näher fühlen, und sogar auch der rassistischen Frau, von deren Verhalten wir uns selbstverständlich abgrenzen, Minderheitsangehörige hingegen sehen sich eher in der Rolle des diskriminierten Schwarzen. ${ }^{18}$ Das macht es für uns als Lehrende so schwer, Filme auszusuchen, wenn wir der Majorität angehören: Automatisch und unreflektiert nehmen wir deren Perspektive ein. Wenn unsere Zielgruppe aber eben aus Minoritätsangehörigen besteht, sind bei dieser Herangehensweise Probleme bei der didaktischen Realisierung wahrscheinlich.

\section{Welche Konsequenzen sind aus den drei Anregungen für die interkulturelle DaF-Filmarbeit zu ziehen?}

Auch der Lehrende befindet sich durch seine Möglichkeit der Filmauswahl in einer Machtposition. Er entscheidet, welche Wirklichkeits-(Re)-Konstruktionen im Unterricht Gesprächsgrundlage werden, und er entscheidet, wie er die gewählten Filmvorlagen einbringen will, welche Aufgaben er dazu bearbeiten lässt, welche Gespräche er anregt, zulässt, fördert - und damit verbunden, welche Konstruktionen kultureller Identität nahegelegt werden. Bevorzugt auszuwählen sind:

- Filme, in denen Kultur und Interkulturalität ein Thema unter mehreren ist,

- Filme, in denen Protagonisten verschiedene Zugehörigkeiten haben; diese können zu Interessenkonflikten führen, Reduzierung auf „Kultur“ allein nicht möglich,

- Filme, in denen sich Positionen/Einstellungen von Personen verändern,

- Filme, in denen Protagonisten mit Identitäten spielen.

16 Auch dieser Gedanke ist nicht neu: Man erinnere sich nur an das Tagebuch der Anne Frank, in dem diese am 22.5.1944 über den Antisemitismus reflektiert: „Ja, es ist traurig, sehr, sehr traurig, daß sich zum soundsovielten Male der alte Spruch bewahrheitet: ,Was ein Christ tut, muss er selbst verantworten. Was ein Jude tut, fällt auf alle Juden zurück““ (Frank 1955: 208). Daraus folgt der Imperativ zum ständig moralisch unanfechtbaren Handeln Minoritätenangehörigen.

17 Dies wurde mir inzwischen mehrfach von Sprachlehrenden sowie einer Erasmusstudentin berichtet.

18 Um es noch einmal zu betonen: Damit ist nicht die Frage gemeint, mit wem man sich solidarisch fühlt, sondern die, in wessen Rolle man sich eher sieht: Wenn eine Diskriminierungssituation aufträte, wäre man dann eher Täter, Opfer oder unbeteiligter Zeuge? Über die Rolle, die einem selbst am nächsten ist, denkt man dann auch am intensivsten nach. 
Bei der Filmauswahl ist zu berücksichtigen: In welcher Relation stehen die Rezipienten zu dem/den Protagonisten? Wer könnte die Person sein, in deren Rolle sie sich am ehesten sehen?

Dies impliziert verschiedene Probleme: In didaktischen Filmen werden Andersgruppenzugehörige oft so dargestellt, dass sie keine Stimme und keine Handlungsfreiheiten haben. Die Filme arbeiten mit einem starren Kulturbegriff und werden oft ausschließlich zum Thema Interkulturalität erstellt. Sie verstellen so den Blick auf multiple Zugehörigkeiten. Diese Filme bieten aber auch Vorteile: Sie sind bereits für den Unterricht zubereitet, zumindest aufbereitet; sie haben eine angemessene Länge, sind sprachlich vereinfacht, sie benutzen eine in unserer Gesellschaft als ,politisch korrekt“ angesehene Sprache - ihr Einsatz ist ganz schlicht und einfach arbeitsersparend, was für im Berufsleben stehende stark belastete Lehrende ein sehr gewichtiges Argument ist.

All diese Vorteile bieten Spielfilme nicht: sie sind zu lang, oft sprachlich zu anspruchsvoll, sie enthalten Passagen, die für Lerner nicht Wort für Wort verständlich sind, sie sind zu schwer, zu sperrig, möglicherweise politisch unkorrekt, Schlägereien enthaltend und Stereotype offen aussprechend. Sie scheinen also zunächst die schlechtere Wahl. Aber in diesen neueren deutschen Spielfilmen finden wir, wie eben an Beispielen erläutert, die erwünschte Vielfalt. Kultur ist ein Thema unter mehreren, (kulturelle) Identitäten wandeln sich, Brüche, Diskontinuitäten und hybride Formen sind vorhanden, die Perspektivenvielfalt möglicherweise sogar schon eingeplant. ${ }^{19}$

Welche Möglichkeiten haben wir als Pädagogen also? Wir sollten Filme bewusst auswählen - und die dem jeweiligen Film angemessenen Aufgabenstellungen entwickeln. Wenn wir uns für einen didaktischen Film mit den oben erwähnten Schwächen entscheiden, müssen wir überlegen, wie der im Film angelegten Rezeptionsweise gegengesteuert werden kann. Wie kann ggf. essentialisierenden Tendenzen entgegengewirkt werden? Filmen inhärente Kulturbegriffe und Identitätskonstruktionen müssen von uns reflektiert werden und daran anknüpfend müssen wir überlegen, welche (möglicherweise auch ausgleichenden) Aufgaben dazu zu entwickeln sind. Rezeptionsmöglichkeiten, unterschiedliche Sicht-Weisen müssen bei der Aufgabenentwicklung berücksichtigt werden: Was ist beispielsweise zu tun, damit beim Schwarzfahrer der Minderheitenangehörige nicht die naheliegenden oben erwähnten Konsequenzen zieht? Man kann die Handlungsmöglichkeiten des Schwarzen reflektieren, auf den Konstruktionscharakter des Films aufmerksam machen, einen konträr angelegten Film als Gegenbeispiel suchen etc. Immer aber sollten wir in unserer didaktischen Filmarbeit Bezug auf Identitätskonstruktionen der Gruppenteilnehmer nehmen, diese möglicherweise auch interaktiv erarbeiten lassen. Für die Arbeit mit Filmen, die nicht in didaktischer Absicht erstellt worden sind, die idealerweise die o.g. problematischen Aspekte nicht aufweisen, dafür aber lang und sprachlich komplex sind, müssen wir mehr Aufgaben zum globalen

19 Dies formuliert beispielsweise Fatih Akin in dem Interview, das als Bonusmaterial der käuflich zu erwerbenden DVD „Gegen die Wand“ beigefügt wurde. Auf die Frage: „Muss man einen Türkenbonus haben, um den Film zu verstehen?", antwortet er, dass er den Film für drei Sichtweisen zu erstellen versucht habe, den deutsch-deutschen Blick (den Blick der Geldgeber), den deutsch-türkischen Blick, welcher eben sein eigener, der für ihn selbstverständliche sei, und den türkisch-türkischen Blick. 
Verständnis des Inhalts erstellen (dies schult durchaus die anfangs erwähnte pragmatische Kompetenz), und uns nur mit einzelnen Aspekten/Szenen des Films genauer auseinandersetzen. ${ }^{20}$

Schließlich ist es wichtig, trotz Didaktisierung das Interesse an den im Film angesprochenen Themenkomplexen nicht zu zerstören: Man sollte einen Film nicht so zerstückeln, dass nichts mehr übrig bleibt. Und damit sind wir wieder bei Schwerdtfeger (1989) angelangt: Die Neugier muss erhalten bleiben.

\section{Literatur}

Bauer, Thomas A. (1997): Kulturen im Wandel. Der Film als Medium interkultureller Verständigung. In: Filmkunst. Zeitschrift für Filmkultur und Filmwissenschaft 154, 54-68.

Blell, Gabriele; Lütge, Christiane (2004): Sehen, Hören, Verstehen und Handeln. Filme im Fremdspracheunterricht. In: Praxis Fremdsprachenunterricht 6, 402-405, 445.

Blumentrath, Hendrick; Bodenburg, Julia; Hillman, Roger; Wagner-Engelhaaf, Martina (2007): Transkulturalität. Türkisch-deutsche Konstellationen in Literatur und Film. Münster: Aschendorff.

Diehr, Bärbel (2004): Brit-Asian films und interkulturelles Lernen auf der Sekundarstufe 1. They go together like „dal and chapatties“. In: Englisch 39/3, 81-86.

Frank, Anne (1955): Das Tagebuch der Anne Frank. Frankfurt a.M. u.a.: Fischer.

Gregori, Luisa; Váčlav, Kubecka; Tschunidova, Elena (2007): „Schwarzfahrer“. In: Fremdsprache Deutsch 36, 26-28.

Hà, Kiên Nhi (2004): Ethniæität und Migration reloaded: Kulturelle Differenæ, Identität und Hybridität im postkolonialen Diskurs. Berlin: wvb.

Hall, Stuart (2000): Cultural Identity and Cinematic Representation. In: Stam, Robert; Miller, Toby (Hrsg.): Film and Theory. An Anthology. Malden, Mass.: Blackwell, 704714.

Hansen, Klaus P. (2003): Kultur und Kulturwissenschaft. Eine Einführung. Tübingen: Francke.

Knopp, Matthias (2006): Identität zwischen den Kulturen: Gegen die Wand. In: Braun, Michael; Kamp, Werner (Hrsg.): Kontext Film. Beiträge zu Film und Literatur. Berlin: Erich Schmidt, 59-77.

Kreuzer, Dorothée (1986): Film in der Fremde. In: LiLi - Zeitschrift für Literaturwissenschaft und Linguistik 62, 134-139.

Linke, Gabriele (2006): Kulturelles Lernen mit Musikvideoclip und Film. In Praxis Fremdsprachen-Unterricht 5, 40-45.

Lundquist-Mog, Angelika (2007): „Türkisch für Anfänger“. In: Fremdsprache Deutsch 36, 29-35.

20 Auch Dokumentarfilme eignen sich übrigens für die interkulturelle Arbeit, so die in der Reihe „100 deutsche Jahre“ entstandene Folge „MannsBilder“, die den Wandel eines Ideals innerhalb der deutschen Kultur innerhalb von einhundert Jahren zeigt. Ein Kulturkontrast muss nicht unbedingt bereits im Film angelegt sein; andere Kontraste, wie hier der Zeitkontrast, sind ebenfalls gut geeignet. Kulturvergleich kann dann auch interaktiv im Unterricht selbst hergestellt werden. 
Sass, Anne (2007): Filme im Unterricht - Sehen(d) lernen. In: Fremdsprache Deutsch 36, 5-13.

Schwerdtfeger, Inge (1989): Sehen und Verstehen. Arbeit mit Filmen im Unterricht Deutsch als Fremdsprache. Berlin u.a.: Langenscheidt.

Surkamp, Carola (2004): Teaching films. Von der Filmanalyse zu handlungs- und prozessorientierten Formen der filmischen Textarbeit. In: Der fremdsprachliche Unterricht Englisch 68, 2-11.

Welsch, Wolfgang (1997): Transkulturalität. Zur veränderten Verfassung heutiger Kulturen. In: Schneider, Irmela; Thomson, Christian W. (Hrsg.): Hybridkultur. Medien, Netəe, Künste. Köln: Wienand, 67-90.

\section{Filme, auf die verwiesen wird}

Gegen die Wand (2004). Spielfilm, Fatih Akin, Deutschland.

Hallo Erkan (2002). Eine Auseinandersetzung zwischen deutschen und türkischen Kindern. Lehrfilm, Institut für Film und Bild in Wissenschaft und Unterricht, 15 Min.

100 Deutsche Jahre (2000). Dokumentarfilmserie. 3 Folgen: Urlaubsträume (Thomas Fischer), Mannsbilder (Rolf Stephan), Weibsbilder (Gabriele Trost), je 30 Min.

Kebab Connection (2005). Spielfilm, Anno Saul, Deutschland.

Kurz und schmerzlos (1998). Spielfilm, Fatih Akin, Deutschland.

Mehmet und Maria (1993). Lehrfilm, Hans-Werner John, 30 Min.

Nazmiyes Kopftuch (2000 neu aufgelegt, urspr. 1981). Lehrfilm, Monika Bach, 18 Min.

Respekt (2000). Lehrfilm (Dokumentarfilm), Bundeszentrale für politische Bildung, Bonn (Hrsg.), 6 Min.

Schwarzfahrer (1992). Kurzspielfilm, Pepe Danquart, Deutschland, 12 Min. 

Christoph Chlosta, Matthias Jung (Hrsg.) (2010): DaF intergriert: Literatur - Medien - Ausbildung. Tagungsband der 36. Jahrestagung des Fachverbandes Deutsch als Fremdsprache 2008. Göttingen: Universitätsverlag, 73-95.

\section{Sebastian Chudak (Poznań, Polen)}

\section{Arbeit mit Filmen im DaF-Unterricht als eine Möglichkeit der Förderung der interkulturellen Kompetenz auf der Fortgeschrittenenstufe}

\section{Einleitung}

Lernt man Fremdsprachen, so lernt man gleichzeitig „fremde Kulturen“ kennen. Und möchte man die kommunikative Kompetenz in einer fremden Sprache entwickeln, so muss man die „fremde Kultur“ kennen lernen. Fremdsprachenlernen ist also mit dem Kennenlernen anderer Kulturen eng verbunden. Es bedeutet immer kultur- und landeskundliches Lernen. Auch das Kennenlernen „fremder Kulturen“ erfordert das Lernen von Fremdsprachen - Sprachen, die die Vertreter der jeweiligen „fremden Kultur“ sprechen.

In einer Zeit der Globalisierung, der pluralistischen Welt muss man niemanden mehr davon überzeugen, dass es notwendig ist, Fremdsprachen zu lernen und somit auch „fremde Kulturen“ kennen zu lernen. Zu betonen ist aber die Tatsache, dass Fremdsprache immer vor dem Hintergrund eigener Sprache gelernt und Fremdkultur immer vor dem Hintergrund eigener Kultur kennen gelernt wird. So kann es durch die verschiedene Ausprägung von Kulturen bei interkulturellen Kontakten zu Verstehensproblemen kommen. Fehlinterpretationen können dabei leicht zu Missverständnissen, stereotypen Haltungen oder sogar Ressentiments führen. Leider wird die Fähigkeit das eigene kulturelle Vorverständnis zu relativieren, die Pluralität von Denkerfahrungen anzuerkennen, nicht automatisch beim Fremdsprachenlernen entwickelt. Sie kann sogar gefährdet werden (z.B. Gefahr einer simplifizierenden Vorstellung der Zielkultur, 
Verstärkung vorhandener Klischees). Es ist deshalb zu fordern, dass im Fremdsprachenunterricht die Lerner darauf vorbereitet werden, sich mit fremd- sowie auch eigenkulturellen Phänomenen auseinander zu setzten - ihre interkulturelle Kompetenz auszubilden. Interkulturelles Lernen und interkulturelle Kommunikation sollten - wie u.a. bereits 1997 der Beirat DaF des Goethe-Instituts und 2001 der Europarat forderten - wesentliche Bestandteile jeder Form von Fremdsprachenunterricht sein. ${ }^{1}$

\section{Interkulturelle Kompetenz als Ziel des Fremdsprachen- unterrichts}

Bereits im kommunikativen Ansatz wurde postuliert, im Fremdsprachenunterricht alle Möglichkeiten zu nutzen, um landeskundliches Wissen einzubeziehen, um den Lernern die Vorgeprägtheit durch ihre eigene Kultur bewusst zu machen und sie zur Perspektivenübernahme zu befähigen. ${ }^{2}$ Heutzutage ist diese Forderung noch deutlicher zu hören. Der interkulturelle Ansatz geht noch stärker auf die kulturspezifischen und individuell geprägten Lebenserfahrungen und Lerngeschichten der Lerner, das Verhältnis von Ausgangs- und Zielkultur sowie Wahrnehmungs- (bewusstes Zuhören und Beobachten, darunter spezifische Sichtweisen der Lerner) und Verstehensprozesse (also Interpretation, Bewertung und Einordnung, darunter auch Stereotype ${ }^{3}$ ) ein.

$\mathrm{Zu}$ den Zielen des Fremdsprachenunterrichts wird neben der Herausbildung der „kommunikativen Kompeten“ nun auch die Herausbildung der bereits erwähnten „,interkulturellen Kompetenz“ gezählt, die sich - wie Volkmann (2002: 12) meint - ,allgemein als Fähigkeit und Fertigkeit von Fremdsprachenlernern, ja überhaupt von Akteuren einer interkulturellen Begegnung begreifen [lässt], über Differenzen zwischen der eigenen und der Zielkultur zu wissen, diese in konkreten Situationen zu erkennen und Strategien zu entwickeln, einfühlsam auf die Gepflogenheiten der anderen Kultur einzugehen." Der pragmatisch-funktionale Ansatz erfährt also eine Erweiterung. Im Mittelpunkt stehen nicht mehr Modelle für die Alltagskommunikation, sondern vielmehr auch die Reflexion über den eigenen kulturellen Hintergrund, Auseinadersetzung mit einer ,anderen“ Kultur (Zielkultur), Sensibilisierung für das Andere, Fremdverstehen, Respekt und Empathie ${ }^{4}$.

1 Der Europarat (2001: 103-130) weist u.a. auf soziokulturelles Wissen, interkulturelles Bewusstsein und interkulturelle Fertigkeiten als Bestandteile der interkulturellen Kompetenz, die zu den Kompetenzen der Sprachverwendenden bzw. -lernenden gehören sollte.

2 Zur Stellung der Landeskunde im Fremdsprachenunterricht (DaF) vgl. Neuner; Hunfeld (1993: 124127), Pfeiffer (2000: 131-133), Adamczak (2000: 150-152), Biechele; Padrós (2003: 44-57), Krumm (2003: 138f.) oder Roche (2005: 233-240).

3 Zu Stereotypen (= kulturgebundenen Deutungsmustern) im interkulturellen Fremdsprachenunterricht vgl. z.B. Pieklarz (2006: 116-119).

4 Laut Adamczak (2000: 159-161) ist Empathie (=Perspektivübernahme) das grundlegende Merkmal für interkulturelle Kompetenz. Adamczak hält sie für „einen möglichen Ausgangspunkt für die Verbindung von kommunikativer Kompetenz, landeskundlichem Wissen, affektiven Einstellungen und Voraussetzungen sowie tatsächlichen Verhaltensweisen im Hinblick auf mehr Völkerverständigung [...]“. Vgl. auch Volkmann (2002: 43) zu den Lernzielen der Interkulturellen Kompetenz und Roche (2005: 227231) zu den Zielen des interkulturellen Trainings. 
Die erwähnte Reflexion bezieht sich wiederum auf viele verschiedene Bereiche: Wortschatz (z.B. soziokulturelle Bedeutungen von Wörtern), Sprechakte (d.h. angemessenes kommunikatives Verhalten), Diskurskonventionen (z.B. Gesprächseröffnung und -beendigung), Unterschiede in kommunikativen Verhaltensweisen und Handlungen (z.B. Sprechlautstärke, Sprechpausen) sowie kulturspezifische Werte und Einstellungen (vgl. Zawadzka 1997, 2000, Pfeiffer 2000: 130). Es wird postuliert, dass man in dem neu (d.h. interkulturell, am Fremdverstehen) orientierten Fremdsprachenunterricht den Lernenden die Möglichkeit gibt, Inhalte (darunter Texte, somit auch Medientexte $(=$ Filme $)$ zu interpretieren, multiperspektivische Darstellungen der fremden Kultur kennen zu lernen, zu vergleichen (d.h. Gemeinsamkeiten und Unterschiede zu identifizieren, für bestimmte Erscheinungen der Fremd-, aber auch der Eigenkultur zu sensibilisieren) und somit Kompetenzen anstelle eines Wissensbestandes zu entwickeln (vgl. Adamczak 2000: 161-164).

Dabei wird die Alltagskultur besonders stark betont, da sie den Vorteil besitzt an die Erfahrungs- und Gefühlswelt der Lerner anzuknüpfen (vgl. Pfeiffer 2000: 136). Man weist darauf hin, dass diese Erfahrungswelt der Lerner ernst genommen werden müsse. Themen dürften deshalb nicht nur aus der Sicht der Länder der Zielsprache dargestellt werden, vielmehr müsse die „Fremdperspektive“ miteinbezogen werden. Diese „Fremdperspektive“ wurde bereits in den Lehrwerken der kommunikativ-pragmatischen Methode einbezogen und ist ebenfalls in den neuesten Fremdsprachenlehrwerken (auch für $\mathrm{DaF}$ ) präsent. Die Umsetzung des interkulturellen Ansatzes stellt allerdings - wie Roche (2001: 163f.) anmerkt - natürlichermaßen große Ansprüche an die Lerner, die Lehrkräfte und das Lehr-/Lernmaterial, und erfordert auch mehr Zeit als das mechanische Umsetzen eines Lehrbuchs.

\section{Interkulturelle Kompetenz und Unterrichtsmaterialien für $\mathrm{DaF}$}

Da die „fremde“ Welt im Fremdsprachenunterricht nicht unmittelbar und direkt, sondern über Medien präsent ist und in den seltensten Fällen eine unmittelbare aktive Anwendung der Fremdsprache in Alltagskommunikation möglich ist, gewinnen Verstehensprozesse als Grundlage des fremdsprachlichen Lernens ein besonderes Gewicht (vgl. Neuner; Hunfeld 1993: 124). Daraus folgt, dass die Inhalte und Themen des Fremdsprachenunterrichts besonders sorgfältig bedacht werden müssen, dass eine verstehens-, d.h. eine medienorientierte Fremdsprachendidaktik entwickelt werden muss.

Eine besondere Stellung kommt hierbei den Lehrwerken zu, da sie in der Praxis des Fremdsprachenunterrichts eine sehr dominante Rolle spielen (vgl. Chudak 2007: 139f.). Gleichzeitig sind sie wichtige Informationsträger über andere Kulturen. In ihnen wird den Lernern immer ein Ausschnitt der Zielsprache und - was im Kontext dieses Beitrags besonders wichtig ist - ein Ausschnitt der Zielkultur präsentiert. Das bestätigt u.a. Jańska (2007: 83), indem sie Folgendes feststellt: ,[...] je nachdem, welcher Unterrichtsmaterialien sich die Lehrkräfte bedienen, werden die Lernenden nur mit der Fremdsprache an sich oder auch mit der weit aufgefassten Kultur des neuen/anderen 
Sprachraums vertraut gemacht." Lehrwerke wirken sich nun also entscheidend darauf aus, was für ein Bild von der Zielkultur sich die Lerner machen bzw. was für ein Bild der jeweiligen Zielkultur im Ausland vertrieben wird.“

Bereits in den 80er und 90er Jahren des 20. Jh. sind die ersten interkulturell ausgerichteten Lehrwerke erschienen. Gemeint sind hier die Lehrwerke „Sichtwechsel“ (Hog; Müller; Wessling, München: Klett, 1984), „Sprachbrücke“ (Mebus; Pauldrach; Rall; Rösler et al., München: Klett, 1987), „Typisch Deutsch?““ (Behal-Thomsen; Landquist-Mog; Mog, Berlin; München: Langenscheidt, 1993) und „Für- und Widersprüche“ (Roche; Webber, New Heaven: Yale University Press, 1995). Diese Lehrwerke folgen dem oben bereits erwähnten ,interkulturellen Ansatz “ ${ }^{5}$ Kurz gefasst bedeutet dieser für ihre Konzeption, dass man über die bloße Vermittlung der Fertigkeiten hinausgeht und sich verstärkt auf das landeskundliche Wissen, das Verstehen der Kultur der Zielsprache ${ }^{6}$ und somit auch auf die rezeptiven Fertigkeiten (vor allem das Lese- und Hörverstehen ${ }^{7}$ ) konzentriert.

Die genannten Lehrwerke geben explizite interkulturelle Ziele an und stellen - wie Roche (2001: 155-163) behauptet - eine gute Grundlage für die Thematisierung vieler interessanter Aspekte dar, die für verschiedene Kulturen relevant sind. Thre Autoren wollen zur aktiven und bewussten Auseinandersetzung mit der fremden (Alltags-)Kultur beitragen. Diese Auseinandersetzung muss allerdings - wie u.a. das Beispiel des Lehrwerks „Sichtwechsel“ zeigt - ,über eine Lehrkraft vermittelt werden, die in Ausgangs- und Zielsprache/-kultur sehr bewandert ist, da das Lehrwerk selbst nicht die spezifischen Interessen, Fragen oder Verstehensbedingungen der Ausgangskulturen der Lerner berücksichtigt" (ebd.). Dies resultiert nach Meinung von Roche daraus, dass „die Texte und Übungen [...] vor allem an der Zielsprache und Zielkultur ausgerichtet [sind] und [...] sowohl die kulturellen Bedingungen als auch die spezifischen Referenzen zu den reflexiven Prozessen der Ausgangskultur der Lerner unberücksichtigt [lassen]." Sind die Autoren wiederum darum bemüht, deutsche Sprache und Kultur aus der Fremdperspektive (d.h. der Perspektive der Lernenden) darzubieten (wie im Lehrwerk „Sprachbrücke“), so konzentrieren sie sich dem Urteil von Roche nach zu stark auf eine Darstellung von Kontrasten, aus denen sich eine interkulturelle Methodik ergeben soll, die allerdings nicht besonders gut dokumentiert ist. Außerdem muss auch noch die Tatsache betont werden, dass die Texte und Übungen hier im Allgemeinen auf die Zielsprache und -kultur ausgerichtet sind und meistens entweder nur wenige oder gar keine Bezüge auf eine Reflexionsphase enthalten, die die Ausgangssprache und -kultur der Lerner berücksichtigen würde. Die genannten Einwände ergeben sich fast automatisch daraus, dass die erwähnten Lehrwerke für eine weltweite Verwendung konzipiert wurden.

\footnotetext{
Vgl. Neuner; Hunfeld (1993: 106ff.), Roche (201: 107ff.), Huneke; Steinig (2002: 174ff.), Neuner (2003: 400), Skowronek (2004: 202).

6 Vgl. hierfür z.B. Pfeiffer (2000: 125ff.) sowie die Beiträge aus dem Band „Dydaktyka jesykón obcych a kompetencja kulturowa i komunikacja interkulturowa" (Mackiewicz [Red.]: 2005).

7 Vgl. Neuner; Hunfeld (1993: 1199ff.), Koenig (1996: 34).
} 
In dieser Zeit erscheinen aber auch ,adressatenspezifische“ Lehrwerke, d.h. Lehrwerke, die aus der Fremdperspektive entwickelt werden, um die bisherige ethnozentrische Sicht zu überwinden (vgl. Götze 1994: 30, Biechele; Padrós 2003: 53f., Chudak 2007: 146f.). Für die Lehrwerke bedeutet dies Regionalisierung. Es entstehen Lehrwerke (wie z.B. die oben erwähnten ,Typisch Deutsch?“ und „Für- und Widersprüche“, die für englischsprachige Nordamerikaner bestimmt sind), die sowohl die Situation des Landes der Zielsprache berücksichtigen als auch die des Landes der Lerner. Die Auswahl von Themen und Inhalten des Unterrichts ist zielgruppenorientiert (vgl. Neuner; Hunfeld 1993: 110f.). Charakteristisch für diese Lehrwerke ist neben einer ausgebauten Methodenpluralität, der Berücksichtigung und Förderung der Lernerfahrungen ${ }^{8}$ und der Lernstrategien der (einzelnen) Lerner auch noch ein ganzheitliches, tendenziell autonomes und die Kognitivierung einschließendes Lernen (vgl. Huneke; Steinig 2002: 177) sowie der Vergleich - das grundlegende Verfahren des interkulturellen DaF-Unterrichts - von Elementen der eigenen Kultur und der Elemente der Kultur der Zielsprache - und somit auch der Vergleich von Sprachen selbst findet auch seinen Platz im Unterricht und in Lehrwerken, und wird - da für den Unterrichtserfolg für wichtig gehalten - ebenfalls thematisiert (vgl. Neuner; Hunfeld 1993: 117). Diese Lehrwerke leisten demnach - wie Roche (2001: 160f.) zusammenfassend feststellt - einen Beitrag zur Verbesserung des kulturellen Verständnisses der Lerner und ihrer sprachlichen Fertigkeiten, d.h., sie fördern einerseits ihre kommunikative andererseits aber auch interkulturelle und kritische Kompetenz (vgl. Biechele; Padrós 2003: 55).

Selbstverständlich leisten auch neuere Lehrwerke für DaF einen Beitrag zur Förderung der „,interkulturellen Kompetenz“ der Lerner. Es stellt sich allerdings die Frage, ob sie das besser machen als die älteren Lehrwerke.

Nimmt man beispielsweise Lehrwerke für den frühen DaF-Unterricht unter die Lupe, die in Polen eingesetzt werden - z.B. „eins, zwei, drei“ (PWN, 1999), ,ich und du“ (PWN, 2005), „Köngookängoo Deutsch“ (REA, 2005), „Kaspertheater rund ums Jahr“ (E. Klett Verlag, 1996), „Tamburin“ (M. Hueber Verlag, 1996) -, so sieht man, wie Jańska (2006) feststellt, dass sie keine ausreichende Grundlage für die interkulturellen Lehr- und Lernprozesse bieten. ${ }^{9}$ Dabei können deutliche Unterschiede zwischen den Unterrichtsmaterialien der polnischen und der deutschen Autoren in Bezug auf den Stellenwert der Kulturvermittlung aufgezeigt werden. Somit bleiben die Schlüsselfiguren der möglichen interkulturellen Lehr- und Lernprozesse die Lehrkräfte. Die polnischen Lehrwerkautoren konzentrieren sich eher auf die Sprachvermittlung, während die deutschen Autoren auch der Kulturvermittlung große Bedeutung zumessen, so Jańska (ebd.). Diesen Zustand erklärt sie mit der beschränkten Unterrichtsstundenzahl (die Lehrwerke der polnischen Autoren finden ihre Anwendung vor allem im systematischen Deutschunterricht mit einer bis zwei Wochenstunden) und mit den fehlenden

\footnotetext{
Auch universeller Lebenserfahrungen als „Brücke“ - wie Neuner; Hunfeld (1993: 112) sagen - für interkulturelle Themenplanung des DaF-Unterrichts.

9 Es ist anzumerken, dass die angeführten Ergebnisse der Untersuchung von Jańska (2006) sich auf die Primarstufe I in Polen beziehen.
} 
Einflechtungsmöglichkeiten in den didaktisch erzieherischen Prozess (sie werden nicht im Rahmen der integrierten Bildung eingesetzt). Für die deutschen Autoren bildet die Kulturvermittlung einen integralen Teil der Sprachvermittlung, was jedoch als nicht ausreichend zu bewerten ist, da interkulturelle Didaktik hinsichtlich der Darstellung des Zusammenhangs von Sprache und Kultur den Einsatz und die Akzeptanz der Ausgangssprache und -kultur der Lernenden erfordert. Das können die Autoren von „universalistischen“ Unterrichtsmaterialien nicht erreichen, da Adressaten ihrer Materialien keiner sprachlich und kulturell näher bestimmten Gruppe angehören. So bleibt die Betrachtungsweise der Inhalte und Aufgaben einseitig (auch wenn die eigenkulturelle Sicht der Lerner insofern einbezogen wird, dass sie z.B. zu Vergleichen zwischen dem Ausgangs- und Zielland aufgefordert werden) und stellt wie bereits erwähnt große Ansprüche an LehrerInnen, die anhand solcher Materialien interkulturelle Lehr- und Lernprozesse gestalten möchten.

Betrachtet man kritisch neuere DaF-Lehrwerke für Jugendliche und Erwachsene, die für den internationalen Markt bestimmt sind - z.B. „Stufen International“ (Ernst Klett Verlag, 1995-2000), „Delfin“ (Max Hueber Verlag, 2001), „Berliner Platz“ (Langenscheidt, 2002-2004), „em“ (Max Hueber Verlag, 1997-2000), „Unterwegs“ (Langenscheidt, 1998-1999),$-^{10}$ so stellt man fest, dass sie meistens ein sehr umfangreiches landeskundliches Informationsmaterial beinhalten. Sowohl die Hör- und Lesetexte (häufig Originaltexte) als auch das mitgelieferte Bildmaterial ermöglichen den Lernern einen Einblick in die Gegebenheiten der D-A-CH-Länder. ${ }^{11}$ Vielfältige (gegenwartsbezogene sowie auch offene und kontroverse) Themen werden hier behandelt. Es werden Angebote zur Reflexion der eigenen und zielsprachlichen kulturspezifischen Verhaltensweisen gemacht. ${ }^{12}$ Dabei werden meistens nicht nur Sitten und Gebräuche, sondern auch sprachliche und nichtsprachliche Routinen (Gestik und Mimik), Werte und Einstellungen thematisiert. Auf diese Weise werden die Lerner für die Wirklichkeit der Länder der Zielsprache sensibilisiert. Man möchte hier soziokulturelles Wissen vermitteln, d.h. das Wissen über die Länder der Zielsprache und ihre Kultur und die Anwendung dieses Wissens in der Interaktion. Es soll den Lernern das Wissen über die Kommunikation in der Gesellschaft und zwischen verschiedenen Kulturen vermittelt bzw. bewusst gemacht werden, man möchte sie für mögliche Unterschiede sensibilisieren. Die Lehrwerke tragen somit auch zur Entwicklung der interkulturellen Kompetenz der Lerner bei. Neben zahlreichen Übungen/Aufgaben finden die Lerner in manchen

10 Die den folgenden Ausführungen zugrunde liegende umfangreichere empirische Untersuchung (s. Chudak 2007) war nicht explizit auf das Problem der „Interkulturellen Kompetenz“ ausgerichtet, sondern sie folgte dem Ziel, den Beitrag der Lehrwerke für DaF zur Förderung der Lernerautonomie erwachsener Lerner zu eruieren.

11 Der Begriff D-A-CH bezeichnet nach gängiger Terminologie die deutschsprachigen Länder „D“eutschland, „A“ustria (Österreich) und „CH“, die Schweiz.

12 Adamczak (2000: 164) stellt in diesem Kontext Folgendes fest: „Die Landeskunde realisiert das Prinzip des Vergleichs konkret im Aufsuchen weltläufig bekannter, kulturübergreifender Begriffe wie z.B. Arbeit, Familie, [...] usw., die diverse kulturspezifische Bedeutung besitzen. Diese ,überkulturellen' Oberbegriffe nutzt sie dann als, tertium comparationis', um Unterschiede und Ähnlichkeiten zwischen den Kulturen herauszuarbeiten und in Beziehung setzen zu können.“ 
der Lehrwerke auch noch Hinweise, die durchaus als explizites Strategietraining für die Entwicklung der interkulturellen Kompetenz bezeichnet werden können, z.B.

\begin{abstract}
„Wie redet der Deudsche man inn solchem fall?
Diese Frage Martin Luthers von 1531 können wir leider nicht so einfach beantworten. Es gibt zu viele Regeln, und sie sind viel zu komplex. Selbst eine Auswahl zu treffen, ist schwer, da die Anwendung der Regeln regional, sozial und individuell unterschiedlich erfolgt und andererseits für Sie je nachdem, aus welchem Land Sie kommen, jeweils unterschiedliche Regeln vertraut bzw. unbekannt sein werden. So bleibt nur der Tipp: Seien Sie immer darauf vorbereitet, dass die mündliche Kommunikation in deutschsprachigen Ländern anders ablaufen kann, als Sie es von zu Hause gewohnt sind. Beobachten Sie: Was machen deutsche Muttersprachler? Wie reagieren Sie? Welche Regeln könnten ihrem Verhalten zugrunde liegen?“
\end{abstract}

(„Ratgeber Lernen“, Unterwegs. Kursbuch: 177)

Zwar sind neuere DaF-Lehrwerke für Jugendliche und Erwachsene im Großen und Ganzen als relativ gute Hilfsmittel bei der Sensibilisierung der Lerner für die kulturellen Unterschiede zwischen den D-A-CH-Ländern und ihrem jeweiligen Heimatland zu bewerten - selbst wenn sie bei weitem nicht all die Kriterien erfüllen, die an Lehrwerke gestellt werden, die das Ziel ,interkulturelle Kompetenz “ zu verfolgen vorgeben. ${ }^{13}$ Zwar trägt die Vielfalt der behandelten Themen, die vielen Anregungen zum Vergleich, die Hinweise auf Differenzen und potentielle Ähnlichkeiten, sowie auch die expliziten Hinweise auf Lernstrategien dazu bei, dass für die Entwicklung der interkulturellen Kompetenz der Lerner im gewissen Maß gesorgt wird. Auch diesen Lehrwerken ist aber vorzuwerfen, dass die Themen meistens aus der Perspektive ihrer in den D-A-CH-Ländern lebenden Autoren dargestellt werden und dass die Perspektive der Adressaten dieser Lehrwerke - ähnlich wie bei den oben erwähnten Lehrwerken für Kinder - (meist) unberücksichtigt bleibt. Manchmal nur versucht man die sog. Fremdperspektive in sie einzubeziehen, indem man fiktive DaF-Lerner als Lehrwerkprotagonisten wählt, die dann aus ihrer subjektiven Perspektive die Gegebenheiten in D-A-CH kommentieren, durch deren Augen die Lernenden Züge der fremden Kultur erleben (vgl. Maijala 2007: 550). Ob sich nun aber die DaF-Lerner mit diesen Lehrwerkfiguren identifizieren, die leider häufig nicht authentisch erscheinen und irritierend wirken, bleibt dahingestellt.

Maijala (2007: 550-553) behauptet in diesem Zusammenhang außerdem, dass man bei der Betrachtung von Lehrwerken den Eindruck nicht los wird, dass relevante Informationen zum Verständnis der Zielsprachenkultur und insbesondere des Alltags nur schwer Eingang in landeskundliche Inhalte finden und dass nicht immer ein realistisches Bild der Zielsprachenkultur hergestellt wird. ${ }^{14}$ Ferner kritisiert sie die Vermittlung landeskundlicher Inhalte als „Stichwortlandeskunde“ sowie die Tatsache, dass manche Lehrwerke immer noch landeskundliche Inhalte ähnlich wie Reiseführer vermitteln,

13 Vgl. Jańska (2007: 84-93, 2006: 150-161) zu einem Kriterienraster für die Evaluation von Materialien für den Fremdsprachenunterricht im Kontext der Entwicklung der interkulturellen Kompetenz.

14 Maijala (2007) hat im Rahmen ihrer Untersuchung diverse Lehrwerke analysiert, die in Finnland und Schweden im DaF-Unterricht ihren Einsatz finden. 
anstatt den Lernenden die Unterschiede zwischen Eigenem und Fremdem bewusst zu machen, zum Nachdenken über die Eigen- und Fremdkultur anzuregen, für einen interkulturellen Sichtwechsel zu sensibilisieren oder Kenntnisse über die Beziehungen von Eigen- und Fremdkultur zu vermitteln, geschweige denn unterschiedliche Perspektiven in die Zielsprachenkultur zu eröffnen (multiperspektivische Betrachtungsweise, dank der die Lernenden selbst ihre Meinung bilden). ${ }^{15}$ Sie weist außerdem darauf hin, dass Lehrwerke oft ein oberflächliches, einseitiges und stereotypes Bild über die fremde Kultur wiedergeben.

\section{Lehrwerke mit Defiziten - was tun?}

Es stellt sich nun die folgende Frage: Wenn Lehrwerke beim Erreichen der Ziele des interkulturellen Fremdsprachenunterrichts nur bedingt helfen, womit kann man dann die Defizite ausgleichen, die ggf. entstehen? Wie könnte man dem Lehrenden helfen, das Kulturbild der Fremdsprachenlernenden zu erweitern und so ihre „interkulturelle Kompetenz" zu fördern?

Man weist in der Fachliteratur auf ergänzende Lehrwerk-Materialien als eine wichtige Quelle von Informationen über die fremde Kultur hin und hebt besonders hervor, dass sie eine Vielzahl unterschiedlicher Perspektiven in die fremde Kultur eröffnen können und dass sie - dadurch dass sie authentisch, glaubwürdig und interessant sind - Anlass zu Diskussion geben (vgl. Maijala 2007: 552). Selbstverständlich könnte man also weitere Hör- und Lesetexte (darunter auch literarische Texte) im Unterricht einsetzen (vgl. Adamczak-Krysztofowicz 2003), die das Materialangebot in Lehrwerken ergänzen würden. Man könnte auch Projekte mit landeskundlichen, soziokulturellen und kulturkundlichen Themen durchführen oder Kontakte mit den Angehörigen einer fremden Kultur/der Zielkultur fördern (vgl. Pfeiffer 2000: 128-131). In diesem Zusammenhang bietet sich aber auch der Einsatz von Hör-Seh-Texten, d.h. von filmischen Materialien jeglicher Art an.

Und wieder könnte man fragen: Warum gerade filmische Materialien? Wie können Filme einen Beitrag zur Entwicklung der interkulturellen Kompetenz der Lerner leisten? Welche Anforderungen sind an Filme zu stellen, die dabei helfen sollen die interkulturelle Kompetenz der Lerner zu fördern?

\section{Interkulturelle Kompetenz und Filme}

Bereits seit Ende der 60er Jahre wurde Video als Lehr- und Lernmittel im DaF-Unterricht eingesetzt (Sprachlehrfilme). In den 80er Jahren erweiterte sich die Bedeutung und der Stellenwert von Video deutlich. Man hat in dieser Zeit u.a. empfohlen, Fernsehsendungen wegen ihrer gesellschaftlichen Relevanz in den Fremdsprachenunterricht einzubeziehen und sie kulturkomparatistisch und medienpädagogisch zu behandeln, kurzum

15 Auch Zawadzka (1997: 16) wies darauf hin, dass „die Lehrbücher [...] nicht sog. typische Situationen darstellen [sollten], sondern man sollte eher kulturkontrastiv vorgehen, d.h. in ihnen solche Situationen präsentiert, die die Notwendigkeit des Beachtens bestimmter soziokulturell bedingter Verhaltensformen sowie Konsequenzen ihres Ausbleibens bzw. eines Verstoßes gegen sie erklären und bewusst machen.“ 
ihr landeskundliches Potenzial zur Entwicklung von kritischem Sehverstehen und „,interkultureller Kompetenz" zu nutzen (vgl. Heyd 1997: 44f.). Selbstverständlich wurden neben Fernsehsendungen auch Spiel-, Zeichentrick und Dokumentarfilme, Werbespots sowie Selbstproduktionen von Lehrenden und Lernenden empfohlen (vgl. Heidecker 1996: 437, Erdmenger 1997: 127-138).

Von der Fremdsprachendidaktik wird die Stellung der audiovisuellen Medien - so auch des Films - recht klar definiert. Es wird behauptet, dass „dem Medium [Film] eine wichtige Funktion vor allem im Auslandsunterricht zukommt, da es auf anschauliche Art unterschiedliche Themen, kommunikative Situationen, Textsorten, sprachliche Register usw. vermitteln und dadurch fremdsprachliche und fremdkulturelle Authentizität ins Klassenzimmer transportieren kann" (Storch 1999: 281). Ein Film kann demnach einerseits zahlreiche authentische Äußerungsanlässe schaffen (Training des Sprechens und Schreibens), zur Förderung der rezeptiven Fertigkeiten unter authentischen Bedingungen eingesetzt werden (Training des Hörverstehens), zum Einüben von Sprache dienen (Wortschatz- und Grammatiktraining) sowie die Aufmerksamkeit der Lernenden auf sich ziehen und dadurch eine motivierende Funktion ausüben. Andererseits kann er aber auch informieren, z.B.: landeskundliches Wissen vermitteln und Modelle für sozial und kommunikativ angemessene Verhaltensweisen in der fremdkulturellen Umgebung bereitstellen (direkter Einblick in authentische zielsprachliche Kommunikation), was im Kontext dieses Beitrags von besonderer Bedeutung ist.

Filme scheinen geradezu ideal für die Realisierung der Aufgabe der Vermittlung landeskundlichen Wissens geeignet zu sein, da ,über [sie] viele Inhalte vermittelt werden: soziale Probleme einer multikulturellen Gesellschaft, zwischenmenschliche Beziehungs- und Verhaltensmuster, Geschlechterrollen, der Stellenwert der Familie und Peer group, Identitätsmuster, Liebe, Glück und Unglück, Lebensziele, Traumklischees usw.“ (Kaupp 2003: 23). Somit erfüllen Filme ein wichtiges Kriterium, das Unterrichtsmaterialien, die dabei helfen sollen, die ,interkulturelle Kompetenz“ der Lerner zu fördern, erfüllen sollten - das Kriterium der Komplexität des Inhalts (vgl. Torenc 2007: 183). So komplex wie die Wirklichkeit der Zielkultur ist, so komplex sind auch die durch Filme vermittelten Inhalte. Dabei sollten - so Torenc (ebd.) - die im Unterricht verwendeten Materialien diese Wirklichkeit in ihrer ganzen Komplexität wiedergeben, also kein vereinfachtes, für didaktische Zwecke aufbereitetes Bild vermitteln.

Filmische Materialien haben aber vor allem den Vorteil, dass sie im gewissen Sinne eine neue Dimension im Unterricht eröffnen, indem sie die Welt des Zielsprachenlandes in den Unterrichtsraum übertragen und den Lernern einen Einblick in diese für sie neue, vielleicht auch fremde Wirklichkeit gewähren. Sie übernehmen einerseits „eine Vermittlungsfunktion, denn über sie haben die Lerner authentischen Zugang zur Zielsprache und zu deren Kulturraum“, was besonders deswegen wichtig erscheint, da „,in nicht deutschsprachigen Ländern dies meist sogar der einzige Zugang ist, der ihnen neben dem Unterricht offen steht“ (Huneke; Steinig 2002: 180). Dabei haben sie gegenüber traditionellen Medien (egal ob Print- oder Audio-Medien) den Vorteil, dass sie „durch bewegte Bilder und die gleichzeitige Einbindung akustischer und gespro- 
chener Informationen den Eindruck einer sehr viel unmittelbareren Konfrontation mit dem dargestellten Inhalt schaffen“ (Fuß 2001: 191). Andererseits erfordern sie aber auch - wie Adamczak-Krysztofowicz (2005: 9) schreibt - „ein Verlassen der Außenperspektive der Lernenden und ein Eindringen in die Innenperspektive der fremden Kultur". So regen sie zum Vergleich, zur kognitiven und affektiven Auseinandersetzung mit den Phänomenen der Kultur des Landes der Zielsprache an und erleichtern oder ermöglichen gar erst den Lernern die Beherrschung der Kunst der richtigen Interpretation sprachlicher Reaktionen von Muttersprachlern und der adäquaten Reaktion auf sprachliche Stimuli, u.a. da sie die verbale Kommunikation durch Elemente der nonverbalen Kommunikation ergänzen. Dadurch erfüllen sie weitere Anforderungen, die an Materialien für den interkulturell orientierten Unterricht gestellt werden (vgl. dazu auch Torenc 2007: 183-187).

Zu fragen wäre jedoch in diesem Zusammenhang, inwiefern Filme auch dabei helfen, die oben erwähnte „Fremdperspektive“ bzw. auch die Perspektive der „Ausgangskultur“ der Lerner zu zeigen? Wessen Perspektive ist das, die der Zuschauer auf dem Bildschirm präsentiert bekommt? Rabbe (2003: 424) weist hier darauf hin, „dass Filmemacher stets ihren eigenen Intentionen folgen und dass es - man denke an Kameraoptik und Montageschnitt - nicht ohne strukturbedingte Manipulationen geht. Beides filtert, verkürzt und verfälscht zwangsläufig die Realität. Daher muss durch Ergänzungen und Korrekturen didaktisch der Gefahr begegnet werden, dass das Gezeigte naiv für wahr genommen wird.“ Auch Erdmenger (1997: 127f.) weist darauf hin, dass das Medium „Film“ nur vorgibt, „,eine objektive Abbildung oder eine wahrheitsgetreue Schilderung zu liefern, aber in Wirklichkeit wird es lediglich Ausschnitte anbieten, suggerieren, dass der Teil das Ganze repräsentiert, und dabei Weggelassenes verschweigen. “ Ähnlich argumentiert auch Heidecker (1996: 440), der darauf hinweist, dass trotz der insgesamt sehr positiven Einschätzung von Video als einem für den Fremdsprachenunterricht geeigneten Lehr-/Lernmittel, auch einschränkende Gründe angeführt werden, die sich vor allem auf den Einsatz von kommerziell gefertigten Videofilmen beziehen. Er behauptet sogar, dass sehr viele Filme für den Fremdsprachenunterricht unbrauchbar sind (bzw. höchstens im Fortgeschrittenenunterricht nützlich), dass Filmemacher schwerwiegende Fehler begehen, indem sie Informationen unterbinden, sich moderner Erzähltechniken bedienen, die Zeit und Ort nicht-linear abbilden usw.

Zusammenfassend kann festgehalten werden, dass diejenigen Filme für das Erreichen des Ziels „,interkulturelle Kompetenz“ besonders gut geeignet sind,

- die authentische Situationen zeigen (vor allem Alltagssituationen),

- die das Bild der Zielkultur nicht verfälschen oder vereinfachen,

- die die Zielkultur aus der Fremdperspektive zeigen (am besten aus der Perspektive der Ausgangskultur der Lerner, um ihnen ihre eigene kulturelle Vorgeprägtheit bewusst zu machen). 


\section{Lernende und das Medium „Film“ (Ergebnisse von Umfragen)}

Ein weiteres Argument für den Einsatz von Filmen im DaF-Unterricht sind die Ergebnisse von Umfragen (s. Chudak 2007b). Sie zeigen nämlich, dass der Einsatz von Filmen im Unterricht von den Lernenden erwünscht ist. Fremdsprachenlernende sind mit der Wahl der Medien für den Unterricht, an dem sie teilnehmen, nicht immer zufrieden. ${ }^{16}$ Die Mehrheit der Befragten klagt darüber, dass im Unterricht fast ausschließlich mit Lehrbüchern gearbeitet wird, die Seite für Seite durchgenommen werden. Mit Videoaufnahmen, von deren Einsatz sich die befragten DaF-Lerner u.a. auch Erweiterung landeskundlichen Wissens (Alltag in D-A-CH-Ländern, Ergänzung und ggf. Revision des Bildes, das im Lehrbuch vermittelt wird, aktuelle Themen, die Menschen in D-A$\mathrm{CH}$ bewegen) versprechen, befasst man sich - wenn überhaupt - nur sehr selten.

Es ist anzumerken, dass es auch Lerner gibt, die sich zwar für den Einsatz von Videomaterialien im Unterricht aussprechen, gleichzeitig aber darauf hinweisen, dass heutzutage fast jeder die Möglichkeit habe, sich DVDs zu besorgen und sich Filme im Originalton anzuschauen oder Fernsehprogramme via Satellit zu empfangen, so dass die Arbeit mit Videomaterial im Unterricht sich erübrige und nur Zeitverschwendung bedeute.

Andere Umfragen bestätigen auch, dass fast 100\% der DaF-Lerner sich deutschsprachiges Fernsehen oder deutschsprachige Filmproduktionen ansehen, z.B. Nachrichtensendungen (98\%), Reportagen und Dokumentationen (70\%), Kochsendungen $(65 \%)$, Serien (52\%), Spielfilme (75\%), Sportsendungen (25\%) Talk-Shows $(50 \%)$, Kindersendungen (15\%). ${ }^{17}$ Dabei gibt es allerdings Unterschiede in der Quantität viele von ihnen machen es selten (35\%) oder sogar sehr selten (25\%). Gefragt danach, warum sie sich deutschsprachiges Fernsehen oder deutschsprachige Filmproduktionen ansehen, antworten die meisten:

- „[...], weil ich damit meine Deutschkenntnisse erweitern kann. Ich habe so Kontakt mit deutscher Sprache."

- „Aus Neugier.“

- „Um mein Hörverstehen zu trainieren bzw. prüfen.“

- „Um mein (landeskundliches) Wissen zu erweitern.“

- „Um Ideen für meinen Unterricht zu sammeln.“

- „Ich finde Fernsehen interessant und aufregend. Ich möchte mir nur einfach eine Sendung ansehen, weil mich das Thema interessiert oder weil ich sonst nichts Besseres zu tun habe."

${ }_{16}$ Die obigen Ausführungen beziehen sich auf eine Umfrage, die im akademischen Jahr 2005/2006 unter insgesamt 190 Germanistikstudenten des ersten und zweiten Studienjahres u.a. an der Adam-Mickiewicz-Universität in Poznan (Polen) durchgeführt wurde (s. Chudak 2007b zu einer genaueren Auswertung der Umfrage).

17 Die weiteren Ausführungen beziehen sich auf eine Umfrage, die im akademischen Jahr 2007/2008 unter insgesamt 53 Germanistikstudenten des vierten und fünften Studienjahres (Lernende im durchschnittlichen Alter von 24/25 Jahren oder älter, die seit ca. 7-11 Jahren Deutsch als Fremdsprache lernen, die meistens stark und gut motiviert sind, die ihr sprachliches Niveau als B1-C2 einschätzen, 
Eine weitere wichtige Frage in diesem Zusammenhang war die Frage danach, wie die Befragten mit dem Medium „Film“ und den darin vermittelten Informationen umgehen. Welche Gewohnheiten und Strategien im Umgang mit dem filmischen Stoff lassen sich bei ihnen feststellen? Sind sie bewusste Lerner, die sich aktiv mit den gesehenen und gehörten Inhalten auseinandersetzen, die mit diesen Inhalten reflexiv und analytisch umgehen, die Vergleiche ziehen, kurzum all das tun, was man von jemandem erwartet, der an der Entwicklung seiner „interkulturellen Kompetenz“ arbeitet. Und so wurden die Probanden gebeten, Protokoll über Ihre Aktivitäten beim Umgang mit filmischen Materialien zu führen. Das Ergebnis: Die meisten Lerner versuchen neue Wörter und Wendungen (ggf. auch die Aussprache ) herauszuhören und sich zu merken $(55 \%)$, sie machen Notizen $(10 \%)$, schlagen in Wörterbüchern nach (5\%). Einige achten auch auf landeskundliche Informationen (15\%). Allerdings geht es ihnen dabei viel mehr um Fakten oder Informationen über aktuelle Ereignisse in D-A-CH als um eine Analyse von Verhaltensweisen usw. Viele konzentrieren sich einfach auf den Filminhalt, d.h., sie verfolgen die Handlung, ohne sich bewusst mit der im Film präsentierten Fremdkultur zu beschäftigen. Die wenigsten Befragten sehen sich Filme bzw. einzelne Filmausschnitte mehrmals an (4\%), um - wie sie selbst sagen - „etwas zu verstehen, was [sie] vorher nicht begriffen habe[n] “. Fragt man aber nach, so erfährt man, dass es dabei vor allem um lexikalische Fragen geht.

Überlegt man, wo die Ursachen des oben beschriebenen Zustands liegen, so kommt man zu der Feststellung, dass höchstwahrscheinlich bestimme Lerntraditionen/-gewohnheiten Schuld daran sind. Wie wird nämlich im Fremdsprachenunterricht mit Filmen gearbeitet? Welche Zielsetzungen werden dabei verfolgt? Welche Arbeitsweisen propagieren Lehrwerke für $\mathrm{DaF}$ ?

\section{Medienkompetenz als ein Teil der Lernkompetenz und als Voraussetzung für die Entwicklung der interkulturellen Kompetenz bei der Arbeit mit Filmen}

In den letzten Jahren wird immer mehr Aufmerksamkeit dem lebenslangen, selbständigen Lernen, der Förderung der Lernerautonomie und der mit ihr eng verbundenen Lernkompetenz geschenkt (vgl. Chudak 2007a: 41-45). Man spricht über Lernstrategien und -techniken, ihre Funktionen, Arten usw. Man scheint dabei allerdings eine Kompetenz zu vergessen, die mit der Lernkompetenz eng verbunden zu sein scheint, da sie die Voraussetzung für einen erfolgreichen (auch selbständigen) Umgang mit filmischen Materialien ist - die Medienkompetenz. Da im auf die Förderung der Lernerautonomie ausgerichteten Unterricht dem Lehrer eine besondere Stellung (Moderator, Helfer, Berater usw.) zukommt, muss zunächst die Frage geklärt werden, welche Anforderungen sind an einen Lehrer im Bereich der Medienkompetenz zu stellen, damit er auch in diesem Bereich die Lernenden entsprechend auf das autonome Lernen, auf die selbständige Auseinandersetzung mit filmischen Inhalten vorbereiten kann. Weiterhin ist zu fragen,

die potentielle künftige DaF-Lehrer/Lehrerinnen sind) u.a. an der Adam-Mickiewicz-Universität und Wyższa Szkoła Języków Obcych in Poznań (Polen) durchgeführt wurde. 
inwiefern diese Kompetenz bei den Lernenden entwickelt ist sowie inwiefern die Lehrwerke (darunter Lehrwerke für DaF) die Entwicklung dieser Kompetenz unterstützen.

\subsection{Medien- und interkulturell kompetenter Lehrer - Versuch einer Charakteristik}

An (Fremdsprachen-)Lehrer werden vielfältige und gleichzeitig sehr hohe Anforderungen gestellt. Die Lehrer werden nicht nur als Instrukteure, Wissensvermittler oder Kontrolleure des Lernfortschritts und der Ergebnisse des Lernprozesses betrachtet, sondern vielmehr als Moderatoren des Lernprozesses, als diejenigen, die den Lernprozess initiieren, gestalten, lenken, evaluieren, als Lernberater und -helfer usw. fungieren (vgl. Pfeiffer 2001: 121-141, Zawadzka 2004: 109-146).

Um den oben erwähnten Anforderungen zu genügen, muss ein Lehrer also über viele verschiedene Kompetenzen verfügen, zu denen u.a.

- die fachliche Kompetenz (im Falle der Fremdsprachenlehrer vor allem die sprachliche Kompetenz - Beherrschung der Sprachfertigkeiten und der Subsysteme der Sprache - und inhaltlich-kognitive Kompetenz - Wissen über landes- und kulturkundliche Aspekte) sowie

- die (glotto)didaktische Kompetenz (Wissen über die verschiedenen Unterrichtsmethoden und -techniken, Fähigkeit den Unterricht zu planen usw.),

- die soziale Kompetenz (Fähigkeit zur Kooperation mit den Lernenden sowie mit anderen Lehrern) und

- die persönliche Kompetenz (Fähigkeit zur Selbstkritik, Selbstreflexion usw.) gezählt werden (vgl. Krämer; Walter 1994: 128-135, Pfeiffer 2001: 194-199 oder Zawadzka 2004: 109-146).

Selbstverständlich ist hier auch die ,interkulturelle Kompetenz“ des Lehrers ausdrücklich zu betonen. Sie steht mit den bereits oben erwähnten Kompetenzen in einem engen Zusammenhang. Besonders hervorgehoben müssen allerdings im Rahmen dieser Kompetenz neben der Ebene des Wissens (u.a. über die Ausgangs- und Zielkultur) auch die Ebene der Einstellungen (u.a. Offenheit, Bereitschaft, Neugierde) und der Handlungen (u.a. Interpretationsvermögen) werden (vgl. Błażek 2007: 73). ${ }^{18}$

Neben den oben erwähnten Dimensionen der Kompetenz des Lehrers wird in manchen Veröffentlichungen zu diesem Thema auch noch die bereits erwähnte Medienkompetenz genannt (vgl. Pfeiffer 2001: 198f., Zawadzka 2004: 43-146). Mit dem Begriff „Medienkompetenz“ bezeichnet man in der (Medien-) Pädagogik (vgl. Baacke 1997) die Fähigkeit, Medien und ihre Inhalte den eigenen Zielen und Bedürfnissen entsprechend effektiv zu nutzen. Das umfasst Folgendes:

- Medien (Bücher, Zeitschriften, Internet, Hörfunk, Fernsehen etc.) kennen und nutzen können,

- sich in der Medienwelt, d.h. unter den vielen verschiedenen Medienangeboten orientieren können,

18 Vgl. Błażek (2007: 75-80) zu den Möglichkeiten und Instrumenten der Messung der Interkulturellen Kompetenz. 
- an medial vermittelten Kommunikationen teilnehmen können,

- eine kritische Distanz zu Medien halten,

- selbst kreativ in der Medienwelt tätig werden.

Man spricht auch über die „Medienkompetenz“ als die Fähigkeit, (1) mit Medieninhalten umzugehen, (2) die Sprache des Mediums zu verstehen und (3) das Medium als übergeordnete kulturelle und kommunikative Umwelt zu erkennen. Man weist ebenfalls auf die folgenden Dimensionen der Medienkompetenz: (1) technische Kompetenz, (2) semantische Kompetenz, (3) pragmatische Kompetenz. ${ }^{19}$

Meistens wird die Medienkompetenz als eine Teilkompetenz der didaktischen Kompetenz aufgefasst. (vgl. Krämer; Walter 1994: 131, Zawadzka 2004: 110f., 143-146) Sie bedeutet dann, dass der Lehrer die verschiedenen Funktionen der unterschiedlichen Medien erkennt (z.B. Abwechslung im Unterricht, Erhöhung der Aufmerksamkeit, Verhinderung der Langeweile) und der ihren Einsatz sorgfältig planen und zielgruppengemäß einsetzen kann. Die „mediale Kompetenz“ bedeutet die Kenntnis der vielfältigen Funktionen der audiovisuellen Medien und - was in letzter Zeit besonders stark hervorgehoben wird - der sog. „,neuen Medien“ sowie die Fähigkeit, diese Medien zu bedienen und im didaktischen Prozess adäquat einzusetzen (vgl. Pfeiffer 2001: 198, Zawadzka 143-146).

Wenn auch über den Einsatz der Computertechnik im Fremdsprachenunterricht viel gesagt wurde und wird, scheint die „Medienkompetenz“ im Bereich der audiovisuellen Medien nicht ausreichend berücksichtigt zu werden. Erst die neueren Arbeiten zum Film beschreiben - wie Biechele (2004: 160f.) resümiert - z.B. filmspezifische Wissensbereiche (Weltwissen, narratives Wissen, filmspezifisches Wissen) für Interaktion und Konstruktion neuen Wissens bei Orientierung auf medienspezifisches strategisches Handeln, weisen auf das Medium „Fernsehen“ als eine Kulturtechnik und fordern spezielle Schulungen für den Umgang damit sowie Hör-Seh-Verstehen als fünfte Fertigkeit einzuführen. ${ }^{20} \mathrm{Zu}$ fordern wäre allerdings auch, dass man die Entwicklung dieser Kompetenz zum integralen Bestandteil der Lehrerausbildung macht, da sie - obwohl sie für „die Schlüsselqualifikation der Gegenwart“ (Biechele 2004: 152) gehalten wird - keine Selbstverständlichkeit ist und die Medienkompetenz des Lehrers als Voraussetzung für die Entwicklung der Medienkompetenz der Lerner gelten kann.

Nicht zu vergessen ist auch die Bedeutung der Medienkompetenz und der interkulturellen Kompetenz des Lehrers im Zusammenhang mit der Förderung der ,,interkulturellen Kompetenz" der Lerner. Da Lehrwerke - wie oben beschrieben - zahlreiche Defizite im diesem speziellen Bereich aufweisen und - was auch Jańska (2006: 295) bestätigt - große Ansprüche an die Lehrkräfte, die anhand solcher Unterrichtsmaterialien interkulturelle Lehr- und Lernprozesse gestalten möchten, die als kulturelle Mittler zwischen der eigenen und der fremden Kultur agieren wollen (vgl. Zawadzka 1997: 16 oder Roche 2001: 164), ist die Ausbildung der interkulturellen Kompetenz und der Medienkompetenz der Lehrkräfte von besonderer Bedeutung. Das ist auch deswegen be-

19 Vgl. Biechele (2004) zu einer Übersicht verschiedener Definitionen des Begriffs „Medienkompetenz“.

20 Vgl. dazu z.B. Schwerdtfeger (1989), Brandi (1996) oder Heyd (1997: 106-118). 
sonders wichtig, weil - wie die Beobachtung der Schulpraxis bestätigt (vgl. Modrzycka; Iżykowska-Staruch 2007: 89) - das Interesse am Einsatz von Filmen im Fremdsprachenunterricht leider minimal ist.

\subsection{Medienkompetenter Lerner}

Ein weiteres im Kontext der (vielleicht auch selbständigen) Arbeit mit Filmen wichtiges Problem ist die Medienkompetenz der (Fremdsprachen-) Lerner. Ist diese Kompetenz ausreichend ausgebildet? Welche Dimensionen der Medienkompetenz bleiben vielleicht unzureichend entwickelt?

Wie die Untersuchungen von Biechele (2004: 156-159) ergaben, ,[sind] die subjektiven Wertungen der Studierenden in Bezug auf das Konstrukt Medienkompetenz $[\ldots]$ sehr vage, lückenhaft und nicht systematisch [... “. Ihre Probanden wiesen vor allem auf die technische und pragmatische Komponente der Medienkompetenz hin. Die wenigsten von ihnen führten die semantische Kompetenz an, d.h. die Fähigkeit, die durch das Medium vermittelten Inhalte verstehen zu können. Wie Biechele konstatiert, entspricht dieser Zustand der Situation, die in der Fachliteratur beklagt wird: Medienausbildung $=$ bloße Technikunterweisung bzw. -bedienung. Ein weiteres Ergebnis der erwähnten Studie war, dass Lernende die Arbeit mit Video und DVD eindeutig in Verbindung mit selbständigem, autonomen Lernen bringen (Biechele 2004: 164). Umso wichtiger scheint daher die Ausstattung der Lerner mit entsprechendem Wissen und entsprechenden Fertigkeiten (vor allem mit der semantischen und pragmatischen Teilkompetenz der Medienkompetenz), um die Arbeit mit den erwähnten Medien zu optimieren (nur ein kompetenter Mediennutzer kann auch effektiv autonom mit Medien Fremdsprachen lernen), damit sie zum erwünschten Ergebnis (darunter auch der interkulturellen Kompetenz) führt.

\subsection{Filme und Medienkompetenz vs. Lehrwerke für DaF}

Wenig Abhilfe schaffen hier leider Lehrwerke, in denen Verweise auf mit den Lehrwerkinhalten korrespondierende filmische Materialien äußerst rar sind. Auch die Anzahl von in Lehrwerke integrierten audiovisuellen Materialien ist umgekehrt proportional zu der Anzahl der Audioaufnahmen, mit denen Lehrwerke reichlich ausgestattet werden. Die Autoren von Lehrmaterialien sind nicht einmal darum bemüht, Tipps und Hinweise für Lehrer in Lehrwerke aufzunehmen, die ihnen die Suche nach und die didaktische Aufbereitung von Filmmaterial für den Unterricht erleichtern würden.

Ausnahmen gibt es allerdings schon. Eine davon ist das im Max Hueber Verlag erschienene Lehrwerk „em“ (1997-2000). Bereits in seinem ersten Teil („,em Brückenkurs“) findet man fünf sog. „Videotipps“ (Hinweise auf Hör- und Sehangebote), die - was im Kontext der doch so aktuellen Forderung nach Förderung von Lernerautonomie im Fremdsprachenunterricht besonders positiv bewertet werden muss (vgl. Chudak 2007) - nicht, wie man es vielleicht erwarten könnte, im Lehrerhandbuch, sondern im Arbeitsbuch ihren Platz gefunden haben. Folgende Filme werden hier erwähnt: „Papa ante portas“ (Reg. Loriot: 11), „Herbstmilch“ (Reg. Joseph Vilsmaier, 1989: 27), „Rossini - oder 
die mörderische Frage, wer mit wem schlief“" (Reg. Helmut Dietl, 1996: 64), „Jenseits der Stille“ (Reg. Caroline Link, 1996: 76), „Out of Rosenheim“ (Reg. Percy Adinos, 1987: 91). Auch vom Inhalt der übrigen Lehrwerkteile wird man nicht enttäuscht. Und so empfiehlt man im „,em Hauptkurs“ fünf weitere Titel: „Himmel über Berlin“ (Reg. Wim Wenders: 32), „Kaspar Hauser“ (Reg. Peter Sehr, 1993: 49), „Yasemin“ (Reg. Hark Bohm, 1987/88: 65), „Die unendliche Geschichte“ (Reg. Wolfgang Petersen: 92), ,Schtonk“ (Reg. Helmut Dietl: 105); und im „em Abschlusskurs“ vier Titel: „Abgeschminkt“ (Reg. Katja von Garnier, 1992: 26), „Schwarzfahrer“ (Reg. Pepe Danquart, 1992: 48), „M - Eine Stadt sucht einen Mörder“ (Reg. Fritz Lang, 1931: 54), „Kleine Haie“ (Reg. Sönke Wortmann, 1992: 76).

Besonders positiv zu betonen ist hier die thematische Einbettung von den in den „Videotipps“ genannten Filmen in die jeweiligen Kapitel des Lehrwerks. Leider ist die didaktische Aufbereitung des filmischen Materials suboptimal. Es handelt sich hier meistens nur um Informationen zum Regisseur oder Filminhalt, mit denen das Leseverstehen trainiert werden kann, sowie um grammatikalisch-lexikalische Übungen oder Aufgaben, mit Hilfe derer die im Unterricht behandelte Grammatik und Lexik gefestigt wird (vgl. em Brückenkurs, Lehrerhandbuch: 11). Das vorhandene Bildmaterial, ist wegen seiner Art und Qualität für vorentlastende Klassengespräche o. Ä. eher ungeeignet. Aufgaben, die auf die Schulung der Medienkompetenz, geschweige denn der „,interkulturellen Kompetenz“ zielen würden, findet man hier nicht. Die relativ offene Konzeption gestattet zwar viel Freiheit im Umgang mit den genannten Filmen, die ggf. auch im Alleingang von den Lernenden in einer „Lernwerkstatt“ oder einem „Selbstlernzentrum“ (vgl. hierfür z.B. Ewel 1993) angeschaut und bearbeitet werden können. Dem Lehrer bleibt aber die Aufgabe, entsprechende Videoaufnahmen samt Übungsmaterial zusammenzustellen, nicht erspart, wobei auch hier Lernende aktiv werden und einen Part übernehmen können, indem sie z.B. bei der Gestaltung von Arbeitsblättern mitwirken oder Filme aussuchen, die für sie von Interesse sind.

Erwähnenswert ist in diesem Zusammenhang auch die Tatsache, dass man in „em“ dem Thema Film ein ganzes Kapitel widmet („em Brückenkurs“, 6. Film: 69-80). Lernende bekommen so nicht nur die Möglichkeit, themenrelevanten Wortschatz zu lernen (u.a. das Drehbuch, der Drehbuchautor, der Kostümdesigner, der Maskenbildner, der Regisseur, der Schauspieler, der Stummfilm, der Zeichentrickfilm, die Probeaufnahme), Informationen über das Leben und Schaffen von Marlene Dietrich zu erhalten oder den Filmklassiker „Der blaue Engel“ (Reg. Joseph von Sternberg, 1930) zu sehen, sondern vor allem - mit Hilfe diverser Übungen und Aufgaben - Strategien für den Umgang mit audiovisuellen Lernmaterialien zu entwickeln, z.B.:

- Zusammenstellung eines themenrelevanten Wortschatzes (z.B. in Form eines Assoziationsigels oder einer Mind-Map),

- Antizipieren des Filminhalts anhand von Postern bzw. Fotografien,

- Umgang mit Lexika (z.B. einem Filmlexikon), Rezensionen, Biographien von Schauspielern,

- Meinungsäußerung (Interpretation, Rezension oder ggf. Diskussion des Gesehenen). 
Fehlgeschlagen ist dagegen der Versuch der Autoren von „Stufen International 1-3. Deutsch als Fremdsprache für Jugendliche und Erwachsene. Lehr- und Arbeitsbuch“ (Vorderwülbecke; Vorderwülbecke, Ernst Klett Verlag, Stuttgart, 1995-1997), Filme in den Kurs zu integrieren. Nicht nur dass man hier lediglich einen Filmtipp findet (s. „Stufen International 1“, Kap. 8. Mobil zum Ziel: 108-123), schlimmer noch ist die Tatsache, dass die Autoren hier einen Film empfehlen („Der Schwarzfahrer“, Reg. P. Danquart, 1992), der dem Sprachniveau der mit dem ersten Teil von „Stufen International“ arbeitenden Lerner leider überhaupt nicht angepasst ist. Zwar wird der Film nur als Zusatzmaterial genannt, dennoch aber wird man den Eindruck nicht los, dass es eine eher weniger überlegte Entscheidung war, ihn an dieser Stelle des Lehrwerks zu erwähnen. Nur der Titel des Films passt zum Inhalt des vorangehenden Kapitels. „Der Schwarzfahrer“, dessen eigentliches Thema Intoleranz und Ausländerfeindlichkeit sind, würde zweifelsfrei besser zu einem anderen Kapitel passen, in dem das Thema „Vorurteile“ („Stufen International 3“: 74-87) zur Sprache gebracht wird. Von Lernenden, die über bessere Sprachkenntnisse verfügen, würde er dann sicherlich nicht nur besser verstanden, sondern vor allem auch geschätzt werden. Nach einem entsprechenden Hinweis sucht man hier aber vergeblich. Auch die Arbeitshinweise sind hier äußerst knapp und beschränken sich auf die folgende Feststellung: „Spielen Sie diesen Film zuerst zweimal ohne Ton ab. Stoppen Sie den Film mehrmals beim zweiten Durchlauf, und sammeln Sie an der Tafel Redemittel: Was sagen die Personen möglicherweise? Sehen Sie sich dann den Film mehrmals mit Ton an. Sammeln Sie anschließend Reaktionen der Gruppe auf den Film. Diskutieren Sie über Situation und mögliche Reaktion in den Heimatländern“ („Stufen International 1": 123).

In den neuesten Lehrwerken für DaF lassen sich wiederum nicht nur Hinweise auf Filme, sondern auch DVDs mit filmischen Inhalten finden. Diese DVDs sind - genau wie Arbeitsbücher, Lehrerhandbücher u.Ä. - integrale Bestandteile der jeweiligen Lehrwerkpakete. Die auf den DVDs enthaltenen Filme fügen sich organisch in das Lehrerkonzept ein und sind der Lehrstoffprogression angepasst. Die Lehrwerke enthalten auch entsprechende Didaktisierungsvorschläge.

So liegt z.B. dem Lehrwerk „Aspekte. Mittelstufe Deutsch. Lehrbuch 1, Niveau B1+“ (Langenscheidt, 2007) eine DVD mit insgesamt zehn Reportagen bei (es handelt sich laut Verlagsprospekt eigentlich um Ausschnitte aus Fernsehreportagen bzw. Dokumentationen des ZDF). Dazu findet man im Lehrbuch jeweils eine Doppelseite zum Filmmaterial, die u.a. Standfotos der Ausschnitte aus dem authentischen Filmmaterial zeigt und weiterführende Aufgaben enthält (diese findet man auch im Arbeitsbuch) und so das Training des Hör-Seh-Verstehens ermöglicht. Das Themenspektrum ist hier recht breit: Frauen in führenden Positionen - „Die Chefin“ (22f.), Wohnen - „Hotel Mama - von Nesthockern und Heimschläfern“ (38f.), Gesundheit - „Alexander-Technik“ (54f.), Freizeit und Unterhaltung - „Fußball, Fans und Leidenschaften“ (70f.), Lernen und Behalten - „Projekt Eule“ (86f.), Berufsbilder - „Servicewüste Deutschland“ (102f.), Für immer und ewig - „Beim Geld hört die Liebe auf“ (118f.), Kaufen, kaufen, kaufen - „Kaufen, kaufen, kaufen“ (134f.), Endlich Urlaub - „Erfurt“ (150f.), Natürlich Natur 
- „Wildtiere in Berlin“ (166f.). Auch das Übungsangebot überrascht positiv durch seine Vielfalt. Die Lerner werden hier aufgefordert, nicht nur das entsprechende Wortfeld zu erarbeiten, Assoziationen zum Thema des Films zu sammeln, Vorwissen zu aktivieren, den Filminhalt vorauszusagen, Vermutungen zu äußern, den Filminhalt zusammenzufassen Fragen zum Filminhalt (ggf. auch zu den einzelnen Filmsequenzen, globales und detailliertes Erfassen des Inhalts) zu beantworten, Notizen anzufertigen, sondern wenn auch nur relativ selten - Mimik und Gestik zu beschreiben, über ihre Eindrücke zu sprechen, Vergleiche mit ihrem Heimatland zu ziehen. Dem Medium „Film“ bzw. dem expliziten Training der Medienkompetenz wird hier kaum Aufmerksamkeit gewidmet (lediglich eine Aufzählung verschiedener Arten von Filmen und einigen Redemitteln: 65).

Auch Grundstufenlehrwerke - z.B. „Planet“ (Max Hueber Verlag, 2004) oder „Geni@1“" (Langenscheidt, 2006) - enthalten mittlerweile immer häufiger DVDs mit Filmsequenzen. Es sind allerdings Filme, die speziell für Unterrichtszwecke erstellt wurden und die zwar die Anforderungen, die an das Filmmaterial welches zur Schulung der „interkulturellen Kompetenz" beitragen soll, nur bedingt erfüllen, aber zur Schulung der oben erwähnten Medienkompetenz durchaus geeignet sind. ${ }^{21}$ Besonders positiv fällt hier das Lehrwerk „Geni@1“ mit dem dazugehörigen „Videotrainer“ (B. Biechele, 2006) auf. Das Lehrwerk enthält zahlreiche Aufgaben und Übungen, die das Training des (Hör-) Seh-Verstehens ermöglichen, einerseits den Lernenden das Sehen und Erleben von Menschen im Gespräch, von Dialogen in ihrem authentischen Kontext ermöglichen, andererseits aber auch Wissen über Filme und Fertigkeiten im Umgang mit Filmsequenzen berücksichtigen (s. Lerntipp - Film, z.B. „Film = Bild + Ton. Was wird gezeigt und wie wird es gezeigt. Achte immer auch auf die Kameraperspektive.“/„Film verstehen = die Musik beachten. Die Musik ergänzt oder ,erklärt' die Situation im Film. “) und zusätzlich auch landeskundliche Einsichten ermöglichen.

\section{Arbeit mit Filmen im DaF-Unterricht - ein Erfahrungsbericht}

Im akademischen Jahr 2006/2007 und 2007/2008 wurde u.a. im Institut für germanische Philologie der Adam-Mickiewicz-Universität (Poznan) ein Pilotprojekt für ein künftiges Filmseminar durchgeführt, an dem insgesamt ca. 120 Studenten des zweiten, dritten und vierten Studienjahres (Niveaustufe B2-C1) teilgenommen haben. Im Rahmen der sog. sprachpraktischen Übungen ${ }^{22}$ sowie eines Didaktik-Seminars wurden zwei Filme behandelt:

1. „Kebab Connection“ (Reg. Anno Saul, 2005) - eine interkulturelle Liebesgeschichte und eine Culture-Clash-Komödie vom Hamburger Kiez,

${ }_{21}$ Vgl. Lundquist-Mog (2007: 34) zu den Möglichkeiten des Einsatzes von Filmen im Kontext interkulturellen Lernens auf der Stufe A1/A2.

22 Der sprachpraktische Unterricht, der im Rahmen des Germanistikstudiums an der AMU in Poznan angeboten wird, eignet sich wegen seines relativ großen Zeitrahmens, meist lockeren Stils und Inhalts am besten dazu sich mit interkulturellen Themen (Alltagsthemen aber auch Stereotype usw.) auseinander zu setzten (vgl. Pieklarz 2006: 117). 
2. „Lichter“ (Reg. Hans-Christian Schmid, 2003) - ein Film, dessen Handlung in der Gegend von bzw. direkt in Frankfurt/Oder und dem polnischen Slubice spielt, die nur von der Oder und der deutsch-polnischen Grenze getrennt sind; mehrfach wird hier der Grenzübergang thematisiert.

Mit jedem der beiden Filme wurde durchschnittlich sechs Unterrichtsstunden lang gearbeitet. Es wurden viele Aufgaben bearbeitet - sowohl Übungen zur Wahrnehmung gesprochener Sprache und nonverbaler Zeichen als auch Übungen, die auf filmspezifische Aspekte vorbereiten, sowohl Übungen zu einzelnen Filmsequenzen als auch sog. Symbolübungen (vgl. Heyd 1997: 113-118, Brandi 1996: 18-74, Schwerdtfeger 1989: 57 180). ${ }^{23}$ Im Vordergrund stand dabei die Vermittlung landeskundlicher Informationen, Sensibilisierung für das Andere, Reflexion über den eigenen kulturellen Hintergrund und die Zielkultur, Wahrnehmungsschulung, Interpretation des Gesehenen usw.

Aus der Auswertung des Pilotprojekts ergibt sich das folgende Fazit:

- Der Unterrichtserfolg, d.h. das Erreichen des Unterrichtsziels, das man als „Sensibilisierung für das Fremde“, ,,bewusste Auseinandersetzung mit der Ausgangs- und Zielkultur“ kurzum „Entwicklung bzw. Förderung der interkulturellen Kompetenz"bei der Unterrichtsplanung festgelegt hat, hängt sehr stark von der Kompetenz, von dem didaktischen Können, insbesondere auch von dem Moderationsvermögen der Lehrkraft ab. Ihr kommt nämlich die Aufgabe zu, durch entsprechende Frage- bzw. Aufgabestellungen, die Aufmerksamkeit und ggf. auch die Gedankengänge der Lerner so zu lenken, dass sie bestimmte Aspekte der Filmhandlung u.v.a.m. überhaupt wahrnehmen und sich damit aktiv und bewusst auseinandersetzen.

- Es hat sich bestätigt, dass die Medienkompetenz und die interkulturelle Kompetenz der Lehrkraft eine Voraussetzung für die Entwicklung der Medienkompetenz und der interkulturellen Kompetenz der Lernenden darstellt. Die Lerner schenken gewohnheitsmäßig fast ihre gesamte Aufmerksamkeit dem Wortschatz und der Grammatik, betrachten die Arbeit mit Filmen als eine weitere Hörverstehensaufgabe.

- Erst durch längeren Umgang mit dem Filmmaterial, mehrmaliges Vorführen des Films bzw. bestimmter Filmsequenzen ist es möglich, die oben erwähnten Ziele zu erreichen. Ansonsten entgeht den Lernenden Vieles, besonders aus dem Bereich der nonverbalen Kommunikation. Optimal wäre hier also der Einsatz von Kurzfilmen, wobei allerdings hier die Auswahl recht beschränkt ist.

- Gewisse Schwierigkeiten bereitet die Auswahl von geeigneten Filmen. Leider ist in den meisten Produktionen die für die Entwicklung der interkulturellen Kompetenz so wichtige Fremdperspektive nicht ausreichend präsent. Besonders schwierig ist es, Filme zu finden, in denen die Perspektive der Ausgangskultur der Lerner (im Falle des genannten Projekts - polnischer Lerner) berücksichtigt wäre. Zwar ist das Aufeinaderprallen unterschiedlicher Kulturen im Falle von „Kebab Connection“ der bewussten Wahrnehmung von kulturellen Differenzen und ggf. auch Ähnlichkeiten

23 Vgl. auch die Aufgaben in dem von der Bundeszentrale für politische Bildung herausgegeben Filmheft zu dem Film „Lichter“ (Thomas Mank 2003; online unter www.bpb.de/filmhefte). 
durchaus förderlich. Im Falle von „Lichter“ sind es aber nur verhältnismäßig wenige Szenen, die die Bewusstmachung und aktive Auseinandersetzung mit dem kulturellen Hintergrund der Protagonisten und auch der Lerner ermöglichen.

- Gewisse Zweifel kommen auch in Bezug auf die Art und Weise der Präsentation der Wirklichkeit des Landes der Ziel- und der Ausgangskultur auf. Man wird den Eindruck nicht los, dass es sich in beiden Fällen und ein stereotypes, teilweise auch verfälschtes Bild handelt. Das muss allerdings nicht zwingend als ein Nachteil bewertet werden, da eine solche Darstellung die Lerner geradezu zu einer intensiveren, aktiveren Auseinandersetzung mit dem Filminhalt provoziert (vgl. z.B. Brandi 1996: 5).

- In Bezug auf die Filmgattung (hier: Komödie, Spielfilm) lässt sich feststellen, dass bestimmte Genres für die Darstellung der Differenzen besonders gut geeignet zu sein scheinen. So wird in der Komödie vieles (Eigenschaften, Verhaltensweisen u.a.m.) überspitzt dargestellt und ist somit für die Lernenden leichter zu erkennen. Besonders wichtig ist das eben dort, wo - wie im Falle Deutschlands und Polens - keine ausgeprägte geographische, kulturräumliche Distanz bzw. keine deutlich anders gearteten gesellschaftlichen Verhältnisse vorzufinden sind (vgl. dazu Neuner; Hunfeld 1993: 124). Hier muss man allerdings der Stereotypenbildung entsprechend vorbeugen. ${ }^{24}$

- Die motivierende Funktion solcher Arbeitsformen, bei denen Filme miteinbezogen werden, wurde hier bestätigt. Die durchgeführten Evaluationsgespräche bestätigen nicht nur, dass Fremdsprachenlerner besonders gern mit filmischen Materialien arbeiten, sondern auch, dass sie sich dazu inspiriert fühlen, auf eine ähnliche Art und Weise bei selbständiger Arbeit mit Filmen vorzugehen, d.h. ihren Blickwinkel vom Wortschatz, von der Grammatik u.Ä. auf andere Aspekte zu richten, die sie bis jetzt nicht bewusst wahrgenommen bzw. verarbeitet haben. Das bestätigt wiederum, dass explizites Training der Medienkompetenz sowie bestimmter Strategien und Techniken im Umgang mit Filmen zur Steigerung der Effizienz des Lernens und somit auch zur Förderung der interkulturellen Kompetenz beiträgt.

\section{Abschließende Bemerkungen}

Als Fazit kann festgehalten werden, dass weder die interkulturelle Kompetenz noch die Medienkompetenz ausreichend empirisch untersucht worden sind. Thre Bedeutung im Kontext des Fremdsprachenlernens wurde aber längst erkannt. Tatsache ist, dass zwischen diesen beiden Kompetenzen ein enger Zusammenhang besteht. Besonders im Kontext der doch so aktuellen Förderung der Lernerautonomie und des lebenslangen Lernens ist es wichtig, diesen Zusammenhang zu erforschen und nach effizienten Trainingsverfahren zu suchen, um die (Fremdsprachen-) Lernenden, die ihre Kompetenzen

${ }^{24}$ Vgl. hier z.B. die Beiträge von J. Żurek („Polnische Stereotypenbilder über Deutschland und Deutsche“) und A. Gross („Ich kenne die Deutschen zu wenig, um mich vor ihnen zu fürchten. Einstellungen polnischer Studierender gegenüber Polen und Deutschen“) in der Zeitschrift „INFO DaF“ (Ausgabe $5 / 1997$ und $1 / 2006)$. 
(darunter die interkulturelle Kompetenz) auch mit Hilfe von filmischen Materialien zu entwickeln versuchen, auf die (vielleicht eben auch selbständige) Auseinandersetzung mit dem Medium „Film“ und mit Hilfe dieses Mediums auch mit der Zielkultur vorzubereiten. Man darf nicht vergessen, dass der uneingeschränkte Zugang zu einem Medium nicht zwingend bedeutet, dass dieses Medium optimal genutzt wird.

Besonders wichtig ist hier die Schulung der interkulturellen Kompetenz und der Medienkompetenz im Kontext der DaF-Lehrerausbildung. Das Training der Medienkompetenz darf sich allerdings nicht nur auf die technische Seite des Umgangs mit dem Medium beschränken, sondern muss vielmehr Wahrnehmungstechniken u.a.m. berücksichtigen, um effiziente Arbeit mit Filmen und das Erreichen des Ziels „,interkulturelle Kompetenz"zu ermöglichen.

\section{Literatur}

Adamczak, Sylwia (2000): Alltagskultur im Fremdsprachenunterricht: Theoretische Fundierung und unterrichtliche Praxis der interkulturellen Landeskundedidaktik. In: Studia Germanica Posnaniensia, XXVI, Poznań: Adam Mickiewicz University Press, 149-167.

Adamczak-Krysztofowicz, Sylwia (2003): Texte als Grundlage der Kommunikation zwischen Kulturen. Eine Studie zur Kultur- und Landeskundevermittlung im DaF-Studium in Polen. Hamburg: Kovač.

Adamczak-Krysztofowicz, Sylwia (2005): Kooperatives Miteinander statt Nebeneinander. Zur Beziehung zwischen der interkulturellen Fremdsprachendidaktik und den Kulturwissenschaften. In: GLOTTODIDACTICA XXX/XXXI, Poznań: Adam Mickiewicz University Press, 5-11.

Baacke, Dieter (1997): Medienpädagogik. Tübingen: Niemeyer.

Beirat DaF des Goethe-Instituts (1997): Deutsch als Fremdsprache - 24 vermittlungsmethodische Thesen und Empfehlungen. In: Jahrbuch Deutsch als Fremdsprache 23/1997, 337-393.

Biechele, Barbara (2004): Medienkompetenz und autonomes Lernen - Analyse und Reflexion empirischer Daten einer Befragung von DaF-Studierenden. In: Barkowski, Hans; Funk, Hermann (Hrsg.): Lernerautonomie und Fremdsprachenunterricht. Berlin: Cornelsen, 152-174.

Biechele, Markus; Padrós, Alicia (2003): Didaktik der Landeskunde. Fernstudieneinheit 31. Berlin u.a.: Langenscheidt.

Błażek, Agnieszka (2007): Möglichkeiten und Grenzen der Messung interkultureller Kompetenz. In: GLOTTODIDACTICA XXXIII, Poznań: Adam Mickiewicz University Press, 71-82.

Brandi, Marie-Luise (1996): Video im Deutschunterricht. Eine Übungstypologie zur Arbeit mit fiktionalen und dokumentarischen Filmsequenzen. Fernstudieneinheit 13. Berlin u.a.: Langenscheidt.

Chudak, Sebastian (2004): „Der Schwarzfahrer“, „Lola rennt“, „Good Bye, Lenin!“,... Zastosowanie materiałów audiowizualnych na lekcjach języka niemieckiego (możli- 
wości - problemy - propozycje). In: Jezyyki Obce w S žkole 5/2004, Warschau: Wydawnictwo CODN, 40-49.

Chudak, Sebastian (2007a): Lernerautonomie fördernde Inbalte in ausgewählten Lebrwerken DaF für Erwachsene. Überlegungen zur Gestaltung und zur Evaluation von Lebr-und Lernmaterialien. Frankfurt a.M. u.a.: Peter Lang.

Chudak, Sebastian (2007b): Der deutsche Film auf Erfolgskurs! Warum nicht auch im Deutsch-als-Fremdsprache-Unterricht?. In: Fremdsprache Deutsch 36, 14-16.

Derenowski, Marek (2006): Elementy kulturowe w nauczaniu języka obcego. In: Ježyki Obce w Szkole 3/2006, Warschau: Wydawnictwo CODN, 4-6.

Europarat (Rat für kulturelle Zusammenarbeit) (2001): Gemeinsamer europäischer Referenzrabmen für Sprachen: lernen, lehren, beurteilen. Berlin u.a.: Langenscheidt.

Erdmenger, Manfred (1997): Medien im Fremdsprachenunterricht. Hardware, Software und Methodik. Braunschweig: Seminar für Englische und Französische Sprache und deren Didaktik an der Technischen Universität.

Fuß, Albert (2001): Videomaterial für den fremdsprachlichen Landeskundeunterricht. In: Jung, Udo O.H. (Hrsg.): Praktische Handreichung für Fremdsprachenlehrer. Frankfurt a.M. u.a.: Peter Lang, 190-196.

Götze, Lutz (1994): Fünf Lehrwerkgenerationen. In: Kast, Bernd; Neuner, Gerhard (Hrsg.): Zur Analyse, Begutachtung und Entwicklung von Lehrwerken für den fremdsprachlichen Deutschunterricht. Berlin: Langenscheidt, 29f.

Heyd, Gertraude (1997): Aufbauwissen für den Fremdsprachenunterricht (DaF). Ein Arbeitsbuch. Tübingen: Narr.

Heidecker, Berit (1996): Video. In: Henrici, Gert; Riemer, Claudia (Hrsg.): Einführung in die Didaktik des Unterrichts Deutsch als Fremdsprache mit Videobeispielen. Baltmannsweiler: Schneider, 437-452.

Huneke, Hans-Werner; Steinig, Wolfgang (2002): Deutsch als Fremdsprache. Eine Einführung. Berlin: Erich Schmidt.

Jańska, Maria Urszula (2006): Interkulturelles Lernen in der bilingualen deutsch-polnischen Erz̨iebung. Evaluation der Unterrichtsmaterialien für den frühen fremdsprachlichen Deutschunterricht in Polen. Wrocław; Dresden: Oficyna Wydawnicza ATUT.

Jańska, Maria Urszula (2007): Entwicklung der interkulturellen Kompetenz anhand von Materialien für den Fremdsprachenunterricht. In: GLOTTODIDACTICA XXXIII, Poznań: Adam Mickiewicz University Press, 83-94.

Kaupp, Cristina Moles (2003): Good Bye, Lenin! Wolfgang Becker, BR Deutschland 2003. Bonn: Bundeszentrale für politische Bildung.

Krämer, Sabine; Walter, Klaus-Dieter (1994): Effektives Lehren in der Erwachsenenbildung. 1. Auflage, Ismaning: Hueber-Holzmann.

Krumm, Hans-Jürgen (2003): Curriculare Aspekte des interkulturellen Lernens und der interkulturellen Kommunikation. In: Bausch, Karl-Richard; Christ, Herbert; Krumm, Hans-Jürgen (Hrsg.): Handbuch Fremdsprachenunterricht. Tübingen: Francke, 138-144. 
Lundquist-Mog, Angelika (2007): „Türkisch für Anfänger“ - eine Sitcom im integrierten Sprach- und Landeskundeunterricht auch bei „Deutsch für Anfänger“? In: Fremdsprache Deutsch 36, 29-35.

Maijala, Minna (2007): Was ein Lehrwerk können muss - Thesen und Empfehlungen zu Potenzialen und Grenzen des Lehrwerks im Unterricht Deutsch als Fremdsprache. In: Info DaF 6, 543-561.

Mihułka, Krystyna (2006): Kultura w nauczaniu języka obcego. In: Ježyki Obce w Szłkole 3/2006, Warschau: Wydawnictwo CODN, 6-20.

Modrzycka, Irina; Iżykowska-Staruch, Marta (2007): Powrót filmów wideo do warsztatu nauczycieli języków obcych. In: Jeżyki Obce w S złoole 1/2007, 89-85.

Neuner, Gerhard; Hunfeld, Hans (1993): Methoden des fremdsprachlichen Deutschunterrichts. Eine Einführung. Fernstudieneinheit 4. Berlin: Langenscheidt.

Pfeiffer, Waldemar (2000): Möglichkeiten und Grenzen interkultureller Sprachvermittlung. In: GLOTTODIDACTICA XXVIII, Poznań: Adam Mickiewicz University Press, 125-139.

Pfeiffer, Waldemar (2001): Nauka jezyków obcych. Odpraktyki do praktyki. Poznań: Wagros.

Pieklarz, Magdalena (2006): Stereotype und Affektivität im interkulturellen Fremdsprachenunterricht. In: GLOTTODIDACTICA XXXII, Poznań: Adam Mickiewicz University Press, 109-121.

Raabe, Horst (2003): Audiovisuelle Medien. In: Bausch, Karl-Richard; Christ, Herbert; Krumm, Hans-Jürgen (Hrsg.): Handbuch Fremdsprachenunterricht. Tübingen: Francke, 423-426.

Roche, Jörg (2001): Interkulturelle Sprachdidaktik: Eine Einführung. Tübingen: Narr.

Roche, Jörg (2005): Fremdsprachenerwerb. Fremdsprachendidaktik. Tübingen: Francke.

Sass, Anne (2007): Filme im Unterricht - Sehen(d) lernen. In: Fremdsprache Deutsch 36, $5-13$.

Schwerdtfeger, Inge (1989): Sehen und verstehen. Arbeit mit Filmen im Unterricht Deutsch als Fremdsprache. Berlin: Langenscheidt.

Torenc, Marta (2007): Nauczanie mięzykulturowe - implikacje glottodydaktyczne. Wrocław: Oficyna Wydawnicza ATUT.

Volkmann, Laurenz (2002): Aspekte und Dimensionen interkultureller Kompetenz. In: Volkmann, Laurenz; Stierstorfer, Klaus; Gehring, Wolfgang (Hrsg.): Interkulturelle Kompetenz: Konzepte und Praxis des Unterrichts. Tübingen: Narr, 11-47.

Zawadzka, Elżbieta (1997): Zu interkulturellen Aspekten des FUs. In: Neofilolog 15, Poznań: Polskie Towarzystwo Neofilologiczne, 10-17.

Zawadzka, Elżbieta (2000): Glottodydaktyczne aspekty interkulturowości. In: Kielar, Barbara Z.; Krzeszowski, Tomasz P.; Lukszyn, Jerzy; Namowicz, Tadeusz (Hrsg.): Problemy komunikacji miedzykulturowej - lingwistyka, translatoryka, glottodydaktyka. Warszawa: Graf Punkt, 451-465.

Zawadzka, Elżbieta (2004): Nauczyciele jezykéw obcych w dobie przemian. Kraków: Oficyna Wydawnicza Impuls. 

Christoph Chlosta, Matthias Jung (Hrsg.) (2010):

DaF intergriert: Literatur - Medien - Ausbildung. Tagungsband der

36. Jahrestagung des Fachverbandes Deutsch als Fremdsprache 2008.

Göttingen: Universitätsverlag, 97-105.

\section{Oliver Eß (Berlin)}

\section{Aschenputtel in China - eine Theaterinszenierung im DaF-Unterricht}

\section{Einleitung}

Theaterspielen im Fremdsprachenunterricht motiviert für die Fremdsprache. Es schafft authentische Handlungsanlässe für sprachliche Auseinandersetzungen in der Zielsprache. Und es ist der ideale Anlass für einen spielerischen Umgang mit Eigenem und Fremdem.

Im Folgenden werde ich zuerst ein Theaterprojekt mit Germanistik- und DaF-StudentInnen des zweiten Studienjahres der Zhejiang Universität für Wissenschaft und Technik in Hangzhou (China) im Studienjahr 2003/2004 beschreiben. Im Laufe von zwei Semestern wurde hier eine Bühnenfassung des Märchens Aschenputtel erarbeitet und in die Praxis des Theaterspielens und der Aufführung umgesetzt. Dann werde ich aufzeigen, welche didaktischen Möglichkeiten ein solches Theaterprojekt eröffnet. Abschließend werde ich meinen Ansatz kurz und thesenartig in den größeren Zusammenhang des handlungsorientierten interkulturellen Literaturunterrichts stellen und dort verorten.

\section{Werkstattbericht}

Die Umsetzung des Theaterprojektes werde ich auf den folgenden drei Ebenen beschreiben:

- der Ebene der Voraussetəungen für das Projekt in Form der institutionellen Vorgaben, der Beschaffenheit der Zielgruppe und der didaktischen Vorgaben,

- der Ebene der einzelnen Phasen der Proben- und Inszenierungsarbeit, sowie

- der Ebene der Auffübrung, also des Resultats des Projektes. 


\subsection{Voraussetzungen}

Die erste institutionelle Vorgabe war der Handlungsrahmen der Hochschule Zhejiang University of Science and Technology (ZUST) in Hangzhou, an der das Projekt durchgeführt wurde.

Die ZUST ist eine Hochschule, die nach deutschem Fachhochschulmodell aufgebaut ist, an der vor allem Studiengänge in Ingenieurswissenschaften angeboten werden und an der seit einigen Jahren eine Deutschabteilung existiert, in der „anwendungsorientierte Deutschlandstudien“ bis zum Bachelor studiert werden können. Daraus ergeben sich für den Unterricht Deutsch als Fremdsprache zwei Zielgruppen: StudentInnen, die Deutsch im Hauptfach studieren, und Studierende der Ingenieurswissenschaften, die in den ersten beiden Studienjahren neben ihrem Fachstudium intensiv Deutsch lernen, weil sie sich zum Weiterstudium an deutschen Fachhochschulen, vor allem in Niedersachsen, qualifizieren wollen.

Weiterhin war zu berücksichtigen, dass mit dem Projekt Neuland betreten wurde, da es an der ZUST bisher weder Theaterprojekte noch Theaterworkshops noch Theater als Verfahren im Deutschunterricht gegeben hatte.

Die dritte, sehr vage Vorgabe institutioneller Art war, dass die Leitung der Deutschabteilung beschlossen hatte, dass eine Theateraufführung ein Projekt sein könnte, das entscheidend zur Verbesserung des Prestiges der Deutschabteilung innerhalb der Hochschule beitragen würde.

Die Zielgruppe im Projekt setzte sich aus neun Germanistinnen und acht Studierenden aus technischen Fächern (Informatik, Bauwesen und Architektur) zusammen, die das Theaterprojekt als freies Wahlfach, also ohne Notendruck und aus purem Interesse belegten. Für diese StudentInnen im Alter zwischen 18 und 20 Jahren war Deutsch die zweite Fremdsprache, die sie erst seit einem Jahr erlernten, da sie ohne Vorkenntnisse auf die Hochschule gekommen waren. Das Sprachniveau der TeilnehmerInnen lag bei Beginn des Projektes auf einem eher schwachen B1-Niveau, das Resultat von ca. 500 Stunden Deutschunterricht im ersten Studienjahr (vgl. Kong 2007: 127).

Meine didaktischen Vorgaben, d.h. die minimalen Vorgaben, die ich für die Arbeit mit der Gruppe am sinnvollsten hielt und für das Projekt festlegte, waren die folgenden drei:

- Deutsch als ausschließliche Unterrichts- bzw. Arbeitssprache, auch wenn das angesichts des Sprachniveaus eine große Herausforderung sein sollte;

- zielgruppenorientiertes Arbeiten: die sprachlichen und thematischen Bedürfnisse der Teilnehmer stehen im Zentrum;

- und als Folge aus der zweiten Vorgabe: eher ein prozessorientiertes denn ein ergebnisorientiertes Arbeiten, da ich erst einmal herausfinden wollte, was mit den Teilnehmern möglich ist, ohne sie zu überfordern. (Allerdings bedingte die ergebnisorientierte institutionelle Vorgabe, dass am Ende des Projektes eine Aufführung stehen sollte.) 


\subsection{Phasen der Probenarbeit}

Für das Projekt standen insgesamt 130 Unterrichtsstunden in zwei Semestern zur Verfügung, davon 34 Stunden im ersten und 68 Stunden im zweiten, und zusätzliche Proben an den Wochenenden in der Schlussphase.

Das Projekt verlief in drei Phasen, die ich im Folgenden detaillierter vorstellen werde im Hinblick auf

- Grundlagen des Schauspielens und der Themenfindung,

- Proben im Klassenraum: Schauspielübungen, Arbeit am Text, Besetzung und Gewerke, und

- Endproben auf der Bühne.

\subsubsection{Phase 1: Grundlagen des Schauspielens und Themenfindung}

In der ersten Phase des Projektes, die auf der Probebühne bzw. im dafür ausgestatten Klassenraum stattfand, standen die thematische und formale Bestandsaufnahme, die schauspielerische Grundlagenarbeit und die Themenfindung im Mittelpunkt.

Hier wurden zunächst grundlegende Schauspielübungen, wie Sprechen, Atmen, Artikulieren und die Bewegung des Körpers im Raum, sowie einfache Improvisationsübungen durchgeführt. Außerdem stellte sich die Frage nach den Voraussetzungen der StudentInnen im Hinblick auf Ihre darstellerischen Präferenzen und Fähigkeiten. Ein Inhalt dabei war z.B. die Übung „Everybody is a star“, bei der jeder Teilnehmer in einer Solonummer das spielt, darstellt, tanzt oder vorträgt, was er am besten zu können glaubt und was ihm am ehesten entspricht. Daraus ergaben sich bereits erste Konturen für die Besetzung, die Spielformen und die Spielelemente der (zukünftigen) Aufführung.

Der zweite Schwerpunkt in dieser Phase war die Annäherung an ein Thema, das szenisch dargestellt werden könnte. Im Gespräch mit den Studierenden ergaben sich zwei zentrale Aussagen, auf formaler und auf inhaltlicher Ebene:

- „Wir wollen ein Märchen spielen, weil das einfach und eine uns bekannte Form ist.“

- „Wir stehen immer unter Druck. Wir haben keine Freizeit. Wir müssen immer nur lernen. Wir werden ständig bevormundet. Wie könnten wir das szenisch darstellen..."

Dies führte uns zur Geschichte einer jungen Frau, die von der Haushaltssklavin zur Prinzessin wird, und dabei einen Befreiungs- und Emanzipationsprozess durchlaufen sollte, also: Aschenputtel.

\subsubsection{Phase 2: Proben im Klassenraum und Erarbeitung der Textfassung}

In einer zweiten, die Hälfte der gesamten Projektzeit umfassenden Phase auf der Probebühne wurden die Schauspielübungen spezifiziert und verfeinert, eine erste Textfassung erarbeitet, die Rollen und Gewerke besetzt, und in szenischen Proben eine grobe Spielfassung des Stückes erstellt.

Bei der Verfeinerung der Schauspielübungen wurde an inneren und äußeren Haltungen gearbeitet, durch das quasi naturalistische Spielen von Grundemotionen oder 
die Darstellung dieser Emotionen durch das entsprechende äußere Gestenrepertoire. Außerdem lag ein Schwerpunkt auf Partnerübungen, mit dem Ziel, Fertigkeiten für das Zusammenspiel zu schulen. Gleichzeitig erstellten wir in mehreren Arbeitsschritten eine szenische Fassung des Märchentextes:

Zuerst machten sich die StudentInnen in einer Hausaufgabe mit einer von mir sprachlich vereinfachten Fassung des deutschen Märchentextes vertraut. Diesen Text haben wir dann, im Kreis sitzend, zusammen gelesen, und anschließend, in einer zweiten Runde, uns gegenseitig in eigenen Worten erzählt. Das Ziel war hier, alle TeilnehmerInnen mit dem genauen Handlungsablauf vertraut zu machen und die Grundlage für eine szenische Fassung zu schaffen.

Im nächsten Schritt erarbeiteten die Studierenden in Zweier- oder Dreiergruppen szenische Adaptationen, was trotz des schwachen Sprachniveaus zu lesbaren Ergebnissen führte. Aus den fünf szenischen Fassungen, die dabei entstanden, habe ich eine szenische Gesamtfassung zusammengestellt, die Elemente aus allen Fassungen enthielt, wodurch die TeilnehmerInnen in der Folge ihren eigenen Text spielten.

Ein gruppendynamisch entscheidender Moment war, dass wir uns nach der Erarbeitung der vorläufigen Textfassung eine ganze Probeneinheit lang Zeit genommen haben, um die einzelnen Rollen zu besetzen und um Verantwortlichkeiten zu vergeben, die den klassischen Gewerken im Theater entsprechen. Bei der Besetzung der Rollen sind wir so vorgegangen, dass bei Mehrfachbewerbungen, z.B. für die Rolle von Aschenputtel, kurze Vorsprechen durchgeführt und dann per Abstimmung die fraglichen Rollen vergeben wurden. Außerdem haben wir, auch um eventuelle Ungerechtigkeiten aufzufangen einen Sprech- und Bewegungschor, den „Chor der Täubchen“, geschaffen. Mit diesem Chor eröffneten und beendeten alle TeilnehmerInnen das Stück gemeinsam. Außerdem stand ein Teil des Chores Aschenputtel stets zur Seite, als (stumme) moralische Stütze und gestischer Kommentar.

Die technischen Theater-Gewerke wie Requisiten, Bühne, Kostüme, Licht, Ton und Musik wurden so verteilt, dass es jeweils einen oder zwei Verantwortliche dafür gab. Zusätzlich besetzt wurden, wie im professionellen Theater, die Positionen der Regieassistentin und der Souffleuse, die unter anderem die Aufgabe hatten, Probenresultate und Veränderungen am Text festzuhalten.

Die szenischen Proben nahmen zeitlich den Hauptteil dieser Phase ein. Hier wurden, immer noch auf unserer Probebühne, grobe Fassungen der Szenen zwischen den Haupt- und NebendarstellerInnen aus der Improvisation heraus erarbeitet, und dann in einer zweiten Arbeitsphase fein abgestimmt. Die Choreographien und Gruppenszenen dagegen wurden auf der Grundlage von klaren Vorgaben von mir erst grob angelegt, und dann im Spiel mit der Gruppe modifiziert und verfeinert. Der Text wurde im ganzen Probenprozess als Stoff behandelt, der jederzeit den szenischen Bedürfnissen angepasst werden konnte. 


\subsubsection{Phase 3: Endproben auf der Bühne}

Inhalt der dritten Phase, des letzten Viertels des Projektes, waren die Endproben auf der Bühne. Auf der Grundlage einer endgültigen Spielfassung, die aus den Aufzeichnungen der Souffleuse und der Regieassistentin erstellt wurde, fand die letzte Probenphase im Veranstaltungssaal der Hochschule statt.

Die Vorgänge aus dem Probenraum wurden nun auf den Aufführungsort umgesetzt. Licht und Musik kamen hinzu: 31 Toneinsätze, die von einem Informatik-Studenten vom Computer aus gefahren wurden. Die Souffleuse übernahm die Lichtregie.

Die Proben fanden als Durchlaufproben in den Kostümen statt, die vom Fachbereich Modedesign der Fakultät für Kunst und Design der Hochschule hergestellt wurden.

Der Probenrhythmus wurde verändert, auf zweimal wöchentlich erhöht, in der Schlussphase kamen noch vier Probentage an zwei Wochenenden dazu. Dadurch steigerte sich die Spannung, die Intensität des Arbeitprozesses bis zur Premiere stetig. Auf der organisatorischen und spielerischen Ebene war es die Phase, in der die Studierenden bzw. die SpielerInnen vom Spielleiter unabhängig wurden.

Bei der Premiere des Stückes stellten die Studierenden bzw. die „SchauspielerInnen“ nach vorsichtigem Abtasten in den ersten Szenen mit zunehmender Freude fest, dass die Inszenierung funktionierte, wurden dadurch von Szene zu Szene sicherer und waren beim Premierenapplaus der Euphorie echter SchauspielerInnen verfallen. Die so entstandene Schauspieltruppe funktionierte von nun an, d.h. in den folgenden Vorstellungen, als autonomes Kollektiv. Das Stück Aschenputtel fand in fünf Vorstellungen insgesamt fast 400 Zuschauer.

\subsection{Die Aufführung: das Resultat}

Das Produkt des Theaterprojektes, die fertige Aufführung, lässt sich am besten anhand von Zahlen, von Spielelementen und von Spielhaltungen beschreiben.

Die Zablen: in 70 Minuten Theater kamen 17 SchauspielerInnen in 29 Rollen zum Einsatz. Dabei wurden 31 Toneinsätze und 25 Lichtstimmungen ,gefahren“. In 29 Szenen spielte das Ensemble vier Gesangs- und fünf Tanznummern, und zwei Chor-Choreographien, bei denen allen SpielerInnen zum Einsatz kamen, jeweils zu Beginn und Ende der Vorstellung.

Die spielerische Ebene zeichnete sich durch das Nebeneinander und die Gleichzeitigkeit von phantastischen und realistischen Spielelementen aus. So gab es z.B. Kostüme, die von Zauberhand geleitet vom Baum herabschweben, genauso wie einen Vater von Aschenputtel, der den ,typischen“ chinesischen Geschäftsmann mit Handy und Businessanzug darstellt, oder einen Prinzen, der in einem Schloss wohnt, aussieht wie ein (chinesischer) Schlagerstar, und auf Partys Karaoke singt.

Auf formaler Ebene wurden diverse Spielhaltungen realisiert, die unterschiedlichen Theatertraditionen entsprechen, wie die ganz von der äußeren Form bestimmten Chorszenen, die beinahe an den klassischen Chor aus dem griechischen Theater erinnerten; oder die durchkomponierten Tanzchoreographien auf den Bällen, bei denen 
sich 14 Spieler gleichzeitig zur Musik bewegten, und durch gemeinsame Pausen Akzente setzten; oder die quasi naturalistischen, psychologischen Momente, in denen Aschenputtel ihren Schmerz über den Tod der Mutter ganz intim und subtil „lebte“; oder, ganz im Gegensatz dazu, die in Brechtscher Tradition stehenden Brüche und inszenierten „Aussteiger“, in denen z.B. Aschenputtel oder die Stiefmutter komplett aus ihren Rollen ausstiegen, um sich direkt an die Zuschauer zu wenden, mit der Frage, ob der gerade gesprochene Monolog verstanden wurde, um dann über Erklärungen und Übersetzungen auf Englisch und Chinesisch wieder ins Spiel zurückzukehren.

Insgesamt entstand ein sehr offenes und heterogenes Theater-Objekt, das von einem Kollektiv getragen wurde, das einerseits die individuellen darstellerischen Stärken betonte und andererseits die Schwächen einzelner Darsteller auffing.

\section{Didaktische Auswertung}

Astrid Ronke beschreibt in ihrer Dissertation zum Stand der Dramenpädagogik an den Hochschulen in den USA, wie Theater im Fremdsprachenunterricht alle Anforderungen des kommunikativen Ansatzes erfüllt. Dabei unterscheidet sie die folgenden Beschreibungskategorien (vgl. Ronke 2005: 99-168):

- kommunikative und sprachliche Aspekte,

- kulturelle Aspekte,

- psychologische, soziale und physische Aspekte.

Diese Kategorien von Ronke dienen mir dazu, das oben beschriebene Projekt auf didaktischer Ebene auszuwerten. ${ }^{1}$ Dabei werde ich bei den einzelnen Aspekten die Punkte betonen, die in unserem Projekt besonders intensiv realisiert wurden.

\subsection{Kommunikative und sprachliche Aspekte}

Sicherlich wurden alle vier Grundfertigkeiten des Fremdsprachenunterrichts, wie Lesen, Schreiben, Sprechen und Hören trainiert. Beispiel dafür ist der „,schulische Erfolg“ der TeilnehmerInnen in der Folge. Denn alle TeilnehmerInnen erzielten bereits im Studienjahr des Projektes Leistungen, die über denen anderer Studierender lagen. ${ }^{2}$

Entscheidender aber ist, dass durch die authentischen Sprechsituationen im Arbeitsprozess vor allem Sprechfertigkeit und Hörverstehen, und damit die allgemeine kommunikative Kompetenz geschult wurde: Der organisatorische Rahmen wurde in der

1 Die englischen Begrifflichkeiten von Ronke verwende ich in ihrer deutschen Übersetzung. Der „physische Aspekt" wird hier vernachlässigt.

2 Zum Beispiel bestanden die Germanistik-Studentinnen unter den TeilnehmerInnen ihre PGG-Prüfung, „eine landesweit einheitliche Feststellungsprüfung für das Germanistik-Grundstudium“ (Kong 2007: 133), die in China nach zwei Jahren Bachelorstudiums absolviert wird, und die IngenieurstudentInnen unter den TeilnehmerInnen ihre hochschulinterne Feststellungsprüfung, die sie dazu berechtigte, ihr Studium an einer deutschen Fachhochschule in Niedersachsen fortzusetzen.

In beiden Prüfungen liegen die Durchfallquoten an der ZUST in der Regel bei ca. 40\%. Die Schwerpunkte in den Prüfungen sind die oben genannten vier Grundfertigkeiten. 
Fremdsprache verhandelt, Spielvorschläge wurden im Inszenierungsprozess verarbeitet (Hörverstehen) oder von den Studierenden selbst formuliert (Sprachproduktion).

Im Projekt lag auf sprachlicher Ebene der Schwerpunkt nicht darauf, literarische Sprache auf dem Theater zu sprechen, sondern die ,instrumental function“ der Fremdsprache auszubilden, also das „using language to get things“ (Ronke 2005: 102).

\subsection{Kulturelle Aspekte}

Gewiss war ein kultureller Aspekt der Aufführung der Umgang mit (kanonisierter) deutscher Literatur. Allerdings gehören Grimms Märchen laut einer Umfrage zur literarischen Vorsozialisation von Germanistikstudierenden, die mit StudentInnen des 3. Studienjahres durchgeführt wurde, zum selbstverständlichen Kulturgepäck eines jungen chinesischen Lesers (Eß 2007: 148).

Doch bei unserem Projekt ging es weniger um kulturelle Inhalte, denn um den Umgang damit. Im Zentrum stand die Verarbeitung kultureller Inhalte, also nicht das statische Kulturwissen, sondern die aktive Produktion eines eigenen Kulturobjektes, eines interkulturellen Theaterobjektes. Im Spiel mit Eigenem und Fremdem entstand dabei ein Drittes. Die Theateraufführung als polysemes Nebeneinander von mehreren Codes, die gleichzeitig bedient werden, und dadurch Elemente aus zwei (oder mehreren) Kulturen neben- und übereinander legt, eignet sich dazu ganz besonders. Im Projekt wurde also nicht (primär) Kulturwissen sondern Kulturkompetenz vermittelt.

\subsection{Psychologische und soziale Aspekte}

Die wichtigsten psychologischen und sozialen Aspekte, die ich in dem Projekt beobachten konnte, lassen sich mit den Kategorien Motivation, Selbstbewusstsein bzw. Selbstwertgefühl und sozialer Kompetenz als gemeinschaftlichem Handeln in bis dahin für die Studierenden unbekannten Arbeits- und Sozialformen beschreiben.

Die Frage der Motivation für das Erlernen der deutschen Sprache ist gerade im chinesischen Kontext ein wichtiger Aspekt. Eine Umfrage zur Wahl des Studienfaches an der ZUST z.B. zeigte (vgl. Eß 2007: 140), dass praktisch kein Germanistikstudent das Studienfach freiwillig wählte, sondern unter dem Einfluss systemimmanenter Faktoren das Fach zugewiesen bekam. Dadurch liegt erst einmal eine reine ,instrumental motivation“ vor: „a practical reason for learning the language“ (Ronke 2005: 141f.). Man studiert Deutsch, weil man es als „Werkzeug“ im Berufsleben als AssistentIn in einem deutsch-chinesischen Joint Venture oder als ReiseführerIn benötigen wird. Diese „,instrumental motivation“ verwandelt sich bei manchen Studierenden im Verlauf des Studiums in eine ,integrative motivation“ (Ronke 2005: 142), die sich folgendermaßen definiert: „the learner has a genuine interest in the target language and/or culture and desires to relate to them" (Ronke 2005: 142).

Das Theaterprojekt förderte diesen Prozess der Motivationsveränderung. Ich konnte beobachten, wie sich die extrinsische Motivation spätestens am Ende des Projektes in eine intrinsische Motivation verwandelt hatte. 
Ein zweiter wichtiger psychologischer Aspekt ist die Steigerung des Selbstwertgefühls und des Selbstbewusstseins, des „,self-esteem“ (Ronke 2005: 144f.). Bei den beiden Studentinnen zum Beispiel, die Aschenputtels Stiefschwestern darstellten, konnte ich beobachten, wie mit den ersten Bühnenproben, bei denen sie spürten, dass sie ihre Rollen beherrschten, das Bewusstsein für die eigene Leistung in der Theaterarbeit zu einem sprachlichen Selbstbewusstsein führte, das sich auch entscheidend auf den Spracherwerb in den folgenden beiden Jahren bis zum Bachelor auswirkte.

Der wichtigste soziale Aspekt des Projektes war, dass die Progression in der Projektarbeit von der geführten Gruppenarbeit bis hin zur autonomen Gruppe, die ihr eigenes Stück spielt, ein Bewusstsein für die Möglichkeiten kollektiven studentischen Handelns schuf. Dies wirkte sich in der Folge an der ZUST auch auf institutioneller Ebene aus, weil dadurch die Grundlage für andere Projektarbeiten im Fachbereich geschaffen wurde, wie z.B. für die erste selbstverwaltete studentische Institutsbibliothek in China, als Ort des autonomen Lernens.

\section{Theater ist handlungsorientierter interkultureller Literaturunterricht}

In dem Maße wie sich der kommunikative Ansatz im Fremdsprachenunterricht etablierte, wurde auch das Theaterspiel als Verfahren und Inhalt des Unterrichtes Deutsch als Fremdsprache (wieder-)entdeckt (vgl. u.a. Esselborn 1998; Schewe 1998). In diesem Zusammenhang verweist Ronke auf Theater im Fremdsprachenunterricht als ,actionoriented, interactive, and affective teaching method“" (2005: 168) und betont dabei das Potential von Dramenpädagogik als idealem Verfahren des kommunikativen Ansatzes.

Meiner Ansicht nach sollte man nun noch einen Schritt weiter gehen und im Kontext von interkulturellem Literatur- und Fremsprachenunterricht damit beginnen, Theater als Verfahren des handlungsorientierten Fremdsprachenunterrichtes zu sehen, oder besser noch als das zentrale didaktische Verfahren des handlungsorientierten interkulturellen Literaturunterrichtes. Denn wie ich am Beispiel des Theaterprojekts in Hangzhou aufzuzeigen versuchte, weist ein Theaterprojekt im Fremdsprachenunterricht geradezu ideal alle Charakteristika von handlungsorientiertem Unterricht auf, als einem ganzheitlichen und schüleraktiven Unterricht, „,in dem die zwischen dem Lehrer und den Schülern vereinbarten Handlungsprodukte die Gestaltung des Unterrichtsprozesses leiten, sodass Kopf- und Handarbeit der Schüler in ein ausgewogenes Verhältnis zueinander gebracht werden können“ (Jank; Meyer 2005: 315). Vor allem vermittelt ein Theaterprojekt aber die beiden zentralen Lehr-Lern-Ziele dieses Unterrichts: interkulturelle Handlungskompetenz, als die „auf interkulturelle Kontexte bezogene Variante einer allgemeinen Handlungskompetenz“ (Bolten 2007: 25); und „literarische Rezeptionskompetenz" (vgl. Eggert; Garbe 2003: 9f.), durch den produktiven Umgang mit Literatur und Kultur beim Herstellen eines literarischen Objektes, eines Kunstobjektes, eines interkulturellen Theaterobjektes. 


\section{Literatur}

Bolten, Jürgen (2007): Was heißt „Interkulturelle Kompetenz“? Perspektiven für die Personalentwicklung. In: Berninghausen, Jutta; Kuenzer, Vera (Hrsg.): Wirtschaft als interkulturelle Herausforderung. Business Across Cultures. Frankfurt a.M.: IKO-Verlag für Interkulturelle Kommunikation, 21-42.

Eggert, Hartmut; Garbe, Christine (2003): Literarische Sozialisation. Stuttgart; Weimar: Metzler.

EB, Oliver (2007): Chang Wazi Pipi - Ein Unterrichtsversuch im DaF-Literaturunterricht in China. In: Göbel, Constanze et al. (Hrsg.): DaF-Didaktik aus internationaler Perspektive. Frankfurt a.M: IKO-Verlag für Interkulturelle Kommunikation, 137-156.

Esselborn, Karl (1988): Theater und szenisches Spiel im Fremdsprachenunterricht Deutsch. In: Info DaF 15/4, 388-406.

Jank, Werner; Meyer, Hilbert (2005): Didaktische Modelle. Berlin: Cornelsen.

Kong, Deming (2007): Die Hochschulen mit dem Fach Germanistik. In: Ammon, Ulrich; Reinbothe, Roswitha; Zhu, Jianhua (Hrsg.): Die deutsche Sprache in China. Geschichte, Gegenwart, Zukunftsperspektiven. München: Iudicium, 123-140.

Schewe, Manfred (1988): Fokus Lehrpraxis: Für einen integrierten, dramapädagogischen Deutsch als Fremdsprache-Unterricht für Fortgeschrittene. In: Info DaF 15/4, 429-441.

Ronke, Astrid (2005): Wozu all das Theater? Drama and theater as a method for foreign language teaching and learning in higher education in the United States. http:/ / opus.kobv.de/tuberlin/ volltexte/2005/1042/ (12.12.2009). 

Christoph Chlosta, Matthias Jung (Hrsg.) (2010): DaF intergriert: Literatur - Medien - Ausbildung. Tagungsband der 36. Jahrestagung des Fachverbandes Deutsch als Fremdsprache 2008. Göttingen: Universitätsverlag, 107-122.

\section{Nils Bernstein (Wuppertal)}

\section{Phraseologismen im Fremdsprachenunterricht. Didaktisierungsvorschläge für den Umgang mit festen Mehrwortverbindungen in literarischen Texten.}

\section{Einleitung}

Feste Mehrwortverbindungen, weiterhin Phraseologismen genannt, werden ebenso wie freie Lexeme erlernt und im Wortschatz gespeichert. Gemeinsam mit freien Lexemen haben diese Wortverbindungen, dass sie trotz polylexikaler Struktur (von MuttersprachlerInnen) wie eine einzige Vokabel abgerufen werden. Für den Spracherwerb stellen sie eine nicht zu umgehende Hürde dar und sollten bereits im Anfängerunterricht thematisiert und zumindest passiv von Lernenden beherrscht werden, da Phraseologismen von MuttersprachlerInnen ausgesprochen häufig angewendet werden.

Im Folgenden sind grundlegende Kriterien von Phraseologismen wie (graduelle) Festigkeit, Polylexikalität und Idiomatizität zu klären. Im Anschluss daran sollen mittels literarischer Textbeispiele aus dem 20. Jahrhundert Didaktisierungsvorschläge für den angemessenen Umgang mit Phraseologismen im Fremdsprachenunterricht gegeben werden. Dabei ist weiterhin darauf einzugehen, welches phraseologische Optimum bzw. Minimum für den Spracherwerb im Fremdsprachenunterricht erstrebenswert sein könnte. 


\title{
1 Eigenschaften von Phraseologismen
}

In der relativ jungen Forschungsdisziplin der Phraseologie herrscht keine einhellige Meinung darüber vor, was unter einem Phraseologismus zu verstehen ist, noch was in den Grenzbereich oder in den Fokus der Phraseologie fällt. Trotz all dieser Unstimmigkeiten werden stets in etwa die gleichen Eigenschaften von Phraseologismen angeführt.

Die gängigste Definition von Phraseologismen stammt von Burger, Buhofer und Sialm aus dem „Handbuch der Phraseologie“:

\begin{abstract}
„Phraseologisch ist eine Verbindung von zwei oder mehr Wörtern dann, wenn (1) die Wörter eine durch die syntaktischen und semantischen Regularitäten der Verknüpfung nicht voll erklärbare Einheit bilden, und wenn (2) die Wortverbindung in der Sprachgemeinschaft, ähnlich wie ein Lexem, gebräuchlich ist.“ (1982: 1)
\end{abstract}

Burger (2007: 32) stimmt dieser Definition in seiner aktuellen Einführung in die Phraseologie immer noch zu. Zumindest die drei elementaren Eigenschaften von Phraseologismen - (1) Polylexikalität, (2) Festigkeit, (3) Idiomatizität - sind in der Definition enthalten. Darüber hinaus lassen sich Phraseologismen durch ihre Expressivität und ihren hohen Grad an Reproduzierbarkeit kennzeichnen.

1. Polylexikalität bezieht sich auf die Mehrgliedrigkeit der Phraseologismen. Somit scheiden Einwortmetaphern wie Schmalspurcasanova oder Grünschnabel aus dem Feld der Phraseologie aus, zumal im Gegensatz zu idiomatischen Phraseologismen meist nur einem Teil des Kompositums eine übertragene Bedeutung zukommt (z.B. Talsohle oder Flussbett). Für Lernende bedeutet Polylexikalität, dass das Erlernen von Phraseologismen mit einem höheren Speicheraufwand verbunden ist, da sie umfangreicher als Einzellexeme sind.

2. Festigkeit bedeutet, dass weder Permutation noch Kommutation möglich sind. Etwas kann klipp und klar sein, nicht aber *klar und klipp, oder *klipp und einleuchtend. Hinzu kommt, dass die Komponente „klipp“ unikal ist. Festigkeit gilt auch in semantischer Hinsicht. Die Bedeutung gilt für den Phraseologismus als ganzen. Das mehrgliedrige image acoustique wird einem einzigen concept zugeordnet. Permutation und Kommutation sind nicht zulässig, werden aber in Alltagssprache und natürlich auch in Gedichten ,als Sprachspielereien, als gewollte Abweichungen von der üblichen Ausdrucksweise“ (Altsleben; Scholze-Stubenrecht 2002: 11) akzeptiert.

Die Kommutationsprobe ist die sicherste Methode zum Nachweis für einen Phraseologismus und greift auch beim dritten Merkmal, der Idiomatizität.

3. Idiomatizität meint die semantische Transformation der Komponenten, die als freie Lexeme üblicherweise in ihrer wörtlichen Bedeutung verwendet werden. Jmdn. auf die Palme bringen ist voll-idiomatisch, hat nichts mit Palmen zu tun und ist daher von Lernenden nicht zu entschlüsseln; auch wenn sie jedes freie Lexem der Wendung übersetzen können, können sie die übertragene Bedeutung höchstens durch den Kontext herleiten. Bei voll-idiomatischen Wendungen ist die Summe der Kompo- 
nenten nicht mehr aus der Bedeutung der einzelnen Komponenten ableitbar, etwa bei auf die schiefe Bahn geraten (und natürlich nicht *auf die schräge Spur geraten). Bei teil-idiomatischen Wendungen hingegen bleibt eine Komponente in ihrer ursprünglichen Form bestehen, z.B. bei einen Streit vom Zaun brechen, da es tatsächlich um einen Streit geht. Nicht-idiomatisch sind Ausdrücke, bei denen alle Komponenten transparent sind wie bei vielen Funktionsverbgefügen (einen Beitrag leisten) oder Kollokationen (sich die Zähne putzen).

Die Metaphorik der Idiomatizität eröffnet ein interessantes Betätigungsfeld der Lyrik bei der Behandlung von idiomatischen Phraseologismen, der ,phraseologische[n] Klasse par excellence“ (Burger et al. 1982: 31). Eine Forschungslücke besteht sicherlich in der Beantwortung der Frage, wie sich das Wissen um die phraseologische Terminologie vor allem für Lyrik interpretatorisch umsetzen lässt.

Der Reiz für Lernende besteht in der Expressivität und der Reproduzierbarkeit von Phraseologismen. Bereits im A1-Niveau wird man feste Mehrwortverbindungen, etwa beim Verfassen von Briefen, verwenden müssen (Sehr geehrte Damen und Herren, Mit freundlichen Grüßen). Hohe Kompetenz der Fremdsprachenbeherrschung wird man damit unter Beweis stellen können, dass man den Stein des Anstoßes oder den Tropfen, der das Fass zum Überlaufen gebracht hat ohne viel Federlesens auf den Punkt bringen kann. Die genannten Aspekte von Phraseologismen lassen deutlich erkennen, warum im Spracherwerb das Erlernen der Phraseologie einer Sprache unerlässlich ist. Denn Phraseologismen

- erleichtern und fördern alltägliche Kommunikation,

- $\quad$ sind Teil der kommunikativen Kompetenz (vgl. Gündoğdu 2007: 13),

- sind höchst frequent in Werbung und Zeitung,

- $\quad$ sind (manchmal) Träger kulturspezifischer Informationen.

Die Schwierigkeit für Lernende besteht in den Flexionsbesonderheiten von Phraseologismen (des Wahnsinns sein, eines Besseren belehren). Andererseits lassen sich Phraseologismen auch daran als solche erkennen, oder aber an ihrer semantischen Inkompatibilität. In jmdm. die Haare vom Kopf fressen wird man Haare sicher nicht mit dem Verb fressen in Einklang bringen können und daher zu einem Wörterbuch greifen, sollte man die übertragene Bedeutung nicht kennen.

\section{Phraseologische Wörterbücher}

$\mathrm{Zu}$ welchem Wörterbuch sollten vor allem Lernende nun greifen? Für das Erörtern dessen, was wir alltagssprachlich und linguistisch wenig exakt (vgl. Burger 2007: 12) als „Redensart“ bezeichnen - genauer wäre der Terminus ,idiomatischer Phraseologismus" - bietet sich das umfangreiche Werk Lutz Röhrichs, das Lexikon der sprichwörtlichen Redensarten, an. Die oftmals vorhandene Bildlichkeit vieler Phraseologismen - man denke an Pieter Brueghels d.Ä. weithin bekanntes Redensartenbild Die niederländischen Sprichwörter (1559) - wird in Röhrichs dreibändigem Nachschlagewerk durch zahlreiche Illustrationen veranschaulicht. Zumindest für Lehrende ist auch der Band 11 des Du- 
dens zu Redewendungen hilfreich (Altsleben; Scholze-Stubenrecht 2002). Dort findet man immerhin zehntausend feste Wendungen, sprichwörtliche Redensarten und Sprichwörter. Zu kritisieren ist hierbei indes, dass die semantische Wertung zahlreicher Phraseologismen nicht hinreichend erklärt wird. Die üblichen Bezeichnungen „umgangssprachlich“, „bildungssprachlich“, „familiär" oder gar „dichterisch“ mögen sich für MuttersprachlerInnen orientierend auswirken, wobei diese Gruppe von SprecherInnen aber wiederum eigene und teilweise widersprechende Konnotationen zu bestimmten Phraseologismen haben. Für Lernende bleiben die Markierungen der Stilschichten aber defizitär (vgl. Lüger 1997: 87) und auch die Anwendungsbeispiele, bei denen Zeitungskommentare neben literarischen Texten stehen, ohne deren durchaus verschiedene Entstehungszusammenhänge zu berücksichtigen, sind nicht in allen Fällen aufschlussreich. Bedauerlich ist auch, dass es für das Deutsche noch kein gutes Nachschlagewerk für Kollokationen gibt, einen Bereich der Phraseologie, der gerade für Deutsch als Fremdsprache-Lernende große Schwierigkeiten mit sich bringt. Um herauszufinden, dass man seine Zähne putzt und seltener bürstet, seine Schnürsenkel bindet und eigentlich niemals knotet usw., müssen Lernende mal zum Duden Band 11, mal zum Band 2 (Das Stilwörterbuch. Grundlegend für gutes Deutsch. Idiomatisches Deutsch; Chiaro 2001) oder aber zum Deutschen Universalwörterbuch greifen.

Das immer noch beste Werk für den DaF-Bereich dürfte Hesskys und Ettingers Wörter- und Übungsbuch Deutsche Redewendungen sein (vgl. Staudacher 1997). Hier findet man 1400 Phraseologismen, die auf lernerfreundliche Weise onomasiologisch sortiert sind. D.h., dass die Suchenden dort unter dem Schlüsselbegriff „,wütend sein“ übertragene Wendungen wie an die Decke gehen oder jmdm. platæt der Kragen finden. Im Übungsteil kann man in konventionellen Einsetzübungen auf etwa 50 Seiten überprüfen, inwiefern man seine Kompetenz auf dem Gebiet der idiomatischen Wendungen erweitert hat.

\section{Phraseodidaktische Übungsformen}

Ein mittlerweile gängiger Klassiker der Phraseodidaktik ist der so genannte phraseodidaktische Vierschritt, 1992 von Kühn noch als Dreischritt entworfen und 1997 von Lüger um die Festigungsphase erweitert. Der Vierschritt umfasst folgende Phasen:

- Erkennen

- Entschlüsseln

- Festigen

- Verwenden

Damit folgen diese Arbeitsschritte der in der Didaktik gängigen induktiven Vermittlung, bei der Lernende die Regelhaftigkeit bestimmter Phänomene aus einem Einzelbeispiel ableiten sollen.

Die aktive Verwendung zahlreicher Phraseologismen ist nicht immer ratsam. Dies betrifft vor allem satzwertige Phraseologismen wie Sprichwörter oder geflügelte Worte. Sie sollten von Lernenden erkannt, nicht aber zwingend benutzt werden. Die Vermittlung der Erkennungsmerkmale ist anzustreben. Hohe kommunikative Dringlichkeit ha- 
ben jedoch bereits im Anfängerunterricht die Routineformeln (vgl. Lüger 1997: 91). Sie dienen mit ihrem hohen Grad an Reproduzierbarkeit der Gesprächssteuerung, der Organisation des Sprecherwechsels, der Intensivierung oder Abschwächung, insgesamt also dazu, ,rekurrente kommunikative Aufgaben primär sozialer Natur auf vorgeprägte Weise zu bewältigen“" (Stein 2004: 270). Es gibt Dankes-, Gruß-, Beileids- oder Entschuldigungsformeln und ähnlich wie Partikeln lassen sich mit Routineformeln Sprechereinstellungen intensivieren oder abschwächen. Dazu gehören bereits themenorganisierende Verbindungen wie ich meine, um auf ... zurück.zukommen, wenn ich mal sagen darf oder dialektal ich sag' mal (immer mit Ach-Laut realisiert).

Wie für Erläuterungen und Übungen zu Phonetik gilt auch für die Vermittlung von Phraseologismen, dass man Einzelstunden mit deren alleiniger Thematisierung vermeiden sollte. Generell mögliche Übungsformen wären beispielsweise eine kleine Geschichte zum Phraseologismus zu erfinden, Phraseologismen Geschichten zuzuordnen oder in Dialogen andere Textstellen durch Phraseologismen zu ersetzen (Gündoğdu 2007: 17). Auch im Grammatik-Übungsbuch von Dreyer-Schmitt (2000: 322f.) findet man Einsetzübungen zu „Redensarten“, daneben sind auch Zuordnungsübungen oder Transformationsübungen denkbar. Gelegentlich aber nicht immer sinnvoll ist die Semantisierung durch Zeichnungen, die vor allem die Bildlichkeit der idiomatischen Phraseologismen erläutern soll. Bei folgendem Bild in Abb. 1 dürften sogar MuttersprachlerInnen Probleme haben, auf den richtigen Phraseologismus zu kommen:

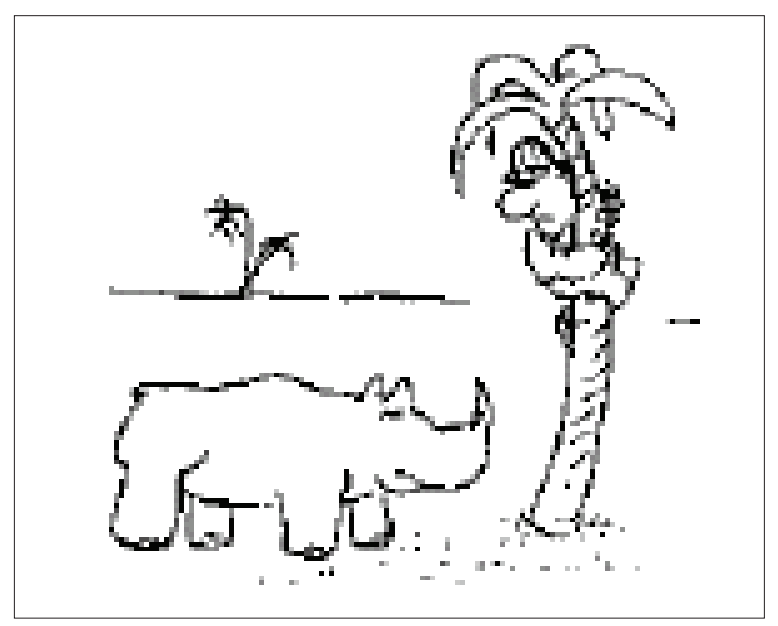

Abb. 1 nach Häussermann; Piepho 1996: 164

Veranschaulicht werden soll der voll-idiomatische Phraseologismus jmdn. auf die Palme bringen. Gleichzeitig wird jedoch einem mit dem Bedeutungsinhalt nicht Vertrauten suggeriert, dass die Wendung etwas mit Angst zu tun haben könnte, die jemanden zur Flucht auf einen Baum treibt. Die Bedeutung ist jedoch mit ,jmdn. wütend machen“ (Altsleben; Scholze-Stubenrecht 2002: 563) korrekt paraphrasiert. Problematisch ist an dieser Wendung der fehlende Grad an Bildkräftigkeit (vgl. Burger 2007: 98). Die 
Verknüpfung zwischen Ausdruck und Inhalt ist völlig arbiträr, ein etymologischer Zusammenhang kann auch von MuttersprachlerInnen selten hergestellt werden. Dies ist nicht bei allen Phraseologismen so. Nach einigem Nachdenken und in kontextueller Einbettung kann man die Bedeutung etwa von das fünfte Rad am Wagen sein oder Öl ins Feuer gießen herleiten, da ein fünftes Rad am Wagen selten sinnvoll ist und man sich ohne große Vorstellungskraft ausmalen kann, was passiert, wenn man Öl in ein Feuer gießt. Bei diesen bildkräftigen Ausdrücken ist eine Semantisierung durch Zeichnungen einleuchtender, andererseits auch oftmals überflüssig.

\section{Phraseologismen in Literatur - Beispiele mit Didaktisierungsvorschlägen}

In den folgenden literarischen Texten, vornehmlich aus der Lyrik stammend, werden Beispiele herangezogen, die sowohl für den Anfänger- als auch für den Fortgeschrittenenunterricht angemessen sind. Phraseologismen erlauben eine Thematisierung vom A1- bis zum C2-Niveau des Europäischen Referenzrahmens. Neben den genannten Arbeitsvorschlägen, die ausschließlich auf Phraseodidaktik abzielen, sind natürlich auch andere Herangehensweisen an die Texte möglich. Die Stunden füllende Auseinandersetzung mit Phraseologismen ist zu vermeiden. Das Einstreuen phraseologischer Lesarten bei der Lektüre ist durchaus sinnvoll und interpretationsentfaltend. Das Gedicht von Cöster kann man bereits in einer A2-Stufe lesen und mit entsprechenden Aufgabenstellungen bearbeiten:

I. Oskar Cöster - Unverbindliches

So-so, aha, alsdann nur Mut, hört-hört, das ist nicht schlecht, jawohl, sehr wahr, ja-ja, gut-gut, wer weiß, sieh an, ganz recht. [...]

Wie spannend, toll, ich halt's nicht aus, wen juckt das, und so fort, sei froh und lach, du lieber Graus, bei Gott, ein wahres Wort.

Da liegst du richtig, Zeit ist Geld, das leuchtet ein, ja eben, das ist nun mal der Lauf der Welt, so ist das halt im Leben.

(Cöster 1979: 12)

Das Bemerkenswerte ist, dass dieses Gedicht - dessen Poetizitätsgehalt sicherlich für einige fraglich ist, was in einem höheren Niveau zur Diskussion gestellt werden könnte - vornehmlich aus Gesprächspartikeln besteht, die eine phatische Funktion erfüllen, also der Aufrechterhaltung der Kommunikation dienen. Es finden sich zahlreiche Routineformeln (ich balt's nicht aus, und so fort, bei Gott) und Gemeinplätze (,so ist das halt im Leben"), die einen hohen Grad an Festigkeit und kommunikativer Reproduzierbarkeit 
aufweisen, darunter auch das von Benjamin Franklin, geflügelte Wort time is money, ,Zeit ist Geld“. Aber die alleinige Häufung dieser Formeln bringt nun noch lange keinen kommunikativen Austausch zustande. Mögliche Fragestellungen wären daher:

- Warum ist dies kein richtiges Gespräch? Was fehlt?

- Wann benutzen Sie diese Redemittel?

- Schreiben Sie einen Dialog zwischen zwei Personen! Benutzen Sie dabei möglichst viele der genannten Wendungen.

Der themenentfaltende Impetus von Phraseologismen kommt in folgendem Gedicht zum Tragen. Hier werden zwei Kinegramme verwendet, also Phraseologismen, die eine nonverbale Geste enthalten und konventionalisiert mit einem bestimmten Inhalt verknüpft ist, z.B. mit den Achseln zucken oder die Stirn runz̧eln.

II. Manfred Hausin - mit offenem mund

seitdem ich

mit offenen augen

und ohren

durch dieses land gehe

krieg ich

den mund nicht mehr zu

(nach Mieder 1992a: 75)

Das Gedicht bringt den Erfahrungswert zum Ausdruck, dass bewusste Wahrnehmung der Außenwelt zu einem Perspektivwechsel der Innenwelt führen kann. Verknüpft sind die beiden Kinegramme dadurch, dass sie im Kern ein Substantiv enthalten, das mit einem Sinn assoziiert wird und der Instanz subjektive Innenwelt oder Außenwelt zugeordnet werden kann: Augen $=$ Wahrnehmung $=$ subjektive Innenwelt dagegen Mund $=$ Kommunikation $=$ Kontakt zur Außenwelt. Die normierte Wendung jmdm. gehen die Augen auf mit der Bedeutungsparaphrase ,jimd. durchschaut plötzlich einen Sachverhalt, erkennt Zusammenhänge, die er vorher nicht gesehen hatte“ (DUW 2007: 204) unterstreicht den prozessualen Charakter der Erkenntnisgewinnung, der das Angleichen der Diskrepanz zwischen Ich und Welt zum Ziel hat. Im Gedicht ist die Wendung modifiziert. Der Prozess wird als abgeschlossen dargestellt, die Augen sind bereits geöffnet. Die Konfrontation von Ich und Welt, die Lyrik seit alters her beschäftigt hat, schlägt sich sprachlich durch das suggestive Kinegramm den Mund nicht mehr zukriegen nieder. Dass es wahrscheinlich soziale Missstände sind, die diesen Zustand des Erstaunens beim lyrischen Ich hervorrufen, müssen sich Lernende zunächst erarbeiten, indem sie den konnotativen Nebensinn interpretatorisch entschlüsseln. Dazu hinleitende Fragen an die Lernenden könnten lauten:

- Worüber könnte das lyrische Ich erstaunt sein?

- Finden Sie eine Situation, in der die Äußerung stattfinden könnte.

- Wann keriegen Sie den Mund nicht mehr zu?

- Was könnte das lyrische Ich dazu gebracht haben, die Augen zu öffnen? 
- Was ist der Unterschied zwischen dem verwendeten Ausdruck und Wendungen wie jmdm. die Augen öffnen (Altsleben; Scholze-Stubbenrecht 2002: 71) oder jmdm. gehen die Augen auf (DUW 2007: 204)?

Das bekannte und auch in der Anthologie Prisma (Tütken 2002: 746) vertretene Gedicht alles für die katz, beginnt Franz Mon mit zwei abgesehen von konsequenter Kleinschreibung nicht modifizierten Phraseologismen. In den weiteren Versen wird in einem für konkrete Lyrik üblichen Permutationsspiel das Substantiv eines Phraseologismus durch das Wort katze ersetzt. Selbst für MuttersprachlerInnen bedarf es einigen Nachdenkens, welcher Phraseologismus ursprünglich gemeint ist.

III. Franz Mon - alles für die katz

die katze aus dem sack lassen

die katze, die sich in den schwanz beißt

die katze steht auf sturm

die katze im wasserglas

die katze hat sich gelegt

die katze hat sich gedreht

sich die katze um die ohren wehen lassen

wie von der katze getroffen $[\ldots]$

(Mon 1981: 139)

Um den Umgang mit in den Unterricht mitgebrachten Nachschlagewerken zu üben, kann man die Lernenden zu deren Verwendung anhalten.

- Wie lauten die Phraseologismen in der ursprünglichen Form?

- Wann werden sie verwendet? Geben Sie ein Beispiel in einem ganzen Satz mit kontextueller Einbettung!

- Welches Substantiv wurde durch „katze“ ersetzt?

Ebenso themenentfaltend ist die Routineformel meine Damen und Herren im Gedicht börprobe von Ernst Jandl. Die ganze Struktur des Gedichtes ist von dem Phraseologismus bestimmt, auf dessen nicht modifizierte Verwendung es hinausläuft. Wegen des geringen zu vermittelnden Wortschatzes ist es bereits in einer Anfängergruppe angemessen.

IV. Ernst Jandl - hörprobe

1

höherhören

höherhören

höherhören

höherhören

höherhören

höherhören

höherhören

höherhören

höherhören

höherhören 


\begin{abstract}
2
höhere hören

und daumen

höhere daumen

und hören

höhere hören

und höhere daumen

meine höheren daumen

meine höheren hören

3

kennen sie mich herren

kennen sie mich herren

kennen sie mich herren

meine damen und herren
\end{abstract}

(Jandl 1997: 37)

Durch die Kommutation bestimmter Vokale, meist „e“ und „o““, entstehen wiederum andere Wörter, die allesamt im deutschen Sprachsystem vorhanden sind, ein Vorgang, der für experimentelle Lyrik nicht zwingend gegeben sein muss, wenn wir uns etwa „Kroklokwafzi“ in Morgensterns berühmtem Das große Lalula oder ,,jolifanto bambla“ in Balls nicht minder bekannter Karawane anschauen. Jandl zieht es vor, Formulierungen zu erzeugen, die aus existierenden Lexemen bestehen, in ihrer syntagmatischen Reihung indes keinen Sinn geben. Die Lernenden könnten aber durch spielerisches Umgehen mit dem Text die eigentlich gemeinten Wörter herausfinden und so das Lautgedicht zu einem semantisch sinnvollen, poetisch natürlich unspektakulären Text machen. Lässt man bei einer ersten Präsentation des Gedichtes den Titel weg, so ließen sich folgende Aufgaben bearbeiten:

- Wie könnte der Titel des Gedichtes lauten?

- Welche Vokale werden durch andere ersetzt?

- Wie würde der Text ,richtig“ lauten?

- Wann benutzen Sie die Formeln aus dem Gedicht „höhere Herren und Damen“ „meine Damen und Herren“?

'Typisch für Grass’ Danziger Trilogie ist der assoziative Gebrauch von Phraseologismen, der an manchen Stellen wie ein phraseologischer Flickenteppich wirkt (vgl. Schweizer 1978, Burger 2007: 19). Oftmals verwendet er das Stilmittel der Remotivierung, wobei ein Phraseologismus, seiner übertragenen Bedeutung beraubt, wörtlich gelesen wird und kontextuell so eingebettet wird, dass die freien Lexeme ihre ursprüngliche Bedeutung erhalten (vgl. Preußer 2005: 66). Bei okkasionellen Modifikationen muss der Autor natürlich stets beachten, dass er nur so viele Komponenten ersetzt, dass der ursprüngliche Phraseologismus von den Lesenden noch erkannt werden kann. Zur Veranschaulichung ein Ausschnitt aus Die Blechtrommel: 


\section{Günter Grass - Die Blechtrommel (Erstes Buch - Die Tribüne)}

„Die Trommel lag mir schon maßgerecht. Himmlisch locker ließ ich die Knüppel in meinen Händen spielen und legte mit Zärtlichkeit in den Handgelenken einen kunstreichen, heiteren Walzertakt auf mein Blech. [...] Schon wollte Oskar verzweifeln, da ging den Fanfaren ein Lichtchen auf, und die Querpfeifen, oh Donau, pfiffen so blau. [...] Die hatten natürlich keine Ahnung von Charleston und ,Jimmy the Tiger'. Die schlugen nicht Jimmy und Tiger, die hämmerten Kraut und Rüben, die bliesen mit Fanfaren Sodom und Gomorrha. Da dachten die Querpfeifen sich, gehupft wie gesprungen. Da schimpfte der Fanfarenzugführer Krethi und Plethi. Aber dennoch trommelten und pfiffen, trompeteten die Jungs vom Fanfarenzug und Spielmannszug auf Teufel komm raus, daß es Jimmy eine Wonne war. [...] Er [der SA-Funktionär Löbsack] aber - und das riet ihm sein Buckel - tanzte dennoch, wollte gute Miene zur bösen Jimmymusik machen und retten, was noch zu retten war."

(Grass 1959: 111f., Hervorhebung NB)

Diese Textstelle entbehrte ihrer Literarizität und ihrer Anspielungskraft, wenn statt der Phraseologismen gleichbedeutende freie Lexemverbindungen verwendet würden. Für Lernende wäre es interessant, diese Probe aufs Exempel einmal anzustellen. Ähnlich wie in Brueghels d.Ä. Redensartenbild wird die Stumpfheit der Gesellschaft durch ihr stereotypes weil durch die Expressivität der Phraseologismen hyperbolisch ausgedrücktes Verhalten vom Erzähler kompromittiert. Dies herauszukristallisieren ist wegen Grass' komplexer Sprachverwendung und dem Zusammenhang der Geschichte des Nationalsozialismus mit dem Inhalt des Buches für eine fortgeschrittene Lernergruppe geeignet. Einerseits könnte auch hier der Umgang mit Nachschlagewerken geübt werden. Dabei und auch bei Mons Gedicht ließe sich das von Lüger vorgeschlagene Arbeitsblatt anwenden (Abb. 2), bei dem Lernende den Verwendungszusammenhang, die Bedeutungsangaben, Varianten und eventuelle muttersprachliche Entsprechungen ausfüllen sollen.

Andererseits bietet sich eine ausgeweitete Diskussion zwischen Phraseologismenverwendung und Grass' Autorintention an, was durch folgende Fragen angeleitet werden kann:

- Welche Wendungen werden verändert, welche sind korrekt verwendet? Welche Komponenten werden ersetzt?

- Wie können Sie die kursivierten Textstellen in eigenen Worten (freier Lexemverbindung) formulieren?

- Wie wird das Verhalten der Gesellschaft durch die verwendeten Phraseologismen ausgedrückt? In welches Licht wird es gerückt?

Dies waren nur einige Beispiele zur Verknüpfung von Phraseodidaktik mit literarischen Texten. Die Terminologie der Phraseologie kann maßvoll eingesetzt werden. Daher wurde in den Aufgabenstellungen meist die linguistisch nicht exakte Bezeichnung „Wendung“ dem Terminus „Phraseologismus“ vorgezogen. Dass sich der multifaktorielle Gebrauch von Phraseologismen bei einer Vielzahl von Autorinnen und Autoren jeweils auf eigene Weise interpretatorisch zuordnen lässt, kann an der umfangreichen 


\section{Arbeitsblatt zu Phraseologismen:}

Grundform: $\quad$ Klassifizierung:

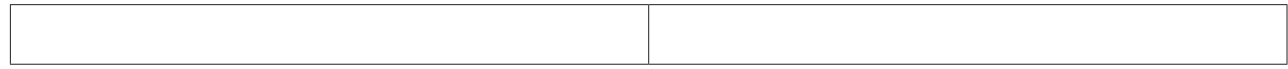

Varianten: morphosyntaktische Restriktionen:

\begin{tabular}{|l|l|}
\hline & \\
\hline
\end{tabular}

Kontext: $\quad$ Gebrauchsbedingungen:

wer? zu wem? wann? wo?

mit welcher Absicht?

\begin{tabular}{|l|l|}
\hline & \\
\hline
\end{tabular}

Bedeutungsangabe, Paraphrase: muttersprachliche Entsprechungen, Umschreibungen:

Oberbegriff, bedeutungsähnliche Aus- historische o.a. Erklärung: drücke

\begin{tabular}{|l|l|}
\hline & \\
\hline
\end{tabular}

Abb. 2 nach Lüger 1997: 125f. 
Literatur belegt werden. Hier einige Beispiele von literarischen Texten und der phraseologisch-interpretatorischen Herangehensweise: Elfriede Jelinek (Glenk 2000), Christian Morgenstern (Palm 1987), Arno Schmidt (Preußer 2007) sowie schließlich Friedrich Dürrenmatt (Mitrache 1999). Die häufigsten Funktionszuordnungen lauten in den genannten Analysen: Sprachporträt der Romanfiguren, Evozierung von Komik, Themenentfaltung, Herstellung der Authentizität durch fiktive Mündlichkeit, Sprach- und Gesellschaftskritik sowie die archivierende Funktion kanonisch randständiger Literatur durch die Anführung von geflügelten Worten.

Phraseologie ist aber nicht nur für literarische Texte, sondern auch für Werbungstexte, Zeitungskommentare, Filmbeschreibungen oder Horoskope charakteristisch, die Wichtigkeit der Vermittlung also auch dadurch belegbar. Auch mit dem Medium Film kann man Phraseodidaktik auf sehr ansprechende Weise gestalten. Loriots Beiträge wären hierfür ein Paradebeispiel. In Sketchen wie die Bundestagsrede oder Internationaler Frühschoppen entlarvt er die Hochgestochenheit von Routineformeln und Gemeinplätzen, deren elaboriert wirkender Zug nicht darüber hinwegtäuschen kann, dass die Akteure sich nichts zu sagen haben, einander nicht zuhören können oder aber ihre Inhalte nicht vermitteln können. Dies lässt sich bedauerlicherweise auf viele Politikerinnen und Politiker übertragen.

\section{Das/Ein phraseologisches Optimum?}

Um herauszufinden, welche Phraseologismen am häufigsten verwendet werden, gibt es verschiedene Ansätze, ein phraseologisches Minimum oder Optimum zu erstellen. Die Schwierigkeiten bei der Erstellung einer einigermaßen verlässlichen Frequenzliste sind mit dem hohen Arbeitsaufwand und dem hohen Bedarf an finanziellen Mitteln verbunden. Sehr einfach, sicherlich aber auch empirisch fragwürdig wenn nicht gar vermessen, ist es, sich auf das eigene Sprachgefühl und die hoffentlich exakte eigene linguistische Intuition zu berufen. Dabei kommen die interessantesten und oftmals stark voneinander abweichenden Ergebnisse von Idiomsammlungen mit den angeblich frequentesten Idiomen heraus. Dennoch ist die eigene linguistische Intuition notwendig, um das phraseologische Ausgangsmaterial herauszuarbeiten, das man bei Befragungen vorlegt. Eine Korpusanalyse ist verlässlicher, ist aber nur an geschriebener nicht an gesprochener Sprache belegbar. Sehr probat und gleichzeitig sehr aufwändig ist die Kombination aus Korpusanalyse und Informantenbefragung.

Der Schwerpunkt der DaF-Lehrwerke liegt immer noch bei Sprichwörtern (vgl. Köster 1998: 113) und somit in einem Grenzbereich der Phraseologie. Auch hier gibt es weit auseinander liegende Feststellungen, welche Sprichwörter zu den bekanntesten gehören. Baur; Chlosta (1996: 22) etwa zählen zu den bekanntesten Sprichwörtern, von denen hier nur die ersten zehn angeführt sein sollen, die folgenden: 
1. Wer A sagt, muss auch B sagen.

2. Man ist so alt, wie man sich fühlt.

3. Aller Anfang ist schwer.

4. Der Apfel fällt nicht weit vom Stamm

5. Erst die Arbeit, dann das Vergnügen.

6. Aufgeschoben ist nicht aufgehoben.

7. Ausnahmen bestätigen die Regel

8. Doppelt hält besser.

9. Wie du mir, so ich dir.

10. Eigenlob stinkt.

Mieder (1992b: 16) zitiert eine andere Erhebung von einem Meinungsforschungsinstitut, in dem andere Sprichwörter enthalten sind. Dort liest man:

1. Morgenstund hat Gold im Mund.

2. Wer andern eine Grube gräbt.

3. Zeit ist Geld.

4. Ohne Fleiß kein Preis.

5. Sicher ist sicher.

6. Die dümmsten Bauern haben die dicksten Kartoffeln.

7. Abends (Am Abend) wird der Faule fleißig.

8. Lügen haben kurze Beine.

9. Reden ist Silber, Schweigen ist Gold.

10. Kommt Zeit, kommt Rat.

Daneben gibt es außerdem den interessanten Forschungsaspekt, der die weit verbreiteten Idiome (widespread idioms) erforscht, also Idiome, die man in möglichst vielen Sprachen nachweisen kann. Beispiele findet man in Mieder (2002: 218) oder dem von der Europäischen Gesellschaft für Phraseologie und von Elisabeth Piirainen angeführten und noch laufenden und zur Teilnahme anregenden Projekt der „Widespread Idioms in Europe and Beyond“" (http://www.piirainen.homepage.t-online.de), wo man nicht allein die Belegzahlen sondern auch die jeweiligen Entsprechungen in den verschiedenen Sprachen finden kann.

Nicht das Optimum von Sprichwörterm, sondern das von idiomatischen Phraseologismen zu erforschen, haben sich Hallsteinsdóttir, Šajánková und Quasthoff (2006) zum Ziel gemacht. Zunächst suchten sie anhand von Nachschlagewerken (etwa dem Übungsbuch von Hessky; Ettinger) und dem Korpus der Universität Leipzig 1112 deutsche Phraseologismen heraus, die sie Informanten vorlegten. Dabei kamen sie zu einem phraseologischen Optimum von 143 empirisch belegbaren Phraseologismen, die sowohl hohe Frequenz als auch hohe Geläufigkeit aufweisen. Eine kleine Auswahl daraus lautet: 
- jmdm. eine Abfuhr erteilen

- am Ball bleiben/sein

- etw. über die Bühne bringen

- unter Dach und Fach sein

- jmdn. um die Ecke bringen

- in die Hose gehen

- jmdm. zur Last fallen

- jmdn. zur Rede stellen

- das Weite suchen

- jmdn. beim Wort nehmen

(vgl. Hallsteinsdóttir; Šajánková; Quasthoff 2006)

Die Schwierigkeiten für Lernende offenbaren sich am augenfälligsten, wenn man sich mit hoffentlich nicht allzu geringer Frustrationstoleranz einmal vergegenwärtigt, welche der aus dem phrasologischen Optimum stammenden idiomatischen Phraseologismen oder der weit verbreiteten Idiome man selbst in einer Fremdsprache beherrscht. Mit den Vorschlägen von Hallsteinsdóttir, Šajánková und Quasthoff hat man aber in jedem Fall einen leicht zugänglichen, umfangreichen Kernbereich an empirisch belegbaren Phraseologismen mit hoher Vorkommenshäufigkeit vorliegen, der Lehrenden in der Phraseodidaktik zur Orientierung dienen kann.

\section{Literatur}

Altsleben, Brigitte; Werner Scholze-Stubenrecht (Hrsg.) (2002): Redewendungen. Wörterbuch der deutschen Idiomatik. Duden Bd. 11 (2., neu bearb. und akt. Aufl.). Mannheim u.a.: Duden.

Baur, Rupprecht S.; Chlosta, Christoph (1996): Welche Übung macht den Meister? Von der Sprichwortforschung zur Sprichwortdidaktik. In: Fremdsprache Deutsch 15, 17-24.

Burger, Harald (2007): Phraseologie. Eine Einführung am Beispiel des Deutschen. 3., neu bearb. Aufl. Berlin: Erich Schmidt.

Burger, Harald; Buhofer, Annelies; Sialm, Ambros (1982): Handbuch der Phraseologie. Berlin; New York: de Gruyter.

Chiaro, Maria Grazia (Hrsg.) (2001): Das Stilwörterbuch. Grundlegend für gutes Deutsch. Idiomatisches Deutsch. Duden Bd. 2 (8., völlig neu bearb. Aufl.). Mannheim u.a.: Duden.

Cöster, Oskar (1979): Kämpfe mit Engeln. Gedichte. Berlin: Fietkau.

Deutsches Universalwörterbuch (2007). Hrsg. von der Dudenredaktion. 6., überarb. und erw. Aufl. Mannheim u.a.: Duden.

Dreyer, Hilke; Schmitt, Richard (2000): Lehr- und Übungsbuch der deutschen Grammatik. Ismaning: Hueber.

Glenk, Eva Maria Ferreira (2000): Die Funktion der Sprichwörter im Text. Eine linguistische Untersuchung anhand von Texten aus Elfriede Jelineks Werken. Wien: Edition Praesens.

Grass, Günter (1959): Die Blechtrommel. Neuwied; Berlin: Luchterhand.

Gündoğdu, Mehmet (2007): Die Behandlung von Phraseologismen im Unterricht Deutsch als Fremd- und Zweitsprache. In: Deutsch als Zweitsprache 2, 11-18. 
Häussermann, Ulrich; Piepho, Hans Eberhard (1996): Aufgaben-Handbuch Deutsch alsFremdsprache. München: Iudicium.

Hallsteinsdóttir, Erla; Šajánková, Monika; Quasthoff, Uwe (2006): Phraseologisches Optimum für Deutsch als Fremdsprache. Ein Vorschlag auf der Basis von Frequenz- und Geläufigkeitsuntersuchungen. In: Linguistik online 27 (http:/ / www.linguistik-online.de/27_06/index.html, 12.12.2009).

Hessky, Regina; Ettinger, Stefan (1997): Deutsche Redewendungen. Ein Wörter- und Übungsbuch für Fortgeschrittene. Tübingen: Narr.

Jandl, Ernst (1997): Poetische Werke. Sprechblasen. Verstreute Gedichte. Bd. 3. Hrsg. von Klaus Siblewski. München: Luchterhand.

Köster, Lutz (1998): Phraseolexeme in Horoskopen. Funktionale Analyse und didaktische Potenz dieser Textsorte für die Vermittlung von Deutsch als Fremdsprache. In: Wirrer, Jan (Hrsg.): Phraseologismen in Text und Kontext. Bielefeld: Aisthesis, 97-120.

Kühn, Peter (1992): Phraseodidaktik. Entwicklungen, Probleme und Überlegungen für den Muttersprachenunterricht und den Unterricht DaF. In: Fremdsprachen lehren und lernen 2, 169-189.

Lüger, Heinz-Helmut (1997): Anregungen zur Phraseodidaktik. In: Beiträge zur Fremdsprachenvermittlung 32, 69-120.

Mieder, Wolfgang (Hrsg.) (1992a): „Deutsch reden“. Moderne Redensartengedichte von Rose Ausländer bis Yaak Karsunke. Frankfurt a.M.: Fischer.

Mieder, Wolfgang (1992b): Sprichwort - Wabrwort?? Studien zur Geschichte, Bedeutung und Funktion deutscher Sprichwörter. Frankfurt a.M.: Lang.

Mieder, Wolfgang (2002): Sprichwort. In: Hilzinger, Sonja u.a. (Hrsg.): Kleine literarische Formen in Einzeldarstellungen. Stuttgart: Reclam, 211-240.

Mitrache, Liliana (1999): Intertextualität und Phraseologie in den drei Versionen der „Panne “von Friedrich Dürrenmatt. Aspekte von Groteske und Ironie. Uppsala: Uppsala University.

Mon, Franz (1997): Gesammelte Texte 4. Poetische Texte 1971-1982. Berlin: Janus Press.

Palm, Christine (1987): Christian Morgensterns groteske Phraseologie - Ein Beitrag zur Rolle der Phraseologismen im literarischen Text. In: Korhonen, Jarmo (Hrsg.): Beiträge zur allgemeinen und germanistischen Phraseologieforschung. Internationales Symposium in Oulu, 13. - 15. Juni 1986. Oulu: Oulun Yliopisto, 221-235.

Preußer, Ulrike (2005): „Das ist ein weites Feld... “Phraseologismen in der Literatur des Deutschunterrichts. In: Der Deutschunterricht 5/57, 62-71.

Preußer, Ulrike (2007): Aufbruch aus dem beschädigten Leben. Die Verwendung von Phraseologismen im literarischen Text am Beispiel von Arno Schmidts Nobodaddy's Kinder. Bielefeld: Aisthesis.

Röhrich, Lutz (1991): Das große Lexikon der sprichwörtlichen Redensarten. Freiburg u.a.: Herder.

Schweizer, Blanche-Marie (1978): Sprachspiel mit Idiomen. Eine Untersuchung am Prosawerk von Günter Grass. Zürich: Juris. 
Staudacher, Jochen (1997): Regina Hessky/Stefan Ettinger: Deutsche Redewendungen. Ein Wörter- und Übungsbuch für Fortgeschrittene. Tübingen: Narr, 1997. [Rezension] In: Beiträge zur Fremdsprachenvermittlung 32, 131-134.

Stein, Stephan (2004): Formelhaftigkeit in Routinen in mündlicher Kommunikation. In: Steyer, Kathrin (Hrsg.): Wortverbindungen - mehr oder weniger fest. Berlin; New York: de Gruyter, 262-288.

Tütken, Gisela (Hrsg.) (2002): Prisma. Begegnung mit Deutschland im Spiegel deutschsprachiger Gegenwartsliteratur. Literarische Texte für den DaF-Unterricht. Regensburg: Fachverband Deutsch als Fremdsprache. 


\section{Uwe Koreik \& Martin Lange \& Timo van Treeck}

\section{Themenschwerpunkt Mediengestütztes Lernen, Bericht}

Seit Jahrzehnten versprechen neue Medien (wie z.B. das Sprachlabor) eine Revolution des Sprachenlernens, Effizienzsteigerung und Personalersparnis inklusive. Gehört „ELearning“ zu einem zeitgemäßen Fremdsprachenunterricht oder handelt es sich nur um einen weiteren Hype?

Im Themenschwerpunkt „Mediengestütztes Lernen“ ging es darum, Erfahrungen aus mediengestützten Unterrichtsprojekten zu präsentieren und reflektieren. Zum Bereich E-Learning im DaF-Unterricht wurden bevorzugt Beiträge herangezogen, die die Effizienz von multimedialem Selbstlernmaterial für Fremdsprachenlernende untersuchen und - nach Möglichkeit - dazu empirische Ergebnisse aufzeigen können.

Teilweise lebten die Beiträge vor allem von der Präsentation des jeweiligen Mediums selbst und seinem Einsatz in konkreten Lernzusammenhängen. In manchen Fällen ergab sich daher, dass keine vertiefende weiterführende Publikation in diesem Band erfolgt. Dies war der Fall in der Präsentation von Hans-Joachim Schulze/Thomas Stagneth, die über den Einsatz von Hörtexten und Videomaterial zu Lehr- und Prüfungszwecken an der Wirtschaftsuniversität Helsinki berichteten. U.a. wird das Medium zum Telefontraining genutzt und für die Leistungsbeurteilung herangezogen. Auch in der Darstellung von Makiko Hoshii (Waseda Universität, Tokyo) und Constanze Niederhaus (Humboldt-Universität, Berlin) zum Thema: „Deutschlernen und -lehren per Videokonferenz? Möglichkeiten und Grenzen" bildete das Medium die Message selbst: Die sicherlich faszinierenden Möglichkeiten, Studierende in Berlin und Tokyo über Kontinente hinweg per Videokonferenz nahezu in eine face-to-face Situation zu bringen, wurden sehr ausführlich durch mitgeschnittenes Filmmaterial dokumentiert. Dabei wurden jedoch auch Probleme der Unterrichtsorganisation deutlich, wie die gemeinsame Findung von Unterrichtszielen, die Nachbereitung oder die Beschränkungen der Möglichkeiten ergänzender E-Mail-Korrespondenzen durch die Zeitverschiebung zwischen beiden Ländern. Die Vielfalt neuer Einsatzmöglichkeiten elektronischer Medien kam schließlich auch im Beitrag von Joachim Quandt zum Ausdruck, der die von ihm begründete Lernplattform „DeutschLern.net“ vorstellte. Interessierte können dortselbst eine „Bauanleitung zu einer Web 2.0. - Lernumgebung“ nachvollziehen (vgl. www.deutschlern.net; Lehrkräfte finden neben Kurzanleitungen zu den Einsatzmöglichkeiten auch druckbare Handbücher, Lernende sehen, wie sie ihren eigenen Bedürfnissen entsprechende Übungen finden können).

Einige der vertretenden Autor/inn/en hatten mitgeteilt, dass ihr Beitrag anderweitig publiziert würde. In der nun folgenden Darstellung des Themenschwerpunktes werden die Namen derjenigen Autorinnen und Autoren im Fettdruck hervorgehoben, deren Beitrag Eingang in den vorliegenden Tagungsband gefunden haben. 
Eingangs des Tagungsverlaufs referierte Nicola Würffel (PH Heidelberg) über die „Nutzung der Potentiale von ,Social-Software-Anwendungen zur Unterstützung des kooperativen Schreibens bei Fremdsprachenlernenden sowie in der Fremdsprachenlehrerausbildung“. Sie zeigte, wie mit Hilfe sog. kooperativer Editorenprogramme (z.B. „Google Texte und Tabellen“) gemeinsames Schreiben von Texten initiiert und unterstützt werden kann. Es zeigt sich, dass die Technik hier tatsächlich neue Formen des Lernens ermöglichen bzw. Formen des kooperativen Lernens auf den Bereich des Schreibens ausgedehnt werden können.

Über die Ergebnisse einer Fallstudie zum Thema Blended Learning in Wirtschaftsdeutschkursen berichtete anschließend Carola Strobl (Universität Gent). Sie hob vor allem auf die Lernerperspektive ab, aus deren Blickwinkel Erfolg und Misserfolg der Medienunterstützung beurteilt wurden. Die Berurteilung des Zusammenspiels von Online- und Präsenzphasen wird u.a. durch technische Voraussetzungen bei der Lernumgebung, durch die eigene Medienkompetenz, aber auch durch den individuellen Sprachstand beeinflusst.

Karin Madlener (Humboldt Universität, Berlin) bezog anschließend bei ihrem Vortrag neuere Theorien der Lernpsychologie zum sog. „Chunking“ ein, der holistischen Verarbeitung von Sequenzen aus dem Input. In ihrem Beitrag „Multimedia-Chunks für DaF - ein E-Learning-Modul zur Entwicklung lexikogrammatischer Kompetenz“ stellte Sie anhand zweier Versuchsreihen (Berlin, St. Petersburg) vor, wie Lernende das Chunking als Lernstrategie nutzen und wie die gewonnenen Erkenntnisse über diese Art des Lernens im Rahmen mediengestützten Lernens Anwendung finden können.

Eines der jüngsten der sog. „neuen Medien“ ist das PodCasting, das im Zentrum zweier Vorträge stand: In einem gemeinsamen Beitrag stellten Sylwia AdamczakKrysztofowicz (Universität Poznań/Polen) und Antje Stork (Universität Marburg) die „Podcastgestützte integrative Hörverstehensentwicklung in universitären Sommerdeutschkursen“ vor. Anhand von Teilnehmerbefragungen bei vier universitären Sommersprachkursen entstand ein übergreifendes Bild der Lernerbedürfnisse für die Teilfertigkeit des Hörverstehens. Es wurde dargestellt, welche didaktischen Konsequenzen sich für das podcastgestützte Lernen ergeben und wo mögliche Grenzen des Mediums liegen. Noch weitgreifender im Ansatz war der Beitrag von Rüdiger Schreiber (ehemals Studienkolleg Münster) „Aktionsforschung zum Einsatz von Podcasts und mp3-Dateien als Interaktionsmedium zwischen Dozenten und Lernenden“, da hier sowohl die Verbesserung rezeptiver (Hörverstehen) als auch produktiver Fertigkeiten (mündlicher Ausdruck) als Ziel des Medieneinsatzes beschrieben werden. Der Kommunikation zwischen Lernenden und Lehrenden über das Medium von mp3-Dateien kommt in diesem Beitrag besondere Bedeutung zu. Schreiber nutzt dabei - wie zuvor Würffel und Strobl - beschreibende Verfahren der Aktionsforschung, für die auf früheren Jahrestagungen ein verstärkter Einsatz gefordert worden war (u.a. durch Riemer auf der Jahrestagung 2007).

Jörg Roche (LMU München) unterzog in seinem Beitrag „Klinisch getestet: Zu Erforschung und Evaluation von e-Mehrwerten“ den Stellenwert elektronisch gestützten 
Lernens ebenso einer kritischen Betrachtung wie auch der Plenarvortrag zum TSP 2 von Dietmar Rösler (Gießen) zum Thema „Deutsch als Fremdsprache mit digitalen Medien - Versuch einer Zwischenbilanz im Jahr 2008“, der insbesondere auf den Lernprozess und die Rollen der beteiligten Akteure einging. U.a. ging Rösler - wie eingangs Würffel - dabei auf ganz neue Formen des kooperativen Schreibens ein und konstantierte eine neue Dimension der Authentizität von Lernertexten.

Zum Abschluss des Themenschwerpunktes stellte Annika Große (Universität Islands, Reykjavik) Grundzüge eines Konzepts für ein Isländisch-Deutsches Projekt vor: „Interkulturelle Landeskunde online: Vorurteilen auf der Spur mit Hilfe von PodcastSendungen“. 



\section{Dietmar Rösler (Gießen)}

\section{Deutsch als Fremdsprache mit digitalen Medien - Versuch einer Zwischenbilanz im Jahr 2008}

\section{Vorbemerkung}

Diese Zwischenbilanz konzentriert sich auf die folgenden Bereiche: Auswirkungen der digitalen Distributionsweisen auf Fremdsprachenlernen und Lehrmaterialentwicklung, Veränderungen der Lehrwerkanalyse durch die Digitalisierung von Lehrmaterial, Veränderungen, die durch von Korpusanalyse und animierten Grammatikdarstellungen in das Fremdsprachenlernen hineingetragen werden könnten, Bedeutung von Online-Tutorierung und programmiertem Feedback, Kooperationen von individuellen Lernenden oder Gruppen von Lernenden mit digitalen Medien und Lernertexte für Lerner.

Letzteres, die Diskussion um Lernertexte für Lerner, ist m.E. zur Zeit eine der produktivsten Entwicklungen. Durch die Geschichte des Fremdsprachenunterrichts hindurch hat es immer wieder Ausbrüche aus dem traditionell eher durch Lehrer und Lehrmaterial bestimmten Unterricht mit dem Ziel gegeben, der inhaltlichen Selbstbestimmung $^{1}$ und den Mitteilungsabsichten der Lernenden mehr Raum zu geben bzw. diese seit der sog. kommunikativen Wende zumindest theoretisch ${ }^{2}$ zum Leitgedanken

1 Die Attraktivität eines Teils der sog. alternativen Methoden machte ja nicht zuletzt aus, dass diese den Mitteilungsabsichten und inhaltlichen Interessen der Lernenden absolute - und manchmal verabsolutierte - Vorfahrt vor Vermittlungsbemühungen zur Form einräumen, was unter dem Gesichtspunkt der möglichst optimalen Vermittlung der Fremdsprache insgesamt sowohl zu spannenden Neuerungen als auch zu durchaus nicht unproblematischen Nebenwirkungen führen kann (vgl. Rösler 1984: 139-180).

2 Dass zwischen dieser Absicht und dem Alltag der kommunikativen Lehrmaterialentwicklung und des kommunikativen Unterrichts manchmal größere Lücken klaffen, kann an dieser Stelle nicht weiter ausgeführt werden (vgl. dazu Rösler 2008). 
des Fremdsprachenlernens werden zu lassen. Durch die digitalen Medien scheint m.E. nun die Möglichkeit gegeben zu sein, der inhaltlichen Selbstbestimmung der Lernenden mehr Raum zur Verfügung zu stellen und damit die berühmte unhintergehbare Künstlichkeit des Fremdsprachenunterrichts doch ein klein wenig zu hintergehen.

\section{Auswirkungen der digitalen Distributionsweise: zielgruppengenaueres Lehrwerk on demand?}

Zunächst einmal ist beim Stichwort Distribution die triviale Tatsache festzuhalten, dass ein Text, den man als PDF-Datei verschickt, schneller und kostengünstiger beim Empfänger ankommt als ein dicker Briefumschlag. Entsprechend häufig findet man auf den Internet-Seiten von Verlagen herunterladbare Arbeitsblätter, MP3-Dateien o.ä. zu ihren Lehrwerken. ${ }^{3}$ Die darüber hinausgehende, unter lehrmaterialanalytischen Gesichtspunkten interessantere Frage ist die, ob einfach nur der Transport preisgünstiger wird oder ob auch im Hinblick auf die Qualität eines Lehrwerks ein Fortschritt zu verzeichnen ist. Wenn z.B. von Lehrenden oder Lernenden Audiodateien heruntergeladen werden, die es zwar auch als Kassette oder CD zu kaufen gibt, die aber an bestimmten Orten nicht gekauft wurden, dann ist das unter dem Gesichtspunkt der Betrachtung eines Lehrwerks als „Werk“ unerheblich, denn am Produkt selbst hat sich nichts verändert. Aber an den Orten, an denen nun Audiodateien verwendet werden, die bei anderer Distribution vorher nicht zum Einsatz kamen, besteht die Chance, dass sich die Qualität des Unterrichts verändert. ${ }^{4}$ Darüber hinaus könnten sich auch die Lehrwerke selbst ändern, wenn durch die digitalisierte Distribution nicht nur das Vorhandene schneller und preisgünstiger an die Lehrenden und Lernenden gebracht wird, sondern wenn über die digitale Distribution hinaus die schnellen Verbindungen dazu genutzt würden, Lehrwerke zielgruppen- und lernergenauer zu gestalten.

So könnten z.B. mehr und bessere Glossare und Lehrerhandbücher entstehen. Man stelle sich ein Lehrerhandbuch nicht als Buch zwischen zwei Deckeln sondern als Datenbank vor, in der sowohl Lehrer, die gerade anfangen zu unterrichten, als auch Lehrer, die mit einem Lehrwerk schon lange arbeiten und deshalb interessante Alternativen zur Routine brauchen, ${ }^{5}$ für sie geeignete ausführliche Erklärungen zur Arbeit mit einer Lektion, Erklärungen zum Text, Alternativen zur Arbeit mit diesem Text usw. finden. Und beim Stichwort Glossare zu einsprachigen, im deutschsprachigen Raum erstellten Lehrwerken kann man sich nicht nur vorstellen, dass es mehr von ihnen gibt zu Ausgangssprachen, für die es bisher noch keine Glossare gab, sondern vor allem, dass diese Glossare anders sind, dass sie nicht lediglich auf eingeschränktem Platz 1:1-Entsprechungen liefern, sondern auch Bildmaterial, Verweise auf Texte, in denen Wortschatz unterschiedlich verwendet wird, Verweise auf korpuslinguistische Recherchen zu einem Wort, Verbindungen zu interkulturellen Erklärungen, die die Grenzen von Wortschatzarbeit und Landeskunde verschwinden lassen usw. usf.

\footnotetext{
Vgl. als ein Beispiel von vielen: http://www.hueber.de/seite/downloads_daf (15.10.2010).

4 Das wäre also eine erfreuliche Nebenwirkung der andersartigen Distribution, ich weiß nicht, wie frequent dieses Phänomen ist, ich kenne es nur anekdotisch von Aussagen von Kollegen aus vom deutschsprachigen Raum weit entfernten Ländern.

5 Vgl. zu den verschiedenen möglichen Funktionen von Lehrerhandbüchern und ihrem Beitrag zur Adaption von Lehrmaterial an konkrete Lernergruppen Rösler (1984: 201-221).
} 
Erstellt werden könnten derartige Erweiterungen von bisher eher vernachlässigten Teilen von Lehrwerken dezentral, von regionalen Autoren-Teams, aber auch kooperativ in Ausbildungsseminaren von Lehrern, in Lehrerfortbildungen usw. In derartigen Kontexten sind schon immer Materialadaptionen vorgenommen, Ergänzungen und Hilfestellungen produziert worden usw., und danach sind sie in den Schubladen der Beteiligten als Kopien gelandet und vielleicht noch im unmittelbaren Umfeld verwendet worden. Da es nun technisch möglich ist, dezentral zu produzieren und zentral zu dokumentieren, könnte es auch didaktisch möglich sein, diese Vielfalt von Variationen zusammenzubringen zu einer komplexen Dokumentation von Lehrmaterial, die es jedem Nutzer an seinem Ort erlaubt, auf das jeweils zielgruppengenaueste Material zuzugreifen, bzw. auf das am wenigsten zielgruppenungenaue, und dann entsprechend daran weiterzuarbeiten, diese Überarbeitung evtl. wieder in die Datenbank einzugeben usw.

Wenn man sich Lehrwerke langfristig als aus Datenbanken generiert werdende Entitäten vorstellt ${ }^{6}$, könnte das gerade für das Fach Deutsch als Fremdsprache im Bereich der Lehrmaterialproduktion einen großen Fortschritt darstellen. Denn zu den Defiziten von Deutsch als Fremdsprache im Vergleich z.B. zu Englisch als Fremdsprache gehört es ja, dass Lerner in vielen Teilen der Welt abhängig davon sind, dass im deutschsprachigen Raum qualitativ hochwertige Lehrwerke produziert werden, die dann aber notgedrungen einsprachig ${ }^{7}$ sind und in bestimmten sprach- und kulturkontrastiven Aspekten und bezogen auf das Eingehen auf Lernerfahrungen notwendigerweise nicht zielgruppengenau sein können ${ }^{8}$.

Optimistisch gesehen könnten also die digitalen Kommunikationswege zu einer neuen Art von Produktion von Lehrmaterial führen, zur zielgruppengenaueren Produktion eines Lehrwerks on demand, das aus einer Datenbank generiert wird und das nicht nur bisher vernachlässigte Teile eines Lehrwerks verstärkt, sondern generell die Lehrwerkproduktion qualitativ verändert. Eine mögliche Vorstellung ist, dass man dabei mit einem Kern von didaktisch vielfach variiert dargestellten grammatischen Strukturen arbeitet, um den herum sich eine vielfältige lernerbezogene Peripherie bezogen auf unterschiedliche Themen, unterschiedliche Lernweisen usw. entwickelt.' Pessimistisch müsste man allerdings dagegenhalten, dass die neuen Distributionsmöglichkeiten auch dazu führen könnten, dass sich dominierende weltweit vertriebene einsprachige Lehrwerke noch schneller und intensiver verbreiten, dass es also zu einer Art Lehrwerk-Microsoft kommen könnte.

${ }_{6}$ Wobei es bei diesem Gedankengang zunächst einmal nicht darauf ankommt, ob man sich dabei ein lediglich digital vorhandenes Lehrwerk, ein Lehrwerk, dessen Teile ausgedruckt und gebunden an die Lernenden weitergegeben werden, oder Mischungen davon vorstellt. Das Datenbankkonzept zielt zunächst einmal nur darauf ab, zielgruppenangemessenere Vielfalt zu ermöglichen.

7 Abgesehen von Glossaren und einigen Versuchen, zweisprachige Arbeitsbücher hinzuzufügen, die aber die grundlegend einsprachige Ausrichtung dieser Lehrwerke nicht ändern.

8 Ein derartiges Lehrwerk ginge in seiner bunten Vielfalt weit über das Konzept der Regionalisierung von Lehrwerken aus den frühen 80er Jahren hinaus (vgl. z.B. Bochow; Schroedter-Albers 1981 oder Gerighausen; Seel 1984).

$9 \quad$ Vgl. dazu ausführlicher Rösler (2006a). 


\section{Auswirkung der Entwicklung von digitalem Material auf die Lehrwerkanalyse}

Die Digitalisierung von Lehrmaterial könnte zu einem Ende der Lehrwerkanalyse, wie man sie heute kennt, führen. Dieser Satz mag etwas dramatisch klingen, ist aber m.E. nicht ganz von der Hand zu weisen. Die Lehrwerkanalyse für DaF hat unterschiedlich produktive Phasen erlebt, nach Sternstunden mit den Mannheimer Gutachten, den Gutachten Deutsch für ausländische Arbeiter und den entsprechenden hitzigen Diskussionen $^{10}$ gab es längere „Ruhephasen“, in denen die Lehrwerkanalyse zwar ab und zu durch einige Arbeiten vorangetrieben wurde, sich im Alltag aber eher in einem mehr oder weniger entwickelten Rezensionswesen manifestierte. Zur Grundproblematik der Lehrwerkanalyse für $\mathrm{DaF}$ gehörte schon immer, dass es eine nicht unproblematische personelle Vermischung von Materialmachern und Kritikern gab. Dieses Phänomen ist lange bekannt, wie das folgende Zitat aus dem Jahre 1979 zeigt:

„Es gibt kein Lehrwerk, in dessen Impressum nicht auch die Namen derer zu finden sind, die auch an anderer Stelle an der fachdidaktischen Diskussion teilnehmen. Soll ein Kollege, der an einem Lehrwerk mitgearbeitet hat, das Lehrwerk, an dem ein anderer Kollege beteiligt ist, als fehlerhaft oder ungeeignet abqualifizieren? Das verstößt nicht nur gegen die ,guten Sitten“ im Umgang gebildeter Menschen; man würde auch riskieren, dass der Kollege hingeht und dasselbe tut.“ (Neuner 1979: 34)

An dieser Grundproblematik der Lehrwerkanalyse im Bereich DaF hat sich seither nichts verändert, unter Kontrolle zu halten ist sie nur durch größtmögliche Transparenz durch Offenlegung von Interessenkollisionen und größtmögliche Zurückhaltung der Materialmacher im Angesicht der Versuchung, bei Artikeln und Vorträgen über ein vermeintlich „,neutrales“ lehrwerkbezogenes Thema Werbung für ihr aktuelles Werk zu betreiben. Bezogen auf digitales Lehrmaterial ändert sich an dieser Grundproblematik nichts, solange es sich dabei nur um eine CD zu einem Lehrwerk handelt oder um eine frei zugängliche oder kostenpflichtige Seite mit Ergänzungen im Netz. Hinzu tritt im digitalen Kontext m.E. nun allerdings eine Veränderung, die die Lehrwerkanalyse, wie sie bisher betrieben wird, beendet: entweder findet sie in Zukunft nicht mehr statt oder sie erreicht eine neue Qualität.

Der Lehrwerkanalytiker aus den Zeiten von Deutsch aktiv ging in die Bibliothek oder die Buchhandlung, besorgte sich Bücher und Kassetten, später auch CDs, und analysierte los. Er betrieb zumeist Werkanalyse und keine empirisch fundierte Rezeptionsanalyse, was sicher zu bedauern war, aber er hatte immerhin seinen Analysegegenstand - das Werk - vollständig vor sich. Was ist aber das Äquivalent zum „Werk“ bei einem digitalen Lehrwerk? Wenn das digitale Lehrwerk ein ernst zu nehmendes Komplettangebot sein will, dann muss es beim jetzigen Stand der Entwicklung von programmiertem Material mit einer Tutorierungskomponente versehen sein, und die Qualität dieser Tutorierung sagt wahrscheinlich mehr über die Qualität des Gesamtangebots aus als die Qualität

10 Vgl. Kommission für Lehrwerke DaF (1978), Engel; Krumm; Wierlacher (1979), die heftigen Reaktionen auf die Mannheimer Gutachten in Heft 2/1978 der Zeitschrift Zielsprache Deutsch und Barkowski et al. (1986). 
einzelner Texte und Aufgaben. Wer also einen Online-Kurs als Lehrwerk analysieren will, kann sich nicht einfach nur das Material anschauen, er muss sehen, wie dieser Kurs tatsächlich abläuft.

Optimistisch betrachtet und positiv gewendet würde dies bedeuten, dass es in der Lehrwerkanalyse endlich zu empirischer Rezeptionsforschung kommen muss, die das Lehrwerk in Interaktion mit den Lernenden und Lehrenden betrachtet. Konsequent zu Ende gedacht hätte man es dabei sogar mit dem Ende der Lehrwerkanalyse durch die Aufhebung auf eine höhere Ebene zu tun. Da es sich bei der Analyse eines tutorierten Online-Werks in Aktion eigentlich um die Analyse dessen handelt, was als Äquivalent zum traditionellen Unterricht im Klassenzimmer zu betrachten ist, würde die Lehrmaterialanalyse aufgehen in empirische Unterrichtsforschung, die ja eigentlich auch immer die Interaktion von Lehrenden, Lernenden und Material zum Gegenstand hat, auch wenn die Rolle des Materials dabei nicht immer die ihr eigentlich gebührende Beachtung findet. So ein „Ende“, ein Ausbrechen aus dem selbstgewählten Getto des werkanalytischen Vorgehens ${ }^{11}$, wäre eine erfreuliche Weiterentwicklung der Lehrwerkanalyse, bei der die werkanalytischen Vorgehensweisen nicht verschwinden, sondern als notwendige Blicke auf Struktur, Themen usw. von Material in das rezeptionsanalytische Vorgehen integriert würden.

Pessimistisch, aber m.E. leider wohl nicht ganz unrealistisch betrachtet könnte das verstärkte Aufkommen von digitalen Kursen hingegen dazu führen, dass es überhaupt keine ernsthafte Lehrwerkanalyse mehr geben wird. Mein subjektiver Eindruck von Fachtagungen der letzten zehn Jahre ist, dass die entsprechenden Sektionen von mehr oder weniger offen als solchen deklarierten Präsentationen von Materialien, meist unter einer an die Fragestellung des Rahmenthemas angelehnten Thematik, dominiert wurden und kritische lehrmaterialanalytische Auseinandersetzungen in der Minderheit blieben. Diese Diskurshoheit der „Bastler“ ist vielleicht ein - notwendiges ${ }^{12}$ - Übergangsphänomen, es wird aber verschärft durch die Frage nach dem Zugang. Zugang erhält man bei Online-Kursen zu ausgewählten Probestücken, diese dienen der Werbung, nützen aber nichts für eine distanzierte Analyse. Wenn Lehrwerkanalyse im digitalen Zeitalter überleben soll, muss also nicht nur dafür gesorgt werden, dass die Präsentation von Online-Materialien durch die Produzenten auch klar als solche erkenntlich ist, sondern auch dafür, dass Zugänge zu den Kursen für Forscher, die nicht identisch mit den Machern sind, selbstverständlich sind, so dass eine Analyse der tatsächlichen Nutzungen von Online-Kursen möglich wird.

11 Aktuelle Versuche, Lehrmaterial in Aktion zu analysieren, beziehen sich auf die Analyse des Umgangs von Lernenden mit Selbstlernmaterial und zeigen, wie komplex und methodisch raffiniert man sich diese Wende der Lehrwerkanalyse vorzustellen hätte. Vgl. Schmidt (2007) oder Würffel (2006).

12 Um keine Missverständnisse aufkommen zu lassen: Es ist sehr wichtig und bei so komplexen Gegenständen wie digitalen Lehrmaterialien unbedingt notwendig, dass sich Macher austauschen, gute Ideen verallgemeinern und so weitgehend wie möglich kooperieren. Dazu bedarf es des Diskurses der Macher. Diese Diskussionen sind aber systematisch zu trennen von empirischen lehrwerkanalytischen Forschungen zu digitalem Lehrmaterial, so wie auch die Präsentation von traditionellem Print-Material auf Kongressen zu trennen ist und oft auch getrennt wird von lehrwerkanalytischen Vorträgen. 


\section{Interessante aktuelle Tendenzen: animierte Grammatik und Einbeziehung der Korpusanalyse}

Aus Platzgründen nur ganz kurz sollen in diesem Kapitel exemplarisch zwei ganz unterschiedliche Aspekte angesprochen werden, die zeigen, wie der Fremdsprachenvermittlung durch Digitalisierung neue Wege erschlossen werden können, die Frage nach der Relevanz animierter Grammatik und die nach der Reichweite der Einbeziehung der Korpusanalyse.

\subsection{Animierte Grammatik}

Wenn man auf die Entwicklung von Lehrwerken zurückblickt, lässt sich feststellen, dass im Laufe der Zeit verstärkt versucht worden ist, mit Visualisierungen zu arbeiten, die den Lernenden das Verstehen erleichtern sollen (vgl. die Beispiele in Funk; König 1991). Wenn man sich hingegen die ersten Grammatikdarstellungen im Netz anschaut, blickt man meist auf Bleiwüsten, auf kopierte komprimierte Grammatikdarstellungen, die hinter die Qualität der Visualisierungen in „Papierwerken“ zurückfielen. Deren Standard müssten die digitalen Darstellungen also auf jeden Fall zunächst nachvollziehen. Aber durch die Digitalisierung können die Bilder das Laufen lernen, d.h. prinzipiell ist zu überlegen, inwieweit eine animierte Grammatik eine Erleichterung und Lernhilfe für die Lernenden darstellen könnte.

Eine beliebter grammatischer Gegenstand für eine Animierung sind z.B. Wechselpräpositionen $^{13}$, eine Figur stellt etwas auf einen Tisch, steht auf einem solchen o.ä. Für einen Selbstlerner, der allein und ohne Interaktion im Klassenzimmer Deutsch lernt, ist so ein kleiner Film, der das Prinzip der Wechselpräpositionen verdeutlicht, eventuell hilfreich. Aber in jedem Klassenraum kann ein Lehrer die Wechselpräpositionen ohne Schwierigkeiten demonstrieren, es gibt genug Leute und Gegenstände, die in einen Raum gehen, in einem Raum sind, etwas in eine Tasche, unter einen Tisch oder wohin auch immer stellen oder legen, worauf die Gegenstände dann unter dem Tisch sind usw. Wenn man weiß, wie aufwändig es ist, gute animierte Grammatikdarstellungen zu produzieren, dann stellt sich zunächst die Frage, für welche grammatischen Phänomene sich der Aufwand eigentlich lohnt.

M.E. sollten Visualisierungen zunächst besonders dazu benutzt werden, kognitiv explizit kaum noch zu vermittelnde Konzepte leichter zugänglich zu machen. So könnte ein schwieriges Kapitel der deutschen Grammatik, die Stellung im Mittelfeld, ${ }^{14}$ von einer animierten Grammatik profitieren, die Komplexität ganzheitlicher darstellen kann als explizite Erläuterungen zu Neuem und Bekanntem, zu Links- und Rechtstendenz, Pronominalisierungen usw. Man stelle sich z.B. eine Straße vor, auf der unterschiedliche Arten von Parkverboten und Halteeinladungen vorhanden sind und unterschiedliche Angaben- und Ergänzungsautos vorbeigefahren kommen, die je nach pronominalem

13 Vgl. z.B. http://www.passwort-deutsch.de/lernen/band2/lektion8/aktivitaet02.htm\#.

14 Bei diesem Gegenstand scheint mir inzidentelles Lernen einem kognitiv expliziten Zugang vorzuziehen zu sein, der entweder zu stark simplifiziert (Beispiel: tekamolo) oder der leicht das Ausmaß einer Linguistik-Vorlesung erreicht. 
oder nominalem Zustand an bestimmten Stellen parken, von einem Parkwächter von bestimmten Stellen verwiesen werden usw. usw. Wenn Animierungen dazu führen, dass etwas Komplexes und Schwieriges leichter verstanden wird, dann tragen sie zu einer neuen Qualität des Lernens bei. Wenn Selbstverständliches oder leicht Verständliches illustriert wird oder wenn die Aufmerksamkeit der Lernenden durch eine Animierung, die eher Ornament ist, vom eigentlich zu Lernenden abgelenkt wird, dann wird eher ein Problem als eine Hilfestellung produziert: ${ }^{15}$

„Animationen eignen sich wesentlich besser zur Darstellung sequenzieller oder kausaler Sachverhalte, aber nur solange auch dies nicht zu einer Reizüberflutung oder Ablenkung führt. [...] An der falschen Stelle eingesetzt nehmen sie daher wichtige Ressourcen von anderen essenziellen Verarbeitungsaufgaben weg. [...] Die scheinbar leichte Verständlichkeit, die durch multimediale Animationen häufig suggeriert wird, verhindert [...] richtiges Verstehen.“ (Roche; Scheller 2004: 14)

\subsection{Korpuslinguistik für den und im DaF-Unterricht?}

Ein zweiter Bereich, der hier nur kurz erwähnt werden soll, ist das Potential, das durch die Verbindung von Computertechnologie und linguistischer Methodik für den Fremdsprachenunterricht nutzbar gemacht werden kann bzw. könnte, das Potential der Korpuslinguistik. Diese ist in der Anglistik weiter entwickelt als in der Germanistik, das gilt sowohl für ihren Kernbereich, die Linguistik, als auch für Versuche, sie für das Fremdsprachenlernen produktiv zu machen (vgl. z.B. Mukherjee 2004 und Mukherjee; Rohrbach 2006). Aber auch im Bereich DaF wird durch die 2008 in der Zeitschrift Deutsch als Fremdsprache eröffnete Reihe von Beiträgen (vgl. Fandrych; Tschirner 2008 und Meißner 2008) die Diskussion systematisiert, und mit FALKO wächst an der Humboldt-Universität ein annotiertes Fehlerkorpus für DaF heran (vgl. Lüdeling u.a. 2008).

In der Linguistik hat die Korpusanalyse eine methodische Neuorientierung bewirkt, an die Stelle einzelner Belege oder der Introspektion des Muttersprachlers tritt die Analyse immer größerer Mengen von Daten. Für den Fremdsprachenunterricht ist die Korpuslinguistik auf zwei Ebenen interessant.

Zunächst ist sie, wiederum auf zwei Ebenen, Lieferantin von Informationen. Zum einen stellt sie empirisch überprüfte Aussagen zur Frequenz von sprachlichen Phänomenen zur Verfügung, von denen Lehrmaterialmacher zumindest jenseits von B1 bei der Erstellung von spezielleren Materialien profitieren können. Zum anderen kann die Korpusanalyse da, wo sie Lernerkorpora analysiert, hilfreiche Daten liefern. Annotierte Fehlerkorpora können über die große Zahl zu einer interessanten Ergänzung psycholinguistischer Erwerbsforschung werden. In diesen beiden Fällen ist die Korpuslinguistik eine interessante Bezugswissenschaft für die Fremdsprachendidaktik.

Offener ist $\mathrm{m}$.E. zur Zeit noch die didaktisch weitergehende Frage, ob und inwieweit ein korpuslinguistisches Vorgehen auch Teil des institutionell gesteuerten Lernens werden sollte, z.B. dadurch, dass Lerner größere Mengen von sprachlichem Material unter für sie zum jeweiligen Stand ihres Spracherwerbs relevanten Gesichtspunkten durchforsten,

15 Vgl. dazu ausführlicher Roche; Scheller (2008). 
inwieweit also die Korpuslinguistik einen Beitrag zum entdeckenden Lernen leisten kann. Dies scheint zunächst eine Frage zu sein, die für Lernende in der Mittelstufe und Oberstufe von Interesse ist, z.B. bei der Beschäftigung mit Kollokationen (vgl. z.B. Ludewig 2005). Wie produktiv ein korpuslinguistisches Vorgehen für DaF-Lernende tatsächlich ist, wird sich erst sagen lassen, wenn entsprechende Unterrichtsforschung vorliegt. Perspektivisch festhalten kann man aber, dass ein korpuslinguistisches Vorgehen zumindest theoretisch das Potential in sich trägt, selbstbestimmtes Lernen, das in der Fremdsprachendidaktik zumeist stärker auf Inhalte bezogen diskutiert wird, auch im Bereich der eher formbezogenen Fragestellungen voranzutreiben.

\section{Tutorierung und programmiertes Feedback}

Feedback ist kein neues Thema der Fremdsprachendidaktik, es gewinnt aber im Kontext der stärkeren Individualisierung, die durch digitale Medien möglich wird, ${ }^{16}$ besondere Bedeutung. Feedback geben traditionell Lehrer und Mitlernende. Wenn das Lernen nicht mehr in einem Raum stattfindet, in dem Lehrende und Lernende gleichzeitig anwesend sind, kann der Lehrer durch einen Online-Tutor ${ }^{17}$ ersetzt werden, was zunächst einmal den Verlust einiger nonverbaler Feedback-Möglichkeiten mit sich bringt, im Hinblick auf Erreichbarkeit für individuell gewählte Lernzeitpunkte aber evtl. für die Lernenden auch eine Verbesserung darstellen kann. Wie gut oder wie schlecht ein Online-Tutor ist, hängt nicht zuletzt davon ab, ob er ein Sprachlernhelfer und Sprachberater ist oder eine schlecht bezahlte Hilfskraft, die nur „Häkchen macht“. Wenn ein Team gut ausgebildeter Online-Tutoren Selbstlernenden zu verschiedenen Zeitpunkten zur Verfügung steht und sie angemessen berät, dann ist Online-Tutorierung zumindest eine ernstzunehmende Angelegenheit.

Ein Phänomen, über das noch relativ wenig bekannt ist, das aber m.E. im Kontext der digitalen Medien eine größere Rolle spielen wird als bisher, ist das Feedback durch Mitlerner, besonders überall da, wo Lernende individuell an einem Lernprogramm arbeiten, sich aber mit anderen Lernenden im gleichen Raum befinden. Hier kann das schon immer vorhandene Tuscheln mit dem Nachbarn im Klassenzimmer, wenn man als Lerner mal wieder nicht verstanden hat, was der Lehrer gesagt hat, ihn aber nicht unterbrechen wollte, oder wenn man sich schnell vergewissern möchte, ob man eine Aufgabe richtig gelöst hat, zu einem immer wichtiger werdenden Bestandteil von Lernprozessen werden. In einem digitalen Kontext, in dem das Lernprogramm nur eines der offenen Fenster auf dem Computer ist, und die Lernenden sich gegenseitig bei zeitgleich vorhandenen Online-Wörterbüchern, Grammatiken, beliebigen Informationsseiten usw. informieren und beraten können, könnte mit derartigen Peer-Beratungen ein qualitativ sehr interessanter Schritt liegen in Richtung eines vielleicht in Zukunft wachsenden Bereich des, paradox formuliert, kooperativen Alleinlernens ${ }^{18}$.

16 M.E. wird durch die digitalen Medien sowohl eine stärkere Individualisierung als auch eine Stärkung von Kooperationen beim Fremdsprachenlernen möglich. Vgl. dazu genauer Rösler (2006b).

17 Zu den verschiedenen Besetzungen des Begriffs Tutor im Kontext der Diskussion um das Fremdsprachenlernen mit digitalen Medien vgl. Rösler (2004: 194ff.)

18 Vgl. dazu die Untersuchung von Schmidt (2007) zum gemeinsamen Arbeiten mit Selbstlernsoftware. 
Beim Thema Feedback und digitale Medien stellt sich neben der Erforschung von durch Computer vermittelten Rückmeldungen von Menschen an andere Menschen vor allem die Frage, was für Alleinlernende eigentlich ein sinnvolles Feedback des impliziten, also des in das Material programmierten, Tutors ist.

Programmiertes Feedback basiert auf dem Abgleichen von Mustern. Je mehr ein Materialmacher vorhersieht, welche Fehler Lernende machen werden und je mehr Energie er darauf verwendet, auf diese Fehler zu reagieren, desto differenzierter kann sein Feedback aussehen. Das gilt für simple Hot Potatoes $^{19}$-Übungen ebenso wie für elaboriertere programmierte Aktivitäten. Es handelt sich dabei um eine Fleißarbeit, die für die Macher frustrierend sein kann. Wer viel Energie in eine schöne Flash-Präsentation steckt, kann sicher sein, dass die Lernenden die Präsentation sehen und hoffentlich auch gut finden. Wer sehr viel Zeit in die Antizipation von Lernerreaktionen und entsprechende Rückmeldungen der Lernsoftware steckt, weiß nicht, ob irgendetwas von dieser vielen Arbeit überhaupt wahrgenommen wird.

Das führt dazu, dass bei vielen Übungen das Feedback sicher weniger differenziert ist, als es technisch sein könnte. Bei offenen Aufgaben ${ }^{20}$ bleibt ohnehin, wenn kein Online-Tutor zur Verfügung steht, an den Lösungen eingesandt werden können, nur die Möglichkeit der Musterantwort, und Musterantworten sind eine zweischneidige Sache. Eine ihrer unerwünschten Nebenwirkungen kann sein, dass ein Lerner, der eine interessante Lösung produziert hat, sehr verunsichert wird, weil er seine gefundene Lösung nicht in Beziehung zur Musterlösung setzen kann.

Der hohe Arbeitsaufwand für das Vorhersehen von und Reagieren auf unterschiedliche Lernereingaben verbunden mit der mangelnden Sichtbarkeit des Feedbacks mag einer der Gründe dafür sein, dass das Feedback bei manchen Aufgaben in der Lernsoftware stark verbesserungswürdig zu sein scheint. Darüber hinaus ist aber auch nicht hinreichend geklärt, wann für welche Lernenden bei welcher Aufgabe welche Art von Feedback denn eigentlich gutes Feedback ist.

$\mathrm{Zu}$ Anfangszeiten der Lernsoftwareentwicklung las man manchmal, Feedback solle freundlich sein und nicht verschrecken. Aber das kann zu Problemen führen, wie mein Selbstversuch aus dem Jahre 1998 zeigte:

„Bei einer graphisch sehr ansprechend gestalteten Übung, bei der ich Substantiven einen definiten Artikel zuordnen muß, macht es offensichtlich einen Unterschied, welchen falschen Artikel ich verwende, denn manchmal erhalte ich bei Fehlern ein aufmunterndes ,stimmt nicht ganz', manchmal ein strenges ,das stimmt nicht'. Sollte es hier eine von der germanistischen Linguistik noch nicht entdeckte Tendenz zum semiakzeptablen Zweitgenus für Substantive geben, deren Angabe die freundlichere Fehlermeldung auslöst?“ (Rösler 1998: 11)

In einer derartigen Situation muss ein Lerner ins Grübeln kommen, er muss annehmen, dass die unterschiedlichen Reaktionen des Programms bedeuten, dass er unterschiedlich

19 Vgl. http://hotpot.uvic.ca/

20 Die Auswahlmöglichkeiten, die Autorensysteme anbieten, führen wohl auch dazu, dass im Netz mehr geschlossene Aufgaben zur Verfügung stehen, als man das für didaktisch sinnvoll halten mag. 
schlecht reagiert hat. Die programmierte Freundlichkeit kann also dazu führen, dass im Kopf der Lernenden fehlgeleitete Verallgemeinerungen in Gang kommen.

Ein anderes Kriterium für die Feedback-Gestaltung, das häufig anzutreffen ist, könnte formuliert werden als: je ausführlicher desto besser. Wenn das Feedback des Programms, wie es in den Anfangszeiten von Übungen auf dem Computer manchmal vorkam, einfach lautete, „Einige der Antworten sind nicht ganz richtig“, dann wäre sicher ein ausführlicheres Feedback besser gewesen. Aber was heißt ausführlich? Soll eine Grammatikübung im Feedback z.B. eine Erklärung liefern, einen Link auf eine Seite, in der das Phänomen dargestellt wird? Oder ist das nicht viel zu aufwändig für einen Lerner, der bei einer geschlossenen Übung nur schnell wissen möchte, ob was er angeklickt hatte richtig oder falsch war. In der Untersuchung von Schmidt (2007) drückte sich Feedbackverdrossenheit dadurch aus,

„dass viele Schülerinnen als Folge der beschriebenen Negativerfahrungen die erscheinenden Meldungen häufig entweder vollständig ignorieren, indem sie sie ungelesen sofort nach ihrem Erscheinen wegklicken, oder aber nur sehr oberflächlich wahrnehmen. So kommt es natürlich häufig vor, dass durchaus gute, informierende, fehlerspezifische Kommentare ebenfalls vollständig unbeachtet bleiben." (ebd.: 291)

Wichtig ist in der momentanen Situation wohl, dass die Antwort auf die Frage, was ein angemessenes Feedback ist, lernerabhängig gestellt werden muss: Die sogenannte Generation Netzkind, für die das Etablieren sozialer Beziehungen im Netz ebenso zum Alltag gehört wie die schnelle Suche nach Informationen im Netz und das schnelle Wegklicken von etwas, was nicht sofort als relevant angesehen wird, wird vielleicht sehr anders mit kognitiv arbeitendem Feedback umgehen als ein älterer Lernender mit anderen Computer- und Lernerfahrungen.

Befänden wir uns in einer Naturwissenschaft und nicht in einem Niemandsland der Forschungsförderung wie der Fremdsprachendidaktik, dann hätten wir sicher schon längst ein millionenschweres Grundlagenforschungsprogramm aufgebaut, bei dem versucht würde zu ermitteln, welche Kriterien für programmiertes Feedback belastbar sind, bezogen auf unterschiedliche Lernertypen, Lernziele, Übungstypen usw. Die häufig beklagte fehlende Breite der empirischen Fremdsprachenforschung ist auch hier ein Hindernis dafür, dass über Argumentationen entlang der reflektierten Erfahrung kaum ${ }^{21}$ hinausgegangen wird. Was man jedoch einigermaßen sicher sagen kann, ist, dass ganz langfristig im Bereich Feedback für programmiertes Material ein großer qualitativer Schritt voran erst gemacht werden kann, wenn Pattern-Matching und die Antizipation von Lernereingaben ergänzt und evtl. einmal sogar ersetzt werden durch eine intelligente Analyse der Lernereingaben, d.h. wenn Fremdsprachendidaktik und Forschung zur künstlichen Intelligenz auf einer Ebene zusammenkommen, ${ }^{22}$ die über

\footnotetext{
21 Vgl. aber z.B. Arbeiten wie Nagata (1993) (Ausführlichkeit von Feedback und Lernerfolg), Pujola (2001) (unterschiedliche Verwendungsmöglichkeiten, Zweischrittigkeit) oder Bangs (2003) (Arten von Feedback).

22 Vgl. dazu Gamper; Knapp (2002) oder Puskas (2005).
} 
die Analyse von Einzelbeispielen hinausgeht. Das wird aber noch eine sehr lange Zeit auf sich warten lassen.

\section{Kooperatives Arbeiten mit digitalen Medien}

Kooperationen gab und gibt es vor und außerhalb des Arbeitens mit digitalem Material. Tandems gab es, bevor es E-Tandems gab, Klassenkorrespondenzen, bevor per E-Mail usw. die Raumüberwindung zwischen Lernergruppen an verschiedenen Orten beschleunigt wurde (vgl. als Überblick Rösler 2004: 49-69). ${ }^{23}$ Rasant geändert haben sich in den letzten zehn Jahren die technischen Möglichkeiten für Kooperationen. Mussten vor ca. zehn Jahren für die Untersuchung von Tamme (2001) zur Ausbildung von Online-Tutoren noch bei vielen der Teilnehmer Modems installiert werden, sind heute alle Beteiligten am Gießener elektronischen Praktikum ${ }^{24}$ in der Lernplattform Moodle zu Hause. Das bedeutet zunächst einmal nur, dass technisch über den einen Modus der schriftlichen Interaktion per E-Mail hinaus inzwischen eine ganze Palette von Kommunikationsmöglichkeiten bereit steht, synchron und asynchron, geschrieben und gesprochen, in Wikis, Chats, Foren oder per Skype. Die didaktisch relevante Frage lautet, ob dabei der didaktische Fortschritt mit dem technologischen Fortschritt Schritt gehalten hat.

Mit E-Mail und Chat waren digitale Kommunikationsweisen in den Fremdsprachenunterricht eingetreten, die in Bezug auf konzeptionelle Schriftlichkeit und Mündlichkeit ${ }^{25}$ nicht immer einfach einzuordnen sind und die für die Fremdsprachendidaktik unter dem Gesichtspunkt der Diskussion der Förderung von Mündlichkeit und Schriftlichkeit interessant waren. Problematisch war es m.E. zu glauben, dass mit den E-Mails und Chats eine Renaissance des Schreibens stattgefunden hatte, stattgefunden hatte auf jeden Fall eine Renaissance des Tippens. Hier kann nun durch die Erweiterung der technischen Möglichkeiten eine Ausdifferenzierung erfolgen. Mit Skype könnte es eher als mit den getippten Chats tatsächlich dazu kommen, dass die Förderung der mündlichen Kommunikationsfähigkeit im Fremdsprachenunterricht stärker in den Fokus des Lernens mit digitalen Medien tritt und mit Wikis ${ }^{26}$ und Blogs könnte es nun tatsächlich zu einer Renaissance des Schreibens und dabei durch das Potential der social software sogar zu einer Stärkung des kooperativen Schreibens kommen (vgl. dazu ausführlicher Würffel 2008).

Digitale Kooperationsprojekte haben zumeist versucht, zumindest die inhaltliche Selbstbestimmung der Lernenden möglichst weitgehend unbeschädigt zu lassen, der Selbstbestimmung der Arbeitsweisen waren durch die „Sachzwänge“ der vorhandenen Kommunikationsweisen, zunächst beschränkt auf E-Mail, Grenzen gesetzt. Durch die Vielfalt der technischen Optionen in Lernplattformen ist in Kooperationsprojekten jetzt

\footnotetext{
23 Vgl. als Überblick über laufende Projekte die Sammlung im Netz http://www.schule.de/englisch/DaF. htm von Reinhard Donath, der für Einstieger auch sehr nützliche Hinweise für das Gelingen von Kooperationsprojekten bereitstellt: http://www.englisch.schule.de/tipps_neu.htm\#zehn.

24 Vgl. Würffel (2004).

25 Vgl. die Analyse von Lemnitzer; Naumann (2001). Vgl. Platten (2003) zu den Besonderheiten der Kommunikation in didaktischen Chats.

26 Zum Schreiben von DaF-Lernenden im Wiki vgl. Platten (2008).
} 
eine weitergehende Selbstbestimmung von Arbeitsweisen der Wahl, eines synchronen oder asynchronen Vorgehens usw. durch die Lernenden möglich; einer Zwischenbilanz in zehn Jahren bleibt es vorbehalten festzuhalten, ob diese größere Freiheit der Wahl der Mittel zu größerer Selbstbestimmung bei der Wahl der Arbeitsweisen geführt hat.

Auch bei größerer Begeisterung für die sich bietenden Möglichkeiten von Lernplattformen sollte man jedoch nicht vergessen, dass die Grundprobleme ${ }^{27}$ sprach- und kulturgrenzenüberschreitender Kommunikation durch diese nicht aus der Welt geschafft worden sind, so dass auf die Gefahren in jedem einzelnen Projekt ebenso wie in der Aus- und Fortbildung von Fremdsprachenlehrern geachtet werden muss. Trotz der erweiterten Kommunikationsmöglichkeiten gilt weiterhin der Gemeinplatz: Wenn man sich nichts zu sagen hat, ist es egal, wie luxuriös die Lernplattform ist, in der man sich nichts zu sagen hat. Die entscheidende Frage lautet weiterhin: Haben Lernende in Kooperationsprojekten anderen Lernenden etwas mitzuteilen?

\section{Lernertexte für Lerner}

Dass Lernende anderen Lernenden oder ihrer Umwelt etwas mitteilen wollen und dass dieses Mitteilungsbedürfnis die Basis des Fremdsprachenlernens sein sollte, ist kein durch digitale Medien aufgekommenes Konzept, sondern Grundannahme aller Versuche, emanzipatorischen Fremdsprachenunterricht zu machen, und Ausgangsüberlegung der Projektdidaktik. Inwieweit tragen durch digitale Medien realisierte Interaktionen dazu bei, diese Grundannahme stärker im Unterrichtsalltag zu verankern? Diese Frage soll in zwei Teilfragen überführt werden, in die Frage, inwieweit „lehrmaterialfreie“ selbstbestimmte Textproduktion durch social software in anderer Weise möglich ist als bisher, und in die nicht so offensichtliche, m.E. aber für die Entwicklung des gesteuerten DaFLernens hochrelevante Frage danach, ob durch die Digitalisierung auch im traditionellen Lehrmaterialkonzept so etwas wie eine stärkere Einbeziehung von Lernertexten möglich ist.

\subsection{Freie Lernertexte im Netz}

Abb. 1 zeigt einen von einem Lerner ins Internet gestellten Text. Wenn derartige Texte von Lernenden produziert und der Welt kund getan werden, ohne dass dieses eine Beziehung zum Unterricht hat, dann handelt es sich zunächst einmal um nichts anderes als um eine mediale Erweiterung von Transfermöglichkeiten. So, wie ein Lerner früher einen muttersprachlichen Touristen im Urlaub angesprochen haben mag, um sein erworbenes Deutsch auszuprobieren, und dabei keinesfalls korrekt gesprochen hat, so kann er jetzt die ganze Welt ansprechen, um sein erworbenes Deutsch auszuprobieren, und er hofft natürlich, dass die Welt ihn zur Kenntnis nimmt.

Etwas anderes ist es, wenn diese Arten von Aktivitäten innerhalb des Klassenzimmers in die Wege geleitet werden, wenn also Lehrende die Lernenden dazu bringen, sich der Welt mitzuteilen. Hier kann m.E. die Idee des freien Sich-Mitteilens in Konflikt geraten mit der Schutzfunktion, die Lehrende einer Gruppe von Lernenden gegenüber

${ }_{27}$ Vgl. dazu z.B. Müller-Hartmann (2000) und O’Dowd; Ritter (2006). 


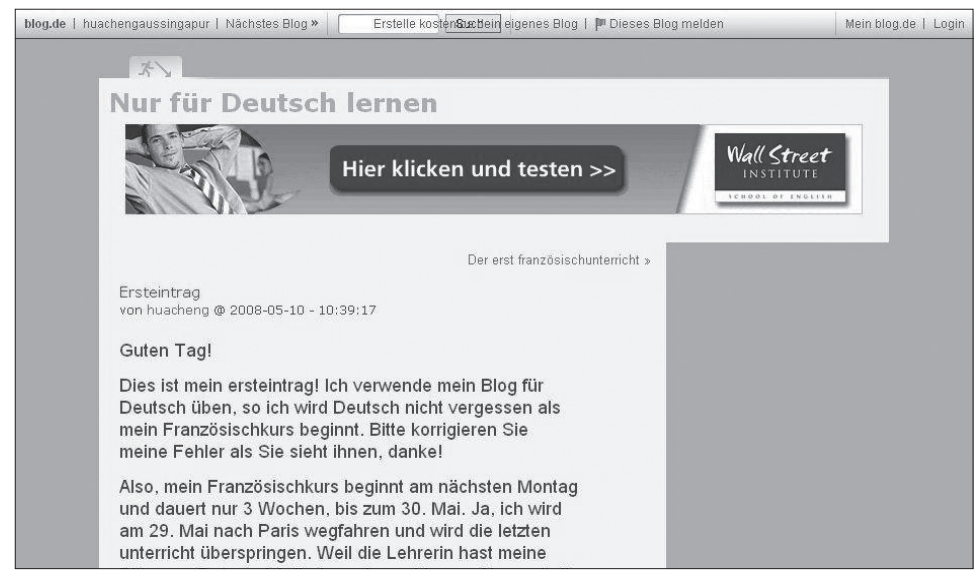

Abb.1: Von einem DaF-Lerner außerhalb des institutionellen Lernens ins Netz gestellter Text. Quelle: http://huachengaussingapur.blog.de/2008/05/10/ersteintrag-4155058 (21.05.2008)

haben, denn im Gegensatz zur Ermunterung zu selbstbestimmtem Schreiben, das zu Plakaten im Klassenzimmer, einer Lesung auf einem Elternabend oder zu einem Brief an eine Partnerklasse führte, liest plötzlich die ganze Welt mit, wenn die Texte nicht entsprechend per Intranet oder sonstigen Schutzmechanismen mit einer Zugangsbeschränkung versehen sind. Nun könnte man einwenden, dieser Verweis auf die Schutzfunktion sei sehr altmodisch, wir lebten schließlich in einer Welt des medialen Exhibitionismus, und von daher sind diese Bedenken wahrscheinlich tatsächlich ein bisschen altväterlich, trotzdem sollte man nicht ganz außer Acht lassen, dass ein gegen sprachliche Normen verstoßender oder inhaltlich selbstentblößender Text natürlich auch gegen den Verfasser verwendet werden kann, z.B. eine ganze Zeit später bei einer Bewerbung, und dass man vielleicht überlegen sollte, inwieweit ein allzu schnelles Ermuntern der Lernenden, sich in der Zielsprache gleich der ganzen Welt mitzuteilen, tatsächlich so notwendig ist.

Trotzdem muss man festhalten, dass mit derartigen weltweit zugänglichen Publikationen die Möglichkeit gegeben ist, über die Grenzen des Klassenzimmers hinauszutreten, und je stärker es z.B. passiert, dass eine Gruppe von Lernenden ein digitales Produkt erstellt und dann in sozialen Netzwerken „,werbend“ dafür sorgt, dass Leute, die keinen didaktischen Grund dafür haben, ${ }^{28}$ dieses Produkt wahrzunehmen, es freiwillig zur Kenntnis nehmen, desto stärker finden Schritte über das Klassenzimmer hinaus in Richtung ,natürliche Kommunikation“ statt, die über die Interaktionsmöglichkeiten klassischer Projektdidaktik hinausgehen.

\subsection{Freie Lernertexte in einer didaktischen Lernumgebung}

Während der Text in Abb. 1 ein Beispiel dafür ist, wie Lernende die digitalen Medien dafür nutzen, ohne didaktischen Kontext sich in der Fremdsprache anderen mitzuteilen

28 Also weder Lehrer, Partnerklasse, Eltern oder sonstige kommunikativ „zwangsverpflichtete“ Personen sind. 


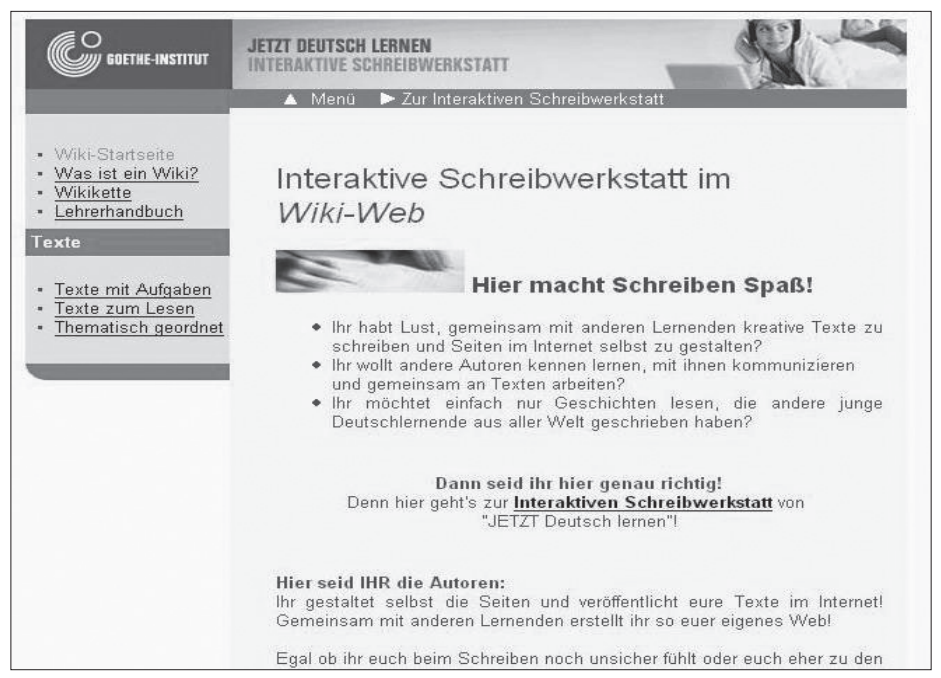

Abb. 2: Kooperatives Schreiben in einem didaktischen Kontext. http://www.goethe.de/z/jetzt/ dejwiki/dejwiki.htm (21.05.2008)

(und zu hoffen, dass irgendwo in der Welt „draußen“ jemand diesen Text als für sich so relevant empfindet, dass er auf ihn antwortet), ist Abb. 2 ein Beispiel für weitgehend freies Schreiben in einem didaktischen Raum.

Abb. 2 zeigt die Startseite der interaktiven Schreibwerkstatt der Lernumgebung für Jugendliche auf Mittelstufenniveau, Jetzt Deutsch Lernen. Diese Schreibwerkstatt stellt ein Wiki bereit, gibt Startinformationen und einen inhaltlichen Impuls. Danach sind die Lernenden freie Autoren, die mit anderen Autoren kooperieren. Verglichen mit dem völlig freien Text in Abb. 1 findet also eine Steuerung statt. In diesem konkreten Fall ist sie sehr gering, Ort, allgemeine Hilfestellung und Impuls werden gegeben (vgl. dazu ausführlicher Platten 2008).

Man kann sich derartige Wikis auch mit stärkeren Eingriffen vorstellen, z.B. mit einem Tutor, der textsortenbezogene Ratschläge gibt, kooperative Aktivitäten moderiert usw. Und man kann sich ein derartiges Wiki noch freier vorstellen, indem selbst der thematische Impuls noch weggelassen wird und lediglich ein bereitgestellter Schreibraum übrig bleibt. Unterschiedlich sein können auch die Motive der Schreiber: sind sie als individuelle Lerner in die Schreibwerkstatt geraten, sind sie von ihren Lehrern dazu „überredet“ worden, ist gar eine ganze Lernergruppe als Teil des Unterrichts zu diesem „freien“ Schreiben verpflichtet worden? Hier bedarf es noch einer ganzen Reihe von Untersuchungen, bis man mehr darüber weiß, welcher Grad von Steuerung, thematischen Anreizen und evtl. auch unterrichtlichen Begleitungen für welche Lerner mit welchen Lernerfahrungen mit welchem Sprachstand für kooperatives Schreiben im Wiki angemessen ist. 


\subsection{Integration von Lernertexten in Lehrmaterial}

Aufgrund der Bedeutung, die Lehrmaterial für das gesteuerte Fremdsprachenlernen hat, zumindest ebenso wichtig ist m.E. die Frage, ob es über diese erweiterten Möglichkeiten des kooperativen freien Schreibens von Texten durch Lernende hinaus auch dazu kommen kann, im Lehrmaterial den Texten von Lernenden mehr Bedeutung zukommen zu lassen. Lernertexte in Lehrwerken waren traditionell vereinzelte Texte von Lernenden, die z.B. auf ein Preisausschreiben geantwortet hatten. Mit der Flexibilität der digitalen Medien ist es nun möglich, diese Art der Integration von Lernertexten voranzutreiben. Abb. 3 zeigt ein weiteres Beispiel aus der Lernumgebung Jetzt Deutsch Lernen. Dort hatte man angefangen, Texte von Lernenden als Reaktionen auf die Texte der Lernumgebung ins Netz zu stellen, und ging danach einen Schritt weiter: die Texte der Lernenden wurden selbst zu didaktisch bearbeiteten Texten, die die Basis von Lerneinheiten bilden.

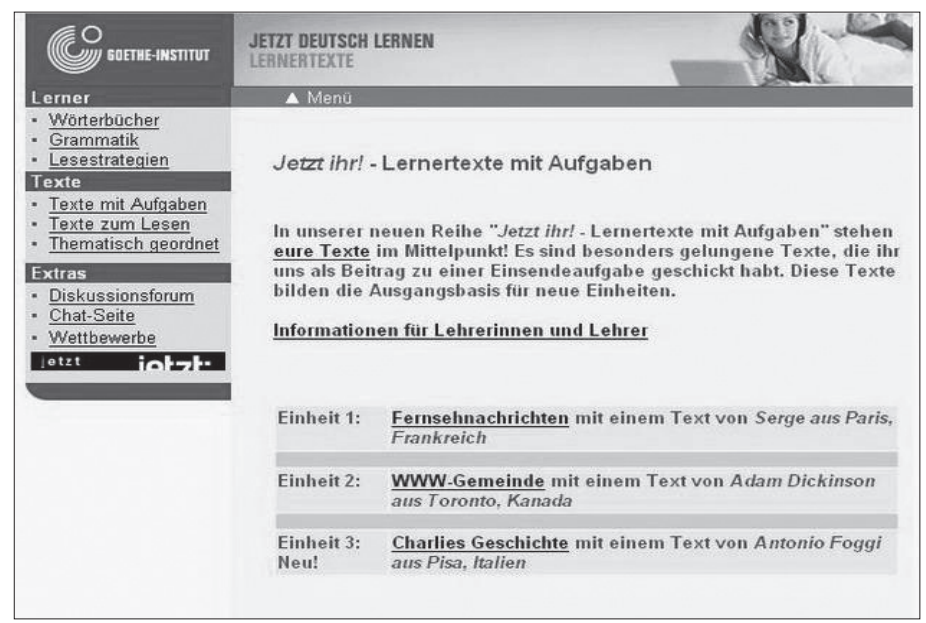

Abb 3: Didaktisierte Lernertexte im Lehrmaterial. http://www.goethe.de/z/jetzt/dejlerte.htm (Abrufdatum 21.5.2008)

Man kann entweder sagen, damit seien sie genau so gut oder genauso schlecht wie alle anderen Lehrwerktexte, man kann aber auch hoffen, dass, wenn derartige Texte kontinuierlich erneuert, weitergesponnen werden usw., auch in Lehrwerken - wenn man sich, wie in Kap. 1 dargestellt, Lehrwerke als Datenbanken und nicht als statische Sequenzen vorstellt - mit diesen Texten eine stärkere Annäherung an Interessen der Lernenden erfolgen kann. Denn von den Lernenden kann ein für sie unangemessener Text in ,ihrem“ Lehrwerk als Aufforderung verstanden werden, selbst aktiv zu werden, zu schreiben, zu inszenieren und diese Texte dann wieder anderen Lernenden zur Verfügung zu stellen, so dass in einem Datenbank-Konzept von Lehrwerk Texte von Lernenden gleichberechtigt neben denen von Materialmachern geschriebenen oder gefundenen stehen könnten, für andere und von anderen Lehrenden und Lernenden ausgewählt nicht danach, ob sie von berühmten Autoren, Lehrwerkmachern oder Lernenden stammen, sondern weil sie für bestimmte Lernende mit bestimmten Lernzielen 
zu einem bestimmten Zeitpunkt die angemessenen Texte sind. Und damit hätte man sich dann ein Stückchen weiter an so etwas wie „didaktische Authentizität“ angenähert, an einen Authentizitätsbegriff, der nicht den Texturheber oder die Textbeschaffenheit verabsolutiert, sondern sich auf die komplexe Situation gesteuertes Fremdsprachenlernen einlässt.

\section{Literatur}

Bangs, Paul (2003): Engaging the learner - how to author for best feedback. In: Felix, Uschi (Hrsg.): Language learning online: Towards best practice. Lisse: Swets \& Zeitlinger, 81-96.

Barkowski, Hans et al. (1986): Deutsch für ausländische Arbeiter. Gutachten zu ausgewählten Lehrwerken. 3. aktualisierte Auflage. Mainz: Werkmeister.

Bochow, Peter; Schroedter-Albers, Henning (1981): Deutsch Aktiv - Adaption für Indien; Didaktische Überlegungen, Unterrichtsbeispiele. In: German Studies in India, 173188.

Engel, Ulrich; Krumm, Hans-Jürgen; Wierlacher, Alois (1979): Mannheimer Gutachten zu ausgewählten Lehrwerken Deutsch als Fremdsprache. Band 2. Heidelberg: Groos.

Fandrych, Christian; Tschirner, Erwin (2007): Korpuslinguistik und Deutsch als Fremdsprache. Ein Perspektivenwechsel. In: Deutsch als Fremdsprache 44/4, 195-204.

Funk, Hermann; König, Michael (1991): Grammatik lehren und lernen. Berlin et al.: Langenscheidt.

Gamper, Johann; Knapp, Judith (2002): A review of intelligent CALL-systems. In: Computer Assisted Language Learning 15/4, 329-342.

Gerighausen, Josef; Seel, Peter (1984): Der fremde Lerner und die fremde Sprache. Überlegungen zur Entwicklung regionalspezifischer Lehr- und Lernmaterialien für Länder der Dritten Welt. In: Jahrbuch Deutsch als Fremdsprache 10, 126-162.

Kommission für Lehrwerke DaF (1978): Mannheimer Gutachten zu ausgewählten Lehrwerken Deutsch als Fremdsprache. Heidelberg: Groos.

Lemnitzer, Lothar; Naumann, Karin (2001): „Auf Wiederlesen!“ - das schriftlich verfaßte Unterrichtsgespräch in der computervermittelten Kommunikation. In: Beißwenger, Michael (Hrsg.): Chat-Kommunikation - Sprache, Interaktion, Sozialität \& Identität in synchroner computervermittelter Kommunikation. Stuttgart: Ibidem 469-491.

Ludewig, Petra (2005): Korpusbasiertes Kollokationslernen: Computer-Assisted Language Learning als prototypisches Anwendungsszenario der Computerlinguistik. Frankfurt a.M. et al.: Lang.

Lüdeling, Anke et al. (2008): Das Lernerkorpus Falko. In: Deutsch als Fremdsprache 45/2, 67-73.

Meißner, Cordula (2008): Eine gebrauchsorientierte Beschreibung des Sprachsystems mit Hilfe der Korpuslinguistik - das Beispiel der Synonyme ewig und unendlich. In: Deutsch als Fremdsprache 45/1, 8-13.

Müller-Hartmann, Andreas (2000): Wenn sich die Lehrenden nicht verstehen, wie sollen sich dann die Lernenden verstehen? Fragen nach der Rolle der Lehrenden in global vernetzten Klassenräumen. In: Bredella, Lothar; Christ, Herbert; Legutke, Michael 
K. (Hrsg.): Fremdverstehen zwischen Theorie und Praxis. Arbeiten aus dem Graduierten-Kolleg „Didaktik des Fremdverstehens“. Tübingen: Narr, 275-301.

Mukherjee, Joybrato (2004): Bridging the Gap between Applied Corpus Linguistics and the Reality of English Language Teaching in Germany. In: Connor, Ulla; Upton, Thomas A. (Hrsg.): Applied Corpus Linguistics: A Multidimensional Perspective. Amsterdam: Rodopi, 239-250.

Mukherjee, Joybrato; Rohrbach, Jan-Marc (2006): Rethinking Applied Corpus Linguistics from a Language-pedagogical Perspective: New Departures in Learner Corpus Research. In: Kettemann, Bernhard; Marko, Georg (Hrsg.): Planning, Gluing and Painting corpora: Inside the Applied Corpus Linguist's Workshop. Frankfurt a.M. et al.: Lang.

Nagata, Noriko (1993): Intelligent computer feedback for second language instruction. In: The Modern Language Journal 77/III, 330-339.

Neuner, Gerhard (1979): Lehrwerkanalyse und -kritik als Aufgabenfeld der Fremdsprachendidaktik - zur Entwicklung seit 1945 und zum gegenwärtigen Stand: In: Neuner, Gerhard (Hrsg.): Zur Analyse fremdsprachlicher Lebrwerke. Frankfurt a.M., 5-39.

O’Dowd, Robert; Ritter, Markus (2006): Understanding and Working with Failed Communication in Telecollaborative Exchanges. In: CALICO Journal 23/3, 1-20.

Platten, Eva (2003): Chat-Tutoren im didaktischen Chat-Raum - Sprachliche Hilfen und Moderation. In: Legutke, Michael K.; Rösler, Dietmar (Hrsg.): Fremdsprachenlernen mit digitalen Medien. Tübingen: Narr, 145-177.

Platten, Eva (2008): Gemeinsames Schreiben im Wiki-Web. Aktivitäten in einer untutorierten Schreibwerkstatt für fortgeschrittene Deutschlernende. In: Zeitschrift für Interkulturellen Fremdsprachenunterricht 13/1, 22 (http://zif.spz.tu-darmstadt.de/jg-131/beitrag/Platten1.htm).

Pujola, Joan-Tomas (2001): Did CALL feedback feed back? Researching learners' use of feedback. In: ReCALL 13/1, 79-98.

Puskas, Csilla (2008): Interaktives E-Learning im Bereich Deutsch als Fremdsprache: Febleranalyse und intelligente Rückmeldung durch Parsing-Systeme. Gießen, http://www.uni-giessen. $\mathrm{de} / \sim \mathrm{gm} 1160 /$ doku/cpu-master-thesis.pdf (21.05.2008).

Roche, Jörg; Scheller, Julija (2004): Zur Effizienz von Grammatikanimationen beim Spracherwerb: Ein empirischer Beitrag zu einer kognitiven Theorie des multimedialen Fremdsprachenerwerbs. In: Zeitschrift für Interkulturellen Fremdsprachenunterricht 9/1, 15ff (http://zif.spz.tu-darmstadt.de/jg09_1_4/beitrag/roche-scheller2.htm).

Roche, Jörg; Scheller, Julija (2008): Grammar Animations and Cognitive Theory of Multimedia Learning. In: Barber, Beth; Zhang, Felicia (Hrsg.): Handbook of Research on Computer Enhanced Language Acquisition and Learning. Hershey et al.: IGI Global, 205-219.

Rösler, Dietmar (1984): Lernerbezug und Lehrmaterialen DaF. Heidelberg: Groos.

Rösler, Dietmar (1998): Autonomes Lernen? Neue Medien und altes Fremdsprachenlernen. In: Info DaF 25/1, 3-20.

Rösler, Dietmar (2004): E-Learning Fremdsprachen - eine kritische Einführung. Tübingen: Staufenburg. 
Rösler, Dietmar (2006a): Zwischen Lehrwerk und Online-Sprachbad. Zur Neubestimmung von Funktion und Gestalt von Lehrmaterialien im Anfängerunterricht. In: Krumm, Hans-Jürgen; Portmann-Tselikas, Paul (Hrsg.): Theorie und Praxis. Österreichische Beiträge zu Deutsch als Fremdsprache. Innsbruck et al.: Studienverlag, 143-154.

Rösler, D.ietmar (2006b): Das scheinbare Paradox des Fremdsprachenlernens mit digitalen Medien: Tendenz zur Individualisierung und zur Stärkung kooperativer Lernformen. In: Scherfer, Peter; Wolff, Dieter (Hrsg.): Vom Lehren und Lernen fremder Sprachen: eine vorläufige Bestandaufnahme. Frankfurt a.M.: Lang, 157-169.

Rösler, Dietmar (2008): Lernziel kommunikative Kompetenz dreiunddreißig Jahre nach Piepho 1974 - ein kritischer Rückblick aus der Perspektive des Deutschlernens auBerhalb des deutschsprachigen Raums. In: Legutke, Michael K. (Hrsg.): Kommunikative Kompetenz als fremdsprachendidaktische Vision. Tübingen: Narr, 115-129.

Schmidt, Torben (2007): Gemeinsames Lernen mit Selbstlernsoftware im Englischunterricht. Eine empirische Analyse lernprogrammgestützter Partnerarbeitsphasen. Tübingen: Narr.

Tamme, Claudia (2001): E-Mail-Tutorien: eine empirische Untersuchung E-Mail-vermittelter Kommunikationen von Deutschstudierenden und Deutsch-als-Fremdsprache-Lehrenden in der Ausbildung.http://geb.uni-giessen.de/geb/volltexte/2003/1009/ (21.05.2008)

Würffel, Nicola (2004): Und wenn die Wellenlänge nicht stimmt? Zum Einfluss affektiver Faktoren auf Verstehensprozesse in elektronischen Lehr-Lernsituationen (Elektronisches Praktikum). In: Fremdsprachen und Hochschule 72, 7-25.

Würffel, Nicola (2006): Strategiegebrauch bei Aufgabenbearbeitungen in internetgestütətem Selbstlernmaterial. Tübingen: Narr.

Würffel, Nicola (2008): Kooperatives Schreiben im Fremdsprachenunterricht: Potentiale des Einsatzes von Social-Software-Anwendungen am Beispiel kooperativer Online-Editoren. In: Zeitschrift für Interkulturellen Fremdsprachenunterricht 13/1, 26 (http:/ / zif.spz.tu-darmstadt.de/jg-13-1/beitrag/Wuerffel1.htm). 
Christoph Chlosta, Matthias Jung (Hrsg.) (2010): DaF intergriert: Literatur - Medien - Ausbildung. Tagungsband der 36. Jahrestagung des Fachverbandes Deutsch als Fremdsprache 2008. Göttingen: Universitätsverlag, 145-157.

\section{Carola Strobl (Gent, Belgien)}

\section{Blended Learning im universitären Fachsprachenunterricht: eine Fallstudie im Fach Wirtschaftsdeutsch an der Universität Gent}

\section{Vorbemerkungen}

Bietet Blended Learning, hier: die Kombination von Präsenzunterricht mit individuellem Online-Lernen, im universitären Fachsprachenunterricht einen Mehrwert gegenüber dem reinen Präsenzunterricht? Wenn ja, worin liegt dieser Mehrwert konkret und welche Bedingungen müssen dafür erfüllt sein? Wie erfahren die Studenten einen derartig zweigeteilten Lernweg, wo liegen ihrer Ansicht nach Schwächen und Stärken?

Dies sind die zentralen Fragestellungen der 2006 bis 2007 durchgeführten Fallstudie für das Fach Wirtschaftsdeutsch an der Universität Gent, Belgien. Im vorliegenden Beitrag werden wir zunächst kurz auf die Ziele und Rahmenbedingungen des Projektes eingehen. Danach erläutern wir das Kurskonzept näher, wobei die Gestaltung des individuellen Onlinemoduls zentral steht. Im Folgenden werden ausgewählte Ergebnisse von anonymen Online-Befragungen der Kursteilnehmer präsentiert und zum Abschluss versuchen wir eine Einordnung des Projektes innerhalb der CALL-Landschaft.

\section{Ziele und Rahmenbedingungen des Projektes}

Das Projekt wurde im Rahmen eines Förderprogramms für innovative Unterrichtsformen der Universität Gent finanziert. Eines der Hauptziele bestand darin, die Möglichkeiten und Grenzen der Online-Lernumgebung der Uni Gent, die auf der 
Open-Source-Software Dokeos beruht, und der hauseigenen Testumgebung für den universitären Fachsprachenunterricht auszuloten. Des Weiteren sollten zwei schwerwiegende Faktoren für die breitere Anwendung der Lernform untersucht werden: einerseits die Akzeptanz seitens der Studenten und andererseits die Rentabilität aus der Sicht der Inhaltsentwickler, also der Dozenten.

Gleich vorneweg soll festgehalten werden, dass diesem Projekt kein experimenteller Forschungsansatz zu Grunde liegt; es geht hier vielmehr um so genannte Aktionsforschung. Auf der Basis von Literaturstudien und eigenen Erfahrungen mit der Lernform in Workshops wurde das Kurskonzept gestaltet. Unsere Ergebnisse beruhen auf quantitativen und qualitativen Untersuchungen der Studentenerfahrungen durch Fragebögen und Portfolios und auf eigenen Beobachtungen. Wir können hier also auch keine handfeste Aussage über messbare Effektivität bieten. Gerne verweisen wir an dieser Stelle stellvertretend für ähnliche Studien auf die jüngst veröffentlichte Doktorarbeit von Rebecca Launer, die auf der Basis von quantitativen Untersuchungen mit einem ,vorsichtigen ,Ja““ (Launer 2008: 222) auf die Frage antwortet, ob Blended Learning eine ernstzunehmende alternative Lernmethode darstellt.

Für die Einordnung der präsentierten Ergebnisse ist es notwendig, die Rahmenbedingungen des Projektes abzustecken. Der Kurs Wirtschaftsdeutsch an der Uni Gent ist ein einsemestriger Kurs mit drei Wochenstunden. Der Kurs wird in erster Linie als Wahlpflichtfach an Volkswirtschaftler im Bachelorstudium und an Studenten des Aufbaustudiums Wirtschaftskommunikation angeboten. Gleichzeitig steht er als freies Wahlfach Hörern aller Fakultäten offen, und zieht also beispielsweise auch Ingenieursund Informatikstudenten an. Das Zielpublikum ist also sehr heterogen in Hinsicht auf Studienhintergrund und -erfahrung. Da es der einzige Kurs seiner Art an der Uni ist und Wirtschaftsdeutsch demnach nicht auf verschiedenen Niveaus unterrichtet wird, ergibt sich auch für das Eingangsniveau der Studenten eine teilweise starke Diskrepanz, die von A1 bis B2 reichen kann, wobei die meisten Studenten sich im Bereich von A2 bis B1 befinden. Nur der Tatsache, dass alle Studenten Niederländisch als Muttersprache haben - das dem Deutschen in vielerlei Hinsicht nahe verwandt ist - ist es zu verdanken, dass in einer solchen Situation überhaupt ein Unterricht stattfinden kann, der für alle Studenten einigermaßen Gewinn bringend ist. Gerade durch diese Ausgangssituation erschien uns der Kurs sozusagen als ein ideales Experimentierfeld für Blended Learning. Wir gingen dabei von der Annahme aus, dass vor allem die schwächeren Studenten - also diejenigen mit einem niedrigeren Eingangsniveau - von dieser Kursform profitieren würden. Bei der Präsentation der Umfrageergebnisse kommen wir noch darauf zurück; hier sei aber schon vorausgeschickt, dass sich diese Annahme als trügerisch erwiesen hat.

\section{Kurskonzept und Gestaltungsprinzipien des Onlinemoduls}

Das individuelle Onlinelernen über die E-Lernplattform der Universität Gent fand parallel zum Präsenzunterricht statt. Zwei von den drei Wochenstunden waren für den Präsenzunterricht reserviert. Für die Arbeit mit dem individuellen Onlinemodul (im 
Folgenden IO abgekürzt) wurde eine Stunde als Richtwert vorgegeben, wobei die tatsächliche Arbeitsdauer je nach Sprachstand und anderen individuellen Faktoren recht unterschiedlich ausfiel (ca. 0,5 bis 2 Stunden). Es ist eine allgemein anerkannte Tatsache, dass der Erfolg eines Blended Learning Kurses eng mit dem Grad der Verzahnung der kombinierten Lernkanäle zusammenhängt (vgl. z.B. Launer 2008: 217). Dieser Zusammenhang war hier einerseits inhaltlich durch den unmittelbaren thematischen Bezug des IO auf die jeweils vorangehende Unterrichtseinheit und andererseits formal durch Feedback in zwei Richtungen, ausgehend sowohl von den Studenten als auch von der Dozentin, gegeben. Für dieses „Zweirichtungs-Feedback“ legten die Studenten elektronische Lernerportfolios auf der Lernplattform an. Darin notierten sie wöchentlich kurz ihre Erfahrungen und Probleme mit dem IO. Diese Erfahrungsberichte wurden dann von der Dozentin mit Anmerkungen und korrigierten Kurztexten aus dem IO - die nicht mit Hilfe von automatischem Feedback korrigierbar waren - versehen. Schließlich wurden wöchentlich im Präsenzunterricht die häufigsten inhaltlichen Probleme und Fehler aus dem jeweiligen IO kurz besprochen. Die Lernerportfolios dienten uns daneben auch als Informationsquelle für die qualitative Beurteilung der Lernform. Diese Methode hat sich als eine sehr aufschlussreiche, aber gleichzeitig sehr zeitaufwändige Lehr- und Lernerfahrung erwiesen. Daher verzichten wir in der Nachprojektphase auf das Portfolio und beschränken das Feedback auf die exemplarische Korrektur häufiger Fehler im Präsenzunterricht.

Bei einer Aufteilung des Lernwegs in zwei Phasen über unterschiedliche Kommunikationskanäle müssen inhaltliche und formale Entscheidungen gefällt werden: Welche Lerninhalte sollen in der Präsenzphase vermittelt werden, welche im IO individuell erworben? In diesem Kurs war dabei die Basisüberlegung bestimmend, dass der Präsenzunterricht maximal für das Trainieren mündlicher Fertigkeiten genutzt werden sollte. Gleichzeitig sollten so viele unterschiedliche Fertigkeiten und Lerninhalte wie möglich im IO angebracht werden, um die Grenzen dieses Kanals abzutasten. In formaler Hinsicht ist die grundlegende Frage zu klären, ob das IO dem Präsenzunterricht als Vorbereitungsphase vorgeschaltet wird oder ob hier vielmehr die Inhalte aus dem Präsenzunterricht nachbereitet und vertieft werden. Angesichts der Heterogenität der Gruppe schien es uns ratsam, letzteren Weg zu gehen und zunächst im Präsenzunterricht eine gemeinsame Ausgangsbasis in inhaltlicher und sprachlicher Hinsicht zu schaffen. Der Unterricht war dabei stark kommunikativ-pragmatisch orientiert, inspiriert vom Lehrwerk „Unternehmen Deutsch“ (Conlin 2001, Neubearbeitung). Wortschatz und Grammatik wurden implizit in Dialogsituationen angewandt und variiert, begleitet durch kurze Basiserläuterungen sprachlicher und grammatischer Strukturen. Des Weiteren fanden Kurzpräsentationen belgischer Tochterunternehmen deutscher Firmen durch die Studenten statt. Der Schwerpunkt lag also deutlich beim Training der mündlichen Ausdrucks- und Reaktionsfähigkeit.

Die im Präsenzunterricht eingeführten sprachlichen Strukturen und Redemittel wurden im IO, teilweise durch Audio- und Videomaterial gestützt, individuell geübt und vertieft. Aber nicht nur Übung fand hier statt. Um die Möglichkeiten einer Onlinelern- 
umgebung auszuloten, wurden ab und zu Erarbeitungsphasen eingebaut, in denen sich die Studenten selbständig anhand von schrittweise aufgebauten interpretationsgerichteten Aufgaben zu komplexeren Texten und Graphiken Lerninhalte aneignen sollten. Schließlich mussten die Studenten auch jede Woche auf der Basis von Vorlagen einen kurzen Text schreiben. Insgesamt lag also der Schwerpunkt im IO auf der Erweiterung und Vertiefung von Kenntnissen und auf dem Einüben der rezeptiven Fertigkeiten sowie in eingeschränktem Maße auch der Schreibfertigkeit.

Die Heterogenität des Sprachstandes der Kursteilnehmer erforderte ein Gestaltungsprinzip des Onlinemoduls, das Flexibilität erlaubte. Daher wurde das Modul grundsätzlich in einen fakultativen Übungs- und einen verpflichtenden Testteil aufgeteilt (vgl. Abbildung 1).

\begin{tabular}{|l|l|l|}
\hline $\begin{array}{l}\text { Teil 1: } \\
\text { Fakultative Übungen }\end{array}$ & $\begin{array}{l}\text { Teil 2: } \\
\text { Autorenumgebung: } \\
\text { Hot Potatoes }\end{array}$ & $\begin{array}{l}\text { Pflichttest } \\
\text { Autorenumgebung: } \\
\text { curios (U Gent) }\end{array}$ \\
\hline $\begin{array}{l}\text { Niveau 3: fortgeschritten } \\
\text { Kombinations- und } \\
\text { Transferaufgaben }\end{array}$ & $\begin{array}{l}\text { Vorbe- } \\
\text { reitung } \\
\text { für } \\
\text { Niveau 3: fortgeschritten } \\
\text { Kombinations- und } \\
\text { Transferaufgaben }\end{array}$ \\
$\begin{array}{l}\text { Niveau 2: mittelschwer } \\
\text { Einüben einzelner } \\
\text { Kenntniselemente }\end{array}$ & $\begin{array}{l}\text { Niveau 2: mittelschwer } \\
\text { Testen einzelner } \\
\text { Kenntniselemente }\end{array}$ \\
\hline $\begin{array}{l}\text { Niveau 1: leicht } \\
\text { Wiederholung der Basisregeln }\end{array}$ & \\
\hline
\end{tabular}

Abb. 1: Gestaltungsprinzip des Onlinemoduls

Der Übungsteil diente der sprachlichen und inhaltlichen Vorbereitung des wöchentlichen Tests und wurde in einem Lernpfad präsentiert. In einem Lernpfad können die Übungen in didaktisch oder inhaltlich sinnvoller Abfolge angeordnet werden. Außerdem ermöglicht er dem Kursleiter eine bessere Übersicht über den Fortgang des Lernprozesses. Aufgaben und Übungen wurden auf drei verschiedenen Niveaus, entsprechend dem Schwierigkeitsgrad und dem Grad der Verarbeitungstiefe, angeboten. Die Niveaus waren angegeben, so dass die Studenten selbst je nach Vorkenntnis die für sie passenden Übungen auswählen konnten. Allerdings zeigte sich, dass die wenigsten Studenten ihren Kenntnisstand sicher einschätzen konnten und den Mut hatten, Aufgaben auf Niveau 1 zu überspringen. Eine Automatisierung dieses Selektionsprozesses durch 
ein adaptives System, wobei die Studenten jeweils abhängig vom Resultat der vorigen zur folgenden Übung weitergeleitet werden, könnte hier gute Dienste leisten.

Für die Erstellung der beiden Teile des Onlinemoduls wurden unterschiedliche Autorenwerkzeuge benutzt. Da mit diesem Projekt unter anderem die Nutzerfreundlichkeit der an der Universität Gent entwickelten Testumgebung geprüft werden sollte, wurde der Pflichttest in dieser Umgebung erstellt und durchgeführt. Für den Übungsteil hingegen schien uns die Autorensoftware HotPotatoes interessanter: Die Eingabe ist auf Grund der nutzerfreundlichen Bedienoberfläche sehr zeitsparend. Außerdem ist die Software mit ihren verschiedenen Übungstypen und den Feedbackmöglichkeiten auf die spezifischen Anforderungen des Fremdsprachenlernens zugeschnitten. Neben den selbst erstellten Übungen enthielten die Lernpfade auch Links zu Übungen im Internet.

\section{Beurteilung des Blended Learning-Konzepts durch die Kursteilnehmer}

\subsection{Allgemeine Informationen zu den Beurteilungsgrundlagen und den Teil- nehmern}

Das besondere Augenmerk galt in diesem Projekt dem Nutzer, hier also den Studenten. Um die Nutzerperspektive zu untersuchen, wurden zweierlei Beurteilungsgrundlagen herangezogen: Die qualitative Untersuchung basierte sich auf den oben erwähnten elektronischen Portfolios, in denen der Umgang mit dem IO, die Lernerfahrungen und der Lernfortschritt der Kursteilnehmer individuell aufgezeichnet und kommentiert wurden. Für die quantitative Analyse wurden umfassende anonyme Befragungen in der Muttersprache zu Beginn und am Ende des Projektes durchgeführt. Bei der Besprechung einzelner Ergebnisse aus den Befragungen werden wir vergleichend auf das Pilotprojekt eingehen, das im Jahr 2006 stattfand. Einige Unterschiede zur Hauptprojektphase 2007 sollten zum besseren Verständnis kurz erwähnt werden: Das IO war in verschiedener Hinsicht noch nicht ausgereift: Die Übungen nahmen nicht deutlich genug Bezug auf die Präsenzphase und wiesen teilweise noch formale Mängel auf; die Evaluation des Pilotprojektes war sehr hilfreich in Hinsicht auf die Verbesserung von Übungsgestaltung und -formen. Außerdem war das IO noch nicht in Übungs- und Testphase unterteilt, was unter anderem mit sich brachte, dass die Arbeit am IO nicht in die Evaluation der Studenten einbezogen wurde. Im Hauptprojektjahr 2007 hingegen konnten die Kursteilnehmer durch erfolgreiches Ablegen der wöchentlichen Tests maximal insgesamt $10 \%$ der Gesamtnote erzielen - nur eine kleine, aber durchaus wirkungsvolle extrinsische Motivation. Des Weiteren war die Zusammensetzung des Kurses sehr unterschiedlich: 2006 belegten 30 der insgesamt 39 Teilnehmer den Kurs als Wahlpflichtfach im Wirtschaftsstudium, acht Ingenieursstudenten kamen als Freie Hörer und nur eine Studentin befand sich im Aufbaustudium „Wirtschaftskommunikation“. Durch Lehrplanänderungen sank der Anteil der Wirtschaftsstudenten 2007 auf acht ab. Die Anzahl der Teilnehmer des Aufbaustudiums dagegen stieg auf 13 und dadurch war ihr Anteil im Hauptprojektjahr wesentlich höher. 


\subsection{Ergebnisse der Befragungen}

\subsubsection{Hintergrund der Kursteilnehmer}

Im Folgenden werden ausgewählte Ergebnisse der Befragungen vorgestellt und kommentiert. Dabei gehen wir zunächst auf Angaben zum Hintergrund der Kursteilnehmer ein, bevor wir zur eigentlichen Beurteilung kommen. Bei der Nennung von zwei Prozentzahlen unmittelbar hintereinander bezieht sich jeweils die erste auf das Jahr 2006 und die zweite auf 2007. Zunächst ist festzuhalten, dass dieser Kurs für einen Großteil der Studenten, nämlich für 90\% bzw. 75\%, die erste Erfahrung mit Blended Learning darstellte. Der höhere Anteil an Studenten mit Vorerfahrung 2007 kann möglicherweise auf die insgesamt längere Studienerfahrung zurückgeführt werden. Wir konnten auch feststellen, dass in diesem Segment keine „,digitale Kluft“ erkennbar ist: 2006 besaßen 62\% der Studenten einen eigenen Laptop und hatten Breitbandanschluss von der Studentenwohnung aus. 47\% (52\%) der gesamten Arbeitszeit im IO fielen folglich auf diese Umgebung. Da die flämischen Studenten beinahe ausnahmslos am Wochenende nach Hause fahren, war es auch aufschlussreich, dass 98\% der Elternhäuser über Breitbandanschluss verfügten. Insgesamt 45\% (31\%) der Online-Arbeit fand dort statt. Nur im Projektjahr 2007 war auch das Rechenzentrum der Fakultät mit 16\% ein weiterer relevanter Online-Arbeitsort.

Eine wichtige Hintergrundfrage bezog sich auf die Einstellung der Kursteilnehmer zur Arbeit am Computer im Allgemeinen. Wie in Abbildung 2 zu sehen ist, arbeitet etwa die Hälfte der Studenten gern am Computer, während die andere Hälfte keine ausgesprochen negative oder positive Haltung dem Computer gegenüber hat. Nur eine verschwindende Minderheit sieht den Computer als notwendiges Übel an.

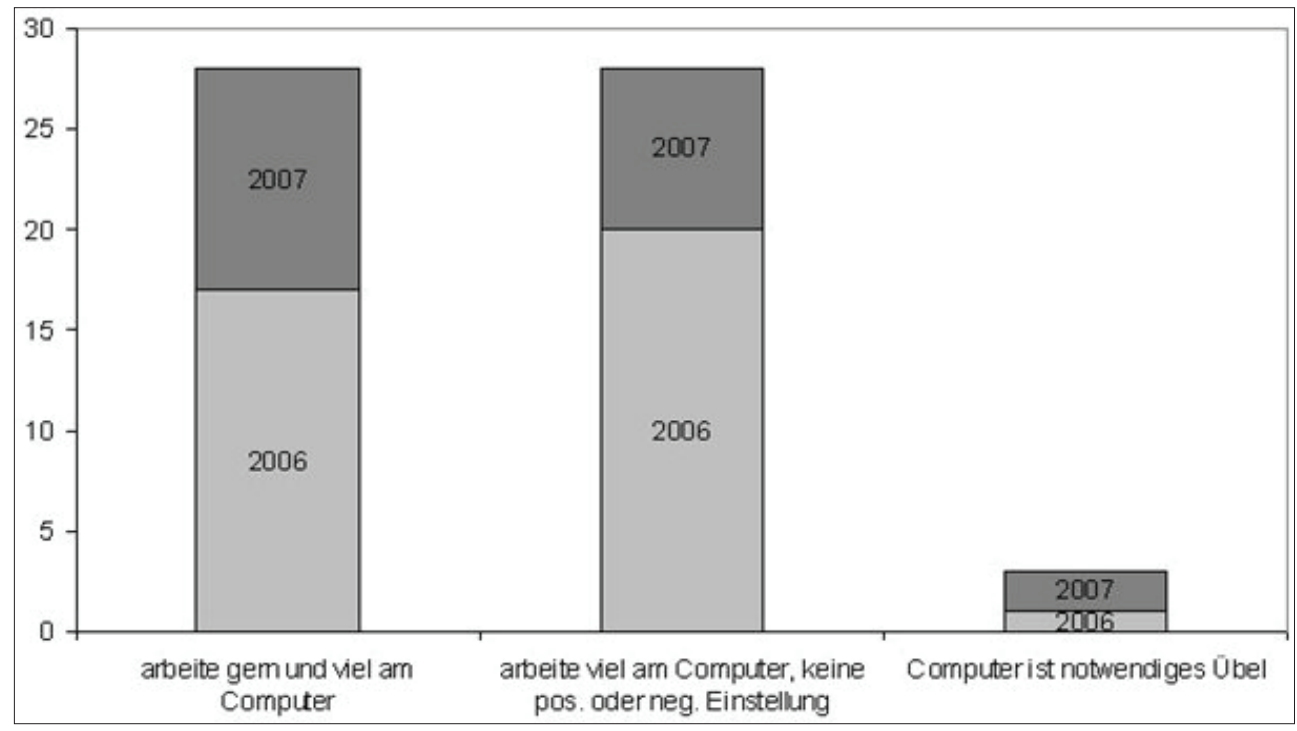

Abb. 2: Einstellung zur Arbeit am Computer $(n=60)$ 
Bei der Korrelation dieser Basis-Einstellungsfrage mit den Einstellungsfragen zum IO stellte sich, wie zu erwarten, ein signifikanter positiver Zusammenhang heraus. Wer also sowieso gerne am Computer arbeitete, bewertete das IO in allen Aspekten besser und hatte eher das Gefühl, dadurch Fortschritte erzielt zu haben.

\subsubsection{Beurteilung des Onlinelernens im Allgemeinen und gesondert nach sprachlichen Kompetenzbereichen}

Kommen wir nun zu den Bewertungen. Hierfür sollten die Studenten ihren Zustimmungsgrad zu bestimmten Aussagen auf einer fünfstufigen Likert-Skala angeben, wobei „1“ die geringste Zustimmung und „5“ die höchste Zustimmung bedeutete. Zunächst wurden die Studenten gebeten, ein allgemeines Werturteil in Hinsicht auf Effektivität bzw. Lernfreude im IO abzugeben (siehe Abbildung 3). Was den Spaß anbelangt, sind sich die Lerner aus beiden Projektjahren einig: er hält sich offenbar in Grenzen. Die Effektivität wurde jedoch 2007 deutlich höher eingeschätzt als im Vorjahr. Dies könnte auf die Tatsachen zurückzuführen sein, dass das IO inhaltlich und formal verbessert war und/ oder dass es einen integrativen Bestandteil des Kurses inklusive der Evaluation darstellte.

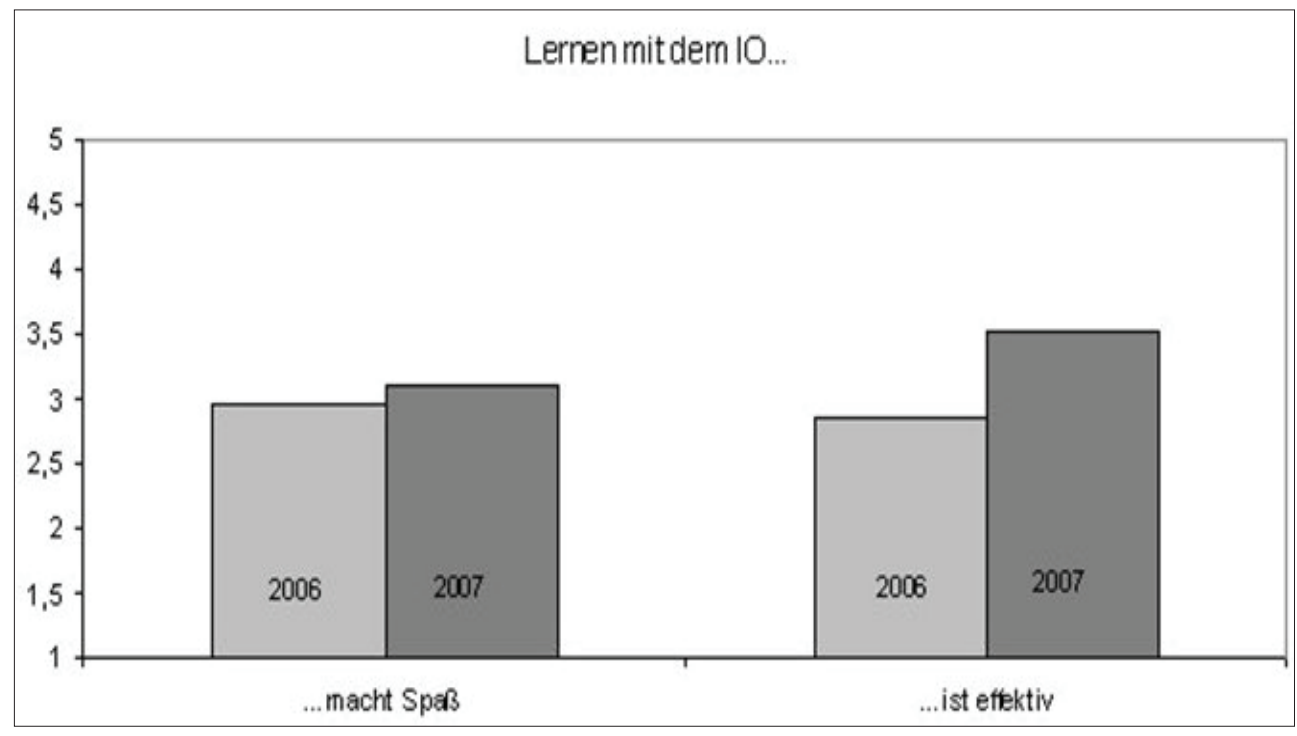

Abb. 3: Einschätzung von Effektivität und Lernfreude bei der Arbeit im Individuellen Onlinemodul (IO) (Likert-Skala: 1 = keine Zustimmung ... 5 = volle Zustimmung)

Dieser deutliche Unterschied zeigte sich auch in der Bewertung des IO in Hinblick auf die Effektivität bei der Verbesserung von bestimmten sprachlichen Bereichen (Abbildung 4). Hier fällt auf, dass das IO vor allem für die Kenntnisentwicklung (Grammatik und Wortschatz) als hilfreich empfunden wurde. Für uns war die zurückhaltende Bewertung des Aspektes ,,selbständiger Umgang mit der Sprache“ überraschend. Auf Grund der ständigen Verpflichtung zum selbständige Problemlösen im IO hätten wir hier positivere Werte erwartet. Möglicherweise ist dieses Ergebnis aber auch auf eine 


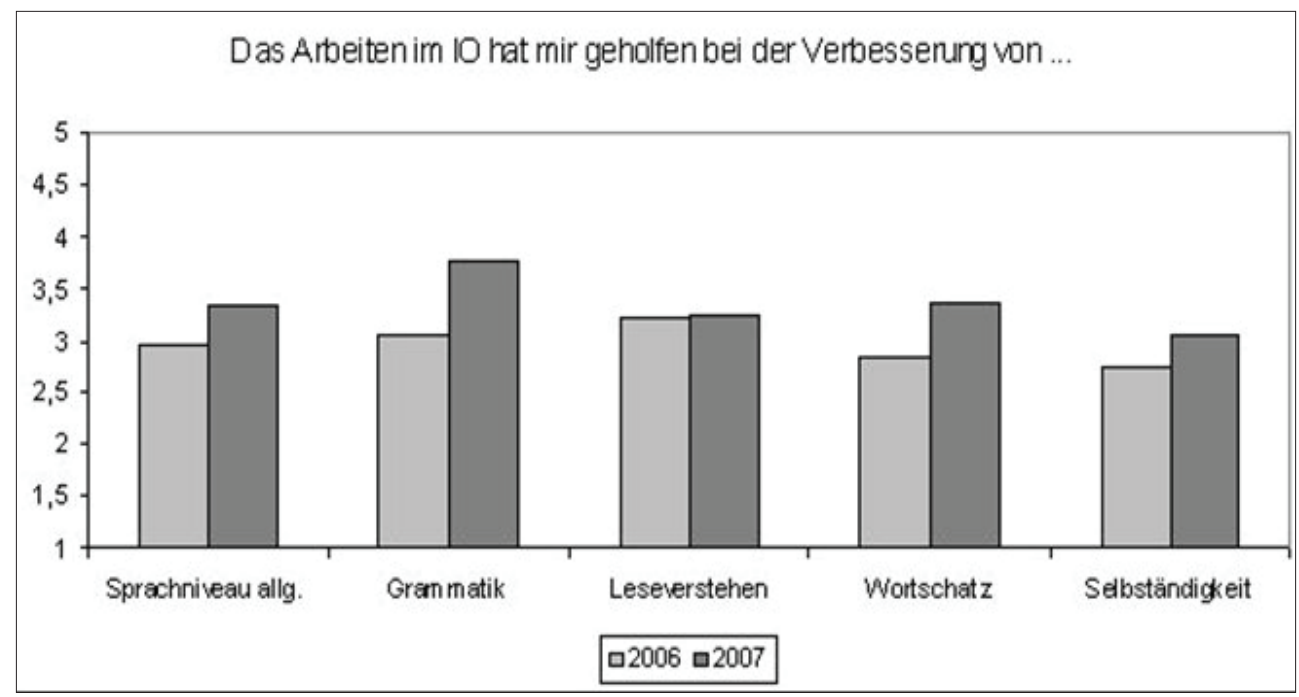

Abb. 4: Bewertung des IO nach dem Grad der Verbesserung von bestimmten sprachlichen Bereichen (Likert-Skala: 1 = keine Zustimmung ... 5 = volle Zustimmung)

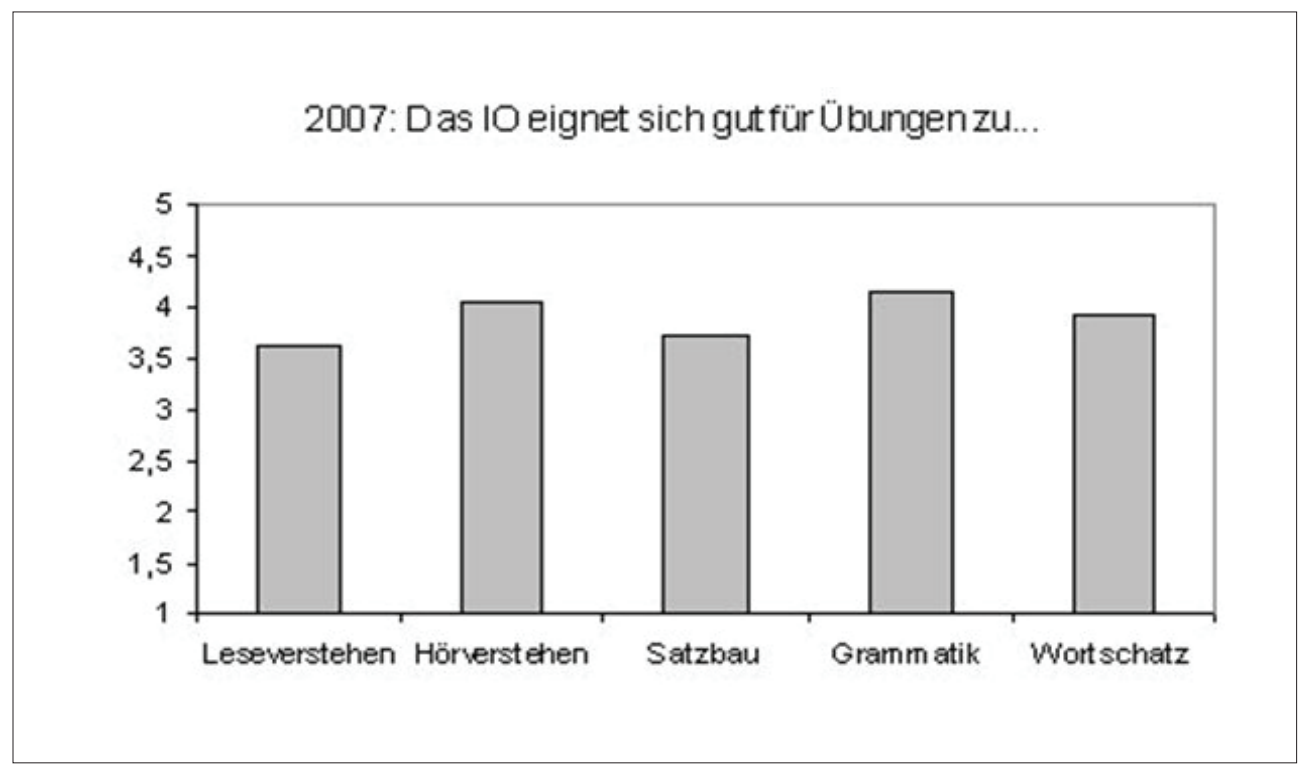

Abb. 5: Eignung des Onlinemoduls zum Üben bestimmter sprachlicher Bereiche (Likert-Skala: $1=$ keine Zustimmung ... 5 = volle Zustimmung) 
unterschiedliche Interpretation des Begriffs „Selbständigkeit“ zurückzuführen. Tatsächlich haben die Studenten im IO ja relativ wenig selbständig mit Sprache auf der Ebene der Produktion experimentiert. Die Selbständigkeit bezog sich für uns vielmehr auf die durch Tipps und Feedback geleitete induktive Suche nach der grammatikalisch bzw. lexikalisch richtigen Form. Wir werden hierauf noch zurückkommen, wenn wir das Projekt innerhalb der CALL-Landschaft einordnen.

Interessant erscheint uns auch der Vergleich der Antworten auf diese und eine ähnlich formulierte Frage (nur in der Umfrage von 2007), nämlich die nach der Einschätzung der prinzipiellen Eignung des IO zum Üben bestimmter sprachlicher Bereiche (Abbildung 5). Es zeigt sich, dass das Potential des IO deutlich höher eingeschätzt wurde als die bei sich selbst festgestellte tatsächliche Verbesserung. Möglicherweise hängt dies schlicht mit der kurzen Dauer des Kurses zusammen. Vielleicht sind aber die Studenten auch der Meinung, dass das Potential eines IO in diesem Kurs nicht voll ausgeschöpft wurde. Leider verfügen wir nicht über entsprechende Daten, um dieses Ergebnis genauer interpretieren zu können.

Die Studenten wurden auch gebeten, die verschiedenen Übungstypen im IO in Hinsicht auf Effizienz und Lernfreude zu beurteilen (Abb. 6). Dabei lässt sich ein umgekehrt proportionales Verhältnis beider Faktoren feststellen: Je mehr Spaß eine Übung macht, desto weniger haben die Studenten das Gefühl, etwas dazuzulernen. Des Wei-

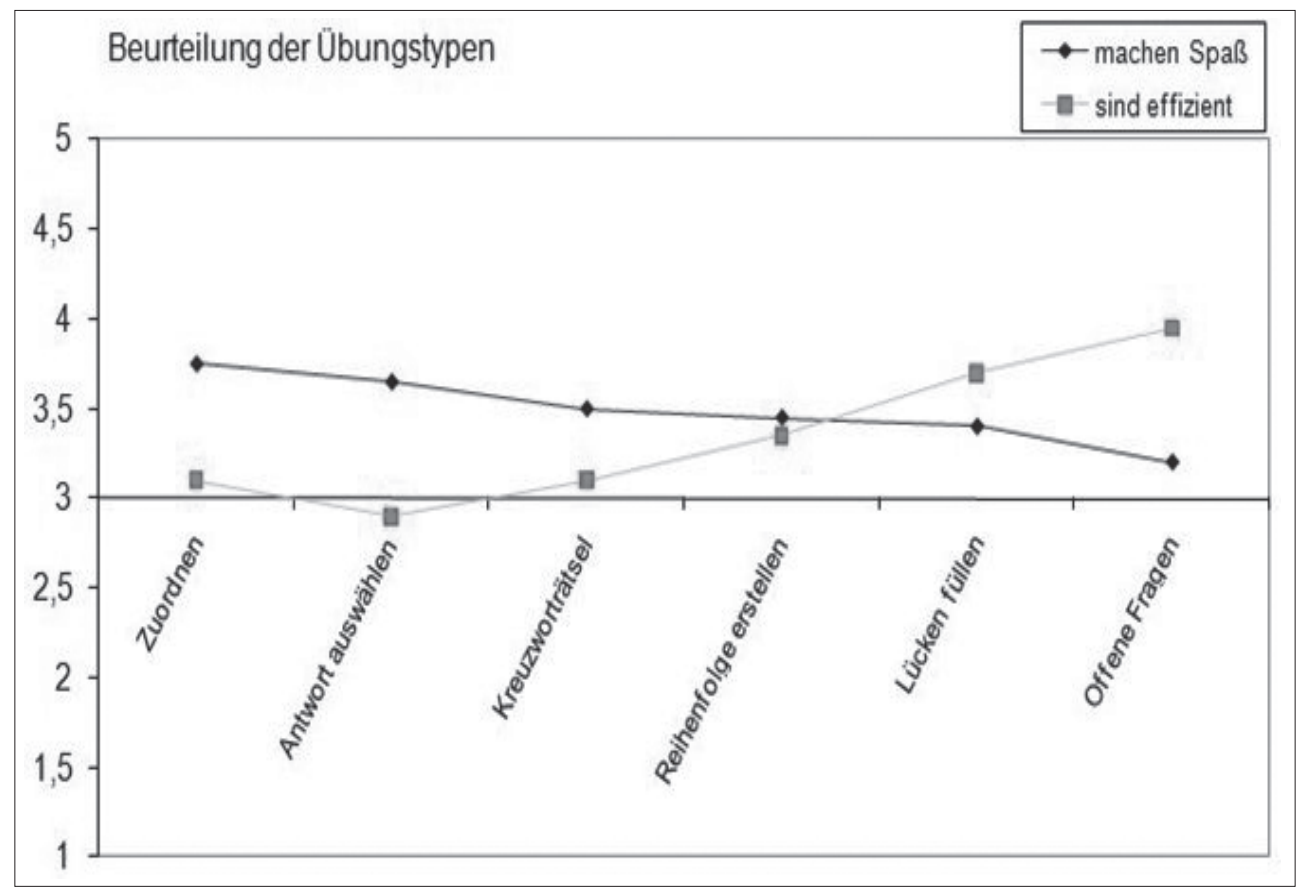

Abb. 6: Beurteilung der Übungstypen im IO nach Effizienz und Lernfreude (Likert-Skala: $1=$ keine Zustimmung ... 5 = volle Zustimmung) 
teren beobachten wir auch eine direkte Entsprechung zwischen der Menge an Text, die selbst eingegeben werden muss und der empfundenen Effizienz: Zuordnungs- und Multiple-Choice-Fragen, bei denen nichts selbst eingegeben werden muss, machen zwar Spaß, aber man lernt nach Einschätzung der Nutzer weniger dabei. Am anderen Ende des Spektrums werden die offenen Fragen, die eine selbständige Textproduktion erfordern und für die es kein unmittelbares automatisiertes Feedback geben kann, als weitaus lernintensiver beurteilt.

\subsubsection{Gewichtung von technischen und inhaltlichen Problemen beim Onlinelernen}

Mit der Umfrage wollten wir uns auch eine Übersicht über etwaige technische und inhaltliche Probleme der Studenten beim Umgang mit dem IO verschaffen. Wie bereits erwähnt, war die individuelle Arbeitsdauer sehr unterschiedlich. Etwa ein Drittel aller Studenten brauchte wesentlich länger als die vorgesehene Stunde, um den wöchentlichen Lernpfad zu durchlaufen. Technische und inhaltliche Gründe hierfür hielten sich die Waage. Die inhaltlichen Probleme hatten oft mit der (zu komplexen) Aufgabenstellung und mit dem (nicht ausreichenden oder missverstandenen) Feedback zu tun: Die ungewohnte Lernumgebung bei gleichzeitiger physischer Abwesenheit des Dozenten der dadurch eine völlig andere Rolle erhält als in der Präsenzphase - kann leicht zu Verunsicherung führen. Daher muss sich auch die didaktische Herangehensweise diesen anderen Bedingungen anpassen: Gute Aufgaben für eine IO zu entwickeln, bei denen u.a. äußerste Kleinschrittigkeit geboten ist, erfordert auch von erfahrenen Fremdsprachenlehrern einen Lernprozess.

Nur 14\% (19\%) der Studenten hatten keine technischen Probleme bei der Arbeit im IO. Die meist genannten Hindernisse waren auf Softwareeinstellungen zurückzuführen: Übungen konnten nicht geöffnet werden (z.B. wegen zu langer Ladedauer oder Einstellungen der Antivirensoftware) bzw. schlecht visualisiert werden (Browsereinstellungen), Audiodateien konnten nicht störungsfrei abgespielt werden (z.B. weil dafür spezifische Player nötig waren oder weil es, beim Gebrauch von iTunes, Interferenz mit der lokalen Musikbibliothek gab). Probleme dieser Art scheinen nicht vermeidbar, so lange man mit clientabhängiger Software arbeitet. Das zur Verfügung gestellte Internetforum zur Hilfe bei allgemeinen und ad hoc auftretenden Problemen, in dem die Dozentin regelmäßig Lösungsansätze und Tipps formulierte, wurde kaum genutzt. Offenbar bedarf es einer zusätzlichen Motivation, um die Studenten selbst zum passiven Gebrauch eines Forums anzuregen, wie beispielsweise der Auslagerung von Informationen, die zur Lösung der Aufgaben im IO nötig sind. Als weniger störanfällig in technischer Hinsicht hat sich die hauseigene Testumgebung der Universität Gent erwiesen, da hier alle nötigen Anwenderprogramme zentral auf dem Server ausgeführt werden, so dass man damit (beinahe) unabhängig von der installierten Software auf den individuellen Computern arbeiten kann. Hier sind es dann wiederum plötzliche Serverausfälle, die für ärgerlichen Verlust getaner Arbeit sorgen können. 
Zusammenfassend lässt sich aus unserer Beobachtung sagen, dass technische Probleme noch immer ein wichtiges Hindernis auf dem Weg zum reibungslosen Onlinelernen darstellen. Hier sei stellvertretend aus dem Portfolio einer Studentin zitiert: ${ }^{1}$

„Insgesamt bin ich keine Befürworterin des IO. Ich hatte viel zu viele technische Probleme und hatte das Gefühl, mich mehr mit dem PC als mit der Sprache - um die es doch eigentlich gehen sollte - beschäftigen zu müssen.“

\subsubsection{Abschließende quantitative Gesamtbewertung und Interpretation auf Grund von Teilnehmeraussagen}

Mit der letzten, zukunftsgerichteten Frage wollten wir ein allgemeines Bild über die Zufriedenheit der Studenten mit dem Blended Learning-Konzept erhalten. Diese Frage musste in den beiden Projektjahren unterschiedlich formuliert werden, da für die Kursteilnehmer 2006 die Aussicht auf einen weiteren Deutschkurs nach dem selben System reell war, während im zweiten Jahr der Aufbaukurs Wirtschaftsdeutsch aus dem Lehrplan gestrichen wurde und die Frage somit rein hypothetisch war. Obwohl also die Antworten nicht unmittelbar vergleichbar sind, lässt sich eine ähnliche Grundtendenz erkennen (siehe Abbildung 7): Jeweils rund 50\% der Befragten möchte bzw. würde einen weiteren Sprachkurs nach dem Blended Learning-Konzept wählen. Dieses Ergebnis war in zweifacher Hinsicht überraschend für uns: Trotz der insgesamt deutlich negativeren Bewertung des IO durch die Kursteilnehmer im Pilotprojektjahr 2006 - im Schnitt lag die Zustimmungsrate bei den positiv formulierten Einstellungsfragen um 0,4 Bewertungspunkte auf der Likert-Skala niedriger als 2007 - gab es bei der Beantwortung dieser Kernfrage keinen signifikanten Unterschied. Die zweite Überraschung war negativer Art: wir hätten erwartet bzw. erhofft, mit dem Projekt mehr Teilnehmer für diese Kursform erwärmen zu können.

\section{Ich möchte nächstes Jahr nach demselben System Deutsch weiterlernen (2006)}

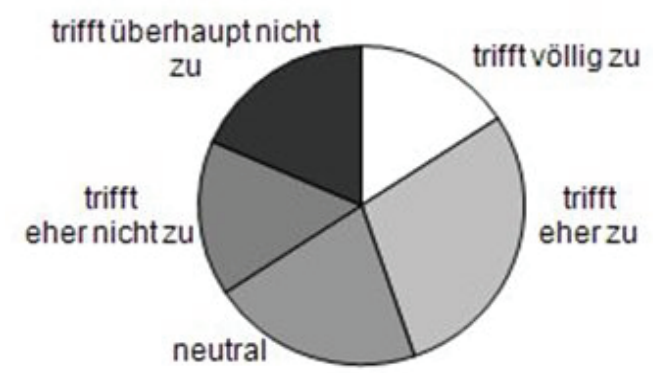

\section{Würden Sie nochmals einen BL-Sprachkurs wählen?}

(2007)

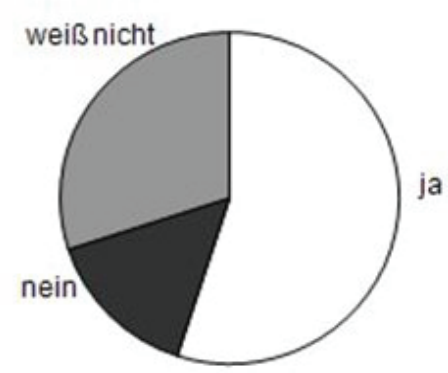

Abb. 7: Vergleich der Antworten auf die abschließende Kernfrage

$\overline{1}$ Alle Zitate aus den Lernerportfolios wurden aus dem Niederländischen übersetzt. 
Eventuelle Gründe für den zurückhaltenden Enthusiasmus der Studenten können wir in ihren Portfolios finden. Hier erfahren wir Genaueres über ihre Befürchtungen und Vorbehalte dieser für sie neuen Lernumgebung gegenüber:

„Ich lerne vor allem durch Aufschreiben; im IO muss ich tippen statt schreiben; daher fürchte ich, dass ich weniger im Gedächtnis behalte.“

„Ich brauche Papier und Bücher zum Lernen; ein IO ist nichts für mich.“

„Meiner Meinung nach ist das IO sehr unpraktisch in Hinsicht auf die Examenvorbereitung: man muss alle Übungen erst noch einmal machen, bevor man sie pauken kann.“

„Mein Sprachniveau ist zu niedrig, um Online-Übungen zu machen. Im Unterricht könnte ich einfach nachfragen, wenn ich nicht weiter weiß.“

Das letzte Zitat bringt uns zur oben erwähnten Ausgangsidee zurück, dass vor allem Studenten mit geringeren Vorkenntnissen vom Onlinelernen im eigenen Rhythmus profitieren könnten. Wie sich herausgestellt hat, haben Akzeptanz und (Einschätzung der) Rentabilität der Lernumgebung nichts mit dem Eingangsniveau der Studenten zu tun. Vielmehr ist hierfür eine Grundeinstellung dem Sprachenlernen gegenüber ausschlaggebend: Wer gerne „,selbständig“ - wobei dieser Begriff mit den in Punkt 3.2.2 erwähnten Einschränkungen zu verstehen ist - seinen Weg durch das Neuland der Fremdsprache sucht, tut dies (auch) gern im IO. Unabhängig von dieser Einstellung waren Studenten mit geringeren Vorkenntnissen trotz vielfältiger angebotener OnlineHilfsmittel und reichem automatischen Feedback leichter verunsichert im IO.

Im Zitat über die Examensvorbereitung offenbart sich ein Problem, das typisch für Studenten aus Ländern mit stark kenntnisorientiertem Fremdsprachenerwerb im Sekundarunterricht ist: Das Lernen einer Fremdsprache ist für sie eng verbunden mit dem Auswendiglernen von Wissensstoff. Das Bewusstsein, dass Anwendung durch Üben ein mindestens ebenso wichtiger Faktor im Fremdsprachenerwerb ist, muss durch gezielte Vermittlung metakognitiver Kompetenz gefördert werden. Man könnte anschließend an diese Überlegung die provokative Frage stellen, ob die heutige Studentengeneration (in Flandern) überhaupt „reif“ für das Onlinelernen ist. Obwohl diese Generation das Internet wie selbstverständlich sowohl für gezielte Informationssuche als auch für Freizeitkommunikation und Unterhaltung nutzt, scheint das Internet als Lernumgebung (noch) nicht auf allgemeine Akzeptanz zu stoßen:

„In theory, the Net Generation should learn better through Internet courses because they have been surrounded by computers all their lives and know how to use the technology already. Just the opposite is true. Net Geners like the social interaction that comes with being in class with their peers. While they may use technology in their daily lives, relationships are a driving force in the learning process." (McNeely 2005: 4.5)

Ein möglicher Lösungsansatz für das Problem lässt sich aus dem letzten Satz des Zitats von McNeely destillieren: Solange die Lerner in der Onlinephase relativ isoliert arbeiten und nicht in Interaktion miteinander treten, kann man den „Nerv“ dieser Net Generation nicht treffen. 


\section{Einordnung des Projektes innerhalb der CALL-Landschaft}

Der Begriff der Interaktion im Internet als Lernumgebung führt uns zu der abschlieBenden Einordnung des vorliegenden Projektes innerhalb der Landschaft des Computer Assisted Language Learning (CALL). Stephen Bax schlägt in seinem Aufsatz „CALL Past, Present and Future" (2003) eine Einteilung in drei Phasen vor, die er mit den Begriffen „Restricted“, „Open“ und „Integrated“ etikettiert. Das vorliegende Projekt weist, wenn man Bax folgt, sowohl Merkmale der ersten als auch der letzten Phase auf: In die Phase des „Restricted CALL“ lässt es sich auf Grund der relativ hohen Anzahl geschlossener Übungen nach dem pattern drill-Prinzip und der minimalen Interaktion zwischen den Lernern einordnen. Andererseits lassen sich auch zukunftsweisende Merkmale des „Integrated CALL“ feststellen: Das Onlinelernen ist integrativer Bestandteil sowohl des Curriculums als auch jeder Unterrichtseinheit. Bax zufolge müsse man einen Zustand der „Normalisierung" anstreben, um das volle Potential von online unterstützten Lernformen ausnutzen zu können. Diesen Zustand beschreibt er folgendermaßen:

„[...] the stage when the technology becomes invisible, embedded in everyday practice and hence ,normalised ${ }^{e}[. .$.$] CALL will reach this state when computers [...] are used$ every day by language students and teachers as an integral part of every lesson $[. .$. Teachers and students will use them without fear or inhibition, and equally without an exaggerated respect for what they can do.“ (Bax 2003: 23f.)

Welche formalen und inhaltlichen Faktoren das Erreichen dieses normalisierten $\mathrm{Zu}$ standes begünstigen, ist unter anderem abhängig von den unterschiedlichen Ausgangsbedingungen, unter denen Fremdsprachen mit Unterstützung durch eine Onlineumgebung gelernt werden. Die Antwort muss demnach auf der Basis von sorgfältig protokollierten und analysierten Projekten immer wieder neu gesucht und formuliert werden.

\section{Literatur}

Bax, Stephen (2003): CALL - past, present and future. In: System 31/1, 13-28.

Conlin, Christine (2000): Unternehmen Deutsch. Neubearbeitung. Amsterdam u.a.: Intertaal (Lizenzausgabe des gleichnamigen Lehrwerks des Klett-Verlags für den niederländischsprachigen Markt).

Launer, Rebecca (2008): Blended Learning im Fremdsprachenunterricht. Konzeption und Evaluation eines Modells. Dissertation: München, Ludwig-Maximilians-Universität, http:// edoc.ub.uni-muenchen.de/8905/ (12.12.2009).

McNeely, Ben (2005): Using Technology as a Learning Tool. Not Just the Cool New Thing. In: Oblinger, Diana G.; Oblinger, James L. (Hrsg.): Educating the Net Generation. Educause e-book, Chapter 4, http://www.educause.edu/educatingthenetgen/ (12.12.2009). 

Christoph Chlosta, Matthias Jung (Hrsg.) (2010): DaF intergriert: Literatur - Medien - Ausbildung. Tagungsband der 36. Jahrestagung des Fachverbandes Deutsch als Fremdsprache 2008. Göttingen: Universitätsverlag, 159-172.

\section{Karin Madlener (Berlin)}

\section{Computergestützte Anwendungen in Spracherwerb und Spracherwerbsforschung: Die „Multimedia- Chunks für Deutsch als Fremdsprache“}

\section{Vorbemerkung}

Die „Multimedia-Chunks für Deutsch als Fremdsprache“ ${ }^{\text {“1 }}$ wurden von Brigitte Handwerker konzipiert und von der Autorin des vorliegenden Beitrags in einer elektronischen Lern- und Forschungsumgebung implementiert.

Der Beitrag, der sich als „Werkstattbericht“ versteht, enthält einen kurzen Überblick über die Zielsetzungen und theoretischen Hintergründe des Projekts (Kap. 2) sowie eine Darstellung des Prototypen der interaktiven Lern- und Forschungsumgebung (Kap. 3) und einen Ausblick auf Optionen für die Weiterentwicklung (Kap. 4). Der Ansatz (Handwerker 2002, 2004, 2008, Handwerker; Madlener 2006, 2009: Kap. 1-4), geht von folgenden Grundfragestellungen aus:

Mit welchem Input und mit welcher Art der Inputverarbeitung können langfristige Erfolge im Fremdsprachenerwerb erzielt werden? Ist Chunking potenziell eine erfolgreiche Strategie auch für den Fremdsprachenerwerb? Wie können Verarbeitungsprozesse gesteuert bzw. optimiert werden?

1 Weitere Informationen unter http://www.linguistik.hu-berlin.de/daf/forschung/multimedia-chunks. php 


\section{Zielsetzungen und Hintergründe}

Das Projekt „Multimedia-Chunks für Deutsch als Fremdsprache“ verfolgt ein doppeltes Ziel: (a) Es wurde eine computergestützte Lernumgebung entworfen, die in Selbstlernkontexten ebenso wie als punktuelle Unterstützung von DaF-Unterricht im Klassenzimmerkontext einsetzbar sein soll. (b) Diese wird zugleich als Instrument für die Überprüfung bestimmter Hypothesen der Spracherwerbsforschung genutzt.

Es ist somit an der Schnittstelle zwischen computergestützten Anwendungen für den Fremdsprachenerwerb (Computer Assisted Language Learning, kurz CALL) und Anwendungen für die computergestützte Fremdsprachenerwerbsforschung (Computer Assisted Second Language Acquisition Research, kurz CASLR) angesiedelt. Im CALL-Kontext (vgl. z.B. Chapelle 2001, Doughty; Long 2003) stehen Überlegungen zu erwerbstheoretisch und psycholinguistisch begründbaren Gestaltungskriterien für computergestützte Lernumgebungen im Mittelpunkt. Diese betreffen u.a. Fragen der Lernerautonomie und Lernersteuerung (z.B. Aufmerksamkeitslenkung, Strategietraining), des Aufbaus von Lernszenarien und der Darstellung von Lerninhalten (z.B. Inputstrukturierung, Verfügbarkeit expliziter Wissensressourcen und negativer Evidenz), der Gestaltung von interaktiven Aufgaben und Korrekturoptionen. Als CASLR-Instrument soll die Online-Version der „Multimedia-Chunks für Deutsch als Fremdsprache“ eingesetzt werden, um authentische Daten zum Nutzerverhalten von Lernern zu erheben; mit Hilfe einer Protokollfunktion können Lerner unauffällig und detailliert bei der Nutzung der Online-Version der Lernumgebung beobachtet werden (Abfolge besuchter Seiten, Nutzung einzelner Komponenten, Bearbeitungszeiten etc.). Ziel ist es, die so erhobenen Nutzerdaten in Kombination mit Sprachstandstests hinsichtlich der Rückschlüsse auszuwerten, die sie u.a. auf das Spracherwerbspotenzial der Materialien, auf spezifische Erwerbsschwierigkeiten und -fortschritte, Verarbeitungsprozesse und -strategien erlauben.

Die zu erwartenden Erkenntnisse sollen zum einen zurückfließen in die Evaluierung und Weiterentwicklung der Lernumgebung, zum anderen der Überprüfung aktueller Hypothesen der Spracherwerbsforschung zu Effekten von Verarbeitungssteuerung und Inputstrukturierung sowie der Entwicklung neuer erwerbstheoretischer Hypothesen dienen. Es ergeben sich folgende Zusammenhänge (vgl. Handwerker; Madlener 2009: Abb. 5.13):

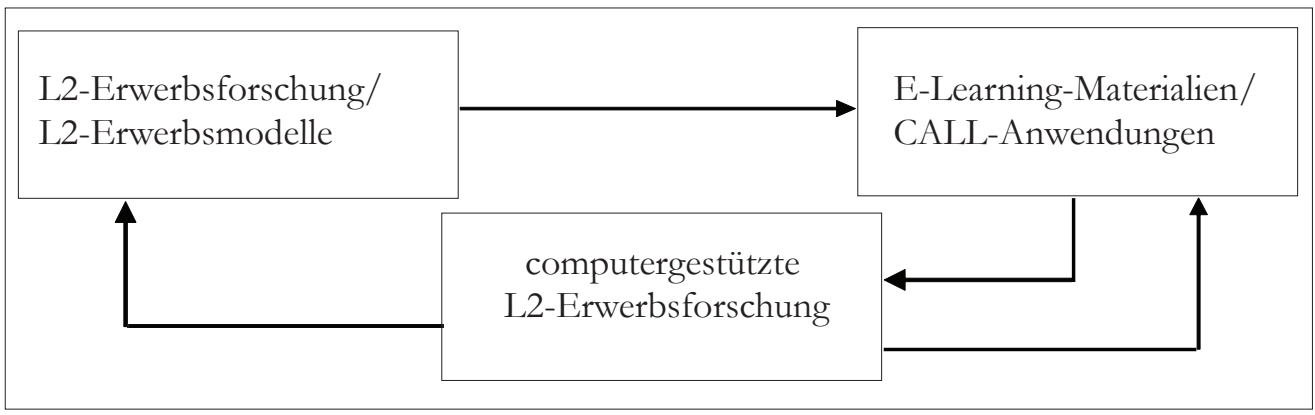

Abb. 1: Zusammenhänge 
Bevor im nächsten Kapitel Aufbau und Komponenten des Prototypen der Lernumgebung beschrieben werden, sollen in knapper Form die theoretischen Hintergrundannahmen des Forschungsansatzes von Handwerker umrissen werden, auf denen die Entwicklung und Anwendung der „Multimedia-Chunks für Deutsch als Fremdsprache“ basiert. Ausführlichere Darstellungen finden sich in Handwerker (2002, 2008) und Handwerker; Madlener (2009, Kap. 1-4).

\subsection{Chunks und Chunking}

Unter Chunks werden hier als Ganzes gespeicherte und wieder abrufbare, zwar intern komplexe und analysierbare, aber holistisch verarbeitete Informationseinheiten verstanden, d.h. Bündel aus Informationen über sprachliche Form und Bedeutung/Funktion in einem bzw. für einen bestimmten Kontext (Handwerker 2002, 2008). Chunking bezieht sich entsprechend auf die holistische Verarbeitung von teil- oder unanalysierten sprachlichen Sequenzen, die sich im Rückgriff auf Routinen, konstruktionelle Muster und vorgefertigte Äußerungsteile niederschlägt (Handwerker 2002, 2008).

Angesichts der Evidenz für die grundlegende Relevanz von Chunking-Prozessen für (a) den rezeptiven wie produktiven Sprachgebrauch in der Muttersprache (L1) ${ }^{2}$ und (b) den Erstsprachenerwerb (L1-Erwerb) ${ }^{3}$ zielt der Ansatz darauf ab, Chunking als Verarbeitungsstrategie auch im Fremdsprachenerwerbskontext (L2-Erwerb) zu forcieren. Statt auf Einzelwörter und Regeln für deren Kombinationsmöglichkeiten zu fokussieren, sollen die Lerner dazu gebracht werden, nützliche „Brocken“ (Chunks) unterschiedlicher Größe und Zusammensetzung aus dem Input zu übernehmen (zu memorisieren bzw. zu kopieren) und in einer ersten Phase holistisch zu verarbeiten. Ein umfangreicher Vorrat an vorgefertigten Einheiten unterschiedlicher Bauart und Einsatzmöglichkeiten soll dem Lerner eine bestmögliche Annäherung an (a) Flüssigkeit (produktions-/rezeptionsstrategischer Einsatz von Chunks) und (b) Idiomatizität des L1-Sprechers (kommunikationsstrategischer Einsatz) erlauben. Später können und sollen die Chunks dann aber auch aufgebrochen und analysiert werden ${ }^{4}$ - ohne dass dabei aber die vorgefertigten Einheiten für flüssigen und idiomatischen Abruf verloren gehen (Handwerker 2002, 2008). Bei der Analyse sollen nicht nur lexikalische Einheiten isoliert werden, sondern vor allem die grammatischen Informationen über Regelhaftigkeiten, die in den Chunks "gefroren“ sind (Handwerker 2002, 2008, siehe auch MacWhinney 2008: 358) extrapoliert werden. Chunks dienen so als Datenbasis für Abstraktionsprozesse von festen, konkreten Sequenzen über Muster mit Leerstellen hin zu schematisierten Konstruktionen (vgl. Ellis 2003) und sollen essentiell zur (Weiter-)Entwicklung der Lernergrammatik beitragen (Handwerker 2002, 2008).

2 Siehe z.B. Pawley; Syder (1983) zur nativelike fluency (Flüssigkeit) und nativelike selection (Natürlichkeit); Sinclair (1991: Kap. 8) zur Gegenüberstellung von open-choice vs. idiom principle; Wray (2002: Kap. 4-5) zu Funktionen der so genannten formulaic language in der L1.

3 Siehe z.B. Wray (2002: Kap. 6-7), Ellis (1996, 2003), Tomasello (2006), Lieven; Tomasello (2008).

4 Allerdings nicht automatisiert bis hin zur kleinsten möglichen Teileinheit, sondern nur jeweils so weit wie nötig bzw. sinnvoll, vgl. Wray (2002) zur needs-only analysis. 
Insgesamt soll die forcierte Nutzung von Chunks im skizzierten Forschungsansatz also (a) zu so genannten Tuning-Effekten führen, d.h. Erwartungshaltungen bezogen auf möglichen bzw. wahrscheinlichen Input ${ }^{5}$ aufbauen helfen, welche verarbeitungsentlastend wirken und den Lerner auch in der Produktion flüssiger und idiomatischer werden lassen; und (b) als Auslöser für die (unbewusste oder bewusste) ${ }^{6}$ Ableitung von Konstruktionsmöglichkeiten, grammatischen Informationen und morphosyntaktischen Regelhaftigkeiten dienen.

\subsection{Chunking, Inputstrukturierung und Formfokussierung}

Empirische Studien (z.B. Bolander 1989, Myles; Hooper; Mitchell 1998, 1999, Weinert 1994) deuten darauf hin, dass Chunking tatsächlich auch im gesteuerten L2-Kontext eine erfolgreiche Strategie sein kann, die allerdings nicht so automatisch zum Erwerbserfolg führt wie im L1-Kontext. ${ }^{7}$

Handwerker (2002, 2008) geht daher davon aus, dass lehrerseitig bestimmte, gezielt verarbeitungssteuernde Maßnahmen getroffen werden müssen, um tatsächlich auch bei erwachsenen DaF-Lernern erwerbsfördernde Chunking- sowie spätere, Fossilisierungen verhindernde Analyseprozesse zu den Chunks auszulösen:

a) kontrollierte Inputstrukturierung bzw. Inputmanipulation (input enhancement nach Sharwood Smith 1993, Wong 2005) im Sinne einer impliziten Formfokussierung (Doughty; Williams 1998, Schifko 2008); die Frequenz ${ }^{8}$ und Salienz der Zielstrukturen im Input wird bewusst erhöht (Inputflut, maximales Angebot positiver Evidenz), wodurch die Wahrscheinlichkeit steigen soll, dass die Lerner auf relevante formale Merkmale des Inputs aufmerksam werden und die notwendigen Form-Bedeutungszuordnungen vornehmen, so dass möglichst reicher Intake $e^{9}$ entsteht; siehe Handwerker (2002, 2008), Handwerker; Madlener (2009: Kap. 1, 2);

b) explizite Formfokussierung ${ }^{10}$ durch ein den vorstrukturierten Input ergänzendes Angebot an Rastern und Regeln (Handwerker 2002) bzw. Lerner- und Lehrerbedürfnissen angemessenen konstruktionsgrammatischen Instrumenten (Handwerker

5 Genauer gesagt bezüglich der (gemeinsamen) Auftretenswahrscheinlichkeiten bestimmter sprachlicher Formen mit bestimmten Funktionen in bestimmten Kontexten.

${ }^{6}$ Im ersten Falle sind die Chunks Grundlage für implizite distributionelle Frequenzanalysen, wie sie für den L1-Erwerb angenommen werden (Ellis 2003), im zweiten Falle Datenbasis für aktives lernerseitiges Hypothesentesten.

7 Vgl. Wrays (2002). Hinweise auf frühe Fossilisierungen im ungesteuerten Erwerb, wo unter Vernachlässigung der erwerbsstrategischen Nutzung von Chunks der kommunikationsstrategische Einsatz zu dominieren scheint, und zur Tendenz bei Erwachsenen, bei Vernachlässigung der grammatischen Informationen lediglich lexikalische Einheiten aus den vorgefertigten Sequenzen zu extrahieren.

8 Zur Frage der Frequenz im Allgemeinen siehe z.B. Ellis (2008), zu detaillierten Hypothesen bezüglich des Zusammenspiels von type frequency und token frequency im Input siehe Bybee (2008); zur Frage der Wirksamkeit speziell von skewed input siehe Goldberg; Casenhiser (2008).

9 Verstanden als der Teil des Inputs, der im Kurzzeitgedächtnis wenigstens minimal verarbeitet wurde und damit für weitere Verarbeitungsschritte bzw. spätere Erwerbsprozesse zur Verfügung steht (VanPatten 2004: 7).

10 Im Sinne eines immer bedeutungszentrierten focus on form, nicht eines pattern drill-ähnlichen focus on forms, siehe Diskussion in Doughty (2001), Long; Robinson (1998). 
2008), expliziten Wissensressourcen (Lexika, Lernergrammatiken, Konstruktionsangaben, Bildmaterial etc.) und negativer Evidenz ${ }^{11}$, kombiniert z.B. mit Consciousness Raising-Aufgaben (Schifko 2008, Sharwood Smith 1997) und/oder Elementen der Verarbeitungssteuerung (Processing Instruction, Wong 2004; siehe Handwerker 2008, Handwerker; Madlener 2009: Kap. 2);

c) explizite Aufforderung zum Chunking und Training der kommunikations- und produktionsstrategischen, vor allem aber auch der erwerbsstrategischen Nutzung vorgefertigter Sequenzen (siehe Handwerker 2002: 228f. zum „Chunk-Sammler" ${ }^{6}$ ).

\subsection{Spracherwerbspotenzial in CALL-Anwendungen}

Für den E-Learning-Kontext formulieren CALL- und CASLR-ForscherInnen (z.B. Chapelle 1998, 2001, Doughty; Long 2003) in deutlicher Parallele zum dargestellten Ansatz folgende Ansprüche bezüglich der Komponenten potenziell erwerbsfördernder Lernumgebungen bzw. -materialien:

a) reicher, elaborierter, vorstrukturierter Input mit verarbeitungsentlastenden natürlichen Redundanzen und salienten, hochfrequenten Zielstrukturen;

b) Gelegenheiten für lernerseitige, verständniserleichternde und vertiefende Inputmodifikationen (interactional modifications bei Chapelle 2001) wie z.B. ein direkt mit dem Input verlinktes Angebot an Lexika und Glossaren, Visualisierungen, Rastern und Lernergrammatiken etc. mit dem Ziel einer

c) impliziten und/oder expliziten Formfokussierung bzw. Aufmerksamkeitslenkung auf kritische formale Inputmerkmale, auch in Form von typographischen oder anderen visuellen Hervorhebungen, Korrekturoptionen bei interaktiven Aufgaben inklusive negativer Evidenz;

d) Förderung von Chunking-Prozessen (Doughty; Long 2003: 63).

\section{Der Prototyp der Lernumgebung}

Die folgende Darstellung des Aufbaus, der Komponenten und Inhalte der Lernumgebung soll verdeutlichen, wie die im skizzierten Ansatz berücksichtigten linguistischen und spracherwerbstheoretischen Hypothesen und Erkenntnisse in Verbindung mit e-didaktischen Überlegungen bei der Entwicklung einer multimedialen, interaktiven (Selbst-) Lernumgebung umgesetzt wurden, welche Angebote für Chunking und Tuning sowie für unterstützende implizite und explizite Formfokussierung bzw. Aufmerksamkeitslenkung also, dem Forschungsansatz entsprechend, im Prototypen der „MultimediaChunks für $\mathrm{DaF}^{\text {“ }}$ zur Verfügung stehen. ${ }^{12}$

\subsection{Aufbau und exemplarische Lerngegenstände}

Die Lernumgebung gliedert sich in drei Bereiche, nämlich eine horizontale Menüleiste, eine vertikale Navigationsleiste und einen Arbeitsbereich (Abb. 1). In der Menüleiste sind die lerngegenstandsübergreifenden Funktionen angesiedelt, u.a. Projektinformationen,

11 Verstanden als das Aufzeigen der Grenzen der Generalisierbarkeit bzw. Anwendbarkeit bestimmter Regeln.

12 Für eine detailliertere Beschreibung siehe Handwerker; Madlener (2009: Kap. 5). 
Druckfunktion und allgemeine Navigationshilfe sowie Glossar, Lexikon und Konstruktionsangaben (siehe hierzu 2.3). Die Hauptnavigation am linken Rand ist immer sichtbar und soll dem Lerner die Orientierung in der Lernumgebung erleichtern, d.h. die Verortung des Lerners im Rahmen der Lernumgebung, das Angebot an weiteren Lernbereichen und die Verfügbarkeit von Materialien und Inhalten transparent machen. Um den Lernern im besten Sinne einer Lernerautonomie die größtmögliche Freiheit in der individuellen Wahl von Lernzielen und Lernpfaden zu garantieren, sind in den „Multimedia-Chunks für Deutsch als Fremdsprache“ keine obligatorischen Lernwege vorgegeben, sondern können alle Lerngegenstände in beliebiger Reihenfolge bearbeitet werden; auch verschiedene Herangehensweisen werden berücksichtigt, insofern als die erste Annäherung an die einzelnen Lerngegenstände jeweils gleichermaßen über die medialen Inputangebote (eher holistisch) wie über die Texte oder Aufgaben (eher analytisch) erfolgen kann. Um die Lerner allerdings nicht durch zu hohe Ansprüche an ihre Selbstlernorganisationsfähigkeit zu überfordern, ${ }^{13}$ kann die Anordnung der Elemente in der Hauptnavigation (z.B. Input $>$ Aufgaben $>$ Grammatiktext oder Videos $>$ Fotos $>$...) als unverbindliche Lernwegsempfehlung verstanden werden.

Die für den Prototypen ausgewählten und umgesetzten Lerngegenstände sind an der Schnittstelle zwischen Lexikon und Grammatik (Handwerker 2004) angesiedelt und fokussieren auf prädikative Partizipialkonstruktionen (sein + Partizip 1, sein + Partizip 2) der so genannten psychischen Wirkungsverben ${ }^{14}$ des Deutschen (enttäuschen, begeistern, freuen, ärgern...). Involviert sind dementsprechend die allgemeinen Lernbereiche „Verbklassen“ und „Partizipien im Deutschen“ sowie die spezifischeren Lerngegenstände „psychische Wirkungsverben“ mit dem Schwerpunkt auf Konstruktionen mit „Partizip 1“/,Partizip 2“.15

\subsection{Vorstrukturierter reicher Input mit Chunk-Angeboten}

Die multimediale Umsetzung der Inputangebote in der Lernumgebung ist nicht dem edutainment ${ }^{16}$-Gedanken geschuldet, sondern soll (a) eine vertiefte, multisensorielle, kognitive und emotionale Inputverarbeitung ermöglichen und (b) speziell bei den fokussierten Lerngegenständen eine natürliche Rezeptionshilfe darstellen, insofern als der oft nicht verbalisierte, für das Verständnis aber grundlegende sogenannte Primärvorgang ${ }^{17}$ durch die visuelle Situierung leichter erschließbar ist.

13 Und um sie implizit auf eine mit den Hypothesen zum Chunking kompatible, d.h. eher holistische Herangehensweise zu orientieren.

14 Zur Abgrenzung der Verbklasse siehe Rapp (1997).

15 Für eine detaillierte linguistische Begründung der Auswahl des Gegenstandsbereichs siehe Handwerker; Madlener (2006, 2009).

16 Zusammensetzung aus den englischen Wörtern education (Bildung) und entertainment (Unterhaltung); bezeichnet ein Konzept der elektronischen Wissensvermittlung, bei dem die Inhalte spielerisch und gleichzeitig unterhaltsam vermittelt werden. Ziel ist die Steigerung der Lernmotivation durch die Präsentation von Inhalten in diversen medialen Formaten (Computerspiele, Fernsehen etc.), siehe http:// de.wikipedia.org/wiki/Edutainment (25.05.2010).

17 Terminus nach Rapp (1997); gemeint ist z.B. bei der Äußerung von Der Film ist umwerfend im Normalfall nicht Begeisterung über die Gestaltung der DVD-Hülle, sondern über eine besondere Schauspieleroder Regieleistung, d.h. der Film ist höchstwahrscheinlich angesehen worden; siehe auch die Überlegungen in Handwerker (2004). 
Implizit formfokussierenden, vorstrukturierten Input mit Chunk-Angeboten bietet die Lernumgebung in drei Formaten, und zwar Videosequenzen, Fotosequenzen und Flash-Animationen. Die Videos ermöglichen das thematische, lexikalische und grammatische Eintauchen in den Lerngegenstand; in den lockeren Rahmen der „Linguistischen Nachrichten“ (Abb. 1) werden hier kurze, durch einen Nachrichtensprecher eingeführte Filmclips (z.B. „Ölkatastrophe in Galizien“, „Preiserhöhung im öffentlichen Nahverkehr“, „Abriss des Palasts der Republik“ etc.) eingebettet. Die Filmskripts wurden korpusbasiert entwickelt und enthalten im Sinne einer Inputflut die Zielstrukturen in großer Zahl, wodurch Tuning-Prozesse ausgelöst werden sollen. In den auf den Videosequenzen beruhenden Fotosequenzen, die zur Vertiefung genutzt werden können, werden die Situationen aus den Filmen wieder aufgenommen und einzelne, auf den Kern reduzierte Exemplare der Zielstrukturen im Bildkontext präsentiert; im schriftlichen Input sind die Zielstrukturen typographisch hervorgehoben, dazu ist jeweils auditiver Input beliebig wiederholbar verfügbar. Die Flash-Animationen sollen der (lexikalischen) Erweiterung und der Ermunterung zum Transfer der Konstruktionen auf neue situative Kontexte dienen. Die angebotenen zielstrukturenhaltigen Äußerungen (a) sind kommunikativ relevant, für die Lerner also nutzbringend als Ganzes speicherund wieder abrufbar (Chunking), sollen aber (b) durch weitgehend parallelen Aufbau auch zur Hypothesenbildung über die Zielstrukturen einladen (Aufbrechen gesammelter Chunks und Regelextraktion).

\subsection{Explizitere Formfokussierungs- und Inputmodifikationsangebote}

Neben impliziter Formfokussierung durch Inputflut und typographische Hervorhebungen etc. ist ein breit gefächertes Angebot mehr oder weniger explizit formfokussierender Ressourcen gegeben, welche - innerhalb bedeutungszentrierter Kontexte - die Aufmerksamkeit der Lerner auf kritische formale Merkmale des Inputs lenken sollen.

So kann der Ablauf der Videosequenzen durch die Lerner gesteuert werden (Pausen-, Rückspul-/Wiederholungsfunktion). Zu allen Videos stehen weiterhin ein Skript zum Ausdrucken sowie ein Skript zum Mitlesen zur Verfügung. Die einzelnen Videoclips werden jeweils in vier verschiedenen Versionen angeboten: ohne Untertitel, mit vollen Untertiteln und mit Einblendung der Zielpartizipien bzw. der vollständigen Zielkonstruktionen. Aus den Fotosequenzen und Animationen führen jeweils direkte Links in den relevanten Lexikoneintrag und zur Konstruktionserklärung. In den Lexikoneinträgen zu den psychischen Wirkungsverben sind neben korpusbasierten Beispielsätzen vor allem Informationen zu den syntaktischen Verwendungsmöglichkeiten des jeweiligen Verbs und der Partizipien, Hinweise zu synonymen und bedeutungsnahen Verben sowie zu lexemspezifischen Besonderheiten und Blockierungen hinterlegt. Die Konstruktionsangaben enthalten eine Aufschlüsselung der entsprechenden Konstruktion und Angaben zu parallelen, bereits bekannten Konstruktionen (z.B. sein + Adjektiv).

Zu jedem Lernbereich bzw. Lerngegenstand stehen außerdem (a) Grammatiktexte, gedacht für Lerner und Lehrer, und (b) in Umfang und Tiefe der Informationen gestaffelte Texte zum Hintergrundwissen für Lerner, Lehrer und linguistisch Interessierte 
sowie perspektivisch auch (c) zusammenfassende Grammatikanimationen ${ }^{18}$ zur Verfügung. Unbekannte grammatische, linguistische und spracherwerbstheoretische Termini können im Glossar nachgeschlagen werden, zudem werden zur Erleichterung des Verständnisses englische Versionen der Texte angeboten, eine Erweiterung auf andere Muttersprachen der Lerner soll folgen.

Mit den interaktiven Aufgaben und den verfügbaren Hilfe- und Korrekturfunktionen ${ }^{19}$ haben die Lerner schließlich die Möglichkeit, neben der bisher beschriebenen positiven Evidenz (Input und Erklärungen) auch negative Evidenz zu ihren Hypothesen zu erhalten. Die Aufgaben können sowohl zum Üben und aktiven Hypothesentesten als auch zur Überprüfung von Lernfortschritten genutzt werden. Bedingt durch die Schwierigkeiten, vorgefertigtes Feedback zu Produktionsaufgaben effektiv zu gestalten, stehen in den „Multimedia-Chunks für Deutsch als Fremdsprache“ lediglich Multiple Choice-, Drag \& Drop- sowie einige stark gelenkte Produktionsaufgaben zur Verfügung. Bei der Entwicklung der einzelnen Übungen wurde besonders darauf geachtet, (a) jeweils einen relevanten Situationsbezug herzustellen und (b) im Sinne der Theorie der Inputverarbeitung/Verarbeitungssteuerung (Input Processing/Processing Instruction, siehe VanPatten 2004, Wong 2004) eine notwendigerweise gleichzeitig bedeutungs- wie formfokussierende Verarbeitung und damit die Herausbildung bzw. Verstärkung der jeweiligen Form-Bedeutungszuordnungen (form-meaning connections bei VanPatten et al. 2004) zu forcieren, so dass auch hier möglichst reicher Intake entsteht.

\section{Der nächste Schritt: Die „Multimedia-Chunks für DaF“ in Moodle}

Angesichts der bisherigen, durchaus als positiv zu wertenden Ergebnisse zur Frage nach den Möglichkeiten, auch in Selbstlernumgebungen Verarbeitungs- und Erwerbsstrategien zu beeinflussen und insbesondere Chunking-Prozesse zu forcieren (Handwerker; Madlener 2009: Kap. 6), haben sich als nächster Teilschritt für die Weiterentwicklung der vorliegenden Lern- und Forschungsumgebung folgende Überlegungen ergeben: Wäre es möglich, den Einsatz von Chunking als Verarbeitungsstrategie bei den Nutzern der bisher entwickelten Materialien zu forcieren, indem mehr Möglichkeiten für Interaktion nicht nur zwischen Lerner und Programm/Input, sondern auch zwischen Lernern, d.h. in der peer group, sowie zwischen Lernern und einem Tutor bestünden? Würden Chunking-Prozesse spontan häufiger stattfinden, wenn zur eigenständigen Beschäftigung mit den Inputmaterialien entsprechende Kommunikationsmöglichkeiten (und damit auch ein gewisser Kommunikationsdruck) kämen? Ließe sich durch ein zusätzliches Angebot freier Produktionsgelegenheiten also einerseits die Nutzung von Chunks als vorgefertigten Sequenzen in bekannten Kontexten, andererseits deren Aufbrechen für eine eigene kreative Produktion auf Grundlage der entdeckten Muster erhöhen? Würde sich damit auch der Erwerbseffekt deutlich verbessern, könnte also im Idealfalle der Zusammen-

18 Im Prototypen exemplarisch für die Frage „Wie funktioniert ein psychisches Wirkungsverb?“

19 Für eine detaillierte Beschreibung der verfügbaren Aufgabentypen, der Entwicklungsprinzipien und implementierten Hilfs- und Korrekturfunktionen siehe Handwerker; Madlener (2009: Kap. 5). 
hang zwischen Chunking, Aufbrechen von Chunks und Weiterentwicklung der Lernerinterimsgrammatik deutlicher als bisher nachgewiesen werden?

Zur Überprüfung dieser Fragestellungen werden in einem von der Multimedia-Kommission des Akademischen Senats der Humboldt-Universität im Rahmen der Multimedia-Förderung 2008 geförderten Teilprojekt mit dem Titel ,'Tutorisierte interaktive und kollaborative Moodle-Kurse für Deutsch als Fremdsprache“ auf Basis der vorhandenen Materialien mehrere Teillerngegenstände entwickelt und in tutorierten Moodle-Kursen umgesetzt. Es sollen im Rahmen dieses Teilprojekts Lernerdaten erhoben werden, die zum einen der weiteren Überprüfung der Hypothesen zum Chunking dienen, zum anderen die oben kurz skizzierten potentiellen Zusammenhänge zwischen Interaktion und Chunking weiter erhellen sollen. AuBerdem soll ein weiteres Lehr- und Lernangebot geschaffen werden, das aufgrund der freien Verfügbarkeit und transparenten Handhabung der Open-Source-Lernplattform Moodle direkt für einen breiten Praxiseinsatz z.B. im universitären Fremdsprachenerwerb des Deutschen im In- und Ausland relevant ist.

\subsection{Die Lernplattform Moodle}

Die Entscheidung für Moodle als Umgebung für die Entwicklung von tutorierten Lern-/Lehreinheiten auf Basis der vorliegenden Materialien aus den Moodle-Kursen fiel aufgrund der positiven Erfahrungen, die bezüglich der Nutzung von Moodle als Plattform für die spezifischen Zwecke des Lehrens und Lernens von Fremdsprachen vorliegen (Madlener; Merz 2007, 2008). ${ }^{20}$

Moodle bietet die Vorteile eines in ständiger Weiterentwicklung begriffenen und mit vielen anderen für den Bereich des Lehrens und Lernens von Fremdsprachen relevanten aktuellen Entwicklungen im Bereich Web 2.0 kompatiblen Rahmens für tutorierte E-Learning-Kurse, wie sie im Rahmen des Teilprojekts entstehen und getestet werden sollen. Insbesondere erlaubt Moodle als lernerzentrierte und auf Lernerautonomie abzielende Lernumgebung den Aufbau und die Aufrechterhaltung eines so genannten virtuellen Klassenzimmers mit vielfältigen Kommunikations- und Interaktionsmöglichkeiten sowie einer feinen Ausdifferenzierung von Lehrer- und Lernerrollen und den damit verbundenen Verantwortlichkeiten und Gestaltungsmöglichkeiten. Für die mit den Moodle-Kursen entstehenden virtuellen Kursklassenzimmer, für die Kommunikation zwischen Lernenden bzw. zwischen Lernenden und Tutor, aber auch für einen potentiell einzubindenden Austausch zwischen Lernenden und externen Experten (Muttersprachlern) sowie für die Interaktion zwischen Lernenden und Materialien und zwischen Lernenden in Lerngruppen (für gemeinsame Aufgabenbearbeitung und Projektarbeiten) können die bereits klassischen Moodle-Aktivitäten wie Nachrichtenforen, Kurznachrichten, Textchat, Wikis (kollaborative HTML-Editoren), persönliche und gemeinschaftliche Glossare und Materialiensammlungen etc. genutzt werden. Mit den neuen COVCELL-Instrumenten stehen zudem weitere Instrumente für synchrone

${ }^{20}$ Interessierte Leser seien in diesem Zusammenhang auf das EU-Projekt COVCELL (Cohort Oriented Virtual Campus for Effective Language Learning, Minerva-Förderung 2005-2007) verwiesen: www.covcell. org und www.linguistik.hu-berlin.de/daf/forschung/COVCELL.php. 
Kommunikation und Interaktion zur Verfügung: interaktives Whiteboard, erweiterter Textchat ${ }^{21}$ und ein (auf Wunsch moderierter) Audio- und Audio-Video-Chat.

\subsection{Tutorierte E-Learning-Kurse und Einsatzkonzept}

Ziel des Teilprojekts Moodle-Kurse ist es, die bisher als reine Selbstlernmaterialien vorliegenden Inhalte der „Tutorisierte interaktive und kollaborative Moodle-Kurse für Deutsch als Fremdsprache“ in einen tutorierten virtuellen Kurskontext einzubetten. Der Vorteil liegt beim tutorierten E-Learning im virtuellen Klassenverband ebenso wie beim Blended Learning darin, ${ }^{22}$ dass der Tutor, ohne auf störende Art und Weise maßregelnd einzugreifen, doch einen gewissen Einfluss auf Verarbeitungs- und Erwerbsstrategien nehmen kann, indem er entweder implizit oder aber explizit bestimmte erwerbsfördernde Strategien anregt bzw. durch den Einsatz geeigneten Inputs und geeigneter Lernaufgaben die Fallstricke anderer, ineffizienter Strategien aufzeigt.

Vorstrukturierter, reicher Input mit Möglichkeiten für implizite Formfokussierung, Chunking und Tuning ist insofern gewährleistet, als die erwerbstheoretisch fundierten Materialien aus den „Multimedia-Chunks für Deutsch als Fremdsprache“ in die MoodleUmgebung implementiert und u.U. durch einige weitere, nach demselben Forschungsansatz (siehe Kap. 2) entwickelte Materialien ergänzt werden. Natürliche Möglichkeiten für eine in bedeutungszentrierte Kontexte eingebettete explizitere Formfokussierung sind in Moodle erwartbar (a) in Lerner-Lerner-Interaktionen bei der gemeinsamen Bearbeitung vertiefender, outputzentrierter Aufgaben (Stichworte: notice the gap, Bedeutungsaushandlungen, peer review etc.); (b) in Lerner-Lerner-Interaktionen bei der in Moodle möglichen gemeinsamen Bearbeitung vorliegender rezeptionszentrierter interaktiver Aufgaben (siehe 3.3) z.B. im interaktiven Whiteboard und (c) durch den Einbezug von Consciousness Raising-Aufgaben mit interaktiven Instrumenten, die zur Hervorhebung von formalen Inputmerkmalen (Zielkonstruktionen) zu Zwecken der Aufmerksamkeitslenkung und Förderung aktiven Hypothesentestens geradezu einladen (z.B. Voicethread ${ }^{23}$ oder Glogster $\left.{ }^{24}\right)$.

Ein konkretes Aufgabenkonzept im Rahmen der geplanten „MultimediaChunks für DaF in Moodle“ könnte also folgendermaßen aussehen: Vor dem beschriebenen Moodle-Hintergrund entwickelt der Tutor, unter Berücksichtigung der Lernzieldefinitionen der Lerner/Lernergruppe, Vorschläge für erwerbsfördernde Lernaufgaben (Eigen- und Gruppenarbeiten) zum vorstrukturierten Input, in denen eine hohe Wahrscheinlichkeit besteht, dass die im Input fokus-

21 Mit der Möglichkeit des Chattens z.B. während der Erstellung eines Posters im Whiteboard oder des gemeinsamen Ansehens eines Videos.

22 Neben der Tatsache, dass freie Produktionsaufgaben zur mündlichen und schriftlichen Bearbeitung für einzelne Lerner und/oder Lernergruppen angeboten werden können.

23 http://voicethread.com: Möglichkeit der Kommentierung von Videosequenzen und der Standbildfunktion für die Markierung von Elementen, hier z.B. zur Verdeutlichung von Primärsituation und Rollenverteilung im Bild, von Konstruktionen in den Untertiteln.

24 http://www.glogster.com 
sierten Zielstrukturen benötigt und genutzt werden, ${ }^{25}$ z.B. „Entwickeln Sie eine virtuelle Galerie mit Kommentaren zu den Ausstellungsstücken und dokumentieren Sie die Reaktionen der Besucher Ihrer Galerie" (in Anlehnung an die Videosequenzen zur „MoMA in Berlin“ ${ }^{26}$ oder „Erstellen Sie anhand einer dokumentierten entgleisenden Therapiesitzung (unser Film ,Paartherapie) einen Ratgeber für Psychotherapeuten zum Umgang mit hochgradig frustrierten Patienten“. Die Lerner nehmen diese, z.T. an den vertiefenden Aufgaben im Lernmodul „Multimedia-Chunks für DaF“ orientierten, erweiterten Lernaufgaben zum Anlass, ihnen relevant erscheinende Materialien (Videos, Texte, Animationen mit Chunk-Angebot, Übungsaufgaben etc.) aus den vorhandenen Ressourcen auszuwählen und zu bearbeiten, um sich inhaltlich auf das Thema einzustellen und sich zudem die benötigten sprachlichen Mittel (vor allem Konstruktionen, Redemittel, Sequenzen) zu erarbeiten. Die Ergebnisse werden online präsentiert und dadurch allen Mitgliedern des virtuellen Klassenverbandes zugänglich gemacht. In vielen Fällen können die Ergebnisse einer Aufgabe wiederum zum Ausgangspunkt für eine neue Aufgabe werden, also gleichzeitig wieder als Ressource dienen. Durch die hier angeregte Abwechslung von mehreren Bearbeitungs-, Peer Review- und Präsentationsschritten, die damit notwendig gemachte mehrmalige intensive Nutzung der Materialien mit vorstrukturiertem Input und die Anregungen zu impliziter und expliziter Formfokussierung soll die Wahrscheinlichkeit für Chunking-Prozesse und Tuning-Effekte zu den jeweiligen Zielstrukturen erhöht werden.

Ein erster Testdurchlauf für die Moodle-Kurse inkl. Tutorenschulung hat im April/ Mai 2009 stattgefunden.

\section{Literatur}

Bolander, M. (1989): Prefabs, Patterns and Rules in Interaction? Formulaic Speech in Adult Learners' L 2 Swedish. In: Hyltenstam, Kenneth; Obler, Loraine K. (Hrsg.): Bilingualism Across the Lifespan - Aspects of Acquisition, Maturity and Loss. Cambridge: Cambridge University Press, 73-86.

Bybee, Joan (2008): Usage-based Grammar and Second Language Acquisition. In: Robinson, Peter; Ellis, Nick C. (Hrsg.): Handbook of Cognitive Linguistics and Second Language Acquisition. New York; London: Routledge, 216-236.

Chapelle, Carol A. (1998): Multimedia CALL: lessons to be learned from research on instructed SLA. In: Language Learning \& Technology 2/1, 22-34.

Chapelle, Carol A. (2001): Computer Applications in Second Language Acquisition. Cambridge: Cambridge University Press.

Doughty, Catherine J. (2001): Cognitive underpinnings of focus on form. In: Robinson, Peter (Hrsg.): Cognition and Second Language Instruction. Cambridge: Cambridge University Press, 206-257.

25 Zum Konzept der task essentialness und des output enhancement siehe Doughty; Williams (1998); zu kognitiven Funktionen von Output und zum Konzept des pushed output bzw. output enhancement siehe Swain $(1995,1998)$.

26 Dank an Victoria Castrillejo für die Anregung (entstanden im Rahmen von COVCELL, s. Fußnote 20). 
Doughty, Catherine J.; Long, Michael H. (2003): Optimal Psycholinguistic Environments for Distance Foreign Language Learning. In: Language Learning \& Technology $7 / 3,50-80$.

Doughty, Catherine J.; Williams, Jessica (1998): Pedagogical choices in focus on form. In: Doughty, Catherine J.; Williams, Jessica (Hrsg.): Focus on Form in Classroom Second Language Acquisition. Cambridge: Cambridge University Press, 197-285.

Ellis, Nick C. (1996): Sequencing in SLA. Phonological memory, chunking and points of order. In: Studies in Second Language Acquisition 18, 91-126.

Ellis, Nick C. (2003): Constructions, Chunking and Connectionism: The Emergence of Second Language Structure. In: Doughty, Catherine J.; Long, Michael H. (Hrsg.): The Handbook of Second Language Acquisition. Malden et al.: Blackwell, 63-103.

Ellis, Nick C. (2008): Usage-based and form-focused language acquisition: The associatve learning of constructions, learned attention, and the limited L2 endstate. In: Robinson, Peter; Ellis, Nick C. (Hrsg.): Handbook of Cognitive Linguistics and Second Language Acquisition. New York; London: Routledge, 372-405.

Goldberg, Adele E.; Casenhiser, Devin (2008): Construction learning and Second Language Acquisition. In: Robinson, Peter; Ellis, Nick C. (Hrsg.): Handbook of Cognitive Linguistics and Second Language Acquisition. New York; London: Routledge, 197-215.

Handwerker, Brigitte (2002): Chunks, Raster und Regeln. Vom Lexikon zur Grammatik in der Fremdsprachenvermittlung. In: Börner, Wolfgang; Vogel, Klaus (Hrsg.): Grammatik und Fremdsprachenerwerb. Kognitive, psycholinguistische und erwerbstheoretische Perspektiven. Tübingen: Narr, 207-230.

Handwerker, Brigitte (2004): Die Wortschatz-Grammatik-Schnittstelle aus der Sprachlernperspektive: Zur Entwicklung lexikalisch-grammatischer Kompetenz am Beispiel der Klassenbildung beim Verb. In: FLuL - Fremdsprachen lehren und lernen 33, 176-191.

Handwerker, Brigitte (2008): Chunks und Konstruktionen. Zur Integration von lerntheoretischem und grammatischem Ansatz. In: Estudios Filológicos Alemanes 15, 49-64.

Handwerker, Brigitte; Madlener, Karin (2006): Multimedia-Chunks für Deutsch als Fremdsprache. Ein Lernmodul zur Entwicklung lexikalisch-grammatischer Kompetenz. In: Hahn, Angela; Klippel, Friederike (Hrsg.): Sprachen schaffen Chancen. Dokumentation zum 21. Kongress für Fremdsprachendidaktik der deutschen Gesellschaft für Fremdsprachenforschung (DGFF), München, Oktober 2005. München; Düsseldorf; Stuttgart: Oldenbourg, 199-206.

Handwerker, Brigitte; Madlener, Karin (2009): Chunks für DaF. Theoretischer Hintergrund und Prototyp einer multimedialen Lernumgebung (mit DVD). Hohengehren: Schneider Verlag.

Lieven, Elena; Tomasello, Michael (2008): Children's first language acquisition from a usage-based perspective. In: Robinson, Peter; Ellis, Nick C. (Hrsg.): Handbook of Cognitive Linguistics and Second Language Acquisition. New York; London: Routledge, 168-196. 
Long, Michael H.; Robinson, Peter (1998): Focus on form: Theory, research, and practice. In: Doughty, Catherine J.; Williams, Jessica (Hrsg.): Focus on Form in Classroom Second Language Acquisition. Cambridge: University Press, 15-41.

Madlener, Karin; Merz, Stefan (2007): Vom Schaukasten zum Baukasten. Moodle und das EU-Projekt COVCELL an der Humboldt-Universität. In: CMS-Journal 29, 72-76.

Madlener, Karin; Merz, Stefan (2008): Moodle is an attitude, not a technology. From the teaching platform to a learning environment. Erscheint in: Arnbjörnsdóttir, Birna; Whelpton, Matthew (Hrsg.) (2008): Open Source in Education and Language Learning Online. Reykjavík: Vigdís Finnbogadóttir Institute of Foreign Languages.

McWhinney, Brian (2008): A unified model. In: Robinson, Peter; Ellis, Nick C. (Hrsg.): Handbook of Cognitive Linguistics and Second Language Acquisition. New York; London: Routledge, 341-371.

Myles, Florence; Hooper, Janet; Mitchell, Rosamond (1998): Rote or rule? Exploring the role of formulaic language in classroom foreign language learning. In: Language Learning 48/3, 323-365.

Myles, F; Hooper, J.; Mitchell, R. (1999): Interrogative Chunks in French L2. A Basis for Creative Construction? In: Studies in Second Language Acquisition 21, 49-80.

Pawley, Andrew; Syder, Frances (1983): Two puzzles for linguistic theory: Native-like selection and native-like fluency. In: Richards, Jack; Schmidt, Richard (Hrsg.): Language and communication. London: Longman, 191-226.

Rapp, Irene (1997): Partizipien und semantische Struktur. Zu passivischen Konstruktionen mit dem 3. Status. Tübingen: Stauffenburg.

Schifko, Manfred (2008): „... oder muss ich expliziter werden?“ Formfokussierung als fremdsprachendidaktisches Konzept: Grundlagen und exemplarische Unterrichtstechniken. In: Fremdsprache Deutsch 38, 36-45.

Sharwood Smith, Michael (1993): Input enhancement in instructed SLA. Theoretical bases. In: Studies in Second Language Acquisition 15, 165-179.

Sharwood Smith, Michael (1997): „Consciousness-Raising“ meets „Language Awareness“. In: FLuL - Fremdsprachen lehren und lernen 26, 24-32.

Siepmann, Dirk (2007): Wortschatz und Grammatik: zusammenbringen, was zusammengehört. In: Beiträge zur Fremdsprachenvermittlung 46, 59-80.

Sinclair, John (1991): Corpus, Concordance, Collocation. Oxford: University Press.

Swain, Merrill (1995): Three functions of output in second language learning. In: Cook, Guy; Seidelhofer, Barbara (Hrsg.): Principle \& practice in applied linguistics: Studies in bonour of H. G. Widdowson. Oxford: University Press, 125-144.

Swain, Merrill (1998): Focus on form through conscious reflection. In: Doughty, Catherine J.; Williams, Jessica (1998): Focus on Form in Classroom Second Language Acquisition. Cambridge: University Press, 64-81.

Tomasello, Michael (2006): Konstruktionsgrammatik und früher Erstspracherwerb. In: Fischer, Kerstin; Stefanowitsch, Anatol (Hrsg.): Konstruktionsgrammatik. Von der Anwendung zur Theorie. Tübingen: Stauffenburg, 19-37. 
VanPatten, Bill (2004): Input Processing in SLA. In: Ders. (Hrsg.): Processing Instruction. Theory, Research, and Commentary. Mahwah, N.J.: Lawrence Erlbaum, 5-31.

VanPatten, Bill et al. (Hrsg.) (2004): Form-Meaning Connections in Second Language Acquisition. Mahwah, N.J.: Lawrence Erlbaum.

Weinert, Regina (1994): Some Effects of a Foreign Language Classroom on the Development of German Negation. In: Applied Linguistics 15/1, 76-101.

Wong, Wynne (2004): The Nature of Processing Instruction. In: VanPatten, Bill (Hrsg.): Processing Instruction. Theory, Research, and Commentary. Mahwah, N.J.: Lawrence Erlbaum, 33-63.

Wong, Wynne (2005): Input Enhancement. From Theory and Research to the Classroom. Boston: McGraw Hill.

Wray, Alison (2002): Formulaic Language and the Lexicon. Cambridge: University Press. 
Christoph Chlosta, Matthias Jung (Hrsg.) (2010): DaF intergriert: Literatur - Medien - Ausbildung. Tagungsband der 36. Jahrestagung des Fachverbandes Deutsch als Fremdsprache 2008. Göttingen: Universitätsverlag, 173-190.

\section{Sylwia Adamczak-Krysztofowicz (Poznań, Polen) \& Antje Stork (Marburg)}

\section{Podcastgestützte integrative Hörverstehensentwicklung in universitären Sommerdeutschkursen}

\section{Einleitung}

Auditive und audiovisuelle Medien, die eine Basis für die Optimierung der Hörverstehenskompetenz bilden, nehmen bereits seit langem im Unterrichtsalltag eine zentrale Rolle ein. Sie haben ihre Ursprünge in der audiolingualen und der audiovisuellen Methode, in denen die Hörschulung als wichtiges Ziel für die korrekte Ausspracheübung galt. Weitergehende Gedanken zum Stellenwert von modernen und neuen Audio- und Videolehrmitteln beim Hörverstehenstraining wurden mit dem Aufkommen der technologischen Errungenschaften (hierzu zählen das computergestützte Lernen sowie das Internet) Ende der 1980er und in den 1990er Jahren angestellt. In diesem Zusammenhang können seit bereits zwei Jahrzehnten Versuche verzeichnet werden, eine spezifische Verstehensdidaktik zu fremdsprachigen Hör- und Hörsehvorlagen zu entwickeln. Die meisten von ihnen beziehen sich auf psycholinguistische Überlegungen zu Hörverstehensprozessen (Neveling 2000, Wolff 2002 und 2003) sowie zu optimalen Verfahren bei der Entfaltung (Rost 2002, Solmecke 2003) und Überprüfung der Hörverstehenskompetenz (Buck 2001, Grotjahn 2005, Zydatiß 2005). Trotz dieser Tatsache gibt es nur wenige Arbeiten, in denen eine lernerorientierte Auswahl und Gestaltung von auditiven und audiovisuellen Unterrichtsmaterialien, geschweige denn von 
Podcasts und Vodcasts, reflektiert werden. Es fehlt auch nach wie vor an Forschungsprojekten, die auf ein integratives Hörverstehenstraining im Zusammenhang mit der Entfaltung der anderen sprachlichen Teilkompetenzen abzielen. In unserem Beitrag sollen daher die didaktischen Einsatzmöglichkeiten von Audio- und Videopodcasts im DaF-Unterricht als Beitrag zu einer integrativen Hörverstehensentwicklung in universitären Sommerdeutschkursen diskutiert werden. Als Ausgangspunkt für unsere methodisch-didaktischen Hinweise dient eine von uns im Sommer 2007 im Rahmen der UNISOM-Studie an vier deutschen Hochschulen (Frankfurt, Kiel, Mainz, Marburg) durchgeführte Kursteilnehmerbefragung.

\section{Ergebnisse der Kursteilnehmerbefragung zu Text- und Aufgabenpräferenzen}

An der von uns im Sommer 2007 durchgeführten quantitativ-qualitativen UNISOMStudie haben insgesamt 126 KursteilnehmerInnen und zehn KursleiterInnen teilgenommen. Ausgewählt wurden für die Untersuchung vier Hochschulen in Deutschland, und zwar in den drei Bundesländern Hessen, Rheinland-Pfalz und Schleswig-Holstein. Es handelt sich hierbei sowohl um sog. Sommeruniversitäten (Frankfurt, Marburg), in deren Rahmen die TeilnehmerInnen Veranstaltungen in ihren jeweiligen Fächern (teilweise auf Englisch) belegen können und begleitend Deutschunterricht erhalten, als auch um internationale Sommerkurse, die sich stärker auf den Sprachunterricht konzentrieren. Im Rahmen des vorliegenden Beitrags möchten wir ausschließlich Erkenntnisse der schriftlichen Kursteilnehmerbefragung berücksichtigen, die uns im Weiteren ermöglichen, Aussagen über die persönlichen Einschätzungen zum Stellenwert der Hörverstehenskompetenz sowie zu textbezogen Verfahrensweisen beim podcastgestützten integrativen Hörverstehenstraining auf der Mittel- und Oberstufe zu machen.

\subsection{Kurze Charakteristik der TeilnehmerInnen}

Für die Auswertung der schriftlichen Kursteilnehmerbefragung standen insgesamt 126 Fragebögen zur Verfügung. Davon stammen die meisten $(78,57 \%)$ von weiblichen Deutschlernenden. Betrachtet man die prozentuale Verteilung der an der Studie beteiligten Sommerkurse bzw. Sommeruniversitäten, so ist festzustellen, dass fast die Hälfte (46,83\%) der auswertbaren Fragebögen von TeilnehmerInnen verschiedener universitärer Sommerkurse in Kiel ausgefüllt wurde. Die Beteiligung der drei übrigen in die Untersuchung einbezogenen deutschen Hochschulen lässt sich aus Abbildung 1 ableiten.

Bei allen Befragten handelte es sich ausschließlich um erwachsene Lernende der Mittel- und Oberstufe, von denen die überwiegende Mehrheit (über 70\%) zum Zeitpunkt der Untersuchung noch ein Hochschulstudium absolvierte (89 Personen). Unter den verbleibenden Befragten waren darüber hinaus 13 Lehrende und jeweils drei SchülerInnen sowie ÜbersetzerInnen. Was die Altersstufe anbetrifft, entfielen die häufigsten Nennungen (knapp 80\%) dementsprechend auf die Altersspanne zwischen 18 und 24 Jahren. 


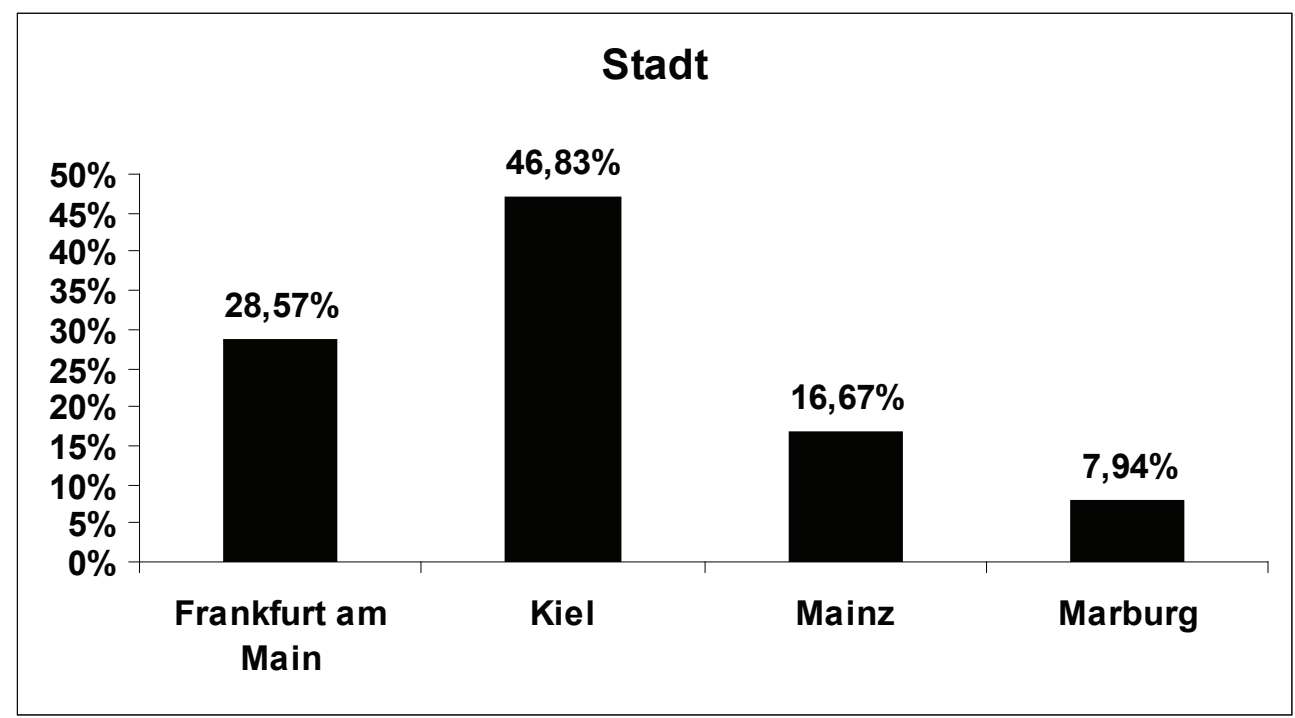

Abb. 1: Verteilung der an der Kurteilnehmerbefragung beteiligten Hochschulen

In Bezug auf die Herkunftsländer der KursteilnehmerInnen kann man aus der Frage zur Nationalität schlussfolgern, dass universitäre Sommerdeutschkurse in Deutschland von relativ vielen Russen (fast ein Fünftel aller Probanden) und Polen (knapp 13\% der Befragten) belegt werden. Im Folgenden möchten wir näher auf den Stellenwert der graduellen Hörverstehensentwicklung in den untersuchten UNISOM-Kursen eingehen und dann relevante textbezogene Präferenzen der Kursteilnehmer in Bezug auf das podcastgestützte integrative Hörverstehenstraining ermitteln.

\subsection{Stellenwert der Hörverstehenskompetenz}

Die Kursteilnehmerbefragung zur Bedeutung des Hörverstehens (vor dem Hintergrund des Vergleichs mit dem Stellenwert der restlichen Sprachfertigkeiten) hing mit der folgenden selbstevaluativ orientierten Frage eng zusammen:

„Hörverstehen, Leseverstehen, Sprechen, Schreiben und Übersetzen finde ich für mich ... (Markieren Sie auf jeder Linie einen entsprechenden Buchstaben von A bis D, ob Sie die betreffende Sprachfertigkeit für A (sehr wichtig), B (wichtig), C (nicht so wichtig) oder D (gar nicht wichtig) halten).“

Aus den Angaben der Befragten zur Relevanz des Hörverstehens und der übrigen sprachlichen Fähigkeiten wurde die folgende Zusammensetzung in Abbildung 2 errechnet: 


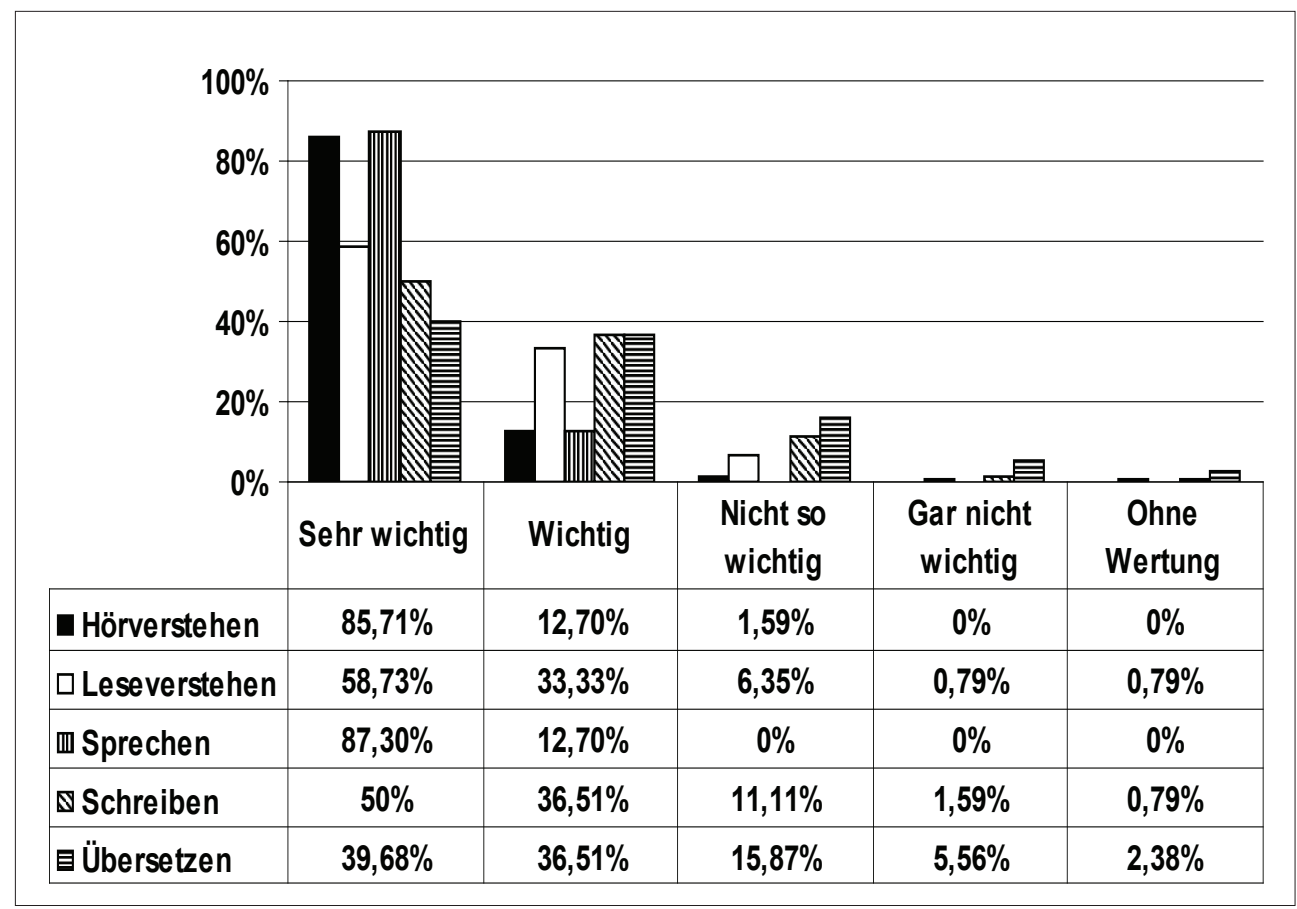

Abb. 2: Stellenwert der sprachlichen Teilkompetenzen

Ein Blick auf Abbildung 2 reicht, um festzustellen, dass fast alle KursteilnehmerInnen Sprechen und Hörverstehen als die wichtigsten Fertigkeiten auffassen und sich über die Schlüsselfunktion der beiden Kompetenzen im alltäglichen Gebrauch der Sprache im Klaren sind. Die in den Kategorien ,sehr wichtig“ und ,wichtig“" konkret zum hörenden Verstehen gemachten Angaben, wenngleich sie von einer führenden Position des verstehenden Hörens in der Alltagskommunikation noch abweichen, ${ }^{1}$ zeigen mit aller Deutlichkeit, dass über 98\% der Lernenden die besondere Bedeutung der Hörverstehenskompetenz für das Lernen und Lehren fremder Sprachen anerkennen und sich somit für eine effektive Förderung dieser Basisfertigkeit in den Deutschkursen für Erwachsene aussprechen.

\subsection{Vorlieben der KursteilnehmerInnen bei der Textauswahl}

Um die Präferenzen der KursteilnehmerInnen bei der Textauswahl zu ermitteln, wurden folgende Fragen gestellt:

- „Im Kurs möchte ich häufiger folgende Texte hören ... (Bitte kreuzen Sie das Zutreffende an und listen Sie sonstige Hörtexte auf.).“

- „Würden Sie gerne (mit Unterstützung durch die Lehrkraft) an der Auswahl von Hörtexten beteiligt werden? Warum?“

1 Das Hörverstehen nimmt in den muttersprachlichen alläglichen Kommunikationssituationen mit 45\% eine führende Position ein, gefolgt vom Sprechen mit 30\%, dem Lesen mit 16\% und schließlich dem Schreiben mit 9\% (Neveling 2000: 3). 
Was die Auswertung der Frage zu bevorzugten auditiven und audiovisuellen Textsorten anbetrifft, ergeben sich die in Abbildung 3 dargestellten Ergebnisse.

Es lässt sich schlussfolgern, dass Kurzfilme und Filmausschnitte nach der Ansicht von fast 88\% der Kursteilnehmer einen zentralen Stellenwert in den universitären Sommerdeutschkursen einnehmen sollten. Die weiteren Angaben zeigen, dass erwachsene Lernende (in absteigender Reihenfolge der Häufigkeit) öfter mit Witzen (67,46\%),

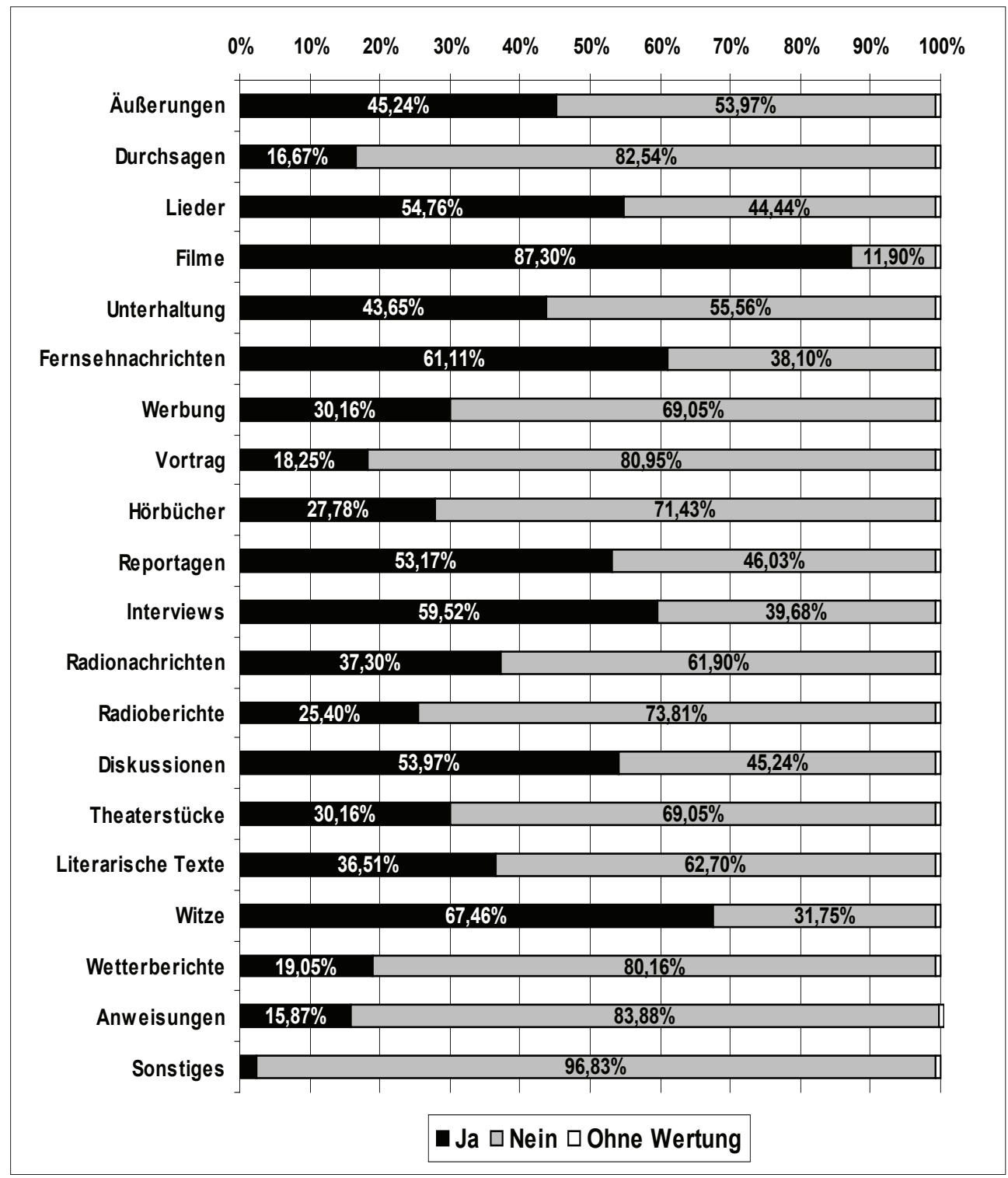

Abb. 3: Lieblingstextsorten für das Hörverstehenstraining mit Erwachsenen 
Fernsehnachrichten (61,11\%), Interviews (59,52\%) und Liedern (54,76\%) beim Hörverstehenstraining arbeiten möchten. Am wenigsten Interesse gibt es für den Einsatz von Wetterberichten, Vorträgen, Durchsagen und Anweisungen. Die freie Option „Sonstige“ wird von fast allen Befragten nicht ergänzt. Bei dieser freien Alternative werden auch keine Podcasts explizit genannt.

In Bezug auf die Verfahrensweise der Textauswahl wünscht fast jeder zweite Kursteilnehmer (vgl. Abbildung 4), an der Auswahl von Hörtexten beteiligt zu werden. Als Begründung für das lernerorientierte Textauswahlverfahren werden von den Befragten solche Faktoren wie Berücksichtigung individueller Interessen, motivierende Wirkung durch stärkere Lernerorientierung, Sammlung neuer Erfahrungen, didaktische Eignung von Hörvorlagen sowie Steigerung der Attraktivität des Kurses genannt:

„Man muss das auswählen, was man bevorzugt und was man mag, ansonsten bringt das keinen Sinn [...].“ (FB 8)

„Dann habe ich die Möglichkeiten, Texte auszuwählen, die meinem Interesse und meinem Sprachniveau entsprechen.“ (FB 50)

„Dann bin ich motiviert. Das verspricht eine aktive Beteiligung am Unterricht, Mitmachung am Unterricht.“ (FB 120)

„Das ist eine neue Sache, vielleicht lerne ich etwas Neues.“ (FB 69)

„Then I would know what's going on and I know I will stay interested.“ (FB 46)

Nach wie vor plädieren aber knapp 17\% der Lernenden dafür, dass der Kursleiter die Textauswahl allein vornehmen soll (was allerdings in der Unterrichtspraxis häufig der Fall ist). In ihren Begründungen zum lehrerzentrierten Textauswahlverfahren heben die Befragten solche Faktoren hervor wie: Beschränktheit der eigenen Kenntnisse und Interessen, die fehlende pädagogische Eignung, Zeitmangel, das mangelnde Interesse an der Einbeziehung der Lernenden in die Textauswahl und Unterrichtsgestaltung sowie Heterogenität der persönlichen Interessenschwerpunkte in der Gruppe:

„Meine Kenntnisse sind ziemlich begrenzt. Deshalb wird meine Beteiligung keine große Hilfe sein.“ (FB 88)

„Es ist mir egal.“ (FB 17)

„Ich habe leider keine Zeit.“ (FB 9)

„Weil ich keine pädagogische Berufung habe.“ (FB 76)

„Mein Interesse ist wahrscheinlich beschränkt. Ich verlasse mich lieber auf die Wahl der Lehrkraft.“ (FB 108)

„Jeder interessiert sich für etwas anderes [...].“ (FB 3)

Diese Aussagen zeugen davon, dass sich knapp ein Fünftel der befragten Kursteilnehmer die lernerbezogene Einschätzung des Schwierigkeitsgrades von fremdsprachigen Hör- und Hörsehvorlagen nicht zutrauen bzw. nicht leisten will. 


\section{Beteiligung}

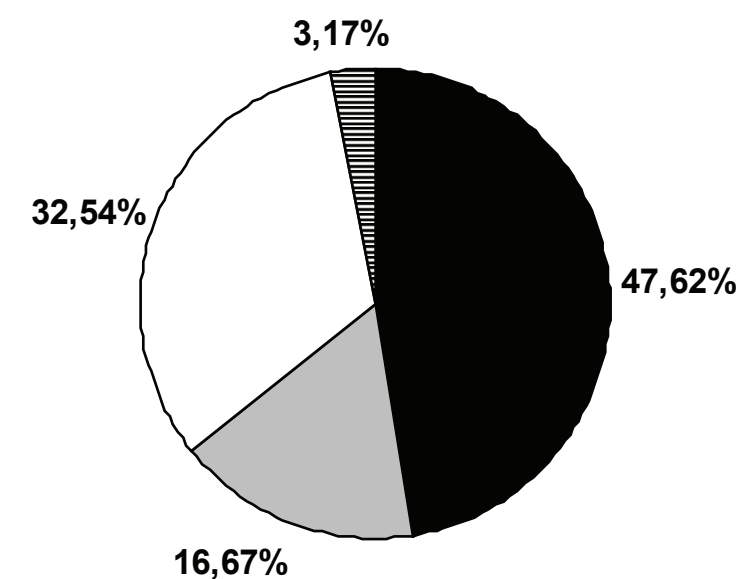

$\square$ Ja $\square$ Nein $\square$ Weiß nicht 目Ohne Wertung

Abb. 4: Verfahrensweise bei der Textauswahl

\section{Didaktische Einsatzmöglichkeiten von Audio- und Videopodcasts}

Das Wort „Podcast“ setzt sich aus „iPod“ (MP3-Player von Apple) und „broadcast“ (dt. „senden“ bzw. „Sendung“) zusammen. Es handelt sich hierbei um Audio- oder Videoaufnahmen, die aus dem Internet herunterladbar sind. Beobachtet werden können zwei Verwendungsweisen des Begriffs, und zwar in einer weiten Begriffsdefinition (sensu largo) und in einer engen Begriffsdefinition (sensu stricto). Podcasts im engeren Sinne enthalten eine Abonnierfunktion, d.h. sie können mit Hilfe einer Software, dem sog. Podcatcher, abonniert werden, so dass neue Ausgaben des Podcasts automatisch auf dem Computer gespeichert und bei Bedarf auf einen MP3-Player übertragen werden können. In einem weiten Sinne werden alle im Internet downloadbaren Audio- und Video-Dateien als Podcasts bezeichnet. In diesem Beitrag verwenden wir den Begriff Podcast, falls nicht anders gekennzeichnet, im weiten Sinne.

Um die didaktischen Einsatzmöglichkeiten von Podcasts näher zu beleuchten, werden wir uns zunächst in Abschnitt 3.1 damit beschäftigen, welche Arten von Podcasts es gibt, und anschließend in Abschnitt 3.2 einen Vergleich mit anderen Medien zur Hörverstehensentwicklung anstellen. 


\subsection{Klassifikationen von Podcasts}

Es gibt in der Fachliteratur zur Hörverstehensentwicklung eine Reihe von Klassifikationsvorschlägen in Bezug auf Hörtexte. Für eine Klassifikation von Podcasts, als eine besondere Form von Hörtexten, halten wir die Unterteilung nach Wahrnehmungskanälen, Präsentationsform, Form der Mündlichkeit und Didaktisierung für relevant in Bezug auf den didaktischen Einsatz von Podcasts im DaF-Unterricht.

\section{a) Art der Wahrnehmungskanäle: \\ 1. Audio-Podcasts (Hörverstehen) \\ 2. Video-Podcasts (Hör-Seh-Verstehen)}

Hörverstehen im weiteren Sinne kann unterschieden werden in Hörverstehen im engeren Sinne und Hör-Seh-Verstehen, das die simultane Verarbeitung von auditiven und visuellen Informationen umfasst (Filme, Videoclips, Fernsehsendungen, Computerprogramme, Fotos, Zeichnungen). Ebenso können bei Podcasts Audio-Podcasts (Hörverstehen im engeren Sinne) und Video-Podcasts (Hör-Seh-Verstehen) unterschieden werden. Hör-Seh-Verstehen hat sich in der Fremdsprachendidaktik seit den 1990er Jahren etabliert, die Forschung dazu ist allerdings noch sehr spärlich, wie bspw. Schwerdtfeger (2003: 299) und Thaler (2007: 13) beklagen.

Beispiele:

- Audiopodcast: Reisepodcast „GeoAudio“ (http://www.geo.de/GEO/reisen/ 5095.html)

- Videopodcast: Videopodcast von Angela Merkel (www.bundeskanzlerin.de)

b) Präsentationsform (vgl. Hüllen 1977: 35):

1. Monologische Podcasts (z.B. Nachrichten, Berichte, Kommentare, Reportagen, Vorträge)

2. Dialogische Podcasts (z.B. Interviews)

3. Multilogische Podcasts (z.B. Diskussionen, Unterhaltungen, Talkshows)

Auktoriale Textsorten, also erzählte oder verlesene Texte (z.B. literarische Texte) stehen nach Hüllen (ebd.) zwischen monologischen und multilogischen Texten.

Grundsätzlich sollten sowohl monologische als auch dialogische und multilogische Podcasts im DaF-Unterricht behandelt werden. Dabei gibt es einige den bzw. die Sprecher betreffende Faktoren, die (unter anderen Faktoren) den Schwierigkeitsgrad von Podcasts bestimmen, und zwar Zahl der Sprecher, ihr Sprechtempo, ihre Aussprache, Dialektfärbungen, Sprecherwechsel, Nebengeräusche, die das Hören erschweren (vgl. z.B. Leupold 2000: 8 oder Solmecke 2001: 896f.).

Beispiele:

- Monologischer Podcast: NDR Kultur Neue Bücher (http://www.ndrkultur.de/service/podcast/index.html) 
- Dialogischer Podcast: RadioDuo auf Bayern 2, halbstündiges Gespräch mit Menschen, „die etwas zu sagen haben“ (http://www.br-online.de/podcast/mp3-download/bayern2/mp3-download-podcast-radioduo.shtml)

- Multilogischer Podcast: Polit-Talkmagazin „Hart aber fair“ (http:/ / podcast.wdr.de/ hartaberfair.xml)

c) Form der Mündlichkeit (vgl. Eggers 1996: 34):

1. Spontan gesprochene Podcasts (z.B. Gespräch, Dialog oder Multilog)

2. Vorbereitete Podcasts (z.B. Nachrichten, Kommentare)

Die Form der Mündlichkeit ist zum einen bei der Auswahl von Podcasts als Unterrichtsmittel zu beachten, aber auch in Bezug auf die Produktion von Podcasts wichtig. Zumeist werden dort vorbereitete Hörtexte zum Einsatz kommen; der Podcast kann aber auch in Teilen spontan gesprochene Podcasts (z.B. Interviews) enthalten.

Beispiele:

- Spontan gesprochener Podcast: Multes Podcast, Beschreibung auf podcast.de: „Spontan begonnen, kein Konzept und chaotisch. Geredet wird über alles mögliche“ (http://www.multe.de/)

- Vorbereiteter Podcast: Tagesschau der ARD (http://www.tagesschau.de)

\section{d) Didaktisierung}

Podcasts können authentisch im engeren, d.h. im sprachlich-linguistischen Sinne, didaktisch-authentisch oder didaktisiert sein.

1. Linguistisch-authentische Podcasts: Zu dieser Gruppe gehören Originalaufnahmen, die mit keiner pädagogischen Absicht produziert und daher nicht für die Unterrichtspraxis verändert worden sind.

2. Didaktisch-authentische Podcasts: Darunter verstehen wir in Anlehnung an die erweiterte Definition von authentischen Texten (vgl. u.a. Honnef-Becker 1996 oder Solmecke 1996) alle Podcasts, die sowohl von Muttersprachlern als auch von Nichtmuttersprachlern im Hinblick auf die Lernsituation produziert wurden, die jedoch in einer realen Kommunikationssituation zum Einsatz kommen könnten. Dafür müssen sie aber möglichst „echt“ wirken und eine Reihe von typischen textinternen und wesentlichen textexternen Merkmalen der jeweils beabsichtigten Textsorte erfüllen, d.h. reale situative Einbettung und eine wirkliche Autorenintention aufweisen, einen wirklichen Adressaten haben, themenbezogen sein und erkennbare Textstrukturmuster besitzen.

3. Didaktisierte Podcasts: Eine Didaktisierung kann erfolgen, indem der Hörtext langsamer gesprochen wird und/oder sprachlich vereinfacht und/oder eine Transkription erhältlich ist und/oder in einem Glossar Vokabeln erklärt werden und/oder Hörverstehensaufgaben beigefügt sind. 
Beispiele für didaktisierte Podcasts:

- Langsam gesprochene Nachrichten bei Deutsche Welle, mit Transkription (http:// rss.dw-world.de/xml/podcast_langsam_gesprochene_nachrichten)

- Top-Thema mit Vokabeln bei Deutsche Welle, langsam gesprochen, sprachlich vereinfacht, mit Glossar und Aufgaben (http://www.dw-world.de/dw/0,2142,8031,00. html)

\subsection{Medienvergleich}

Braucht man überhaupt besondere didaktisch-methodische Prinzipien bei der podcastgestützten integrativen Hörverstehensentwicklung? Sind die didaktisch-methodischen Prinzipien, die für die Hörverstehensentwicklung mit „,konventionellen“ Medien entwickelt wurden nicht ausreichend? Um diese Frage zu beantworten, werden wir im Folgenden die Besonderheiten von Audio-Podcasts und von Video-Podcasts im Vergleich zu anderen Medien zur Entwicklung des Hör-(Seh-)Verstehens vergleichen.

Audio-Podcasts können im Internet heruntergeladen und auf einen an den Rechner angeschlossenen MP3-Player übertragen werden. Beim Podcast handelt es sich nicht wie beim Radio um ein Prozessmedium (vgl. Tabelle 1), bei dem der Verstehensvorgang erfolgen muss, während eine Sendung ausgestrahlt wird, sondern wie bei Kassette und Video um ein Produktmedium, d.h. die Hörtexte können mehrfach gehört werden (nach der Terminologie von Jung 2002: 15). Wenn Podcast-Episoden online angehört werden, kann über einen kleinen Audio-Player, der in die entsprechende Web-Seite eingebaut ist, vor- und zurückgespult werden (verschieben der Markierung auf der Fortschrittsanzeige mit der Maus, vgl. auch Horn; Fiene 2007: 17). Ein Podcast besteht in der Regel aus verschiedenen Episoden, die in regelmäßigen oder unregelmäßigen Abständen im Internet veröffentlicht werden. Einzelne Episoden oder ganze Podcasts können auf den Computer heruntergeladen werden. Während Radio, Kassette und CD ein festgelegtes Programm haben, ist es bei der Arbeit mit Podcasts möglich, ein beliebiges Programm mit Podcastepisoden auf einen MP3-Player zu übertragen. Podcasts sind (im Gegensatz zu Kassette und CD) tagesaktuell und in einer sehr großen Fülle im Internet erhältlich. Horn; Fiene (ebd.) unterteilen das derzeitige Angebot an Podcast in sechs verschiedene Arten: Meta-Podcasts (Podcasts über das Podcasten), Musik-Podcast, Radio-Podcasts (aufgebaut wie klassische Radiosendungen), Personality-Podcasts (Podcaster sprechen über sich, ihren Alltag, über Bücher, Filme etc.), Themen-Podcasts (Podcasts zu speziellen Themen, die oft im Radio keinen Platz finden), Video-Podcasts. Es handelt sich hierbei sowohl um professionelle Produktionen von Radiosendern als auch um Amateurproduktionen von Privatpersonen. Die inhaltliche und akustische Qualität der Hörtexte ist sehr unterschiedlich. Die meisten Podcasts sind (im Gegensatz zu Kassette und $\mathrm{CD}$ ) nicht kostenpflichtig. Die Produktion von Podcasts ist recht einfach und für DaF-Lerner realisierbar. Benötigt werden als Mindestanforderung ein Computer, ein Mikrofon, ein Paar Kopfhörer, ein Aufnahmeprogramm und eine Speichermöglichkeit im Netz (vgl. Horn; Fiene 2007: 48). 


\begin{tabular}{|l|l|l|l|l|}
\hline & Radio & Kassette & CD & $\begin{array}{l}\text { Audio-Pod- } \\
\text { cast }\end{array}$ \\
\hline Gerät & $\begin{array}{l}\text { Radio/ } \\
\text { Computer }\end{array}$ & $\begin{array}{l}\text { Kassetten- } \\
\text { rekorder/ } \\
\text { Walkman }\end{array}$ & $\begin{array}{l}\text { (transportabler) } \\
\text { CD-Player/ } \\
\text { Computer }\end{array}$ & $\begin{array}{l}\text { Computer/ } \\
\text { MP3-Player }\end{array}$ \\
\hline $\begin{array}{l}\text { Produkt-/ } \\
\text { Prozessmedium }\end{array}$ & $\begin{array}{l}\text { Prozess- } \\
\text { medium }\end{array}$ & $\begin{array}{l}\text { Produkt- } \\
\text { medium }\end{array}$ & $\begin{array}{l}\text { Produkt- } \\
\text { medium }\end{array}$ & $\begin{array}{l}\text { Produkt- } \\
\text { medium }\end{array}$ \\
\hline $\begin{array}{l}\text { Festgelegtes } \\
\text { Programm }\end{array}$ & Ja & Ja & Ja & Nein \\
\hline Aktualität & Sehr hoch & Mittel & Mittel & Sehr hoch \\
\hline Materialfülle & Ja & Begrenzt & Begrenzt & Ja \\
\hline Kosten & Nein & Ja & Ja & Nein \\
\hline $\begin{array}{l}\text { Produktions- } \\
\text { möglichkeit }\end{array}$ & Nein & Ja & Nein & Ja \\
\hline
\end{tabular}

Tab. 1: Vergleich von Medien zur Entwicklung des Hörverstehens

Video-Podcasts (auch Vodcasts genannt), die seit dem Jahr 2005 in immer größer werdender Anzahl verbreitet werden, können ebenso wie Audio-Podcasts im Internet heruntergeladen und auf einen an den Rechner angeschlossenen MP3-Player übertragen werden (vgl. Tabelle 2). Auch beim Video-Podcast handelt es sich (im Gegensatz zu Video und DVD) um ein Produktmedium. Die Eigenschaften der Audio-Podcasts gelten analog auch für die Video-Podcasts. Auch sie stechen im Gegensatz zu Video und DVD durch Aktualität, Materialfülle und geringe Kosten hervor. Die Produktion von Video-Podcasts kann über verschiedene Aufnahmegeräte erfolgen, z.B. über Handy, Digitalkamera, eine ins Laptop eingebaute Webcam oder eine Videokamera (vgl. auch Horn; Fiene 2007: 89).

\begin{tabular}{|l|l|l|l|l|}
\hline & Fernsehen & Video & DVD & $\begin{array}{l}\text { Video-Pod- } \\
\text { cast }\end{array}$ \\
\hline Gerät & $\begin{array}{l}\text { Fernseher/ } \\
\text { Computer }\end{array}$ & $\begin{array}{l}\text { Video- } \\
\text { rekorder }\end{array}$ & $\begin{array}{l}\text { (transportabler) } \\
\text { DVD-Player/ } \\
\text { Computer }\end{array}$ & $\begin{array}{l}\text { Computer/ } \\
\text { MP3-Player }\end{array}$ \\
\hline $\begin{array}{l}\text { Produkt-/ } \\
\text { Prozessmedium }\end{array}$ & $\begin{array}{l}\text { Prozess- } \\
\text { medium }\end{array}$ & $\begin{array}{l}\text { Produkt- } \\
\text { medium }\end{array}$ & $\begin{array}{l}\text { Produkt- } \\
\text { medium }\end{array}$ & $\begin{array}{l}\text { Produkt- } \\
\text { medium }\end{array}$ \\
\hline $\begin{array}{l}\text { Festgelegtes } \\
\text { Progamm }\end{array}$ & Ja & Ja & Ja & Nein \\
\hline Untertitel & Manchmal & Nein & Ja & Nein \\
\hline Aktualität & Sehr hoch & Mittel & Mittel & Sehr hoch \\
\hline Materialfülle & Ja & Begrenzt & Begrenzt & Ja \\
\hline Kosten & Nein & Ja & Ja & Nein \\
\hline $\begin{array}{l}\text { Produktions- } \\
\text { möglichkeit }\end{array}$ & Nein & Ja & Nein & Ja \\
\hline
\end{tabular}

Tab. 2: Vergleich von Medien zur Entwicklung des Hör-Seh-Verstehens 
Fazit: Podcasts stellen keine technisch völlig neuartigen Möglichkeiten zu Verfügung, aber sie bieten für den DaF-Unterricht eine Reihe von Vorteilen, die zu einer quantitativen und qualitativen Weiterentwicklung der Hörverstehensschulung führen können (vgl. Abschnitt 4):

a) Über das Internet ist eine sehr große Vielfalt an Hör- (und Hör-Seh-)Texten kostenlos erhältlich. Somit können nicht nur die Lehrer leichter authentische, lehrbuchunabhängige Hörmaterialien in den Unterricht einbringen, sondern die Lernenden können und sollten im Sinne einer Textauswahlkompetenz (vgl. Abschnitt 4.1) an der Auswahl von Hörtexten beteiligt werden.

b) Durch die kostengünstige und unkomplizierte Möglichkeit, selbst Podcasts zu produzieren, ergibt sich für den DaF-Unterricht die Möglichkeit einer podcastgestützten integrativen Hörverstehensschulung (vgl. Abschnitt 4.2).

\section{Didaktisch-methodische Prinzipien beim Einsatz des Mediums „Podcast“ bei der integrativen Hörverstehens- entwicklung in universitären DaF-Sommerintensivkursen}

\subsection{Textauswahlkompetenz für Podcasts}

Wie die Ergebnisse der UNISOM-Studie (vgl. Abschnitt 2) gezeigt haben, möchte etwa die Hälfte der Sommerkursteilnehmer (ca. 48\%) an der Auswahl von Hörtexten beteiligt werden. Die Beteiligung der Deutschlernenden an der Auswahl von Hörtexten wird in den letzten Jahren dadurch erleichtert, dass ihnen im Internet eine Vielzahl von Hörtexten in Form von Podcasts zugänglich ist. Ohne diese Verfügbarkeit wäre eine Einbeziehung der Lernenden sehr schwierig zu realisieren. Hier bieten Podcasts somit einen Mehrwert im Vergleich zu älteren technischen Medien. Auch Bühler (2008: 227) weist darauf hin, dass die Bewusstmachung qualitativer Auswahl- und Beurteilungskriterien im Sinne einer explorativen „media literacy“ erfolgen sollte.

Wir begreifen die Fähigkeit, Podcasts für das eigene Sprachenlernen auswählen zu können als Kompetenz, und zwar als Teil der Textauswahlkompetenz (vgl. Stork; Adamczak-Krysztofowicz 2007). Diese Kompetenz sollte im Fremdsprachenunterricht ähnlich wie die Hörverstehenskompetenz prozessorientiert entwickelt werden. Die Auswahl des Podcasts besteht aus vier Schritten: ${ }^{2}$

A Art des Podcasts: Es wird die Art des Podcasts ausgesucht (Textsorten oder Art des Podcasts)

B Thema: Es wird ein Thema ausgewählt

C Recherche und Beschaffung: Es wird nach einem Podcast gesucht und dieser heruntergeladen

D Überprüfung der Eignung: Die Eignung des Podcasts wird überprüft

2 Im Folgenden passen wir in Stork; Adamczak-Krysztofowicz (2007) vorgestelltes Modell auf Podcasts an. 
Die Schritte A und B hängen zusammen, die Reihenfolge ist austauschbar. Um die Kompetenz zu entwickeln, kann der Lerner unterschiedlich stark in jeden der Bereiche einbezogen werden. Dabei ist zu beachten, dass der Grad der Beteiligung eigentlich als Kontinuum zu verstehen ist.

1. alleinige Durchführung des Lehrers

2. Beteiligung des Lerners

3. alleinige Durchführung des Lerners

Eine besondere Schwierigkeit stellt die Überprüfung der Eignung des Podcasts dar. Im Sinne einer Autonomieförderung des Lerners ist es aber wichtig, dass er an Eignungskriterien herangeführt wird. Im Folgenden stellen wir in Anlehnung an AdamczakKrysztofowicz; Stork (2008: 473ff.) einen Fragekatalog vor, der Lehrenden, aber auch Lernenden bei der Überprüfung der Eignung von Podcasts behilflich sein kann.

\section{Fragenkomplex, der den thematischen Schwerpunkt des Podcasts reflektiert}

- Ist das im Text behandelte Thema aktuell und relevant für die erwachsenen Teilnehmer?

- Bietet die Thematik des Podcasts eine schrittweise Annäherung der Teilnehmer an sprachliche Varietäten des Deutschen und die kulturelle Vielfalt des deutschsprachigen Raums?

- Regt der Inhalt des Podcasts erwachsene Lernende zum Nachdenken und zum Reden über das dargestellte Thema an?

- Sind die Informationsschwerpunkte über den ganzen Hörtext verteilt, um den fremdsprachigen Prozess des Textverstehens nicht zu behindern?

\section{Fragenkomplex, welcher erwachsene Kursteilnebmende als Subjekte des Lernprozesses fokussiert}

- Entspricht der Podcast den altersspezifischen Interessen und Bedürfnissen der erwachsenen Kursteilnehmenden? (Berücksichtigt er die Erwartungshaltung der Hörer?)

- Ist der Hörtext der linguistischen Kompetenz der Teilnehmer angemessen?

- Entspricht der Hörtext dem intellektuellem Niveau und der Erfahrungswelt der Kursteilnehmer?

- Knüpft der Hörtext an das vorhandene Sprach- und Weltwissen der Teilnehmer an? (Fordert er Hörende zur Hypothesenbildung sowie zu Stellungnahmen heraus?)

3. Fragenkomplex, der im Zusammenhang mit dem Schwierigkeits- und Authentizitätsgrad der Podcasts zu stellen ist

- Ist der Hörtext von seinem sprachlichen und syntaktischen Schwierigkeitsgrad her für die Teilnehmer angemessen? (Ist er nicht zu lang? Wie hoch ist der Anteil neuer Vokabeln und unbekannter syntaktischer Erscheinungen?)

- Sind die Teilnehmer mit der jeweiligen Art des Podcasts und der Textorganisation vertraut?

- Ist der Hörtext klar strukturiert und deutlich in Abschnitte gegliedert, um top-down Verstehensprozesse in Gang zu setzen? 
- Ist der Hörtext von seinem inhaltlichen Schwierigkeitsgrad her für die Teilnehmer angemessen? (Wie hoch ist seine Informationsdichte bzw. seine Informationsredundanz? Sind die Teilnehmer mit dem thematisch-inhaltlichen Gegenstand vertraut?)

- Wirkt der Podcast authentisch? (Erfüllt er eine Reihe von typischen textinternen und textexternen Merkmalen der jeweils beabsichtigten Textsorte?)

4. Fragenkomplex, der mit didaktisch-methodischen Verfahren der Podcastbehandlung zusammenbängt

- Welche Verständnisschwierigkeiten sollten zum Gegenstand des Unterrichts gemacht werden?

- Wie gründlich und genau sollte der jeweilige Podcast behandelt werden?

- Welche Hörstile und Verstehensstrategien lassen sich bei der Textbehandlung am besten fördern?

- Lassen sich typische Textmerkmale der jeweiligen Podcastart erkennen, um sie dann im Unterricht heraus zu arbeiten?

- Eignet sich der Podcast für ein möglichst breites Spektrum an Aufgaben und Folgeaktivitäten? Fördert er handlungsorientiertes Lernen?

- Besteht ein Informationsdefizit? Müssen die erwachsenen Lernenden Hintergrundwissen erwerben?

Bei der Suche und Auswahl von Podcasts empfiehlt sich, sowohl den thematischen Schwerpunkt des Podcasts als auch erwachsene Kursteilnehmende in den Mittelpunkt zu stellen und erst dann jeweils einen zusätzlichen Fragenkomplex (d.h. entweder die didaktisch-methodische Eignung oder den Schwierigkeits- und Authentizitätsgrad des Textes) zu reflektieren. Darüber hinaus ist bei der Recherche auf eine größtmögliche Variation verschiedenartiger Vodcasts und Podcasts zu achten. Bei der Materialienbeschaffung sollten jedoch solche Texte häufiger Berücksichtigung finden, die von den Kursteilnehmenden als besonders motivierend und interessant bezeichnet werden. $\mathrm{Zu}$ dieser Gruppe gehören laut unserer Untersuchungsbefunde in erster Linie Filme, Witze, Fernsehnachrichten, Interviews und Lieder.

\subsection{Podcastgestützte integrative Hörverstehensschulung}

Wenn wir im Folgenden von podcastgestützter Hörverstehensschulung sprechen, so lehnen wir uns damit an den Begriff „mediengestützt“ an. Abel (1995: 323) bezeichnet einen Unterricht als mediengestützt, „in dem die unterschiedlichen Medien vom gedruckten Text bis hin zum Computer zur Unterstützung des Lehr- und Lernprozesses herangezogen werden“ (im Gegensatz zum sog. mediengeleiteten Unterricht, bei dem ein Medium bzw. mehrere Medien Steuerungsfunktionen übernehmen). Unter podcastgestützter Hörverstehensschulung verstehen wir daher eine Hörverstehensschulung, in der Podcasts zur Unterstützung des Lehr- und Lemprozesses herangezogen werden.

Integrativ ist eine Hörverstehensschulung dann, wenn das Hörverstehen nicht isoliert geübt, sondern mit anderen Fertigkeiten (Sprechen, Lesen, Schreiben) verknüpft 
wird. Dahlhaus (1994: 127f.) fasst die wichtigsten Gründe für eine Integrierung im Unterricht unter folgenden Stichworten zusammen:

a) kommunikative Gründe: In realen Kommunikationssituationen kommt es fast immer zu einer Verbindung von zwei oder mehr Fertigkeiten, z.B. in einem Dialog mit einem Gesprächspartner (Hören und Sprechen), oder wenn an einem Vortrag zuhört und sich Notizen macht (Hören und Schreiben).

b) lernpsychologische Gründe: Es gibt keine isoliert funktionierenden Hör-, Sprech-, Lese- und Schreibzentren im Gehirn, sondern zwischen diesen gibt es intensive Wechselwirkungen.

c) motivationale Gründe: Eine Unterrichtsstunde, in der mehrere Fertigkeiten geübt werden, ist abwechslungsreicher und damit im Allgemeinen motivierender für die Lernenden.

d) unterrichtspraktiche Gründe: Viele Übungs- und Testformen können nicht nur im Bereich Hörverstehen, sondern auch in den anderen Fertigkeitsbereichen Verwendung finden.

Eine podcastgestützte integrative Hörverstehensschulung zielt somit unter Einbeziehung von Podcasts auf die Entwicklung des Hörverstehens in Verbindung mit weiteren sprachlichen Fertigkeiten. Podcasts sind für eine integrative Hörverstehensschulung besonders geeignet. Es ist relativ leicht, Podcasts mit einer DaF-Lerngruppe zu produzieren. Innerhalb eines solchen Projekts zur Produktion von Podcasts zu einer bestimmten Themenstellung können alle Fertigkeiten auf sinnvolle und authentische Weise integriert werden. Im Vorfeld ist es zumeist erforderlich, dass sich die Lernenden mit Podcasts vertraut machen und somit eine Reihe von Podcasts anhören. Bei der Planung des Podcasts müssen die Lernenden miteinander sprechen, Ideen aufschreiben und Informationen lesen und zusammentragen. Bei der Produktion von Podcasts kann entsprechend dem Sprachniveau und sonstiger Voraussetzungen der DaF-Lernenden bestimmt werden, ob die zu produzierenden Podcasts spontan gesprochene Hörtexte, vorbereitete Hörtexte oder beides enthalten sollen. Das Podcast kann in einen Blog eingebunden werden, so dass Interessierte dort Kommentare zu den Podcastepisoden abgeben können. Diese werden von den Lernenden gelesen und eventuell beantwortet. Für den Fremdsprachenunterricht wurde die Produktion von Podcasts im Rahmen eines e'Twinning-Projekts (Kraus 2007) und als Hausaufgabe (Dorok 2008) vorgeschlagen. Beides eignet sich allerdings nicht für den Einsatz in universitären Sommerdeutschkursen. Hier bietet sich die Produktion von Radio-Podcasts an, wie sie bspw. Peuschel (2007) beschreibt.

\section{Fazit}

Immer wenn neue technische Möglichkeiten entstehen und neue Medien populär werden, wird versucht, diese auch für den Fremdsprachenunterricht nutzbar zu machen. In unserer Studie mit Teilnehmern an universitären Sommerdeutschkursen hat sich gezeigt, dass diese gerne häufiger mit Filmen, Witzen, Fernsehnachrichten, Interviews und Lie- 
dern beim Hörverstehenstraining arbeiten möchten. Besonders für Fernsehnachrichten und Interviews bieten sich Podcasts an, die abonniert werden können und somit quasi automatisch auf den Rechner geladen werden. Des Weiteren kommen Podcasts weiteren Interessen der Deutschlernenden entgegen, und zwar in ihrem Wunsch nach einer Beteiligung an der Hörtextauswahl.

Wir schließen uns der Einschätzung von Schilder (1995: 507) an, dass nicht jede technische Neuerung ,zwangsläufig zu einer Begünstigung der Lehr-, Lern- und Arbeitsprozesse im Fremdsprachenunterricht führt". Es gilt genau zu prüfen, ob und welcher didaktische Nutzen damit verbunden sein kann. Oftmals wird in der fremdsprachendidaktischen Literatur zunächst auf die technischen Möglichkeiten und VOraussetzungen eines neuen Mediums hingewiesen (für Podcasts vgl. z.B. Godwin-Jones 2005, Stoks 2005) und Einsatzbeispiele (,,best practice“) gegeben (für Podcasts vgl. z.B. Kraus 2007). Dies ist zweifellos sehr wichtig, und zwar, weil die Lehrenden mit diesen Medien vertraut sein müssen, um sie in ihrem Unterricht einzusetzen und es hilfreich ist, an Praxisbeispielen zu sehen, wie ein methodisch-didaktisch sinnvoller Einsatz aussehen kann. Allzu leicht wird aber im Zuge der Euphorie über technische Möglichkeiten vergessen, dass das technische Medium nur ein Mittel zum Fremdsprachenlernen ist. So genügt es in Bezug auf Podcasts nicht, die Internetadressen von den für den DaF-Unterricht geeigneten Podcasts zu kennen oder an die Lernenden weiterzugeben. Hinzutreten muss die didaktisch-methodische Vorgehensweise, also z.B. die Höraufgaben, die in den drei Phasen der Hörverstehensschulung (Vorentlastungsphase, Podcasthörphase und Podcastverarbeitungsphase) gestellt werden.

In unserem Beitrag haben wir versucht, das besondere Potential von Podcasts im Hinblick auf universitäre Sommerdeutschkurse herauszuarbeiten. Es liegt zum einen in der Möglichkeit, die DaF-Lernenden an der Auswahl von Hörtexten zu beteiligen (und dazu zu befähigen). Zum anderen kann podcastgestützt eine integrative Hörverstehensschulung erfolgen, indem die anderen Fertigkeiten (Sprechen, Schreiben, Lesen) sinnvoll und in authentischen Kontexten einbezogen werden.

\section{Literatur}

Abel, Brigitte (1995): Mediengestützter und mediengeleiteter Unterricht. In: Bausch, Karl-Richard; Christ, Herbert; Krumm, Hans-Jürgen (Hrsg.): Handbuch Fremdsprachenunterricht. 3., überarbeitete und erweiterte Auflage. Tübingen; Basel: Francke, 323-325.

Adamczak-Krysztofowicz, Sylwia; Stork, Antje (2008): Texte lernerorientiert auswählen. Folgerungen aus einer quantitativen Studierendenbefragung für die Textauswahl und Textarbeit im universitären Fremdsprachenunterricht. In: Chlosta, Christoph; Leder, Gabriela; Krischer, Barbara (Hrsg.): Auf neuen Wegen. Deutsch als Fremdpsrache in Forschung und Praxis. Tagungsband der 35. Jabrestagung des Fachverbandes Deutsch als Fremdsprache 2007 an der Freien Universität Berlin. Göttingen: Universitätsverlag, 463485.

Buck, Gary (2001): Assessing Listening. Cambridge: Cambridge University Press. 
Bühler, Peter (2008): Podcasting im Hörverstehensunterricht. Rezeptive und produktive Einsatzmöglichkeiten. In: Praxis Fremdsprachenunterricht 1, 25-30.

Dahlhaus, Barbara (1994): Fertigkeit Hören. Berlin et al.: Langenscheidt.

Dorok, Sebastian J. (2008): Hausaufgaben-Podcasts im Englischunterricht der Sek I. In: Praxis Fremdsprachenunterricht 1, 31-36.

Eggers, Dietrich (1996): Hörverstehen: Bestandsaufnahme und Perspektiven. In: Kühn, Peter (Hrsg.). Hörverstehen im Unterricht Deutsch als Fremdsprache. Theoretische Fundierung und unterrichtliche Praxis. Frankfurt a.M. u.a.: Peter Lang, 13-44.

Godwin-Jones, Robert (2005): Emerging technologies. Skype and Podcasting - disruptive technologies for language learning. In: Language Learning \& Technology 9/3, 9-12.

Grotjahn, Rüdiger (2005): Testen und Bewerten des Hörverstehens. In: Ó Dúill, Michéal; Zahn, Rosemary; Höppner, Kristina D.C. (Hrsg.): Zusammenarbeiten. Eine Festschrift für Bernd Voss. Bochum: AKS-Verlag, 115-144.

Honnef-Becker, Irmgard (1996): Hörverstehen in Sprachlehrwerken Deutsch als Fremdsprache. In: Kühn, Peter (Hrsg.): Hörverstehen im Unterricht Deutsch als Fremdsprache. Theoretische Fundierung und unterrichtliche Praxis. Frankfurt a.M. et al.: Lang, 4578.

Horn, Dennis; Fiene, Daniel (2007): Das Podcast-Buch. Das Radio des Web 2.0. Poing: Franzis Verlag.

Hüllen, Werner (1977): Hörverstehen im Fremdsprachenunterricht der Sekundarstufe I. In: Dirven, René (Hrsg.): Hörverständnis im Fremdsprachenunterricht. Kronberg: Scriptor, 27-39.

Jung, Udo O.H. (2002): Medien im Fremdsprachenunterricht - Wozu braucht man sie eigentlich? In: Fremdsprachen und Hochschule 66, 7-44.

Kraus, Alexander (2007): e'Twinning. Projektarbeit mit Podcasts in virtuellen Lernumgebungen. In: Der fremdsprachliche Unterricht. Franä̈sisch 87, 34-39.

Leupold, Eynar (2000): Didaktische Aspekte des Hörverstehens. In: Der fremdsprachliche Unterricht. Französisch 6, 4-10.

Neveling, Christiane (2000): Hörverstehen im Fremdsprachenunterricht. Psycholinguistische Grundsatzüberlegungen. In: Praxis Fremdsprachenunterricht 47/1, 3-9.

Peuschel, Kristina (2007): Kommunikation und Teilhabe. Wie Deutschlernende in Radio- und podcast-Projekten zu medial präsenten Sprachnutzenden werden. In: Deutsch als Zweit-sprache 2, 33-41.

Rost, Michael (2002): Teaching and researching listening. Harlow: Longman.

Schilder, Hanno (1995): Unterrichtsmittel und Medien. In: Bausch, Karl-Richard; Christ, Herbert; Krumm, Hans-Jürgen (Hrsg.): Handbuch Fremdsprachenunterricht, dritte, überarbeitete und erweiterte Auflage. Tübingen; Basel: Francke, 503-508.

Schwerdtfeger, Inge C. (2003): Übungen zum Hör-Sehverstehen. In: Bausch, KarlRichard; Christ, Herbert; Krumm, Hans-Jürgen (Hrsg.): Handbuch Fremdsprachenunterricht. 4., vollständig neu berarbeitete Auflage. Tübingen; Basel: Francke, 299-302. 
Solmecke, Gert (1996): Authentische Texte - authentisches Hören? In: Kühn, Peter (Hrsg.). Hörverstehen im Unterricht Deutsch als Fremdsprache. Theoretische Fundierung und unterrichtliche Praxis. Frankfurt a.M. et al.: Lang, 79-92.

Solmecke, Gert (2001): Hörverstehen. In: Helbig, Gerhard et al. (Hrsg.): Deutsch als Fremdsprache. Ein internationales Handbuch. 2. Halbband. Berlin; New York: Walter de Gruyter, 893-900.

Solmecke, Gert (2003): Das Hörverstehen und seine Schulung im Fremdsprachenunterricht. In: Der fremdsprachliche Unterricht. Englisch 37/64-65, 4-11.

Stoks, Gé (2005): Podcasts: new materials for teaching listening comprehension. In: Babylonia 4, 46-47.

Stork, Antje; Adamczak-Krysztofowicz, Sylwia (2007): Plädoyer für einen lerner- und prozessorientierten Umgang mit Texten im fortgeschrittenen Deutschunterricht. Überlegungen und Vorschläge aus der Sicht polnischer Studierender im Studiengang Angewandte Linguistik der Universität Poznań. In: Orbis Linguarum 32, 171-194.

Thaler, Engelbert (2007): Schulung des Hör-Seh-Verstehens. In: Praxis Fremdsprachenunterricht 4, 12-17.

Wolff, Dieter (2002): Fremdsprachenlernen als Konstruktion: Grundlagen für eine konstruktivistische Fremdsprachendidaktik. Frankfurt a.M. et al.: Peter Lang.

Wolff, Dieter (2003): Hören und Lesen als Interaktion: zur Prozesshaftigkeit der Sprachverarbeitung. In: Der fremdsprachliche Unterricht Englisch 64-65, 11-16.

Zydatiß, Wolfgang (2005): Bildungsstandards und Kompetenzniveaus im Englischunterricht. Konzepte, Empirie, Kritik und Konsequenzen. Frankfurt a.M et al.: Lang. 
Christoph Chlosta, Matthias Jung (Hrsg.) (2010): DaF intergriert: Literatur - Medien - Ausbildung. Tagungsband der 36. Jahrestagung des Fachverbandes Deutsch als Fremdsprache 2008. Göttingen: Universitätsverlag, 191-211.

\section{Rüdiger Schreiber (Münster)}

\section{Aktionsforschung zum Einsatz von Podcasts und MP3 als Interaktionsmedium zwischen Dozenten und Lernenden}

\section{Vorwort}

„Obwohl dies häufig nicht geglaubt wird, kann Forschung von Sprachlehrpersonen auch in tatsächlichen Klassenzimmern betrieben werden." (Albert; Coster 2002: 2) ${ }^{1}$

Im Wintersemester 2007/2008 fand am Studienkolleg Münster ein Unterrichtsprojekt statt, das zum Ziel hatte, die Vorbereitung von Präsentationen der Studierenden zu unterstützen, die Aussprache individuell zu fördern und das Hörverstehen mit mündlichen Hausaufgaben zu verknüpfen.

Dafür wurden in den beteiligten zwei Kursen Audio- und Videopodcasts sowie MP3-Audiodateien als Mailattachment verwendet.

Der unterrichtsmethodische Ansatz lag in der Verlagerung wesentlicher Anteile der Aktivitäten in die Zeit außerhalb der Unterrichtsstunden, sowohl für die Studierenden als auch für den Lehrenden.

Inspiriert von den Aufforderungen Claudia Riemers (2002/2007), wurde das Unterrichtsprojekt mit Mitteln der Aktionsforschung vorbereitet, begleitet und dokumentiert.

1 Sie plädierten allerdings für eine nicht experimentelle, quantitative Forschung: „Alles, was man braucht um Forschung zu betreiben, ist Neugier, eine Menge Geduld, etwas Wissen über Statistik und eine gehörige Portion gesunden Menschenverstand.“ 


\section{Vorbemerkungen zur Aktionsforschung}

Aktionsforschung ist ein Forschungsdesign, welches für Unterrichtspraktiker sehr geeignet ist. Eigentlich haben diese sogar sehr gute Voraussetzungen, im Rahmen dieses Designs selbst als Forscher lebendiges Unterrichtsgeschehen zu untersuchen, denn sie sind ihrer Lerngruppe nicht fremd, ihre Lerngruppen sind mehr oder weniger zufällig zusammengesetzt und nicht zu Forschungszwecken ausgewählt worden, ihre Lerngruppen stehen in einem vielfältigen Kontext von realem Unterrichtsgeschehen. Lehrkräfte sind ohnehin gewohnt, die Entwicklung ihrer beruflichen Tätigkeit als kontinuierlich und (hoffentlich) auch fortschreitend zu betrachten (Wallace 1998).

Auf die Gefahr hin, längst Bekanntes mitzuteilen, soll an dieser Stelle zunächst ein idealisiertes Modell der Aktionsforschung zur Veranschaulichung vorgestellt werden (siehe Abb. 1):

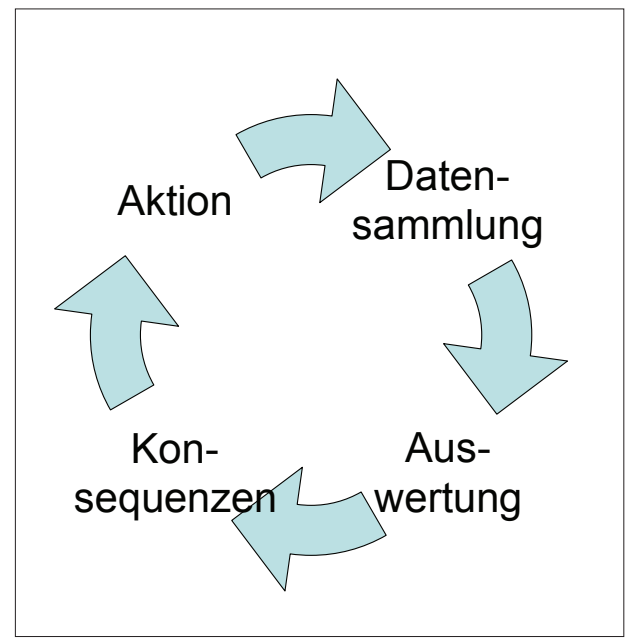

Abb. 1: Modell zur Aktionsforschung

Am Anfang steht eine (erste) Forschungsfrage, darauf folgt der Einstieg in den Zyklus der Unterrichtsentwicklung durch die Datensammlung. Der „Ausstieg“ aus dem Zyklus ist die Publikation der Ergebnisse. Wie die Grafik nahelegt, genügt ein einmaliger Durchlauf nicht, da in der Phase der Aktion wiederum Daten anfallen und erneut Daten erhoben werden, die ausgewertet werden und zu Modifikationen des Unterrichts führen.

Der Unterschied von Aktionsforschung zu allgemeiner Unterrichtsreflexion mag angesichts des Modells nicht sofort einleuchten. Zu den verbreiteten Merkmalen von Unterrichtsreflexion gehört die individuelle und vielleicht auch nur punktuelle Nachbereitung in Form von Notizen nach dem Unterricht, Gesprächen im Kollegium, bei Bedarf auch Gesprächen mit der Lerngruppe. Evaluationsbögen werden gelegentlich eingesetzt. Aktionsforschung bringt zusätzliche Elemente in die Unterrichtsreflexion, aber auch in seine Planung. Dazu gehört die systematische Datenerhebung in Form von 
Tagebüchern, Speicherung von Mails, Audioaufzeichnungen, Fragebögen und deren Auswertung. Die Beteiligung der Lerngruppe an der Planung des Forschungsprojekts unterscheidet Aktionsforschung von quantitativen Studien mit Fremdbeobachtung. Aktionsforschung ist demokratisch strukturiert, baut auf Mitwirkung der „Beforschten“, ist vertraulich und setzt voraus, dass Fragebögen und alle anderen Daten anonymisiert werden. Aktionsforschung zielt andererseits auf die Veröffentlichung der Ergebnisse und die saubere Dokumentation des Geschehens, so dass vorab das Verfahren der Datensammlung im Kurs zu vereinbaren ist, das Einverständnis zur Veröffentlichung a priori einzuholen ist. Personenbezogene Daten werden, wenn überhaupt nötig, nur mit Namenskürzeln oder Aliasnamen veröffentlicht (Riemer 2002: 136-140). Altrichter und Posch (2007: 116-124) erklären die Beachtung dieser Verfahrensweisen und des demokratischen Ansatzes zu Gütekriterien von Aktionsforschung. Detaillierte Vorschläge zur Datensammlung und Formen der Daten finden sich bei Wallace (1998: 35-75), er schlägt unter anderem vor, die Lerner selbst als Beobachter zum Einsatz kommen zu lassen (ebd.: 106). Ein interessanter demokratischer Ansatz, doch zeigt sich an vielen Stellen die Schule der quantitative studies, und dass Datenerhebung in einem erheblichen Umfang quantifizierend gemeint ist (ebd.: 113-123).

\subsection{Die digitalen Medien und die Aktionsforschung in der wissenschaftlichen Diskussion und die Folgerungen für das Unterrichtsprojekt}

\subsubsection{Digitale Medien und Autonomie}

Grundsätzlich stellt sich die Frage, ob man das, was man mit digitalen Medien erreichen will oder kann, nicht auch auf anderen Wegen genauso gut, vielleicht schneller und besser im direkten Unterricht, erreichen kann, wie eine Kursteilnehmerin zu Beginn des Projekts kritisch anmerkte.

Warschauer; Kern (2000: 2) weisen in etwas anderem Kontext als bei diesem Projekt darauf hin, dass eine Spezifizierung der Forschung beim Einsatz digitalen Medien notwendig sei, in dem Sinne, dass jeweils besondere Anwendungen, bezogen auf besondere Gruppen, untersucht werden müssten. Dazu können Beispiele aus dem Unterricht, entwickelt, begleitet und dokumentiert mit Mitteln der Aktionsforschung, beitragen.

Rösler (2006) stellt fest, dass die Erweiterung der technischen Möglichkeiten in der Vergangenheit allein kein Fortschritt war, das diese auch bedeuten konnte, dass unangemessen viel Material zur Verfügung stand und dass Kooperationen nicht didaktisch, sondern nur durch das Vorhandensein der Kanäle motiviert waren. Seine Bestandsaufnahme beschäftigt sich mit der Frage, wie digitale Medien zur Individualisierung des Fremdsprachenlernens beitragen und wie sie kooperative Formen des Lernens fördern.

In seiner Unterscheidung von Einzelarbeit, Selbstlernen, Fernlernen, Präsenzlernen, E-Learning/Blended Learning auf der einen Seite und selbstbestimmtem, selbstgesteuertem oder autonomem Lernen auf der anderen Seite weist er darauf hin, dass die letztgenannten Konzepte sind, die sich auf die Einstellungen der Lernenden zum Lernprozess 
und zu den Materialien beziehen, mithin also Eigenschaften des Lernenden und nicht des Materials oder der Medien bezeichnen.

In diesem Sinne soll auch bei dem hier vorgestellten Forschungsprojekt nicht der Eindruck erweckt werden, durch die Verlagerung eines Großteils der Aktivitäten von Lehrkraft und Studierenden in die häusliche Arbeit am Computer sei per se autonomes Lernen erreicht. Bei der Findung von inhaltlichen Schwerpunkten innerhalb der vorgegeben Themenstellung und bei Einteilung der Aufgaben innerhalb der Arbeitsgruppen waren die Studierenden ,autonom“. Das ist jedoch unabhängig von den Medien zu sehen.

Selbstlernen und Blended Learning dagegen sind Sozialformen, die in diesem Unterrichtskonzept eine wichtige Rolle spielten, die Selbstbestimmung beschränkte sich dabei im Wesentlichen auf die Wahl des Zeitpunktes und des Ortes sowie des Umfangs des Lernens.

Die Grundbedürfnisse, die Motivation steuern, nämlich soziale Integration, die Kompetenz- und Autonomieerfahrung (Alm 2007), konnten in diesem Projekt vor allem in der Phase der Präsentationen, die letztgenannten auch in der selbstgesteuerten Arbeit am Computer zu Hause verwirklicht werden. Freude und Stolz waren nach den Präsentationen unübersehbar.

\subsubsection{Quantitative oder qualitative Forschung - ist Aktionsforschung überhaupt Forschung?}

Einen ausgezeichneten Überblick über die weitgehend englischsprachige Fachliteratur bietet Anne Burns (2005). In ihrem Beitrag wird deutlich, welch verschiedenes Verständnis von action research sich im Laufe der Zeit entwickelt hat, und was der aktuelle Diskussionsstand dazu im Bereich des Englischunterrichts ist. Unterschiedliche Auffassungen werden im Folgenden an einigen Beispielen skizziert, kommentiert und mit den Projektüberlegungen verknüpft.

Brown (2001: 1-8) unterscheidet zwischen sekundärer und primärer Forschung. Zu sekundärer Forschung rechnet er die Nutzung vorhandener Literatur, bei primärer unterscheidet er zwischen Formen, die zu statistischen Ergebnissen führen können, Formen, die Befragungen schriftlicher und mündlicher Art umfassen, und qualitativen Forschungen. Damit kennzeichnet er implizit die Mittel der Aktionsforschung, nämlich Befragungen, Tagebücher und Protokolle, als seriöse Formen primärer Forschung. Auch Testergebnisse und Beobachtungen im Klassenraum zählt er dazu, wobei offen bleiben muss, ob diese Beobachtung von außen oder von der beteiligten Lehrkraft selbst durchzuführen ist.

Daten sind demzufolge alle Informationen, ob qualitativ oder quantitativ, die z.B. aus individuellen Interviews, Gesprächen in der Gruppe oder Fragebögen resultieren. Befragungen in der Gruppe könnten zwar zu gruppendynamischen Anpassungen der Äußerungen führen. Da in der Aktionsforschung die Beteiligung der Gruppe an der Planung vorgesehen ist, lässt sich die Angleichung an Erwartungen der Lehrkraft und Meinungen der Mitstudierenden nicht ausschließen, könnte aber, falls Zweifel bestehen, 
bei einem Mitschnitt des Gesprächs und folgender Gesprächsanalyse entdeckt werden. Die Planungsgespräche für dieses Projekt und die Präsentationen liegen als komplette Mitschnitte vor.

Der Fragebogen ist im Unterricht ausgefüllt worden. Dieses Verfahren bietet nach Brown (2007: 7) mehrere Vorteile: Die Studierenden dürften sich verpflichtet fühlen, die Bögen auszufüllen, so dass die Rücklaufquote 100\% erreichen kann. Eventuelle Unklarheiten können im Gespräch beseitigt werden. Das ist hier unterblieben, um keinerlei Einfluss auf das Ergebnis zu nehmen, hat aber sicher in einem Fall zu einer fehlerhaften, d.h. höchstwahrscheinlich anders gemeinten Eintragung geführt, wie entsprechende Gegenfragen auf dem Fragebogen deutlich machen. Der dritte Vorteil ist, dass man genau die Bedingungen kennt, unter denen der Fragebogen ausgefüllt wurde - ein nicht zu unterschätzender Vorteil, wenn man bedenkt, welche Bedeutung Ablenkungen und Beeinflussungen aller Art bei selbstverwalteten schriftlichen Befragungen zu Haus oder im Büro haben können.

Befragungen können offen oder geschlossen sein. (Brown 2007: 9-13) Die Entscheidung hier war, im Interview offene Fragen zu stellen, um kreative Beiträge zur Gestaltung des Projekts zu bekommen, und geschlossene Fragen im Fragebogen, um statistisch auswertbares Material zu erhalten. In jedem Fall scheint ein wichtiges Charakteristikum qualitativer Forschung zu sein, die Geschichte des Projekts und der involvierten Partner darzulegen. Diese Darstellungen variieren von Projekt zu Projekt. In hybriden Formen der Forschung wie hier werden qualitative und statistische Formen von Forschung kombiniert. Fragebögen empfiehlt Brown bei der Curriculumentwicklung und bei der Bedarfsanalyse für Sprachprogramme. Er sieht die Studierenden als Klienten, deren Bedürfnisse zu befriedigen sind.

In diesem Projekt wurde der Bedarf nicht durch Fragebögen ermittelt. Das mag ein Versäumnis sein, doch zeigte sich bei früheren Untersuchungen am Studienkolleg (Nellessen 2002), dass Studierende das Lernen einer Sprache unter dem Gesichtspunkt von Grammatik betrachteten. Am häufigsten wurde Grammatik als nützlichstes Element des DaF-Unterrichts genannt, am wenigsten Referate. Demgegenüber wurde unter den gewünschten Veränderungen „,mehr sprechen“ am häufigsten genannt. Das könnte auf eine Inkonsistenz bei der Beantwortung der Fragebögen hindeuten. Jedenfalls wurde im Fall dieses Projekts das Ziel „Präsentationen“ nur vorgegeben und im Planungsgespräch ausgelotet. Der Bedarf allerdings hatte sich objektiviert in dem Moment, als von Studierenden vorbereitete Präsentationen wortlos projiziert worden waren. Hier zeigte sich ein eklatantes Defizit, und so wurde es von den Beteiligten auch empfunden. Das war die Motivation für das Projekt.

In der Aktionsforschung wird zwar mit Gesprächsprotokollen und Bandaufzeichnungen gearbeitet, doch eine Gesprächsanalyse, die mit Transkriptionen arbeitet und dabei auch Faktoren wie Tonhöhenverlauf, Betonungen usw. dokumentiert und auswertet, ist in diesem Projekt nicht vorgesehen. Eine konversationsanalytische Auswertung gar wäre mit einem „,enormen Aufwand bei der Datenerhebung und -aufbereitung“ (Albert; Coster 2002) verbunden und dürfte im Alltag von forschenden Lehrkräften nur 
in Ausnahmefällen und bei sehr speziellen eingegrenzten Konfliktbereichen in Betracht kommen.

Bei quantitativen Untersuchungen käme es darauf an, den Untersuchungsgegenstand so genau wie möglich zu umreißen, um zu aussagekräftigem Zahlenmaterial zu gelangen. Es müsste z.B. für die Frage, ob die Methode X oder die Methode Y das Hörverstehen besser fördern kann, erreicht werden, den Faktor Hörverstehen von anderen Faktoren hinreichend zu isolieren. (Albert; Coster 2002: 5) Dieses Projekt im Rahmen der Aktionsforschung dagegen ist nicht quantifizierend angelegt, es ist ein offener Prozess unter planerischer Beteiligung der Lernenden. Die Datenerhebung dokumentiert daher auch kaum Zahlen, sondern sie weist Statements der Beteiligten nach und dokumentiert so sich verändernde Einstellungen und planerische Entscheidungen zu einem komplexen und relativ globalen Gesamtziel, der Verbesserung der Präsentationsfähigkeit.

Eine Falsifizierung oder Verifizierung von Hypothesen zu dem „Ausmaß“ der Veränderung durch die geleistete Arbeit im Sinne einer statistischen Beweisführung scheidet daher aus. Was quantifizierbar ist, ist der Grad der Zustimmung oder Ablehnung zu bestimmten Aspekten eines Projekts oder des Unterrichtsvorhabens insgesamt. Fraglich bleibt dennoch, ob nicht die qualitative Auswertung von konkreten Statements der Beteiligten zu offenen Fragestellungen ergiebiger ist. So jedenfalls arbeitet Aktionsforschung.

Der quantifizierende Nachweis von Erfolg oder Misserfolg, Fortschritt oder Stillstand bei einzelnen Studierenden, z.B. im Bereich der Aussprache einzelner Segmentalia, wäre auf der Basis der vorliegenden Dokumentationen theoretisch möglich, doch würde solch ein nachträglich Faktoren isolierendes Verfahren der Komplexität des Unterrichtsprojektes, in dem Hörverstehen, Ausspracheschulung, Materialbeschaffung, Leseverstehen, der Umgang mit den zugrunde liegenden Audioprogrammen, z.T. auch noch Umgang mit Präsentationssoftware und vieles andere mehr eine Rolle spielen, insgesamt nicht gerecht.

Der größte Teil der Daten stammt aus offener Beobachtung und aus dem Mailverkehr zwischen Sprachlehrer und Studierenden. Die offene Beobachtung ist demokratisch, sie setzt die Zustimmung der Beteiligten voraus und unterscheidet sich somit rechtlich und moralisch von verdeckten Beobachtungen in Laborschulen (Albert; Coster 2002: 17). Sie wurde durchgeführt mittels Tonaufzeichnungen und Unterrichtsbeobachtung eines Kollegen. „Bei der Beobachtung fallen erheblich mehr Informationen an, als in die Auswertung eingehen können. Deshalb ist bei der Beobachtung ganz besonders wichtig, dass eine systematische Auswahl von Beobachtungskriterien getroffen wird“, fordert Albert (2002: 18f.). Da bei diesem Projekt der Aktionsforschung jedoch Quantifizierungen kaum eine Rolle spielten, genügte die Möglichkeit, die Gesamtaufnahmen nachträglich abzuhören und auf bedeutsame Erscheinungen zu untersuchen, sowie bei der Unterrichtsbeobachtung die - vorher abgesprochene - Fragestellung, wie gut die Präsentationen der Studierenden zu verstehen waren. Diese offene Frage lässt sich sehr gut beantworten, ihre Beantwortung berührt selbstverständlich verschiedenste 
Kompetenzbereiche der Beteiligten, wie das naturwissenschaftliche Verständnis und Vorwissen von Sprechern und Hörern, die Qualität der Visualisierungen, die eingesetzten Redemittel, die Artikulationsqualität, sowie Wortschatz und Grammatik. Deren Qualität, oder besser, die Qualitätsveränderung, lässt sich kaum exakt quantifizieren. Sicher kann man aber sagen: Wo vorher fast nichts war, ist jetzt eine ganze Menge.

Die Befragung der Studierenden ist ein wesentliches Element der Datenerhebung in der Aktionsforschung, und sie ist ein konstitutives Element der Beteiligung der Studierenden an Planung und Durchführung des Projekts. Leider hat eine Befragung ihre Tücken. Sie ist natürlich keine reine Einholung von Informationen, sondern Kommunikation zwischen Personen, mehr noch in diesem Fall, Kommunikation von Forschenden und Handelnden, Beobachteten in einer Person. Fragen und Antworten werden geprägt vom situativen Kontext, von Erwartungen und Zu- oder Abneigungen. Antworten stellen die Erinnerung an erlebte Ereignisse im Rahmen des Projekts dar, sie spiegeln Erwartungen des Lehrers oder an den Lehrer. Sie zeigen also ,gefilterte Wirklichkeit“ (Albert; Coster 2002: 24), besonders daraus gewonnene Zahlen wären „,kontaminiert“ (Riemer 2008, mündlich).

Ein Beispiel: M. hat sich an erheblichen Elementen des Projekts nicht beteiligt: keine Hörverstehensarbeit, keine Ausspracheschulung, keine Präsentationssoftware. Möglicher Hintergrund: Eine als schwach bewertete Klausur. M. gibt aber einen Fragebogen mit allerlei zustimmenden Kreuzchen ab. Solche „Daten“ sind offensichtlich zu verwerfen, geben aber durchaus Aufschluss über soziale Prozesse. Diese waren jedoch nicht (auch noch) Untersuchungsgegenstand.

Ein anderes Beispiel: P. bittet am 24. April, also sieben Wochen nach Projektende, darum, ihre Hausaufgabe, in diesem Fall zum Leseverstehen, wieder als Audiodatei abgeben zu dürfen.

Zwei Einzelfälle, die jedoch unterschiedlich zu gewichten sind. Im ersten Fall verfälschen gegenseitige Erwartungen und Vermutungen das Ergebnis bis zur Wertlosigkeit, im zweiten Fall ist die unverhoffte, aus eigenem Antrieb und in der individuellen Gewissheit um den Wert des Projekts gemachte Äußerung ein wertvoller, sachdienlicher Hinweis auf das bisher Erreichte und das eigentlich noch zu Erreichende.

\subsubsection{Action Research oder Classroom Research}

Was anmutet wie der berühmte Streit um des Kaisers Bart, soll hier dennoch referiert werden:

Ausführliche Beispiele von Studien, die auf Aktionsforschung beruhen, legt Hopkins (2002) vor. Schon stilistisch auffällig ist die häufige Verwendung der ersten Person im Bericht. Äußerungen in dieser Form enthalten Absichtserklärungen, Berichtsbruchstücke, Gefühlsäußerungen, Meinungen, Hypothesen. Auch unbeantwortete Fragen verstärken den Anschein einer subjektiven Schreibweise. Ist das nun dennoch Forschung? Ja, schreibt Hopkins, diese Äußerungen können dokumentieren, wie der Prozess in einem Projekt tatsächlich gesteuert wurde, und vermeiden zunächst auf der 
reinen Datenbasis vorschnelle Objektivierungen. Die Forderung, in Tagebüchern auch Gefühle zu protokollieren (Altrichter 2007 u.a.) trägt dem Rechnung.

Hopkins möchte eine Unterscheidung treffen zwischen Aktionsforschung bzw. action research und Forschung im Klassenraum, mit seinen Worten: classroom research. (2002: 42-54). Die Unterscheidung ist ein recht feinsinniger Kampf um Begriffe. Er kritisiert, dass der Begriff ,action research“ aufgrund von Missverständnissen eines sehr alten Buches des Soziologen Lewin über ,,action research an minority problems“ von 1946 in die Pädagogik übernommen worden sei. Lewins Konzept habe mit externen Interventionen zu tun, sei funktionalistisch und präskriptiv. Dies habe aber nichts gemein mit „classroom research“ durch Lehrkräfte, welche eher eklektizistisch sei. Er bemängelt außerdem, dass die starren Konzepte von „,action research“ Lehrkräfte in die Falle fester Prozessschritte locken könnten. (ebd.: 50) In „action research“ sei außerdem zu oft von Bedarfsanalysen, Problemlösungen und Verbesserungen die Rede, was von einer defizitorientierten Wahrnehmung zeuge. Stattdessen schlägt er eben den Begriff „classroom research“ vor und meint damit weniger ein Schritt-für-Schritt-Verfahren als ein Bündel von Instrumenten zur Erforschung des eigenen Unterrichts. (ebd.: 51) Die vorgeschlagenen Maßnahmenbündel sollen offenbar ein niedrigschwelliges Angebot an Lehrkräfte sein, den eigenen Unterricht zu erforschen, ohne sich von angeblich zu strukturierten Modellen wie denen der Aktionsforschung abschrecken zu lassen. Die vorgeschlagenen Mittel und Regeln sind aber in der Tat eher etwas trivial und unterscheiden sich nicht von den Faustregeln anderer Autoren. Ein Beispiel ist seine Faustregel eins: Der Unterricht bleibt immer die Hauptaufgabe. Es war Zeit, dass das endlich einmal jemand sagte.

Schön übersichtlich und mit motivierenden Beispielen versehen ist dagegen das Kapitel über Methoden der Datengewinnung, in dem Vor- und Nachteile bestimmter Methoden gegenübergestellt werden (ebd.: 102-128). Zum ersten Einstieg sind diese Ausführungen wertvoll.

Die vorgeschlagenen Techniken sind: Notizen während und unmittelbar nach dem Unterricht, Audio- und Videoaufnahmen, die er aber nur in ganz besonderen Fällen punktuell eingesetzt sehen will, weil Anhören und ggf. Transkription zu aufwändig seien, Tagebücher der Lernenden, Interviews natürlich und Fragebögen, für die er einige sehr schöne kindgerechte Beispiele anbietet.

Mackey und Gass (2005) unterscheiden ebenfalls zwischen Classroom Research und Action Research. Viele der Datenerhebungstechniken für qualitative Studien seien nicht nur im Klassenraum verwendbar, wie z.B. Tagebücher der Lerner.

Grundsätzlich gelte natürlich ein fundamentaler Unterschied zwischen Untersuchungen im Klassenraum und denen unter Laborbedingungen, wo die Variablen eines Experiments eng kontrolliert werden können. Ob Ergebnisse einer Studie unter Laborbedingungen verallgemeinert werden können für die Bedingungen in einem Klassenraum, ist eine empirische Frage. Deshalb wächst das Bewusstsein in der Forschung dafür, dass Studien in den verschiedensten Kontexten durchgeführt werden müssen, um der Komplexität des Fremdsprachenerwerbs gerecht zu werden. 
Die Autoren gehen von einer externen Beobachtung im Klassenraum aus, und fordern die Beachtung von Verhaltensregeln und einer gewissen Etikette gegenüber den Beobachteten, um nicht die Ergebnisse und das Verhalten einschließlich der Produktivität durch die Beobachtung zu beeinflussen und verweisen auf den sogenannten Hawthorne-Effekt. Auch wenn diese Bemerkung auf externe Beobachtung gemünzt war, so ist sie doch lehrreich auch für den selbst forschenden Lehrer. Die Verabredung eines Projekts mit einem Kurs und die Vereinbarungen über die Protokollierung und Aufzeichnung von Aktionen der Lernenden können sicher dazu führen, dass das Bewusstsein des Beobachtetseins selbst Veränderungen des Verhaltens hervorruft.

Die Autoren verweisen daneben auf die Frage der Objektivität der Beobachtung unter Kollegen. Beobachter aus dem eigenen Haus könnten tatsächlich von Empathie und Respekt vor der Mehrarbeit eines Kollegen zu Ergebnissen kommen, die Erscheinungen zu positiv bewerten. Im Falle dieses Projekts hat - eine typische Konstellation - ein befreundeter Kollege eine Doppelstunde beobachtet. Trotz allen Lobes über das Projekt an sich und über die Leistungen der Beteiligten enthalten seine Aufzeichnungen jedoch überwiegend kritische Anmerkungen zu den Defiziten bei den Studierenden, an denen in Zukunft noch zu arbeiten wäre.

Classroom Research verstehen Mackey und Gass ganz offensichtlich trotz des Hinweises auf qualitative Absichten als basiert auf der Erhebung quantitativer Daten. Sie schlagen deshalb eine große Bandbreite von Codierungs- und Beobachtungsschemata vor, mit deren Hilfe Verhalten quantifizierend beschrieben werden könnte. Sie konzedieren allerdings, dass ein Teil dieser Formen der Datenerhebung sehr zeitraubend seien. Das genau dürfte an dem quantifizierenden Verfahren liegen, welches auf Fremdbeobachtung beruht, damit einen erheblichen logistischen und Kostenaufwand verursachen würde und nicht zuletzt den Lehrer als Forscher außen vor lässt.

Action Research dagegen ist Mackey und Gass gerade fünf Seiten ihres umfangreichen Werkes wert. Ihr Blick ist dementsprechend kritisch-distanziert. Während Classroom Research im Regelfall der Theoriebildung und der Testmethodik diene, werde Action Research von Praktikern durchgeführt, die konkrete Probleme und Fragestellungen des Unterrichts bearbeiten wollten. Action Research sei somit weniger theoriebildend als vielmehr orientiert an der Verbesserung von Unterricht. Zumindest aber, und das erwähnen die Autoren nicht, ist sie aber in der Lage, Hypothesen zu generieren und zur Diskussion zu stellen. Damit ist auch eine Veröffentlichung gerechtfertigt.

Für qualitative Studien sei erforderlich, Daten von mehr als einer Quelle zu gewinnen. Das können Gespräche mit Kollegen über deren Beobachtungen sein, Fragebögen, Think-Aloud-Protokolle, direkte Befragungen der Studierenden und Lernertagebücher. In diesem Projekt wurde teilweise so verfahren, mit der Einschränkung, dass im Klassenraum oft nichts zu beobachten war, weil die zentrale Aktivität zu Hause bei Lernern und Lehrer stattfand, und dass die Lerner keine Tagebücher führten.

Die Validität von Action Research sei weiterhin eingeschränkt durch das Fehlen von Vergleichsgruppen. Das ist sicher richtig, doch stand bei der Entscheidung über die Arbeit mit den parallelen Lerngruppen die Verantwortung für den Lernfortschritt aller 
Teilnehmer im Vordergrund. Die Bildung von Vergleichsgruppen mit entsprechend unterschiedlichem Unterricht ist nicht zu verantworten, wenn man der Ansicht ist, das zu untersuchende Verfahren sei wahrscheinlich das bessere.

Nicht zuletzt werfen Mackey und Gass einen kritischen Blick auf die Qualität der Veröffentlichungen von Aktionsforschungsprojekten und fordern, dass diese wenigstens die grundlegenden Standards für Publikationen erreichen sollten, wenn sie schon nicht die Standards der etablierten Forschung erreichten. Solche Bemerkungen können schon abschrecken, sollten es aber nicht, da andere Autoren die Aktionsforschung positiver beurteilen.

\section{Projektbericht}

\subsection{Projektidee und Ausgangshypothesen}

Am Anfang standen Wahrnehmungen: Da gibt es auf der einen Seite eine neue Generation von Studierenden, für die der Umgang mit dem PC selbstverständlich geworden ist, die surft, mailt, skyped, nicht zuletzt um die Verbindungen mit der Heimat aufrecht zu erhalten. Und auf der anderen Seite Beobachtungen im Unterricht zur Qualität und Quantität im mündlichen Ausdruck generell und bei Präsentationen (bei Sprechern und Hörern) im Besonderen, die nahe legten, etwas zur Unterstützung der Studierenden zu entwickeln. Ein spezieller Punkt war die Feststellung, dass Aussprachekorrekturen in heterogenen Gruppen zu Langeweile, Unruhe und gut gemeintem lautem Einhelfen derjenigen führte, bei denen das bearbeitete Aussprachephänomen kein Problem war.

Daraus folgten die Ideen, mit Podcasts das Hörverstehen zu individualisieren, indem nun die Teilnehmer nach eigenem Ermessen Hörfrequenz und Pausen bestimmen, und den mündlichen Ausdruck vor allem in häuslicher Arbeit und in Interaktion per Mail mit dem Lehrer zu entwickeln. Diese Elemente ordneten sich dem Ziel unter, die Präsentationsfähigkeit insgesamt zu verbessern und die Präsentationen gewinnbringend einzusetzen.

Der Idee, den mündlichen Ausdruck in häuslicher Arbeit zu entwickeln, lag die Annahme zugrunde, dass sich so Redehemmungen leichter abbauen ließen.

Der Gedanke, das Ganze an Präsentationen anzubinden, geht von der Vorstellung aus, dass bei Präsentationen die Referenten den anderen Kursteilnehmern gegenüber eine Verantwortung für das Gelingen der Kommunikation tragen, so dass die Bedeutung des mündlichen Ausdrucks evident wird.

Erste Inspirationen zum Zusammenhang von Sprechen, Denken und Hörverstehen im DaF-Unterricht verdankt der Verfasser Roland Forster (1997: 64f.), welche bei der Entscheidung eine Rolle gespielt haben, das Hörverstehen und das Sprechen in demselben Projekt zu bearbeiten. 


\subsection{Ausgangssituation}

\subsubsection{Die Kurse}

Heterogene Lerngruppen sind am Studienkolleg wie auch in Sprachkursen der Universitäten der Normalfall. Diese haben individuell verschiedene Lernbedürfnisse und Lerngewohnheiten. Einige weitere Details sollen die bessere Einschätzung der Forschungsdaten ermöglichen: Teilnehmer des Unterrichtsprojekts waren zwei parallel unterrichtete T-Kurse, die sich um die Jahreswende 2007/2008 am Anfang ihres zweiten Semesters am Studienkolleg befanden. T-Kurse haben nur 12 Wochenstunden Deutsch und werden überwiegend in Mathematik und Naturwissenschaften, natürlich in deutscher Sprache, unterrichtet. Die Ausgangssprachen waren vor allem Arabisch und Thai, außerdem Russisch, Portugiesisch, Nepalesisch und Spanisch. In dieser Phase wiesen Hörverstehensfertigkeit und mündlicher Ausdruck eine Bandbreite von B1 bis C2 auf. Bis auf einen Studenten hatten alle einen eigenen PC, überwiegend auch einen eigenen Internetzugang. Die anderen sollten sich mit anderen Kursteilnehmern verabreden, was aber aufgrund der großen Entfernungen zwischen den Wohnorten kaum funktioniert hatte, oder ins Internetcafe gehen.

\subsubsection{Methodische Erfahrungen vor dem Planungsgespräch}

Phonetikeinheiten im Frontalunterricht waren wichtig für die Vermittlung von Problembewusstsein und von Ableitungen, Übungen aber führten zu Unruhe (s.o.). Gruppenarbeit und Gruppenpräsentationen waren geübt, die Verwendung von Medien wie Präsentationssoftware und Plakaten gelang nicht in befriedigendem Ausmaß. Insbesondere steigerte der Einsatz von Präsentationssoftware eher noch die Wortkargheit.

\subsection{Projektablauf}

Das Schema in Abbildung 2 soll veranschaulichen, wie in diesem Projekt die Prinzipien der Aktionsforschung umgesetzt wurden und die Projektentwicklung in Interaktion zwischen Studierenden, Lehrer und Dritten ablief.

Berater sind hier „kritische Freunde“, die unterstützen und herausfordern (Altrichter). Im Falle dieses Projekts war eine direkte Beobachtung nur punktuell möglich, da ein Großteil der Aktivitäten beim Lehrer und bei den Studierenden zu Hause stattfand. Ihre Anregungen und Tipps im Vorfeld und ihre Beobachtungen und Ratschläge waren unverzichtbar.

\subsubsection{Das Planungsgespräch und die Folgerungen daraus}

Dem Planungsgespräch ging ein erster Versuch voraus, Fragen zu einem Videopodcast in häuslicher Arbeit mündlich zu beantworten und die Aufnahme zu schicken.

In dem Planungsgespräch gab es kritische und selbstkritische Stimmen, aber auch konstruktive Vorschläge und Zustimmung. 


\begin{tabular}{|c|c|c|}
\hline Berater & Lehrer & Studierende \\
\hline \multirow[t]{3}{*}{$\begin{array}{l}\text { Forschungs- } \\
\text { methode }\end{array}$} & $\begin{array}{l}\text { Beobachtungen, } \\
\text { Erprobungsabsicht } \\
\text { Planung }\end{array}$ & Aktionen \\
\hline & $\begin{array}{l}\text { Interpretationen } \\
\text { Veränderte Planung }\end{array}$ & Planungsgespräch \\
\hline & $\begin{array}{l}\text { Datensammlung } \\
\text { Auswertung, Variation }\end{array}$ & Aktionen \\
\hline \multirow[t]{3}{*}{$\begin{array}{l}\text { Protokoll, } \\
\text { Beratung }\end{array}$} & Dokumentation & Präsentationen \\
\hline & $\begin{array}{l}\text { Auswertung, Statictik, } \\
\text { Protokoll }\end{array}$ & $\begin{array}{l}\text { Fragebögen, } \\
\text { Auswertungs- } \\
\text { gespräch }\end{array}$ \\
\hline & Variation & Aktion \\
\hline $\begin{array}{l}\text { Methodische } \\
\text { Tipps }\end{array}$ & Auswertung aller Daten & \\
\hline
\end{tabular}

Abb. 2: Projektablauf 
Einwände gegen das Verfahren waren:

$\begin{array}{ll}\text { „S1 } & \begin{array}{l}\text { Aber durs MP3 anworten, das ist schwer su verstehen, was Ausländer } \\ \text { wie wir wirklich sagen müss - möchten }\end{array} \\ \text { Lehrer } & \text { Hm - hab ich nicht ganz verstanden } \\ \text { S1 } & \text { Phonetik } \\ & \text { Meinen Sie, es ist leichter wenn man sich sieht, wenn man sich ansehen } \\ & \text { kann } \\ \text { S1, S2 } & \text { Ja } \\ \text { S1 } & \text { Ja dann wei ich sofort was sie nich verstehen, ja ich weiß, aber bei mp3 } \\ & \text { wenn ich fasch Phontetik sprechen, dann merk ich gan(i).. oder... Für } \\ \text { Lehrer } & \text { Sehen die da ne Lösung? } \\ \text { S1 } & \text { Selbst hören oder weiter versuken ---- mit Computer su sprechen ist } \\ & \text { schwerer als mit Menschen su sprechen“ }\end{array}$

Das Transkript kann aber auch zeigen, dass offenbar bisher die Erfahrung gemacht wurde, dass Kommunikationshindernisse wie eine stark von der Norm abweichende Aussprache mit nonverbalen Mitteln kompensiert werden können.

Sehr selbstkritisch zeigt sich eine andere thailändische Studentin, die im privaten Umfeld so negative Erfahrungen gemacht hatte, dass ihr die Ausspracheschulung als ganz zentrales Ziel erscheint: „Damit bin ich ganz einverstanden, weil mein Hörverstehen und mein mündlicher Ausdruck ist ganz schlecht. Ich hab - ja - Samstag war ich in Fitnessstudio, un ich habe mei, ich habe mit Deu- eine Deutsche getroffen, das war eine Katastrophe für mich, wei - sie hat mich gar nich verstanden, was ich gesagt habe, und, - un au wenn sie sagte, ik muss ich, ich sagte immer nokma bitta, nokma, es is, ohh" Das Hauptinteresse richtet sich so oder so bei den meisten Studierenden auf die Phonetik. Die Sensibilisierung und selbstkritische Wahrnehmung der Sprechleistungen ist offenbar nicht nur den vorangegangenen Unterrichtseinheiten zur Phonetik geschuldet, sondern basiert auch auf privaten Erfahrungen, so dass man ohne Übertreibung sagen kann, dass auch Phonetikschulung im Unterricht mit Fortgeschrittenen nicht nur studienpropädeutisch, sondern auch integrativ wirken kann und angebracht ist. Die Frage ist nur wie, und darauf versucht dieses Forschungsprojekt eine mögliche Antwort zu finden.

\subsubsection{Video- oder Audiopodcasts?}

Schon im Planungsgespräch erwies sich aufgrund vorheriger unterrichtlicher Erfahrungen, dass das Bild als hilfreich wahrgenommen wird. Das ist wahrlich keine Überraschung, doch interessant war die Feststellung, dass das Bild auch bei nur abgefilmten Expertengesprächen, beispielsweise bei Ausschnitten der Sendung „delta“ des Senders 3sat, eine wichtige Erleichterung darstellte. Ein Student berichtet, dass er seinem Freund die Antwort geschickt habe mit der Bitte, sie zu prüfen. Er habe nur die Hördatei gedownloadet, der Freund habe ihm dann auch das Video gezeigt, und sie hätten festgestellt, dass es mit Video der Gesprächsrunde leichter sei. Damit war aber schon 
in der Planungsphase weitgehend entschieden, dass für das Hörverstehen in der Regel Videopodcasts eingesetzt werden sollten.

Das Unterrichtsverfahren war dementsprechend so, dass im Unterricht selbst in das Thema eingeführt wurde und in häuslicher Arbeit Fragen zum Videopodcast bearbeitet wurden, und zwar in der Regel mündlich.

\subsubsection{Zu Hause oder im Unterricht MP3-Aufnahmen anfertigen?}

Für die Hausarbeit sprechen einige gewichtige Argumente. Das erste ist, dass niemand sich im Unterricht langweilen muss, für den ein bestimmtes Wort oder Phonem kein Hindernis darstellt. Zweitens sehen die Studierenden selbst die Zeitersparnis: „Ah ja, aber wenn wir vor der Klasse das machen, dann können wir nicht alles machen, gleichzeitig“. Drittens berichteten die Studierenden, dass sie z.T. sehr lange an den ersten Aufnahmen (also den mündlichen Antworten auf Fragen zum Hör-/Sehverstehen) gearbeitet hätten. Sie empfanden ihre Stimme als zunächst als fremd, was völlig normal ist. Aber ihnen selbst gefiel ihre Aussprache nicht, was bedeutet, dass sie durchaus eine Vorstellung von normgerechter Aussprache des Deutschen haben: „Es gibt noch ein anderes Problem: Vielleicht kennen alle Leute schon wie man ausspricht, aber wenn man gleichzeitig denken, dann wird die Phonetik wie die Muttersprache." Durch die Art der Aufgabe initiiert begann ein Prozess selbstgesteuerten Lernens: Sie verbesserten sich selbst, veranlasst durch die Aufgabe und das Medium. Ein Student sagt: „Wenn man am Mikrofon spricht kann man sich besser konzentrieren." Ein anderer stimmt zu: „Man kann es zu Hause so oft machen wie man will, so kommt man zu dem, was man will.“

Die Arbeit an der Aussprache im Plenum der Lerngruppe wird von manchen als belastend empfunden: „Zu Hause kann man viel korrigieren, natürlich auch im Unterricht, aber es gibt die Zeit und viele Leute." In der Tat ist die Stimme etwas sehr Privates, die Beziehung Lehrer-Lerner in diesem Falle auch. So gibt es durchaus Beispiele dafür, dass Gesangsschüler irgendwann ein wenig nach ihren Lehrern klingen. Korrekturen greifen in die Privatsphäre ein, und vor der Gruppe mögen sensible Gemüter sich zu sehr unter Beobachtung und unter Druck fühlen. Bei dem zitierten Studenten kam es zu völligen Blockaden, die erst durch die häusliche Arbeit mit MP3 wieder gelöst werden konnten.

Insgesamt wurde die Arbeit individualisiert, indem das Lerntempo (und zum Teil auch die angestrebten Lernziele) selbst bestimmt werden konnte, indem die Selbstkorrektur eine wichtige Rolle einnahm, indem die Podcasts beliebig oft gehört und gesehen werden konnten, indem die arbeitsteiligen Beiträge für zukünftige Gruppenpräsentationen per Mail ausgetauscht wurden.

\subsubsection{Der weitere Verlauf des Projekts, Probleme und Veränderungen}

Die Tagebucheintragungen des erstens Monats beleuchten die positive Grundstimmung bei allen Beteiligten. Das Gefühl der gegenseitigen Wertschätzung war gewachsen, weil die Studierenden sich als Partner in einem Forschungsprojekt verstanden, bei dem ihre Meinung und Erfahrung wichtig war und bei dem sie Einfluss auf Planung und Verlauf 
hatten. Die Eintragungen zeigen aber auch die ersten Mühen und Zweifel wegen des anfänglich hohen Arbeitsaufwands für den Lehrenden und die Lernenden. War es wirklich der richtige Weg, 30 Studierende individuell abzuhören und von zu Hause aus per Mail und eigenen Aufnahmen zu korrigieren? Wäre es eine Möglichkeit, eine Antwortversion des Lehrers für alle aufzusprechen, um des offenbar enormen Arbeitsaufwandes Herr zu werden? Die erste individuelle Korrektur hatte 30 Minuten gedauert! Oder würde damit die Wertschätzung der Leistung der Studierenden zu gering?

Stabilisierend in dieser Phase des Zweifels und des Suchens nach Optimierungen war, dass bei einigen Studierenden sich erste Fortschritte in der Aussprache zeigten. Irritierend war jedoch, dass bei manchen Satzmelodie und Klangfarbe des Lehrers gleich mit übernommen wurden (s.o.).

Die Versuche erstreckten sich über einen Zeitraum von drei Monaten. Relativ schnell fanden sich bessere Nutzungsmöglichkeiten der Software, die zu einer erheblichen Beschleunigung der Korrekturen führten: Indem zwei Audioprogramme gleichzeitig genutzt wurden, z.B. der Mediaplayer für die Wiedergabe der Antworten der Studierenden, und Audacity für die Korrekturaufnahme des Lehrers, sank die Bearbeitungszeit von 30 Minuten, wie sie für das Hineinschneiden der Korrektur in das Band des Studenten gebraucht wurden, auf zehn, später, mit etwas Routine, sogar auf gut fünf Minuten pro eingesandter Hausarbeit. Das Konzept der althergebrachten Sprachlaborarbeit, bei der nach der Aufnahme jeweils eine Stimme die „richtige“ Antwort spricht, erwies sich für diese Arbeitsform als ungeschickt. Nun bekamen die Studierenden vom Lehrer das komplette Paket ihrer persönlich intendierten Aussagen zurück, grammatisch und im Hinblick auf die Aussprache korrekt, inhaltlich ebenfalls richtig gestellt, soweit nur Kleinigkeiten zu korrigieren waren.

Geringfügige Veränderungen führten jeweils zur schrittweisen Optimierung und Beschleunigung des Korrekturverfahrens. Schließlich wurde - nach einer zweiten Planungsphase gemeinsam mit den Studierenden - dazu übergegangen, das Verfahren selbst zu individualisieren. Einige Studierende empfanden es als hilfreich, einzelne Laute sowie deren Ableitungen und einzelne Wörter vorgesprochen zu bekommen. Zu spät kam die Idee, eine Kamera zu nutzen, um gleich eine Videoaufnahme der Lautbildung bei dem fraglichen Phonem oder Wort mitzuliefern. Der Aufwand wäre der gleiche geblieben.

Andere wiederum fanden für sich wichtiger, das, was sie sagen wollten, von einem Muttersprachler im Zusammenhang vorgesprochen zu bekommen.

Teilweise wurde dazu übergegangen, die Aufgaben zu den Podcasts sowohl als Worddatei als auch als MP3 zu bearbeiten, denn die inhaltliche Korrektur wurde immer wieder einmal wichtig wegen der Erfassung des Unterrichtsgegenstandes. Außerdem konnte der selbst geschriebene Text als Vorlage für die eigene Aufnahme dienen.

Insgesamt zeigte sich, dass bei regelmäßiger Mitarbeit die Beiträge nachhaltig besser wurden, was an den vorliegenden Zweitfassungen der Studierenden nachvollziehbar ist. Die Verbesserungen betrafen sowohl Segmentalia, bei L1 Thai z.B. „n““ nach „ei“", bei 
L1 Russisch die Assimilation, als auch Suprasegmentalia wie Melodie und Rhythmus. Damit konnte der Weg, auch ganze Sätze vorzusprechen, nicht falsch sein.

All diese Versuche durften nur einen kleinen Teil des Unterrichtsgeschehens ausfüllen, schließlich waren Klausuren in vielen Fächern zu schreiben, die Abschlussprüfung rückte unerbittlich näher, der DaF-Unterricht durfte die anderen Aspekte der Sprachvermittlung nicht vernachlässigen. Das Projekt war also eingebunden in den ganz normalen Gang der Dinge für einen T-Kurs an einem Studienkolleg. Somit richteten sich die Themen der Unterrichtseinheiten in DaF nach ihrer Relevanz für Studienfächer, die mit dem T-Kurs-Abschluss studiert werden können. Einige Themen während der Dauer des Projekts waren: Intelligenz bei Pflanzen, Intelligenz bei Primaten, magnetische Deklination, Computer im Haushalt der Zukunft, Frachtschiffe mit Kitesegel, Bionik, Plattentektonik, Aufbau der Erde.

Bei all diesen kurzen Einheiten kamen Podcasts und MP3-Aufnahmen für die Antworten zum Einsatz.

\subsubsection{Der Höhepunkt: die Präsentationen der Studierenden}

Zwei Parallelkurse hatten unterschiedliche Themenfelder aus dem Bereich der Geowissenschaften für den jeweils anderen Kurs vorbereitet: Schwarze Raucher und Gashydrate. Die Themenfelder waren von den Studierenden selbstständig in verschiedene Unteraspekte aufgeteilt und arbeitsteilig in Gruppen erarbeitet worden. Alle hatten wie gefordert den Einsatz von Visualisierungen und Medien vorbereitet, z.B. Wandzeitungen, Tafelskizzen, Filmausschnitten und PowerPoint-Präsentationen.

Im Vorfeld war der Stoff der Präsentationen als klausurrelevant deklariert worden. Es hing also viel von der Qualität der Präsentationen und der Qualität der Mitschrift bei den Zuhörern ab. Um die Ergebnisse zu sichern, konnten die ausformulierten Mitschriften als E-Mail eingesandt werden und wurden bei Bedarf auf demselben Wege auch inhaltlich richtig gestellt. Die Mitschriften konnten zeigen, dass die Präsentationen wirklich gut gemacht waren, trotz aller angemerkten Möglichkeiten der Optimierung. Die Ankündigung, über den Stoff der Vorträge Klausuren schreiben zu lassen, wurde wahr gemacht. Tatsächlich baute die abschließende DaF-Klausur des 2. Semesters kurze Zeit später auf diesen Vorträgen auf.

\subsubsection{Beobachtungen}

Die Präsentationen wurden zur späteren Auswertung aufgenommen und außerdem von einem Kollegen beobachtet. Dieser stellte fest, dass er alles verstanden habe, die Informationsdichte sei hoch gewesen und die Lautstärke immer gut. Er bemängelte aber auch, dass teilweise zu schnell gesprochen wurde, dass die Aussprache bei einigen fehlerhaft war - auch falscher Atemtechnik geschuldet - und dass einige Plakate zu klein waren. Zu üben seien noch die Planung von Sprechpausen, die Gestik, der Kontakt mit den Hörern sowie die Strukturierung des Vortrags: Themenaufriss am Anfang sowie Zusammenfassung am Ende. Zu den Möglichkeiten, daran im DaF-Bereich zu arbeiten, sei auf Forster (1997: 237-294) verwiesen. 
Befreundete Kollegen mögen zu Bewertungen kommen, die zu positiv sind, doch in diesem Fall überwiegen in seinen Notizen trotz genereller Anerkennung der Leistung der Studierenden die kritischen Anmerkungen. Und tatsächlich gab es in dieser stressreichen Situation des „Ernstfalls“ in einer Vortragssituation bei einigen Teilnehmern Rückschritte in der Qualität des mündlichen Ausdrucks. Die Beobachtungen des Kollegen waren aufgrund der Aufnahmen gut zu verifizieren.

Bald nach den Präsentationen wurde ein Evaluationsbogen ausgefüllt, wie weiter oben beschrieben. Die Evaluationsbögen zeigten, dass das gesamte Projekt positiv bewertet wurde, insbesondere den Präsentationen wurde ein hoher Stellenwert beigemessen. Aber auch die Arbeit mit MP3-Aufnahmen wurde zu diesem Zeitpunkt immer noch positiv gesehen. Interessant ist, dass nach wie vor die Aussprache als sehr wichtig angesehen wurde und dass das Gefühl beim freien Sprechen besser ist als die Selbstwahrnehmung tatsächlicher Verbesserungen der Aussprache selbst. Auf einer sechsstufigen Skala (0-5) wurden folgende Bewertungen abgegeben (Abb. 3):

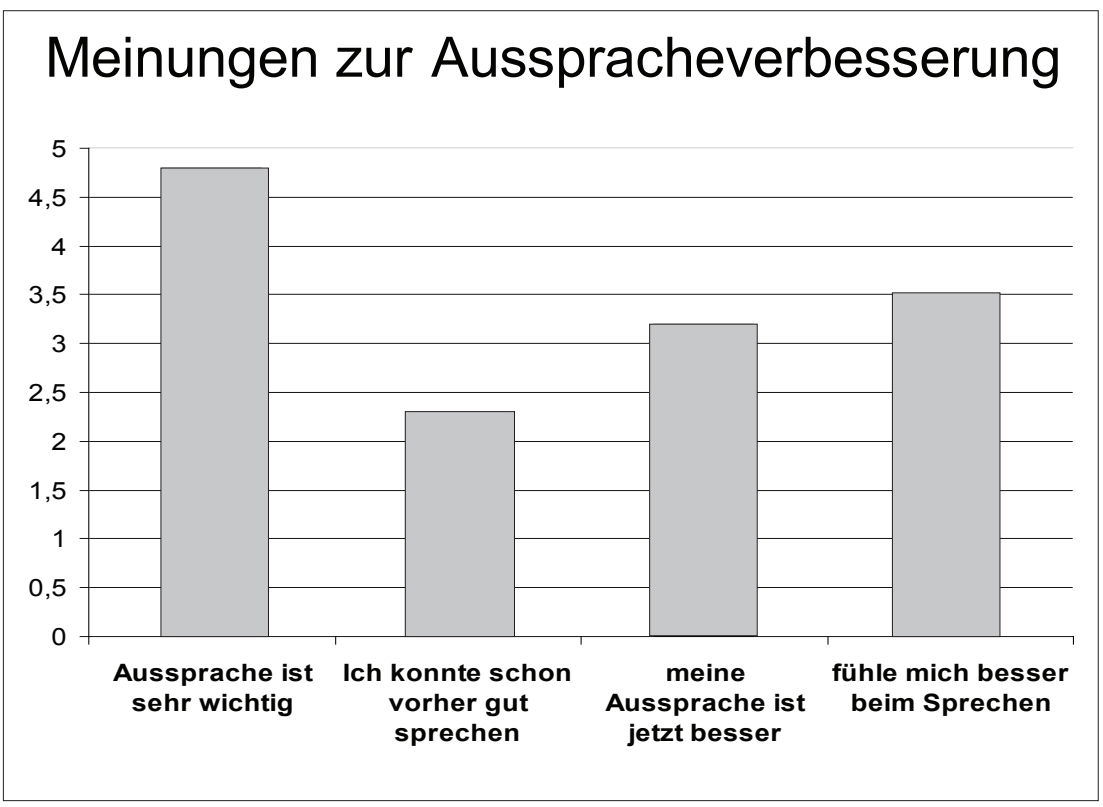

Abb. 3: Meinungen zur Ausspracheverbesserung

Auf die Frage, ob mit den Aussprache-Korrekturen des Lehrers zu Hause gearbeitet worden war, wurde insgesamt zustimmend geantwortet. Doch zeigen die Zahlen, dass die Aufnahmen des Lehrers wohl häufiger nur angehört wurden und nicht so häufig mit deren Hilfe wirklich geübt wurde. Immerhin schien die Evaluation zu zeigen, dass die Studierenden eine Veränderung des Sprechtrainings in Hausarbeit oder gar ein Ende des Projekts überhaupt nicht wünschten. Andererseits zeigten die Zahlen auch, dass es individuell unterschiedliche Präferenzen zur Methode und dem Schwerpunkt der Kor- 


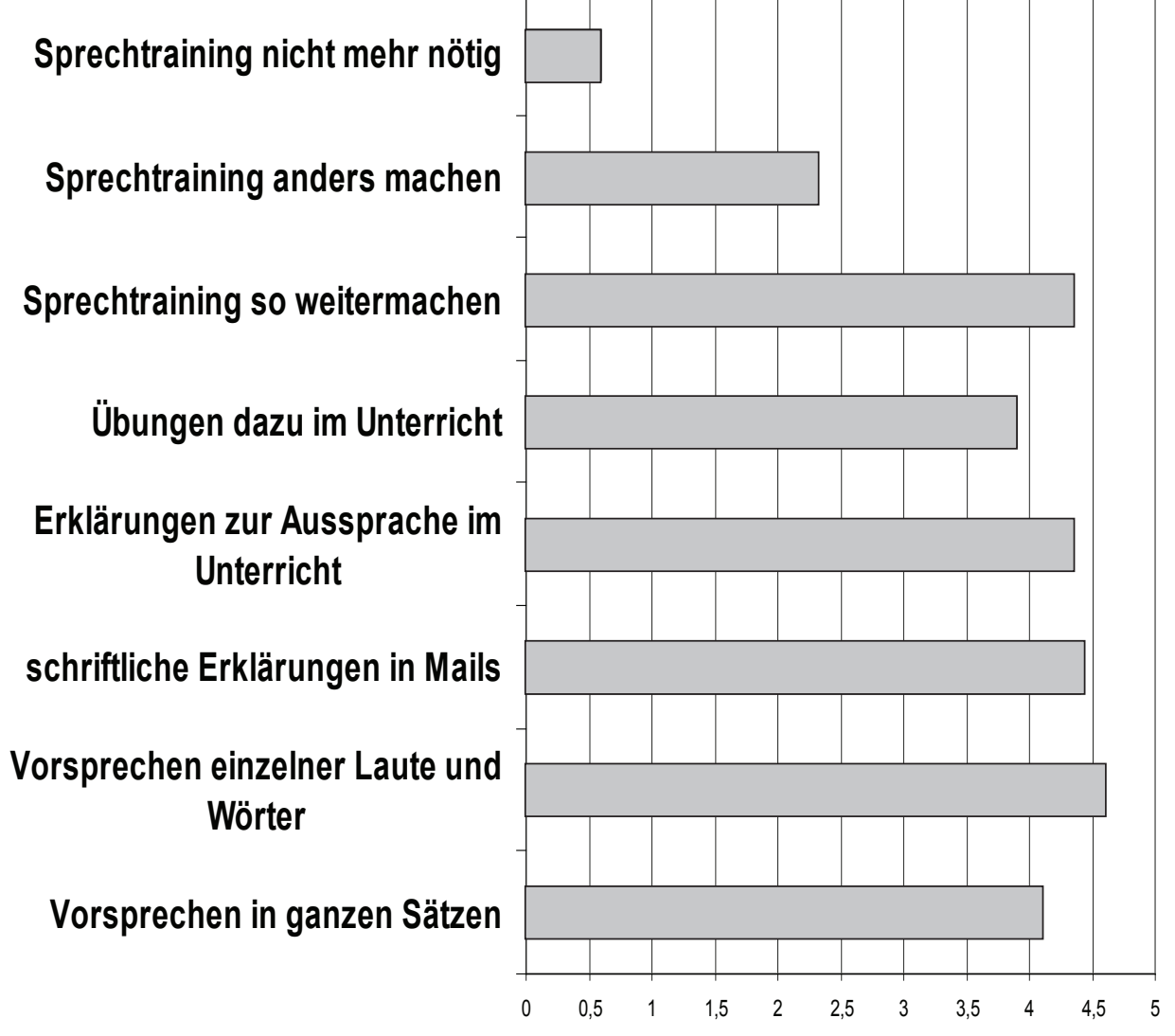

Abb. 4

rekturen geben könnte. Tendenziell zeichnet sich ab, dass auch individuelle Erklärungen per Mail höher geschätzt werden als Erklärungen für das Plenum im Unterricht. Abbildung 4 zeigt die Angaben wiederum auf einer sechsstufigen Skala (0-5):

\subsubsection{Diskussion der Ergebnisse mit den Studierenden und allgemeine} Folgerungen für eine Wiederholung eines solchen Verfahrens

Der Eindruck, dass die individuelle Betreuung höher geschätzt wurde als die im Unterricht, bestätigte sich in der anschließenden „Halbzeitkonferenz“, also der Diskussion des Projekts und des Verfahrens bis zu diesem Zeitpunkt. Einige bevorzugten tatsächlich ganze Sätze als Aussprachekorrektur durch den Lehrer, um die Satzmelodie aufzunehmen, Formulierungsvorschläge und sich Idiome einzuprägen. Andere wollten „schwere“ Wörter und Laute, aber auch ganze Sätze langsam und deutlich vorgesprochen haben, eine dritte Gruppe wollte zunächst die Ableitungen von Phonemen wiederholt im Unterricht üben und auch dort Korrekturen erfahren, dann aber zu Hause 
mit Hilfe der MP3-Aufnahmen individuell weiterüben. Das ist allerdings ein wichtiges Ergebnis des gesamten Projekts, denn es ist letztlich ein Plädoyer für die Individualisierung des Trainings und eine Reduzierung der Plenumsarbeit bei der Phonetik.

Die unterschiedlichen Wünsche wurden in Listen festgehalten und in der Folgezeit berücksichtigt.

Ein Widerspruch zwischen den Daten des Evaluationsbogens und eigenen Aufzeichnungen klärte sich dort ebenfalls. Die Auflösung liegt, wie zu zeigen sein wird, in einem ernsthaften Verständnis von Autonomie des Lernens seitens der Studierenden. Der Widerspruch bestand darin, dass einerseits mit einer Zustimmungsrate von 3,7 (bei einer Skala von 0-5) angegeben worden war, die Korrektur des Lehrers werde zu Hause nachgesprochen, dass andererseits die Quote der Zweitfassungen von MP3-Aufnahmen nach erfolgter Lehrerkorrektur im Laufe der Wochen stark rückläufig geworden war von ursprünglich 55\% auf fast $0 \%$. Mit anderen Worten, immer weniger verbesserte Fassungen der gesprochenen Hausaufgaben kamen beim Lehrer an!

Im Gespräch deuteten die Studierenden an, dass der Aufwand, eine Zweitversion zu erstellen, noch höher sei als bei der Erstfassung, weil sie drei Programme bzw. Programmfenster gleichzeitig handhaben müssten, nämlich das Programm zur Wiedergabe des Podcasts, das zur Wiedergabe der Lehrerkorrektur und das zum Aufsprechen der Zweitversion der Aufgabe. Außerdem waren das Aufgabenblatt und das Mailprogramm zu handhaben. Einige werden tatsächlich so gearbeitet haben, allerdings ist es nicht notwendig, alle Arbeitsschritte zur gleichen Zeit zu erledigen. Selbst in dieser fortgeschrittenen Phase des Projekts offenbarte sich bei wenigen, dass sie bei der Handhabung der Programme noch unsicher waren. Eine schriftliche Anleitung zur Bedienung mit Screenshots wäre für die Zukunft zu empfehlen.

Der tiefere Grund für die zunehmende Zurückhaltung bei der Versendung von Zweitfassungen scheint aber zu sein, dass die Studierenden selbst ihre Entwicklung immer eigenständiger planen und kontrollieren wollten. Dann genügt allerdings das Anhören und Nachsprechen - den Vergleich können die Studierenden selbst ziehen und Veränderungsbedarf identifizieren. Die Verbesserung gelingt auch ohne Rückmeldung an den Lehrer. Der entscheidende Test war für sie die Präsentation.

\subsubsection{Die letzte Projektphase}

Die Tagebucheintragungen aus dieser Zeit zeigen, dass die Grundstimmung weiterhin positiv blieb. Einzelne haben nun für sich individuelle Verbesserungswege gefunden und praktizieren diese auch. Eine Studentin hat auf das Zungen-R umgestellt. Das bringt eine klare Verbesserung der Verständlichkeit. Die Hausaufgaben, d.h. die Erstfassungen (s.o.) haben inzwischen allgemein eine hohe Qualität, insbesondere gibt es deutliche phonetische Verbesserungen. Bei einem Vergleich der leider sehr wenigen Zweitversionen in der Abschlussphase des Projekts mit den ersten Aufnahmen drei Monate zuvor zeigt sich ebenso: Es gibt mit dieser Methode Verbesserungen von zum Teil beachtlichem Ausmaß. Bemerkenswert und nachhaltig waren folgende Verbesserungen: 
- Bei L1 Thai der Ich-Laut, etliche Konsonantencluster, das „R“

- Bei L1 Portugiesisch die Vokalqualität, das stimmhafte „S“, der Hauchlaut und auch Konsonantencluster

- Bei L1 Russisch der Ich- und der Ach-Laut, der Hauchlaut, der Knacklaut, die Färbung der Vokale und Umlaute

\section{Schlussbetrachtung}

Die Methode der Aktionsforschung muss recht konsequent gehandhabt werden. Das gilt z.B. für die Auswertung der gesammelten Daten. Transkripte und Statistiken sollten zeitnah erstellt werden, weil sonst die Gefahr besteht, eigene Beobachtungen wieder zu vergessen und gute Anregungen der Lerngruppe zu verpassen.

Das Positive überwiegt: Das Projekt erfuhr eine konstant hohe Akzeptanz. Die Selbstbestimmung in Lerngruppen sowie die planerische Beteiligung am Forschungsprojekt hatten eine befreiende Wirkung. Der Aufwand für die Lehrenden ist unter Berücksichtigung der Erfahrungen, die in diesem Projekt gemacht wurden, gering. Nachhaltige Aussprachefortschritte können auch bei fortgeschrittenen Lernern erreicht werden. Deshalb kann gesagt werden, dass die hier erprobte Methode für heterogene Sprachkurse an den Universitäten geeignet ist und übertragbar ist. Damit kann am Beispiel dieses Projekts festgemacht werden, dass Studien im Rahmen der Aktionsforschung tatsächlich in der Lage sind, Hypothesen zu generieren.

\section{Literatur}

Albert, Ruth; Koster, Cor. J. (2002): Empirie in Linguistik und Sprachlehrforschung. Ein methodologisches Arbeitsbuch. Tübingen: Narr.

Alm, Antonie: Motivationstheoretische Grundbedingungen für den erfolgreichen Einsatz von Neuen Medien im Fremdsprachenunterricht. In: Zeitschrift für den Interkulturellen Fremdsprachenunterricht 12/1 (http:/ / zif.spz.tu-darmstadt.de/ig-12-1/beitrag/ Alm1.htm).

Altrichter, Herbert; Posch, Peter (2007): Lehrerinnen und Lehrer erforschen ihren Unterricht. Bad Heilbrunn: Klinkhardt.

Brown, James Dean (2001): Using Surveys in Language Programs: Cambridge: Cambridge University Press.

Burns, Anne (2005): Action Research. In: Hinkel, Eli (Hrsg.): Handbook of Research in Second Language Teaching and Learning. Mahwah, New Jersey: Lawrence Erlbaum Associates. 241-256.

Forster, Roland (1997): Mündliche Kommunikation in Deutsch als Fremdsprache. Gespräch und Rede. St. Ingbert: Röhrig.

Hopkins, David (2002): A Teachers Guide to Classroom Research. Buckingham; Philadelphia: Open University Press.

Mackey, Alison; Gass, Susan M. (2005): Second Language Research. Methodology and Design. Mahwah, New Jersey: Erlbaum. 
Nellessen, Horst (2002): Auswertung einer Umfrage unter ehemaligen Studierenden des Studienkollegs. In: Schreiber, Rüdiger (Hrsg): Deutsch als Fremdsprache am Studienkolleg. Unterrichtspraxis, Tests, Evaluation. Materialien Deutsch als Fremdsprache 63. Regensburg: Fachverband Deutsch als Fremdsprache, 144-161

Riemer, Claudia (2002): Für und über die eigene Unterrichtspraxis forschen. Anregungen zur Lehrerhandlungsforschung. In: Schreiber, Rüdiger (Hrsg): Deutsch als Fremdsprache am Studienkolleg. Unterrichtspraxis, Tests, Evaluation. Materialien Deutsch als Fremdsprache 63. Regensburg: Fachverband Deutsch als Fremdsprache, 129143.

Riemer, Claudia (2007): DaF/DaZ und empirische Forschung. Wechselnde Herausforderungen. In: Info DaF 34/5, 445-459.

Rösler, Dietmar (2006): Das scheinbare Paradox des Fremdsprachenlernens mit digitalen Medien. Tendenz zur Individualisierung UND zur Stärkung kooperativer Arbeitsformen. In: Scherfer, Peter; Wolff, Dieter (Hrsg): Vom Lehren und Lernen fremder Sprachen. Eine vorläufige Bestandsaufnahme. Frankfurt a.M.: Lang, 157-169.

Wallace, Michael J. (1998): Action Research for Language Teachers. Cambridge: Cambridge University Press.

Warschauer, Mark; Kern, Richard (2000): Introduction: Theory and practice of network-based language teaching. In: Dies. (Hrsg.): Network-based Language Teaching. Concepts and Practice. Cambridge: Cambridge University Press, 1-19.

\section{Danksagung}

An Claudia Riemer, die mich unterstützt und die Motivation immer hochgehalten hat. 

Christoph Chlosta, Matthias Jung (Hrsg.) (2010):

DaF intergriert: Literatur - Medien - Ausbildung. Tagungsband der

36. Jahrestagung des Fachverbandes Deutsch als Fremdsprache 2008.

Göttingen: Universitätsverlag, 213-224.

\section{Jörg Roche (München)}

\section{Klinisch getestet: Zur Erforschung und Evaluation von e-Mehrwerten}

\section{Vorbemerkung}

Sicher haben wir eigentlich die Phase hinter uns gelassen, in der wir die Medien entweder nur als Allheilmittel des Fremdsprachenlernens oder als Konkurrenz zur Kompetenz der Lehrer sehen. Allein schon die Verbreitung der modernen Medien im Lebens- und Berufsalltag spricht für eine Behandlung im Unterricht. Entsprechende Forderungen nach einer stärkeren Aufnahme in den Unterricht haben sich, wie erwartet, in den letzten Jahren rapide verstärkt. Die Akzeptanz der Medien hat sowohl bei Lernern und Lehrenden zugenommen. Aber genügt es, vor allem diesem Aspekt der Authentizität im Unterricht nachzukommen? Gibt es nicht auch lernpsychologische und didaktische Aspekte für die Nutzung moderner Medien, für die Nutzung verschiedener Medien in der Sprach- und Kulturvermittlung? Und lösen die Möglichkeiten der neuen Medien nicht eine grundsätzliche Reflexion der Vermittlungspraxis aus?

Ich meine, sie sollten es. Eine Analogie sei hier gestattet, um die Dringlichkeit zu verdeutlichen: In welchem anderen wissenschaftlichen Bereich oder Berufsfeld würde man nicht selbstverständlich und umgehend neue Instrumente erproben und weiterentwickeln? Ist es etwa vorstellbar, dass in der Medizin die Möglichkeiten der Lasertechnologie nicht bis zum Äußersten erprobt würden oder alle Natur- und Werkstoffwissenschaften die Erkenntnisse der Nanotechnologie schamlos ausbeuten würden? Kann man sich vorstellen, dass irgendeine moderne Wissenschaft oder irgendein Berufszweig heute ohne die neuen Medien auskämen? Wofür brauchen wir dann unter Fremdspra- 
chenlehrern und -lehrerinnen die oft polarisierte und polemisierende Debatte um die Nutzung neuer Medien beim Sprachenlernen? Warum gelingt es dem Feld nicht, einmal nüchtern und sachlich zu untersuchen, wie man den Spracherwerb - auch im Unterricht - beschleunigen könnte? Im Mittelpunkt der Diskussion müsste also die Qualitätsentwicklung des Lehrens und Lernens von Sprachen stehen, nicht die Medialität an sich. Diese steht möglicherweise nur mittelbar in Bezug zur Lösung der Hauptaufgabe.

Dieser bescheidene Beitrag versucht, an Hand einiger empirischer Forschungsergebnisse die Problematik der Bestimmung des medialen Mehrwertes, anders gesagt, der Evaluation, zu skizzieren und Impulse für eine Intensivierung der Lehr- und Lernforschung in diesem Bereich zu geben. Auf allgemeine Verständlichkeit und Anschaulichkeit wird geachtet. Angaben zur weiterführenden Literatur zeigen Möglichkeiten zur vertiefenden Beschäftigung mit dem Thema auf.

\section{Wie man es nicht machen sollte}

Die Suche nach verlässlichen Bewertungskriterien gestaltet sich recht schwierig, weil es gar nicht so leicht ist, festzulegen, was guter oder erfolgreicher Unterricht überhaupt ist (vgl. die Bemühungen um Standards und um Qualitätsentwicklung und Qualitätsmanagement). Versucht man, sich gezielter an Evaluationskriterien für elektronische Lernprogramme zu orientieren, so verschlechtert sich die Lage zunehmend. Roche (2008a:

62) bietet einen Überblick über die spärlichen Ansätze (wie etwa Hubbard 1992 oder auch Hufeisen; Leitner 2007) und enthält einen eigenen Vorschlag mittels eines Kriterienrasters.

Auch Zeitschriften, die einen öffentlichen Auftrag für solide Recherchen und Information hätten, beteiligen sich an der Evaluation von Software, meist jedoch holistisch oder sträflich vereinfachend. Der Bericht der Stiftung Warentest vom 21.09.2007, deren Name eigentlich für verlässliche Tests stehen sollte, zeigt, wie schwer es fachfremden Testern fällt, sich ein Bild von medial vermittelten Lernprozessen zu machen. Die folgenden Ausschnitte des Testberichtes, wie er im Internet zur Verfügung steht, illustrieren, dass der unterhaltsame Stil des Testberichts einer wissenschaftlichen Überprüfung in keiner Weise stand halten kann.

Sehen wir uns das exemplarisch an ein paar Ausschnitten aus der Bewertung an (die Namen der Produkte und Firmen sind hier anonymisiert, http://www.test.de/themen/ bildung-soziales/weiterbildung/test/-Lernsoftware/1567887/1567887/1576553/):
„Bei der IS von ABC geht es fast zu wie beim Privatunterricht: ,Very good', lobt der virtuelle Tutor Tim begeistert, wenn sein Schüler den Lückentext fehlerfrei ausgefüllt hat. Bei korrekter Aussprache des ,th' ertönt sogar: ,You are a genious' [sic!] (Du bist ein Genie). Manchen Nutzern machen solche ermutigenden Kommentare mehr Lust am Pauken - eine wichtige Voraussetzung für Selbstlernprogramme. “

Der geneigte Leser mag sich ausmalen, wie viel mehr Lust er am Lernen verspürt, wenn eine maschinelle Stimme ihn wegen jeder Belanglosigkeit ein Genie nennt. Sprachenlernen als Variante des Cheerleading? Und geht es beim Sprachenlernen nur um Lückentexte? Welches didaktische Konzept, welche Lerntheorie verbirgt sich hinter Lücken- 
texten? Vielleicht ist es doch nur Pattern Drill-Methodik, die auf einem Lernkonzept basiert, das zu den Zeiten unserer Urgroßeltern erfunden wurde. Wie kompetent kann zudem ein Evaluator sein, wenn er meint, selbst triviale Bestätigungen, die er zudem falsch schreibt (,genius“), müssten übersetzt werden?

„Die beste Lernsoftware bietet CBA TMS. Neben einem vielseitigen Lernprogramm enthält es viele originalsprachliche Filmausschnitte. Das bringt Abwechslung beim Üben. 50 Euro sind hier sinnvoll investiert. Mit ebenfalls gut gewählten Lerninhalten und ausgeklügelten didaktischen Methoden haben noch drei weitere Programme gepunktet: DEF, ABC sowie der Englisch-Kurs auf CD-Rom von XYZ. Letzterer rutschte jedoch wegen schwieriger Installation und langer Wartezeiten ins Mittelfeld.“

Hier wagt der Evaluator einen Ausflug in den kommunikativen Unterricht: Originalsprachliche Ausschnitte werden angeboten. Nicht schlecht vielleicht, aber was soll denn damit gemacht werden? Und was, wenn der Lerner diese nicht versteht? Und was sind didaktische Methoden? Sind das vielleicht Methoden, die von einem theoretisch fundierten Konzept abgeleitet sind oder doch nur Methoden, die verhindern sollen, dass der Lerner beim Üben vor Langeweile einschläft? Vielleicht wäre dann gleich Kabel-TV finanziell und didaktisch effizienter.

„Besonders wichtig bei Sprachkursen am Computer sind Hör- und Leseverstehen, Sprechen und Schreiben. Der Kurs von DEF übt Hörverstehen so: Drei Personen unterhalten sich. Der Nutzer hört zu. Kaum ist das letzte Wort gesprochen, muss er Fragen zum Gespräch beantworten. Hatte Erin früher glattes oder lockiges Haar? Hat Andrew zugenommen oder ist er dünner geworden?““

Besonders wichtig ist also alles. Wieso wird das so umständlich ausgedrückt? Und wieso kommt uns diese geniale Abfragetechnik so bekannt vor? Allein die Themen, die sich hinter den gestellten Fragen zu verbergen scheinen, also ob Andrew zugenommen hat oder nicht, werden alle Jugendlichen und alle Diätfanatiker vom Hocker hauen..., weil jüngeren Lernern sicher gleich die Persiflage des Liedes „Living next door to Alice“ von Smokie in den Sinn kommen wird, die mit den bekannten Metakommentaren versetzt ist „Who the f... is Alice?" (und es, das wäre doch kulturkundlich interessant, damit auch unter die britischen Top 10 geschafft hat). Also: Who the hell is Andrew?

„Der T-Sprachtrainer von GHI, der inhaltlich gleiche KLM aus dem T-Verlag sowie der

Englisch-Sprachkurs von OPQ sind dagegen sehr sprachlastig."

Die Quadratur der Evaluation! Sprachlastige Sprachlernsoftware als Ausschlusskriterium.

Kaum zu unterscheiden ist die Sprache der Evaluatoren in derart vor Kompetenz strotzenden Bewertungen von der Sprache des Marketings der Produzenten. Hier finden sich ganz ähnliche Kriterien wie bei der Testbewertung. Ein paar Auszüge aus dem Werbematerial der getesteten Software verdeutlichen die Ähnlichkeiten:

,$[\ldots]$ ist die Lernsoftware für absolute Anfänger und Wiedereinsteiger. In interaktiven Dialogen und abwechslungsreichen Übungen vermittelt der Sprachkurs umfassende Kenntnisse in den Bereichen Grammatik, Wortschatz, Hör- und Textverständnis. [...] 
In der neuen Version unterhalten Sie sich wie in einer realen Gesprächsituation mit Ihrem persönlichen Sprachlehrer: In den großformatigen Videodialogen können Sie Ihre neu erworbenen Sprachkenntnisse sofort einsetzen. Der aktuelle Newsfeed informiert Sie über Land und Leute und hält viele Sprachtipps für Sie bereit. Und mit den neuen Anfängerlektionen finden Sie sich auch als absoluter Anfänger schnell in der fremden Sprache zurecht.“

Bei genauerer Betrachtung stellt sich also heraus, dass solche Evaluationen nicht selten undifferenzierte, beliebig gemischte und irrelevante Kriterien heranziehen, diese aber nie (!) auch empirisch testen. Der einzige belegbare Maßstab ist die subjektiv angenäherte Einschätzung eines oder mehrerer Personen ohne jegliche Möglichkeit der Überprüfbarkeit. Einfach gesagt: der Bauch ersetzt wissenschaftliche Methodik.

Man kann mutmaßen, warum sich Softwareproduzenten und Computerzeitschriften vor belastbaren und nachvollziehbaren Tests drücken:

1. Solche Tests setzen solide und umfangreiche Forschung voraus. Diese liegt nicht vor. Die vorliegende Forschung ist nicht leicht zugänglich.

2. Weder Produzenten noch Tester sind vom Fach oder verstehen viel davon.

3. Im Vordergrund stehen Verkaufs- nicht Qualitätsinteressen.

4. Entwickler wissen, dass die Software nie einen auf Lerneffizienz ausgerichteten Test bestehen würde.

Im Folgenden soll exemplarisch gezeigt werden, wie sich die Forschung dem zuerst genannten Problem nähert, auch wenn dies von den Entwicklern oder Testverantwortlichen nicht zur Kenntnis genommen wird. Die drei weiteren Probleme lassen sich in einem Beitrag wie diesem nur deutlich ansprechen. Klären muss sie der Kunde, und er sollte es mit mehr Selbstbewusstsein tun.

\section{Forschung und Evaluation}

\subsection{Qualitätsmanagement und Evaluation}

Langfristige Nutzbarkeit von Lern- und Lehrmaterialien setzt kontinuierliche Evaluation und systematisches Qualitätsmanagement voraus. Über Verfahren der kontinuierlichen Erprobung schon während der Entwicklungsphasen kann sichergestellt werden, dass bereits im Entwicklungsprozess wichtige Qualitätsparameter eingehalten werden (formative Evaluation). Darüber hinaus ist es aber nötig, auch nach der Fertigstellung eines Programms systematisch seine Nutzbarkeit, Aktualität und Effizienz zu bewerten und, wo nötig, Nachbesserungen zu veranlassen. Diese Verfahren kann man als summative Evaluation bezeichnen. Zu einem Qualitätsmanagement gehören daher regelmäßige Befragungen der Nutzergruppen, vor allem der Lerner, der Betreuerinnen und Betreuer und der Anbieter-/Lizenznehmer-Institutionen sowie der technischen Betreuung, des Marketings und des Vertriebs. Regelmäßiger Kontakt unter und mit den Lehrkräften kann vor allem durch Tutoren-Chats, aktive Tutoren-Foren, Tutorentreffen $\mathrm{zu}$ thematischen Schwerpunkten, Fortbildungsveranstaltungen, Stichproben bei Korrekturen und Forumsgestaltung mit Feedback, regelmäßige Informationen zu neuen 
Entwicklungen und Nachschulungen zu neuen Angeboten und Kursformen hergestellt werden.

Während des laufenden Kursbetriebs von Online-Programmen sollten die Lerner selbst Bearbeitungsstatus, Bearbeitungszeit und die Häufigkeit der Bearbeitung einer Aufgabe einsehen können. Tutorin und Tutor sollten die Möglichkeit haben, Benutzerlösungen der Teilnehmer einzusehen und so den Lernfortschritt zu überprüfen. Im Hintergrund sollte ein Be- und Auswertungssystem die Lerneraktionen aufzeichnen und die Lernerlösungen abspeichern. Diese Lernerdaten geben ebenfalls Aufschluss über den ordnungsgemäßen Betrieb der Programme. Auf diese Lernerdaten kann ferner auch für langfristige Forschungszwecke zugegriffen werden.

\subsection{Forschungsprojekte}

In Forschungsprojekten kann darüber hinaus die Effizienz der Nachhaltigkeit des Lernens empirisch gemessen werden: Wie nehmen Lerner und Betreuer das Programm an, wie lernen sie mit dem Programm, wie lässt sich die Nachhaltigkeit des Lernens erhöhen, welche Fehler machen Lerner und in welchen Sequenzen verläuft der Grammatikerwerb, wie reagieren Lerner auf Korrekturen, wie nutzen sie die frei verfügbaren Lern- und Arbeitsressourcen? Es muss eine Hauptaufgabe der Sprachlehr- und -lernforschung sein, angesichts der vielen offenen Fragen mehr empirische Lern- und Lehrforschung zu betreiben. Diese scheitert meist jedoch an dem enormen Aufwand und der Schwierigkeit der Beobachtung authentischen Lern- und Lehrverhaltens sowie der Komplexität der Einflussfaktoren.

Die offenen Medien bieten hier jedoch neue Möglichkeiten als unauffällige aber effiziente und sehr ergiebige Forschungswerkzeuge, weil mit ihnen ohne Einflussnahme auf den Lernprozess Forschung betrieben werden kann. Durch direkte Eingriffsmöglichkeiten in Online-Programme lassen sich zudem regelrechte Lernexperimente auch im Regelbetrieb arrangieren und durchführen. ${ }^{1}$

Im Folgenden sollen exemplarisch drei Forschungsbereiche an Hand neuerer Untersuchungen dargestellt werden. Hier geht es lediglich darum zu zeigen, wie vielfältig die Forschungsfragen und -ansätze sind, was die Sprachlehre daraus lernen kann und wie viel weitere Forschung nötig ist, um zu einem kohärenten Modell mediengestützter Sprach- und Kulturvermittlung zu gelangen.

\footnotetext{
Vgl. etwa Scheller 2009 zu Grammatikanimationen. Interessierte Leserinnen und Leser seien u.a. auf folgende empirische Studien verwiesen: Reeder; Shapiro et al. (2007) zur Effizienz von Lernerkorrekturen, Scheller (2009), Roche; Scheller $(2004,2008)$ und Caplan (2002) zum Einsatz kognitionslinguistischer Modelle in der Grammatikvermittlung und Todorova (2009 i.V.) zu kulturspezifischen Präferenzen der Mediennutzung. Überblicke über die Forschungslandschaft bieten darüber hinaus Zhang; Barber (2008), die Fokusnummer der e-Zeitschrift für den Interkulturellen Fremdsprachenunterricht 9.1/2004, Rösler (2004) und Roche (2007, 2008b).
} 


\subsubsection{Beispiel 1: Stärken-/Schwächenanalyse verschiedener Lehr-/ Lernformate: Präsenz-, Online-, Blended Learning}

Einsatzmöglichkeiten der neuen Medien gibt es verschiedene, mit je unterschiedlichen Anteilen von eigener Steuerung und Gestaltung durch die Lerner und Betreuung durch Lehrer und Tutorinnen. Die Bandbreite reicht dabei vom reinen „e-learning“, das heißt dem unbetreuten Lernen mit elektronisch vermittelten Lernprogrammen, bis hin zum medienassistierten Präsenzunterricht. Dementsprechend unterscheidet man auch zwischen Formaten des Selbstlernens, Formaten des betreuten Lernens im Medienmix (Blended Learning) und der mediengestützten Präsenzlehre (etwa im Medienlabor oder in besonders ausgestatteten Räumen). In welchem Verhältnis welche Medien zu welchem Zeitpunkt für welche Zwecke gemischt werden, hängt von verschiedenen $\mathrm{Pa}$ rametern ab. Klare Definitionen gibt es hierfür nicht. Das Standardformat von Blended Learning-Programmen besteht aus einem Treffen in der Gruppe am Anfang eines Kurses, einer e-Lernphase, gegebenenfalls einem weiteren Gruppentreffen, weiteren e-Lernphasen und einem Abschlusstreffen. Zwischen den Treffen kommunizieren die Kursteilnehmer untereinander und mit ihrem Tutor über die vorhandenen Kommunikationskanäle und gegebenenfalls auch durch Einsendung schriftlicher Hausaufgaben. Launer (2008) führte eine explorative und vergleichende Studie zu den Einstellungen der Lerner in unterschiedlichen Formaten durch. Dabei stellt sich heraus, dass Verfahren der Präsenzlehre unter bestimmten Bedingungen den Lernern mehr Sicherheit gewährleisten und daher besser angenommen werden. Formate des e-Lernens bieten Unterstützung und Reparaturmöglichkeiten dagegen nur bedingt. Dennoch ist erstaunlich, wie gut fortgeschrittene Lerner mit diesem Format umgehen und welche guten Ergebnisse sie erzielen.

„Es wurde deutlich, dass Blended Learning dann eine ernstzunehmende alternative Lernmethode sein kann, wenn

1. Lehrer und Lerner das nötige Rüstzeug haben, um die unterschiedlichen Lernphasen effektiv zu nutzen und

2. die Lerninhalte so auf die Selbstlern- und Präsenzphasen verteilt sind, dass man zum einen den individuellen Lernervariablen gerecht wird und zum anderen der Präsenzunterricht eine neue Qualität erhält, indem er, mehr noch als bisher, Raum zum interaktiven Sprechhandeln bietet und die kommunikative Handlungsfähigkeit der Lerner fördert.

Dazu ist es jedoch notwendig, die Lehrer so auszubilden, dass sie diese Fähigkeiten selbst besitzen und an die Lerner weitergeben können. Die Entwicklung der Lernerautonomie muss folglich einen wichtigen Platz in der Lehreraus- und -fortbildung einnehmen.“ (Launer 2008: 222)

\subsubsection{Beispiel 2: Kulturspezifische Differenzen}

Die Nutzung der elektronischen Medien ist in kultureller Hinsicht auch technisch nicht indifferent, wie es die internationale Uniformität der Hard- und Software leicht vorspiegelt. Wie alle anderen Technologien ist das Internet an erster Stelle ein soziales Produkt, und alle sozialen Produkte stehen unter dem Einfluss kultureller Werte ih- 
rer Produzenten (Castells 2001). Die Entwickler des Internets waren schließlich zum größten Teil angloamerikanische Ingenieure und Wissenschaftler, die ,schnellen und unbeschränkten Zugang zu gleich gesinnten Menschen suchten“" (Anderson 1995: 13) und deren Wertesystem und Berufskultur individualistisches und offensives Wettbewerbsverhalten fördern. Darüber hinaus spielen in ihren Kulturen Geschwindigkeit, Reichweite, Offenheit, schnelle Reaktion und Informalität in der Kommunikation eine ausschlaggebende Rolle. Auch in einer Untersuchung eines kanadischen Online-Programms (Reeder et al. 2004 und Chase et al. 2002) stellen die Autoren und Autorinnen ähnliche kulturspezifische Einflüsse im Design fest. Sie bemerken ferner, dass auch weit verbreitete Lernplattformen wie WebCT auf gleichen kulturspezifischen Annahmen aufbauen. Es existiere also eine unsichtbare Internetkultur, die jedoch bei genauem Hinsehen deutlich die kulturellen Werte ihrer Entwickler erkennen lasse. Innerhalb des genannten Online-Programmes werden kommunikative kulturelle Werte explizit sowie implizit durchgesetzt. Die implizite Umsetzung dieser Werte geschieht unter anderem mittels der technischen Infrastruktur des Kurses, zum Beispiel in einem Diskussionsforum, das öffentliche Beiträge und Antworten zur Voraussetzung macht und damit bestimmte Kommunikationsformen unreflektiert übernimmt. Die Kommunikationskultur des Internets im Allgemeinen und die des Online-Kurses im Spezifischen werden gleichzeitig explizit durch direkte Anweisungen, Aussagen und Forderungen von Kursleiterinnen und einigen Lernenden eingefordert. Insofern ist es nicht verwunderlich, dass Teilnehmerinnen und Teilnehmer aus anderen Lernkulturen große Schwierigkeiten mit Lernplattformen dieser angloamerikanischen Prägung aufweisen.

Kulturelle Differenzen im Kommunikationsverhalten machen sich also nicht nur im Kursdesign und seiner Umsetzung bemerkbar, sondern zeigen sich auch in der Art und Weise, wie individuelle Teilnehmer Online-Kurse nutzen. So stellt die genannte kanadische Studie fest, dass bezüglich der Präsentation der eigenen Person, das heißt in den Beiträgen der Teilnehmer zur Selbstvorstellung, und in ihren Vorstellungen über Identitätskonstitution große strategische Unterschiede innerhalb der multikulturellen Gruppe bestehen.

Die Nutzung der Lernmedien im kulturübergreifenden Kontext wirft damit Fragen nach der Akzeptanz und Effizienz von Lernprogrammen und Lernformaten in unterschiedlichen Lernerkulturen auf. Da heute offene Lernumgebungen mehr und mehr Verbreitung finden, interessiert vor allem die Frage, wie verschiedene Lernerkulturen mit offenen Lernumgebungen umgehen, die auf einem konstruktivistischen Lernkonzept aufbauen. Wie gehen sie mit dem individuellen Gestaltungspotenzial und mit der größeren Verantwortung um und welche Lernergebnisse erzielen sie dabei.

Eine neuere kontrastive Arbeit von Todorova (2009) untersucht den Einfluss der Lernerdispositionen auf die Akzeptanz der neuen Lernerrolle im Spracherwerb. Die Untersuchung von bulgarischen und litauischen Lernergruppen (Studierende) ergab zwar deutliche Unterschiede in wesentlichen Bereichen der Lernerdisposition der beiden Gruppen (z.B. Interesse, Konzentrationsfähigkeit, Präferenzen für Steuerung versus Eigenständigkeit), aber es zeigten sich insgesamt weniger Differenzen, als man 
aufgrund der bereits vorliegenden Untersuchungen annehmen konnte. Eine Korrelation von Lernerdispositionen und der Akzeptanz der neuen Lernerrolle ergab sich dabei nicht. Auch zwischen Lernerdispositionen und Lernerfolg konnte keine Korrelation festgestellt werden. Lediglich zwei Variablen waren für die erreichte sprachliche Leistung der Gruppen jeweils von Bedeutung: das Vorwissen und die extrinsische Motivation, wobei der Einfluss des Vorwissens deutlich stärker als der Einfluss der extrinsischen Motivation war. In einem weiteren Schritt wurden alle Teilnehmer durch eine Cluster-Analyse in Bezug auf die Variable „Leistung“ in zwei Gruppen aufgeteilt. Aus den statistischen Analysen ergab sich kein Einfluss der durch die kulturspezifischen Lerntraditionen bedingten Lernpräferenzen und der kognitiven Lernstile auf die Effektivität des Medieneinsatzes.

Inwieweit die Lerner eine stärker individualisierte Lernrolle tatsächlich akzeptieren, hängt aber stark von den Eigenschaften der elektronischen Lernumgebung ab. Es ist höchst aufschlussreich zu sehen, dass Selbsteinschätzung und tatsächliche Präferenzen gerade in dem Bereich der Steuerung des Lernprozesses eklatant auseinander klaffen können. So geben die litauischen Lerner in der Studie an, dass sie stärker Instruktionen der Lehrer und Steuerung durch diese akzeptieren würden als die bulgarischen. Zumindest wenn das Lernprogramm Grammatikanimationen und authentisches Material enthält und aktuell und relevant ist (d.h. die Interessen der Lerner anspricht), wie das in der Studie verwendete, übernehmen Lerner auch selbstverständlich mehr Verantwortung für den Lernprozess (z.B. bei Schreibaufgaben mit einem direkten Bezug zum Studium bzw. Studiumsaufenthalt in Deutschland). Sie kommen also mit wesentlich weniger Steuerung durch die Lehrkraft aus, als sie selbst vermutet oder gewollt hätten.

\subsubsection{Text- und Bildverarbeitung}

Mit den neuen Medien lassen sich verschiedene Präsentationsmodi aus Text, Bild und Ton kombinieren. Daher ist auch die Bezeichnung ,,multimodal“ statt „,multimedial“ für digitale Programme vorgeschlagen worden (vgl. Sauer 2004). Aus dieser prinzipiellen Darstellbarkeit ergibt sich unmittelbar die Frage, wie man einen Mehrwert in der Mediennutzung durch optimale Abstimmung der Modi erzielen kann. Nach der Dual Coding Theory von Paivio (1986) ist davon auszugehen, dass Bildinformation und Sprachinformation getrennt voneinander verarbeitet werden und daher die passgenaue Koordination der Verarbeitungsprozesse für eine Erleichterung der Verarbeitung essentiell ist. Im Bereich der Visualisierung stellt sich daher im Unterricht oder bei der Erstellung von Lehrmaterial die Alternative, ob mit Animationen oder statischen Illustrationen gearbeitet oder komplett auf Illustrationen verzichtet werden soll. Eine scheinbar problemlose Verständlichkeit der Lerninhalte mit Animationen führt nicht notwendigerweise zu einer intensiveren Auseinandersetzung mit den Inhalten. Der menschliche Wahrnehmungsapparat ist so ausgelegt, dass Bewegungen, Farbänderungen und ähnliches automatisch die Aufmerksamkeit auf sich lenken. Zu viel, zu früh, zu schnell, zu spät oder verwirrend präsentierte visuelle Information ist der Verarbeitungsaufgabe daher eher abträglich. An der falschen Stelle oder mit der falschen Intensität eingesetzt, bindet 
visuelle Information daher wichtige Aufmerksamkeitsressourcen, die für andere essentielle Verarbeitungsaufgaben benötigt würden. Eine schnelle Abfolge von Informationseinheiten verlangt nämlich zusätzliche Ressourcen und kann die Verarbeitung der eigentlichen Aufgabe erschweren, zum Beispiel wenn sich der Lerner gerade auf eine andere Aufgabe konzentrieren muss. Daher muss die Präsentationsgeschwindigkeit von Bildinformationen der Verarbeitungsgeschwindigkeit angepasst sein. Diese Abstimmung kann durch Steuerungsmechanismen gewährleistet werden, mit denen ein Lerner auf die individuellen Lernbedürfnisse flexibel reagieren kann. Die Koordination von Bild und Text ist essentiell für eine Verarbeitungserleichterung.

Die duale Kodierungstheorie gilt inzwischen in ihrer weiterentwickelten Form als eine generelle Theorie der menschlichen Kognition. Die empirische Grundlage dafür waren jedoch Gedächtnisexperimente, die gezeigt hatten, dass Bilder zumindest kurzfristig besser behalten werden als Wörter, die auf die gleichen Gegenstände referieren. Der Bildüberlegenheitseffekt, der aus der doppelten Kodierung der Information entsteht, ist der wichtigste Beleg für diese Theorie. Demnach können Wörter besser behalten werden, wenn sie durch gleichzeitige bildhafte Assoziationen und das Generieren von mentalen Bildern in einem multisensorischen Zusammenhang verarbeitet werden. Zwischen beiden Systemen werden referentielle Verbindungen gebildet, anschließend stehen dem Lerner unterschiedliche Zugangswege zu der gespeicherten Information zur Verfügung, was wiederum den Abruf erleichtern und sich behaltensfördernd auswirken soll. Auf dieser Annahme basieren die Erwartungen an die Wirksamkeit multimedialer Lernangebote (vgl. Scheller 2009).

Die duale Kodierungstheorie und ihre Modifizierungen (vgl. die multimodale Kodierungstheorie von Engelkamp; Zimmer 2006) ist für die Erforschung des Spracherwerbs nicht nur in Bezug auf die Verarbeitung von Bildmaterial von Bedeutung (hierzu ausführlicher Roche 2008a: 35ff). Die Grundlagen der Theorie stimmen mit wesentlichen Postulaten der kognitiven Grammatik (Langacker 1999, Evans; Green 2006) überein. Auf dieser Basis entwickelt Scheller (2009) ein Untersuchungsdesign, mit dem sie verschiedene Lernergruppen experimentell testen kann: Gruppen, die mit oder ohne Animationen lernen, und Gruppen, die mit oder ohne einem kognitiven Modell die Grammatik lernen. Die Ergebnisse ihrer Arbeit zur Kasuswahl bei Wechselpräpositionen zeigen deutlich, dass Animationen gut geeignet sind, die Kasuswahl zu veranschaulichen und die Lerner bei der Bildung mentaler Modelle zu unterstützen. Die Studien zeigen aber auch die Grenzen der Wirksamkeit von Animationen auf: von einer generellen lernfördernden Wirkung der Animationen kann demnach nicht ausgegangen werden. Erst in Verbindung mit einem kognitiven Modell der Grammatikvermittlung entfaltet die mediale Realisierung (Animation) den Lernmehrwert. So zeigten die Animationen in Verbindung mit dem formalen wo/wohin-Ansatz lediglich wenig ausgeprägte oder nur kurzfristige Verbesserungen der Lernleistung. Der kognitive Erklärungsansatz der Grenzüberschreitung in seiner statischen Version reichte ebenfalls nicht aus, um eine deutliche und langfristige Verringerung der Fehler zu bewirken. Dieser Erklärungsan- 
satz bleibt möglicherweise zu abstrakt und bietet wenige Anhaltspunkte für mentale Modellierungsprozesse.

Kontiguitätseffekte der Präsentationsmodi für ein sinnstiftendes Lernen entstehen demnach nur, wenn sprachliche und visuelle Information in ein gemeinsames mentales Modell integriert sind. Durch gute Koordination der Modi entstehen generative Effekte. Bei mangelnder Koordination entstehen Interferenzen und Ablenkungen (vgl. Seel 2000).

\section{Zusammenfassung}

Diese Beispiele neuerer Forschung zeigen, wie wichtig fundierte Studien zur Überprüfung von (verbreiteten) Vorannahmen der Sprachvermittlung sind. Der Lern-/Lehrmodus ist möglicherweise weniger von medialen und kulturspezifischen Einflüssen geprägt als gemeinhin angenommen. Die individuellen Faktoren der Lernerdisposition spielen offenbar eine gewichtigere Rolle bei der Erzielung eines Lernerfolgs. Der elektronisch vermittelte Sprachunterricht ist dabei nicht grundsätzlich ineffizienter als der Präsenzunterricht. Vielmehr ergeben sich für jeden Lehr- und Lernmodus bestimmte Stärken, die je nach den Zielen und Bedingungen des Unterrichts in gemischten Verfahren Mehrwert steigernd kombiniert werden könnten. Auch die Annahme „Ein Bild sagt mehr als 1000 Worte" kann in dieser verbreiteten Allgemeinheit kaum Gültigkeit beanspruchen. Vielmehr bedarf es dabei einer engen semantischen, konzeptuellen und zeitlichen Abstimmung der Informationspräsentation und -verarbeitung. Die Erforschung des Spracherwerbs ist also nach wie vor ein weites und ein lohnendes Feld. Die neuen Medien bieten dafür vergleichsweise einfache, wenig interferierende und hoch effiziente Instrumente, die von der Wissenschaft und von der Lehrpraxis bisher kaum entdeckt worden sind und bisher bedauerlicherweise nur marginal genutzt werden.

\section{Literatur}

Anderson, Jon (1995): Cybarites, Knowledge Workers and New Creoles on the Superhighway. In: Anthropology Today 11/4, 13-15.

Caplan, Elisabeth A. (2002): The Effects Of Animated Textual Instruction On Learners' Written Production Of German Modal Verb Sentences. http://purl.fcla.edu/fcla/etd/ SFE0000042/Caplan2002c.pdf (29.10.2010).

Castells, Manuell (2001): The Internet galaxy: Reflections on the Internet, business and society. Oxford: Oxford University Press.

Chase, Mackie et al. (2002): Intercultural Challenges in Networked learning: Hard Technologies Meet Soft Skills. In: First Monday 7/8.

Engelkamp, Johannes; Zimmer Hubert D. (2006): Lehrbuch der kognitiven Psychologie. Göttingen: Hogrefe.

Evans, Vyvyan; Green, Melanie (2006): Cognitive Linguistics: An Introduction. Edinburgh: Edinburgh University Press. 
Hubbard, Philip (1992): A methodological framework for CALL courseware development. In: Sharp, D.; Pennington; Martha C.; Stevens, Vance (Hrsg.): Computers in applied linguistics: An international perspective. Clevedon: Multilingual Matters, 39-65.

Hufeisen, Britta; Leitner, Peter; Seminarteilnehmer (2007): Zur Entwicklung und Anwendung eines Analyserasters zur Analyse von Sprachlernsoftware. Darmstadt: Sprachenzentrum der Technischen Universität.

Langacker, Ronald W. (1999): Grammar and Conceptualization. Berlin; New York: de Gruyter.

Launer, Rebecca (2008): Blended Learning im Fremdsprachenunterricht - Konzeption und Evaluation eines Modells. http:/ / edoc.ub.uni-muenchen.de/8905/1/Launer_Rebecca.pdf.

Paivio, Allan (1986): Mental representations: A dual coding approach. New York: Oxford University Press.

Reeder, Kenneth et al. (2008): A Computer-based Reading Tutor for Young Language Learners. In: Zhang, Felicia; Barber, Beth (Hrsg.): Handbook of Research on ComputerEnhanced Language Acquisition and Learning. Hershey: IGI Global, 159-188.

Reeder, Kenneth; Macfadyen, Leah P.; Roche, Jörg; Chase, Mackie (2004): Negotiating Cultures in Cyberspace: Participation Patterns and Problematics. In: Language Learning \& Technology 8/2 (http://llt.msu.edu/vol8num2/reeder/), 88-105.

Roche, Jörg (2008a): Handbuch Mediendidaktik. Ismaning: Hueber.

Roche, Jörg (2008b): Fremdsprachenlernen online. In: Issing, Ludwig J.; Klimsa, Paul (Hrsg.). Online-Lernen - Handbuch für das Lernen mit Internet. München: Oldenbourg Wissenschaftsverlag, 389-399.

Roche, Jörg (Hrsg.) (2007): Fremdsprachen lernen medial - Entwicklungen, Forschungen, Perspektiven. Berlin: Lit-Verlag.

Roche, Jörg; Scheller, Julia (2004): Zur Effizienz von Grammatikanimationen beim Spracherwerb - Ein empirischer Beitrag zu einer kognitiven Theorie des multimedialen Fremdsprachenerwerbs. In: Zeitschrift für Interkulturellen Fremdsprachenunterricht, 9/1 (http://zif.spz.tu-darmstadt.de/jg-09-1/beitrag/roche-scheller2.htm).

Roche, Jörg; Scheller, Julia (2008): Grammar Animations and Cognitive Theory of Multimedia Learning. In: Barber, Beth; Zhang, Felicia (Hrsg.): Handbook of Research on Computer Enhanced Language Acquisition and Learning. Hershey: IGI Global, 205-219.

Rösler, Dietmar (2004): E-Learning Fremdsprachen - eine kritische Einführung. Tübingen: Stauffenburg.

Sauer, Christoph (2004): Der Stoff, aus dem die Texte sind. Vorläufige Betrachtungen zu Erscheinung und Materie von Texten. In: Röller, Dirk (Hrsg.): Dinge - Zeichen Gestalten. Tagungsdokumentation Internationale Semiotische Herbstakademie. Lüneburg: Jansen Verlag (http://www.semiotik.eu/export_download.php?id=292).

Scheller, Julija (2009): Animationen in der Grammatikvermittlung: Multimedialer Spracherwerb am Beispiel von Wechselpräpositionen. Münster: Lit-Verlag.

Seel, Norbert M. (2000): Psychologie des Lernens. Lebrbuch für Pädagogen und Psychologen. München, Basel: Reinhardt. 
Stiftung Warentest: Damit lernen Sie richtig. http://www.test.de/themen/bildung-soziales/weiterbildung/test/-Lernsoftware/1567887/1567887/1576553/ (21.09.2007).

Todorova, Dessislava (2010): Einsatżöglichkeiten der elektronischen Medien im interkulturellen DaF-Unterricht: Evaluation des Sprachlernprogramms www.uni-deutsch.de seitens bulgarischer und litanischer Studierender unter Berücksichtigung der Lerndispositionen. Münster: Lit-Verlag. Zeitschrift für Interkulturellen Fremdsprachenunterricht (2004): 9/1.

Zhang, Felicia; Barber, Beth (Hrsg.) (2008): Handbook of Research on Computer-Enhanced Language Acquisition and Learning. Hershey: IGI Global. 


\section{Ernst Apeltauer \& Susanne Duxa \& Andreas Westhofen}

\section{Themenschwerpunkt Lehreraus- und -fortbildung}

Mit der in Bologna vereinbarten Umstellung der universitären Ausbildung auf BA- und MA-Studiengänge und der Integration der Lehrerausbildung in diese neuen Studiengänge hat in ganz Europa ein Um- und Neustrukturierungsprozess begonnen. Der Themenschwerpunkt 3 (künftig TSP 3) beschäftigte sich mit Konsequenzen, die sich daraus für die Lehreraus- und -fortbildung ergeben. Thematisiert wurde die Ausbildung von DaZ- und DaF-Lehrkräften in Deutschland. Berichtet wurde aber auch über die Aus- und Fortbildung von DaF-Lehrkräften in Ländern wie Finnland, der Ukraine, Portugal und Brasilien sowie über Qualitätssicherungsmaßnahmen. Aus den im Rahmen dieses Themenschwerpunktes gehaltenen Vorträgen wurde eine Auswahl getroffen, die für die Druckfassung überarbeitet wurde.

Nach Vorträgen zur Sprachförderung (Michalak) und zum Förderunterricht in Deutschland (Baur, Seipp) sowie zu fachsprachlichen Schwierigkeiten beim Übergang von der Schule in die Berufsausbildung (Ohm) haben die Vortragenden und ein Vertreter aus dem Ministerium für Schule und Weiterbildung (Stiller) die Thematik in einer abschließenden Podiusmdiskussion nochmals thesenartig zusammengefasst und unter folgenden Fragestellungen diskutiert:

- Wie können Theorie und Praxis besser verzahnt und methodische Vorgehensweisen nicht nur erprobt, sondern auch evaluiert werden?

- Welche Grundfertigkeiten sollten für die Sprachdiagnostik und die Sprachförderung vermittelt werden, damit sie später bedarfsorientiert eingesetzt werden können?

- Wie können Studierende Gesprächs- und Beratungskompetenz erwerben?

Die dort vorgetragenen Thesen können im Anhang nachgelesen werden.

In einem zweiten Teil wurde über den „DaF-Markt“ in Deutschland berichtet und über die Anforderungen, mit denen sich DaF-Absolventen dort konfrontiert sehen (Jung). Weitere Vorträge beschäftigten sich mit der Qualitätsicherung im fachbezogenen DaF-Unterricht in Finnland (Schlabach/Sormunen/Grasz) sowie mit der DaFAusbildung in Deutschland (am Beispiel von Leipzig) und der Ukraine, Portugal und Brasilien. Den Abschluss bildete wiederum eine Podiumsdiskussion, in deren Verlauf die folgenden Fragen diskutiert wurden:

- Welche Möglichkeiten gibt es, um Schüler für Deutsch als (Zweit-)Fremdsprache zu motivieren?

- Wie sieht ein künftiger Bedarf an Deutschlehrkräften in Osteuropa und in Skandinavien aus?

- Welche Rolle können Universitätsnetzwerke und Fortbildungsprojekte für die künftige Aus- und Fortbildung spielen? 
Den ersten Vortrag hielt Magdalene Michalak (Universität Lüneburg) über das Thema „Sprachförderung Deutsch als Zweitsprache - ja, aber von wem?“ In ihrem Vortrag berichtete Magdalena Michalak über eine Befragung von Studierenden (künftigen Lehrkräften für DaZ), die sie auf der Grundlage allgemeiner Vorgaben und Vorschläge, wie sie in der Fachliteratur diskutiert werden, entwickelt und erhoben hat. Das Fazit ihrer Studie lautet: Je mehr Wissen Lehrkräfte erwerben, desto weniger intuitiv müssen sie handeln. Sie kritisiert, dass es nach wie vor kein einheitliches DaZ-Curriculum gibt und zu wenig sachgerechte DaZ-Themen während des allgemeinen Studiums behandelt werden.

Im zweiten Vortrag berichtete Rupprecht Baur (Universität Duisburg-Essen; Thema „Förderunterricht im Rahmen einer Lehrerausbildung“") über ein Projekt, in dem zur Zeit ca. 800 Schüler mit Migrationshintergrund aus den Sekundarstufen I und II von etwa 110 Studierenden aus 14 Herkunftsländern unter Anleitung und mit Supervision unterrichtet werden. Zwei Ziele werden damit angesteuert: Auf einer schulischen Ebene die Förderung von Chancengleichheit von Schülern mit Migrationshintergrund, auf einer universitären Ebene die Qualifizierung von Studierenden für die Vermittlung von Sprach- und Sachwissen sowie die Entwicklung von Gesprächs- und Beratungskompetenz bei diesen Studierenden für den Umgang mit mehrsprachigen Schülern und Eltern.

Bettina Seipp (Universität Dortmund; „DaZ-Sprachförderkompetenz im Unterricht aller Fächer") berichtete über ein Modell, das an der Universität Dortmund im Zusammenhang mit dem Förderprojekt der Stiftung Mercator (und in Anlehnung an die langjährige Tradition an der Universität Essen) entwickelt wurde. Eine zweisemestrige theoretische Ausbildung wird ergänzt durch eine einjährige Praxisphase (mit Sprachförderung in Höhe von vier Stunden pro Woche), wobei eine Veranstaltung der Universität Dortmund mit einer Veranstaltung der RAA kombiniert werden soll. Unklar ist, ob ein solches „Ausbildungs-Minimum“ das sehr viel umfangreichere Ausbildungsangebot an anderen Standorten (etwa an der Universität Essen) ersetzen kann bzw. ausreicht, um Studierende auf ihre Aufgabe angemessen vorzubereiten.

In seinem Vortrag „Fachliche Schwierigkeiten sind sprachliche Schwierigkeiten. Müssen Fachlehrer auch Sprachlehrer sein?“ berichtete Udo Ohm (Univerität Jena/ Bielefeld) über Probleme von Jugendlichen mit Migrationshintergrund in der beruflichen Ausbildung, die sich u.a. auf fehlende sprachliche Kompetenzen zurückführen lassen. Es sollen deshalb Sprachfördermaßnahmen für diese Adressatengruppe konzipiert werden, die gezielt an fach- und ausbildungsbezogenen Inhalten ausgerichtet werden. Theoretischer Ausgangspunkt ist Wygotskis Modell von den Mittler-Reizen (Begriffe, Artefakte und Tätigkeiten) und die damit verbundenen Teilkompetenzen: Textsorten, Textstruktur, Diskursfunktionen, fachsprachliche Mittel, die es zu vermitteln gilt. Sie sollen anhand konkreter Beispiele exemplarisch eingeführt und mit Hilfe von Scaffolding entwickelt, erläutert und abgesichert werden.

In seinem Vortrag „DaF-Ausbildung am Markt vorbei? Bestandsaufnahme und Vorschläge“ kritisiert Matthias Jung die gängigen Berufsbilder für DaF-Lehrkräfte (Analytiker oder Forscher), die indirekt oder direkt in Ausbildungsgängen vermittelt werden. 
Er weist darauf hin, dass auf dem freien Markt DaF-Lehrkräfte mehr und mehr auch Organisations- und Managementaufgaben übernehmen müssen, worauf DaF-Absolventen gegenwärtig kaum vorbereitet werden. Aus dieser Bestandsaufnahme leitet er curriculare Konsequenzen ab. Eine solche Konsequenz besteht für ihn darin, dass DaFAbsolventen individuelle Qualifizierungsstrategien entwickeln müssen, um sich auf die Anforderungen des Marktes vorzubereiten. Dieser Beitrag findet sich am Ende dieses Bandes im Forum „Beruf und Qualifizierung“.

Über ein DaF-Fortbildungsprojekt in Finnland berichteten Joachim Schlabach, Edeltraut Sormunen und Sabine Grasz. Unter dem Titel „Qualitätssicherung im fachbezogenen Deutsch als Fremdspracheunterricht mündliche Kommunikation“ erkläuterten sie ein dreisemestriges Fortbildungsprojekt (QualiDaF), dessen Ziel es ist, Empfehlungen für Qualitätsstandards für die Unterrichtspraxis zu erarbeiten. Zunächst wurde dazu der „Ist-Zustand“ erfasst und beschrieben (Phase I) und bewertungsrelevante Deskriptoren erarbeitet (Phase II), ehe ausgehend von konrekten Unterrichtsbeispielen und Prüfungsformen an einer Weiterentwicklung gearbeitet wurde. Das Projekt ist ein Teilprojekt im Netzwerk der finnischen Universitätssprachenzentren, das mit externen Experten zusammenarbeitet.

Die Möglichkeiten und Grenzen einer Neustrukturierung germanistischer Studiengänge im Rahmen von Bologna diskutierte Carmen Schier (Leipzig) vor dem Hintergrund ihrer beruflichen Erfahrungen in der Ukraine, Portugal, Brasilien und Deutschland. In ihrem Beitrag „Alle anders, alle gleich? - Herausforderungen und Gestaltungsmöglichkeiten germanistischer Studiengänge nach Bologna“" plädiert sie dafür, die Funktionalität der Ziele und Inhalte von Studiengängen stärker in den Blick zu nehmen und auf transdisziplinäre Konzepte zu setzen. 

Christoph Chlosta, Matthias Jung (Hrsg.) (2010):

DaF intergriert: Literatur - Medien - Ausbildung. Tagungsband der

36. Jahrestagung des Fachverbandes Deutsch als Fremdsprache 2008.

Göttingen: Universitätsverlag, 229-243.

\section{Magdalena Michalak (Lüneburg)}

\section{Sprachförderung Deutsch als Zweitsprache $-\mathrm{Ja}$, aber von wem?}

\section{Einleitung}

Eines der wesentlichen Ergebnisse der PISA- und IGLU-Studie für das deutsche Schulsystem ist die Feststellung, dass Kinder und Jugendliche mit Migrationshintergrund im Vergleich zu den deutschen Schülern weitaus schlechtere Chancen der Bildungsbeteiligung haben. Der deutliche Leistungsrückstand in der Lesekompetenz wirkt sich nicht nur negativ auf das Unterrichtsfach Deutsch aus. Vielmehr wurde nachgewiesen, dass auch Mängel in mathematischen und naturwissenschaftlichen Leistungen auf die Defizite im Leseverständnis zurückzuführen sind (vgl. Bos et al. 2003; Kristen 2004). Während die monolingualen deutschen Kinder erst die basalen sprachlichen Kompetenzen erwerben und anschließend die komplexeren Sprachstrukturen nacheinander lernen, müssen Zweitsprachelerner dies parallel tun. Die Anforderungen an sprachliche Lernerfolge orientieren sich an denen von einsprachig aufwachsenden deutschen Schülern. Das hat oft seine Konsequenzen: Viele Schüler mit Migrationshintergrund scheitern an den immer höher werdenden Ansprüchen der Unterrichtskommunikation (vgl. Kuchenreuther; Michalak 2008: 31). Sie stehen in der Schule ständig vor der Herausforderung, Sprache nicht allein als Medium der Kommunikation, sondern vor allem als ein Instrument des Wissenserwerbs einzusetzen. Zu den zentralen Voraussetzungen für schulisches Lernen zählt die Fähigkeit, mit Texten umgehen und dadurch dem Unterrichtsstoff folgen zu können. Denn der schulische Wissenserwerb in fast allen Fächern basiert überwiegend auf Texten (vgl. Riedel 2004). Die entscheidende Hürde 
für den schulischen Erfolg von Schülern aus zugewanderten Familien bildet also die Beherrschung der deutschen Sprache, wobei darunter schriftsprachlich geprägte Kompetenzen verstanden werden.

Nach der Untersuchung des Wissenschaftszentrums Berlin für Sozialforschung von 2006 hängt der Bildungserfolg auch von der Erwartung in die Fähigkeiten der Schüler ab: Kinder und Jugendliche mit Migrationshintergrund lernen schlechter, weil weniger von ihnen erwartet wird (vgl. WZB 2006; Schofield 2006). Sie werden in der Schule unterfordert und dadurch nicht motiviert. Die Bildungsrückstände liegen demnach auch in dem Versäumnis der Bildungsinstitutionen begründet, den Zweitspracherwerb erfolgreich zu fördern und durch die Präsentation anspruchsvoller Lerninhalte benachteiligte Schüler optimal zu unterstützen. Diese Tatsachen sind nicht neu: Schon seit Mitte der 60er Jahre finden sich in zahlreichen Erlassen und Empfehlungen u.a. des Deutschen Bildungsrats und der Kultusministerkonferenz Forderungen nach planmäßiger Sprachförderung von Schülern mit Migrationshintergrund (vgl. KMK 1964, Puskeppeleit; Krüger-Potratz 1999). Eine systematische Umsetzung ist jedoch nicht erfolgt. Zahllose Modellversuche werden gestartet und wieder eingestellt. Dennoch haben die Resultate der PISA-Studie eine weitaus größere Wirkung als alle bis dahin aufgestellten Forderungen und bildungspolitischen Maßnahmen erzielt: Zahlreiche Bundesländer haben in der jüngsten Vergangenheit Verfahren entwickelt und teilweise bereits verbindlich etabliert, mit denen die sprachlichen Defizite der Kinder bereits vor dem Schuleintritt erkannt werden sollen.

Aktuell wird darüber diskutiert die Förderung des Deutschen als Zweitsprache als Aufgabe aller Fachlehrer zu definieren. DaZ soll in alle Fächer und Lernbereiche integriert werden, um Sach- und Sprachlernen miteinander zu verbinden. In der Praxis müssen also alle Lehrkräfte in der Lage sein, Sprachbedarf zu erkennen und den Sprachstand zu diagnostizieren, konstruktiv auf zweisprachliche Probleme und durch den Unterricht in deutscher Sprache bedingte Lernbehinderung zu reagieren sowie DaZ-Förderkonzepte zu beurteilen und zu entwickeln (vgl. Benholz; Lipkowski 2000, Rösch 2005). Dazu brauchen sie das nötige theoretische und praktische Wissen, um darauf im Unterricht auch gezielt eingehen zu können und die Sprachförderung als integralen Bestandteil des Unterrichts zu gestalten. Die Lehrkräfte müssen Förderentscheidungen pädagogisch verantwortungsbewusst und auf wissenschaftlichen Erkenntnissen beruhend treffen und dabei unterrichtsrelevante Sprachkompetenz vermitteln. Es stellt sich daher die Frage, ob Lehramtstudierende und -anwärter darauf adäquat vorbereitet werden. Werden Aspekte der Zwei- bzw. Mehrsprachigkeit bei Kindern und Jugendlichen in der Lehrerausbildung explizit berücksichtigt und behandelt? Welche Standards, Kompetenzen und Inhalte sind dabei erforderlich? 


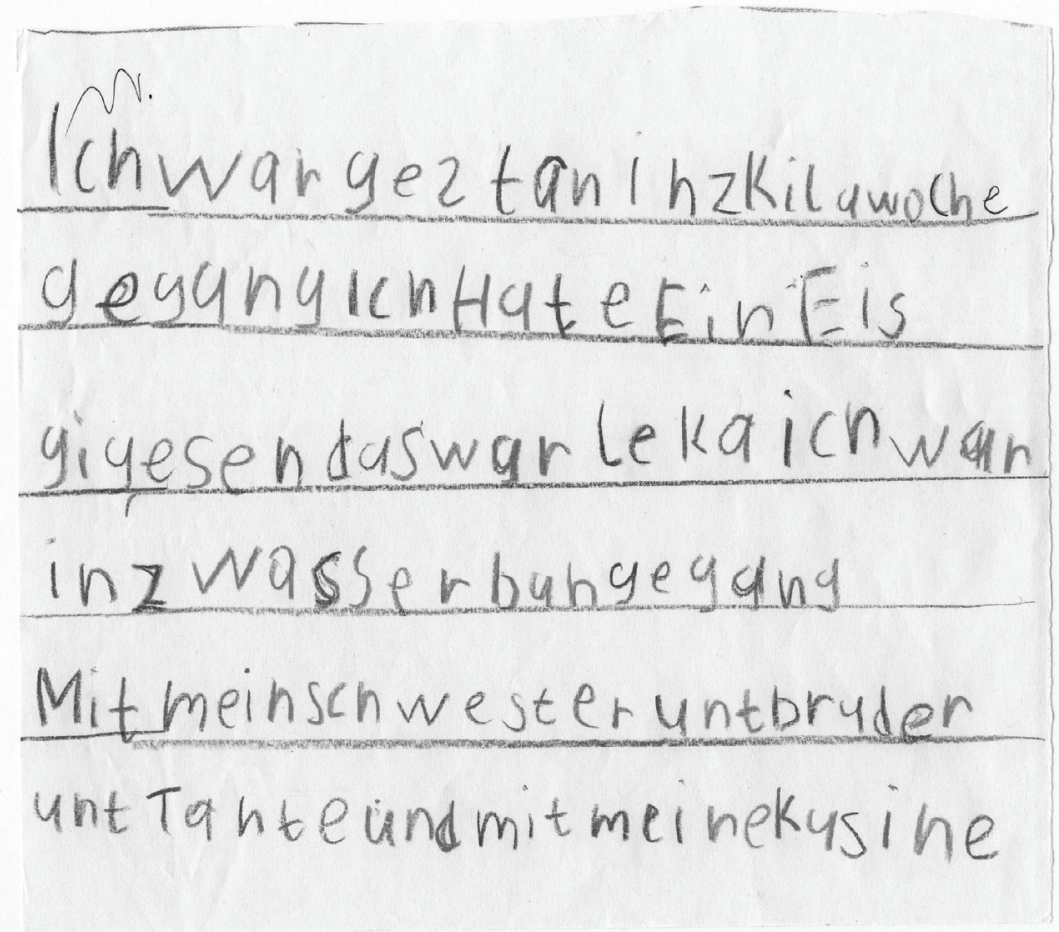

Abb. 1: Beispielhafter Schülertext. Der Text wurde von Linda, acht Jahre alt, in ihrer Freizeit verfasst. Zu dem Zeitpunkt war Linda in der zweiten Klasse. Sie ist in Russland geboren, aber den Kindergarten hat sie in Deutschland besucht. Zu Hause wird nur Russisch gesprochen. Die Mutter liest dem Mädchen auch auf Russisch vor. Linda hat zwei ältere Geschwister - Seiteneinsteiger, die sehr erfolgreich in der Schule sind und kaum Schwierigkeiten mit der deutschen Sprache haben. Die Kleine spielt oft mit Kindern anderer Nationalitäten. Die Mutter - ruhig und weltoffen, aber relativ streng - ist Hausfrau. Sie liest gern russische Literatur auf Russisch. Sie besucht einen Integrationskurs DaZ. Der Vater, Elektriker, spricht ein wenig Deutsch.

\section{Analyse eines Schülertextes}

Im Folgenden wird versucht, diesen Fragen an einem Beispiel nachzugehen (s. Abb. 1).

Betrachtet ein Lehramtstudierender den Text, so wird er vermutlich in erster Linie einige Schwierigkeiten haben, ihn zu lesen. Der Text muss zuerst verstanden werden. Dazu ist es allerdings erforderlich, ihn zu ,übersetzen“, d.h. die mögliche Bedeutung von Wörtern und Gedanken zu rekonstruieren. Die schriftlichen Leistungen sind teilweise stark von der Erstsprache beeinflusst, in der die Kinder aus zugewanderten Familien zu Hause kommunizieren. Für deutsche Lehrer stimmen die oft „unlesbaren“ Wörter mit ihren sonstigen Fehlererfahrungen bei den deutschen Schülern nicht überein. Zu der Andersartigkeit von den Fehlern der Zweitsprachelerner ist nicht selbstverständlich 
ein Zugang vorhanden. Daraus folgt, dass auf den ersten Blick unverständliche Wörter und Strukturen voreilig abgewiesen werden, weil sie nicht zu entziffern seien. Es bedarf also einer Hinführung zum Verstehen der Besonderheiten von Fehlern bei Kindern mit Migrationshintergrund.

Des Weiteren müsste sich der angehende Lehrer ein Bild von der Leistung der Schülerin machen, dadurch dass er auf seine diagnostischen Kompetenzen zurückgreift. Die Lehrkraft sollte also die Stärken und Schwächen des Lernenden feststellen: Was für den Lehrer als Fehler gilt, kann für das Kind durchaus im Einklang mit seiner Übergangskompetenz, mit der Lernersprache stehen (vgl. Kleppin 2000: 52). Fehlerhafte Äußerungen sind nämlich wie bei Erstsprachelernern auch ein Hinweis darauf, dass die Schüler durchaus nach logischen Lösungen bei der Anwendung der Zweitsprache suchen. Als Beispiel kann hier die Übergeneralisierung der Präposition ,inz“ in Lindas Text dienen. Die daraus resultierende Konsequenz ist: Um den Fehler deuten zu können, muss der Lehrer über fundiertes Wissen über Erwerbsprozesse, Lerntheorien und Lernstrategien verfügen.

Mit Hilfe von Sprachstandsindikatoren lassen sich Rückschlüsse auf vermutlich bereits angeeignete und verinnerlichte Sprachkenntnisse ziehen und somit - durch die Analyse der Erwerbsabfolgen - eine ungefähre Einordnung der Sprachentwicklung vornehmen. Dazu sind das Wissen über den Sprachaneignungsprozess sowie Kenntnisse des Erst- und Zweitspracherwerbs erforderlich. Dieses Verfahren zielt nicht auf alterstypische Aneignungsbereiche ab, sondern ermöglicht vielmehr eine Verortung des individuellen Könnens in Bezug auf ein bestimmtes sprachliches Phänomen (vgl. Apeltauer; Glumpler 1997, Apeltauer 1998). So wird ein Sprachprofil des Kindes erstellt, denn „der Erwerb des Deutschen als Zweitsprache ist neben vielen von Lerner zu Lerner weniger stark schwankenden Besonderheiten durch stabile Regelmäßigkeiten gekennzeichnet" (Grießhaber 2008a: 32). Verwendet das Kind den Dativ, so kann man davon ausgehen, dass es schon den Akkusativ, den Nominativ und erste Präpositionen mit Kasus - aber möglicherweise noch nicht den Genitiv bilden kann (vgl. Apeltauer 1997). In dem exemplarischen Schülertext ist zu sehen, dass das Mädchen anscheinend keine Probleme mit dem Akkusativ hat. Erste Versuche der Anwendung von verschiedenen Präpositionalphrasen sind noch nicht immer gelungen: Sie übergeneralisiert die Präposition „in“. Ähnlich lässt sich die Entwicklung der Wortstellung diagnostizieren, da die Stellungsregeln der finiten und infiniten Verbteile in einer bestimmten Reihenfolge erworben werden, wobei die höheren Erwerbsstufen den vorherigen Erwerb der jeweiligen niedrigeren Stufe voraussetzen (vgl. Grießhaber 2008a). In Bezug auf den Beispieltext ist zu erkennen, dass die Schülerin zwar nur einfache Äußerungen produziert, die Sätze mit dem Subjekt beginnt, aber die Satzklammer anwendet, indem sie die finiten und infiniten Verbteile schon separiert, z.B. „Ich hate ein Eis gigesen“. Somit ist der Text der Erwerbsstufe 2 nach Grießhaber zuzuordnen (vgl. Grießhaber 2008b: 222).

Der nächste Schritt wäre die Identifizierung und Erklärung der Fehler. Dafür muss die Lehrkraft in erster Linie fähig sein, über die deutsche Sprache zu reflektieren und sie 
muss die Normen der deutschen Standardsprache kennen. Das Wissen hilft nicht nur, die Fehler möglichst zu erklären, sondern auch nach ihren Ursachen zu forschen. Wie Neumann schreibt: „Ein gut ausgebildeter Lehrer erkennt die Fehler und kann deren Zustandekommen im Einzelnen begründen“ (Neumann 1981: 18).

Die Auseinandersetzung mit möglichen Ursachen von Fehlern kann ohne den Rückgriff auf die Strukturen der Herkunftssprachen der Schüler nicht erfolgen. Ausgehend von den einzelnen Fehlern wird danach gefragt, wie die jeweiligen sprachlichen Gegebenheiten in anderen Sprachen sind. In dem Fallbeispiel ist das Russische die Ausgangssprache. Einige Unzulänglichkeiten in dem Beispieltext können sich auf die Interferenzen aus der Erstsprache der Schülerin beziehen: Defizite bei der Anwendung der Possessivpronomen (im Russischen werden diese ausgelassen, daher: mit mein Schwester, unt bruder unt tante), bei der Satzstellung (Im Russischen gibt es keine Satzklammer.; s. letzter Satz im Beispieltext), bei Erkennung der Quantität der Vokale (Kila, hate, gigesen) sowie unzureichende Verschriftlichung des Schwalautes und des vokalisierten „,r“ (gestan, gegang, gigessen, leka) oder die Anwendung von , z“ in Verbindung mit der Präposition „,in“, was auf das russische stimmhafte „, $z$ “ eventuell zurückzuführen wäre, vorausgesetzt, dass der Schülerin die russische Schrift bekannt wäre. ${ }^{1}$ Um solche Fehler adäquat interpretieren zu können, ist breites Wissen über die Migrantensprachen und die kontrastive Sprachanalyse unerlässlich.

Bei der Textanalyse sollen auch die Person der Schülerin und alle außersprachlichen Faktoren, die ihre Sprachleistungen beeinflussen, berücksichtigt werden: ihre Lernbiographie, Lerngewohnheiten, die Voraussetzungen, die sie zum Sprechen und Schreiben in der Zweitsprache mitbringt, und die Bedingungen, unter denen sie Deutsch lernt sowie andere Lernervariablen (Hinweise zur Lesesozialisation und zur familialen Sprachkultur, eigene Motivation sowie Anregungen seitens der Eltern oder soziale Kontakte usw.). Das impliziert Grundlagewissen über sprachliche und literale Sozialisation der Schüler.

Erst auf der Grundlage dieser Analyseergebnisse lässt sich der Unterricht mit mehrsprachigen Kindern inhaltlich und methodisch planen und durchführen. Dementsprechend müsste dem angehenden Lehrer während seiner Ausbildung die didaktischmethodische Kompetenz im Bereich DaZ vermittelt werden. Bei der Unterrichtsvorbereitung müssen u.a. die Anforderungen der konzeptionell schriftlichen Schulsprache, die Hinführung zu einem dekontextualisierten Verstehen und Verwenden der Sprache, die Vermittlung von Textkompetenz, die Verbindung von Sprach- und Fachlernen, das Einüben von Lerntechniken sowie das Prinzip eines sprachbewussten Unterrichts gleichermaßen berücksichtigt werden (vgl. auch Rösch 2007: 36f.). Ausgehend von den spezifischen sprachlichen Defiziten der jeweiligen Zweitsprachelernergruppe muss der Lehrer nicht nur die Lehrziele bestimmen können, sondern auch die angemessenen Materialien auswählen oder diese selbst erstellen. Darüber hinaus hängt der Erfolg der DaZ-Förderung damit zusammen, wie die Anweisungen und Aufgabenstellungen im Unterricht formuliert werden (vgl. Michalak 2009). Die Lehrkraft muss sich demzufol-

1 In unserem Beispiel trifft es aber nicht zu, denn die Schülerin beherrscht die kyrillische Schrift nicht. 
ge Gedanken über das eigene Lehrverhalten und die Unterrichtsinteraktion machen. Darüber hinaus müssen die Formen des Darstellens und des Erklärens an die Zweitsprachelerner angepasst werden (vgl. Portmann-Tselikas 2002: 18f.). Zu den Lehrerqualifikationen kommt noch der Umgang mit Vielfalt und Heterogenität, was hiermit als interkulturelle Kompetenz bezeichnet wird (vgl. Luchtenberg 1999, 2000). Dies bedeutet u.a., dass die deutsche Sprache auch aus der Perspektive von DaZ-Lernenden zu betrachten ist.

Unter der Prämisse der Vielfalt stellt der Unterricht von heute neue Anforderungen an die angehenden Lehrkräfte. Reich und Roth merken diesbezüglich an:

\begin{abstract}
„Benötigt werden (heute) sowohl spezifische Qualifikationen, wie die Didaktik des Deutschen als Zweitsprache und die Didaktik des Herkunftssprachenunterrichts, als auch allgemeine Qualifikationen wie das Nutzen mehrerer Sprachen zu fachlichen Zwecken und das bewusste Handhaben der (deutschen) Sprache als des wichtigsten Mediums in (fast) allen Fächern.“ (Reich; Roth 2002: 43)
\end{abstract}

\title{
2 Geforderte Lehrkompetenzen im Kontext des Deutschen als Zweitsprache
}

Die nötigen Fach- und Methodenkompetenzen werden im Folgenden zusammengefasst. Als Basisqualifikation dient Grundlagewissen im Bereich interkultureller Pädagogik, Lernpsychologie sowie des Spracherwerbs mit Berücksichtigung der sprachlichen Sozialisation unter Migrationsbedingungen, um kompetenten Umgang mit sprachlicher Vielfalt zu entwickeln. Erst die Reflexion über das interkulturell-pädagogische Handeln in der entsprechenden Situation erlaubt eine pädagogische Herangehensweise. Ferner sollen fundierte Kenntnisse des Deutschen (d.h. die Normen der deutschen Sprache) und dessen Schwierigkeiten für den DaZ-Lerner in der Lehrerausbildung vermittelt werden. Das Wissen über Regelmäßigkeiten der deutschen Sprache ist hierbei relevant, denn die sprachliche Förderung der Kinder nicht deutscher Herkunft hat besonders den Aspekt zu berücksichtigen, sie in die normgerechte Schriftförmigkeit der Unterrichtskommunikation einzuführen. Die Hinführung zur konzeptionell schriftlichen Sprache verlangt ein besonderes Engagement von allen Lehrkräften: Jedes Thema muss vorerst auf sprachliche Phänomene analysiert werden. Danach ist zu überlegen, in welcher Weise diese Stolpersteine in einer Unterrichtseinheit vorbereitet und wann welche Elemente in welchem Kontext eingeführt werden können. Da Spracharbeit auch den Sach- und Fachunterricht betrifft, müssen in der Lehrerausbildung die Besonderheiten der deutschen Fachsprachen mit einbezogen werden. Die sprachlichen Defizite von Schülern mit Migrationshintergrund bedürfen der differenzierten Diagnose und Förderung, da sie individuell unterschiedlich sind (vgl. Allemann-Ghionda; Auernheimer; Grabbe; Krämer 2006: 252). Darauf müssen die künftigen Lehrenden in ihrer Schulpraxis eingehen. Der Lehrer muss die Sprachenvielfalt in seiner Klasse wahrnehmen und sich mit den Fragestellungen befassen, die sich aus dieser Vielfalt ergeben (vgl. Chlosta; Ostermann 2005: 33f.). Die Auseinandersetzung mit den Herkunftssprachen, in Abrissen ein strukturelles Wissen über die Muttersprachen der Schüler und das Kon- 
trastieren von Sprachen mit Elementen der Fehleranalyse bilden u.a. die Grundlage der diagnostischen Kompetenz. Der Studierende muss lernen, sprachliche Veränderungsprozesse zu beobachten und einzuschätzen und dies nicht nur in Bezug auf das Deutsche, sondern im Verhältnis des Deutschen zu anderen Sprachen. Durch dieses Wissen kann die Lehrkraft die Kinder in die Lage versetzen, „zwischen beiden Sprachsystemen eine Beziehung herzustellen“ (Allemann-Ghionda et al. 2006: 252). Darüber hinaus soll der Lehrer „über mögliche Effekte von Korrekturmaßnahmen oder anderen Formen der Intervention informiert sein“ (Knapp-Potthoff 2007: 378). Anzustreben ist, dass die Zweitsprachelerner ihre Normenverstöße erkennen und bearbeiten können. Das Prinzip der sprachlichen Korrektheit darf aber ihre Kommunikationsbedürfnisse nicht hemmen (vgl. Rösch 2007: 37). Zu erweben sind didaktisch-methodische Lehrkompetenzen im Deutschen als Zweitsprache, wobei DaZ als Förderunterricht, als Teil des regulären Deutschunterrichts und als Spracharbeit im Fachunterricht definiert wird. Diese Kenntnisse helfen geeignete Übungs- und Sozialformen einzusetzen sowie den Unterricht bei stark heterogenen Lernergruppen durch Binnendifferenzierung besser zu gestalten. Der Lehrer muss in der Lage sein, DaZ-Förderkonzepte zu beurteilen und zu entwickeln sowie einzelne Unterrichtssequenzen gezielt aufzuarbeiten, um die Schüler systematisch zu fördern. Er braucht auch die Fähigkeit, den Zweitsprachelernern die nötigen Lern- und Arbeitsstrategien, vor allem Texterschließungsverfahren zu vermitteln. Gleichzeitig muss er Kompetenzen entwickeln, um DaZ-Lehrwerke und Lehrmaterialien auf der Basis einer linguistischen Analyse als geeignet für eine bestimmte Lernergruppe einschätzen zu können und selbst Lehrmaterial bezogen auf die Bedürfnisse einzelner Schüler zu erstellen. Zur Lehrerqualifizierung gehören zusätzlich Beratungsansätze für die Eltern, damit sie ihre Kinder beim Spracherwerb und der kognitiven Entwicklung auch unterstützen können.

Um Theorie und Praxis in der Ausbildung zu verbinden, ist es wünschenswert, während des Studiums Fachpraktika mit wissenschaftlicher Begleitung anzubieten. Diese sollten zur Sprachförderung und zum Spracherwerb im Hinblick auf DaZ-Kompetenzen und zur Kompetenz im Unterrichten durchgeführt werden. Die Grundlagen sollen während der Lehrerausbildung gelegt werden, damit die Studienabsolventen in ihrer beruflichen Tätigkeit als Lehrer eine pädagogische Handlungskompetenz entwickeln können. Mit anderen Worten: Fehlen das sprachwissenschaftlich und sprachdidaktisch fundierte Wissen und die Sensibilisierung für die Folgen von Zuwanderung in der Schule und in der Gesellschaft, so wird es schwierig eine pädagogische Kompetenz aufzubauen, die auf theoretischem Wissen, Selbstreflexion und Handlungsroutinen gründen soll. Es wird dann eher von intuitivem Lehrerhandeln ausgegangen.

$\mathrm{Zu}$ überlegen ist, ob die Förderlehrer ausreichendes Wissen erworben haben, um den Förderunterricht zu erteilen. In diesem Zusammenhang werden im nächsten Schritt einzelne Förderprojekte unter dem Gesichtspunkt ausreichender Lehrerkompetenzen für eine erfolgreiche Förderung der zweisprachigen Schüler exemplarisch betrachtet. 


\section{Kompetenzen von Förderlehrkräften in exemplarischen Projekten}

Im Rahmen der Sprachförderprojekte arbeiten vorwiegend Deutschlehrer, Lehramtstudierende, evtl. Erzieherinnen oder Sozialarbeiter als Förderlehrkräfte. Im Projekt „Sprachstube Deutsch“ in Berlin werden sogar Jugendliche mit Migrationshintergrund zu Sprachförderern „,ausgebildet“, wie es in der Projektbeschreibung steht, und führen mit Kindern im Vorschulalter Sprachübungen durch (vgl. Bundesministerium 2003). Die jugendlichen „Sprachlehrer" arbeiten vermutlich sehr engagiert und vielleicht verbessern sie dabei selbst ihre schulischen Leistungen, weil sie bestimmte Lernbereiche bewusster analysieren. Der Vorteil für die Kinder: Es wird mit ihnen gesprochen. Hier müsste man jedoch nach den Kompetenzen der Förderlehrer fragen, die auf fundiertem Wissen basieren sollen. Die Wirksamkeit der Sprachförderung ist in diesem Zusammenhang nicht sehr überzeugend.

In den meisten Projekten nehmen die Förderlehrer an begleitender Fortbildung teil - häufig nur um die diagnostischen Kompetenzen zu entwickeln, die in dem jeweiligen Projekt gefordert werden, oder sie werden in die Arbeit mit bestimmten Arbeitsblättern angeleitet, wie es z.B. im Projekt Hippy der Fall ist (vgl. Kiefl 1996). Nach den zugänglichen Informationen ist dennoch kein einheitliches Gesamtcurriculum für die DaZ-Fortbildungen vorhanden.

An dieser Stelle wird exemplarisch Bezug auf die Vorbereitung der Förderlehrkräfte im Rahmen des Projekts „Förderunterricht für Kinder und Jugendliche mit Migrationshintergrund“ genommen. Das Projekt wird von der Stiftung Mercator gefördert und basiert auf dem Essener Modell „Förderunterricht für Kinder und Jugendliche ausländischer Herkunft an der Universität Essen“. Der Unterricht wird mittlerweile an 35 Standorten bundesweit angeboten. In Kleingruppen von drei bis sieben Teilnehmern erhalten Kinder und Jugendliche der Sekundarstufe I und II Sprach- und Fachunterricht von Lehramtsstudierenden. Ein Gesamtcurriculum für die Vorbereitung der Lehrkräfte ist nicht verfügbar. Die thematischen und inhaltlichen Ausarbeitungen variieren von Standort zu Standort. Einige Konzepte - wie es z.B. in Berlin der Fall ist, umfassen auch Theaterprojekte, die bestimmt viel leisten, denn Handlungsorientierung schafft Motivation. Durch die Arbeit an Theaterstücken wird ein persönlicher Zugang zu den Jugendlichen erreicht. Unter anderem steht die Vermittlung von sozialer und kreativer Kompetenz im Mittelpunkt. Es werden Texte gelesen und Dialoge erarbeitet. Es wird das Hörverstehen trainiert. Die Aneignung der unterrichtsrelevanten Sprachkompetenzen ist aber dabei fragwürdig: Nach Stanat und Müller hat erst die Kombination aus impliziter und expliziter Sprachförderung nachhaltige Effekte auf den Bereich der Sprachkompetenz, der für den schulischen Erfolg zentral ist, nämlich auf die Schreibund Lesekompetenz (vgl. Stanat; Müller 2005: 25).

Als Auswahlkriterien für die Förderlehrkräfte werden oft Flexibilität und Zuverlässigkeit verlangt, keine anderen Voraussetzungen. In welchem Maße die Studierenden dann auf die Stolpersteine der deutschen Sprache und die Spezifik des Deutschen als Zweitsprache sensibilisiert wurden, ist nicht ganz eindeutig. Im Rahmen der von 
der Stiftung Mercator bundesweit unterstützten Sprachförderprojekte wird häufig an Universitäten ein Fortbildungsprogramm mit Basisqualifikationen in Blockseminaren, auch als Wahlpflichtmodul, zur Verfügung gestellt, das u.a. Grundlagen des Deutschen als Zweitsprache, Spracharbeit in allen Fächern, Leseförderung und Methodentraining beinhaltet. Die Vorbereitung der Förderlehrer im Rahmen von Sprachförderprojekten verläuft also eher punktuell. Können aber einige begleitende Blockseminare dazu beitragen, dass die Studierenden DaZ effektiv unterrichten, an die Lernprobleme gezielt herangehen und lernerorientierten Sprachförderunterricht vorbereiten? Da den Förderunterricht meist Studierende übernehmen, die im Bereich DaZ nicht angemessen ausgebildet sind, sind sie bei ihrer Arbeit vor allem in der Anfangsphase oft überfordert.

\section{Untersuchungsergebnisse zu Lehrkompetenzen}

Dies bestätigt auch die Studie, die an der Universität Lüneburg durchgeführt wird. ${ }^{2}$ Im Rahmen des Projekts „Förderunterricht Deutsch als Zweitsprache für Kinder und Jugendliche mit Migrationshintergrund“ werden die Lehrkompetenzen im Kontext des Deutschen als Zweitsprache erforscht. Die Untersuchung verfolgt das Ziel, explizit die sprachwissenschaftlichen und -didaktischen Kompetenzen der Förderlehrer im Bereich $\mathrm{DaZ}$ zu evaluieren und infolge dessen die Lehrerausbildung basierend auf der Erfassung schulpraktischer Anforderungen in mehrsprachigen Klassen unter sprachwissenschaftlichen und sprachdidaktischen Gesichtspunkten konzeptionell zu verbessern. Die Daten dazu werden aus der Analyse des DaZ-Förderunterrichts in drei Lüneburger Hauptschulen seit 2006 gewonnen, in denen Deutschlehramtsstudierende als DaZ-Förderlehrer eingesetzt werden. Den Ausgangspunkt der Untersuchung bildet die These, dass die angehenden Lehrer im Rahmen ihres Studiums nicht ausreichend auf die Arbeit mit heterogenen Klassen und mit Schülern mit Migrationshintergrund vorbereitet sind.

Als Voraussetzung für die Mitarbeit an dem Projekt gilt die Teilnahme an einem Vorbereitungsseminar, in dem die Studierenden in das Förderungskonzept eingeführt werden. Nach dem Beginn ihres eigenständigen Förderunterrichts sind sie auch dazu verpflichtet, ein Begleitseminar zu Deutsch als Zweitsprache zu besuchen. Um über eigene Arbeit und die erworbenen Lehrkompetenzen zu reflektieren, können die Studierenden ein Lehrportfolio oder einen Projektbericht schreiben. In der Anfangsphase ihrer Arbeit werden alle Förderlehrkräfte zur Selbsteinschätzung ihrer Lehrkompetenzen im Hinblick auf ihre zukünftige Arbeit in mehrsprachigen Klassen befragt, wobei zu dem Zeitpunkt die Studierenden nur einzelne Seminare im Bereich DaZ belegt hatten. Darüber hinaus wird in dem von ihnen durchgeführten Unterricht regelmäßig hospitiert. Die bereits gesammelten Daten wurden im Zeitraum vom September 2006 bis April 2008 erhoben. Die Datenerhebung basiert auf einer Methodenkombination und umfasst folgende Komponenten: Unterrichtsbeobachtungsprotokolle, Lehrportfolios sowie offene Interviews mit den DaZ-Förderlehrern. Bisher wurden insgesamt 32 För-

2 Die Untersuchung wird parallel zu dem Förderunterrichtsprojekt in Lüneburg seit 2006 durchgeführt. Die Studie dauert somit bis 2011. In dem Beitrag erfolgt die Auswertung der ersten Ergebnisse. 
derlehrkräfte mittels Leitfadeninterviews befragt. Die Fragen beziehen sich auf alle in diesem Beitrag aufgelisteten lingusitischen und sprachdidaktischen Lehrkompetenzen im Kontext des Deutschen als Zweitsprache: Kenntnisse des Zweitspracherwerbs und die Berücksichtigung seiner Besonderheiten bei der Unterrichtsplanung und -durchführung, Einschätzung eigener diagnostischer Kompetenzen, Kenntnisse der Regeln der deutschen Sprache, Miteinbeziehen der Herkunftssprachen, Beurteilung eigener didaktisch-methodischer Kompetenzen, Lehrmaterialienauswahl sowie Reflexion über die Vorbereitung im Rahmen des Studiums auf den Umgang mit mehrsprachigen Klassen.

Die Erhebung zeigt, dass sich die Studierenden bei ihrer Arbeit als Förderlehrer vor allem in der Anfangsphase überfordert fühlen. Sie können mit den Besonderheiten des Zweitspracherwerbs nicht angemessen umgehen. Die Fehler der Förderschüler werden meistens auf Interferenzen reduziert, und ihre Schwächen werden als besondere Probleme im Bereich Orthographie definiert. Die Dominanz der Fehler im Bereich Morphologie und Syntax wird leider übersehen (vgl. Fix 2002). Sehr beliebt sind dementsprechend Diktate, da - wie mehrere Studierende festgestellt haben - die meisten Förderschüler deswegen schlechte Noten im Deutschunterricht bekommen und weil Diktateschreiben auch von den Klassenlehrern erwartet werde.

In Frage sind auch das Sprachbewusstsein der Studierenden bezüglich der deutschen Sprache und ihre diagnostische Kompetenz zu stellen. Alle Studierenden bestätigten, in Seminaren auf die Stolpersteine der deutschen Sprache sensibilisiert worden zu sein. Ihr eigenes Sprachwissen schätzen sie aber sehr kritisch ein: Von 32 Befragten gaben 22 zu, die Normen der deutschen Sprache kaum zu kennen. Sie handeln im Unterricht intuitiv, ohne auf fundiertes Wissen in diesem Bereich zurückzugreifen. Wo jedoch das Wissen hoch ausgeprägt ist, lässt intuitives Handeln deutlich nach. Bemerkenswert ist, dass sich die Förderlehrer meistens auf ihre eigenen Erfahrungen, auch Schulerfahrungen beziehen, anstatt auf die theoretischen Grundlagen. In diesem Bereich arbeiten Förderlehrer mit Migrationshintergrund (drei der Befragten) sicherer, da sie auf ihr linguistisches Wissen und eigene Lernstrategien Bezug nehmen können. Bei der Frage nach Beurteilungskriterien der Schülertexte wurde - bis auf drei Befragte - zwischen Rechtschreibund Grammatikfehler nicht unterschieden. Die Schülertexte werden in erster Linie unter dem Aspekt der Groß- und Kleinschreibung korrigiert. Keiner der Befragten setzte sich bisher mit den Herkunftssprachen der Schüler auseinander. Die Erstsprachen der Schüler werden auch weder bei der Korrektur der Texte noch bei der Unterrichtsplanung mit einbezogen. Als Grund dafür wurde von 25 Förderlehrern mangelnde Zeit für Sprachenlernen genannt. Eine Studentin kommentierte: „Ich kann kein Wort Türkisch oder Russisch. Da kann ich mich doch auf diese Sprachen nicht beziehen." Nur eine Studentin behauptete, auf die Sprachstandsindikatoren zu achten. Der Begriff war sonst noch nur drei anderen Befragten bekannt, aber sie würden sich danach bei der Analyse von Schüleräußerungen nicht richten. Lernbiographien und -gewohnheiten wurden bei der Unterrichtsplanung - meistens aus Zeitmangel - nicht beachtet. Besonders kritisch schätzen die Studierenden ihre eigenen diagnostischen Kompetenzen im Bereich DaZ ein. Auf Grund der häufig bereits recht gut entwickelten mündlichen Kommunikations- 
fähigkeiten überschätzen die Förderlehrer die Sprachkenntnisse, über die ihre Schüler in der Zweitsprache verfügen. Konzeptionell schriftliche Fertigkeiten werden im Förderunterricht selten berücksichtigt und trainiert. Trotz der Einführung in die Spezifik des Deutschen als Zweitsprache erwarten die Studierenden oft, dass sie im Unterricht Schülern begegnen, die gar kein Wort Deutsch sprechen. Eine Studentin bemerkte: „Die Schüler sprechen ja fließend Deutsch. Was soll ich denn bei ihnen fördern?“ An dieser Stelle ist anzumerken, dass $82 \%$ der in dem Projekt in Lüneburg unterstützten Schüler in Deutschland geboren sind. Gefördert werden Schüler ab der 5. Klasse der Sekundarstufe I, d.h. es ist vorauszusetzen, dass sie die anderen Klassenstufen in einer deutschen Schule auf Deutsch absolviert haben.

Des Weiteren mangelt es den Förderlehrkräften an Kenntnissen und Fähigkeiten der didaktisch-methodischen Umsetzung von spezifischen Grundsätzen der unterrichtlichen Förderung des Zweitspracherwerbs. Infolgedessen werden die Schüler im Unterricht oft unterfordert. Bei der Lernzielbestimmung stehen die Motivation der Schüler, Förderung der Kreativität und Spaß am Unterricht an erster Stelle. Auf das Verfassen von Texten wird im Förderunterricht gern verzichtet, denn - wie eine Studierende im 7. Semester bemerkte - „Die Schüler mögen es nicht.“ Problematisch ist auch die Arbeit an Texten. Immer wieder nehmen die Studierenden das Nichtverstandene und das Detail zum Ausgangspunkt des „Verstehens“ und begehen dabei den klassischen Fehler, zuerst nach unbekannten Vokabeln zu fragen, anstatt sich auf den Inhalt zu konzentrieren. Angefangen wird meist mit der Aufgabe: „Unterstreiche die Wörter, die du nicht verstanden hast."

Die Studie zeigt, dass die Studierenden im Rahmen eines solchen Projekts ein sehr hohes Maß an Interesse und Motivation mitbringen, weil sie zwar angeleitet, aber doch selbstaktiv für sich Lehrprozesse organisieren können und unter Realisierung und Weiterentwicklung unterschiedlicher Fähigkeiten praxisbezogene Aufgaben bewältigen können. Nach ihren Praxiserfahrungen bemerkten alle Befragten, dass sie durch das Studium nicht ausreichend auf den Umgang mit Heterogenität im Unterricht vorbereitet sind. Mehrsprachigkeit wird in einigen Veranstaltungen für Lehramtsstudierende nur aus der Perspektive der interkulturellen Pädagogik angesprochen, unter dem sprachlichen Aspekt aber kaum thematisiert. Erwartet werden jedoch konkrete didaktische Durchführungsmöglichkeiten der DaZ-Förderung. Durch die Arbeit entdecken die Studierenden selbst, wo sie als angehende Lehrer noch Lücken haben. Alle Befragten gaben $\mathrm{zu}$, dass es sie motiviert, intensiver zu studieren und sich auf bestimmte Bereiche stärker zu konzentrieren. Alle Studierenden behaupteten, dass sie erst durch die Mitarbeit an dem Projekt für die besonderen Probleme, die diese Verknüpfung von fachlichem und von sprachlichem Lernen speziell Schülern aus einem schriftfernen Milieu bereiten kann, genügend sensibilisiert sind.

Dies beweist, dass die entsprechende Qualifizierung im Kontext des Deutschen als Zweitsprache in der ersten und zweiten Phase der Lehrerausbildung erforderlich ist. Sind aber die heutigen Strukturen geeignet, die spezifische Bildungsproblematik erfolgreich zu kompensieren? 


\section{Fazit}

Deutsch als Zweitsprache kommt in den neuen lehramtsbezogenen Bachelor- und Master-Studiengängen praktisch zu kurz. Eine linguistische und sprachdidaktische Ausrichtung auf Deutsch als Zweitsprache wird in dem Studium häufig leider nicht ausdrücklich betont. Es fehlt meines Erachtens u.a. an der Verknüpfung zwischen dem Sprach- und Inhaltslernen sowie an der Sensibilisierung für Gemeinsamkeiten und Unterschiede zur Didaktik des Deutschen als Mutter-, Zweit- und als Fremdsprache. In der Lehrerausbildung wird das Hauptaugenmerk auf Ansätze der interkulturellen Pädagogik als Vorbereitung auf den Umgang mit Mehrsprachigkeit gelegt. In den Bereich fallen Programme zur Verbesserung der interkulturellen Didaktik, interkultureller Kompetenzen und Sprachförderprogramme für den Deutschunterricht (vgl. Luchtenberg 2000). Jedoch fehlen immer noch Kenntnisse über die Prozesse, mit denen die Einstellungen der Lehrer nachhaltig beeinflusst werden. In den Curricula für alle Schularten wird zwar gefordert, das Verständnis für andere Sprachen und Kulturen anzubahnen sowie die Mehrsprachigkeit mit einzubeziehen, jedoch ohne die Durchführungsmöglichkeiten konkret zu spezifizieren. Die an den Universitäten bundesweit angebotenen DaZ-Module sind oft für Lehramtsstudierende aller Fächer nicht verpflichtend (vgl. Rösch 2005). Aktuell wird über die Sprachförderung in allen Fächern diskutiert, denn in jedem Fach spielt die Sprache eine zentrale Rolle für das Lernen. Eine Sprachförderung, die sich allein auf die begrenzten Deutschunterrichtsstunden stützt, kann auf keinen Fall den vielfältigen sprachlichen Anforderungen insbesondere in den Fachsprachen gerecht werden. Gleichzeitig bietet jeder Unterricht Sprachfördermöglichkeiten, die genutzt werden müssen. Untersuchungen dazu, über welche sprachwissenschaftliche und didaktisch-methodische Kompetenzen im Bereich DaZ die angehenden Fachlehrer verfügen sollen und in welcher Form sie in der Lehrerausbildung zu vermitteln wären, gibt es kaum. Die Folge: Das Thema „Mehrsprachigkeit“ wird in die universitären Lehrveranstaltungen mit einbezogen, aber konkrete Möglichkeiten der Sprachförderung von Kindern und Jugendlichen mit Migrationshintergrund in allen Fachbereichen werden nicht gezeigt. Dieses Dilemma hat seine Ursache darin, dass bisher nicht erfasst worden ist, welche spezifischen linguistischen und didaktisch-methodischen Kompetenzen sich aus den Anforderungen der Schulpraxis im Kontext des Deutschen als Zweitsprache ergeben. Ebenso wenig existiert ein hochschulübergreifendes systematisiertes Wissen im Bereich DaZ darüber, welche Qualifikationsanforderungen und Ansprüche an deren Vermittlung Lehramtsstudierende in Bezug auf den Umgang mit mehrsprachigen Klassen erwarten und formulieren (vgl. Duxa 2001; Portmann-Tselikas 2002). Und nicht zuletzt ist bisher unreflektiert geblieben, wie die Qualifizierung durch die Hochschuldozenten sich systematisch vernetzt in den Gesamtprozess der Ausbildung einfügen soll. ${ }^{3}$ Diese Fragestellungen berühren natürlich elementar auch Hochschuldozenten in allen Fachbereichen der Lehramtsstudiengänge: Sie müssen auf der Basis ihrer Fachdisziplin

3 Gemeint sind damit die Verknüpfung zwischen Deutsch als Zweitsprache und anderen Fachdidaktiken sowie die Verzahnung der einzelnen BA- und MA-Module unter diesem Aspekt. 
in kooperativer Interdisziplinarität mit den Kollegen des Faches Deutsch die Bezüge zum Gegenstandsbereich herstellen und entsprechend die Kompetenzen vermitteln.

Zusammenfassend lässt sich Folgendes feststellen: Die Lehrerbildung ist der Schlüssel dafür, dass Lehrer zum Spracherfolg und damit zum Schulerfolg der Schüler mit Migrationshintergrund beitragen können. Dabei müssen alle künftigen Lehrkräfte die besonderen sprachlichen Schwierigkeiten ihres Unterrichts kennen und differenziert darauf reagieren. Erreicht werden kann dies durch wissenschaftlich fundierte und praxisnahe Ausbildung, in der nötige Kompetenzen vermittelt werden. Alle Lehrkräfte müssen sich über den Sprachstand der Lerner bewusst sein und davon ausgehend die Interaktion aufbauend strukturieren. Diese Aufgabe stellt vor allem Fachlehrkräfte vor eine große Herausforderung. Das verlangt ein hohes Maß an sprachlicher Bewusstheit seitens aller Lehrenden. Daher der Appell, die Lehrerausbildung im Allgemeinen deutlich sprachorientierter zu gestalten.

\section{Literatur}

Allemann-Ghionda, Christina et al. (2006): Beobachtung und Beurteilung in soziokulturell und sprachlich heterogenen Klassen: die Kompetenzen der Lehrpersonen. In: Kompetenzen und Kompetenzentwicklung von Lehrerinnen und Lehrern: Ausbildung und Beruf. Zeitschrift für Pädagogik 51. Beiheft, 250-266.

Apeltauer, Ernst (1997): Kasusmarkierungen als Sprachstandsindikatoren. In: Lernen in Deutschland 2, 118-133.

Apeltauer, Ernst (1998): Verben als Sprachstandsindikatoren im Schuleingangsbereich. In: Apeltauer, Ernst; Glumpler, Elisabeth; Luchtenberg, Sigrid (Hrsg.): Erziehung für Babylon. Baltmannsweiler: Schneider Verlag Hohengehren, 38-67.

Apeltauer, Ernst; Glumpler, Edith (1997): Ausländische Kinder lernen Deutsch: Lernvoraussetzungen, methodische Entscheidungen, Projekte. Berlin: Cornelsen Scriptor.

Benholz, Claudia; Lipkowski, Eva (2000): Förderung in der deutschen Sprache als Aufgabe des Unterrichts in allen Fächern. In: Deutsch lernen 1, 1-10.

Bos, Wilfried et al. (Hrsg.) (2003): Erste Ergebnisse aus IGLU. Schülerleistungen am Ende der vierten Jahrgangsstufe im internationalen Vergleich. Münster et al.: Waxmann.

Bundesministerium für Familie, Senioren, Frauen und Jugend (2004): Sprachstube Deutsch. http://www.deinkiez.de/ easytool/index/3358/ (10.04.2008).

Chlosta, Christoph; Ostermann, Torsten (2005): Sprachenvielfalt in der Grundschule. In: Bartnitzky, Horst; Speck-Hamdan, Angelika (Hrsg.): Deutsch als Zweitsprache lernen. Frankfurt a.M.: Grundschulverband - Arbeitskreis Grundschule e.V., 33-43.

Duxa, Susanne (2001): Fortbildungsveranstaltungen für DaZ-Kursleiter in der Weiterbildung und ibre Wirkungen auf das professionelle Selbst der Lehrenden. Materialien Deutsch als Fremdsprache 57. Regensburg: Fachverband DaF.

Fix, Martin (2002): „Die Recht Schreibung ferbesern“ - Zur orthografischen Kompetenz in der Zweitsprache Deutsch. In: Didaktik Deutsch 12, 39-55.

Grießhaber, Wilhelm (2008a): Zweitspracherwerbsprozesse als Grundlage der Zweitsprachförderung. In: Ahrenholz, Bernt (Hrsg.): Deutsch als Zweitsprache - Vorausset- 
zungen und Konzepte für die Förderung von Kindern und Jugendlichen mit Migrationshintergrund. Freiburg: Fillibach Verlag, 31-48.

Grießhaber, Wilhelm (2008b): Zu den Bedingungen der Förderung in Deutsch als Zweitsprache. In: Ahrenholz, Bernt (Hrsg.): Zweitspracherwerb. Diagnosen, Verläufe, Voraussetzungen. Beiträge aus dem 2. Workshop Kinder mit Migrationshintergrund. Freiburg: Fillibach Verlag, 211-227.

HIPPY Deutschland e.V. (Home Instruction for Parents of Preschool Youngsters): http:/ / www.hippy-deutschland.de (10.10.2008).

Kiefl, Walter (1996): Sprungbrett oder Sackgasse? Die HIPPY-Hausbesucherin auf dem Weg zur Integrationshelferin. In: Soziale Arbeit 45/1, 10-17.

Kleppin, Karin (2000): Febler und Feblerkorrektur. Fernstudieneinheit 19. Kassel, München, Tübingen: Langenscheidt.

Knapp-Potthoff, Annelie (2007): Fremdsprachenunterricht. In: Knapp, Kalfried et al. (Hrsg.): Angewandte Linguistik. Ein Lehrbuch. Tübingen: Francke, 369-388.

Kristen, Cornelia (2004): Migranten im deutschen Schulsystem: Zu den Ursachen ethnischer Unterschiede. In: Recht der Jugend und des Bildungswesens 52, 11-22.

Kuchenreuther, Michaela; Michalak, Magdalena (2008): Verständnisbarriere. Sachtexte eine besondere Herausforderung für Schüler mit Migrationshintergrund. In: Grundschulmagazin $05,31-36$.

Luchtenberg, Sigrid (1999): Lehrerkompetenzen für die Vielfalt im Deutschunterricht der Grundschule. In: Deutsch lernen 3, 273-302.

Luchtenberg, Sigrid (2000): (Keine) Zeit für Deutsch als Zweitsprache in der Deutschlehrerausbildung - ein altes Problem neu beleuchtet. In: Deutsch lernen 1/2000, 12-32.

Michalak, Magdalena (2009): Arbeitsanweisungen verstehen. Vermittlung unterrichtsspezifischen Vokabulars. In: Deutsch differenziert 2, 40-45.

Neumann, Rosemarie (1981): Sprachkontrast Deutsch-Türkisch im Bereich von Aussprache und Rechtschreibung. In: Deutsch lernen 2, 3-22.

Portmann-Tselikas, Paul (2002): Textkompetenz und unterrichtlicher Spracherwerb. In: Portmann-Tselikas, Paul; Schmölzer-Eibinger, Sabine (Hrsg.): Textkompetenz: Neue Perspektiven für das Lernen und Lehren. Innsbruck: Studienverlag, 13-44.

Puskeppeleit, Jürgen; Krüger-Potratz, Marianne (1999): Bildungspolitik und Migration. Texte und Dokumente zur Beschulung ausländischer und ausgesiedelter Kinder und Jugendlicher 1950 bis 1999. 2 Bde. iks - interkulturelle studien 31. Münster: Arbeitsstelle Interkulturelle Pädagogik, 32.

Reich, Hans; Roth, Hans-Joachim (2002): Spracherwerb zweisprachig aufwachsender Kinder und Jugendlicher. Ein Überblick über den Stand der nationalen und internationalen Forschung. Eine Einführung. Hamburg; Tübingen: Freie und Hansestadt Hamburg - Behörde für Bildung und Sport, Amt für Schule; Narr.

Riedel, Sabine (2004): Lernen in der zweiten Sprache. In: Bonnet, Andreas; Breidbach, Stephan (Hrsg.): Didaktiken im Dialog. Konzepte des Lehrens und Wege des Lernens im bilingualen Sachfachunterricht. Frankfurt a.M. et al.: Peter Lang, 77-88. 
Rösch, Heidi (2005): Aus- und Fortbildung in Deutsch als Zweitsprache (DaZ) - Überblick. In: Bartnitzky, Horst; Speck-Hamdan, Angelika (Hrsg.): Deutsch als Zweitsprache lernen. Frankfurt a.M.: Grundschulverband - Arbeitskreis Grundschule e.V., 121130.

Rösch, Heidi (2007): Deutsch als Zweitsprache. Sprachförderung. Grundlagen, Übungsideen-Kopiervorlagen. Braunschweig: Schroedel.

Schofield, Janet Ward (2006): Migrationshintergrund, Minderheitenzugehörigkeit und Bildungserfolg Forschungsergebnisse der pädagogischen, Entwicklungs- und Sozialpsychologie. AKI-Forschungsbilanz 5, http://www.wzb.eu/zkd/aki/files/aki_forschungsbilanz_5.pdf (10.04.2008).

Stanat, Petra; Müller, Andrea (2005): Förderung von Schülerinnen und Schülern mit Migrationshintergrund. In: Bartnitzky, Horst; Speck-Hamdan, Angelika (Hrsg.): Deutsch als Zweitsprache lernen. Frankfurt a.M.: Grundschulverband - Arbeitskreis Grundschule e.V., 20-32.

Wissenschaftszentrum Berlin für Sozialforschung (WZB) (2006): Wer fordert, fördert den Lernprozess. Migrantenkinder lernen schlechter, weil weniger von ihnen erwartet wird. WZB Presse, http://www.wzb.eu/presse/mitteilungen_2006/migrantenkinder.de.htm (10.04.2008). 

Christoph Chlosta, Matthias Jung (Hrsg.) (2010):

DaF integriert: Literatur - Medien - Ausbildung. Tagungsband der

36. Jabrestagung des Fachverbandes Deutsch als Fremdsprache 2008.

Göttingen: Universitätsverlag, 245-250.

\section{Rupprecht S. Baur (Essen)}

\section{Mehrsprachige Schüler - einsprachige Lehrer?}

\section{Einleitung}

Obwohl seit den 70er Jahren bekannt ist, dass die Förderung von SchülerInnen mit Migrationshintergrund die Schule vor neue Aufgaben stellt, ist es bis heute nicht gelungen, aus dieser Erkenntnis die notwendigen Konsequenzen zu ziehen. Bevor ich auf die Lehrerausbildung eingehe, gebe ich einige Grunddaten aus Essen an, die man als repräsentativ für die Städte in NRW ansehen kann. ${ }^{1}$

Im Jahr 2002 wurden rund 19.000 Essener Grundschüler über die von ihnen verwendeten Sprachen befragt (Chlosta; Ostermann; Schroeder 2003). Von den befragten Kindern waren rund 28\% mehrsprachig, d.h. sie gaben an, außer Deutsch mindestens eine weitere Sprache in ihrem Elternhaus zu sprechen. Auf die Frage Welche Sprache sprecht ibr zu Hause außer Deutsch gaben die mehrsprachigen Kinder insgesamt 122 unterschiedliche Antworten. Bei genauer Betrachtung kann man hinter den Antworten der Kinder etwa 80 verschiedene Sprachen erkennen. Das Augenmerk möchte ich dabei auf Folgendes richten: Wenn wir von SchülerInnen mit Migrationshintergrund sprechen, denken wir häufig in erster Linie an SchülerInnen mit der Herkunftssprache Türkisch. Die Tatsache, dass die türkischen Kinder innerhalb der Migranten die größte Teilgruppe bilden, darf aber nicht den Blick dafür verstellen, dass mehr als zwei Drittel der mehrsprachigen Kinder von anderen Sprachen und Kulturen geprägt sind. Mehrsprachigkeit und Multikulturalität in Schule und Gesellschaft ernsthaft zu berücksichtigen, würde bedeuten, alle Kinder mit Migrationshintergrund in ihrer Spezifik wahrzunehmen und

1 Die Untersuchung von Fürstenau; Gogolin; Yagmur (2003) in Hamburg kommt zu ähnlichen Ergebnissen. 
sie aufgrund ihrer Sprache und Herkunft nicht zu benachteiligen. Das würde ein Umdenken erforderlich machen, indem man sich nicht nur auf die großen Gruppen - und das sind dann in der Regel diejenigen mit türkisch- und russischsprachigem Hintergrund - konzentriert.

Wie die PISA-Studien aufgedeckt haben, hat die Lehrerausbildung in Deutschland versagt. Anstatt die Lehrerausbildung in der ersten und zweiten Phase konsequent auf die durch Immigration verursachten gesellschaftlichen Veränderungen hin zu reformieren, haben die Länder in den 80er Jahren mit Lehrerfortbildungen darauf reagiert, die insgesamt wirkungslos geblieben sind. Auch der PISA-Schock und neue Lehrerausbildungsgesetze (LABG) haben an dieser Situation nichts wesentlich verändert: Dies soll am Beispiel der Situation im Land NRW, dem Land mit der größten Anzahl von SchülerInnen mit Migrationshintergrund exemplarisch gezeigt werden. So wurde beispielsweise in $\int 5$ („Übergreifende Studieninhalte") der Lehramtsprüfungsordnung (LPO) für die Erste Staatsprüfung von 2003 des Landes NRW ein Passus aufgenommen, dass die Lehramtsstudierenden „Grundkenntnisse in interkultureller Bildung und der Förderung von Schülerinnen und Schülern in Deutsch als Zweitsprache erwerben“ sollen. Da den Universitäten aber ,standortspezifische und individuelle Schwerpunktbildungen" eingeräumt wurden ( $(9)$, hatte die LPO die Funktion eines moralischen Appells ohne verpflichtenden Charakter. Allein das „Didaktische Grundlagenstudium Deutsch für die Sekundarstufe" schien im LABG von 2002 ein Schritt in die Richtung einer sprachlichen Grundqualifikation in DaZ für alle LehrerInnen darzustellen (vgl. Didaktisches Grundlagenstudium o.J.), doch ist dieses Grundlagenstudium in den Beratungen einem neuen LABG in NRW gewichen, das im Jahr 2009 in Kraft treten soll, und durch sechs verpflichtende Kreditpunkte ersetzt worden (was konkret bedeutet, dass lediglich zwei Veranstaltungen im Laufe von fünf Jahren besucht werden müssen!). Letztlich haben sich die Ausbildungsstrukturen an keiner Universität durch die Lehrerausbildungsreform von 2003 in Bezug auf die Funktion von Deutsch als Zweitsprache (DaZ) grundlegend geändert. Denn konsequenterweise hätte ja eine Veränderung der Ausbildungsinhalte im Sinne der Einführung von Pflichtveranstaltungen oder verpflichtenden Volumina im Bereich DaZ auch eine Veränderung der Personalstruktur zur Folge haben müssen - und das hätte in diesem Fall bedeutet: mehr Stellen für die Ausbildung für DaZ in der Germanistik anzusiedeln. Solche Strukturfragen an den Hochschulen hätte das Hochschulministerium übrigens im Jahre 2003 noch beeinflussen können - nach Einführung des Hochschulfreiheitsgesetzes in NRW, das die Hochschulen zu vom Land unabhängigen Institutionen macht, die über ihre Studiengänge und Strukturen selbst entscheiden, dürfte es ungleich schwieriger sein, die notwendigen Strukturen zu schaffen.

\section{Warum bestehende Zusatzqualifikationen nicht greifen}

Um noch in der Ausbildung befindlichen oder bereits ausgebildeten LehrerInnen die Möglichkeit zu geben, sich für die Bereiche DaZ und Interkulturelle Pädagogik (IP) nachzuqualifizieren, kann in NRW seit 1987 eine Zusatzqualifikation DaZ/IP an den 
Universitäten Bielefeld, Duisburg-Essen, Köln und Münster studiert werden. Diese Zusatzqualifikation (aktualisiert in der Verordnung des MSWF NRW vom 29.09.2000) bildet genau die Qualifikationen aus, die eigentlich alle LehrerInnen in einem grundständigen Studium erwerben müssten:

- „die Fähigkeit, die sprachlichen Leistungen der Schülerinnen und Schüler nicht deutscher Muttersprache auf dem Hintergrund ihrer spezifischen sprachlichen Sozialisation zu verstehen und angemessene Fördermaßnahmen durchzuführen;

- die Fähigkeit, durch andere Kulturen geprägtes Verhalten zu verstehen und in mehrsprachigen und multikulturellen Lerngruppen gemeinsames Lernen zu fördern;

- die Fähigkeit, aufgrund der Kenntnis von Ursachen und Folgen von Migration die Lebenslage von Kindern nicht deutscher Muttersprache zu verstehen;

- die Fähigkeit, die personale Entwicklung von Schülerinnen und Schülern unterschiedlicher Nationalitäten im Spannungsfeld von kulturellem Widerspruch und Integration zu verstehen und zu fördern“"

(Zitat aus der Verordnung zum Erwerb einer Zusatzqualifikation Deutsch als Zweitsprache/Interkulturelle Pädagogik 2003).

Warum sollten sich aber angehende LehrerInnen der Mühe unterziehen, diese Zusatzqualifikation zu erwerben, wenn das Land NRW dafür keinerlei Anreize schafft? Weder erhalten LehrerInnen Stundenerlässe für ein solches Studium, noch werden die Studiengebühren für diejenigen übernommen, die sich im öffentlichen Interesse qualifizieren wollen und sollten. Hier müssen unbedingt Regelungen geschaffen werden, die für den Erwerb nützlicher und notwendiger Zusatzqualifikation motivieren!

\section{LehrerInnen mit Migrationshintergrund an die Schulen}

In Punkt 8 des „Aktionsplans Integration“ der Landesregierung NRW soll dafür geworben werden, dass mehr LehrerInnen mit Migrationshintergrund an die Schulen kommen und dass mehr SchülerInnen mit Migrationshintergrund den Lehrerberuf ergreifen. In diesem Kontext werden wichtige Funktionen angesprochen, die von LehrerInnen mit Migrationshintergrund wahrgenommen werden könnten und sollten:

1. Die Mittlerfunktion zwischen Schule, Schülern und Elternhaus,

2. die Unterstützung und Orientierung mehrsprachiger SchülerInnen,

3. die Förderung der interkulturellen Qualifizierung der Lehrerschaft.

Dem eigentlichen Ziel ist voll zuzustimmen, den drei Punkten „im Prinzip“ auch. Es gilt aber ein Kernproblem zu lösen: Nämlich wie erhalten die LehrerInnen mit Migrationshintergrund selbst die Qualifikation, um diese Funktionen wahrnehmen zu können? Man darf auf keinen Fall von der Vorstellung ausgehen, dass diese Qualifikationen durch den Migrationshintergrund selbst sozusagen naturwüchsig ausgebildet sind oder werden. Was die künftigen LehrerInnen mit Migrationshintergrund brauchen, ist eine qualifizierte Ausbildung in allen drei o.g. Bereichen. Eine solche Ausbildung ist an den Universitäten bislang nicht vorhanden, sondern muss geschaffen und erprobt werden. 
In Gesprächen, die ich mit Studierenden mit Migrationshintergrund ${ }^{2}$ geführt habe, wurden zu den Anforderungen an eine solche Ausbildung folgende Meinungen geäußert:

\section{Zum Studium:}

Tülay: „Im Studium ist leider von einem Eingehen auf die Bedürfnisse mehrsprachiger Studierender nichts zu erkennen. Für mich war die türkische Schreibwerkstatt eine große Hilfe. Man sollte an den Universitäten auch Schreibwerkstätten für Studierende mit anderen Herkunftssprachen einrichten. Die Besonderheiten der jeweiligen Sprachen sollten im Sprachvergleich berücksichtigt werden. So etwas fehlt.“

Tham: „Ja, das Augenmerk auf die Mehrsprachigkeit aller Studierenden wird im Studium komplett vernachlässigt. Ich habe bemerkt, dass viele Nichtdeutsche Angst hatten, im Studium Referate zu halten, aus sprachlichen Gründen.“

\section{Zur Bedeutung der Kenntnis von Sprachen:}

Tham: „Vietnamesisch spielt natürlich keine besondere Rolle in der Schule, aber ich habe auch andere Sprachen gelernt. Und wenn man auch selber bereits eine Migrantensprache kennt und andere dazu lernt, dann kann man viel eher verstehen, dass beim Lernen, beim Spracherwerb und auch bei der Anwendung von Fachsprachen ähnliche Probleme vorliegen."

Tülay: „Ich könnte jetzt die ganze Liste von Migrantensprachen aufzählen. Es ist einfach sehr wichtig, die Struktur der Sprache zu kennen, um typische Fehler erkennen und beheben zu können. Gerade das muss durch eine Ausbildung gefördert werden.“

Veronika: „Man muss für andere Sprachen und Kulturen sensibilisiert werden, nicht nur für die eigene. Und natürlich müssen wir das Bewusstsein der Kinder für ihre eigenen Muttersprachen im Kontrast zum Deutschen stärken. Der Rückgriff auf die Muttersprachen soll bei der Spracharbeit gefördert werden. Dazu sollten die Lehrer mit Migrationshintergrund ausgebildet werden. Und Deutschlehrer müssen auch die Sprachstrukturen anderer Sprachen kennen, damit sie nachvollziehen können, wo gewisse Probleme liegen, damit sie wissen, warum die russischen und die türkischen Kinder z.B. keine Artikel und andere Präpositionen gebrauchen. Auch die Satzstellung ist in diesen Sprachen völlig anders. Das müssen die Deutschlehrer wissen. Deshalb habe ich auch noch Türkisch gelernt."

Zwei Dinge, die in den Zitaten deutlich werden möchte ich hervorheben. Erstens: Auch begabte Studierende mit Migrationshintergrund brauchen häufig eine besondere Betreuung, damit ihre Fähigkeiten entwickelt werden können. Zweitens: Die Studierenden mit Migrationshintergrund sehen sich nicht nur als Ansprechpartner für Migrantenkinder ihrer eigenen Ethnie an, sondern wollen etwas über Sprachstrukturen und Spracherwerb lernen, um einer mehrsprachigen Schülerschaft gerecht zu werden.

Zusätzlich möchten die Studierenden mit Migrationshintergrund aber auch Expertinnen für ihre eigene Muttersprache werden. Sie sind sich dabei darüber im Klaren, dass sie auch hier eine besondere Ausbildung brauchen, wie die folgenden Zitate zeigen.

2 Tülay A. hat einen türkischen, Veronika S. einen russischen und Tham L. einen vietnamesischen Hintergrund. 


\section{Muttersprachen und Muttersprachlicher Unterricht}

Tülay: „Man muss für einen Vergleich mit der Muttersprache speziell ausgebildet werden. Nur weil ich Deutsch studiere und zufällig Türkisch als Muttersprache habe, kann ich nicht im Muttersprachlichen Unterricht eingesetzt werden. Ich bin zwar fachlich ausgebildet in Deutsch, aber ich könnte nicht die Brückenfunktion übernehmen in einer Schule. Dafür sollten definitiv ausgebildete Kräfte eingesetzt werden. Es wäre nicht richtig zu meinen, dass alle, die Türkisch sprechen, auch Türkisch unterrichten können. So wird das Fach abgewertet."

Veronika: „Es muss gelehrt werden, wie man die Sprache richtig vermittelt. Man kann seine Muttersprache sprechen, z.B. Türkisch oder Russisch, aber man weiß nicht, wie die Sprache funktioniert, und es wäre total falsch, solche nicht ausgebildeten Lehrer im muttersprachlichen Unterricht einzusetzen. Sie könnten den Kindern nicht helfen."

Diese Beiträge der Studierenden belegen, dass es sehr sinnvoll wäre, bei einer Lehrerausbildung von Studierenden mit Migrationshintergrund den schulischen Unterricht insgesamt zu betrachten und die einzelnen Fachunterrichte, den Förderunterricht für Migrantenkinder und den Muttersprachlichen Unterricht in einem größeren Zusammenhang zu sehen und so in einer spezifischen Ausbildung echte Synergieeffekte zu erzielen. Die Interdependenz von muttersprachlicher Entwicklung und der Zweitsprache Deutsch wird im deutschen Schulsystem nicht gesehen, wie die folgende Aussage der türkischen Muttersprachenlehrerin Emel Ö. bestätigt:

Emel Ö.: „Ich finde, dass hier auch die Einstellung der Schulleitung sehr wichtig ist. Die Schulleitungen sehen immer nur die Deutschkenntnisse im Vordergrund und sehen nicht die Verbindung zu den Muttersprachen der Schüler. Hier müsste sich generell etwas in der Einstellung ändern. Dann würden LehrerInnen mit Migrationshintergrund nicht eingestellt, weil sie ebenso gut Deutsch können wie deutsche Muttersprachler oder weil eine gewisse Ausländerquote erfüllt werden muss, sondern weil man die Verbindung zwischen der Muttersprache und der Zweitsprache Deutsch sieht. Deutschunterricht, Fachunterricht, Förderunterricht und muttersprachlicher Unterricht stehen für mich im ganz engen Zusammenhang."

\section{Was muss getan werden?}

- Alle Lehramtsstudierenden sollten eine Grundausbildung in Deutsch als Zweitsprache erhalten, damit die Sprachförderung auf breiter Basis greifen kann. Dadurch wird verhindert, dass unqualifizierte LehrerInnen zur Förderung eingesetzt werden und dass der Einsatz von LehrerInnen mit Migrationshintergrund dazu führt, dass die Verantwortung für den Schulerfolg von Migrantenkindern auf die Migranten (in diesem Fall die entsprechenden LehrerInnen) abgewälzt wird.

- Es sollte ein Modellversuch eingerichtet werden, in dem mehrsprachige Studierende ein spezielles Ausbildungsprogramm zusätzlich, aber begleitend zu der regulären Ausbildung erhalten.

Dieses Ausbildungsprogramm sollte obligatorische Kernbereiche enthalten wie berufsbezogene Kommunikation, Förderung der deutschen Sprache, Sprachvergleich zu der Muttersprache, Sensibilisierung für andere Herkunftssprachen (Vermeidung 
von zu enger Spezialisierung) sowie Sprachberatung von Eltern mit Migrationshintergrund.

- Die Lehramtstudierenden mit Migrationshintergrund können gleichzeitig zu LehrerInnen für den Muttersprachlichen Unterricht in ihrer jeweiligen Herkunftssprache ausgebildet werden. ${ }^{3}$ Dadurch kann die Verbindung zwischen dem Fach Deutsch, dem Fachunterricht, der Sprachförderung und dem Muttersprachenunterricht verwirklicht werden.

- Die spezielle Ausbildung sollte sich sich nicht nur auf LehrerInnen der Primarstufe und Sek I beschränken, sondern auch das Gymnasium und insbesondere das Berufskolleg und Förderschulen mit einschließen.

\section{Literatur}

Chlosta, Christoph; Ostermann, Torsten; Schroeder, Christoph (2003): Die „Durchschnittsschule“ und ihre Sprachen: Ergebnisse des Projekts Spracherhebung Essener Grundschulen (SPREEG). In: ELiSe: Essener Linguistische Skripte - elektronisch 3/1 (http://www.uni-due.de/imperia/md/content/elise/ausgabe_1_2003_spreeg. pdf, 12.12.2009), 43-139.

Didaktisches Grundlagenstudium. Universität Duisburg-Essen. www.uni-due.de/DGD (12.12.2009).

Fürstenau, Sara; Gogolin, Ingrid; Yagmur, Kutlay (Hrsg.)(2003): Mehrsprachigkeit in Hamburg. Ergebnisse einer Spracherhebung an den Grundschulen in Hamburg. Münster: Waxmann.

Ordung der Ersten Staatsprüfung für Lebrämter an Schulen in NRW (2003). Ministerium für Schule und Weiterbildung des Landes Nordrhein-Westfalen. www.schulministerium. nrw.de/BP/Schulrecht/Lehrerausbildung/LPO03.pdf (12.12.2009).

Projektgruppe SPREEG (2001): Was Kinder sprechen! Überlegungen zu einer Sprachenerhebung an Essener Grundschulen. In: ELiSe: Essener Linguistische Skripte elektronisch 1/2 (www.uni-due.de/EliSe, H.1, 12.12.2009), 75-89.

Verordnung zum Erwerb einer Zusatzqualifikation Deutsch als Zweitsprache/Interkulturelle Pädagogik (2000). Universität Duisburg-Essen. http://www.uni-due.de/imperia/md/ content/daz-daf/zip-ordnung.pdf (12.12.2009).

Dazu bedarf es eines speziellen Ausbildungsprogramms, das nicht mit einem philologischen Fachstudium identisch ist. Aus Platzgründen kann eine solche Konzeption (die im Übrigen auch nirgendwo angeboten wird) hier nicht weiter ausgeführt werden. Die Qualifikation sollte durch die zusätzliche Ausbildungsangebote für die Studierenden mit Migrantionshintergrund erreicht werden. Teilweise sind die Inhalte mit einer DaZ-Ausbildung identisch; zusätzlich müssen jedoch das sprachpraktische Niveau in der Herkunftssprache und fremdsprachenmethodische Fertigkeiten sowie sprach- und kulturkontrastive Kenntnisse vermittelt werden. 
Christoph Chlosta, Matthias Jung (Hrsg.) (2010): DaF intergriert: Literatur - Medien - Ausbildung. Tagungsband der 36. Jahrestagung des Fachverbandes Deutsch als Fremdsprache 2008. Göttingen: Universitätsverlag, 251-269.

Bettina Seipp (Dortmund)

\section{Sprachförderkompetenz Deutsch als Zweitsprache im Unterricht aller Fächer. Übertragung des Projekts „Förderunterricht für Kinder und Jugendliche mit Migrationshintergrund“" der Stiftung Mercator in die neue Lehrerbildung in Nordrhein-Westfalen}

\section{Das Projekt Förderunterricht am Standort Dortmund}

\subsection{Entstehung und Projektverbund}

Das „Dortmunder Förderprojekt Sprachliche Kompetenz für Schüler/innen mit Migrationshintergrund“ ist ein Transfer des seit über 30 Jahren bestehenden Essener Fördermodells „Förderunterricht für Kinder und Jugendliche ausländischer Herkunft an der Universität Essen“. Dieses hatte seinen Ursprung, als griechische, jugoslawische und türkische Schüler/innen im Rahmen verschiedener DFG-Projekte zur Untersuchung von Zweisprachigkeit sprachliche und fachliche Förderung durch Studierende der Universität Essen erhielten. Nach Projektabschluss ging von diesen Schüler/inne/n die Initiative aus, bei der Universität fortdauernde Förderung einzufordern (Benholz; Iordanidou; Thomas 2005). Der große Erfolg dieses Förderunterrichts war Anlass, das Projekt ab dem Schuljahr 1999/2000 auf weitere Städte Nordrhein-Westfalens zu übertragen; im Schuljahr 2004 initiierte die Essener Stiftung Mercator die bundesweite Ausweitung des Projekts „Förderunterricht“. 
Dortmund ist einer von inzwischen 35 Standorten des Projekts der Stiftung Mercator, die dafür insgesamt 10 Millionen Euro zur Verfügung stellt. Insgesamt werden ca. 6.500 Schüler/innen durch ca. 1.200 Studierende in 14 Bundesländern gefördert. ${ }^{1}$ In den beiden Schuljahren 2005/2006 und 2006/2007 bestand weiterhin eine Kooperation mit dem Projekt FörMig (Förderung von Kindern und Jugendlichen mit Migrationshintergrund) der ehemaligen Bund-Länder-Kommission (BLK), für welches das Dortmunder Projekt einen Förderbaustein darstellte. ${ }^{2}$

Das Dortmunder Förderprojekt „Sprachliche Kompetenz“ ist im Sommer 2003 in einem Verbund verschiedener Dortmunder Institutionen gegründet worden. Die Partner im Projektverbund sind:

- die Pädagogischen Dienste/Regionale Arbeitsstelle zur Förderung von Kindern und Jugendlichen (RAA) der Stadt Dortmund

- zunächst das Sprachenzentrum der Technischen Universität Dortmund, abgelöst durch den Verein DOsS e.V. (Dortmund steht zur Sprache)

- das Zentrum für Lehrerbildung der Technischen Universität Dortmund

- das Institut für Deutsche Sprache und Literatur der Technischen Universität Dortmund

- die am Projekt beteiligten Schulen der Stadt Dortmund

- das Schulverwaltungsamt der Stadt Dortmund

- das Schulamt der Stadt Dortmund

Das Projekt folgt einer zweifachen Ausrichtung:

a) Zusätzlich zum Regelunterricht erhalten die Förderschüler/inne/n spracblichen und fachlichen Förderunterricht, der die beiden Merkmale Deutsch als Zweitsprache und ergänzenden schulbegleitenden Unterricht in den Unterrichtsfächern in sich kombiniert, also Deutsch als Zweitsprache im Unterricht aller Fächer. Diese zweifache Ausrichtung sollte in jeder Unterrichtsstunde gekoppelt sein. Der Förderunterricht ist also kein reiner Deutschunterricht, kein reiner Nachhilfe-Unterricht und keine reine Hausaufgabenbetreuung. Mit dem so konzipierten Förderunterricht verbinden sich die vier Ziele:

- kurzfristig die Verbesserung der Fachnote(n), um die Versetzung und/oder den Übergang in weiterführende Schulen zu erreichen

- mittel- und langfristig die Verbesserung des Lese- und Sprachverständnisses im Deutschen, so dass sprachbedingte fachliche Rückstände auf Dauer ausgeglichen werden können,

- langfristig der Verbleib der geförderten Schüler im Bildungssystem und die Erlangung der Allgemeinen Hochschulreife,

- kurz-, mittel- und langfristig die Erhöhung des Interesses an schulischen Inhalten sowie die Verbesserung bzw. Stabilisierung des erfolgsorientierten schulischen Selbstkonzepts.

www.mercator-foerderunterricht.de

2 www.blk-foermig.uni-hamburg.de 
b) Der Förderunterricht wird von Lehramtsstudierenden der Technischen Universität Dortmund durchgeführt. Sie betreuen Lerngruppen von drei bis sechs Schüler/ inne/ $\mathrm{n}$ und werden an der Hochschule ausgebildet. Der Förderunterricht findet in eigener Verantwortung der Förderlehrer/innen statt und wird mit $€ 10$,- pro Zeitstunde vergütet.

Da zunächst die Fachnoten verbessert werden sollen, basiert der eigenständige Unterricht seitens der Förderlehrer/innen inhaltlich idealerweise auf Absprachen mit den Klassen- und/oder Fachlehrer/inne/n. Maßgebend sind also die inhaltlichen Vorgaben der klassenspezifischen Stoffverteilungspläne bzw. der Bildungsstandards.

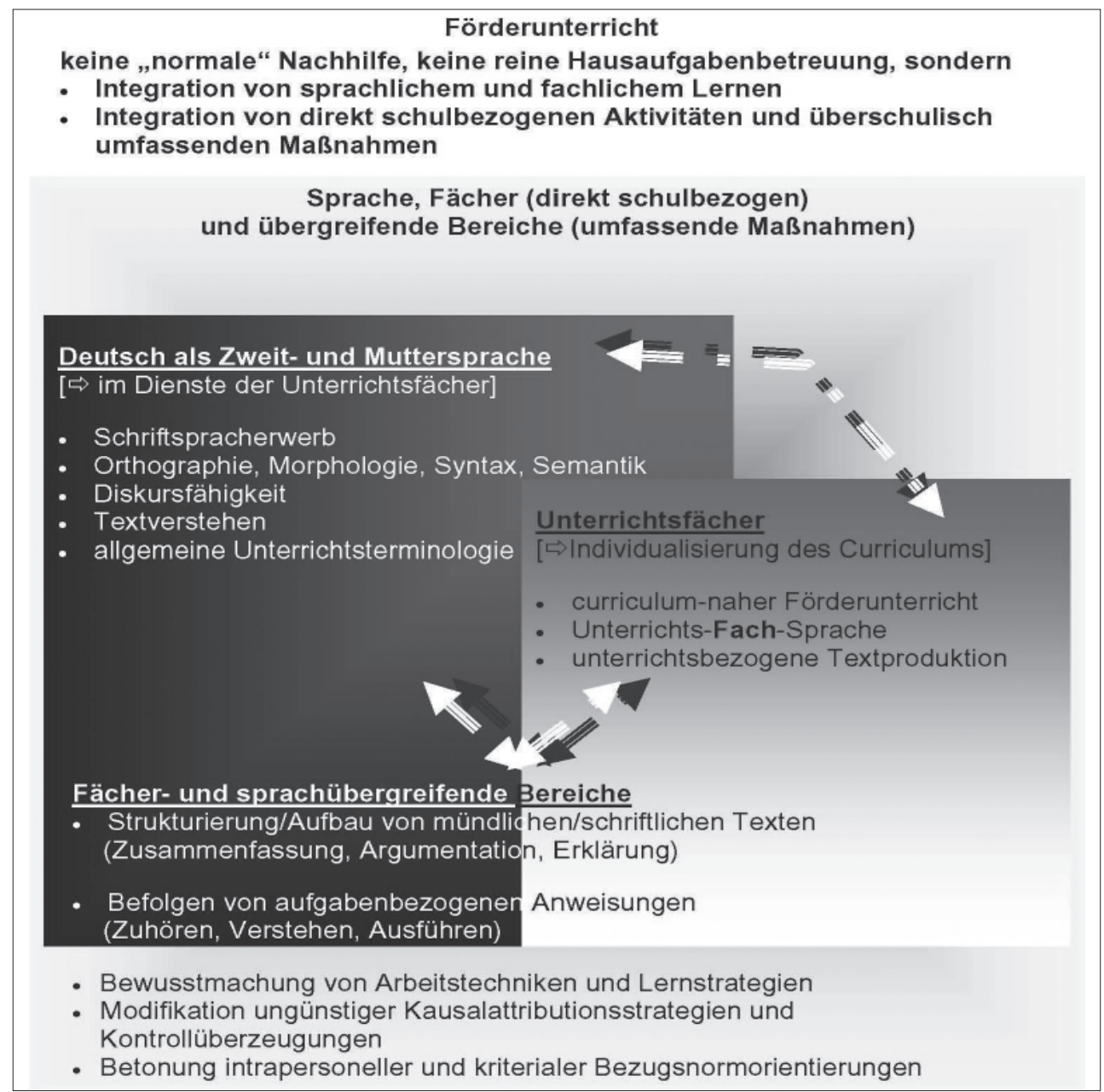

Abb. 1: Konzept des Förderunterrichts am Standort Dortmund 
Im Gegensatz zum regulären Unterricht handelt es sich hier um einen ,individualisierten Kleingruppen-Unterricht“, bei dem die Förderung der einzelnen Schüler/innen im Mittelpunkt steht. Die Förderlehrer/innen sollen dazu befähigt werden, den Förderbedarf sowohl hinsichtlich der sprachlichen Fertigkeiten im Deutschen als auch hinsichtlich der fachlichen Kompetenzen bei jedem Förderschüler individuell einzuschätzen, um angemessene Maßnahmen für den Förderunterricht planen zu können.

Der Unterricht wird an den beteiligten Schulen entweder schulbegleitend oder aber im Rahmen des Nachmittagsangebots der Schule durchgeführt. Dennoch findet der Förderunterricht in unabhängigen Organisationseinheiten zusätzlich zum und unabhängig vom regulären Unterricht in den Klassen und im Fach statt. Dadurch soll der Unterricht für die Förderschüler/innen unabhängig von der Beobachtung und Sanktionierung durch die Klassen- bzw. Fachlehrer/innen sein. Der neue Verbund soll zudem das Wir-Gefühl der geförderten Schüler/innen, eine schützende Zusammengehörigkeit und das Gefühl bewirken, gezielt Unterstützung bzw. Hilfe zu erhalten.

Die Teilnahme einzelner Schüler/innen am Förderunterricht ist prinzipiell freiwillig. Hat sich ein/e Schüler/in zur Teilnahme entschlossen, so muss er/sie jedoch regelmäBig teilnehmen, da die Maßnahme nur dann erfolgreich sein kann. Der Förderunterricht ist für die Schüler/innen kostenlos.

\subsection{Projektausbau}

Am Standort Dortmund startete das Projekt im Jahr 2004 mit Förderunterricht in den Klassen 3 und 4 der Grundschule und 5 und 6 an Schulen aller Schulformen. Im Jahresdurchschnitt sind 60 studentische Förderlehrer/innen in 60 Fördergruppen an 17 Schulen tätig und erteilen Förderunterricht Deutsch als Zweitsprache in den Fächern Biologie, Deutsch, Englisch, Erdkunde, Gesellschaftslehre, Mathematik und Naturwissenschaften. Im Jahr 2006 kam ein zweites Projekt in den Klassen 7 bis 10 an 12 Schulen der Sekundarstufe I hinzu, in dem das Förderfach auf Mathematik und Physik begrenzt ist. Ein Schwerpunkt der Förderung liegt hier zudem auf dem Gebiet der Berufswahlorientierung, die implizit über die Auswahl zu besprechender Aufgaben erfolgt. Hier sind im Jahresschnitt 55 Gruppen aktiv. Seit Frühjahr 2007 wurde die Förderung um ein drittes Projekt in den Klassen 11 bis 13 an acht Schulen der Sekundarstufe II erweitert. Hier findet Förderunterricht in den Fächern Biologie, Deutsch, Elektrotechnik, Englisch, Geschichte, Mathematik und Physik in durchschnittlich 28 Gruppen statt. In diesen Jahren wurden insgesamt ca. 2.780 Schüler/innen mit Migrationshintergrund gefördert und knapp 500 Lehramtsstudierende zu Studentischen Förderlehrer/inne/n ausgebildet ${ }^{3}$.

\footnotetext{
3 Die Projekte werden ermöglicht durch die großzügige finanzielle Unterstützung seitens der Stiftung Mercator GmbH mit $€ 450.000$, der Stadt Dortmund mit $€ 225.000$, dem Bundesministerium für Bildung und Forschung mit $€ 60.000$, der Dortmund-Stiftung mit $€ 10.000$, SpenDObel mit $€ 10.000$ sowie privater Spender mit $€ 3.500$.
} 


\subsection{Theorie und Praxis in der Ausbildung der Studentischen Förderlehrer/innen}

Lehramtsstudierende beklagen in Befragungen seit Jahrzehnten eine mangelnde Praxisnähe und -orientierung ihres Studiums. Mehr als in jeder Form von Schulpraktikum werden in diesem Projekt Theorie und Praxis in der Ausbildung von Lehramtsstudierenden miteinander verzahnt und rückgekoppelt. Lehramtsstudierende, deren Studienprofil (Schulform, Unterrichtsfächer, mindestens zweites Semester) zum Profil freier Stellen passt, werden jeweils im Sommersemester eines Jahres in einem obligatorischen Vorbereitungsseminar der Universität auf ihre Tätigkeit als Studentische Förderlehrer/innen vorbereitet. Das stark theoretisch geprägte Seminar konzentriert sich auf Kenntnisse und Fertigkeiten auf dem Gebiet Deutsch als Zweitsprache. Dabei werden die grundlegenden Unterschiede und Gemeinsamkeiten zwischen Deutsch als Fremdsprache, Deutsch als Zweitsprache und Deutsch als Muttersprache sowie Formen, Bedeutung und Nutzbarmachung von Multikulturalität und Mehrsprachigkeit in der Schule besprochen. Zudem werden Ergebnisse der large scale studies PISA und IGLU behandelt, die die Problematik des kumulativen negativen Effekts mangelnder deutschsprachlicher Fertigkeiten auf die Leistung in Sachfächern empirisch greifbar machen. Neben Modellen zwei(t)sprachiger Erziehung werden zentrale Theorien, z.B. zum Zweitspracherwerb und zu kognitiven Auswirkungen von bestimmten Niveaus von Zweisprachigkeit vorgestellt. In einem zweiten großen, stärker praktisch orientierten Block werden exemplarisch und ansatzweise Sprachvergleiche Deutsch - Türkisch - Russisch in ihrer Bedeutung und Funktion für die Erkennung, Erklärung und Behebung von „Fehlern“ durchgeführt, grundlegende Grammatikkenntnisse für DaZ-Förderlehrer/innen identifiziert und vermittelt, Grammatik- und Sprachspiele für den DaZ-Förderunterricht vorgestellt, selbst erstellt und durchgespielt sowie didaktische und methodische Prinzipien für den DaZ-Unterricht vermittelt. Den inhaltlichen Abschluss des Vorbereitungsseminars bilden eine Vorstellung von Instrumenten der Sprachstandsdiagnose allgemein, eine Einführung in die Fehleranalyse speziell, Übungen zum Umgang mit Fehlern bzw. der Fehlerkorrektur sowie die exemplarische Vorbereitung der ersten Förderstunden.

Während der vorlesungsfreien Zeit beginnt der eigenständige Förderunterricht mit dem neuen Schuljahr. Zu Beginn des Wintersemesters startet für die Förderlehrer/innen ein - ebenfalls obligatorisches - Begleitseminar an der Universität. Dieses ist im Vergleich zum Vorbereitungsseminar stärker auf die praktischen Belange des Förderunterrichts ausgerichtet. Auf der einen Seite werden jedoch auch hier die theoretischen DaZ-Kenntnisse erweitert, indem die wesentlichen Unterschiede zwischen Allgemein-, Unterrichts- und Fachsprache mit einem Schwerpunkt auf den lexikalischen, morphologischen und syntaktischen Besonderheiten von Fachsprache(n) und einer sprachlichen Analyse von Sach- und Fachtexten im Hinblick auf den Einsatz im Förderunterricht behandelt werden. In einem weiteren, stark praktisch angelegten Strang werden ein Methodenbaukasten für die Fach-/DaZ-Förderung in den Bereichen Lerntechniken, Leseverstehen, Wortschatzarbeit, Textproduktion und mündliche Kommunikation erarbeitet sowie eigenes Unterrichtsmaterial und Unterrichtseinheiten erstellt und die Beschäftigung mit Fehleranalyse an Schülertexten sowie mit Sprachstandsdiagnose-Instru- 
menten fortgesetzt. Den dritten Schwerpunkt dieses Seminars bildet die Reflexion der im eigenständigen Förderunterricht gemachten Erfahrungen, ihr Rückbezug auf die in den Projekt- und anderen fachwissenschaftlichen und fachdidaktischen Lehrveranstaltungen vermittelten Theoriekenntnisse, verbunden mit der Erarbeitung von Lösungsansätzen für Fragen, die der Förderunterricht aufwirft. Dieses Seminar wird flankiert von einem freiwilligen und sporadisch stattfindenden Methodik- und Didaktik-Seminar unter der Leitung der Projektmitarbeiter der RAA Dortmund. Dieses versucht vornehmlich, von DaZ und Fachunterricht unabhängige, im Pädagogischen angesiedelte Fragen aufzuarbeiten, die vor allem zu Beginn des Förderunterrichts den Studentischen Förderlehrer/inne/n besondere Probleme bereiten, speziell was Disziplin, Motivation und Aufmerksamkeitssteuerung betrifft.

Nach diesem Studien- und Schuljahr besteht für interessierte Förderlehrer/innen die Möglichkeit, den Förderunterricht in weiteren Schuljahren durchzuführen; diese Möglichkeit nehmen ca. 60\% der ausgebildeten Förderlehrer/innen wahr.

Um die beschriebene enge Theorie-Praxis-Verzahnung durch vertiefte Reflexion zu stärken, führen die Studentischen Förderlehrer/innen ein Portfolio (in dem u.a. die Seminare bewertet und das Zurechtkommen mit der Fördergruppe längsschnittlich eingeschätzt werden). Das Kernstück dieses Portfolios stellt ein Lerntagebuch dar, das den eigenen Kompetenzerwerb unter Rückbezug auf wissenschaftliche Theorien und eigene Praxiserfahrung in seiner Entwicklung beschreibt.

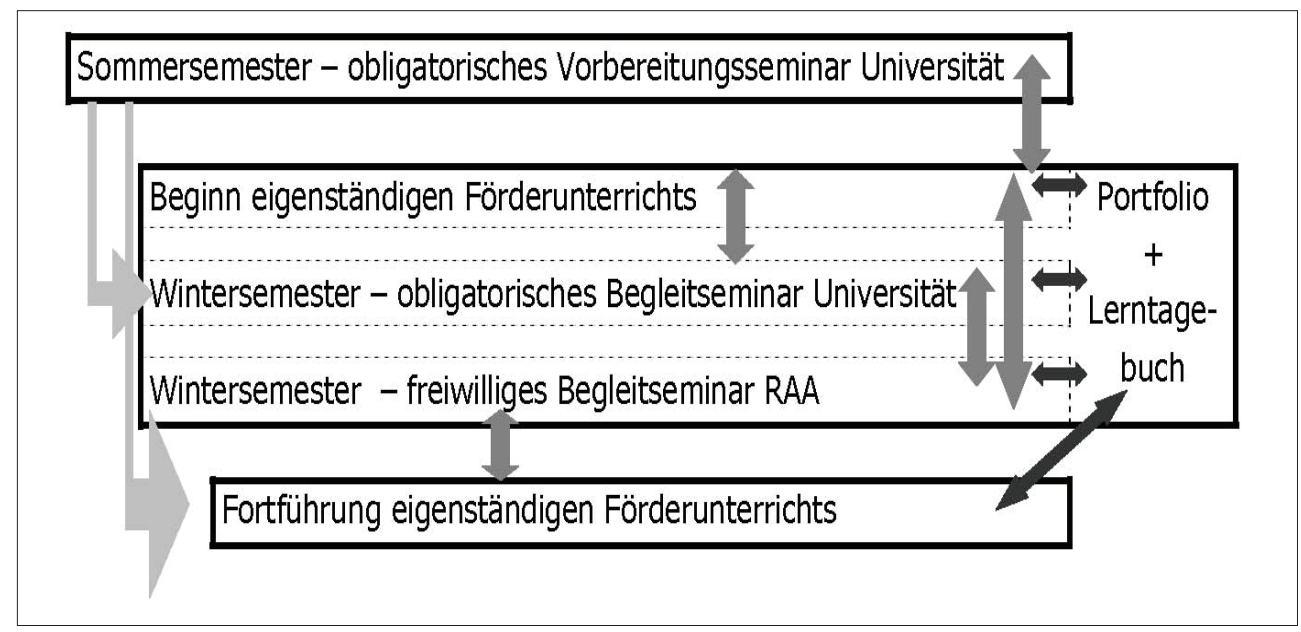

Abb. 2: Verzahnung von Theorie und Praxis in der Ausbildung zu und der Tätigkeit als Studentische/n Förderlehrer/inne/n

\subsection{Integration des Projekts Förderunterricht in das reguläre Lehramtsstudium}

Die in den Seminaren erbrachte Leistung (aktive Teilnahme, Führen des Lerntagebuchs) werden - je nach Schulform und gewählten Fächern - auf die nach den Studienordnungen in den Dortmunder Bachelor- und Master-Studiengängen zu erbringenden 
Leistungen angerechnet. Zudem können durch den Förderunterricht Teile verschiedener Dortmunder Praxisphasen abgeleistet werden. Derzeit stellen diese Anerkennungen die einzige Verknüpfung zwischen dem Projekt Förderunterricht und dem regulären Lehramtsstudium dar. Ab dem kommenden Schuljahr (2009/2010) ist eine engere Verknüpfung mit einem obligatorischen Studienelement des Bachelor vorgesehen. Dabei wird da sich das Projekt aus finanziellen Gründen nicht an alle Lehramtsstudierende richten kann - das schulische Orientierungspraktikum nicht mehr nur in seiner ursprünglichen Form als vierwöchiger Block angeboten, sondern zudem in einer Variante, in der sich das Praktikum über ein ganzes Schuljahr erstreckt. Der vollständig als dieses Praktikum angerechnete Förderunterricht findet zunächst bis zu den Herbstferien nur als zweistündige „Hospitations-Assistenz“ im Fachunterricht der Klasse statt, aus der die Förderschüler/innen stammen, und danach sowohl als Assistenz (zwei Stunden) als auch als eingeständiger Förderunterricht in Kleingruppen (zwei Stunden). Zudem werden für die Studierenden, die sich für diese Variante des Orientierungspraktikums bewerben und angenommen werden können, inhaltlich spezifizierte praktikumsbegleitende Seminare (die an sich für alle Praktikanten Pflicht sind) durchgeführt, die sich thematisch mit interkultureller Erziehung sowie mit Fragen der Disziplin und Motivation befassen und mit den Seminarleitern des Projekts abgestimmt werden.

Damit ist ein erster kleiner Schritt zur Integration des Projekts Förderunterricht in die reguläre Ausbildung der Lehramtsstudierenden getan, auf dem aufgebaut werden kann, wenn es darum geht, die Vorgabe des Gesetzes zur Reform der Lehrerausbildung umzusetzen. ${ }^{4}$ Darin wird festgelegt, dass für alle Lehramtsstudierenden, also unabhängig von der angestrebten Schulform und den gewählten Fächern, eine Ausbildung in Deutsch als Zweitsprache - hier allerdings bedauerlicherweise umbenannt in „Deutsch für Schüler und Schülerinnen mit Zuwanderungsgeschichte (DfZ)“ - obligatorisch ist.

Das Gesetz wurde im Mai 2009 verabschiedet, nachdem die Verbändeanhörung im September 2008 beendet und die Stellungnahmen der Hochschulen eingegangen waren. Die sich auf DaZ bzw. DfZ beziehenden Formulierungen lauten folgendermaßen: „Leistungen in Deutsch für Schülerinnen und Schüler mir Zuwanderungsgeschichte sind für alle Lehrämter zu erbringen“ (GzRL 2009: Art. 1, Abs. III, \ 11 (7), S. 6) bzw. „3. Grundkompetenzen in der Förderung von Schülerinnen und Schülern in Deutsch für Schülerinnen und Schüler mit Zuwanderungsgeschichte im Zusammenhang interkultureller Bildung“ (LZV 2009: \10, S. 7). In allen Lehrämtern soll diese Ausbildung

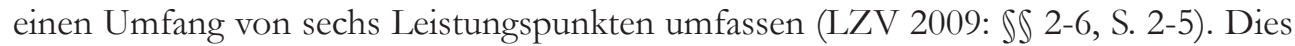
entspricht nach der Rechnung 1 LP = 30 Zeitstunden einem Umfang von 180 Stunden für Anwesenheit, eigenständiges Lernen und Prüfung. Diese Anteile standen bis zum Abschluss der Anhörungsphase in einem Bereich, der, was die Aufteilung der Leistungspunkte anbelangt, zur Erziehungswissenschaft gezählt wird. Eine solche Zuordnung zur Erziehungswissenschaft erschien jedoch allen Mitliedern in den verschiedensten Arbeitsgruppen zu diesem Thema als unsinnig: Vielmehr musste Deutsch als Zweitsprache entweder als eingeständiger Bereich definiert oder eindeutig der Germa-

4 Siehe www.zfl.tu-dortmund.de - Menüpunkt Lehramtsstudium TU-Dortmund. 
nistik und den Fachdidaktiken zugeordnet werden. Die zu vermittelnden Kompetenzen in Deutsch als Zweitsprache oder Deutsch für Schüler/innen mit Zuwanderungsgeschichte können sich inhaltlich-logisch nur auf Germanistik und auf die Übertragung sprach-didaktischer Elemente auf die besonderen Anforderungen im Sachfach-Unterricht beziehen. Diesen Eingaben wurde bis zur Verabschiedung des Gesetzes Rechnung getragen; DaZ stellt jetzt einen eigenen Bereich dar. Damit ist die Möglichkeit gegeben, die inhaltliche und organisatorische Verantwortung für den Bereich anders zu verorten; beispielsweise derart, dass Deutsch als Zweitsprache der Sprachwissenschaft/Sprachdidaktik Deutsch und, um die Verbindung zwischen DaZ und Fachunterricht herzustellen, auch den Fachdidaktiken der andren beteiligten Fächer zuzuordnen.

Im neu gestalteten Lehramt Grundschule, in dem Lernbereiche, davon mathematische und sprachliche Grundbildung als Pflicht-Lernbereiche, vorgeschrieben sind, kann , an Stelle eines dritten Lernbereichs oder eines Unterrichtsfachs (...) auch das vertiefte Studium von Deutsch für Schülerinnen und Schüler mit Zuwanderungsgeschichte treten, in dessen Rahmen bis zur Hälfte des Studienumfangs auch eine Vorbereitung auf herkunftssprachlichen Unterricht erfolgen kann.“ (LZV 2009: \2, S. 2). Hier beträgt der Umfang mindestens 55 Leistungspunkte.

\section{Kompetenzerwerb bei Studentischen Förderlehrer/innen}

Bei den Diskussionen darüber, wie die nicht großzügig bemessenen sechs Leistungspunkte ausgestaltet werden können, und für die Beantwortung der Frage, ob die ge-

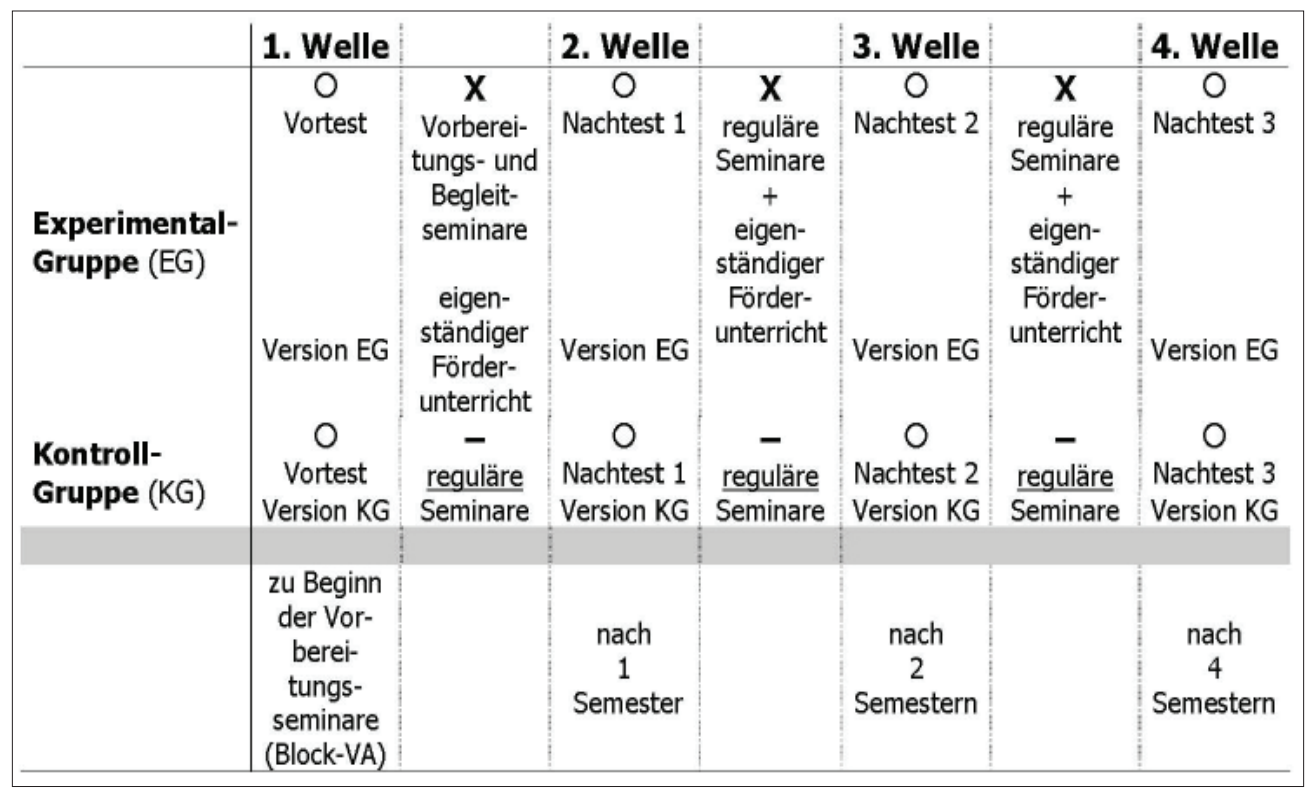

Abb. 3: Design der Evaluationsstudie im Projekt Förderunterricht am Standort Dortmund 
fundene inhaltliche Lösung hinreichend sein kann, werden für den Standort Dortmund auch Ergebnisse der Evaluation bei den Studentischen Förderlehrer/inne/n herangezogen (Seipp 2007).Die Evaluation erfolgte in den ersten beiden Projektjahren (2004/2005 und 2005/2006) als FragebogenLängsschnittstudie in Experimental- (Förderlehrer/innen) und Kontrollgruppen (Lehramtsstudierende, die nicht am Projekt beteiligt waren und entweder ein Seminar zu Migrantenliteratur oder ein Seminar der Erziehungswissenschaft besuchten).

Die Entwicklung der beiden Gruppen wurde über vier Messzeitpunkte hinweg verglichen, um die Hypothese zu testen, dass sich die selbst eingeschätzten Kompetenzen der Förderlehrer/innen in den Bereichen Deutsch als Zweit- und Muttersprache, Umgang mit kultureller Heterogenität, Aufmerksamkeitssteuerung und Disziplin deutlicher erhöhen als bei den Studierenden der Kontrollgruppe. Ebenso wurde erwartet, dass sich die subjektiv eingeschätzte Eignung für den Lehrerberuf und die berufliche Selbstwirksamkeit der Förderlehrer/innen gegenüber der Gruppe der Kontrollstudierenden positiver entwickeln und die vorweggenommene Bedrohung durch Berufsaspekte entsprechend stärker vermindert wird. Über alle vier Zeitpunkte hinweg nahmen in der Experimentalgruppe 35 und in der Kontrollgruppe 33 Personen teil.

\subsection{Zentrale Ergebnisse der Evaluationsstudie}

\subsubsection{Wissen in Deutsch als Zweitsprache}

Skaleninformation

Items: $\quad 27$

Quelle: $\quad$ Martin*, Winters-Ohle*

Beispiel: Wofür steht das Akronym CALP? [communicative alternative linguistic progress; common alphabetical language programme; cognitive academic linguistic proficiency; bin mir noch nicht sicher]

Skalierung: keine [Auswertung: Bewertung tatsächlich gewählter Antwort + Dichotomisierung in richtig/falsch]

* Von Projektmitgliedern entwickelt und daher ohne Literaturangabe.

Zwischen den ersten beiden Messzeitpunkten findet bei den Förderlehrer/inne/n eine deutliche Verschiebung von noch nicht vorhandenem Wissen zur richtigen Antwort und ein deutlicher Anstieg in der Anzahl richtiger Lösungen in der Gesamtskala statt. Danach bleibt das erlangte Wissen stabil über den gesamten Zeitraum von zwei Jahren. Die Antworten der Kontrollgruppe verändern sich über die zwei Messzeitpunkte unsystematisch, die Anzahl richtiger Lösungen steigt wesentlich geringer an. Auch die Überprüfung dessen, was über das Wiedererkennen richtiger Antworten hinaus gelernt wurde (offene Antworten), zeigt denselben Erfolg für die Experimentalgruppe sowohl in den Einzelaufgaben als auch in der Gesamtskala. ${ }^{5}$

\footnotetext{
Bei der Kontrollgruppe wurde diese Skala nicht eingesetzt.
} 


\subsubsection{Eignung für die Schule und den Lehrerberuf sowie Unterstützung der vorhandenen Eignung durch das Studium}

Skaleninformation

- Eignung Schule - ich glaube, dass ich...

- Eignung persönliche Eigenschaften - ich glaube, dass ich...

- Förderung Schule - inwieweit glauben Sie, hilft Ihnen das Lehramtsstudium, diese Fähigkeiten (weiter) zu entwickeln?

- Förderung persönliche Eigenschaften - s.o.

Items: $\quad$ Eignung und Förderung je $9+8$

Quelle: $\quad$ Seipp*

Beispiel: $\quad$...Verhaltensauffälligkeiten erkennen kann.

Skalierung: $\quad 1=$ stimmt gar nicht/in sehr geringem Maße; $4=$ stimmt genau/in sehr hohem Maße

* Von Projektmitgliedern entwickelt und daher ohne Literaturangabe.

Die Einschätzung der eigenen Eignung für die Schule und den Lehrerberuf steigt in der Gruppe der Förderlehrer/innen an, wobei die 35 Personen dieser Gruppe innerhalb jedes Messzeitpunktes sehr homogene Urteile abgeben. Die Studierenden der Kontrollgruppe bleiben bei ihrer anfänglichen Einschätzung, so dass die Gruppen sich am Ende der zwei Jahre deutlich zugunsten der Förderlehrer/innen voneinander unterscheiden.

Die Bewertung der Unterstützung der vorhandenen Eignung durch das Studium ist bereits zu Projektbeginn bei den Förderlehrer/inne/n etwas höher und bleibt auf diesem Niveau, während die Erwartung der anderen Studierenden absinkt. Daher unterscheiden die beiden Gruppen sich auch in dieser Variablen am Ende der zwei Jahre zugunsten der Förderlehrer/innen.

\subsubsection{Kenntnis und angenommene Verwertbarkeit theoretischen Wissens zur Zweitsprachendidaktik}

Skaleninformation

Items: $\quad 3$

Quelle: $\quad$ Seipp*

Beispiel: $\quad$ Ich kenne die Ergebnisse von Forschungsarbeiten auf dem Gebiet der Zweitsprachendidaktik.

Skalierung: $\quad 1$ = stimmt gar nicht; $4=$ stimmt genau

* Von Projektmitgliedern entwickelt und daher ohne Literaturangabe.

Die subjektiv eingeschätzte Kenntnis und die angenommene Verwertbarkeit, die zu Projektbeginn in beiden Gruppen eher niedrig ausgeprägt sind, steigen bei den Förderlehrer/inne/n mit der Zeit auf ein hohes $\mathrm{Ma}$ an, während sie in der Kontrollgruppe unverändert bleiben bzw. sogar absinken (angenommene Verwertbarkeit). Somit zeigen die Studierenden, die am Projekt teilgenommen haben, auch hier einen hohen Gewinn gegenüber ihren Kommiliton/inn/en der Kontrollgruppe. 


\subsubsection{Kompetenzen}

Skaleninformation

Items: $\quad 34$

Quelle: $\quad$ Achilles*; Oser (1997a, 1997b), Seipp*

Beispiel: $\quad$ Ich habe gelernt, ... was unter Binnendifferenzierung zu verstehen ist.

Skalierung: $\quad 1$ = stimmt gar nicht; $4=$ stimmt genau

* Von Projektmitgliedern entwickelt und daher ohne Literaturangabe.

Der Vergleich der mittels ausgewählter Standards konkretisierten Kompetenzen (Vertrautheit mit diesen Standards) über die Zeit zeigt, dass alle befragten Studierenden subjektive Kompetenzzuwächse zu verzeichnen haben. Er zeigt auch, dass es je nach inhaltlich definierter Standardgruppe unterschiedliche Zuwächse gibt: Im Bereich allgemeiner Unterrichtsaufgaben steigt die subjektive Vertrautheit mit den Standards zunächst in beiden Gruppen etwas an. Während sich die Kontrollgruppe dann aber auf einem immer noch niedrigen Niveau stabilisiert, steigt die Vertrautheit bei den Förderlehrer/inne/n deutlich weiter an. Die Vertrautheit mit Standards zur (Inter)Kulturalität steigt in beiden Gruppen vergleichbar deutlich an. Sie startet allerdings bei einer praktisch nicht vorhandenen Kenntnis und bleibt daher insgesamt auf einem auch nur mittleren Niveau.

Von den Anforderungen, die der Umgang mit gemischt muttersprachlichen Klassen mit sich bringt, war zu Projektbeginn praktisch nichts gelernt. Die Studierenden der Kontrollgruppe haben hier nur einen eher kleinen Zugewinn, die Förderlehrer/innen dagegen können ihre Vertrautheit mit den Standards sehr stark steigern.

\subsubsection{Kompetenzerwerb in den Bereichen Heterogenität, Aufmerksamkeit, Disziplin und Deutsch im Unterricht aller Fächer}

Skaleninformation

Kompetenzen im Bereich „Heterogenität“

Items: $\quad 17$

Quelle: $\quad$ Seipp*

Beispiel: $\quad$ Ich habe mir Methoden zum Umgang mit Heterogenität praktisch angeeignet.

Skalierung: $\quad 1$ = stimmt gar nicht; 4 = stimmt genau

Kompetenzen im Bereich "Aufmerksamkeit/Konzentration"

Items: $\quad 14$

Quelle: Seipp*

Beispiel: $\quad$...indem ich Theorien dazu für ein spezielles Problem/eine spezielle Situation abwandle.

Skalierung: $\quad 1=$ nie; $5=$ immer

Kompetenzen im Bereich „Dišiplin“,

Items: $\quad 20$

Quelle: $\quad$ Seipp* 
Beispiel: $\quad$ Ich kenne Methoden zur Wahrung von Disziplin.

Skalierung: $\quad 1$ = stimmt gar nicht; 4 = stimmt genau

Kompetenzen im Bereich „DaZ im Unterricht aller Fächer",

Items: $\quad 15$

Quelle: $\quad$ Seipp*

Beispiel: $\quad$ Ich habe die Grenzen der Anwendbarkeit von Theorien zur Förderung von Schülern in DaZ im Fachunterricht in der Praxis erkannt.

Skalierung: $\quad 1=$ stimmt gar nicht; $4=$ stimmt genau

* Von Projektmitgliedern entwickelt und daher ohne Literaturangabe.

Der Kompetenzerwerb wurde in der Experimentalgruppe ab dem zweiten Messzeitpunkt dreimal und in der Kontrollgruppe zweimal erhoben. Hierbei kommt zum Ausdruck, dass eher Methoden als Theorien und erstere eher praktisch als theoretisch angeeignet werden. Bei Konfrontation mit den vier genannten Anforderungsgebieten im Unterricht wird in allen Fällen vor allem intuitiv gehandelt. Die Förderlehrer/innen allerdings weichen im Laufe des Förderunterrichts etwas mehr von dieser intuitiven Lösung ab und ziehen vermehrt Theorien oder theoriegeleitete Methoden heran. Dieser Effekt zeigt sich erst nach einem Jahr Förderunterricht und ist auf dem Gebiet Deutsch als Zweitsprache im Unterricht aller Fächer besonders deutlich. Deutsch als Zweitsprache ist auch das einzige Gebiet, auf dem Förderlehrer/innen - nach einer Weile - stärker auf Theorien zurückgreifen als Studierende der Kontrollgruppe glauben, dies in ihrem späteren Unterricht zu tun. Auf den anderen Gebieten ziehen die Förderlehrer/innen in der Praxis tatsächlich weniger theoretisch Gelerntes heran als Studierende der Kontrollgruppe glauben, dies später zu tun. Erklären lässt sich das eventuell damit, dass die Förderlehrer/innen in DaZ nicht nur deutlich höhere subjektive Kompetenzen aufweisen als ihre Kommiliton/inn/en, sondern auch höhere als in den drei anderen Gebieten (Heterogenität, Aufmerksamkeit, Disziplin). Nur wenn man auf sicheres Wissen schnell zurückgreifen kann, kann es in Situationen, in denen wenig Zeit zum Überlegen ist, auch handlungswirksam werden.

\section{Mögliche Ausgestaltung der Grundkompetenzen in Deutsch als Zweitsprache}

Diese hier nur sehr knapp zusammengefassten Ergebnisse, die anhand der zweiten Projekt-Kohorte repliziert wurden, zeigen, dass das Ausbildungskonzept, das auf die Studentischen Förderlehrer/innen angewandt wird und das - was das Vorbereitungsseminar betrifft - dem Curriculum der Einführung/Grundlagen in DaZ des Instituts für deutsche Sprache und Literatur der TU Dortmund entspricht, Kompetenzen auf einem Niveau ausbildet, das es ermöglicht, sie im (Förder-)Unterricht nach einer gewissen Routinierungsphase anwendbar werden zu lassen. Auf der Grundlage dieser Erkenntnisse und der Überlegungen der Mitglieder diverser Arbeitsgruppen (s.u.) können Vorschläge für die Ausgestaltung eines (oder mehrerer) DaZ-Moduls gemacht werden. 


\subsection{Modul Deutsch als Zweitsprache}

\subsubsection{Vorüberlegungen}

Mit der Erarbeitung von Möglichkeiten, wie die o.g. ministeriellen Vorgaben sowohl organisatorisch als vor allem auch inhaltlich umgesetzt werden können, sind verschiedene Arbeits- und Expertengruppen befasst. Eine solche ist die Arbeitsgruppe DaZ-Modul bei der Stiftung Mercator GmbH, in der Mitglieder der Förderunterricht-Projektkonsortien, der Institute für Deutsch und der Zentren für Lehrerbildung der Universität zu Köln, der Universität Duisburg-Essen und der Technischen Universität Dortmund sowie ein für die Lehrerbildung Verantwortlicher des Ministeriums für Schule und Weiterbildung vertreten sind. Daneben arbeiten universitätsinterne Arbeitsgruppen, um die Anpassung der dort erarbeiteten Rahmenvorgaben für ein solches Modul/für solche Module an die Strukturen und Möglichkeiten der einzelnen Hochschulen zu gewährleisten und sie standortspezifisch auszugestalten.

An der TU Dortmund beispielsweise wird bei der Ausgestaltung und Implementation eines DaZ-Moduls angestrebt, den notwendigen Bezug zwischen Deutsch als Zweitsprache und dem Unterricht im Sachfach aufzugreifen, um schon in der Ausbildung künftiger Lehrer/innen der Vorstellung vorzugreifen, Sprachförderung für Schüler/ innen mit Zuwanderungsgeschichte sei die ausschließliche Aufgabe der Deutschlehrer/ innen - eine Vorstellung, die heute sowohl in der Hochschule als auch in der Schule selbst immer noch weit verbreitet ist. Der Umstand, dass die Sachfächer in deutscher Sprache unterrichtet werden, erscheint vielen Kolleg/inn/en bereits als hinreichend. Demgegenüber muss es aber darum gehen, den Unterricht und die Lehrerausbildung allgemein deutlich sprachorientierter zu gestalten (vgl. 2009: 11-12). Daher macht es sich die Arbeitsgruppe zum Ziel, drei Maßnahmen umzusetzen:

a) den Fachdidaktiken die Aufgabe der Vermittlung von DaZ im Dienste ihres Faches als notwendig und machbar dazustellen

b) Fachdidaktiker/innen in die Lage zu versetzen, derartige Lehrveranstaltungen durchzuführen

c) Veranstaltungsformen zu entwickeln, um allen Studierenden entsprechende Kompetenzen vermitteln zu können. Dabei sollen die notwendigen DaZ-Grundlagen durch das Fach Deutsch und die Anwendung von DaZ-Prinzipien im Sachfach durch die Fachdidaktiken vermittelt werden.

Mit allen drei dieser Maßnahmen sind hohe Herausforderungen verschiedenster Art verbunden. Maßnahme a erfordert ein hohes $\mathrm{Maß}$ an Überzeugungsgeschick; die Kolleg/inn/en der Fachdidaktiken müssen davon überzeugt werden, diesen sprachlichen Aspekt der Vermittlung als eine immanente Aufgabe - auch Forschungsaufgabe - ihrer Fachdidaktik zu begreifen, zu akzeptieren und sich für sie verantwortlich zu fühlen, statt sie an Andere abzugeben. Es ist davon auszugehen, dass diese Argumente zunächst auf Ablehnung stoßen werden, zumal damit absolutes Neuland betreten wird, was als Überforderung aufgefasst werden kann. Daher ist es besonders wichtig, den Kolleg/inn/en zu verdeutlichen, dass es für sie nicht darum geht, zusätzlich auch noch 
Experte/Expertin auf dem Gebiet der deutschen Sprachwissenschaft zu werden. Vielmehr geht es darum, sich z.B. Methoden zu Eigen machen zu müssen, die helfen, die besonderen Charakteristika von Sach- und Fachtexten und die darin gerade für Schüler/ innen mit Zuwanderungsgeschichte verborgenen Hürden zunächst zu erkennen, um dann fachspezifisch verbale und non-verbale Mittel zu (er)finden, um Texte und Aufgaben verständlich zu machen, ohne dabei das notwendige Sprachniveau „einfach“ durch alltagssprachliche Formen zu ersetzen, und die fachliche Sprache so zu verfestigen, dass alle Schüler/innen sie auch aktiv auf angemessenem Niveau zur Anwendung bringen können.

Die mit Maßnahme b verbundene Herausforderung besteht in der Schulung der Kolleg/inn/en, die diese Veranstaltungen konzipieren, leiten und Leistungen prüfen sollen. Gedacht ist in einem ersten Schritt daran, Sitzungen in einer Form von assistierendem Team-Teaching durchzuführen, indem einem Fachdidaktiker ein Kollege mit DaZ-Expertise zur Seite gestellt wird. Dieses Verfahren ist allerdings kostspielig, zeitaufwändig und vor allem personalintensiv und setzt die Bereitschaft voraus, sich beobachten zu lassen. Eine Möglichkeit wird darin gesehen, erfahrene Studentische Förderlehrer/innen, die bereits DaZ mit dem zur Debatte stehenden Fach gefördert haben, dafür heranzuziehen und ihnen diese Tätigkeit als Praktikum anzurechnen oder ihnen ein Zertifikat zu verleihen.

Mit der letzten Maßnahme verbindet sich vor allem ein großes Kapazitätsproblem. Insbesondere an Hochschulen, die wie die TU Dortmund alle Lehramtsstudiengänge anbieten, kommt eine extrem große Menge an Studierenden auf das Fach Deutsch zu, die in die Grundlagen von DaZ eingeführt werden müssen. Zumindest für eine Teilmenge dieser müssen zudem ganz eigene, neue Veranstaltungen im Vergleich zu den im Fach etablierten konzipiert werden, da nicht alle das Fach Deutsch studieren und daher weder in sprachwissenschaftlichem Vokabular und Theorien geschult sind, noch sich explizit mit der deutschen Grammatik auseinandergesetzt haben. Das Fach Deutsch muss also mit sehr viel zusätzlichem Personal ausgestattet werden. Nicht nur ist das kostspielig, es ist zur Zeit auch nicht sicher, dass dieses Personal überhaupt in so hoher Zahl existiert. Hinsichtlich der fachdidaktischen Veranstaltungen stellt sich die Frage, ob dies eigene Seminare bzw. Übungen zum Bereich DaZ sein sollen oder ob die DaZ-Thematik in reguläre Veranstaltungen integriert werden soll. Abgesehen davon, dass schon die Leistungspunktezuteilung eigene Veranstaltungen nahe legt (die sich dann ausschließlich dieser Thematik widmen), spricht die Erfahrung mit einem Studienbereich im Dortmunder Modellversuch Gestufte Lehrerbildung gegen eine Integration in ein Fach: Erfahrungsgemäß werden die fraglichen Inhalte dann nur äußerst rudimentär und ohne Ausrichtung an den für den Bereich vorgesehenen Standards und Kompetenzen vermittelt (Seipp 2008).

\subsubsection{Modulvorschlag}

Ein mögliches, im sechs-semestrigen Bachelor-Studium angesiedeltes Modul könnte - unter Außerachtlassung der eben genannten Hürden - folgendermaßen aussehen: 
und Umgang mit Fehlern befasst und vom Fach Deutsch verantwortet wird. Die zweite Veranstaltung findet in der Didaktik eines der beiden Unterrichtsfächer statt und beinhaltet die Sprachlichkeit fachlichen Lernens sowie Fragen fachbezogener Fördermöglichkeiten und das Erstellen konkreter Förderpläne DaZ im Fach. ${ }^{6}$ Beendet wird das Modul durch eine Wahlpflicht-Veranstaltung aus den Gebieten Migrantensprache, Migrantenliteratur, Interkulturelle Kommunikation/Erziehung oder einer QuasiWiederholung der Sachfach-Veranstaltung in der Didaktik des zuvor nicht gewählten Unterrichtsfachs oder Ähnliches. Voraussetzung ist, dass jedes an der Lehrerbildung beteiligte Fach mindestens eine Veranstaltung in das Modul einspeist. Das Modul wird durch eine kompetenzorientierte Modulabschlussprüfung abgeschlossen, in der die Studierenden nachweisen, dass sie aktiv mit den Anforderungen der DaZ-Förderung umgehen können, indem sie beispielsweise eine Fehleranalyse an authentischen Schülertexten durchführen und auf deren Grundlage einen Förderplan für eine Unterrichtseinheit aufstellen. Solche Abschlussarbeiten sollten als Gruppenarbeiten mit Aufgabenteilung durchgeführt werden können.

Die Berechnung der Leistungspunkte ist hier so streng angesetzt wie bei der Durchführung eines Moduls mit gleichem Umfang an Hochschulen des Landes Berlin. ${ }^{7}$ Es ist sehr zu erwarten, dass die Hochschulen in Nordrhein-Westfalen dieser Rechnung (1 LP $=30$ Zeitstunden) nicht folgen werden, sondern eine an den alten Semesterwochenstunden ausgerichtete Umrechnung im Verhältnis 2 SWS $=3$ LP zugrunde legen. Das im Land (betrieben durch die Arbeitsgruppe DaZ-Modul bei der Stiftung Mercator) entstehende und den Hochschulen und der zu wählenden Akkreditierungsgesellschaft vorzuschlagende Basis-Modul mit sechs Leistungspunkten wird daher deutlich „kleiner“ ausfallen. Bedauerlich, aber möglich wäre es, auf den oben beschriebenen Wahlpflichtbereich ganz zu verzichten bzw. die Pflichtveranstaltung für die Studierenden mit dem Fach Deutsch am Modulstart dadurch zu ersetzen. Nach Ansicht der Verfasserin ist es jedoch möglich, Grundlagenveranstaltungen, in denen es vorrangig um Wissensvermittlung ohne eine hohe Eigenaktivität der Studierenden zur Vorbereitung auf eben solche Leistungen geht, mit nur einem Punkt zu kreditieren (bei 15 Sitzungen ergeben sich 22,5 Stunden „Kontaktstudium“ und 7,5 Stunden Nachbereitung (= Wiederholung). Die Kreditierung der Veranstaltungen des zweiten Blocks geht davon aus, dass hier, wo Eigenleistungen von den Studierenden zum Zweck des über pures Wissen hinausgehenden Kompetenzerwerbs notwendig sind, nicht von der alten SWS-Rechnung, sondern tatsächlich der studentischen workload ausgegangen wird, Veranstaltungen also nicht regelmäßig wöchentlich stattfinden sollten, sondern Zeiten für Eigenaktivitäten eingeplant werden, so dass die Studierenden sich pro Veranstaltung im Semester insgesamt 60 Stunden mit der Thematik befassen. Gerade hier, bei der Entwicklung eines gänzlich neuen Moduls zu einem bisher noch nie in der Lehrerbildung behandelten Themas (Daz im Sachfach), besteht die Möglichkeit, solche Veranstaltungsformen zu entwickeln.

Das Unterrichtsfach sollte an dieser Stelle nicht das Fach Deutsch sein.

http://studium.hu-berlin.de/lust/lehrer/DaZ; http://www2.tu-berlin.de/fak1/zfl/bama/Modulkatalog_Ma_Ewi_und_DaZ_07.pdf (21.08.2009) 
Die Themenfelder, die für diesen Modulvorschlag genutzt wurden, stammen aus einer ersten Überlegung der Arbeitsgruppe DaZ-Modul bei der Stiftung Mercator. Diese lag zeitlich vor der Veröffentlichung des Referentenentwurfs und ging von großzügigen 14 Leistungspunkten aus. Dabei wurden vier Veranstaltungen für das Modul geplant:

a) Grundlagen von Sprache und Kommunikation

Grammatische Grundbegriffe

Spracherwerbstheorien

Mehrsprachigkeit

Mündlichkeit und Schriftlichkeit

b) Sprachliche Kompetenzen

Analyse sprachlicher Handlungsfähigkeiten (Texte und Diskurse)

Sprachvergleiche (Deutsch und Herkunftssprachen)

Interkulturelle Kommunikation

c) Von der Sprachdiagnose zur Sprachförderung

Diagnoseverfahren

Umgang mit Fehlern

Förderkonzepte

d) Fachliches und sprachliches Lernen - Schnittstelle Fachdidaktik

Fachtexte und Fachsprache

Schulbücher und Lernmittel

Kommunikation im Fachunterricht: Analyse und Bewertung

Fachspezifisches Kommunikationstraining

\subsection{Offene Fragen - Schulformbezug, Studienphase, Grundlagen- und Aufbaumodul, Praxis}

Im Laufe des Gesetzgebungsprozesses ließ sich die erfreuliche Erfahrung machen, dass der Gesetzgeber die Argumente der Experten auf dem Gebiet DaZ gehört und ernst genommen hat. Somit sind Vorgaben entstanden, die eine seit Langem fällige Reaktion auf einen seit Jahrzehnten bekannten Wandel der Gesellschaft in angemessener Verortung darstellen. Diese sind zwar durch die Vorgabe von sechs Leistungspunkten einerseits die strikteste Vorgabe überhaupt - und stellen damit zumindest dieses Mindestmaß sicher! - lassen aber andererseits den Hochschulen einen sehr weiten Spielraum.

Bei der Planung des Moduls kann ein Modul für alle Studierenden unabhängig von der von ihnen angestrebten Schulform entwickelt werden oder aber es können schulformspezifische Module ausgearbeitet werden, was im Sinne der Professionalisierung der Lehrerbildung begrüßenswert erscheint. Vor allem der Umstand, dass alle Studierenden für das Grundschullehramt den Lernbereich Sprachliche Grundbildung studieren müssen (also im Fach Deutsch eingeschrieben sind), legt ein eigenes Modul für sie nahe, da die Grundvoraussetzungen bei ihnen andere sind. Eine Untergruppe dieser Studierenden wird zudem an Stelle des dritten Lernbereichs die Vertiefung DaZ wählen; auch hier wäre zu überlegen, ob für sie ein Grundlagenmodul nicht anders aussehen sollte als für diejenigen, die nur dieses eine Modul belegen werden. Wenigstens aber 
sollte durch die Auswahl an Sach- und Fachtexten, die der sprachlichen Analyse dienen, ein Schulformbezug enthalten sein.

Die Frage der Positionierung des Moduls wird von sehr verschiedenen Argumenten gespeist. Für eine Zusammenfassung der Thematik in einem statt zwei Modulen spricht eindeutig der geringe Punkteumfang, der sich, wenn man nicht wie in Berlin rechnet, nicht auf zwei Module aufteilen lässt. Zudem würde eine Aufteilung sich nachteilig auf den Kompetenzerwerb von Studienortwechslern auswirken, da die konkrete inhaltliche Ausgestaltung den Hochschulen überlassen bleibt. Positiv diskutiert wird aber die Alternative, eine Grundmodul im Bachelor-Studium anzusiedeln und ein ebenso großes als optionales Vertiefungsmodul im Master of Education. Dadurch wird zumindest versucht, die Lücke zu schließen, die dadurch entsteht, dass bei einer Positionierung des Moduls im Bachelor ohne Wiederaufgreifen der Kompetenzen im Master eine große zeitliche Spanne bis zum Eintritt in die zweite Phase und in den Schuldienst entsteht.

In keinem der zur Zeit diskutierten Lösungsansätze findet sich eine Verankerung des Förderunterrichts, der Praxis also, die das Projekt den Studierenden ermöglicht. Bei einem Umfang von sechs Punkten kann eine Praxisphase keinen Raum haben, schon gar nicht eine, die sich mit vier Förderstunden über ein Schuljahr erstreckt, was aber aus der Perspektive der geförderten Schüler/innen das Minimum darstellt. Die aus dem Projekt Förderunterricht an den Hochschulen entstandene Expertise kann für das Modul gewinnbringend genutzt und die in seinem Zusammenhang etablierten Lehrveranstaltungen können verstetigt und auf eine breite Basis gestellt werden. Der Förderunterricht selbst aber ist nur über eine Anknüpfung an eine oder mehrere der in der neuen Lehrerbildung vorgesehenen und hier deutlich ausgeweiteten Praxisphasen zu erreichen.

\section{Literatur}

Benholz, Claudia; Iordanidou, Charitini; Thomas, Christine (2005): Informationen zum Projekt und Jahresbericht 2004 / 2005. www.uni-essen.de/foerderunterricht/downloads. html (Januar 2007).

GzRL [Gesetz zur Reform der Lehrerausbildung] (2009): www.zfl.tu-dortmund.de Menupunkt Lehramtsstudium TU-Dortmund.

Homepage der Stiftung Mercator GmbH: www.mercator-foerderunterricht.de (Januar 2007).

Homepage des BLK-Projekts FörMıg: www.blk-foermig.uni-hamburg.de/ Januar 2007).

LZV [Lehramtszugangsvoraussetzung] (2009): www.zfl.tu-dortmund.de - Menüpunkt Lehramtsstudium TU-Dortmund.

Michalak, Magdalena (2009): Sprachförderung Deutsch als Zweitsprache - Ja, aber von wem? In: Chlosta, Christoph; Jung, Matthias; Semmler, Stephan (Hrsg.): DaF integriert: Literatur - Medien - Ausbildung. Tagungsband der 36. Jahrestagung des Fachverbandes Deutsch als Fremdsprache 2008. Göttingen: Universitätsverlag, 227-241. 
Oser, Fritz (1997a): Standards in der Lehrerbildung. Teil I: Berufliche Kompetenzen, die hohen Qualitätsmerkmalen entsprechen. In: Beiträge zur Lebrerbildung 15/1, 26-37.

Oser, Fritz (1997b): Standards in der Lehrerbildung. Teil II: Wie werden Standards in der Schweizerischen Lehrerbildung erworben? Erste empirische Ergebnisse. In: Beiträge zur Lebrerbildung 15/2, 210-228.

Referentenentwurf zum Gesetz der Reform der Lehrerausbildung (2008): www.zfl.unidortmund.de/content/service/downloads/Referentenentwurf_Gesetz_zur_Reform_der_Lehrerausbildung.pdf (Oktober 2008).

Seipp, Bettina (2007): Sprache fördern - Kulturvielfalt erleben. Lehrerausbildung praxisnah. In: Fokus Lehrerbildung 1. Dortmund: Zentrum für Lehrerbildung der Universität Dortmund.

Seipp, Bettina (2008): Sechs Semester BiWi - Evaluation des Studienbereichs Bildung und Wissen an der Technischen Universität Dortmund. In: Fokus Lehrerbildung 7 (http://www.zfl.uni-dortmund.de/cms/Medienpool/Downloads/Fokus_Lehrerbildung/biwi_fokus_lehrerbildung_7_2008.pdf, 05.10.10). 

Christoph Chlosta, Matthias Jung (Hrsg.) (2010): DaF intergriert: Literatur - Medien - Ausbildung. Tagungsband der 36. Jahrestagung des Fachverbandes Deutsch als Fremdsprache 2008. Göttingen: Universitätsverlag, 271-284.

\section{Udo Ohm (Jena)}

\section{Fachliche Schwierigkeiten sind sprachliche Schwierigkeiten. Müssen Fachlehrer und Ausbilder auch Sprachlehrer sein?}

\section{Einleitung}

Beim Eintritt in die berufliche Ausbildung sollten Jugendliche über eine bildungssprachliche Kompetenz verfügen, die sie in die Lage versetzt, fach- bzw. berufbezogene Aufgabenstellungen durch einen fachlich angemessenen Gebrauch sprachlicher Mittel zu bewältigen. Erfahrungen von Lehrenden und Ausbildenden in der Schule und im Betrieb zeigen jedoch, dass vor allem - aber nicht ausschließlich - Lernende nichtdeutscher Herkunftssprache dieses Niveau in der Zweitsprache Deutsch häufig nicht erreichen und somit den Anforderungen der beruflichen Ausbildung nicht gewachsen sind. Eine sprachliche Förderung im Fachunterricht und in der beruflichen Ausbildung ist für diese Zielgruppe - das haben nicht zuletzt die PISA-Ergebnisse gezeigt (z.B. Baumert; Schümer 2001: 375-379) - daher dringend nötig.

Es stellt sich nun die Frage, wie eine solche Förderung aussehen kann und von wem sie geleistet werden soll. Im vorliegenden Beitrag wird die Ansicht vertreten, dass sprachliche Förderung gerade bei der Zielgruppe der Jugendlichen mit Migrationshintergrund am produktivsten ist, wenn sie dort erfolgt, wo die sprachlichen Schwierigkeiten auftreten: im Fachunterricht und am Arbeits- bzw. Ausbildungsplatz. Fachlehrer und Ausbilder sollten auf sprachliche Schwierigkeiten, die bei der Vermittlung fachlicher Inhalte und beruflicher Tätigkeiten auftreten, im Unterricht und in der Ausbildung sofort reagieren können. 
Für eine möglichst fach- und ausbildungsnahe Sprachförderung - so das zentrale Argument des vorliegenden Beitrags - spricht die Annahme, dass bildungssprachliche Fähigkeiten konstitutiv für die Befähigung zum Handeln im fachlichen bzw. beruflichen Kontext sind. Ich werde dies im Folgenden zunächst theoretisch mit Vygotskijs Begriff der vermittelten Beziehung zwischen handelndem Subjekt und Objekt des Handelns begründen. Anschließend werde ich exemplarisch Situationen des fachlichen Lernens und des beruflichen Handelns auf das entstandene Modell abbilden. Dabei werde ich konkretisieren, welches die Lerngegenstände einer fach- und ausbildungsbezogenen Sprachförderung sind. Ich werde argumentieren, dass fachliches Lernen und berufliches Handeln über Bildungssprache vermittelt werden. Die Förderung bildungssprachlicher Fähigkeiten sollte daher aus fachlichen Überlegungen zu den Kernaufgaben von Fachlehrern und Ausbildern gehören. An welchen Prinzipien sich eine solche Förderung orientieren kann, werde ich abschließend aufzeigen.

\section{Vermittelte Beziehung zwischen Subjekt und Objekt des Handelns}

Der Begriff der Vermittlung ist von zentraler Bedeutung in soziokulturellen Zweitsprachenerwerbstheorien, die sich in der angloamerikanischen Forschung spätestens seit Mitte der neunziger Jahre - anfangs vor allem mit Fokus auf Migrationskontexte - zu etablieren begannen. Der soziokulturelle Begriff der Vermittlung geht auf Vygotskijs Begriff des Mittler-Reizes zurück (vgl. u.a. Vygotskij 1992: 122ff.). Demnach zeichnet es den Menschen aus, dass er nicht nur unmittelbar und unwillkürlich auf Reize seiner Umwelt reagiert, sondern dass er auch in der Lage ist, seine Reaktionen durch die Einführung künstlicher Reize selbst zu steuern. In Abb. 1 wird diese Differenzierung in stark vereinfachter Form dargestellt (vgl. Lantolf; Thorne 2006: 62).

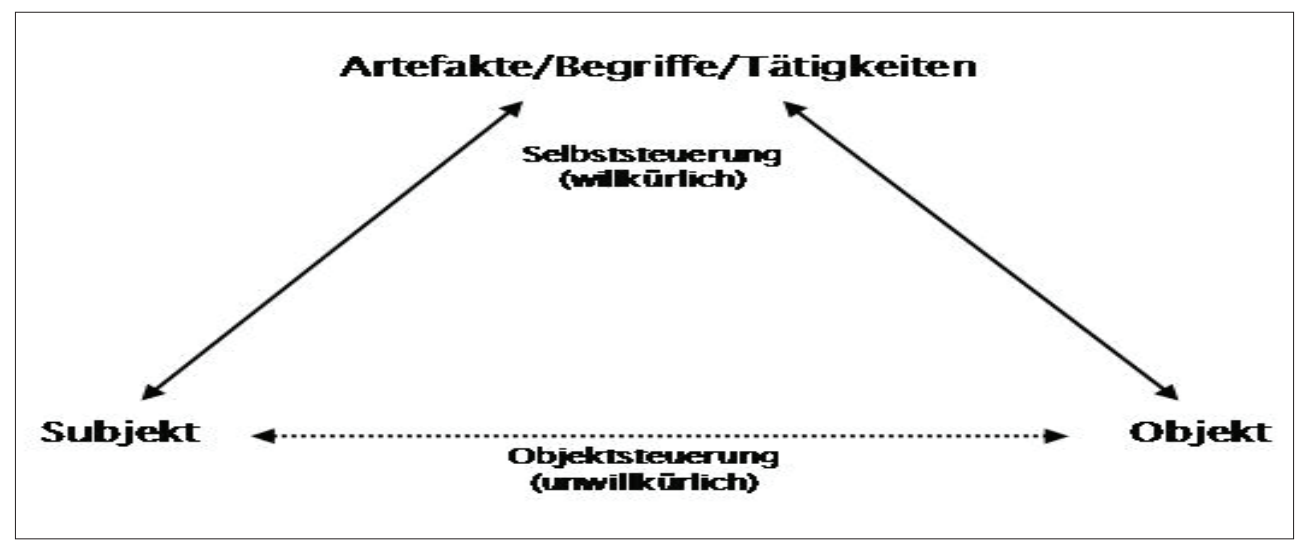

Abb. 1: Vermittelte Mensch/Welt-Beziehung (mittig)

Die mittelbare Beziehung des Subjekts zum Objekt seines Handelns wird durch die durchgezogenen Linien, die unmittelbare Beziehung durch die gepunktete Linie repräsentiert. Zur unmittelbaren Beziehung zählen u.a. die unwillkürliche Aufmerksamkeit 
(z.B. das unwillkürliche Umwenden in Richtung auf ein lautes Geräusch), der unwillkürliche Reflex (z.B. das Schließen des Augenlieds beim Auftreffen eines Fremdkörpers) und die unwillkürliche Erinnerung (z.B. an emotional aufgeladene Erlebnisse, die immer wieder ins Bewusstsein drängen). Die mittelbare Beziehung umfasst die sich historisch aufschichtende kulturelle Hervorbringung von Mittler-Reizen, die zwischen das Subjekt und die geistigen und physischen Objekte seines Handelns treten. Als Mittler-Reize können alle künstlichen, d.h. vom Menschen hervorgebrachten, geistigen oder physischen Objekte („Artefakte“) - zu denen Vygotskij auch das künstliche „Signalsystem“ Sprache zählt (vgl. u.a. Vygotskij 1992: 138-143) -, Begriffe (z.B. der Begriff der Gerechtigkeit, der Freiheit, der Demokratie, der Familie, des Erfolgs, der Kundenzufriedenheit) und Tätigkeiten im Sinne sozialer Praktiken (habitualisierte Formen des Handelns wie z.B. Essgewohnheiten und Begrüßungsformen, aber auch standardisierte Handlungsabläufe am Arbeitsplatz) fungieren.

Durch die Einführung künstlicher Mittler-Reize ist das Subjekt in der Lage, seine eigenen Reaktionen auf Objekte zu beeinflussen. Ein einfaches Beispiel, das sich auch schon bei Vygotskij findet (z.B. 1992: 126-131), ist der Knoten, den wir in ein Taschentuch machen, um in einer zukünftigen Situation unsere Aufmerksamkeit auf etwas in unserem Gedächtnis zu lenken, das wir andernfalls womöglich vergessen hätten. Durch die Einführung des künstlichen Mittler-Reizes Knoten-im-Taschentuch sind wir somit in der Lage, unsere natürliche Gedächtnisfunktion zu erweitern. Laut Vygotskij entstehen mit der Schaffung von künstlichen Mittler-Reizen höhere, d.h. komplexere, Formen des Verhaltens. Zwar wird das Verhalten von Menschen auch von gegebenen Reizen determiniert, aber insbesondere das „Signalsystem der Sprache“ versetzt Menschen in die Lage, auf ihr eigenes Verhalten (Selbststeuerung) und das Verhalten anderer Menschen (Fremdsteuerung) einzuwirken (vgl. Vygotskij 1992: 143). Während Vygotskij das Werkzeug als „Mittel der äußeren, auf die Unterwerfung der Natur gerichteten Tätigkeit des Menschen“ betrachtet (1992: 154), ist das Zeichen - und dazu zählt vor allem das sprachliche Zeichen - ein „Mittel der inneren, auf die Selbststeuerung ausgerichtete Tätigkeit des Menschen“. Das Zeichen ist „ein Medium der psychischen Einwirkung auf das Verhalten - auf fremdes wie auf eigenes“ (Vygotskij 1992: 154).

Zusammenfassend kann man sagen, dass Menschen Sprache dazu gebrauchen, ihr eigenes Verhalten und das anderer zu steuern, und dass sie auf diese Weise wechselseitig ihr Verhalten koordinieren. Sprache ist demnach mehr als ein Mittel zum Informationsaustausch. Erst der Gebrauch von Sprache befreit uns vom Zwang zur unmittelbaren und unwillkürlichen Reaktion auf unsere Umgebung. Erst der Gebrauch von Sprache versetzt uns in die Lage, unsere Aufmerksamkeit willentlich zu steuern, willentlich unsere Wahrnehmungs- und Beurteilungsperspektiven zu ändern, Bedeutungen und Sinnzusammenhänge zu (re)konstruieren sowie arbeitsteilig und kooperativ zu handeln. In Wissensgesellschaften muss dies in der Lern- und Arbeitswelt weitgehend unabhängig von lokalen Kontexten und unmittelbarer Face-to-Face-Kommunikation geleistet werden. Für die Steuerung des eigenen Verhaltens und des Verhaltens anderer wird deshalb eine kaum auf kontextuelle Einbettung angewiesene Bildungssprache benötigt. Im 
Folgenden werde ich exemplarisch zeigen, dass Fachlernen und berufliches Handeln über spezifische sprachliche Mittel, Textsorten und Diskursfunktionen vermittelt werden. Der Erwerb von Fachwissen und von beruflicher Handlungsfähigkeit ist daher untrennbar mit der Aneignung entsprechender Wissensbestände in diesen Teilbereichen bildungssprachlicher Kompetenz verbunden.

\section{Bildungssprache und Fachlernen. Beispiel: Informationen aus Fachtexten entnehmen}

Die PISA 2000-Studie hat gezeigt, dass 22,3\% der 15-Jährigen nicht über die erste Lesekompetenzstufe hinauskommen, die verlangt, dass man sich mit Hilfe von Überschriften und Druckkonventionen einen Eindruck vom Hauptgedanken eines Textes verschaffen und eine explizit genannte Information entnehmen kann. In diesen 22,3\% sind 9,3\% enthalten, die noch nicht einmal die erste Stufe erreichen, was bedeutet, dass sie aus einem Text in der Regel keine Informationen entnehmen können (vgl. Schaffner et al. 2004: 102-103). Zu dieser Gruppe der „schwachen Leser“ zählen überdurchschnittlich viele Jugendliche mit Migrationshintergrund (vgl. Artelt et al. 2001: 116-120). Vertiefende Untersuchungen zu den PISA-Ergebnissen deuten an, dass sich eine schwache Lesekompetenz kumulativ auf Leistungen in allen Fächern auswirkt (vgl. Stanat; Schneider 2004: 257-260).

In der Berufsausbildung wird von den Jugendlichen im Bereich der Lesekompetenz deutlich mehr verlangt, als eine einzelne Information aus einem Text zu entnehmen. Das Verstehen von Fachbuchtexten setzt beispielsweise voraus, dass Auszubildende sowohl auf lokaler als auch auf globaler Textebene Kohärenz herstellen können (vgl. Ohm et al. 2007: 137-140). An dieser Stelle wollen wir uns aber einmal anschauen, was die basalen Vorraussetzungen der Informationsentnahme aus Fachtexten sind, oder anders ausgedrückt, welche bildungssprachlichen Fähigkeiten für einen selbstgesteuerten Zugang zu einem Fachtext benötigt werden.

Das Textbeispiel in Abb. 2 wurde dem Lesetest der Kompetenzstufe I aus der PISA 2000-Studie entnommen (Deutsches PISA-Konsortium 2001: 526). Die Aufgabe zu diesem Text lautete: „An einer Stelle in dem Artikel heißt es: ,Ein guter Sportschuh sollte vier Kriterien erfüllen. 'Welche Kriterien sind das?“ (Artelt et al. 2001: 91). Über welches sprachliche Wissen muss ein Leser verfügen, damit er diese Aufgabe lösen kann?

Zunächst muss er die Stelle im Text identifizieren, an der die gesuchte Information zu finden ist. Er muss also das Zitat im Text ausfindig machen. Dabei kann er die Überschriften zur ersten Orientierung im Text nutzen. Die Zwischen-Überschrift „Schützen, stützen, stabilisieren, dämpfen“ zählt die vier Kriterien ja bereits stichwortartig auf. Nachdem er die Stelle identifiziert hat, an der die Kriterien genannt werden, muss er den Textabschnitt auswählen, in dem die gesuchten Informationen enthalten sind. Es handelt sich um den mittleren Textabschnitt und dort um die vier Absätze nach dem in der Aufgabe zitierten Satz. Um dies leisten zu können, muss er die grundlegenden Strukturierungskonventionen von Fachtexten kennen. Er muss wissen, dass Zwischen- 
14 Jahre lang wurden am Sportmedizinischen Zentrum Lyon (Frankreich) die Verletzungen junger Amateurund Profisportler untersucht. Die Studie beweist, dass Vorbeugung ... und gute Schuhe ... der beste Schutz sind.

Stöße, Stürze und Verschleiß ...

Achtzehn Prozent der Spieler im Alter von 8 bis 12 haben bereits Verletzungen an den Fersen. Der Knorpel im Knöchel eines Fußballers steckt Erschütterungen schlecht weg. $25 \%$ der Profis haben am eigenen Leibe herausgefunden, dass dies ein besonderer Schwachpunkt ist. Der Knorpel des empfindlichen Kniegelenks kann ebenfalls irreparabel geschädigt werden, und wenn man nicht bereits von Kindheit an aufpasst (im Alter von 10-12 Jahren)، kann dies zu frühzeitiger Arthrose führen. Auch die Hüfte bleibt von Schaden nicht verschont, und ein Spieler, besonders wenn er müde ist, läuft Gefahr, sich bei einem Sturz oder Zusammenstoß Knochenbrüche zuzuziehen.

Die Untersuchung besagt, dass sich bej Fußballern, die seit mehr als zehn Jahren spielen,
Knochenauswüchse am Schienbein oder an der Ferse entwickeln. Dies ist der sogenannte "Fußballerfuß", eine Deformierung, die durch Schuhe mit zu flexiblen Sohlen und Knöcheibereichen entsteht.

Schützen, stützen, stabilisieren, dämpfen

Wenn ein Schuh zu steif ist, schränkt er die Bewegung ein. Wenn er zu flexibel ist, vergrößert sich das Verletzungsund Verstauchungsrisiko. Ein guter Sportschuh sollte vier Kriterien erfüllen:

Erstens muss er äußeren Schutz bieten: gegen Stöße durch den Ball oder einen anderen Spieler schützen, Bodenunebenheiten ausgleichen und den Fuß warm und trocken halten, selbst wenn es eiskalt ist und regnet.

Er muss den FuB und besonders das Knöchelgelenk stützen, um Verstauchungen,

\author{
Schwellungen und \\ andere Probleme zu \\ vermeiden, die sogar das \\ Knie betreffen können. \\ Er muss dem Spieler \\ auch eine gute Stabilitöt \\ bieten, so dass er auf \\ nassem Boden oder \\ einem zu trockenen \\ Belag nicht rutscht. \\ Schließlich muss er \\ Stöße dämpfen, \\ besonders bei Volleyball- \\ und Basketballspielern, \\ die permanent springen.

\section{Trockene FüBe} \\ Um kleinere, aber \\ schmerzhafte Beschwer- \\ den, wie z.B. Blasen und \\ sogar Risswunden oder \\ Pilzinfektionen zu \\ verhindern, muss der \\ Schuh das Verdunsten \\ von Schweiß ermög- \\ lichen und äußere \\ Feuchtigkeit am \\ Eindringen hindern. Das \\ ideale Material hierfür ist \\ Leder, das imprägniert , \\ werden kann, um zu \\ verhindern, dass der \\ Schuh beim ersten \\ Regen durchnässt wird.
}

Abb. 2: PISA-Aufgabenstamm „Fühl dich wohl in deinen Turnschuhen“

überschriften einen Text in Sinneinheiten unterteilen und dass Absätze kleinere Sinneinheiten oberhalb der Satzebene darstellen. Außerdem muss er zumindest die phorische Funktion des Personalpronomens „er" kennen, denn das Wort „Schuh“ wird in dem relevanten Textabschnitt nur im einleitenden Absatz explizit genannt. In den nachfolgenden Absätzen, in denen die Kriterien behandelt werden, wird jeweils lediglich mit dem Pronomen rückverweisend auf den vorwähnten Schuh Bezug genommen. Anzunehmen ist außerdem, dass der Leser die Funktion der Textadverbien „erstens“ und „schließlich“ und deren Klammerfunktion kennen muss. Wenn er die Klammerung mit der Strukturierung durch die vier Absätze und der jeweiligen Wiederaufnahme der Referenz durch das Pronomen „er“ in Verbindung bringt, kann er die Auswahl der relevanten Textteile leicht vornehmen. Nur wenn er über dieses - bildungssprach- 
liche - Wissen verfügt, kann er seine Aufmerksamkeit anschließend gezielt auf die in den Absätzen enthaltenen Informationen fokussieren. Die Beantwortung der Frage verlangt sodann, dass er die Informationen des Absatzes verdichtet. Es wäre nicht angemessen, wenn er jeweils den gesamten Absatz oder auch nur den Satz mit dem zentralen Informationsgehalt abschreiben würde. Vielmehr wird im Idealfall erwartet, dass er die Informationen stichwortartig bezeichnen kann (z.B.: „1. Äußeren Schutz bieten; 2. Fuß und besonders Knöchelgelenk stützen; 3. Dem Spieler gute Stabilität bieten; 4. Stöße dämpfen").

Bilden wir die bildungssprachlichen Fähigkeiten, die für die Entnahme der Kriterien aus dem Text und ihre Aufzählung in Form einer Stichwortliste benötigt werden, auf das oben eingeführte Schema ab, erhalten wir in etwa die in Abb. 3 gezeigte Darstellung.

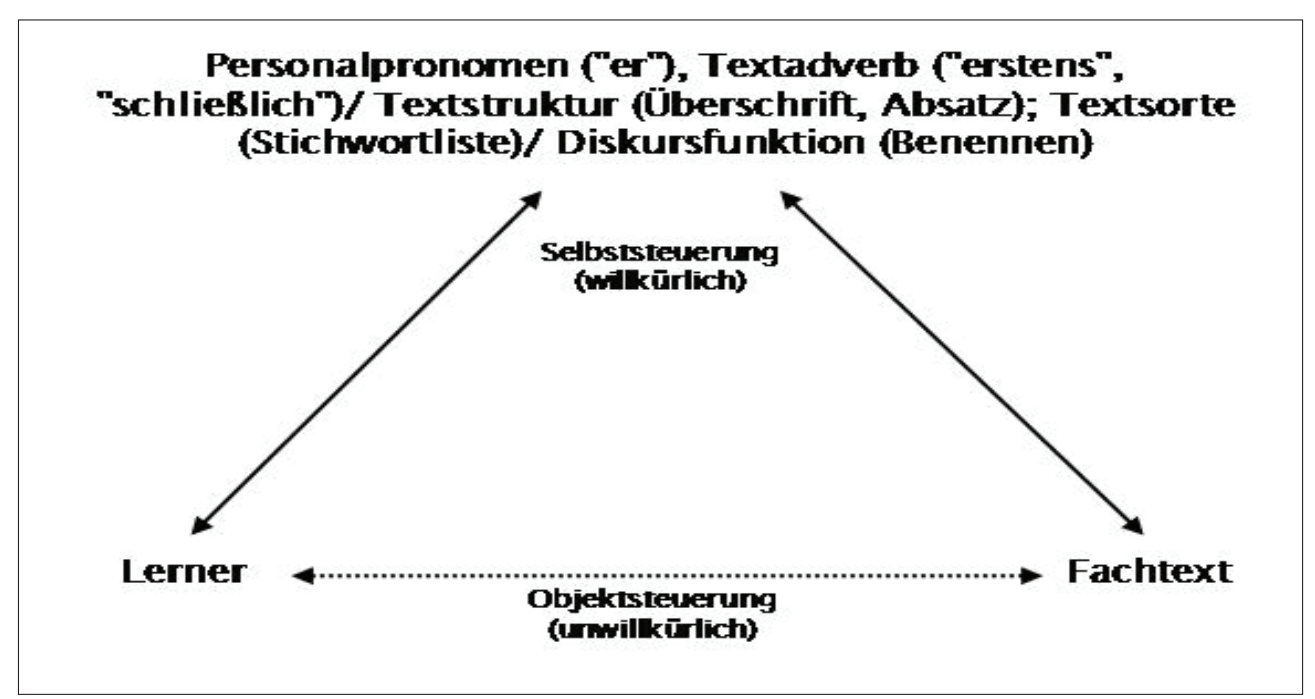

Abb. 3: Vermittelte Beziehung zwischen Lernendem und Fachtext

Um ihre Aufmerksamkeit willkürlich, d.h. selbstgesteuert, auf die relevanten Passagen in Fachtexten lenken zu können, müssen Lernende grundlegende sprachliche Mittel und Textstrukturen kennen. Damit sie die erfragten Informationen entnehmen und fachgerecht darstellen können, müssen sie zudem über Textsortenwissen (hier: Stichwortliste) verfügen. Erst dieses bildungssprachliche Wissen versetzt sie in die Lage, die beschriebenen sprachlich-kognitiven Operationen (Identifizieren, Auswählen, Fokussieren, Verdichten, Bezeichnen) auszuführen.

Die genannten sprachlich-kognitiven Operationen sind Teilaktivitäten einer für fachliches Lernen grundlegenden Diskursfunktion, die mit Vollmer et al. (2008) als Benennen (naming) bezeichnet werden kann. Sie wird in einfacher Form bereits von Grundschülern verlangt und im Verlauf der Sekundarstufe I in den einzelnen Schulfächern auf immer komplexere und fachspezifischere Lerngegenstände und Lernhandlungen angewendet. Während es in der Grundschule in der Regel darum geht, dass Schüle- 
rinnen und Schüler Gegenstände und Personen sowie einfache Ereignisse, Prozesse und Sachverhalte, die sie aus ihrem eigenen Erfahrungsbereich kennen, mit gebräuchlichen Wörtern zu bezeichnen lernen, müssen Schülerinnen und Schüler in höheren Klassenstufen lernen, komplexe Phänomene, die in vielen Fällen nicht mehr unmittelbar auf eigene Erfahrungen bezogen werden können, mit standardisierten sprachlichen Mitteln oder Fachbegriffen zu benennen (vgl. das obige Beispiel: ,äußeren Schutz bieten“, „Knöchelgelenk stützen“, „Stabilität bieten“, „Stöße dämpfen“). Die Diskursfunktion Benennen ist darüber hinaus konstitutiv für komplexere Diskursfunktionen wie Beschreiben (describing), Erklären (explaining), Argumentieren (arguing) etc., deren Ausführung ebenfalls spezifische sprachliche Mittel verlangt (vgl. Vollmer et al. 2008). Auch diese Diskursfunktionen werden von Schulbeginn an im Unterricht vermittelt und praktiziert und im Verlauf der Schulzeit in den Fächern gemäß den fachspezifischen Anforderungen ausdifferenziert (z.B. im Kunstunterricht ein Bild beschreiben vs. im Chemieunterricht einen Versuch beschreiben). Je nach Fach werden Diskursfunktionen durch die Anwendung sprachlicher Mittel in mündlichen oder schriftlichen kommunikativen Aktivitäten als Textsorten realisiert.

\section{Bildungssprache und berufliches Handeln. Beispiel: Eine Werkstattrechung erklären}

Von Fachlehrern und Ausbildern wird immer wieder beklagt, dass Auszubildende nicht in der Lage sind, Kunden eine Rechnung zu erklären. Wir alle sind potenzielle Empfänger von Rechnungen und wissen aus eigener Erfahrung, dass diese Textsorte häufig schwer zu „lesen“ - geschweige denn zu verstehen - ist. Das trifft insbesondere auf Werkstattrechnungen zu, da diese eine Vielzahl unterschiedlicher Leistungen und Materialkosten auflisten. Ein typisches Beispiel zeigt Abb. 4.

Für das Erklären einer Werkstattrechnung müssen Auszubildende die Diskursfunktionen Benennen, Beschreiben und Erklären beherrschen. Vor allem müssen sie zusammenfassend beschreiben können, welche Arbeiten durchgeführt wurden. Dazu müssen sie zum einen die einzelnen Leistungen und zum anderen die Angaben, die für die Berechnung der Einzel- und Gesamtpreise relevant sind, auswählen und benennen. Während es bei der Informationsentnahme im oben diskutierten TurnschuhText darum ging, dass der Lerner seine eigene Aufmerksamkeit durch Nutzung von Textstrukturierung und sprachlichen Mitteln auf die relevanten Textstellen lenkt, muss ein Auszubildender, der eine Rechnung erklärt, die Aufmerksamkeit des Kunden auf die relevanten Textabschnitte und Angaben der Rechnung lenken. Dazu muss er wissen, dass die Textsorte Rechnung in der Regel eine tabellenförmige Struktur aufweist, die zeilenweise die unterschiedlichen Leistungen und spaltenweise die zugehörigen Mengen und Preisangaben darstellt. Des Weiteren muss der Auszubildende in der Lage sein, solche sprachlichen Mittel produktiv einzusetzen, mit denen er den Aufmerksamkeitsfokus des Kunden auf die zu benennenden Textabschnitte bzw. Angaben lenken kann. Dazu zählen vor allem Lokaladverbialien („rechts neben dem Einzelpreis“; ,unter der Aufzählung der Leistungen“; ,,rechts unten“), die häufig in Verbindung mit Zeigegesten 


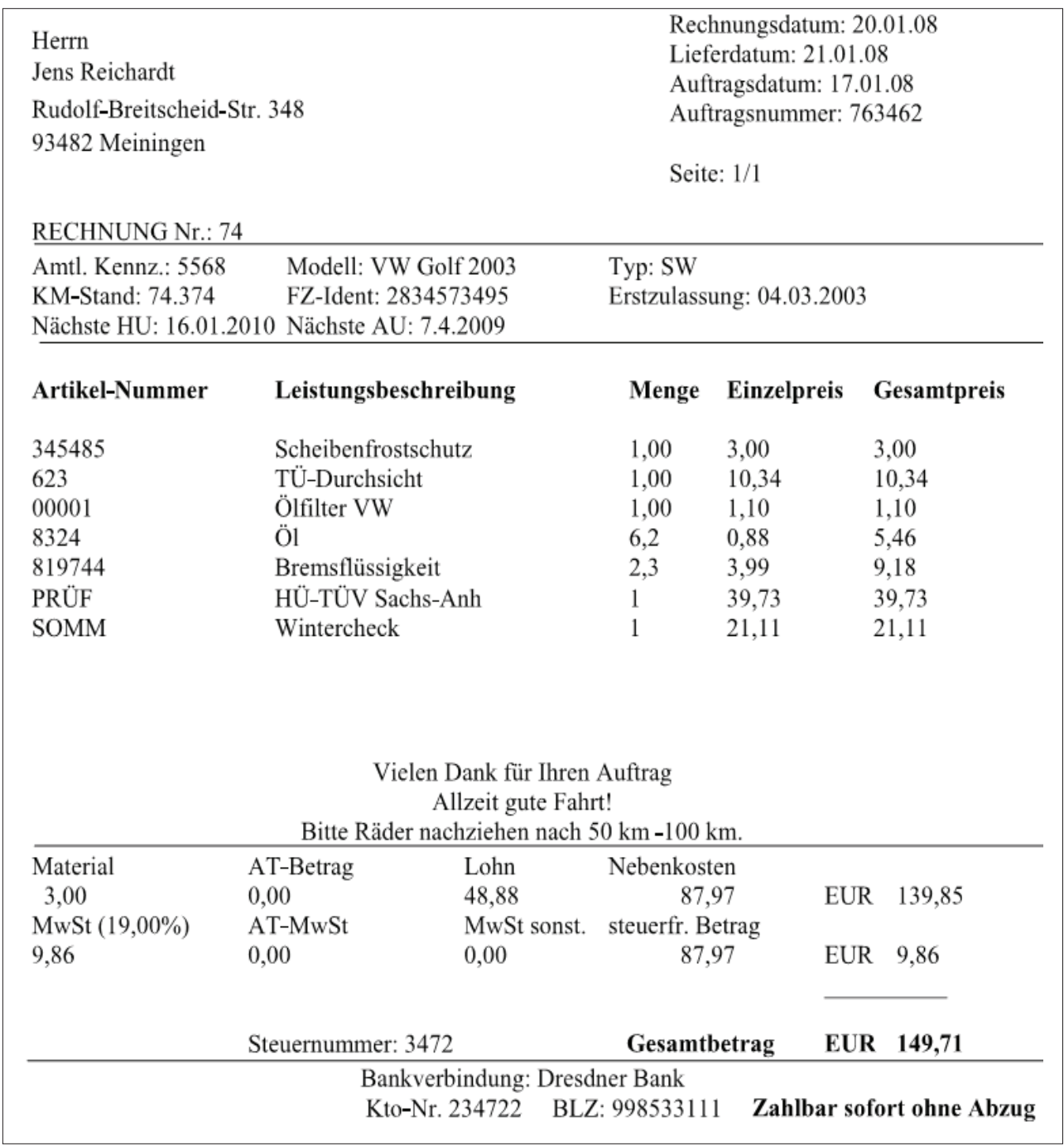

Abb. 4: Werkstattrechnung

benutzt werden („hier“; ,in dieser Spalte“). Für die zusammenfassende Beschreibung der durchgeführten Arbeiten muss in der Regel das Perfekt („Wir haben den Scheibenfrostschutz nachgefüllt.“) oder auch das werden-Passiv im Präteritum („Die Bremsflüssigkeit wurde nachgefüllt.") beherrscht werden. Um dem Kunden die Notwendigkeit einer Leistung zu erklären, müssen ggf. Konstruktionen mit dem Modalverb „müssen“ verwendet werden („Wir mussten Bremsflüssigkeit nachfüllen.“/„Bremsflüssigkeit musste nachgefüllt werden.“; „Der Ölfilter musste ausgetauscht werden.“ etc.).

Bilden wir auch hier die bildungssprachlichen Fähigkeiten auf das weiter oben eingeführte Schema ab, erhalten wir in etwa die Darstellung in Abb. 5. 


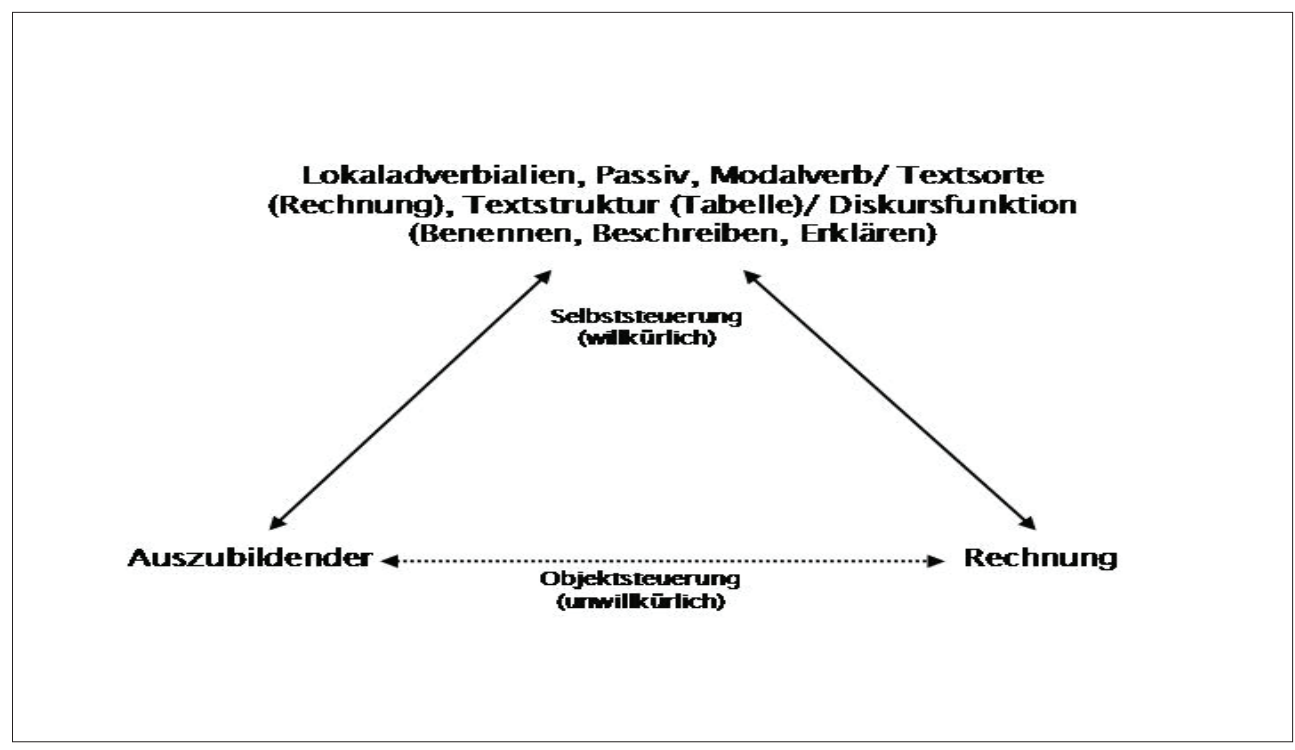

Abb. 5: Vermittelte Beziehung zwischen Ausbildendem und Objekt beruflichen Handelns

\section{Was können Fachlehrer und Ausbilder zur Sprachförderung beitragen?}

Die Schule sollte eigentlich in der Lage sein, ihren Schülerinnen und Schülern bis zum Ende der Sekundarstufe I neben einem ausreichenden Fachwissen auch die grundlegenden sprachlichen Fähigkeiten zu vermitteln, die zur Bewältigung der Anforderungen einer beruflichen Ausbildung und zu einem selbstständigen Weiterlernen befähigen. Wie u.a. die Ergebnisse der PISA-Untersuchungen zeigen, wird diese Erwartung jedoch in vielen Fällen nicht erfüllt. In Abschnitt 3 wurde im Hinblick auf Lesekompetenz argumentiert, dass die Gruppe der schwachen Leser, die einen überproportional hohen Anteil von Jugendlichen nicht-deutscher Herkunftssprache aufweist, noch nicht einmal mit den grundlegenden sprachlichen Mitteln und Textstrukturen operieren kann, die für die Entnahme von einfachen Information aus Texten benötigt wird. Es verwundert daher nicht, dass das sprachliche Wissen, das für berufliches Handeln und für berufliche Weiterqualifikation benötigt wird, in vielen Fällen nicht oder nur unzureichend zur Verfügung steht. Auf diese Ausgangslage muss mit einer fach- und ausbildungsbezogenen Sprachförderung reagiert werden. Die Aneignung sprachlicher Mittel und der Erwerb von Textsortenwissen muss als integraler Bestandteil fachlichen Lernens und beruflicher Ausbildung betrachtet werden.

\subsection{Fach- und ausbildungsbezogene Sprachförderung}

Anders als eine Förderung in separaten, vom Fachunterricht und den Aktivitäten am Ausbildungsplatz weitgehend abgekoppelten Sprachkursen hat eine fach- und ausbildungsbezogene Sprachförderung den Vorteil, dass das für das fachliche Lernen und das 
berufliche Handeln unmittelbar relevante sprachliche Wissen vermittelt und sogleich angewendet werden kann. Das wirkt sich in jedem Fall positiv auf die Motivation der Lernenden aus, denn diese müssen sich das sprachliche Wissen nicht auf Vorrat, d.h. für dessen mögliche Anwendung in zukünftigen Handlungssituationen, aneignen, sondern können es direkt im fachlichen bzw. beruflichen Kontext nutzen. Zugleich erfahren die Lernenden bei der Anwendung des sprachlichen Wissens auf konkrete Gegenstände fachlichen Lernens und beruflichen Handelns, dass ihnen das sprachliche Wissen die Bewältigung von Lernaufgaben und Situationen beruflichen Handelns erleichtert bzw. überhaupt erst ermöglicht. In einer fach- und ausbildungsbezogenen Sprachförderung ist die Förderung von Sprachbewusstheit somit mit angelegt und muss nicht als zusätzlicher Lerngegenstand eingeführt werden.

Nun vermittelt sich das sprachliche Wissen auch im Rahmen einer fach- bzw. berufsbezogenen Sprachförderung nicht von selbst. Genauso wie Sprachlehrer in Sprachkursen müssen Fachlehrer und Ausbilder Lernprozesse didaktisch-methodisch strukturieren und begleiten. Wie das aussehen kann, werde ich im Folgenden umreißen.

\subsection{Scaffolding als didaktisch-methodisches „Einrüsten“ der Sprachförderung}

Eine didaktisch-methodische Strukturierung und Planung von Lehr-Lern-Prozessen, die den aktuellen Entwicklungsstand eines Lerners und den potenziellen Entwicklungsschritt, zu dem er in der Lage ist, berücksichtigt, wird insbesondere im Kontext der Sprachförderung in Migrationskontexten häufig mit dem Begriff Scaffolding bezeichnet. Dabei handelt es sich um ein „Gerüst“ aus didaktisch-methodischen Maßnahmen, das einen individuellen Lernprozess im Bereich der potenziellen Entwicklung stützen soll und das wieder abgebaut werden kann, wenn der Lerner in der Lage ist, die ihm gestellten Aufgaben selbstständig zu bewältigen. Nun erschöpft sich Scaffolding nicht einfach darin, dass von leichten zu schwierigen Aufgabenstellungen, von einfachen zu komplexen Lerngegenständen fortgeschritten wird. Weder der Einsatz eines sprachlich vereinfachten Fachtextes noch der Einsatz von Lückentexten ist schon Scaffolding. Scaffolding geht auf Vygotskijs Begriff der „Zone der eigenen Entwicklungsmöglichkeiten eines Lebewesens“ zurück (1992: 215) und muss im Kontext seines lerntheoretischen Ansatzes gesehen werden.

Ausgehend von der Prämisse, dass Bedeutungen und Handlungen zunächst in sozialer Interaktion hervortreten und erst in einem zweiten Schritt als individuelle Wissenselemente und Fertigkeiten internalisiert werden, ist Scaffolding keine Methode oder Technik der Wissensvermittlung neben anderen, sondern ein Grundprinzip des lerntheoretischen Ansatzes von Vygotskij. Im vorliegenden Fall der fach- und ausbildungsbezogenen Sprachförderung heißt das, dass nicht für einzelne Aufgaben „Lerngerüste“ zu entwickeln sind, sondern dass der Lehr-Lern-Prozess als Ganzes in einer Weise strukturiert wird, dass die Lernenden in die Lage versetzt werden, ihre sprachliche Fähigkeiten im Kontext ihres fachlichen Lernens und beruflichen Handelns weiterzuentwickeln. An dieser Stelle sollen drei Eckpunkte umrissen werden, an denen sich Fachlehrer und Ausbilder orientierten können. 


\subsubsection{An Erfahrungen und sprachlichem Vorwissen anknüpfen}

Schwierige Fachtexte können dadurch vorentlastet werden, dass Vorerfahrungen der Auszubildenden aktiviert werden. Dies kann z.B. dadurch geschehen, dass mit den Lernenden zunächst über eigene Erfahrungen mit den im Text angesprochenen Inhalten gesprochen wird. Ohm et al. schlagen beispielsweise vor, als Einstieg in einen Text zum Thema „Wundverband“ mit Lernenden eigene Erfahrungen aus vergleichbaren Alltagssituationen zu besprechen. Folgende Frage könnte gestellt werden: „Sie haben sich beim Obstschälen in den Finger geschnitten. Die Wunde blutet leicht. Wie versorgen Sie die Wunde?" (2007: 117). Kann nicht direkt auf eigene Erfahrungen Bezug genommen werden, gibt es zumindest die Möglichkeit, abstrakte und schwer nachvollziehbare Fachtexte durch bildliche Darstellungen zu ergänzen, die der alltäglichen Wahrnehmung näher kommen als die Textdarstellungen (vgl. Weidenmann 1997: 60). Gute Fachbücher bieten entsprechendes Bildmaterial an. Schließlich kann sprachliches Vorwissen mit verschiedenen Methoden aktiviert und zusammengetragen werden. Zur Vorentlastung kann z.B. mit Hilfe eines Wortigels Wortschatz zum Thema eines Fachtextes erarbeitet werden. Zur Vorbereitung auf sprachlich ungewohnte oder anspruchsvolle Kommunikationssituationen im Beruf können vorab die benötigten sprachlichen Mittel gemeinsam erarbeitet werden, indem auf eigene Erfahrungen in vergleichbaren Situationen Bezug genommen wird. So könnten Auszubildende beim Thema „Verkaufsgespräch“ Erfahrungen einbringen, die sie selbst als Kunden mit der Gesprächsführung von Verkäufern gemacht haben.

\subsubsection{An Erfordernissen fachlichen Lernens und beruflicher Handlungssituationen orientieren}

Weiter oben hatten wir festgehalten, dass eine fach- und ausbildungsbezogene Sprachförderung sich durch ihre konkrete Orientierung auf fachliche Lerngegenstände und auf Erfordernisse beruflichen Handelns auszeichnet. In diesem Zusammenhang sind vor allem zwei Fragen relevant: Welche sprachlichen Mittel werden benötigt? Welche sprachlichen Mittel können nutzbringend systematisiert werden?

Im Hinblick auf das Lernen mit Fachtexten wird Wissen über relevante Textsorten und textsortenspezifische sprachliche Mittel benötigt. Grundlegend sind Kenntnisse über die Strukturierung von Fachtexten (vgl. das o.g. Beispiel des Turnschuh-Textes der PISA-Untersuchung). Um Fachtexte zu verstehen, müssen Lernende eine Reihe sprachlicher Mittel zumindest rezeptiv beherrschen. So werden Auszubildende des Berufsfelds Pflege in Fachbüchern sehr häufig dem Passiv begegnen. Es hat dort in der Regel die Funktion, Handlungen zu benennen, die durchgeführt werden müssen (z.B: „Metallspritzen werden vor der Reinigung in die Einzelteile zerlegt.“, Vieten 2002: 103). Die Auszubildenden müssen diese Sprachform und ihre Funktion daher lernen. Zugleich lohnt es sich, das Passiv mit Hilfe von Beispielen aus den Fachtexten systematisch einzuführen, weil die Auszubildenden bei ihrer zukünftigen Arbeit mit Fachtexten davon profitieren. Ein Beispiel auf der Wortebene sind Adjektivsuffixe. In vielen Fächern bzw. Berufsfeldern lohnt es sich, gemeinsam mit den Auszubildenden eine Liste von Adjek- 
tivsuffixen zu erarbeiten, in der deren Bedeutungen festgehalten und jeweils mit einem Beispiel verdeutlicht werden. Anhand dieser Liste können die Auszubildenden bei ihrer zukünftigen Arbeit mit Fachtexten die Bedeutung unbekannter Adjektive selbstständig erschließen (vgl. Ohm et al. 2007: 39-42).

Je nach beruflicher Handlungssituation benötigen Auszubildende sprachliche Mittel, die sie in die Lage versetzen, die jeweils notwendigen sprachlichen Handlungen auszuführen und die erwarteten Textsorten zu produzieren. Tabelle 1 zeigt einen Ausschnitt aus dem „Szenario Körperpflege eines Patienten“, für das im Rahmen des Projekts „Sprachtraining für Fachunterricht und Beruf“" gegenwärtig ein Online-Lernmodul entwickelt wird.

\begin{tabular}{|l|l|l|l|}
\hline Situation & sprachliche Handlungen & $\begin{array}{l}\text { sprachliche } \\
\text { Mittel }\end{array}$ & Textsorte \\
\hline $\begin{array}{l}\text { Unterstüt- } \\
\text { zung beim } \\
\text { Waschen }\end{array}$ & $\begin{array}{l}\text { Gewohnheiten/Wünsche erfragen } \\
\text { über das Vorgehen informieren }\end{array}$ & $\begin{array}{l}\text { Imperativ } \\
\text { Konjunktiv }\end{array}$ & Dialog \\
& $\ldots$ & $\ldots$ & \\
& $\begin{array}{l}\text { Pflegehandlungen und Beobach- } \\
\text { tungen dokumentieren }\end{array}$ & $\begin{array}{l}\text { Adjektive } \\
\text { Adverbien }\end{array}$ & Pflegebericht \\
& $\ldots$ & $\ldots$ & $\ldots$ \\
\hline
\end{tabular}

Tab. 1: Ausschnitt aus „Szenario Körperpflege eines Patienten“

Die Situation Unterstützung beim Waschen erfordert in der Interaktion mit dem Patienten beispielsweise die sprachlichen Handlungen „Gewohnheiten/Wünsche erfragen“ und „über das Vorgehen informieren“. Um diese ausführen zu können, müssen u.a. der Imperativ („Umdrehen bitte!") und der Konjunktiv („Würden Sie das bitte mal halten?`) beherrscht werden. Die Textsorte, die bei dieser Tätigkeit produziert wird, ist der Dialog. Nach der Durchführung der Pflegehandlungen müssen diese dokumentiert werden. Dazu werden z.B. Adjektive benötigt, mit denen u.a. der Gesamtzustand des Patienten, das Aussehen von Hautstellen und ggf. der Zustand von Wunden benannt werden können. Adverbien werden zur Charakterisierung des Verhaltens des Patienten benötigt. Die Pflegehandlungen werden in Form eines Pflegeberichts dokumentiert. Die Auszubildenden müssen dessen Struktur kennen und wissen, welche Angaben in das Formular einzutragen sind.

\subsubsection{Auf selbstständiges Weiterlernen und berufliche Handlungsfähigkeit abzielen}

Ein wesentliches Ziel tätigkeitsbezogener Sprachförderung muss es sein, die Lern- und Handlungsfähigkeit der Auszubildende langfristig zu unterstützen. Bezüglich der Lernfähigkeit geht es vor allem darum, Techniken und Strategien für das selbstständige Weiterlernen zu vermitteln. Dazu zählen z.B. Techniken zur Erarbeitung und Systematisierung von Wortschatz sowie von Redemitteln für Situationen beruflichen Handelns. Von herausragender Bedeutung für das selbstständige Weiterlernen sind aber zweifellos die Lesestrategien. Sie werden sowohl im beruflichen Alltag als auch in Weiterbildungspha-

1 Informationen zum Projekt im Internet unter http://www.daf.uni-jena.de/sprachtraining/ (11.11.2008). 
sen benötigt. Die Handlungsfähigkeit von Auszubildenden kann auf sprachlicher Ebene dadurch gefördert werden, dass die für eine berufliche Handlungssituation benötigten sprachlichen Mittel zunächst gemeinsam erarbeitet und anschließend in Rollenspielen angewendet werden. In Rollenspielen werden sprachliche Mittel mit sinnlichen Erfahrungen und selbst entworfenen und erlebten Handlungen verknüpft und mit diesen gemeinsam angeeignet. In konkreten beruflichen Handlungssituationen können sie deshalb in der Regel besser aktiviert werden.

\section{Zusammenfassung}

Nicht nur Bildungsstudien, sondern auch die Erfahrungen von Lehrenden und Ausbildenden zeigen, dass vor allem Jugendliche mit Migrationshintergrund beim Eintritt in die berufliche Ausbildung noch nicht einmal über grundlegende bildungssprachliche Fähigkeiten verfügen, die zur Bewältigung fach- und berufsbezogener Aufgabenstellungen benötigt werden. Daran können auch nachträgliche Stützkurse in Deutsch als Zweitsprache häufig nicht viel ändern. Schon unter motivationalen Gesichtspunkten und im Hinblick auf eine Förderung der Sprachbewusstheit erscheint eine fach- und ausbildungsbezogene Sprachförderung Erfolg versprechender. Fach- und ausbildungsbezogene Sprachförderung bedeutet, dass Sprachförderung am besten dort stattfindet, wo die sprachlichen Schwierigkeiten auftreten, nämlich im Fachunterricht und am Ausbildungsplatz, dass sie dann einsetzt, wenn sich Schwierigkeiten zeigen, wenn also das fachliche bzw. berufliche Lernen betroffen ist, und dass sie als integraler Bestandteil des Fachlernens und der beruflichen Qualifikation begriffen wird, nämlich als Förderung von Kompetenzen, die zum Lernen, zum Weiterlernen und zum beruflichen Handeln befähigen.

Sprache ist - nach Vygotskij - ein Mittel zur Steuerung des eigenen Verhaltens und des Verhaltens anderer. Im fachlichen und beruflichen Kontext bedeutet das, dass Lernende und Auszubildende nicht-deutscher Herkunftssprache nur dann in der Lage sind, sich Fachwissen anzueignen und Situationen beruflichen Handelns zu bewältigen, wenn sie über die entsprechenden bildungssprachlichen Fähigkeiten in der Zweitsprache Deutsch verfügen. Dazu zählt das Wissen über fachrelevante sprachliche Mittel und Strukturen, das Wissen über Textsorten und die Fähigkeit, auf der Basis dieses Wissens grundlegende sprachlich-kognitive Operationen auszuführen.

Bei der Förderung der bildungssprachlichen Fähigkeiten sollten Fachlehrer und Ausbilder das Grundprinzip des Scaffoldings berücksichtigen. Dazu wurden im vorliegenden Beitrag folgende Eckpunkte genannt: Erstens sollte auf die Erfahrungen und das sprachliche Vorwissen der Lernenden zurückgegriffen werden. Zweitens sollte sich die Sprachförderung auf die jeweiligen Gegenstände fachlichen Lernens und auf die Erfordernisse der jeweiligen Situationen beruflichen Handelns beziehen. Drittens sollte Sprachförderung möglichst immer so angelegt werden, dass die Fähigkeit zum selbstständigen Weiterlernen und die langfristige berufliche Handlungsfähigkeit gefördert werden. 


\section{Literatur}

Artelt, Cordula; Demmrich, Anke; Baumert, Jürgen (2001): Selbstreguliertes Lernen. In: Deutsches PISA-Konsortium (Hrsg.): PISA 2000. Basiskompetenzen von Schülerinnen und Schülern im internationalen Vergleich. Opladen: Leske + Budrich, 271-298.

Baumert, Jürgen; Schümer, Gundel (2001): Familiäre Lebensverhältnisse, Bildungsbeteiligung und Kompetenzerwerb. In: Deutsches PISA-Konsortium (Hrsg.): PISA 2000. Basiskompetenzen von Schülerinnen und Schülern im internationalen Vergleich. Opladen: Leske + Budrich, 323-407.

Deutsches PISA-Konsortium (Hrsg.) (2001): PISA 2000. Basiskompetenzen von Schülerinnen und Schülern im internationalen Vergleich. Opladen: Leske + Budrich.

Lantolf, James. P.; Thorne, Steven L. (2006): Sociocultural Theory and the Genesis of Second Language Development. Oxford: Oxford University Press.

Ohm, Udo; Kuhn, Christina; Funk, Hermann (2007): Sprachtraining für Fachunterricht und Beruf. Fachtexte knacken - mit Fachsprache arbeiten. Münster et al.: Waxmann. Online-Module zur Veröffentlichung unter http:/ / www.sprachtraining-beruf.de (11.11.2008).

Schaffner, Ellen et al. (2004): Lesekompetenz. In: PISA-Konsortium Deutschland (Hrsg.): PIS A 2003. Der Bildungsstand der Jugendlichen in Deutschland-Ergebnisse des zweiten internationalen Vergleichs. Münster et al.: Waxmann, 93-110.

Stanat, Petra; Schneider, Wolfgang (2004): Schwache Leser unter 15-jährigen Schülerinnen und Schülern in Deutschland: Beschreibung einer Risikogruppe. In: Schiefele, Ulrich; Artelt, Cordula; Schneider, Wolfgang; Stanat, Petra (Hrsg.): Struktur, Entwicklung und Förderung von Lesekompetenz. Vertiefende Analysen im Rabmen von PIS A 2000. Wiesbaden: Verlag für Sozialwissenschaften, 243-273.

Vieten, Markus (Hrsg.) (2002): Handbuch der Arzthelferin. 3., völlig neu bearb. und erw. Aufl.. Stuttgart: Hippokrates.

Vollmer, Helmut J. et al. (2008): Elements of a Framework for Describing the Language of Schooling in Subject-Specific Contexts: A German Perspective. Strasbourg: Council of Europe (unveröffentl. Ms.).

Vygotskij, Lev S. (1992): Geschichte der höheren psychischen Funktionen. R. Kämper (Übs.). Münster; Hamburg: Lit (russ.: Istorija razvitija vysšich psichičeskich funkcii, 1960).

Weidenmann, Bernd (2002): Multicodierung und Multimodalität im Lernprozess. In: Issing, Ludwig J.; Klimsa, Paul: Information und Lernen mit Multimedia und Internet. Lehrbuch für Studium und Praxis. 3. überarb. Aufl.; Weinheim: Beltz, Psychologie-Verl.Union, 45-62. 


\author{
Joachim Schlabach (Turku, Finnland) \& \\ Sabine Grasz (Oulu, Finnland) \& \\ Edeltraud Sormunen (Kuopio, Finnland)
}

\title{
QualiDaF - Qualitätssicherung im fachbezogenen Deutsch als Fremdsprache-Unterricht mündliche Kommunikation
}

\section{Vorbemerkung}

Nachdem sich systematische Qualitätsentwicklung und -sicherung in weiten Bereichen des Lebens durchgesetzt haben, wird Qualitätsmanagement auch für Lehr- und Lernprozesse zunehmend wichtiger. Wie solche Ansätze für die konkrete DaF-Praxis umgesetzt werden können, wird im vorliegenden Beitrag am Beispiel des Fortbildungsprojektes zur Qualitätssicherung im fachbezogenen Deutschunterricht an finnischen Universitätssprachenzentren, kurz QualiDaF, dargestellt. Eingangs werden die Rahmenbedingungen beschrieben, danach das eigentliche Projekt und abschließend werden erste Ergebnisse dargestellt.

\section{Rahmenbedingungen: Zum Fremdsprachenlernen in Finnland}

Traditionell kommt dem Fremdsprachenlernen in Finnland eine relativ große Bedeutung zu. Offiziell ist Finnland zweisprachig, wobei Finnisch von mehr als 90\% der Bevölkerung als Erstsprache angegeben wird und Schwedisch von ungefähr 5\%. In der 
neunjährigen Gesamtschule wird die jeweils zweite Landessprache als Pflichtfach ab der 7. Klasse gelernt. Davor beginnen die SchülerInnen in der Regel in der 3. Klasse mit ihrer ersten Fremdsprache, heute ist das fast immer Englisch. Später können noch weitere Fremdsprachen als Wahl- oder Wahlpflichtfächer gelernt werden. So haben 2007 ca. 30\% der finnischen AbiturentInnen neben Englisch und Schwedisch auch Deutsch gelernt, ca. 20\% Französisch und ca. 11\% Spanisch (vgl. Statistisches Zentralamt, Finnland).

An den Universitäten nimmt der Sprach- und Kommunikationsunterricht eine wichtige Stellung ein. Er wird in der Regel von Sprachenzentren oder vergleichbaren Spracheninstituten organisiert. In allen Studienrichtungen wird neben der zweiten Landessprache der Nachweis zumindest einer Fremdsprache, in der Praxis ist das Englisch, verlangt. Der dem Bachelor vergleichbare „Kandidaatti“-Abschluss fordert dabei ausreichende Sprach- und Kommunikationsfähigkeiten und der dem Master vergleichbare „Maisteri“-Abschluss gute Sprach- und Kommunikationsfähigkeiten. Die Anforderungen im Wirtschaftsbereich sind noch höher, denn in fast allen Wirtschaftsstudiengängen sind neben den beiden Landessprachen zwei Fremdsprachen obligatorisch. Hier nimmt Deutsch nach Englisch die zweitstärkste Position vor Französisch, Spanisch und Russisch ein.

Die finnischen Sprachenzentren sind traditionell gut vernetzt. So gab es bis Mitte der 1990er Jahre ein zentrales Sprachenzentrum an der Universität Jyväskylä, das für und in Kooperation mit den anderen Sprachenzentren Unterrichtsmaterialien entwickelte, Fortbildungskurse anbot und auch Forschung im Bereich Fremdsprachendidaktik und Fachsprachen betrieb. Nach seiner Umwandlung in ein Institut für angewandte Sprachforschung mit einem breiteren Wirkungsfeld entstand eine Lücke, die im Jahre 2001 von dem Netzwerk FINELC (Finnish Network of Language Centres) gefüllt wurde. Die Ziele FINELCs, das wiederum Mitglied in CercleS (Europäischer Verband der Hochschulsprachenzentren) ist, sind die Stärkung von Mehrsprachigkeit durch ein breites Angebot an Sprachkursen an den Universitäten und die Entwicklung von Evaluationspraktiken und Qualitätssicherung in enger Zusammenarbeit zwischen den Sprachenzentren und in Kooperation mit europäischen Partnern. Die Arbeit von FINELC wird vom finnischen Unterrichtsministerium durch Projektfinanzierungen unterstützt. Das „Virtuelle Sprachenzentrum“, ein FINELC-Projekt der Jahre 2002 bis 2006 förderte die Entwicklung von frei zugänglichem Online-Material, das in Zusammenarbeit zwischen mehreren Sprachenzentren entwickelt wurde. Im aktuellen FINELC-Projekt „LAAKEA“ (2007-2009) geht es vorrangig um Methoden der Qualitätssicherung an den Sprachenzentren. Das Projekt QualiDaF ist dabei eines von fünf LAAKEA-Teilprojekten. 


\section{Das Projekt QualiDaF}

\subsection{QualiDaF als Entwicklungs-, Qualitätssicherungs- und Fortbildungsprojekt}

Das Projekt QualiDaF kommt aus mehreren Bereichen, verfolgt recht unterschiedliche Ziele und lässt sich somit auch aus verschiedenen Perspektiven beschreiben. Einerseits ist es ein Entwicklungsprojekt, bei dem Standards für das Curriculum, für den Unterricht und für die Bewertung von Lernerleistungen formuliert werden sollen. Die im Gemeinsamen europäischen Referenzrahmen vorliegenden recht allgemein gehaltenen Kannbeschreibungen sollen für ausgewählte kommunikative Handlungen und vor dem Hintergrund der konkreten Lernbedingungen an den finnischen Universitäten präziser formuliert werden. Es geht dabei auch um eine einheitlichere Beschreibung von Kursen und Kursinhalten. In Zukunft soll es damit leichter sein, die an verschiedenen Hochschulen erworbenen Sprachkompetenzen miteinander zu vergleichen.

Andererseits ist QualiDaF auch ein Qualitätssicherungsprojekt für die Praxis des Deutsch als Fremdsprache-Unterrichts mündliche Kommunikation. Durch gemeinsame Formulierung von Lernzielen, Bewertungskriterien und Kalibrieren von Bewertungsformen sollen Standards und Transparenz geschaffen werden. Es geht also um fachdidaktische Prozesse und ihre „Produkte“. Eng verbunden mit dem Aspekt der Qualitätssicherung ist auch die Profilierung des Faches Deutsch als Fremdsprache, da die Stellung von Deutsch an finnischen Hochschulen weniger sicher als früher ist. In Zeiten von zahlreichen Hochschulreformen sowie von Bestrebungen nach formaler Ausbildungsqualität (Qualitätshandbücher, Hochschulaudits) ist es für alle Beteiligten wichtig, sich für ein positives Profil ihrer Sprache und ihrer Arbeit einzusetzen.

Und schließlich ist QualiDaF auch ein Fortbildungsprojekt: QualiDaF folgt dabei nicht dem Konzept der Top-Down-Fortbildung im Sinne einer Applikationsdidaktik mit Expertenvortrag, Diskussion und dann eventuell erfolgender Umsetzung. Ein solch herkömmliches Konzept impliziert ein Defizit bei den Fortzubildenden, während die Experten und Fachwissenschaftler wüssten, was wie gelehrt und gelernt werden sollte (vgl. Legutke 1999: 8). Mit Bezug auf Reuter (1997) ist gerade der Gegenstand mündliche Kommunikation für das andere Konzept einer Bottom-Up-Fortbildung prädestiniert. Die Fortbildung ist zunächst nicht rezeptiv, sondern reflexiv: Die Projektmitglieder sind zugleich Subjekt und Objekt der Fortbildung. Ihre Unterrichtstätigkeit steht im ständigen Wechselspiel mit der Reflexion, das Projekt ist Anleitung und Ansporn dazu. Die eigentliche Fortbildungsleistung findet im Selbst-Tun statt, bei der eigenen Tätigkeit als Deutschlehrender (vgl. Raasch 2003: 487f.). Die Projektmitglieder orientieren sich am Referenzrahmen, konkretisieren die darin gesammelten Deskriptoren auf Basis ihrer eigenen Unterrichtspraxis, vergleichen die Umsetzung miteinander und suchen nach gemeinsamen Formulierungen für die gewählten Themenbereiche. Quali$\mathrm{DaF}$ ist damit Anleitung zur eigenen Fortbildung. Die Experten und die teilnehmenden Koordinatoren sind gleichberechtigte Dialogpartner. 


\subsection{Inhalte und Ziele von QualiDaF}

Der Gegenstand von QualiDaF ist die Qualitätssicherung im fachbezogenen Deutsch als Fremdsprache-Unterricht mündliche Kommunikation. Es geht dabei nicht um die Umsetzung der von außen vorgegebenen und auf organisatorische Abläufe gerichteten Qualitätssicherungsmaßnahmen, sondern um die konkrete fachdidaktische Arbeit von DaF-Lehrenden. Die Ziele sind immanent fachdidaktisch, sie kommen aus der Fachdidaktik und sind gerichtet auf die Fachdidaktik.

Die Konzeption von QualiDaF folgt in weiten Teilen dem Ansatz von Bärenfänger (2007, 2008), bei dem der Gemeinsame europäische Referenzrahmen als Instrument zur Qualitätssicherung genutzt wird. Mit Bezug auf die in der Industrie entwickelten Verfahren zum Qualitätsmanagement beschreibt Bärenfänger drei Verfahren zur Verwendung des Referenzrahmens zur Qualitätssicherung. Am bekanntesten sind die verschiedenen Skalen zur Beschreibung von fremdsprachlichen Kompetenzen und ihre Zuordnungen zu den sechs Niveaustufen A1-C2. Dadurch ist es nun möglich, fremdsprachliche Kompetenz sprachenübergreifend als ein standardisiertes „Produkt“ zu beschreiben. Darüber hinaus ermöglicht der Referenzrahmen über Fragen an die Nutzer die Prozessdimension des Fremdsprachenlernens und -lehrens bei der Planung zu berücksichtigen. Und schließlich lassen sich die Kompetenzdeskriptoren für die Erstellung von Bewertungskriterien und damit als Instrument für die Qualitätsprüfung einsetzen (vgl. Bärenfänger 2007: 40ff.). Der Referenzrahmen bietet also für alle relevanten fachdidaktischen Arbeitsschritte von der Curriculumsplanung über die Unterrichtspraxis bis hin zum Bewerten und Evaluieren die Instrumente, die für eine fachbezogene Qualitätssicherung notwendig sind. Die Deskriptoren ermöglichen eine Standardisierung von Lernzielen und Bewertungskriterien und dadurch, dass diese innerhalb des Projekts und später in Kursbeschreibungen, Studienführern und Sprachzeugnissen explizit gemacht werden, entsteht Transparenz.

Da der Referenzrahmen bewusst allgemein formuliert ist und als Referenz nicht auf Domänen und Kommunikationsbereiche festgelegt ist, ist die Adaption auf einer konkreteren Ebene und für bestimmte Bereiche notwendig. Für QualiDaF relevante Konkretisierungen sind beispielsweise „Profile deutsch“, die von der deutschen Wirtschaft entwickelten Deskriptoren in „Arbeitsplatz Europa“ oder das an einem der beteiligten finnischen Spracheninstitute entwickelte „Hankens CEFR-Profil“.

Im Fokus steht die mündliche Kommunikation im fachbezogenen Unterricht Deutsch als Fremdsprache. Dieser Sprachbereich ist aufgrund der Flüchtigkeit der gesprochenen Sprache eine besondere Herausforderung für die Unterrichtspraxis und das Bewerten. An finnischen Universitätssprachenzentren sind die Deutschkurse in der Regel fachbezogen und berufs- sowie studienorientiert. QualiDaF bezieht sich hier auf die Fachbereiche Wirtschaft, Technik und Recht und ist auf drei Themenbereiche begrenzt. Es sind dies die drei als allgemein relevant erscheinenden Ausschnitte aus der Unterrichtspraxis Präsentation bzw. Vortrag, Bewerbungsgespräch sowie Verbalisierung von Zahlen und Daten. Der erste Themenbereich repräsentiert eher monologische, der zweite eher dialogische Formen, der dritte Themenbereich ist besonders für wirtschaftliche Kurse relevant. 


\subsection{Projektarbeit}

Das Projekt hat 20 Mitglieder, die als LektorInnen oder Lehrbeauftragte alle Universitätssprachenzentren bzw. Spracheninstitute repräsentieren. Sie sind an ihren Instituten für die mündliche Kommunikation zuständig. Zwei externe Experten begleiten das Projekt: Prof. Dr. Ewald Reuter (Professor für Deutsche Sprache und Kultur, Universität Tampere) als Fachmann für den mündlichen Fachfremdsprachenunterricht sowie Ari Huhta (Forscher am Zentrum für angewandte Sprachforschung an der Universität Jyväskylä) als Experte für die Entwicklung und Methodik von Sprachprüfungen. Eine Koordinierungsgruppe entwickelt Aufgaben und Ziele und organisiert die Projektarbeit. QualiDaF hat eine Laufzeit von drei Semestern und ist in drei Arbeitsphasen gegliedert. In jeder Phase gibt es ein zweitägiges Plenumstreffen mit Vorträgen, Berichten aus den drei Themenbereichen und Arbeit in Kleingruppen. Die kontinuierliche Arbeit läuft über die Lernplattform Moodle als virtuellem Arbeitsraum (mit Arbeitsräumen für Themenbereiche, Dokumentations- und Materialbank, Wiki, Kalender sowie E-Mail). Zwei der Treffen werden gemeinsam mit der jährlichen Fortbildungstagung „DaF-Tag“ organisiert, die von den Deutschabteilungen der drei Wirtschaftsuniversitäten mit Unterstützung durch das Goethe-Institut Finnland veranstaltet werden. Weitere Kooperationspartner für Finanzierung sind der DAAD Bonn sowie Solki, das Institut für angewandte Sprachforschung an der Universität Jyväskylä.

\section{Durchführung und erste Ergebnisse}

Die Projektarbeit gliedert sich in folgende drei Arbeitsphasen:

- Beschreibung des Ist-Zustands,

- Beschreibung von Lernzielen auf den Niveaustufen A2, B1 und B2,

- Entwicklung und Beschreibung von Beurteilungskriterien, Arbeit mit konkreten Unterrichtsbeispielen und Kalibrierung von Bewertungsformen.

In der ersten Arbeitsphase beschreiben alle QualiDaF-Projektmitglieder in einer Umfrage den Ist-Zustand bei den DaF-Kursen zur mündlichen Kommunikation an ihren Instituten. In der Befragung sind neben einer Erfassung der institutionellen Rahmenbedingungen alle Bereiche der Unterrichtspraxis, von der Planung bis zur Evaluation, von den Lehr- bis zu den Lernbedingungen enthalten. Konkret geht es unter anderem um Zulassungsbedingungen, Lernziele, Kursinhalte, Kursmaterialien und im Kurs verwendete Medien, um Beurteilungsformen, Kursevaluation und -entwicklung und um Formen der Qualitätssicherung. Eine derart breite Erhebung mit Daten von allen finnischen Sprachenzentren ist bisher noch nicht durchgeführt worden.

Ein zentraler und direkt auf die Arbeit von QualiDaF bezogener Bereich ist die Beschreibung der Lernziele. Hier gibt es recht unterschiedliche Formen, was dazu führt, dass diese Beschreibungen oft nur wenig transparent sind und es damit schwierig ist, nach einem Hochschulwechsel Sprachkurse anrechnen zu lassen. Dieses Ergebnis verwundert insofern nicht, da es keine für den Universitätsbereich geltenden Rahmencurricula gibt und auch externe Sprachprüfungen an den finnischen Universitäten nicht 
sehr verbreitet sind. Die Lehrenden haben dadurch sehr viele Freiheiten bei der Wahl und auch bei der Beschreibung der Lernziele und Lerninhalte. An vielen Institutionen werden seit einigen Jahren die Kannbeschreibungen des Referenzrahmens für diesen Zweck herangezogen, die jedoch aufgrund ihrer allgemeinen Ausrichtung nur wenige konkrete Beschreibungen von fachbezogenen Kompetenzen bieten.

Ein weiterer zentraler Bereich beschäftigt sich mit Fragen zur Praxis des Beurteilens und Bewertens. Für die Etablierung einer funktionierenden Qualitätssicherung ist von elementarer Bedeutung, dass für die jeweilige Lernsituation angemessene Test- und Bewertungsverfahren ausgewählt werden (vgl. Bärenfänger 2007: 42f.). Dazu gehört die Klärung, wer ist der Prüfer, was wird wie überprüft (z.B. das Erreichen bestimmter Lernziele oder eher eine allgemeine fremdsprachliche Kompetenz bzw. kontinuierlich oder punktuell, am Ende oder im Laufe eines Kurses) sowie wie wird es schließlich bewertet.

Es zeigt sich, dass es bislang nur sehr wenige standardisierte Beurteilungsformen im Bereich der mündlichen Kommunikation gibt. Zumeist erfolgt die Bewertung kontinuierlich, seltener durch eine oder mehrere Prüfungen während oder am Ende der Kurse. Die meisten Prüfungen sind insofern standardisiert, dass alle KursteilnehmerInnen die gleichen Aufgaben bekommen. Ausnahmen sind gleiche Aufgaben auf Institutsebene und Aufgaben auf Basis einer externen Prüfung (z.B. mündlicher Teil PWD - Prüfung Wirtschaftsdeutsch International). Zumeist sind die Lehrenden alleine für die Prüfung bzw. die kontinuierliche Beurteilung der Leistungen verantwortlich. Zudem gibt es nur wenige Maßnahmen zur Sicherung der Vergleichbarkeit und Zuverlässigkeit der Beurteilungen.

Mit Hilfe der Befragung konnte eine Bestandsaufnahme der Praxis vorgenommen werden. Es ist nun klar zu erkennen, wo Intransparenz und Unsicherheit herrscht. Dadurch ist es im weiteren Verlauf des Projekts möglich, ganz gezielt zu diesen Themen arbeiten zu können. Die Befragung führt zudem zu einer Reflexion und einem kritischen Hinterfragen der eigenen Unterrichtspraxis. Außerdem erfüllt die Befragung auch noch einen dritten Zweck: Es wird dadurch die für das Projekt zentrale Begrifflichkeit eingeführt, was vor allem bei einer, gemischtsprachlichen`Gruppe nützlich ist.

In der zweiten Arbeitsphase beschäftigen sich drei Kleingruppen mit den einzelnen Themenbereichen Präsentation/Vortrag, Bewerbungsgespräch und Verbalisierung von Zahlen und Daten. Zu Beginn steht ein Vergleich darüber, in welchen Kursen, für welche Studierenden (sprachliche Vorkenntnisse, Studienfach, Studienabschnitt etc.), in welchem Umfang und mit Hilfe welcher Materialien diese Themen an den verschiedenen Institutionen unterrichtet werden. Gemeinsam werden ganz konkret die in den Bereichen zu erlangenden Kompetenzen (Wortschatz, Strukturen, pragmatische Kompetenzen usw.) für die Niveaustufen A2-B2 festgelegt und mit Hilfe der Kannbeschreibungen des Referenzrahmens ergänzt und für den fach- bzw. studienspezifischen Unterrichtskontext adaptiert. Als Ergebnis liegen damit sowohl globale als auch detaillierte Kannbeschreibungen vor. Nach Möglichkeit werden auch zentrale Redemittel für die einzelnen Niveaustufen beschrieben. 
Beispiel 1: Lernziele für den Themenbereich Verbalisierung von Zahlen und Daten:

B2

Kann die zentrale Botschaft eines Schaubilds (einer Grafik oder Tabelle), sowie komplexe graphisch oder tabellarisch dargestellte Datenreihen klar, systematisch und detailliert beschreiben, sowie Besonderheiten und Zusammenhänge hervorheben. Verfügt über ein ausreichend breites Spektrum an (Fach-)Wortschatz und Redemitteln, um Rangordnungen, Vergleiche, Tendenzen zu erläutern und zu kommentieren. Kann komplexere Fragen aufgreifen und in gewandter Weise darauf eingehen.

Beispiel 2: Auszug aus den detaillierten Kannbeschreibungen für den Themenbereich Bewerbungsgespräch:

Paralinguistische Kompetenzen: z.B. Höflichkeitsformen, Blickkontakt, Körpersprache, Feedbackfloskeln

A2

Angemessene Anrede kann benutzt werden; Blickkontakt ist noch etwas unregelmäßig, da Konzentration auf Sprechakt; außer vorhandenem Händedruck ist die Körpersprache noch wenig ausgeprägt, da Konzentration auf Sprechakt; einige einfache Feedbackfloskeln werden beherrscht, aber die Hauptverantwortung für das Gespräch liegt beim Interviewer.

Diese Beschreibungen sind nicht als für alle verbindliche Lernziele zu verstehen, sondern dienen als gemeinsam verhandelte Empfehlungen und Ausgangspunkt für die Planung der konkreten Kurse an den jeweiligen Institutionen.

In der dritten Arbeitsphase sollen ausgehend von den gemeinsam formulierten Lernzielen Kriterien für die Beurteilung in den Teilbereichen erarbeitet werden. Auch dafür werden die Kannbeschreibungen aus dem Referenzrahmen herangezogen, die sprachliches Können nicht nur beschreiben, sondern auch Hinweise auf dessen Qualität geben: Z.B. „Kann sich in vertrauten Gesprächssituationen ausreichend korrek.t verständigen, ...“. Oder: „Kann auf viele Fragen situationsangemessen reagieren und entsprechend Auskunft geben“ (Profile deutsch, Interaktion mündlich, B1; Hervorhebung durch Autoren).

Um eine transparente und stärker übereinstimmende Beurteilungspraxis von mündlichen Leistungen zu erreichen, ist es notwendig, die entwickelten Kriterien konkret anzuwenden und ihre Umsetzung miteinander zu vergleichen. Dazu sollen authentische Prüfungs- und Übungsaufnahmen (Audio oder Video) gemeinsam analysiert und die studentischen Leistungen beurteilt werden. Das dient einerseits der Schulung in der Verwendung der Beurteilungskriterien, andererseits sind diese Aufnahmen und gemeinsamen Beurteilungen auch Referenzbeispiele bzw. Benchmarks. Eine Sammlung von Benchmarks, die direkt aus dem relevanten Unterrichtskontext stammen, ist neben der Abgleichung mit anderen nationalen und internationalen Testbeispielen ein zentraler Arbeitsschritt für die Qualitätssicherung in der Beurteilungspraxis.

Geplant ist, die Beschreibungen der Lernziele und Beurteilungskriterien zusammen mit den Beispielen zu veröffentlichen und sie auf nationalen und internationalen Foren vorzustellen und zu diskutieren. So können sie in Zukunft bei Schulungen und Weiterbildungsveranstaltungen eingesetzt werden und als ein wichtiges Hilfsmittel bei der 
Einführung neuer Lehrkräfte dienen. Außerdem können die veröffentlichten Ergebnisse als Referenz für Benchmarkingzwecke für andere Sprachen und andere Institutionen mit ähnlichem Vorhaben im In- und Ausland nützlich sein.

Ferner ist geplant, mit anderen vergleichbaren Projekten zusammenzuarbeiten und die Ergebnisse mit ähnlichen Projekten über Sprachen- und Ländergrenzen hinaus zu vergleichen. Entscheidend ist jedoch, inwieweit QualiDaF seine Ziele als Entwicklungsund Fortbildungsprojekt erreicht und die entwickelten Standards, Empfehlungen für Lernziele, Bewertungskriterien auch in der Praxis umgesetzt werden.

\section{Literatur}

Bärenfänger, Olaf (2007): Qualitätsmanagement mit dem Gemeinsamen europäischen Referenzrahmen für Sprachen. In: Deutsch als Fremdsprache 1, 37-45.

Bärenfänger, Olaf (2008): Qualitätsmanagement auf der Basis des Gemeinsamen europäischen Referenzrahmens für Sprachen. Modelle und Vorgehensweisen. Vortrag auf dem DaF-Tag 2008 in Helsinki.

Deutscher Industrie- und Handelskammertag e.V. (2007): Arbeitsplatz. Europa. Sprachkompetenz, wird messbar. 3. Auflage. Berlin: DIHK.

Europarat (2001): Gemeinsamer europäischer Referenzrahmen für Sprachen. Straßburg: Europarat und Berlin: Langenscheidt.

Glaboniat, Manuela et al. (2005): Profile deutsch. Berlin: Langenscheidt (CD-Rom).

Hankens CEFR-Profil (2007). In: Breckle, Margit; Båsk, Märta; Rodenbeck, Rolf (Hrsg.): Wirtschaftssprache Deutsch in Studium und Beruf. Curriculumentwicklung an der Schwedischen Wirtschaftsuniversität in Finnland. Helsingfors: Hanken, 86-92.

Legutke, Michael K. (1999): Fort- und Weiterbildung. Einflussfaktoren und Brennpunkte. In: Fremdsprache Deutsch Sondernummer 1999: Lehrerfortbildung, 6-11.

Raasch, Albert (2003): Fort- und Weiterbildung von Fremdsprachenlehrern. In: Bausch, Karl-Richard; Christ, Herbert; Krumm, Hans-Jürgen (Hrsg.): Handbuch Fremdsprachenunterricht. 4. Auflage. Tübingen; Basel: Francke, 486-492.

Reuter, Ewald (1997): Mündliche Kommunikation im Fachfremdsprachenunterricht. Zur Empirisierung und Reflexivierung mündlicher Kommunikationstrainings. München: Iudicium.

Statistisches Zentralamt, Finnland (Tilastokeskus): Subject choices of completers of upper secondary general school education in 2007. http://www.tilastokeskus.fi/til/ava/2007/ ava_2007_2007-12-14_tie_001_en.html (10.10.2008). 
Christoph Chlosta, Matthias Jung (Hrsg.) (2010): DaF intergriert: Literatur - Medien - Ausbildung. Tagungsband der 36. Jahrestagung des Fachverbandes Deutsch als Fremdsprache 2008. Göttingen: Universitätsverlag, 293-315.

\section{Carmen Schier (Leipzig)}

\section{„Alle anders, alle gleich?“ - Herausforderungen und Gestaltungsmöglichkeiten germanistischer Studiengänge nach Bologna}

\section{Vorbemerkung}

„Alle anders - alle gleich“ ist der Titel einer europäischen Kampagne für Vielfalt, Menschenrechte und Partizipation. Es könnte im besten Falle auch das Motto für die Reformierung des europäischen Studiensystems und dem damit verbundenen Nachdenken über zeitgemäße Inhalte der Interkulturellen Germanistik sein. Nach über zehn Jahren universitärer Auslandstätigkeit in der Interkulturellen Germanistik (u.a. als DAADLektorin) in der Ukraine, Portugal und Brasilien arbeite ich seit Oktober 2006 wieder in Deutschland und unterrichte am Herder-Institut der Universität Leipzig in den neuen modularisierten BA- und MA-Studiengängen sowie im auslaufenden Grund- und Hauptstudium des alten Magisterprogramms und erleb(t)e darüber hinaus die Versuche meiner Universitäten in der Ukraine und in Portugal, die Studiengänge in Germanistik umzustellen bzw. zu modernisieren. In meiner derzeitigen Tätigkeit als Lehrkraft für besondere Aufgaben mit einer halben Stelle am Herder-Institut der Universität Leipzig, die in Sachsen Lehrverpflichtungen im Umfang von 12 SWS vorsieht, ${ }^{1}$ bin ich vor allem für den Bereich Deutsch als Zweitsprache (DaZ) zuständig. Diese Lehrveranstaltungen

1 Dieser Fakt markiert ganz nebenbei und unabhängig von meiner Person schon einmal eine kleine Rahmenbedingung, die man unter dem Stichwort des veränderten und schwindenden „klassischen“ akademischen Mittelbaus betrachten könnte. 
wurden neu in die modularisierten Studiengänge aufgenommen. Außerdem erteile ich Seminare und Übungen im Bereich Kulturstudien und Didaktik/Methodik DaF.

\section{Fachinhalte und Profilbildung}

1999 einigten sich in der Bologna-Erklärung 29 europäische Staaten auf gewisse formale Zielvereinbarungen wie vergleichbare Abschlüsse, arbeitsmarktrelevante Qualifikationen, ein Studium mit zwei Hauptzyklen und ein dazugehöriges Leistungspunktesystem. In diesem Zusammenhang standen auch Fragen der Mobilität, der transnationalen Qualitätssicherung und einer Curriculumsentwicklung zur Diskussion, mit dem Ziel der Schaffung eines einheitlichen europäischen Hochschulraums bis zum Jahr 2010 (vgl. Bollenbeck; Wende 2007: 7). Jede universitäre Einrichtung aber soll, will und muss sich nach wie vor vorteilhaft positionieren. Diese standortspezifische Profilbildung, die etwas mit den Traditionen der Einrichtung und gewachsenen Kompetenzen zu tun hat, schließt eine Debatte über Fachinhalte, die unter gemeinsamen Rahmenbedingungen zu einer Art Kerncurriculum führen könnten, nicht aus. Doch wie vereinheitlicht man etwas, ohne alle Unterschiede aufzuheben; wie verändert man etwas und bleibt sich dennoch treu?

Die Probleme der Germanistik im traditionellen Selbstverständnis ihrer Fächer und Teilgebiete sind nicht neu. Im Inland und besonders im Ausland gab und gibt es in der Germanistik eine unterschiedliche Hinwendung zu Linguistik oder Literaturwissenschaft, die Landeskunde hat sich ohnehin erst in den letzten Jahren stärker auch als ein wissenschaftlich eigenständiger Bereich definiert. Die Besonderheit der Germanistik besteht darin, dass sie eine Nationalphilologie ist. Der Fokus der Auslandsgermanistik ist naturgemäß sehr viel weiter gespannt. Der Wandel der Germanistik zu einer interdisziplinär betriebenen Kultur- und Medienwissenschaft ist in meinen Augen eine Bereicherung, die allerdings Konflikte mit den herkömmlichen Kompetenzen in sich birgt. Mit Blick auf die vielfach angestrebte Interdisziplinarität fragt Georg Mein nicht zu Unrecht: „,Wohin mit all den Kultur- und Medienwirten, den Absolventen der mannigfaltigen internationalen, interdisziplinären, interkulturellen und transmedialen BA's? Was machen die vielen Master of European Studies?" (2006: 9). Mein sieht das als Flucht in eine fragwürdige Moderne, eine Verjüngung durch Kultur- und Medienwissenschaften und verweist darauf, dass das Neue nicht gegen das Alte ausgespielt werden darf, wenn ,statt auf philologische Kernkompetenzen auf den Hype von Medien und Kultur gesetzt wird.“ (ebd.: 12) Das Fach Germanistik leistet einen wichtigen Beitrag für das kulturelle Gedächtnis einer Gesellschaft. Die Idee, dass ein Kerncurriculum daher den funktionalen Status des Faches im Kontext von Kultur und Gesellschaft widerspiegeln muss, halte ich für länderübergreifend praktikabel. „Es ist die Germanistik, die zur ,Lesbarkeit ${ }^{`}$ der vergangenen und gegenwärtigen Kultur einen zentralen Beitrag leistet, indem sie symbolische und ästhetische Repräsentationen und mündliche wie schriftliche Wissensformen ebenso entschlüsseln hilft wie Repräsentationen des Anderen und Fremden“ (ebd.: 13). Im Mittelpunkt steht damit die Frage, in welcher Weise die philologischen Kernkompetenzen, die ein grundständiges Germanistikstudium 
vermittelt, für die Praxis fruchtbar gemacht werden können. Rolf Parr bringt es auf den Punkt: Es geht um nicht mehr und nicht weniger als um die „Integration von Fachidentität, Studiengangsstruktur und Ausbildungszielen“ (Parr 2006: 32). Dabei kommt es in der Auslandsgermanistik und in den hiesigen DaF-/DaZ-Studiengängen meines Erachtens darauf an, insgesamt vor allem im Bachelor stärker auf ein transdisziplinäres Konzept zu setzen. Ich meine dies keineswegs nur mit Blick auf die Landeskunde oder die Kulturstudien, sondern auch hinsichtlich einer sinnvollen Verbindung von DaF mit anderen Studieninhalten.

Neben den Inhalten spielt in einer globalisierten Welt längst auch die Organisation von Lernprozessen eine Rolle. Metawissen gewinnt zunehmend an Bedeutung. Lernen bedeutet „in erster Linie die prinzipielle Kompetenz, mit Veränderungen und Unsicherheiten der Lebens- und Arbeitswelten, mit neuen Strukturen und unbekannten Situationen reflektierend und kritisch, aber auch kreativ, einfallsreich und offen umgehen zu können." (Wende 2006: 113) Waltraud Wende schlägt deshalb themen- und problembezogene Fragestellungen zur Erprobung kulturvergleichender Projektarbeit und Methodenkenntnisse unter Einbeziehung von Literatur und durch Medien transportierter Wirklichkeitsfelder vor. Als Beispiele nennt sie Fragen nach „Identität stiftenden Funktionen von Nationenkonstruktionen, nach nationalen Selbst- und Fremdzuschreibungen, gegenwärtigen wie historischen Freund- und Feindbildern, wechselseitigen Differenzerfahrungen, europäischen, nationalen, territorialen, gruppenspezifischen Vorstellungsbildern, transnationalen und nationalen Werten, Sitten und Gebräuchen [...] Folgeerscheinungen von Migration und Europäisierung [...] dem Zusammenhang von Sprachkompetenzen, Kommunikation und Verständigung [...]“ (ebd.: 117). In diesem Kontext könnte auch der Stellenwert von literarischen und filmischen Wirklichkeitsinterpretationen für das Zusammenwachsen von Europa betrachtet werden.

Alle im länderübergreifenden kulturellen Diskurs stehenden Themen wie Zeit, Raum, Wertorientierungen und Identität (ich beziehe mich hier auf das von Claus Altmayer vertretene Konzept der kulturellen Deutungsmuster im Rahmen eines kulturwissenschaftlichen Ansatzes für die Landeskunde) bieten interdisziplinäre Ansatzpunkte und meines Erachtens auch enge Verbindungen zu literaturwissenschaftlichen Inhalten (Altmayer 2006: 56).

Für die Linguistik beschreibt Rüdiger Weingarten neben den klassischen Bereichen drei Aufgabenfelder, die sich durch den europäischen Integrationsprozess ergeben: Sprachtypologie und Sprachkontaktforschung, Europäische Sprachengeschichte und Literalitätsforschung (Weingarten 2006: 52).

Die Grenzen der Disziplin geraten in Bewegung. Während die Studentenzahlen der sogenannten Inlandsgermanistik ungebrochen hoch sind, müssen in einigen Ländern die Universitäten um den Fortbestand ihrer Germanistik fürchten. Die Verantwortlichen müssen deshalb in der inhaltlichen Planung oft mutiger, rigoroser sein, um ihre Germanistik zu retten und durch mehr Interdisziplinarität und Transdisziplinarität lukrativer zu machen. Transdisziplinarität kann sich letztlich aber nur dort fruchtbar entfalten, wo ein disziplinäres Fundament vorhanden ist. So wird längst nicht aus jeder Verbindung 
der Germanistik mit Wirtschafts- oder Medienkunde automatisch ein fachlich tragendes Angebot. Wo bleiben die soliden fachübergreifenden Module? Parr schlägt beispielsweise für ein integratives Modul, in dem „alte“ philologische und „neue“ mediale Kernkompetenzen verbunden werden, die „Analyse hybrider Text/Bild-Korrelate“ vor. (Parr 2006: 35).

Aus meiner Sicht liegt in gemeinsamen Konzeptionen von ganzen Modulen mit anderen Fachbereichen die Zukunft. Doch solche Angebote sind bisher eher die Ausnahme. Sie könnten durch fachübergreifende Problemstellungen gerade in den neuen Studiengängen eine Breite liefern, die die Tiefe nicht vermissen lässt. Der Frage der Breite begegnet man im Ausland oft noch anders. Viele Germanistikstudenten besuchen im Rahmen eines Pflichtprogramms zusätzlich zahlreiche fachübergreifende Lehrveranstaltungen, worauf ich später noch zurückkommen werde.

\section{Rolle der qualifizierten Lehre und Praxisbezug}

Im Zuge der Anforderungen des Bologna-Prozesses zeigt sich ein altes Dilemma vieler deutscher Universitäten auf neue Weise. Bei allen Bemühungen einzelner Einrichtungen gibt es gegenüber den Universitäten in Portugal, Brasilien und der Ukraine immer noch eine relative Geringschätzung der Lehre gegenüber der Forschung. Zwar will der Wissenschaftsrat generell an den Universitäten einen neuen Professorentyp mit dem Schwerpunkt Lehre einführen und durch diese neuen Stellen die Qualität der Lehre stärken, diese Empfehlung ist jedoch nach wie vor nicht unumstritten (vgl. Die Zeit-online 2007 und Hartung; Wiarda 2008: 61). Der qualifizierte Mittelbau deutscher Universitäten ist geschrumpft, Lehraufträge und LfbA-Stellen (Lehrkraft für besondere Aufgaben) - nicht selten als Teilzeitstellen - haben ihn nur teilweise ersetzt. Es ist wohl der allgemeinen Arbeitsmarktlage geschuldet, dass man für ein Stundenhonorar von 16,00 Euro $^{2}$ an einer Universität überhaupt qualifizierte Kräfte für Lehraufträge verpflichten kann, bezahlt werden natürlich nur die gehaltenen Stunden, keine Rede von den Vor- oder Nachbereitungen oder Korrekturleistungen. Nicht wenige deutsche Bildungsträger, die im DaF-/DaZ-Bereich Kurse anbieten, vergüten die Arbeit ihrer Lehrkräfte nicht leistungsgerecht. Sowieso wird in Deutschland in diesem Bereich vorrangig auf Honorarlehrer gesetzt, eine feste, auch befristete Anstellung ist seltener.

Die Schnittstelle Schule-Hochschule scheint mir ebenfalls noch immer ein Stiefkind zu sein, die Verbindung von Wissenschaft und Schule beginnt sich aufzulösen. Das z.B. war an den drei bereits erwähnten ausländischen Universitäten in Brasilien, Portugal und in der Ukraine ganz anders. So waren alle drei ausländischen Universitäten, die in den jeweiligen Ländern zu den führenden Einrichtungen in der Germanistikausbildung zählen, immer auch engagierte Anbieter von Lehrerfortbildungsveranstaltungen. Dadurch war nicht nur eine Aktualisierung der didaktisch-methodischen Kenntnisse der Lehrer möglich, sondern das Hineintragen von Forschungsdebatten des jeweiligen

2 Beispielsweise beginnt der Honorarsatz für Lehraufträge am Herder-Institut der Universität Leipzig mit 16,00 Euro. Im Fachbereich Deutsch als Fremdsprache an der Universität Jena werden knapp 19,00 Euro gezahlt, Stand Dezember 2007. 
Fachbereiches in die Schulen und Bildungseinrichtungen, und zwar aus erster Hand. Und natürlich hat das Feedback der vor Ort in Schulen und Spracheinrichtungen unterrichtenden Kollegen auch ein realitätsnahes Bild von den Möglichkeiten und Grenzen der Lehre in die Universitäten gebracht.

Entgegen aller - meiner Meinung nach berechtigten - Überlegungen, im DaF-Kontext neben dem DaF-Lehrer für Absolventen neue Berufsbilder zu skizzieren, wollen weit über 80\% der von mir im Juni 2007 befragten 145 Studenten am Herder-Institut aller Kurse, also in den alten und neuen Studiengängen, Deutsch als Fremdsprache unterrichten. Nur rund 16\% aller kreuzten bei der Frage: Möchten Sie einmal DaF unterrichten?, nein oder eher nein an. Nehmen wir ernst, dass der weitaus größte Teil der Absolventen später tatsächlich $\mathrm{DaF}$ lehren möchte, dann muss eine solide didaktischmethodische Ausbildung Bestandteil des Studiums sein, denn diese Studenten absolvieren kein klassisches Lehramtsstudium, sie werden kein Referendariat absolvieren und müssen dennoch nach ihrem Studium in der Lage sein, Deutsch als Fremdsprache für höchst unterschiedliche Zielgruppen im In- und Ausland zu vermitteln. Abgesehen von der Tatsache, dass zum gegenwärtigen Zeitpunkt Absolventen des BA-Studiengangs z.B. an Schulen gar nicht unterrichten dürfen, steht die Frage nach einem praxisorientierten Studium mehr denn je im Raum. Was also kann man nach einem Bachelor-Studium in $\mathrm{DaF}$ tatsächlich machen? Erst die nächsten Jahre werden belegen, wie ernst der Markt diesen Studienabschluss wirklich nimmt und was er ohne ein weiteres Studium wert ist.

Offen ist auch, welche Chancen BA-Absolventen gegen ihre Bewerberkonkurrenz der Magister- und Masterabsolventen haben werden, beispielsweise eine Stelle als DAAD-Fremdsprachenassistent zu bekommen. Diese Situation können wir als Hochschullehrer nur bedingt beeinflussen, uns aber fragen, welche Studieninhalte die Studenten wozu befähigen (sollen und können). Sollte es bei der Tatsache bleiben, dass im Grunde erst ein Masterstudium zur DaF-Lehre qualifiziert - was argumentativ nicht ohne Grund so gesehen wird -, dann müssten BA-Wahlmodule, aber auch das Kerncurriculum meiner Meinung nach verstärkt andere berufliche Möglichkeiten eröffnen (z.B. in Richtung Beratungsarbeit, Arbeit in Kultureinrichtungen und internationalen Organisationen, Öffentlichkeitsarbeit, Arbeit im Bereich Medien). Das eng gestrickte System von Pflichtmodulen in den BA-Kursen, das im Unterschied zum alten Magisterstudium eine stärkere Orientierung auf ein Fach zur Folge hat, lässt aber derzeit nur sehr wenig Spielraum für den Wahlbereich. Ohnehin muss man ein ganzes Jahr warten, sollte die Koordination des Wahlbereiches mit dem Kernbereich nicht auf Anhieb gelingen, da die Pflichtmodule in $\mathrm{DaF}$ nur einmal jährlich angeboten werden und nur als Ganzes absolviert werden können. Längst nicht allen Studenten, die einen großen Wahlbereich anstreben, gelingt dies organisatorisch. Was aber kann ein kleiner Wahlbereich tatsächlich abdecken? Im Interesse einer soliden wissenschaftlichen Bildung muss das BA-Studium inneruniversitär gestärkt werden.

In Bezug auf die Chancen der Master-Absolventen auf dem Arbeitsmarkt und eine über den klassischen DaF-Bereich hinausgehende Spezialisierung hat das Herder-In- 
stitut der Universität Leipzig schon sehr interessante Perspektiven zu bieten. Neben zahlreichen Möglichkeiten an ausländischen Partneruniversitäten sein Studium fortzusetzen oder ein Praktikum zu absolvieren, haben mit der Universität Salamanca in Spanien und der Universität Guadalajara in Mexiko im Wintersemester 2008/2009 die ersten bi-nationalen Masterstudiengänge begonnen. In diesem Jahr folgte der gemeinsame Studiengang mit der Ain-Schams-Universität Kairo in Ägypten, im Wintersemester 2009/2010 startet der gemeinsame Masterstudiengang mit der UFPR Curitiba in Brasilien. Die kühne Vision ist, in absehbarer Zeit einmal rund 30\% der Studenten in diesen forschungsorientierten Masterstudiengängen am Herder-Institut in solchen Programmen auf doppelte Weise zu Spezialisten auszubilden.

Zurück zur Schnittstelle Schule-Hochschule. In Portugal wurden, nicht nur an der Universität Coimbra, Referendare nach ihrem Germanistikstudium von einem Lehrer der jeweiligen Schule und einem Universitäts-Tutor gemeinsam betreut. Ein Praktikum wurde hinsichtlich der Qualität kontinuierlich geprüft. Vorbildlich war auch an der Universidade Federal do Paraná (UFPR) in Curitiba die praxisnahe Ausbildung der Studenten, die im eigenen Sprachenzentrum der Universität (CELIN) schon frühzeitig die Möglichkeit hatten, selbst Deutschkurse zu geben. Derzeit lernen etwa 500 Studenten der UFPR am hauseigenen Sprachenzentrum Deutsch (bis zum Niveau Ende Mittelstufe), die Lehrer sind Absolventen der Deutschabteilung oder Studenten höherer Studienjahre und arbeiten dort für ein in Brasilien durchaus angemessenes Honorar. Einmal wöchentlich treffen sich diese Lehrer mit ihrem betreuenden Hochschullehrer, der ihren Prozess begleitet und ihnen didaktisch-methodische Hilfestellung gibt. Nicht wenige ehemalige Studenten der Deutschabteilung der UFPR Curitiba besuchen als Gasthörer weiterhin Seminare an der Universität.

Am Herder-Institut begann im Herbst 2008 erstmals ein Qualifizierungslehrgang für Lehrkräfte in der zweitsprachlichen Alphabetisierung und wir unterstützen im Bereich der Fortbildung ausländischer DaF-Lehrkräfte die Arbeit von interDaF e.V. Dennoch wären aus meiner Sicht ein berufsbegleitender Studiengang oder einfach nur ein Blockseminar oder ein „Sommermodul“ für hiesige DaF-Lehrende wünschenswerte Angebote. Dies wäre nicht nur für ausgebildete $\mathrm{DaF}-/ \mathrm{DaZ}-L e h r e r$ interessant, sondern auch für Lehrer für Deutsch als Muttersprache, die sich an ihren Einrichtungen zunehmend mit DaF- und DaZ-Sprechern konfrontiert sehen.

Für eine erfolgreiche Arbeit ist lebenslanges Lernen längst eine Grundvoraussetzung, denn die Wissensbestände veralten zunehmend schneller. Welche Konsequenzen ergeben sich daraus? Wir sehen schon länger einer Planung entgegen, die für jedes Fach Ziele in Form von kompetenzorientierten und evaluierbaren Anforderungskriterien anstrebt. Wenn diese Orientierung weg von den inhaltsorientierten Lehrplänen hin zur Outputorientierung, also den überprüfbaren Kompetenzen, anhält, dann wäre auch zu fragen, inwiefern ein wie auch immer ausgerichtetes Kerncurriculum dem Rechnung tragen kann/soll oder muss. In diesem Kontext wäre auch das Verhältnis von Paratwissen und Metawissen mitzudenken und die Rolle von Wissensmanagement, auf die auch Peter Colliander verweist (vgl. 2007). 


\section{Bildung versus Ausbildung}

Hans-Jochen Schiewer sieht - immer disziplinär orientiert - das Ziel universitärer Ausbildung in der Entwicklung von Problemlösungskompetenzen und in der Anleitung zu theoretisch und methodisch transparenten systematischen Arbeitsweisen (vgl. 2006: 54). Roggausch spricht mit Blick auf die zahlreichen Studierenden von einer „Ausbildung für die mittlere Höhe“ (2006: 22), die eine solide Grundqualifikation vermitteln soll, die sich aus Fachinhalten und Schlüsselqualifikationen zusammensetzt. Wissen, Kenntnisse und Lernen selbständig organisieren und verwalten zu können, ist ein Ziel von heute. Dies verlangt nach Bildung, nicht nach berufsspezifischer Ausbildung, sagt Waltraud Wende (vgl. Wende 2007: 112). Bildung und Ausbildung sind für mich kein Widerspruch, wissenschaftlicher Anspruch muss nicht verloren gehen. Eine zu stark berufsbezogene Ausbildung ist zwar nicht angebracht, da Berufsbilder kommen und gehen, dennoch müssen Curricula darauf Rücksicht nehmen, Grundlagen bieten und Schlüsselqualifikationen vermitteln. Nicht jeder BA-Studierende wird zum künftigen klassischen wissenschaftlich-akademischen Nachwuchs gehören. Mit der Umstellung auf das neue Studiensystem werden hierzulande Teile des Humboldtschen Bildungsideals und die Einheit von Forschung und Lehre in Frage gestellt, man sieht die wissenschaftliche Tiefe bedroht. Verfügen also die Studierenden im Ausland, die teilweise seit Jahren in diesen Strukturen lernen, als Absolventen über eine geringere akademische Qualifikation? Die Verschulung des Studiums war in der Ukraine, in Portugal und teilweise in Brasilien - und nicht nur da - aufgrund anderer Lerntraditionen lange vor Bologna eine Realität. Sie brachte allerdings keineswegs nur Wissen reproduzierende, unkreative Absolventen hervor. Konkret heißt das, es gab dort sehr weitgehend eingehaltene Regelstudienzeiten um die fünf Jahre, viele Pflichtfächer, eingeschränkte Wahlmöglichkeiten und engere, später teilweise vom Arbeitsmarkt mitbestimmte Zielsetzungen. Dies hängt nicht nur mit einer anderen Bildungstradition zusammen, sondern auch damit, dass Deutsch dort als Fremdsprache gelehrt wird. Diese Studiengänge hat dies in Gänze keineswegs automatisch qualitativ minderwertig gemacht. Auch unsere Regelstudienzeit betrug im Übrigen fünf Jahre... Etwas provokativ gefragt, wollen wir in unserer so häufig beschworenen Leistungsgesellschaft die physikalische Formel „Arbeit = Leistung in der Zeit“" so arg vernachlässigen? Ziel einer modernen Universität bleibt die Verbindung von Lehre, Forschung, Praxis und Dienstleistung. Ich denke nicht, dass ein BA-Studium automatisch eine Abkopplung von der Forschung zur Folge haben muss. Positivstes Beispiel meiner Erfahrungen in der Auslandsgermanistik ist für mich die in Brasilien praktizierte Iniciação cientifica. Ein Hochschullehrer arbeitet gemeinsam mit einer kleinen Gruppe von Studenten an einem Projekt, das zu einer Publikation führen kann, Teil eines größeren Projekts ist, eine Studie zum Ziel hat o.ä.; die Studenten erhalten für diese Forschungsarbeit verwertbare Leistungspunkte. Natürlich setzt so ein Verfahren geringere Studentenzahlen in den Seminaren voraus und bessere Betreuungsverhältnisse. Diese Faktoren bleiben trotz der neuen Studienstruktur in Deutschland diskussionswürdig. 


\section{Inhaltliche Spielräume im Ausbildungsgang, organisatorische Probleme und ein Blick über die Grenzen}

Holger Dainat verweist darauf, dass sich nur schwer zwischen Effekten der Übersteuerung und grundlegenden Konstruktionsmängeln unterscheiden lässt und betont in diesem Zusammenhang die Überlagerung des Bologna-Prozesses von einem tief greifenden Strukturwandel in der höheren Bildung und in der Hochschulpolitik (Dainat 2007: 91). Bürokratische Ausmaße, die Verwaltungsakte zugunsten inhaltlicher Arbeit fordern, nehmen zu. Die vielen quantifizierenden Diagnoseinstrumente wie Betreuungsrelationen, Auslastung, Studiendauer, Publikationsmenge, Drittmitteleinwerbung oder Promotions- und Habilitationszahlen allein sagen nicht viel aus. Die Chance liegt für mich in der Verständigung über Kernkompetenzen und Schlüsselqualifikationen, also in der Verständigung über moderne und neue Inhalte. Fehlt diese Verständigung oder wird sie verkürzt, täuschen die veränderten Strukturen lediglich neue Inhalte vor. Und so stimme ich Peter Colliander zu, der als einen der „Bösewichte“ den ,inhaltliche[n] Konservatismus der Studiengänge“" nennt (Colliander 2007: 148).

Während wir am Herder-Institut wie viele Einrichtungen auf das Modell 3+2 setzen, hat die Ukraine sich - übrigens schon vor zehn Jahren - für das Modell 4+1 entschieden (vgl. Anlage I). Ich kann diesem Grundmodell, das dem ersten Studium mehr Zeit gibt, einige Vorteile abgewinnen. Nach wie vor dominiert in Kiew, wo insgesamt ca. 150 Studenten in kleinen Gruppen von max. 20 Teilnehmern Germanistik studieren, eine hohe Pflichtstundenzahl. Breite fachliche und fachübergreifende Anforderungen mischen sich mit teilweise interdisziplinären Ansätzen. Die von den ukrainischen Kollegen benannten Probleme beziehen sich vor allem auf ein vom Ministerium und der Universitätsleitung eingeführtes Credit-Modul-Bewertungsverfahren. Dabei ist der Modulbegriff nicht mit unserem zu vergleichen. Positiv an dem Bewertungsverfahren der Kiewer Universität ist, dass die Studenten eigenverantwortlicher um ihre Punktzahl kämpfen, um sich durch viele Punkte bestimmte Prüfungen ersparen zu können. Letzteres kenne ich übrigens aus meiner eigenen Studienzeit. Ein durchaus - sagen wir zunächst instrumenteller - Anreiz für höhere Leistung und mehr Aktivität. Nach der Abschaffung einer Art Zwischen-Abschluss als „Spezialist“ (4+1 Semester), könnte sich für die Kiewer Taras-Schewtschenko-Universität ein Problem finanzieller Art ergeben, denn dieser Abschluss wurde ursprünglich geschaffen, da BA-Absolventen keine guten Chancen auf dem ukrainischen Arbeitsmarkt haben. Vor allem leistungsschwächere, zahlende Studierende konnten so ihre Qualifikation „,aufbessern“. Inzwischen wurde das Studienprogramm überarbeitet. Im Wintersemester 2009/2010 wird erstmals ein zweijähriger Masterstudiengang beginnen und damit das Modell 4+2 in Kraft treten.

Ein weiteres Problem besteht darin, dass es für im Ausland erbrachte Studienleistungen während der BA-Phase noch keine Anerkennung von ukrainischer Seite gibt.

In Brasilien sind die Zahlen der jeweiligen Seminargruppen ähnlich. Das Studium ist in diesen beiden Ländern durchaus ansatzweise vergleichbar und dennoch in Brasilien viel flexibler. Trotz zahlreicher Initiativen verschiedener Institutionen (z.B. neu entstandene Goethe-Institute und deutsche Lesesäle in Osteuropa, die „Go East-Kampagne“ 
des DAAD für deutsche Studierende und Graduierte) wird dem Markt für DaF in Osteuropa und der damit verbundenen Anbindung hochqualifizierter Absolventen an die deutsche Wissenschaft und Wirtschaft nach meinem Dafürhalten zu wenig Beachtung geschenkt. Dies aber ist ein eher gesellschaftspolitisches Problem.

Die Struktur des Studiengangs Germanistik an der UFPR Curitiba lässt gegenüber dem Kiewer Modell eine sehr individuelle Gestaltung des Stundenplanes zu (vgl. Anlage II). Sie ermöglicht Studenten, die bereits mit guten Deutschkenntnissen das Studium beginnen, flexibel und entsprechend ihres Sprachstandes in den Sprach- und Landeskundeunterricht einzusteigen. Nach einem Spracheinstufungstest und einem Gespräch erfolgt die Zuordnung zum jeweiligen Kurs, wodurch einzelne Studenten in dem Fach Língua gegebenenfalls ganze Semester überspringen können. Fast alle Lehrveranstaltungen (z.B. alle Literaturkurse und die Kurse in Didaktik/Methodik DaF) finden in deutscher Sprache statt, dies galt und gilt auch für die Taras-Schewtschenko-Universität Kiew in der Ukraine. In Brasilien sind außerdem ab einem bestimmten Niveau auch in den Pflichtbereichen verschiedene Kurse frei in ihrer Reihenfolge wählbar. Es gibt ein Angebot an Wahlpflichtfächern, das sich stark an den Interessen, Wünschen und Bedürfnissen der Studenten orientiert, die Studierenden können den Dozenten sogar selbst Vorschläge unterbreiten. Das individuelle Lernen wird stärker gefördert. Im deutschen Studienalltag der BA-Kurse geht es derzeit eher um das Konsumieren eines „Wissensprogramms“ mit wenig Platz für eigene kreative Lösungen und praktische Übungen, der autonome Lerner bleibt mitunter ein theoretisches Konstrukt der Didaktik. Das Leipziger BA-Programm ist anspruchsvoll, doch prüfungstechnisch noch zu überladen. (vgl. Auszüge BA-Prüfungsordnung, Anlage III) Noch muss jeder BAStudent am Ende jedes Seminars im Semester eine Note durch eine Hausarbeit, Projektarbeit etc. nachweisen. Jeder dieser Leistungsnachweise bedarf einer Zweitkorrektur, die bei Referaten, Präsentationen der Studenten usw. laut Prüfungsordnung die Anwesenheit eines zweiten Dozenten voraussetzt. Nun aber finden diese Präsentationen von den 80 Studenten in einem BA-Kurs (Kern- und Wahlbereich zusammen) längst nicht nur in einer Lehrveranstaltung statt... die Ausmaße des organisatorisch-bürokratischen Aufwandes für die Dozenten überlasse ich an dieser Stelle der Phantasie des Lesers. Ist durch die Einführung der neuen Studiengänge am Herder-Institut der Universität Leipzig auch die Zahl der DaF-Studierenden begrenzt worden, so bleibt die Zahl von max. 40 zugelassenen Studenten pro Seminar - eine „erholsame“ Zahl im Vergleich zu früheren Seminargrößen im alten Magisterstudiengang - doch hoch im Vergleich zu den genannten ausländischen Universitäten. In Brasilien und in der Ukraine sind auch in den didaktisch-methodischen, linguistischen oder literaturwissenschaftlichen Seminaren und Übungen die Gruppen klein. Der Erfolg der Studenten dort erklärt sich u.a. durch eine hohe Arbeitsintensität in den kleinen Gruppen, befördert durch ein noch sehr persönliches Verhältnis zwischen Studenten und Dozenten. Vielleicht ist unter diesem Aspekt in Deutschland nicht nur die Kapazitätsverordnung zu überdenken (vgl. Wiarda 2007: 85f.), sondern grundsätzlich zu hinterfragen, wie viel Studenten mit welchen Voraussetzungen zum Studium zugelassen werden sollten. Kleinere Gruppen 
und ein zahlenmäßig besseres Betreuungsverhältnis ermöglichen nicht nur eine bessere Binnendifferenzierung, sondern eine, Prüfungen, Tests, Hausarbeiten etc. ergänzende, zusätzliche und kontinuierliche Leistungsbewertung über das ganze Semester hinweg. Es gab in allen drei Ländern auch unkonventionellere Prüfungsformen. So habe ich z.B. die mündlichen Gruppenprüfungen, in der drei bis fünf Studierende sich im Dialog mit fachlichen Thesen und Problemstellungen auseinandersetzen, als sehr effizient, fachlich anregend und für die Studenten als relativ entspannt erlebt. Wir haben uns bisher in Leipzig nicht an diese laut Prüfungsordnung durchaus mögliche Prüfungsform gewagt. Im Masterprogramm gibt es im Unterschied zu den BA-Kursen eine stärkere Differenzierung zwischen Prüfungsvorleistungen und Prüfungsleistungen sowie eine größere Vielfalt an Prüfungsformen.

Auch in Portugal absolvieren die Studenten ein umfangreiches Programm mit vielen zusätzlichen Fächern außerhalb der Germanistik. Die Leistungen der Studenten wurden allerdings durch die Tatsache, dass außer dem reinen Sprach- und Landeskundeunterricht und der Didaktikseminare keine weiteren Lehrveranstaltungen auf Deutsch gehalten wurden, deutlich gemindert. In Coimbra kann man die Licenciatura (BA) auf vier Wegen bestreiten, von einer Kombination zweier Fremdsprachen (Deutsch, Spanisch, Französisch, Englisch oder Italienisch), über Portugiesisch in Verbindung mit einer Fremdsprache bis hin zu Möglichkeiten einer monodisziplinären Ausbildung. Die Germanistikausbildung setzt sich zusammen aus den großen Bereichen Sprache, Linguistik, Literatur und Kultur (vgl. Anlage IV). Der danach folgende Mestrado em Ensino (Lehrerausbildung) ist aber nur noch in der Kombination mit Englisch oder Portugiesisch möglich. Um diesen Kurs besuchen zu können, müssen die Studenten 100 ECTS in Portugiesisch und Englisch und 60 ECTS in der anderen Sprache erwerben. Ein Problem ergibt sich prinzipiell durch die Fächerreduktion. Auf Grund der inzwischen drastisch gesunkenen Studentenzahlen sind die „Opções disciplinares“ keine wirklichen Wahlfächer, weil nur das Minimum angeboten wird. Nur der Mestrado-Studiengang wird mit einer Abschlussarbeit abgeschlossen. Das Einstiegsniveau in Bezug auf die deutsche Sprache ist in den letzten Jahren gesunken, die Zahl der Nullanfänger gestiegen. Im Februar 2008 wurde auf dem internationalen Kongress „Kulturbau“ des Portugiesischen Germanistenverbandes APEG in Lissabon vom Leiter des Institutes für Deutsche Sprache an der Universität Coimbra von zwölf Neueinschreibungen in der Germanistik gesprochen. Die geburtenschwachen Jahrgänge allein können diesen drastischen Rückgang der Neueinschreibungen im Vergleich zu denen vor ca. zehn Jahren nicht erklären.

\section{Ein weitgehend unbestelltes Feld: Fachsprache}

Ausbildungstechnisch weitgehend unbeachtet bleibt in der Auslandsgermanistik wie in den meisten DaF-Studiengängen der Bereich der Fachsprache Deutsch. Zwar haben wir in Leipzig mit einem Modul, das auch Deutsch für den Beruf thematisiert, eine erste Orientierung, aber wenig Chancen, junge, schon spezialisierte Lehrer für Wirtschaftsdeutsch oder Fachsprachen als Absolventen zu bekommen. Gerade dieser Bereich ist 
im Ausland aber verstärkt gefragt und wird gebraucht, um Spezialisten verschiedener Fachbereiche (vor allem aus den naturwissenschaftlichen Feldern) zu einer Promotion oder Qualifikation in Deutschland motivieren zu können und letztlich dadurch Langzeit-Multiplikatoren für eine noch engere Zusammenarbeit mit ausländischen Universitäten zu gewinnen. Noch zahlt der DAAD weltweit den ausgewählten Stipendiaten aller Fachbereiche Sprachintensivkurse zur Vorbereitung auf eine Promotion in Deutschland. Deutsch wird Englisch als Wissenschaftssprache zwar nicht den Rang ablaufen, hat aber noch immer Chancen, im akademischen Bereich außerhalb der Juristen und Philosophen als zweite oder dritte Fremdsprache zu bestehen. Ein Modulangebot in Zusammenarbeit mit naturwissenschaftlichen Fachbereichen könnte hier meiner Meinung nach eine echte Marktlücke bedienen. Normalerweise erwirbt man bisher diese Fachsprachenkompetenz erst mühsam im Arbeitsprozess.

\section{Ein Blick nach vorn}

Auf der Tagung der Gesellschaft für Interkulturelle Germanistik (GIG) zum Thema „Kann man vom Deutschen leben?“ im finnischen Tampere im August 2007 haben viele Kollegen der Inlands- und Auslandsgermanistik ihre Vorschläge für eine Verbesserung der germanistischen Ausbildung unterbreitet, von denen ich einige Stichworte zur Anregung und Fortsetzung der Diskussion im Anhang unkommentiert zusammengestellt habe (vgl. Anlage V).

Von der Auslandsgermanistik kann man sich einiges abschauen. Aus meiner Sicht ist auch eine stärkere Kenntnisnahme der Forschung im Ausland wünschenswert. Mehr gemeinsame Projekte, über die bestehenden jeweiligen Unikontakte hinaus, die die Fachinhalte zum Diskussionsgegenstand machen, würden den Austausch zu Fragen eines Kerncurriculums sicher fördern. Die Reaktion der Studenten auf die veränderten Lerninhalte und die qualitative Umsetzung dieser fachübergreifenden Inhalte sind zu hinterfragen. Wenn auch künftig die wissenschaftlich-akademische Orientierung vor allem für die Masterstudenten gilt, bleibt die Bachelor-Ausbildung doch ein Studium, das im Ausland zu mehr als zu Sekretariatsaufgaben mit deutschsprachigem Schriftverkehr qualifiziert. Auch die Germanistik muss auf die veränderten Bedingungen in einer globalisierten Welt reagieren.

Studiengänge konzipiert man nicht alle drei Jahre neu. Deshalb sollten wir dem neuen System eine Chance geben, seine Fehler aber beizeiten konsequent zu beheben versuchen, damit das Programm nicht abstürzt. Es würde nicht schaden, bei diesen „Reparaturarbeiten“ häufiger den Blick in verschiedene Himmelsrichtungen schweifen zu lassen und genauer erfolgreiche ausländische Ausbildungsgänge anzuschauen. „Die Zukunft der Bildung unter den Bedingungen der Globalisierung muss den Mut zur Vielfältigkeit aufbringen“ (Schily 2007: 60). Den Weg dahin muss jede Universität selber finden. Dafür müssen allerdings bestimmte Rahmenbedingungen geschaffen werden, für die die Universität nicht allein verantwortlich ist. Wenn ich mir bestimmte bildungspolitische Entscheidungen in Deutschland ansehe, so vermisse ich manches Mal den 
kämpferischen Geist, sowohl unter den Studenten als auch unter den Dozenten und Forschern und den starken Wind für inhaltlich frischere Studienangebote.

Alle anders, alles gleich? Viele Wege führen nach Bologna und von Bologna in die Welt.

\section{Literatur}

Altmayer, Claus (2006): „Kulturelle Deutungsmuster“ als Lerngegenstand. Zur kulturwissenschaftlichen Transformation der „Landeskunde“. In: Fremdsprachen Lehren und Lernen 35, 44-59.

Bollenbeck, Georg; Wende, Waltraud (2007): Was soll man überhaupt gegen Bologna sagen? Zur Einleitung. In: Bollenbeck, Georg; Wende, Waltraud (Hrsg.): Der BolognaProzess und die Veränderung der Hochschullandschaft. Heidelberg: Synchron, 7-9.

Colliander, Peter (2007): Nicht die BA-MA-Struktur ist der Bösewicht. Betrachtungen zur Lage der Germanistik in Dänemark. In: Bollenbeck, Georg; Wende, Waltraud (Hrsg.): Der Bologna-Prozess und die Veränderung der Hochschullandschaft. Heidelberg: Synchron, 147-157.

Dainat, Holger (2007): Die Germanisten in Europa: ratlos. Über disziplinäres Driften in Zeiten der Studien- und Hochschulreform. In: Bollenbeck, Georg; Wende, Waltraud (Hrsg.): Der Bologna-Prozess und die Veränderung der Hochschullandschaft. Heidelberg: Synchron, 89-103.

Die Zeit - online (29.01.2007): Stärkung der Lehre. http://www.zeit.de/campus/online/2007/05/wissenschaftsrat (21.08.2009).

Die Zeit - online (22.10.2007): Expertenrat. Kampf der guten Lehre. http://www.zeit. de/campus/online/2007/43/expertenrat-vorhaben (21.08.2009).

Hartung, Manuel; Wiarda, Jan-Martin (2008): Der große Feldversuch. In: Die Zeit 4/2008, 61.

Mein, Georg (2006): Plädoyer für ein Kerncurriculum Germanistik. In: Mein, Georg (Hrsg.): Kerncurriculum BA-Germanistik. Chancen und Grenzen des Bologna-Prozesses. Bielefeld: transcript, 7-20.

Parr, Rolf (2006): Einige Vorüberlegungen zu einem Kerncurriculum „Germanistik“. Am Beispiel eines Moduls „Text/Bild-Korrelate“. In: Mein, Georg (Hrsg.): Kerncurriculum BA-Germanistik. Chancen und Grenzen des Bologna-Prozesses. Bielefeld: transcript, 29-44.

Prüfungsordnung des Bachelorstudiengangs DaF: http://www.uni-leipzig.de/herder/ hi.site,postext, ba-studiengang,a_id,442.html (21.08.2009).

Roggausch, Werner (2006): Praxisbezug versus Wissenschaft? Eine falsche Opposition! In: Mein, Georg (Hrsg.): Kerncurriculum BA-Germanistik. Chancen und Grenzen des Bologna-Prozesses. Bielefeld: transcript, 21-28.

Schiewer, Hans-Jochen (2006): Zur Situation der Mediävistik. In: Mein, Georg (Hrsg.): Kerncurriculum BA-Germanistik. Chancen und Grenzen des Bologna-Prozesses. Bielefeld: transcript, 53-64. 
Schily, Konrad (2007): Die Internationalisierung und Europäisierung der deutschen Hochschule. In: Bollenbeck, Georg; Wende, Waltraud (Hrsg.): Der Bologna-Prozess und die Veränderung der Hochschullandschaft. Heidelberg: Synchron, 53-61.

Weingarten, Rüdiger (2006): Zur Situation der Linguistik im Kontext des Bologna-Prozesses. In: Mein, Georg (Hrsg.): Kerncurriculum BA-Germanistik. Chancen und Grenzen des Bologna-Prozesses. Bielefeld: transcript, 45-52.

Wende, Waltraud (2007): Wozu Germanistik? Der Bologna-Prozess als Chance für längst überfällige Modernisierungsprozesse. In: Bollenbeck, Georg; Wende, Waltraud (Hrsg.): Der Bologna-Prozess und die Veränderung der Hochschullandschaft. Heidelberg: Synchron, 105-121.

Wiarda, Jan-Martin (2007): Kapazitätsverordnung. Die fiese Formel. Wie eine alte Verordnung die Hochschulen zum Stillstand verurteilt. In: Die Zeit 39/2007, 85-86. 


\section{Anlage I}

\section{Lehrveranstaltungen des Lehrstuhls für Germanische Philologie der Nationalen Taras-Schewtschenko Universität Kiew, Studienjahr 2007/2008}

Fächer: Deutsch/Englisch; Deutsch/Niederländisch; Deutsch/Schwedisch

\section{Studienjahr}

Linguolandeskunde

Deutsch (Hauptfach)

Einführung in die Germanistik

Zweite Fremdsprache

\section{Studienjahr}

Deutsch (Hauptfach)

Einführung in die Übersetzungs-

wissenschaft

Praxis der Übersetzung

Wissenschaftliches Arbeiten

Jahresarbeit

Zweite Fremdsprache

4. Studienjabr

Kontrastive Lexikologie

Probleme der kognitiven Linguistik

Textlinguistik

Didaktik DaF

Übersetzung von Fachtexten

Stilistik

Theoretische Grammatik

Deutsch (Hauptfach)

Zweite Fremdsprache

Praxis der Übersetzung der 2. FS

Linguolandeskunde (2. FS)

Schulpraktikum DaF

Bakkalaurusarbeit 


\section{Studienjahr (Spezialist)*}

Moderne Informationstechnologien

Geschäftskommunikation in der zweiten Fremdsprache

Theorie und Praxis der zweiten Fremdsprache

Theoretische Grundlagen der Sprachvermittlung

Europäische Sprachen in der interkulturellen Kommunikation

Abschlussarbeit

\section{Studienjahr (Master)**}

Probleme der modernen Linguistik

Probleme der modernen Übersetzungswissenschaft

Dialektologie

Geschäftskommunikation in der zweiten Fremdsprache

Theorie und Praxis der Übersetzung in der ersten FS

Theorie und Praxis der Übersetzung in der zweiten FS

Vergleichende Stilistik

Einführung in die Rhetorik

Arbeit mit verschiedenen Textsorten

Kommunikation und Kommunikationsstrategien

Praktikum der Übersetzung

Pädagogisches Praktikum

Masterarbeit

Darüber hinaus haben die Studenten Vorlesungen und Seminare in anderen - auch nicht philologischen - Fächern, die für sie Pflicht sind: Antike Literatur und Weltliteratur, Philosophie, Geschichte der Ukraine, Ukrainische Literatur, Logik, Soziologie, Psychologie und Pädagogik, Informatik und in Wirtschaftstheorien.

Nach dem 4. Studienjahr wird die Bakkalaurusarbeit verteidigt und drei Prüfungen werden abgelegt (Deutsch, Praxis des Übersetzens und Weltliteratur). Nach dem 5. Studienjahr legen die Spezialisten die Staatsprüfungen in beiden Sprachen ab und verteidigen die Diplomarbeit. Die Masterstudenten legen ebenfalls beide Staatsprüfungen ab und verteidigen die Masterarbeit. Die Arbeiten werden in der Regel auf Ukrainisch geschrieben, aber auf Deutsch verteidigt.

Alle Lehrveranstaltungen mit Ausnahme der Linguolandeskunde, der Einführung in die Germanistik und der Didaktik werden auf Deutsch gehalten.

Ab Herbst 2009 gilt 4+2 (BA+Master), das Spezialistenprogramm 4+1 entfällt. Für das Masterstudium ist ein bestimmter Notendurchschnitt Voraussetzung.

* ein Semester

** zwei Semester

Quelle der Angaben: Leiter des Lehrstuhls für Germanische Philologie, Prof. Dr. Iwan Sojko, unter verantwortlicher Mitarbeit von Dr. Olga Kuchma, Mai 2008. 


\section{Anlage II}

\section{Studienabschluss in Germanistik an der Universidade Federal do Paraná (UFPR) Curitiba (Brasilien)}

Die Graduação im Fach Deutsch endet in der Regel nach neun Semestern mit der Licenciatura. Dabei kann Deutsch mit Portugiesisch kombiniert werden. Eine andere Sprache (z.B. Englisch) kann aufgrund des Stundenplanes erst nach dem Abschluss von Deutsch hinzugewählt werden. Das Studium kann im Grunde als Lehramtsstudiengang betrachtet werden. Danach kann eine Pos-Graduação erfolgen (Spezialisierung, Mestrado oder Doutorado). In diesem Bereich werden keine Fächer auf Deutsch angeboten, der Dozent kann aber entsprechend seinem Fachgebiet auf Portugiesisch Seminare anbieten (z.B. zu Literaturtheorie, zu ausgewählten Schriftstellern/Epochen/Motiven, zu Übersetzungstheorien etc.)

\section{Struktur der Licenciatura}

Pflichtstunden in Língua + Deutsche Literatur I-IV + „Vertiefungsfächer“ (Wahlpflicht) + Wahlfächer („Obtativas“)

\section{Língua und Deutsche Literatur (Pflicht)}

Básico I und II (pro Semester 8 Wochenstunden = SWS)

Língua I bis VI (je ein Semester, 4 SWS)

Der Einstieg ist flexibel und erfolgt auf der Basis eines Einstufungstests. Studenten mit sehr guten Vorkenntnissen der deutschen Sprache haben die Möglichkeit, ihre Sprachkenntnisse auf hohem Niveau durch den Besuch von Wahlpflichtfächern und Wahlfächern zu erweitern.

Deutsche Literatur I bis IV (3 SWS, Pflicht)

„Vertiefungsfächer" (2 SWS, Wahlpflichtfächer) geben den Studenten die Möglichkeit, unzureichende Grundfertigkeiten zu trainieren. Sie können diese Fächer, die mehrfach auf unterschiedlichen Niveaustufen angeboten werden, entsprechend ihren Vorkenntnissen auswählen:

- Leitura e Escrita da Língua Alemã

- Audição e Conversação em Lingua Alemã

- Grammatik/Orthographie

- Weiterhin stehen Kurse zur Phonetik zur Wahl oder Orientação Monográfia oder Didaktik DaF.

Fortgeschrittene Lerner (in der Regel ab dem dritten Jahr) können zwei Wablfächer (2 oder 4 SWS) frei auswählen. Diese Fächer reichen von Angeboten in der Übersetzung, spezifischen literarischen Seminaren (zu Märchen, zu Thomas Mann, zum Theater etc.) über Didaktik DaF bis hin zu freien interdisziplinären Veranstaltungen (z.B. Seminare zum Thema „Macht“, „Traum“ oder „Zeit"). Die Dozenten wie der DAAD-Lektor ha- 
ben hier freies Vorschlagsrecht, die Studenten können Wünsche äußern. Das Angebot ist quasi damit auch „kundenorientiert“.

\section{Besonderheit:}

Fortgeschrittene Lerner haben die Möglichkeit, am Sprachenzentrum der Universität, CELIN, (derzeit 18 Sprachen mit etwa 500 Deutschlernern) selbst zu unterrichten und Deutschkurse zu geben. Dieses Projekt wird durch wöchentliche Tutorien von Dozenten begleitet.

Zum Training der Lesefertigkeit werden für Studenten anderer Fachbereiche (z.B. Jura) Kurse = „Instrumental“(4 SWS) angeboten.

Die Anzahl der Studenten für die Germanistik ist zulassungsbeschränkt. Neben den Studenten der Philologischen Fakultät studieren etwa weitere 35 Studenten, die zusätzlich andere Fächer wie Informatik, Recht, Tourismus oder Theaterwissenschaften studieren, Deutsch. Sogenannte isolados, Externe, können sich ebenfalls einschreiben. Die Arbeit in der Germanistik teilen sich drei Dozenten, der DAAD-Lektor und zeitweise ein Assistent.

Zusammengestellt von Carmen Schier, Universität Leipzig, Stand: Mai 2008. 
Bachelor of Arts Deutsch als Fremdsprache (Seite 1 von 3)

\section{Anlage zur Prüfungsordnung des Studienganges \\ Bachelor of Arts Deutsch als Fremdsprache}

\begin{tabular}{|c|c|c|c|c|c|c|c|}
\hline $\begin{array}{l}\text { Modul/zugehörige } \\
\text { Lehrveranstaltungen } \\
\text { mit Gegenstand und Art } \\
\text { (Umfang der LV) }\end{array}$ & 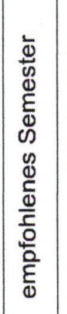 & 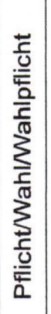 & 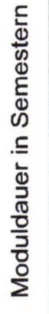 & Prüfungsvorleistungen & $\begin{array}{l}\text { Prüfungsleistung } \\
\text { Art/Dauer }\end{array}$ & 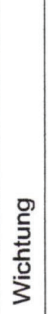 & 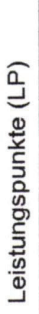 \\
\hline \multicolumn{8}{|l|}{ Wahlbereichsplatzhalter 1-6 } \\
\hline $\begin{array}{l}\text { 04-004-1001 } \\
\text { Lexikologie der deutschen } \\
\text { Gegenwartssprache }\end{array}$ & 1. & $\mathrm{P}$ & 1 & & & & 10 \\
\hline \multicolumn{8}{|c|}{$\begin{array}{l}\text { Vorlesung "Grundzüge der Lexikolgie der deutschen } \\
\text { Gegenwartssprache" (2SWS) }\end{array}$} \\
\hline \multicolumn{4}{|c|}{ Seminar "Lexikologie/Wortbildung" (2SWS) } & & Hausarbeit & 1 & \\
\hline \multicolumn{4}{|c|}{ Seminar "Lexikologie/Phraseologie" (2SWS) } & & Klausur 90 Min. & 1 & \\
\hline $\begin{array}{l}\text { 04-004-1002 } \\
\text { Didaktik/Methodik Deutsch als } \\
\text { Fremdsprache }\end{array}$ & 1. & $P$ & 1 & & & & 10 \\
\hline \multicolumn{8}{|c|}{$\begin{array}{l}\text { Vorlesung "Einführung in die Didaktik/Methodik des } \\
\text { Deutschen als Fremdsprache" (2SWS) }\end{array}$} \\
\hline \multicolumn{4}{|c|}{$\begin{array}{l}\text { Seminar "Lemen und Lehren einer Fremdsprache" } \\
\text { (2SWS) }\end{array}$} & & Hausarbeit & 1 & \\
\hline \multicolumn{4}{|c|}{$\begin{array}{l}\text { Seminar "Analyse und Entwicklung von Lehr- und } \\
\text { Lernmaterialien" (2SWS) }\end{array}$} & & Projektarbeit & 1 & \\
\hline Fachnahe Schlüsselqualifikation & $\begin{array}{l}1 . / 2.1 \\
3 . / 4.1 \\
5 . / 6 .\end{array}$ & $\mathrm{P}$ & 1 & & & & 10 \\
\hline $\begin{array}{l}\text { Fakultätsübergreifende } \\
\text { Schlüsselqualifikation }\end{array}$ & $\begin{array}{l}1 . / 2.1 \\
3 . / 4.1 \\
5.16 .\end{array}$ & $\mathrm{P}$ & 1 & & & & 10 \\
\hline $\begin{array}{l}\text { 04-004-1003 } \\
\text { Phonetik/Phonologie/Rhetorik }\end{array}$ & 2. & $\mathrm{P}$ & 1 & & & & 10 \\
\hline \multicolumn{8}{|c|}{ Seminar "Angewandte Phonetik/Rhetorik" (2SWS) } \\
\hline \multicolumn{4}{|c|}{$\begin{array}{l}\text { Vorlesung "Einführung in die Phonetik/Phonologie" } \\
\text { (2SWS) }\end{array}$} & & Klausur 90 Min. & 1 & \\
\hline \multicolumn{4}{|c|}{ Seminar "Grundlagen der Phonetik" (2SWS) } & & Hausarbeit & 1 & \\
\hline Gr-004-1004 & 3. & $\mathrm{P}$ & 1 & & & & 10 \\
\hline \multicolumn{8}{|c|}{$\begin{array}{l}\text { Vorlesung "Grammatiktheorien und Grammatikographie" } \\
\text { (2SWS) }\end{array}$} \\
\hline \multicolumn{4}{|l|}{ Seminar "Morphologie" (2SWS) } & & Mündliche Prüfung 20 Min. & 1 & \\
\hline \multicolumn{4}{|l|}{ Seminar "Syntax" (2SWS) } & & Klausur 90 Min. & 1 & \\
\hline
\end{tabular}


Bachelor of Arts Deutsch als Fremdsprache (Seite 2 von 3)

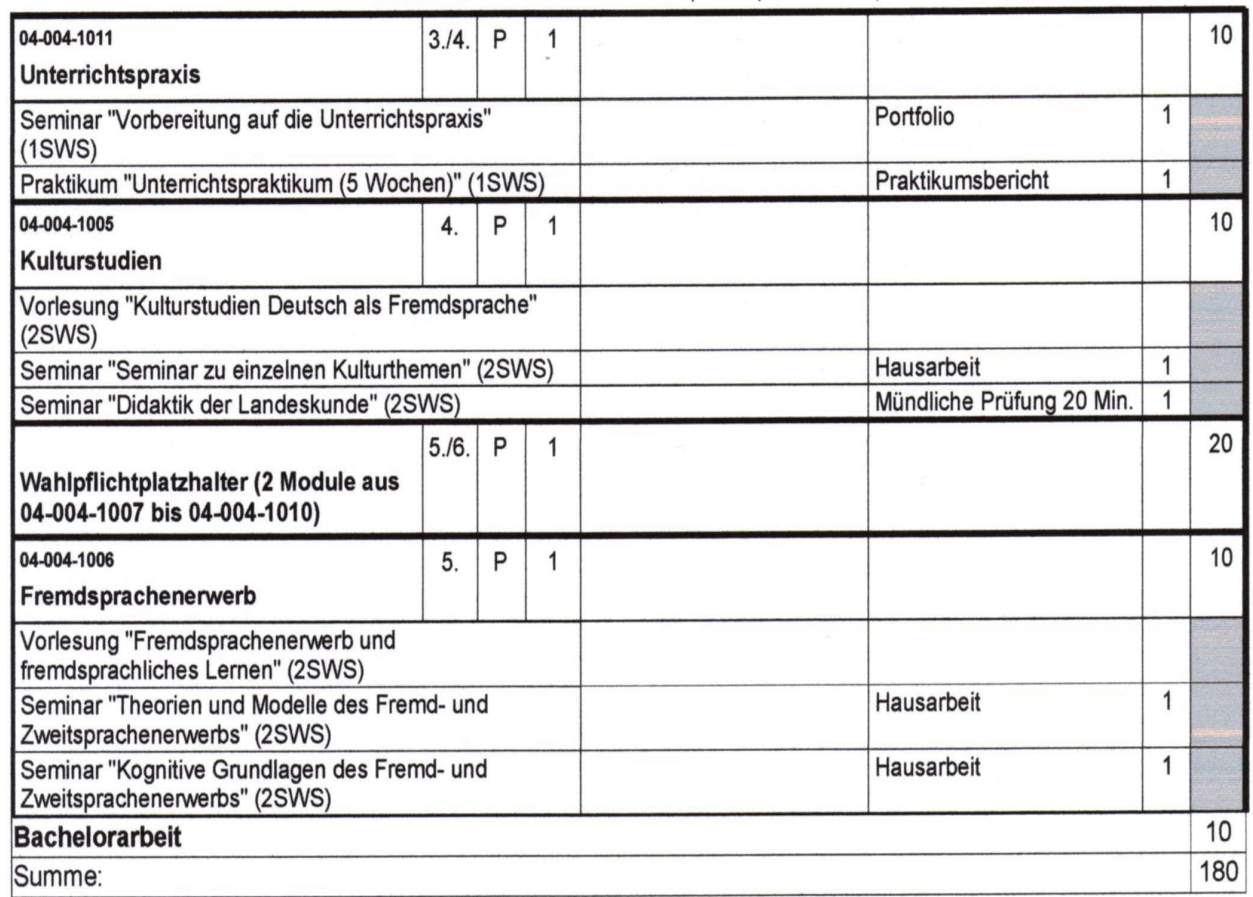


Bachelor of Arts Deutsch als Fremdsprache (Seite 3 von 3)

Wahlpflichtmodule Bachelor of Arts Deutsch als Fremdsprache

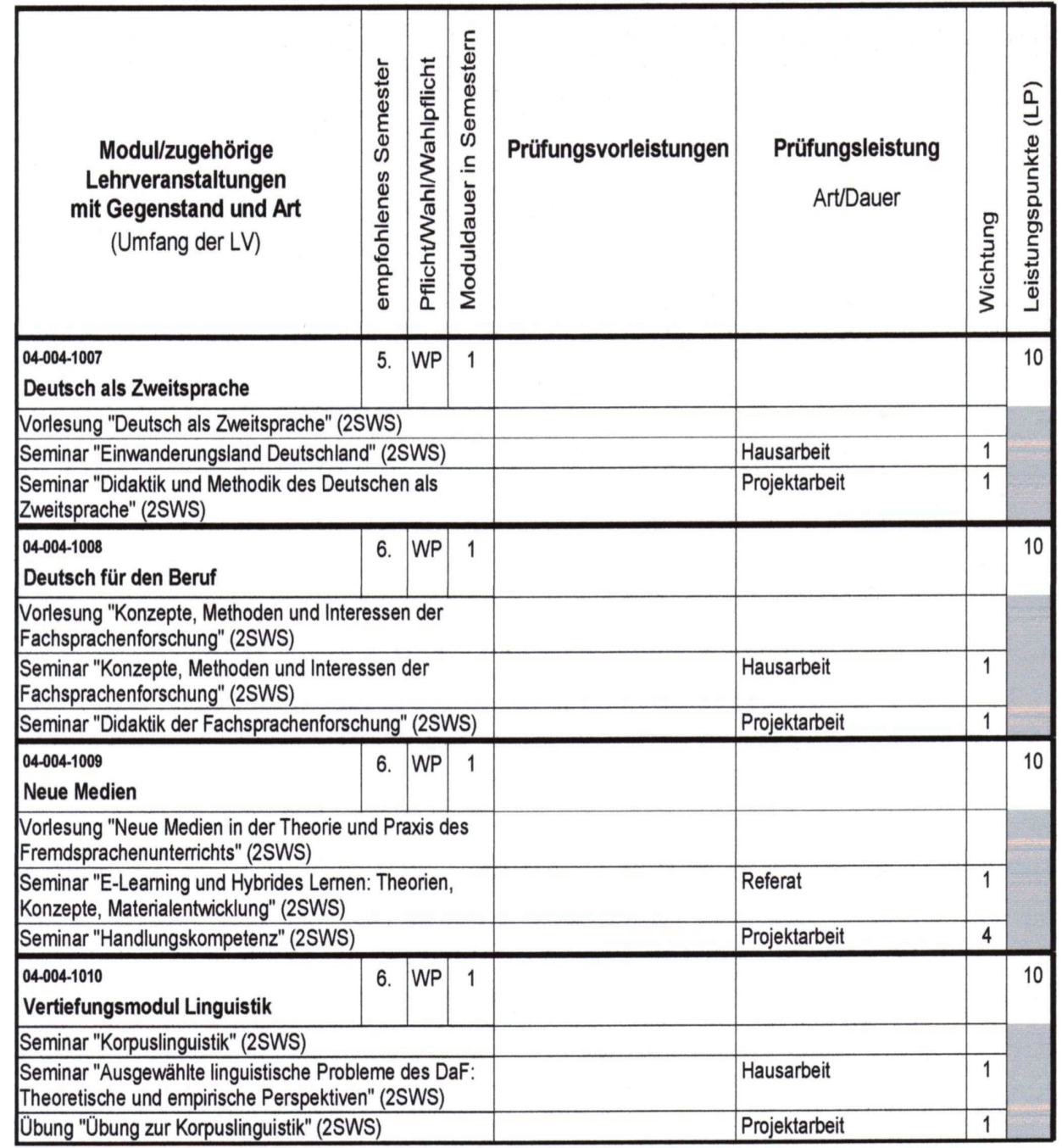




\section{Anlage IV}

Elenco de Cadeiras dos Cursos 2008-2009

Curso - Línguas Modernas (1 ${ }^{\circ}$ Ciclo de Bolonha)

\begin{tabular}{|c|c|}
\hline $1^{\circ}$ Semestre & $2^{\circ}$ SEMESTRE \\
\hline \multicolumn{2}{|c|}{ Língua } \\
\hline $\begin{array}{l}\text { Alemão } 1: 2 \text { Turmas } \\
1 \mathrm{~s} / \text { conhecimentos }(6 \mathrm{~h}) ; 1 \mathrm{c} / \text { conhecimentos } \\
(4 \mathrm{~h})\end{array}$ & $\begin{array}{l}\text { Alemão 2: } 2 \text { Turmas } \\
1 \mathrm{~s} / \text { conhecimentos }(6 \mathrm{~h}) ; 1 \mathrm{c} / \text { conhecimentos } \\
(4 \mathrm{~h})\end{array}$ \\
\hline $\begin{array}{l}\text { Alemão 3: } 2 \text { Turmas } \\
1 \mathrm{~s} / \text { conhecimentos }(6 \mathrm{~h}) ; 1 \mathrm{c} / \text { conhecimentos } \\
(4 \mathrm{~h})\end{array}$ & $\begin{array}{l}\text { Alemão 4: } 2 \text { Turmas } \\
1 \mathrm{~s} / \text { conhecimentos (6h); } 1 \mathrm{c} / \text { conheci- } \\
\text { mentos (4h) }\end{array}$ \\
\hline $\begin{array}{l}\text { Alemão 5: } 2 \text { Turmas } \\
1 \mathrm{~s} / \text { conhecimentos }(6 \mathrm{~h}) ; 1 \mathrm{c} / \text { conhecimentos } \\
(4 \mathrm{~h})\end{array}$ & $\begin{array}{l}\text { Alemão 6: } 2 \text { Turmas } \\
1 \mathrm{~s} / \text { conhecimentos }(6 \mathrm{~h}) ; 1 \mathrm{c} / \text { conhecimentos } \\
(4 \mathrm{~h})\end{array}$ \\
\hline \multicolumn{2}{|c|}{ Linguística } \\
\hline \multicolumn{2}{|l|}{$\begin{array}{l}\text { Introdução aos Estudos Linguísticos } \\
1 \text { Turma }-2 \mathrm{~h} \text { ou (se houver acordo com o } \\
\text { GEAA); } 2 \text { Turmas }-4 \mathrm{~h}\end{array}$} \\
\hline \multirow[t]{2}{*}{ Linguística Alemã 1: 1 Turma - 2h } & Linguística Alemã 2: 1 Turma - 2h \\
\hline & Linguística Alemã 3: 1 Turma - 2h \\
\hline \multicolumn{2}{|c|}{ Literatura } \\
\hline $\begin{array}{l}\text { Int. aos Estudos Literários: } 1 \text { Turma } \\
-2 \mathrm{~h}\end{array}$ & Literatura Alemã 1: 1 Turma - 2h \\
\hline Literatura Alemã 2: 1 Turma - 2h & Literatura Alemã 3: 1 Turma - 2h \\
\hline \multicolumn{2}{|c|}{ Cultura } \\
\hline $\begin{array}{l}\text { Introdução aos Estudos Culturais: } \\
1 \text { Turma }-2 \mathrm{~h} \quad \text { ou } \quad 2 \text { Turmas }-4 \mathrm{~h}\end{array}$ & Cultura Alemã 1: 1 Turma - 2h \\
\hline Cultura Alemã 2: 1 Turma -2h & Cultura Alemã 3: 1 Turma -2h \\
\hline \multicolumn{2}{|c|}{ Outras } \\
\hline & $\begin{array}{l}\text { Metodologia do Trabalho Científico: } 1 \\
\text { Turma }-2 \mathrm{~h}\end{array}$ \\
\hline \multicolumn{2}{|c|}{ Opções Condicionadas } \\
\hline 1 Turma (LE+Port / 1LE) (3ㅇ sem.) & 1 Turma (1LE) (2o sem.) \\
\hline \multirow[t]{2}{*}{1 Turma (LE+Port / 1LE) (5 sem.) } & 1 Turma (1LE) (2o sem.) \\
\hline & 1 Turma (LE+Port / 1LE) (4 sem.) \\
\hline
\end{tabular}




\begin{tabular}{|c|c|}
\hline & 1 Turma (LE+Port / 2LE) (6 $\left.6^{\circ} \mathrm{sem}.\right)$ \\
\hline & 1 Turma (LE+Port) (6 sem.) \\
\hline \multirow{2}{*}{$\begin{array}{l}\text { Análise de Textos e Técnicas de Redacção } \\
\text { em Língua Alemã ( } 2^{\circ} \text { e } 3^{\circ} \text { anos): } 1 \text { Turma } \\
-2 \mathrm{~h}\end{array}$} & $\begin{array}{l}\text { Introdução à Literatura Comparada (To- } \\
\text { dos os anos): } 1 \text { Turma }-2 \mathrm{~h}\end{array}$ \\
\hline & $\begin{array}{l}\text { Relações entre a Literatura e as Artes } \\
\text { Plásticas (Todos os anos): } 1 \text { Turma }-2 \mathrm{~h}\end{array}$ \\
\hline \multirow[t]{2}{*}{$\begin{array}{l}\text { Tradução Português-Alemão }\left(2^{\circ} \text { e } 3^{\circ}\right. \\
\text { anos): } 1 \text { Turma - } 2 \mathrm{~h}\end{array}$} & $\begin{array}{l}\text { Tradução Alemão-Português }\left(2^{\circ} \text { e } 3^{\circ}\right. \\
\text { anos): } 1 \text { Turma }-2 \mathrm{~h}\end{array}$ \\
\hline & $\begin{array}{l}\text { Teoria da Literatura ( } 3^{\circ} \text { ano): } 1 \text { Turma } \\
-2 \mathrm{~h}\end{array}$ \\
\hline \multicolumn{2}{|c|}{ Opções de Língua } \\
\hline Iniciação à Língua Alemã I & Iniciação à Língua Alemã II \\
\hline Iniciação à Língua Alemã III & Iniciação à Língua Alemã IV \\
\hline \multicolumn{2}{|c|}{ Cursos Livres de Alemão } \\
\hline Iniciação ao Alemão I & Iniciação ao Alemão II \\
\hline Iniciação ao Alemão III & Iniciação ao Alemão IV \\
\hline Iniciação ao Alemão V & Iniciação ao Alemão VI \\
\hline Iniciação ao Alemão VII & Iniciação ao Alemão VIII \\
\hline
\end{tabular}

Curso - Mestrado em Estudos Literários e Culturais ( ${ }^{\circ}$ Ciclo de Bolonha)

\begin{tabular}{|l|l|}
\hline $1^{\circ}$ SEMESTRE & $2^{\circ}$ SEMESTRE \\
\hline Teoria da Literatura Comparada & Temas de Literatura Comparada \\
\hline Opção (Língua) & $\begin{array}{l}\text { Questões de História Literária / Opção } \\
\text { (Língua) }\end{array}$ \\
\hline Culturas Contemporâneas & Culturas de Língua Alemã \\
\hline Literaturas de Língua Alemã I & Literaturas de Língua Alemã II \\
\hline
\end{tabular}

Curso - LLM (Ramo de Formação Educacional)

Seminário

Núcleos de Estágio

Curso - Mestrado em Ensino de Línguas ( $2^{\circ}$ Ciclo de Bolonha)

\begin{tabular}{|l|l|}
\hline Didáctica do Alemão I & Didáctica do Alemão II \\
\hline Língua Alemã I & Língua Alemã II \\
\hline
\end{tabular}

Curso - CET ou Mestrado em Tradução

Quelle: Universidade de Coimbra, Institut für Deutsche Sprache, Dr. Maria de Fátima Gil. Stand:

Mai 2008. 


\section{Anlage V}

Intensivierung der Sprachpraxis

Möglichst viel in der Zielsprache unterrichten

Zusammenarbeit von Akademikern und Praktikern

Neue Unterrichts-, Arbeits- und Prüfungsformen

Wissenschaftsbereichsübergreifende Lerninhalte

Aufwertung des Übersetzens und Dolmetschens Abstimmung der Fremdsprachenphilologien

Sinn für Gemeinsamkeiten und Unterschiede der Weltkulturen schärfen

Stärker die Leistungsfähigkeit des eigenen Faches darstellen „Vermarktung“ germanistischer Qualifikationen

Fortbildung aller Dozenten

Bedarfsanalysen des Marktes + wiss. Fundierung

Öffnung des traditionellen Germanistikstudiums

Neue Module für Tourismus, Medien, Wirtschaftsdeutsch

Lehrende überzeugen durch lebenslanges Lernen und das eigene „Arbeitsportfolio“

Multinational zusammengesetzte Arbeitskreise Intensive wissenschaftliche Betreuung

Quelle: Ideenbörse der Tagung der Gesellschaft für Interkulturelle Germanistik (GIG), Tampere (Finnland), August 2007. Idee und Zusammenstellung: Ewald Reuter.

Auswahl und Ergänzungen: Carmen Schier (Univ. Leipzig). 



\section{Magdalena Michalak (Lüneburg)}

\section{Thesen zur Podiumsdiskussion}

Die Frage nach notwendigen Lehrkompetenzen, also die Frage danach, was alle angehenden Lehrer im Kontext des Deutschen als Zweitsprache wissen und können müssen, um ihre Aufgaben hinreichend erfüllen zu können - und wie sie dazu ausgebildet werden müssen - hat in den letzten Jahren eine besondere Bedeutung erhalten: Infolge des PISA-Schocks konzentrieren sich Bildungspolitik und Didaktik auf die Sprachförderung von Schülern nicht deutscher Herkunft. Gleichzeitig wird oft vergessen, dass gerade die Lehrkräfte für die Schulerfolge von Kindern und Jugendlichen mit Migrationshintergrund mitverantwortlich sind, denn es gehört zu ihren Obliegenheiten, sie sprachlich angemessen zu fördern. Sprache gilt dabei als Medium des Lernens in allen Fächern. Somit bietet jeder Unterricht Sprachfördermöglichkeiten, die genutzt werden müssen. Dazu brauchen angehende Lehrer aller Fächer das nötige theoretische und praktische Wissen, um die besonderen sprachlichen Schwierigkeiten ihres Unterrichts wahrnehmen und differenziert darauf reagieren zu können.

Bisher war die Mehrsprachigkeit in Bezug auf die Lehrervorbereitung eher eine Domäne der interkulturellen Pädagogik. Diese zielt einerseits auf die Integration von Schülern mit Migrationshintergrund, andererseits auf die interkulturelle Erziehung aller Schüler. Das reicht aber nicht aus, um die Schüler mit Migrationshintergrund in der Zweitsprache sinnvoll zu fördern. Denn die interkulturelle Pädagogik vermittelt keine Kenntnisse der sprachlichen Kompetenzen, die für die erfolgreiche Arbeit mit DaZLernern in allen Fächern erforderlich sind. Hier muss das Fach Deutsch eingreifen. Das Thema Mehrsprachigkeit ist in der Lehrerbildung unter dem sprachwissenschaftlichen und sprachdidaktischen Aspekt explizit zu thematisieren. Der sprachbewusste (Fach-) Unterricht ist somit die Grundlage für adäquate sprachliche Förderung von Schülern mit Migrationshintergrund.

Aus diesen Überlegungen lassen sich folgende Fragestellungen für die DaZ-Didaktik und die Bildungspolitik ableiten:

1. Welches sind die linguistischen und didaktisch-methodischen Kompetenzen, die Lehramtsstudierende aller Fächer in ihrem Studium erwerben müssen, damit sie in ihrem Berufsfeld im Umgang mit sprachlicher Vielfalt in deutschen Schulklassen kompetent und professionell handeln können?

2. Wie sollen diese Qualifikationen im Rahmen der universitären Lehrerbildung vermittelt werden? Welche Methoden/Lernformen sind am besten geeignet, die DaZLehrkompetenzen zu erwerben? Wie kann das theoretische Wissen mit der schulischen Praxis verknüpft werden?

3. In welchen Punkten müssen die Hochschullehrenden professionalisiert werden, um die erforderlichen Kompetenzen im Kontext des Deutschen als Zweitsprache am effektivsten zu vermitteln? 


\section{Udo Ohm (Jena)}

\section{Thesen zur Podiumsdiskussion}

Um die schulischen Anforderungen, die Anforderungen in der Berufsausbildung und am späteren Arbeitsplatz bewältigen zu können, müssen Kinder und Jugendliche bildungssprachliche Fähigkeiten erwerben, mit denen sie anspruchsvolle kognitive Operationen und dekontextualisierte Sprachhandlungen ausführen können. Von besonderer Bedeutung ist dabei die sprachliche Förderung von Kindern und Jugendlichen nichtdeutscher Herkunftssprache, weil Bildungsstudien bei dieser Gruppe einen engen Zusammenhang zwischen mangelnder bildungssprachlicher Kompetenz in Deutsch als Zweitsprache und verminderten Bildungschancen aufgezeigt haben.

Da die Aneignung von Fachwissen und von beruflichen Fähigkeiten grundlegende bildungssprachliche Fähigkeiten voraussetzt, sollte Sprachförderung dort erfolgen, wo sich sprachliche Defizite in Schule und Berufsausbildung zeigen: in den Fächern und am Ausbildungsplatz. Eine fach- und ausbildungsplatzbezogene Sprachförderung ist auch deshalb angezeigt, weil Kinder und Jugendliche auf diese Weise die Relevanz sprachlichen Wissens unmittelbar selbst erfahren, was sich wiederum positiv auf ihre Sprachbewusstheit und ihre Sprachlernmotivation auswirkt.

Sowohl die Ergebnisse internationaler Bildungsstudien als auch die alltäglichen Erfahrungen von Lehrern und Ausbildern belegen zwar, dass sich bildungssprachliche Defizite negativ auf den Bildungserfolg von Kindern und Jugendlichen nicht-deutscher Herkunftssprache auswirken, sie zeigen aber auch, dass viele Kinder und Jugendliche deutscher Herkunftssprache mit ähnlichen Schwierigkeiten zu kämpfen haben. Eine stärkere Förderung der sprachlichen Entwicklung in allen Fächern wird sich daher insgesamt positiv auf das schulische Lernen und die berufliche Ausbildung auswirken.

Einer sprachlichen Förderung von Kindern und Jugendlichen in separaten Förderkursen ist mit Skepsis zu begegnen: Erstens wird dadurch die Förderung der sprachlichen Entwicklung aus dem Kontext des fachlichen Lernens herauslöst; zweitens besteht die Gefahr, dass die Verantwortung zur Förderung der sprachlichen Entwicklung aus dem Kernbereich von Bildung und Ausbildung entfernt und in den Bereich von Reparaturmaßnahmen verlagert wird; drittens wird auf diese Weise die gängige Praxis der Fixierung des Fachlernens auf die Vermittlung von Fachwissen bei gleichzeitiger Ausblendung der sprachlichen Ebene der Wissensvermittlung zementiert.

Lehrkräfte aller Fächer und Berufsfelder müssen für den Zusammenhang von Fachlernen und sprachlicher Entwicklung sensibilisiert werden. Insbesondere für die Förderung in der Zweitsprache Deutsch benötigen sie daher grundlegende diagnostische, didaktisch-methodische und interkulturelle Kompetenzen. Dies muss bereits in der Ausbildung von Lehrkräften aller Fächer angemessen berücksichtigt werden. Die derzeit zweifellos dringend gebotenen Nachqualifizierungen im Rahmen von Weiterbildungsmaßnahmen können eine grundständige Qualifizierung nicht ersetzen. 


\section{Bettina Seipp (Dortmund)}

\section{Thesen zur Podiumsdiskussion}

1. Eine Evaluation bei Studentischen Förderlehrer/innen im Dortmunder Förderprojekt Sprachliche Kompetenz für Schüler/innen mit Migrationshintergrund, die in einem zwei Semesterwochenstunden umfassenden Seminar zu Deutsch als Zweitsprache auf diese Tätigkeit vorbereitet und in einem weiteren Seminar desselben Umfangs parallel zu ihrer Tätigkeit begleitet wurden, zeigt, dass bei diesem Umfang Kompetenzen auf einem Niveau ausgebildet werden können, das es ermöglicht, diese im (Förder-)Unterricht - nach einer gewissen Routinierungsphase - anwendbar werden zu lassen.

Es kann also möglich gemacht werden, mit den leider nur sechs Leistungspunkten, die für die neue Lehrerbildung in NRW vorgesehen sind, umfassenden Vorgaben eine Ausbildungskonzeption zu entwickeln, um zukünftigen Lehrer/inne/n die geforderten Basiskompetenzen zu vermitteln. Von grundlegender Bedeutung dürfte es hier allerdings sein, dass dabei eine Beschränkung auf die tatsächlich notwendigen Kenntnisse und Fähigkeiten erfolgt.

2. Äußerst wünschenswert ist eine Verknüpfung des theoretisch Erworbenen mit praktisch Erprobtem und Vertieftem. Eine Praxisphase, wie sie das Projekt Förderunterricht der Stiftung Mercator ermöglicht, ist bei einem Umfang von sechs Leistungspunkten nicht denkbar. Daher muss jede Hochschule nach eigenem Ermessen Möglichkeiten entwickeln, den Förderunterricht in seiner bisherigen oder in angepasster Form an vorgeschriebene Praxisphasen anzubinden. Hierzu sollte keine Festlegung erfolgen, da sich je nach Projektauslegung unterschiedliche Praxisanteile hierfür anbieten.

Um die für den Kompetenzerwerb notwendige Kontinuität zu gewährleisten, sollte möglichst in allen Praxisphasen - evtl. je nach inhaltlicher Schwerpunktsetzung der Studierenden - eine Anbindung oder Wiederaufnahme der Thematik ermöglicht werden. So könnten erste Erfahrungen mit dem Thema in Kleingruppen in den Praxisphasen des Bachelor gemacht und diese beispielsweise in Form von Lehrforschungsprojekten in dem für Nordrhein-Westfalen geplanten Praxissemester wieder aufgegriffen und in den größeren Kontext von Schule und Unterricht mit dem Schwerpunkt Diagnostik und Förderung integriert werden.

3. Die Hochschulen sollten die Möglichkeit nutzen, neben einem Basismodul im Bachelor ein fakultatives vertiefendes Aufbaumodul DaZ im Master of Education anzusiedeln und die Möglichkeit bieten, aus diesem heraus - in NRW in Kombination mit dem Praxissemester - Masterarbeiten anzufertigen. 
4. Deutsch als Zweitsprache ist entweder als eingeständiger Bereich definiert oder eindeutig der Germanistik und den Fachdidaktiken zuzuordnen:

Die zu vermittelnden Kompetenzen in Deutsch als Zweitsprache oder für Schüler/ innen mit Zuwanderungsgeschichte können sich inhaltlich-logisch nur auf Germanistik und auf die Übertragung sprach-didaktischer Elemente auf die besonderen Anforderungen im Sachfach-Unterricht beziehen. Sie sollten schwerpunktmäßig einerseits auf das Diagnostizieren-Können sprachlicher Schwierigkeiten, die den Verstehens- und damit den Lösungsprozess fachlicher Aufgaben beeinträchtigen/verhindern, und von dort aus auf die Sprachförderung im Dienste gelingender Aufgabenbewältigung fokussieren. Dazu sind bestimmte sprachwissenschaftliche/sprachdidaktische Fähigkeiten von Lehrer/inne/n nötig, die allein aus der Germanistik beigetragen werden können. Insbesondere trifft das auf Kompetenzen in den Bereichen Grundlagen der Kommunikation, grammatische Grundbegriffe, Zweitsprachenerwerb und Grundlagen von Sprach(stands)tests für diejenigen Studierenden zu, die nicht das Fach Deutsch studieren. Von dieser Grundqualifizierung aus muss dann eine Spezifizierung der Förderkompetenz (Analyse der sprachlichen Besonderheiten der deutschen Fachsprachen, Methoden der Textentlastung, Sprachlichkeit fachlichen Lernens, konzeptionelle Schriftsprachlichkeit (CALP) etc.) in den einzelnen Fachdidaktiken erfolgen. Die Erkenntnis, dass sich sprachliche Defizite von Schülern mit Zuwanderungsgeschichte kumulativ in den Sachfächern auswirken, ist die zentrale Erkenntnis der PISA-Analysen.

Die Vermittlung der hier nur kurz angerissenen Kompetenzen kann auf gar keinen Fall durch Personal der Erziehungswissenschaft geleistet werden - aus rein fach-logischen Gründen. Es geht ja hier tatsächlich um Deutsch als Zweitsprache und nicht um Ansätze der weiter und inhaltlich ganz anders gefassten interkulturellen Pädagogik. Diese haben sicher auch ihre Berechtigung und sollten unbedingt von der Erziehungswissenschaft flankierend beigesteuert werden, aber: Kenntnisse über soziologische Gegebenheiten im Kontext von Migration, Perspektivenwechsel im Schulalltag und Fremdverstehen im Unterricht unter Einbeziehung kultureller Vielfalt können die sprachlichen „Defizite“ der betroffenen Schüler/innen nicht beseitigen!

Viele Erziehungswissenschaftler hätten es sicher begrüßt, den in diesem Sinne von ihnen missverstandenen Bereich DaZ bei sich angesiedelt zu finden. Deshalb ist es im Dienste der Sache extrem wichtig, die Zuordnung zur Germanistik und den Fachdidaktiken deutlich und verbindlich herauszustellen - auf der einen Seite, um Grabenkriege zwischen der Erziehungswissenschaft und der Germanistik innerhalb einzelner Hochschulen zu vermeiden, auf der anderen Seite aber auch, um das Fach Germanistik und die Fachdidaktiken (an einigen Hochschulen) nicht aus der Verantwortung zu entlassen. 


\section{Edwin Stiller (Düsseldorf)}

\section{Thesen zur Podiumsdiskussion}

\section{Ausgangssituation}

Die zurzeit gültige Lehramtsprüfungsordnung (LPO) 2003 schreibt im \5 „Übergreifende Studieninhalte“ vor, dass Studierende „Grundkenntnisse in interkultureller Bildung und der Förderung von Schülerinnen und Schülern in Deutsch als Zweitsprache erwerben."

Die Lehrer ausbildenden Standorte lösen diesen Anspruch sehr unterschiedlich ein. Die Zusatzqualifikation DaZ/Interkulturelle Pädagogik kann an den Universitäten Bielefeld, Duisburg-Essen, Köln und Münster studiert werden. Deutsch für Schülerinnen und Schüler mit Zuwanderungsgeschichte (ehemals DaZ) im engeren Sinne wird aber auch an diesen Standorten nicht überall angeboten, sondern durch erziehungswissenschaftliche Module zum Bereich interkulturelle Pädagogik ersetzt. Damit wird die Vorgabe der Lehramtsprüfungsordnung 2003 faktisch nur teilweise umgesetzt. Im Didaktischen Grundlagenstudium Deutsch (Lehramt Grund-, Haupt- und Realschule) werden Ansätze einer sprachlichen Grundqualifikation gelegt.

Im derzeit gültigen Lehrerausbildungsgesetz sind folgende Praxisphasen im Lehramtstudium vorgesehen: Orientierungspraktikum (vier Wochen) im ersten Studienjahr, im Hauptstudium sind Praktika im Mindestumfang von zehn Wochen zu absolvieren (außerschulisch, fachdidaktisch und/oder erziehungswissenschaftlich orientiert).

\section{Perspektiven des neuen Lehrerausbildungsgesetzes (LABG)}

Im Gesetz zur Reform der Lehrerausbildung sowie der begleitenden Verordnung wird der Bereich „Deutsch für Schülerinnen und Schüler mit Zuwanderungsgeschichte“ verbindlich mit sechs Leistungspunkten (als Minimalnorm) in allen lehramtsbezogenen Studiengängen verankert ( $\$ 2$ ff. der Lehramts-Zugangsverordnung). Im $\$ 10$ dieser Verordnung wird diese Aufgabe als eine der übergreifenden Kompetenzbereiche ausgewiesen: „Grundkompetenzen in der Förderung von Deutsch für Schülerinnen und Schüler mit Zuwanderungsgeschichte im Zusammenhang interkultureller Bildung." Folgende Praxiselemente sieht das neue LABG vor:

- Eignungspraktikum: mindestens 20 Praktikumstage, kann vor Aufnahme des Studiums und soll möglichst vor Beginn des Orientierungspraktikums abgeleistet werden

- Orientierungspraktikum: vier Wochen im ersten Studienjahr

- Außerschulisches oder schulisches Berufsfeldpraktikum: vier Wochen im Bachelorstudium

- Praxissemester: fünf Monate im Masterstudium (Schulforschungsmodule und Schulpraxismodul) 
Alle neuen Praxiselemente können grundsätzlich mit der besonderen Perspektive der besseren Förderung von Schülerinnen und Schülern mit Zuwanderungsgeschichte verknüpft werden. Eine Kommission wird die curricularen Grundlagen für das Schulpraxismodul erarbeiten. Auf dieser Basis können dann Verknüpfungsmöglichkeiten geprüft werden. Schulforschungsmodule können von den Lehrer bildenden Hochschulen durchaus auch mit einem Schwerpunkt „Deutsch für Schülerinnen und Schüler mit Zuwanderungsgeschichte" durchgeführt werden.

\section{Weitere Perspektiven}

Zurzeit wird gemeinsam mit dem Ministerium für Generationen, Familie, Frauen und Integration geprüft, inwieweit das Projekt Förderunterricht der Stiftung Mercator unterstützt und ausgeweitet werden kann.

Weiterhin werden Anstrengungen unternommen, die Seminarausbilder in den Studienseminaren im Bereich „Deutsch für Schülerinnen und Schüler mit Zuwanderungsgeschichte" weiter zu qualifizieren. Auch die Kompetenzteams in den 54 Kreisen und Städten bieten Fortbildungsbausteine in diesem Feld an. 


\section{Silvia Demmig \& Susan Kaufmann}

\section{Themenschwerpunkt Integrationskurse}

Der Themenschwerpunkt Integrationskurse auf der Jahrestagung 2008 bot die Gelegenheit, eine vorläufige Bilanz der Entwicklungen im Bereich der Sprachförderung für erwachsene Einwanderinnen und Einwanderer zu ziehen. Nachdem diese seit 2005 in der Zuständigkeit des BAMF liegt, sind einige neue Entwicklungen zu verzeichnen. Allen voran ist das Rabmencurriculum für Integrationskurse Deutsch als Zweitsprache zu nennen, das im Zusammenhang mit der skalierten Abschlussprüfung Deutschtest für Zuwanderer erstellt wurde. Das Rahmencurriculum versteht sich als migrantenspezifische Umsetzung des GER und wird voraussichtlich einen deutlichen Fortschritt für die inhaltliche und didaktische Kursgestaltung bringen. In dem Beitrag von Demmig und Kaufmann wird dieses Projekt vorgestellt. Das Rahmencurriculum unterstreicht die sprachliche Handlungsfähigkeit im Alltag als Ziel der Integrationskurse und definiert, in welchen gesellschaftlichen Bereichen Zugewanderte sprachlich handeln müssen. Im Unterricht selbst muss Handlungsorientierung ein durchgängiges Prinzip sein.

Dass Integration mit dem Erwerb der deutschen Sprache nicht getan ist und dass das Lernen der deutschen Sprache nicht nur von der Entscheidung und dem Willen der Einwanderinnen und Einwanderer abhängt, behandelt Ohm in seinem Beitrag. Er zeigt, dass Zugewanderte vielfach Handlungseinschränkungen auch durch Zugangskontrollen durch Zielsprachensprecher erfahren und der Zweitsprachenerwerb mit Verunsicherung und Gefährdung der Selbstidentität einhergehen kann, und leitet Forderungen für die Integrationskurse ab.

Die Lehrwerke, die in den Integrationskursen eingesetzt werden, sind das Forschungsgebiet von Ucharim. Sie analysiert in ihrem Beitrag auf der Grundlage der thematischen Diskursanalyse, die in den Erziehungswissenschaften für die Analyse von Sach- und Sozialkundebüchern entwickelt wurde, am Beispiel des Themenfelds „Arbeit", wie die in den Lehrwerken angebotenen Texte aus kulturwissenschaftlicher Sicht zu beurteilen sind.

Für eine Lockerung der engen Bindung des Zweitsprachen-Lernens an das Lehrwerk appelliert Michalak in ihrem Beitrag zum informellen Spracherwerb, der auf Ergebnissen einer empirischen Untersuchung der Lerngewohnheiten, Einstellungen und Schwierigkeiten beim Zweitspracherwerb von Integrationskurs-Teilnehmenden basiert. Michalak fordert, den Spracherwerb erwachsener Lernerinnen und Lerner in Integrationskursen und im Alltag miteinander zu verknüpfen, um so die Fähigkeit der Lernenden zum autonomen, außerunterrichtlichen Lernen zu stärken, und diskutiert die didaktischen Konsequenzen.

Dem nicht nur aktuell im Zusammenhang mit der Förderung der sog. ESF-Kurse durch das Bundesamt für Migration und Flüchtlinge wichtigen Themengebiet des berufsbezogenen Deutschunterrichts widmet sich der Beitrag von Szablewski-Çavuş. 
Sie skizziert, dass die Förderung der zweitsprachlichen Kompetenz am Arbeitsplatz zu einem wichtigen Bestandteil in der beruflichen Bildung und Weiterbildung mit MigrantInnen geworden ist, und stellt Qualitätskriterien vor, die vom „Facharbeitskreis Berufsbezogenes Deutsch“ auf der Grundlage der vorliegenden Erfahrungen im Bereich Deutsch als Zweitsprache und Arbeit entwickelt wurden.

Die besondere Bedeutung des Integrationskurses und speziell des inbegriffenen Orientierungskurses, der Grundkenntnisse der Rechts- und Gesellschaftsordnung und der Lebensverhältnisse in Deutschland vermittelt, wird in der öffentlichen Debatte um Einwanderung immer wieder betont. Vernachlässigt wird darüber die Erörterung der Folgemaßnahmen. Aus Erfahrungen von Arbeitsvermittlern und Kursträgern wird jedoch deutlich, dass vor allem arbeitsmarktbezogene Weiterbildungsmöglichkeiten, die an den Integrationskurs anschließen, dringend notwendig sind, um die Nachhaltigkeit des Lernprozesses zu sichern. Einen Bericht dazu liefert der Beitrag von Daase. Sie stellt ein Gesamtkonzept für die arbeitsmarktbezogene Sprachförderung vor, das im Kreis Herford entwickelt wurde, auf die Bedürfnisse der Teilnehmenden sowie die Bedarfe des Arbeitsmarktes ausgerichtet ist und von einem breiten Netzwerk getragen wird. Daase zeigt Probleme der widersprüchlichen Förderpolitik auf.

Dass der Integrationskurs bereits vor den Grenzen Deutschlands beginnt, da seit 2007 ausländische Ehepartner, die nach Deutschland ziehen möchten, schon bei der Beantragung des Visums einfache Deutschkenntnisse - die bestandene „Start 1-Prüfung" nachweisen müssen, schildert Gobeyshi. Sie hat in einer Pilotstudie die Teilnehmenden dieser Prüfungen befragt und stellt die bisher in der Fachdiskussion kaum berücksichtigten Sprachprüfungen für nachziehende Ehegatten aus der Türkei vor. 
Christoph Chlosta, Matthias Jung (Hrsg.) (2010): DaF intergriert: Literatur - Medien - Ausbildung. Tagungsband der 36. Jabrestagung des Fachverbandes Deutsch als Fremdsprache 2008. Göttingen: Universitätsverlag, 325-334.

\section{Silvia Demmig (Jena) \& Susan Kaufmann (Mainz)}

\section{Das Rahmencurriculum für die Integrationskurse}

\section{Einleitung}

Seit dem Inkrafttreten des neuen Zuwanderungsgesetzes am 01.01.2005 sind die Deutschkurse für Neuzuwanderer und schon länger in Deutschland lebende Einwanderer, die früher von verschiedenen Ministerien gefördert und verwaltet wurden, ${ }^{1}$ in die Zuständigkeit des Bundesamts für Migration und Flüchtlinge (BAMF) übergegangen. Das BAMF hatte zunächst in Anlehnung an die bis dahin gängige Praxis der Sprachkursförderung grobe Rahmenrichtlinien erlassen, eine Liste zugelassener Lehrwerke erstellt und ein Lehrerfortbildungsprogramm etabliert. Ein Curriculum für die Sprachkurse wurde jedoch nicht erstellt.

Spätestens im Zusammenhang mit dem Wunsch des BAMF, eine Abschlussprüfung für die Integrationskurse einzuführen, stellte sich die Frage nach dem Curriculum in aller Dringlichkeit: Wie sollte eine Prüfung erstellt werden, wenn die Kursinhalte nicht definiert waren? 2007 erging daher an das Goethe-Institut der Auftrag, gleichzeitig ein Rahmencurriculum und eine Abschlussprüfung für die Integrationskurse zu entwickeln. Der Auftrag des BAMF an das Goethe-Institut lautete folgendermaßen:

- Entwicklung einer skalierten Sprachprüfung für Zuwanderer zur Feststellung von fertigkeitsbezogenen Sprachkompetenzen auf den Stufen A2-B1 des Gemeinsamen Europäischen Referenzrahmens (GER).

\footnotetext{
Vgl. Krekeler (2001: 20).
} 
- Entwicklung eines Rahmencurriculums, das maximal mögliche Lernziele und -inhalte für die Integrationskurse vorgibt und als Grundlage zur Erstellung von Kursmodellen und Stoffverteilungsplänen dient.

Mit der Vorgabe der Orientierung am Gemeinsamen Europäischen Referenzrahmen waren grundsätzliche Probleme verbunden: Aus Sicht der ExpertInnengruppe ${ }^{2}$, die das Rahmencurriculum entwickelt hat, ist die sprachliche Realität der Kursteilnehmenden in den Integrationskursen nur bedingt mit der von Fremdsprachenlernenden vergleichbar, für die der GER zunächst beispielhaft seine Referenzniveaus definiert. Die Autoren des GER fordern, dass der GER multifunktional sein solle, „nutzbar für die ganze Bandbreite von Zwecken und Zielsetzungen bei der Planung und Bereitstellung von Sprachlernmöglichkeiten“ (GER 2001: 20) und der jeweiligen Zielgruppe angepasst werden müsse. Die ExpertInnengruppe sah sich also der Herausforderung, den GER für die Zielgruppe der Zweitsprachenlernenden zu adaptieren, gegenüber. Die Zweitsprachenlernsituation ist gekennzeichnet durch

- die vitalen Orientierungs- und Handlungsbedürfnisse der Migrantinnen und Migranten im Land der Zielsprache,

- ein hohes Maß an außerunterrichtlichem, ungesteuertem Spracherwerb, der nicht linear in den Stufen des GER abläuft,

- eine extreme Heterogenität der Lernenden, ${ }^{3}$ die durch den außerunterrichtlichen Spracherwerb noch verstärkt wird,

- die Verbindung des sprachlichen Lernens mit nichtsprachlichen Kompetenzen, z.B. der Fähigkeit zur Verständigung in interkulturellen Begegnungssituationen,

- eine Grammatikvermittlung, die die Sprachverwendung unterstützt,

- die Gefahr eines Stillstands des Lernprozesses und folgender „Fossilierung“ von nicht standardmäßiger Sprache.

Ein Curriculum für diese Kurse muss dieser Situation gerecht werden und vor allem die Lehrkräfte in den Integrationskursen unterstützen, mit den vielfältigen Herausforderungen umzugehen. Möglicherweise ergibt sich z.B. aus der Situation des Zweitspracherwerbs eine andere Erwerbsreihenfolge oder eine ungleichmäßige Entwicklung der Fertigkeiten. So verfügen Zweitsprachenlernende im Vergleich zu Fremdsprachenlernenden beispielsweise über einen sehr großen Wortschatz, häufig dagegen über wenig explizites Grammatikwissen.

Diese Besonderheiten der Zweitsprachenerwerbssituation sind jedoch bisher nicht ausreichend in empirischen Forschungsprojekten untersucht worden. Wünschenswert wäre die Erstellung eines „Profile DaZ“, einer Adaption des GER auf die Zweitspracherwerbssituation, in der Kann-Beschreibungen aus der Sicht von DaZ-Lernenden formuliert sind. Im Rahmencurriculum sind zu den ausgewählten Handlungsfeldern bereits Kann-Beschreibungen entwickelt worden.

2 Hans Barkowski, Rosemarie Buhlmann, Silvia Demmig, Konrad Ehlich, Susan Kaufmann, Angela Kilimann, Helen Schmitz, unter der Leitung von Karin Ende.

3 Vgl. Demmig (2003: 28f). 
Die Forschungslage im Umfeld der Integrationskurse zeichnet sich dadurch aus, dass u.a. durch den Sprachverband Deutsch e.V., der in der Vergangenheit Tagungen und Fortbildungen organisiert hat, durch einzelne engagierte Fachkollegen und -kolleginnen auch im Rahmen von FaDaF-Tagungen und unabhängige Gremien wie dem Transnationalen ExpertInnenforum Sprache und Integration ${ }^{4}$ seit vielen Jahren der Diskurs über das DaZ-Lernen geführt wird, es jedoch wenig relevante Veröffentlichungen im Bereich Deutsch als Zweitsprache mit erwachsenen Lernenden gibt. Mit der Zusammenstellung der ExpertInnengruppe ist dieser Situation bei der Erstellung des Rahmencurriculums Rechnung getragen worden. Durch die einzelnen Mitglieder und ihren jeweiligen Arbeits- und Forschungshintergrund konnte sehr viel Expertise über die Zweitsprachenerwerbssituation in die Entwicklungsarbeit eingebracht werden. So konnten im Rahmencurriculum bereits viele Kann-Beschreibungen speziell für das DaZ-Lernen formuliert werden (s.u.).

\section{Arbeitsschritte: Wie entsteht ein Rahmencurriculum?}

Das Rahmencurriculum ist in folgenden Entwicklungsschritten entstanden:

\section{Erhebung des Sprachbedarfs der Zielgruppe}

Es wurden zwei Erhebungen durchgeführt: eine Sprachbedarfserhebung bei Lehrenden, Lernenden, VertreterInnen von Trägern und Institutionen durch das Forschungsprojekt InDaZ unter der Leitung von Konrad Ehlich (mit Montanari; Hila 2007), eine zweite - unveröffentlichte - anhand eines Fragebogens, der von ca. 250 Teilnehmenden an Integrationskursen ausgefüllt und für die Erstellung des Rahmencurriculum ausgewertet wurde.

\section{Beschreibung der Zielgruppe}

Ausgehend von den Befragungen und einer eingehenden Literaturrecherche wurden Besonderheiten der Zielgruppe und mögliche Charakteristika spezieller Untergruppen beschrieben.

\section{Entwicklung des konzeptionellen Formats}

Die inhaltliche und strukturelle Gestaltung des Rahmencurriculums ist das Ergebnis von vielen Sitzungen in der ExpertInnenrunde. Die Aufteilung in sprachliche Handlungsfelder (s.u.) und handlungsfeldübergreifende Kommunikationsbereiche (s.u.) entspricht den Erkenntnissen aus der Sprachbedarfserhebung und aus vorangegangenen Projekten 6 .

\section{Definition der Lernziele}

Innerhalb der einzelnen Handlungsfelder wurden mithilfe der Kann-Beschreibungen des GER und von Profile Deutsch detaillierte Lernzielbeschreibungen erstellt. Diese Lernziele sind als Rahmen für eine Kursgestaltung zu verstehen, aus dem je nach Bedarf und Bedürfnissen der einzelnen Lerngruppen,

\footnotetext{
Siehe http://www.spracheundmigration.info (12.12.2009).

Siehe www.goethe.de/integration (12.12.2009).

Z.B. Barkowski (1982).
} 
mit Rücksicht auf die Heterogenität der Teilnehmenden eine Auswahl getroffen werden muss.

Kalibrierung der Lernziele

Die Lernziele sind den Niveaustufen des GER zugeordnet worden.

Erprobung

Das Rahmencurriculum ist in den Integrationskursen des Goethe-Institutes erprobt worden.

\section{Evaluierung durch Kursleitende}

Eine Evaluierung und Beurteilung durch Kursleitende aus dem gesamten Bundesgebiet ist vorgenommen worden. Änderungsvorschläge und Kommentare wurden aufgenommen.

Begutachtung

Das Rahmencurriculum wurde weiteren Experten (Prof. David Little, Trinity College Dublin, Prof. Dr. Hans H. Reich, Universität Koblenz-Landau und Dr. Dieter Dräxler, Goethe-Institut München) zur Begutachtung vorgelegt. Anregungen und Änderungsvorschläge wurden eingearbeitet.

\section{Veröffentlichung}

Im Januar 2008 wurde das Rahmencurriculum veröffentlicht und offiziell vorgestellt. Es kann unter www.integration-in-deutschland.de heruntergeladen werden.

\section{Förderung der sprachlichen Handlungsfähigkeit: die im Rahmencurriculum definierten Lernziele}

Das Rahmencurriculum enthält unterschiedliche Teile, die für den Bereich Deutsch als Zweitsprache relevant sind, so z.B. auch die Anfangskapitel, die sich mit den Charakteristika des Erwerbs von Deutsch als Zweitsprache und der sprachlichen Handlungsfähigkeit als Ziel der Integrationsförderung befassen.

An dieser Stelle werden wir jedoch vor allem auf den Kernbereich des Rahmencurriculums, die Auflistung der Lernziele, eingehen. 


\subsection{Kommunikation in Handlungsfeldern}

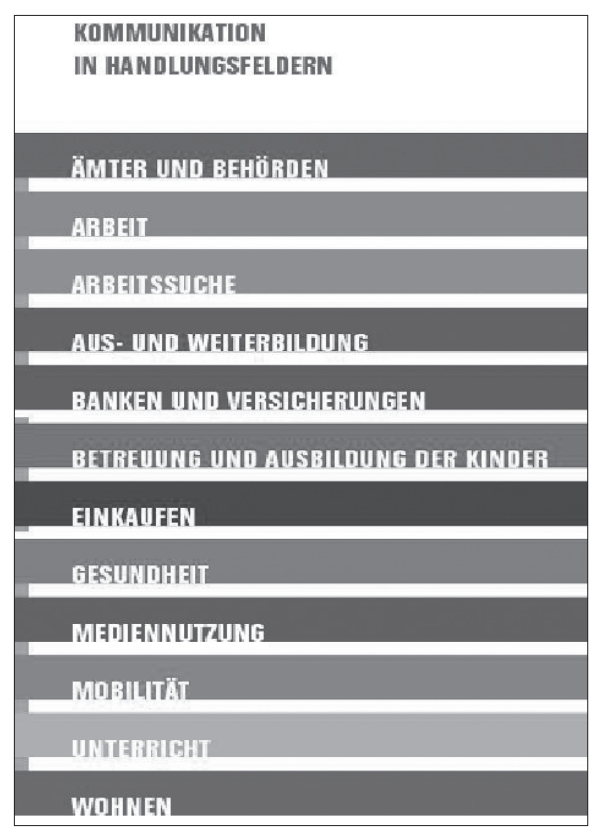

Die Ergebnisse der Bedarfserhebungen führten zur Festlegung von zwölf Handlungsfeldern, in denen Migrantinnen und Migranten agieren (siehe Abbildung 1).

Abb. 1: Kommunikation in Handlungsfeldern

\subsection{Die Struktur der Handlungsfelder}

Die einzelnen Handlungsfelder sind in sich wieder in Teilbereiche - von der anonymen, formellen Informationsbeschaffung und Kommunikation hin zur informelleren Kommunikation mit Gleichgestellten - geordnet. Im Handlungsfeld „Betreuung und Ausbildung der Kinder" beispielsweise sind es die folgenden Teilbereiche:

- Sich einen Überblick über Betreuungs- und Ausbildungsmöglichkeiten der Kinder verschaffen

- Kommunikation mit Betreuungseinrichtungen, Schulen und Behörden

- Kommunikation mit Erzieher/-innen, Lehrkräften bzw. Schulleitung

- Kommunikation mit Eltern bzw. Mitschüler/-innen des Kindes

\subsection{Lernziele}

In tabellarischer Anordnung finden sich zunächst die als Kann-Beschreibungen formulierten Lernziele, denen ein Anwendungsbeispiel hinzugefügt wurde. ${ }^{7}$

7 Die folgenden Beispiele sind dem Handlungsfeld „Betreuung und Ausbildung der Kinder“ entnommen, siehe Buhlmann et al. (2008: 83). 
Beispiel:

\begin{tabular}{|l|}
\hline Lernziel \\
\hline Kann Formulare ausfüllen, z.B. Antrag auf \\
Kindergeld, Zuschuss zu einer Klassenfahrt \\
$\ldots$
\end{tabular}

\subsection{Fertigkeiten}

In der Spalte „Aktivitäten“ ist die Fertigkeit aufgelistet, in der die sprachliche Handlung ausgeführt wird (schreiben, lesen, hören, sprechen und - für die mündliche Interaktion - am Gespräch teilnehmen). In fast allen Handlungsfeldern überwiegt der mündliche Ausdruck.

Beispiel:

\begin{tabular}{|l|l|}
\hline Lernziel & Aktivitäten \\
\hline Kann Formulare ausfüllen, z.B. Antrag auf & schreiben \\
Kindergeld, Zuschuss zu einer Klassenfahrt & \\
$\ldots$ & \\
\hline
\end{tabular}

\subsection{Niveau des Lernziels nach dem GER}

In der Spalte „Niveau“ wurde die dem GER entsprechende Stufe notiert. Da Zugewanderte komplexe Handlungen auch schon nach kurzer Aufenthaltsdauer ausführen müssen, lange bevor sie gelernt haben, dies in entsprechend sprachlich komplexer Weise zu tun, wurden die Lernziele im Rahmencurriculum zunächst jeweils der niedrigsten Stufe zugewiesen, auf der sie sinnvoll umgesetzt werden können. Das Rahmencurriculum empfiehlt jedoch, die Lernziele zyklisch progredient immer wieder aufzugreifen.

\begin{tabular}{l|l|l|l|}
\hline \multirow{3}{*}{ Beispiel: } & Lernziel & Aktivitäten & Niveau \\
\cline { 2 - 4 } & $\begin{array}{l}\text { Kann Formulare ausfüllen, z.B. Antrag auf } \\
\text { Kindergeld, Zuschuss zu einer Klassenfahrt } \\
\ldots\end{array}$ & schreiben & A2 \\
\hline
\end{tabular}

\subsection{Zielgruppen}

Weiterhin wurde in der Tabelle die jeweilige Zielgruppe zugeordnet. Zuvor war die in sich äußerst uneinheitliche Zielgruppe in folgende Untergruppen aufgeteilt worden:

- Gruppe A: Diese in sich immer noch sehr heterogene Zielgruppe definiert sich hinsichtlich der guten Lernvoraussetzungen (vorhandenen Lernerfahrungen, Schul- und Berufsabschlüssen) und dezidierten Bildungs- und Berufswünschen. Personen in dieser Untergruppe sind relativ kurz in Deutschland und vergleichsweise jung.

- In Gruppe B finden sich Personen, die deutlich auf Familie und die Betreuung bzw. schulische Begleitung der Kinder, also nicht auf die Aufnahme einer beruflichen Tätigkeit ausgerichtet sind. Sie unterscheidet sich von Gruppe A auch durch ein niedrigeres Bildungsbzw. Qualifizierungsniveau, das sich u.a. an schriftsprachlichen Schwierigkeiten zeigt.

- Auch Gruppe C zeigt im Vergleich zu Gruppe A ein niedrigeres Bildungs- und Qualifizierungsniveau. Sie weist im Vergleich der drei Gruppen den höchsten Altersdurchschnitt sowie die längste Aufenthaltszeit in Deutschland auf. Gruppe B und Gruppe 
C sind sich in verschiedener Hinsicht ähnlich, doch ist Gruppe C deutlich auf den Erhalt bzw. die Wiederaufnahme einer Beschäftigung ausgerichtet.

Beispiel:

\begin{tabular}{|l|l|c|c|c|c|}
\hline Lernziel & Aktivtäten & Niveau & A & B & C \\
\hline $\begin{array}{l}\text { Kann Formulare ausfüllen, z.B. } \\
\text { Antrag auf Kindergeld, Zuschuss } \\
\text { zu einer Klassenfahrt ... }\end{array}$ & schreiben & A2 & x & x & x \\
\hline
\end{tabular}

\subsection{Fokus Landeskunde}

In der Spalte „Fokus Landeskunde“ ist das landeskundliche Wissen ergänzt, ohne das das Lernziel nicht zu realisieren ist.

\begin{tabular}{|c|c|c|c|c|c|c|c|}
\hline \multirow[t]{2}{*}{ Beispiel: } & Lernziel & $\begin{array}{l}\text { Aktivi- } \\
\text { täten }\end{array}$ & Niveau & A & B & C & $\begin{array}{l}\text { Fokus Landeskun- } \\
\text { de }\end{array}$ \\
\hline & $\begin{array}{l}\text { Kann Formu- } \\
\text { lare ausfüllen, } \\
\text { z.B. Antrag auf } \\
\text { Kindergeld, } \\
\text { Zuschuss zu } \\
\text { einer Klassen- } \\
\text { fahrt ... }\end{array}$ & $\begin{array}{l}\text { schrei- } \\
\text { ben }\end{array}$ & $\mathrm{A} 2$ & $\mathrm{x}$ & $x$ & $\mathrm{x}$ & $\begin{array}{l}\text { Weiß, dass es } \\
\text { Kindergeld gibt. } \\
\text { Weiß, dass es bei } \\
\text { der Familienkasse/ } \\
\text { Bundesagentur für } \\
\text { Arbeit beantragt } \\
\text { werden muss. }\end{array}$ \\
\hline
\end{tabular}

\subsection{Sprache ist nicht alles: Das Zusammenspiel von Kompetenzen}

Mit der expliziten Aufnahme landeskundlicher, interkultureller und strategischer Kompetenzen wird herausgestellt, dass die Kompetenz, am gesellschaftlichen Leben einer Gesellschaft teilzunehmen, nicht nur die Beherrschung der Zielsprache, sondern das Zusammenwirken verschiedener Kompetenzen erforderlich macht. Missglückte Kommunikation ist häufig nicht Folge eines sprachlichen Defizites im Deutschen, sondern auf fehlende landeskundliche Kenntnisse, auf interkulturelle Missverständnisse oder auch Mangel an strategischer Kompetenz zurückzuführen. Aus diesem Grund sind im Rahmencurriculum zu den sprachlichen Lernzielen auch nichtsprachliche Kompetenzen aufgeführt.

Beim obigen Beispiel „einen Antrag auf Kindergeld stellen“ aus dem Handlungsfeld „Betreuung und Ausbildung der Kinder“, wären verschiedene Kompetenzen erforderlich:

- Landeskundliches Wissen ist die Kenntnis darüber, dass es Kindergeld gibt und wo man es beantragen kann.

- Interkulturelle Kompetenz zeigt sich in der Sensibilität für die unterschiedliche Aufteilung von Erziehungsaufgaben auf Familien und öffentliche Einrichtungen.

- Sprachliche Kompeten z braucht man, um das Formular auszufüllen, oder aber auch - und damit kommt auch die strategische Kompetenz mit ins Spiel - um sich zu erkundigen, wer beim Ausfüllen helfen kann. 


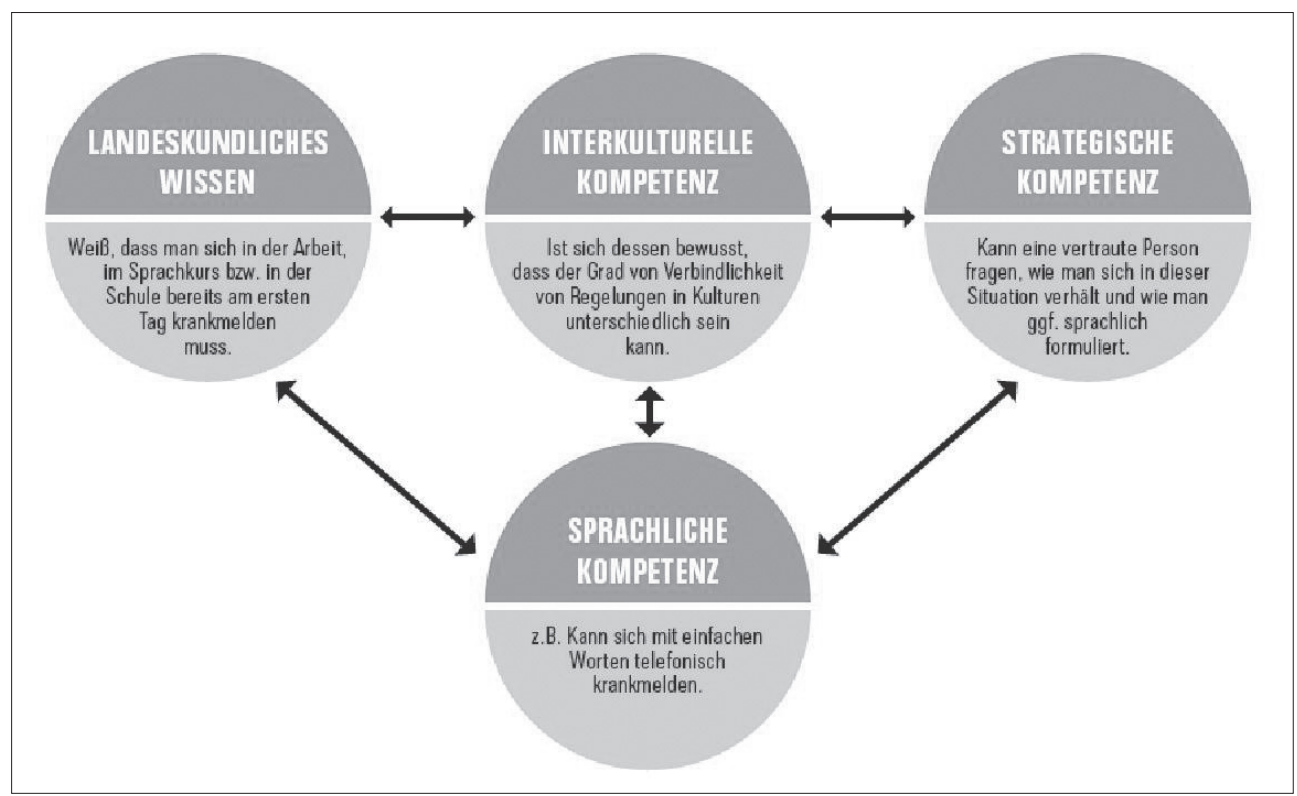

Abb. 2: Das Zusammenspiel von Kompetenzen

\subsection{Handlungsfelder übergreifende Kommunikation}

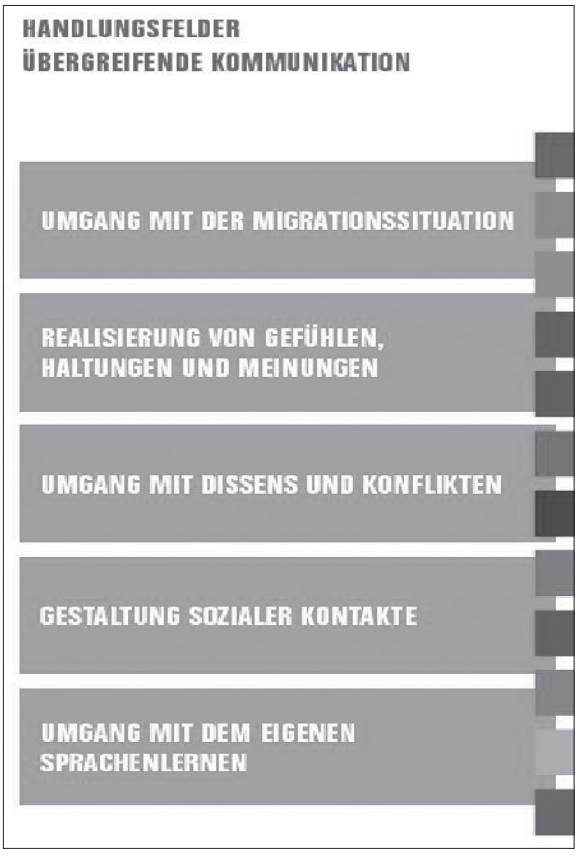

Die Sprachbedarfserhebungen haben ergeben, dass Migrantinnen und Migranten zusätzlich zu den Kompetenzen, die in den Handlungsfeldern oben aufgeführt sind, auch sprachliche Kompetenzen benötigen, die, die in unterschiedlichen Kontexten immer wiederkehren. Sie müssen z.B. in allen Handlungsfeldern nachfragen und ggf. um Wiederholung bitten können, wenn etwas nicht verstanden wurde. Daher wurden den sprachlichen Handlungsfeldern „Handlungsfelder übergreifende Kommunikationsbereiche “ hinzugefügt (siehe Abbildung 3).

Abb. 3: Handlungsfelder übergreifende Kommunikation 
Die aufgeführten Kommunikationsbereiche haben für Migrantinnen und Migranten eine besondere Relevanz, so z.B. „Umgang mit dem eigenen Sprachenlernen“ oder sind mit speziellen Problemfeldern im Kontext von Migration und Integration verknüpft, wie z.B. „Umgang mit Dissens und Konflikten“.

Die Kommunikationsbereiche sind ähnlich strukturiert wie die oben beschriebenen Handlungsfelder, allerdings sind sie in thematische Teilbereiche gegliedert. Beim Kommunikationsbereich „Umgang mit der Migrationssituation“ sind dies z.B. die Bereiche:

- Über Migrationserfahrung berichten

- Umgang mit der interkulturellen Begegnung

- Eigene Kompetenzen darstellen

- Umgang mit Wissensdivergenz und Kompetenzlücken

- Umgang mit der individuellen Sprachigkeit

\begin{tabular}{|c|c|c|c|c|}
\hline \multirow[t]{2}{*}{ Beispiel: } & Lernziel & Aktivitäten & Niveau & $\begin{array}{l}\text { Handlungs- } \\
\text { ziele }\end{array}$ \\
\hline & $\begin{array}{l}\text { Kann einfach und kurz über } \\
\text { seine/ihre Gründe für die } \\
\text { Migration sprechen, z.B. über } \\
\text { die familiäre oder politische } \\
\text { Situation, den Wunsch nach } \\
\text { einer Arbeitsstelle. }\end{array}$ & $\begin{array}{l}\text { am Gespräch } \\
\text { teilnehmen }\end{array}$ & $\mathrm{A} 2$ & $\begin{array}{l}\text { Möchte sich } \\
\text { über die } \\
\text { Gründe und } \\
\text { Ziele der } \\
\text { Migration } \\
\text { austauschen. }\end{array}$ \\
\hline
\end{tabular}

\section{Abschließende Bemerkung}

Das Rahmencurriculum findet seinen Niederschlag in der neu für Integrationskurse entwickelten Abschlussprüfung auf den Niveaus A2 und B1, dem Deutsch-Test für Zuwanderer. Nicht nur bietet jede Prüfungsversion einen Ausschnitt aus dem Lernzielkatalog des Rahmencurriculums, ${ }^{9}$ die einzelnen Prüfungsitems wurden auf ihre Angemessenheit für Migrantinnen und Migranten begutachtet. Das Rahmencurriculum wird auch Eingang finden in die Lehrwerke für Integrationskurse, die derzeit überarbeitet werden.

Für die Kursplanung bietet das Rahmencurriculum die Möglichkeit, für jede Lernsituation und Lerngruppe das passende individuelle Curriculum aus den angebotenen Handlungsfeldern und Lernzielbeschreibungen auszuwählen.

\section{Literatur}

Barkowski, Hans (1982): Kommunikative Grammatik und Deutschlernen mit ausländischen Arbeitern (= Lernen mit Ausländern. Modelle und Perspektiven). Königstein: Scriptor.

Barkowski, Hans; Demmig, Silvia (2007): Konzept für die Entwicklung eines Rabmencurriculums für den Unterricht Deutsch als Zweitsprache im Kontext der Integrationskurse gemäß Zuwanderungsgesetz. (i.F. RC DaZfZ). Prinzipien - Struktur - Funktionalität (unveröffentlichtes Manuskript).

8 Zur Zeit der Drucklegung dieses Texts lag erst ein erster Modelltest vor, siehe http://www.telc.net (12.12.2009).

9 Vgl. Buhlmann et al. (2008: 17). 
Buhlmann, Rosemarie et al. (2007): Konzeption für die Zusatzqualifizierung für Lehrkeäfte Deutsch als Zweitsprache. Erstellt vom Goethe-Institut im Auftrag des Bundesamts für Migration und Flüchtlinge. Nürnberg: BAMF (www.bamf.de, 12.12.2009).

Buhlmann, Rosemarie et al. (2008): Rahmencurriculum für Integrationskurse Deutsch als Zweitsprache. Erstellt im Auftrag des Bundesministeriums des Innern. Nürnberg: BAMF und München: Goethe-Institut (www.integration-in-deutschland.de).

Bundesamt für Migration und Flüchtlinge (2005): Konzept für einen bundesweiten Integrationskurs. Nürnberg: BAMF (www.bamf.de, 12.12.2009).

Demmig, Silvia (2007): Das professionelle Handlungswissen von DaZ-Lehrenden in der Erwachsenenbildung am Beispiel Binnendifferenzierung. Eine qualitative Studie. München: iudicium.

Ehlich, Konrad; Montanari, Elke; Hila, Anna (2007): Recherche und Dokumentation hinsichtlich der Sprachbedarfe von Teilnehmenden an Integrationskursen DaZ - InDaZ - im Rabmen des Projektes des Goethe-Instituts zur Erstellung eines Rahmencurriculums für Integrationskurse. Unter: http://www.goethe.de/lhr/prj/daz/pro/InDaZ_Recherche.pdf (12.12.2009). München.

Europarat und Rat für kulturelle Zusammenarbeit (Hrsg.) (2001): Gemeinsamer Europäischer Referenzrabmen für Sprachen: lernen, lebren, beurteilen. Europarat: Straßburg, Berlin; München: Langenscheidt.

Glaboniat, Manuela et al. (2002): Profile Deutsch. Lernzielbestimmungen, Kannbeschreibungen und kommunikative Mittel für die Niveaustufen A1, A2, B1 und B2 des „Gemeinsamen europäischen Referenzrahmens für Sprachen “. Berlin; München: Langenscheidt.

Kaufmann, Susan (2008): Ein Rahmencurriculum für Integrationskurse in Deutschland. In: Krumm, Hans-Jürgen; Portmann-Tselikas, Paul (Hrsg.): Theorie und Praxis. Österreichische Beiträge zu Deutsch als Fremdsprache 12/2008. Innsbruck; Wien: Studienverlag.

Krekeler, Christian (2001): Sprachförderung für Spätaussiedler: ein erfolgreiches Auslaufmodell. In: Deutsch als Zweitsprache 1, 13-22 (http:/ /www.daz-didaktik.de/Krekeler_Spaetaussiedler.pdf, 12.12.2009).

telc; Goethe-Institut (Hrsg.) (2008): Deutschtest für Zuwanderer. Modelltest 1. Frankfurt a.M.: telc $\mathrm{GmbH}$ (www.telc.net) und München: Goethe-Institut. 
Christoph Chlosta, Matthias Jung (Hrsg.) (2010): DaF intergriert: Literatur - Medien - Ausbildung. Tagungsband der 36. Jabrestagung des Fachverbandes Deutsch als Fremdsprache 2008. Göttingen: Universitätsverlag, 335-350.

\section{Anja Ucharim (Leipzig) \\ „In meiner Heimat war ich Jurist [...] und jetzt fahre ich Taxi.“ \\ Die diskursive Konstruktion der Arbeitswelt in Lehr- werken für Integrationskurse}

\section{Einleitung}

Grundlage des vorliegenden Beitrags ist ein Dissertationsprojekt in den Kulturstudien Deutsch als Fremdsprache, in dem die diskursive Konstruktion von Wirklichkeit in Lehrwerken für Integrationskurse analysiert wird. Exemplarisch erfolgt die Analyse anhand des Themas Arbeit, das sowohl in der Landeskundedidaktik als auch in Curricula eine Rolle spielt. Auf der Grundlage eines aus der Schulbuchforschung adaptierten Verfahrens werden insbesondere die sprachlichen, aber auch die visuellen Mittel untersucht, mit deren Hilfe der Wirklichkeitsausschnitt Arbeit in den Lehrwerken konstituiert wird. Dabei handelt es sich um die thematische Diskursanalyse, die von den Frankfurter Erziehungswissenschaftlern Thomas Höhne, Thomas Kunz und Frank-Olaf Radtke für die Analyse von Sach- und Sozialkundebüchern entwickelt und bislang noch nicht zur Analyse landeskundlicher Inhalte in Lehrwerken für Deutsch als Fremd- und Zweitsprache angewendet worden ist. Im ersten Teil des Beitrags werden zunächst das der Untersuchung zugrunde liegende Konzept von Wirklichkeit erläutert und die Wahl des Wirklichkeitsausschnitts Arbeit begründet; der zweite Teil beinhaltet einen kurzen Überblick über die Methode und die exemplarische Analyse eines Lehrwerktextes im Hinblick auf die diskursive Konstruktion der Arbeitswelt. 


\section{Das Thema Arbeit als Gegenstand landeskundlichen Lernens}

Wie in der Einleitung erwähnt, soll in dem dem Beitrag zugrunde liegenden Dissertationsprojekt die Konstruktion der Wirklichkeit in Lehrwerken für Integrationskurse am Beispiel des Themas Arbeit analytisch nachvollzogen werden. Im folgenden Abschnitt wird zunächst die Auffassung von Wirklichkeit erläutert, die sich aufgrund der theoretischen Positionierung des Projekts in den Kulturstudien Deutsch als Fremdsprache ergibt. Anschließend wird die Entscheidung für den Wirklichkeitsausschnitt Arbeit mit seiner Rolle in landeskundlichen Themenkatalogen, Curricula sowie den Lehrwerken selbst begründet.

\subsection{Zum Wirklichkeitsbegriff in den Kulturstudien Deutsch als Fremdsprache}

Die Kulturstudien Deutsch als Fremdsprache vertreten einen konstruktivistischen Wirklichkeitsbegriff (vgl. Altmayer 2006a: 185f., 2006b: 51); dabei lehnen sie sich an die qualitative Sozialforschung an, deren Interesse an symbolischen Sinnstiftungsprozessen die Grundlegung konstruktivistischer Ansätze sowohl in erkenntnis- und wissenschaftstheoretischer als auch in methodologischer Hinsicht nahelegt (vgl. Keller 2004: 7, Flick 2005: 20 u. 23, Steinke 2007: 322).

Der Plural weist bereits darauf hin, dass es nicht den Konstruktivismus, sondern unterschiedliche konstruktivistische Ansätze gibt, die allerdings eine Grundannahme teilen (vgl. auch im Folgenden Flick 2005: 20ff.): die Infragestellung der Möglichkeit eines unmittelbaren Zugangs zur äußeren Wirklichkeit, eines Zugangs

„[...] unabhängig von Wahrnehmungen und Begriffen, die wir verwenden und konstruieren. Wahrnehmung wird nicht als positiv-rezeptiver Abbildungsprozess [wie im erkenntnistheoretischen Realismus oder Positivismus, A.U.], sondern als aktiv-konstruktiver Herstellungsprozess verstanden.“ (Flick 2005: 21)

Das bedeutet nicht, dass Wirklichkeit als solche nicht existiert; bestritten wird jedoch ihre Zugänglichkeit außerhalb von Deutungsprozessen. Unterschiedliche Ausgestaltungen dieser Grundannahme begründen die zwei Hauptstränge des Konstruktivismus: den radikalen und den sozialen Konstruktivismus. Ersterer wird etwa von Ennst von Glasersfeld vertreten und knüpft wesentlich an Jean Piaget an. Die Konstruktion von Wirklichkeit wird hier als Effekt neurobiologischer Prozesse betrachtet; Subjekt der Wirklichkeitskonstruktion ist somit das Individuum. Als Kriterium der Validität oder besser Viabilität - dieser subjektiven Konstruktionen dient die Ermöglichung von Orientierung und Handlungsfähigkeit, die sich in der Interaktion mit anderen Individuen erweisen muss (vgl. hierzu auch Rusch 1998: 280f.). Hingegen nehmen Vertreterinnen und Vertreter des sozialen Konstruktivismus wie beispielsweise Ken Gergen mit Peter Berger und Thomas Luckmann an, dass Wirklichkeit gesellschaftlich hergestellt wird. Dem Individuum ist Wirklichkeit demnach nur über ,soziale [...] Konventionalisierungen, die Wahrnehmung und Wissen im Alltag beeinflussen“, zugänglich; ihre Konstruktion basiert also auf „sozialen Austauschprozessen“ (Flick 2005: 21 u. 23). 
Dass dieser Austausch über Sprache geschieht (Flick 2005: 23), ist evident und stellt für die Kulturstudien Deutsch als Fremdsprache ${ }^{1}$ einen wesentlichen Anknüpfungspunkt an den sozial-konstruktivistischen Ansatz dar. Ein weiterer Grund, der aus Sicht der Kulturstudien für diese erkenntnistheoretische Position spricht, ist das Moment des Sozialen, das mit ihrem Kulturbegriff korreliert. Denn im Gegensatz zum radikalen Konstruktivismus interessieren sie sich „nicht primär für die individuellen Sinnzuschreibungen [...], sondern für den Bestand an kollektivem Wissen, auf dem diese beruhen“ (Altmayer 2006a: 186). Dieses Wissen wird mit dem Begriff der kulturellen Deutungsmuster gefasst; sie sind allen Mitgliedern einer Kommunikationsgemeinschaft zugänglich und dienen ihnen zur diskursiven Konstruktion und Deutung einer gemeinsamen Wirklichkeit (vgl. Altmayer 2006a: 186f., 2006b: 51). Darüber hinaus tragen sie zur Konstitution der Kommunikationsgemeinschaft selbst bei und werden von den einzelnen Mitgliedern im Verlauf ihrer Sozialisation erworben (vgl. Altmayer 2006a: 186). In ihrer Gesamtheit bilden die kulturellen Deutungsmuster die Kultur einer Kommunikationsgemeinschaft (vgl. Altmayer 2006b: 51); gespeichert und überliefert sind sie - und hier tritt der Aspekt der Sprache zutage - in deren kulturellem Gedächtnis, das allerdings nicht kognitiv-mental, sondern sprachlich-textuell repräsentiert ist (vgl. Altmayer 2005: 253, 2006a: 186f., 2006b: 51f.). Wenn demnach Wirklichkeit unter Rückgriff auf kulturelle Deutungsmuster und damit letztlich unter Rückgriff auf Texte, also sprachlich-diskursiv hergestellt wird (vgl. auch Keller 2004: 63), bedeutet das für ihre Erforschung, dass sie nur über die Analyse von ,zeichenhaften Sinnzuschreibungsprozessen, also [...] Kommunikation, Sprache, Texten, kurz: [...] Diskursen“" (vgl. Altmayer 2006a: 191) erschlossen werden kann.

In dem Dissertationsprojekt, auf dem der vorliegende Beitrag basiert, soll die Herstellung von Wirklichkeit in der spezifischen Diskursform Lehrwerk untersucht werden. Da es aber auch im Rahmen einer Dissertation nicht möglich ist, die gesamte LehrwerkWirklichkeit zu betrachten, ist die Eingrenzung eines Themenfelds nötig, anhand dessen die diskursive Konstruktion von Wirklichkeit exemplarisch analysiert werden kann.

\subsection{Der Wirklichkeitsausschnitt Arbeit in Landeskundedidaktik, Curricula und Lehrwerken}

Orientierung bei der Wahl eines Themenfelds bietet ein Modell von Claus Altmayer, das als Grundlage für ein landeskundliches Curriculum dienen soll. Das Modell stellt eine Weiterentwicklung von Gerhard Neuners Konzept der „universelle[n] Lebenserfahrungen“ (1988: 11) dar, einem offenen Katalog landeskundlicher Themen, mit denen - so der Anspruch - alle Menschen weltweit in irgendeiner Weise konfrontiert sind, z.B. „Wohnen“, „Erfahrung von Geschichtlichkeit (Zeiterfahrung)“, „Personale Identität (,Ich“/Existenz/personale Eigenschaften)“ oder „Erfahrung von Norm- und Wertsystemen“ (1988: 23). Altmayer hat diesen Katalog systematisiert und die einzelnen Themen in Anlehnung an Teske (vgl. 2002) zu vier Kategorien zusammengefasst:

1 Im Folgenden werden die Kulturstudien Deutsch als Fremdsprache verkürzt als „Kulturstudien“ bezeichnet. 
Raum, Zeit, Identität und Werte (vgl. 2006a: 192f., 2006b: 55f.). Unter diesen Kategorien können nicht nur die universellen Lebenserfahrungen aus dem Konzept von Gerhard Neuner subsumiert werden, sondern beliebig viele weitere Themenfelder, etwa die Themen Länder, Grenzen, Wohnen oder Reisen unter der Kategorie Raum, die Themen Lebensalter, Jahreszeiten, Arbeit oder Freizeit unter der Kategorie Zeit, die Themen personale, geschlechtliche, nationale oder hybride Identität - inutile dictu unter der Kategorie Identität und die Themen Luxus, Glück, Gerechtigkeit oder auch Kriminalität unter der Kategorie Werte.

Um das Themenfeld für die Analyse festzulegen, wurden einerseits der Untersuchungsgegenstand selbst, die Lehrwerke für Integrationskurse, und andererseits Gesetze und Curricula, die die Integrationskurse unmittelbar betreffen oder auf die sich die Lehrwerke explizit beziehen, konsultiert. Von den Lehrwerken für Integrationskurse, die Lehrwerke für den Sprach- und für den Orientierungskurs umfassen, wurden die Sprachlehrwerke Berliner Platz, Mit uns leben, Pluspunkt Deutsch und Schritte ausgewählt, von den Lehrwerken für den Orientierungskurs 45 Stunden Deutschland, Orientierungskurs - Geschichte, Institutionen, Leben in Deutschland, Pluspunkt Deutsch - Der Orientierungskurs Deutsch als Zweitsprache, Zur Orientierung - Basiswissen Deutschland und Miteinander leben. Auswahlkriterien waren unter anderem das den Vorworten, Klappentexten und Lehrerhandreichungen zu entnehmende Selbstverständnis als Inlands- oder ZweitsprachenLehrwerk, die Zulassung durch das Bundesamt für Migration und Flüchtlinge (BAMF) ${ }^{2}$ und die - relative - Aktualität des Erscheinungsjahrs. Durch die Auswahl von Lehrwerken aus unterschiedlichen Verlagen ist zudem eine gewisse Vielfalt gewährleistet. Gesetze und Curricula, die die Integrationskurse betreffen oder auf die sich die Lehrwerke beziehen, sind das Zuwanderungsgesetz (2004) und die Integrationskursverordnung $(2004)^{3}$, sowie das Konzept für einen bundesweiten Integrationskurs (2005), das Rahmencurriculum für Integrationskurse Deutsch als Zweitsprache (2008) und das Curriculum für einen bundesweiten Orientierungskurs (2007) aber auch der Gemeinsame Europäische Referenzrahmen (2001).

Eines der Themen, das sowohl in den Lehrwerken als auch in den Gesetzen und Curricula eine Rolle spielt, ist das Thema Arbeit, das in dem Modell von Claus Altmayer der Kategorie Zeit zugeordnet werden kann. Der folgende Überblick über den Inhalt der einzelnen Lehrwerkbände für den Sprachkurs zeigt, dass sich pro Lehrwerk mindestens vier Lektionen finden, die dieses Thema behandeln (Lehrwerke 1-4). Ein anderes Bild ergibt sich bei den fünf vom BAMF zugelassenen Lehrwerken für den Orientierungskurs, von denen lediglich zwei das Thema Arbeit in einer eigenen Lektion behandeln; bei den anderen drei lassen sich jedoch immerhin Bezüge herstellen, etwa wenn in Lektionen über den Sozialstaat die Arbeitslosenversicherung thematisiert wird (Lehrwerke 5-9).

2 Vgl.: http://www.integration-in-deutschland.de/cln_101/nn_283562/SharedDocs/Anlagen/DE/Integration/Downloads/Integrationskurse/Lehrkraefte/liste-zugelassener-lehrwerke.pdf_IP,templateId $=$ raw,property=publicationFile. pdf/liste-zugelassener-lehrwerke-pdf_IP.pdf; 30.07.2008.

3 Das Zuwanderungsgesetz und die Integrationskursverordnung (IntV) traten zum 01.01.2005 in Kraft (vgl. Zuwanderungsgesetz 2004: Artikel 15, Abs. 3, IntV 2004: \23), wurden aber bereits 2004 veröffentlicht. 


\section{Berliner Platz, (2002ff.)}

Band 1: $\quad$ Lektion 8: „Ich arbeite bei ....“

Band 2: $\quad$ Lektion 16: "Schule und danach“4

Band 3: $\quad$ Lektion 20: $\quad$ "Jobsuche“ $26: \quad$ "Was kann ich für Sie tun?" [Dienstleistungsberufe im Hotel]

Lektion 35: „Arbeit - Neue Perspektiven“

2. Mit uns leben (Neubearbeitung, 2003ff.)

$\begin{array}{lll}\text { Band 1: } & \text { Lektion 5: } & \text { "Ich bin ..." }[\text { Berufe] } \\ \text { Band 2: } & \text { Lektion 2: } & \text { "Ich arbeite ..." } \\ & \text { Lektion 10: } & \text { "Ich orientiere mich ...“ } \\ & \text { Mobilität] } \\ \text { Band 3: } & \text { Lektion 5: } & \text { „Ich lerne und arbeite“ }\end{array}$

3. Pluspunkt Deutsch (2003ff.)

Band 1 a: Lektion 1:

Band 2 a: Lektion 3:

Lektion 6:

Band 2 b: $\quad$ Lektion 7:

Band 3: Lektion 4:

Lektion 8: „Ein neuer Start“ [Selbständigkeit]

4. Schritte (2003ff.)

$\begin{array}{lll}\text { Band 2: } & \text { Lektion 8: } & \text { „Beruf und Arbeit" } \\ \text { Band 3: } & \text { Lektion 4: } & \text { "Arbeitswelt" } \\ & \text { Lektion 6: } & \text { "Schule und Ausbildung“" } \\ \text { Band 5: } & \text { Lektion 5: } & \text { "Eine Arbeit finden“" }\end{array}$

5. 45 Stunden Deutschland (2008)

Modul 1: $\quad$ „Politik in der Demokratie“, Kapitel „Sozialstaat“

Modul 3:, Mensch und Gesellschaft“, Kapitel „Erziehung und Bildung in Deutschland“

6. Orientierungskurs - Geschichte, Institutionen, Leben in Deutschland (2005)

Lektion 2: Wo ist meine Zeit geblieben?" [unter anderem: Arbeitszeit]

Lektion 7: "Arbeit und soziale Sicherung“

Lektion 9: Bildung und Weiterbildung“"

7. Pluspunkt Deutsch - Der Orientierungskurs Deutsch als Zweitsprache (2006)

Modul 4: „Sozialstaat.“

8. Zur Orientierung - Basiswissen Deutschland (2006)

Lektion 2: "Rechtsstaat und Sozialstaat Deutschland“

Lektion 3: "Geschichte, Migration, soziale Marktwirtschaft“

9. Miteinander leben (2006)

Modul 8: Bildung“ [unter anderem: Ausbildung]

Modul 12: „Arbeit“

Modul 13: Wirtschaft"

Modul 14: "Sozialsystem“

4 Da das Thema Ausbildung insofern im Zusammenhang mit dem Thema Arbeit steht, dass es die Möglichkeit zukünftiger beruflicher Tätigkeiten wesentlich bestimmt, wird es bei der Analyse ebenfalls berücksichtigt. 
Es überrascht nicht, dass der Befund aus den Lehrwerken im Wesentlichen die inhaltlichen Vorgaben der im Auftrag des BAMF entwickelten Konzepte und Curricula für die Integrations- und Orientierungskurse widerspiegelt. Am deutlichsten zeigt sich dies anhand der Lehrwerke für den Orientierungskurs, die erst nach der Einrichtung dieser Kurse durch das Zuwanderungsgesetz bzw. durch die Integrationskursverordnung im Jahr 2005 erschienen sind und die sich dementsprechend unmittelbar nach den Vorgaben des BAMF richten. Die Lehrwerke für den Sprachkurs sind hingegen bereits vor der Einrichtung der Integrationskurse entstanden. Sie bedürfen jedoch der Zulassung durch das BAMF, dessen Kriterien sich am Konzept für einen bundesweiten Integrationskurs orientieren. ${ }^{5}$

Im Einzelnen sieht das Konzept für einen bundesweiten Integrationskurs die Themen „Arbeit und Beruf“ sowie „Erziehung/Ausbildung/Lernen“ als Inhalte für den Basis- und Aufbausprachkurs und die Themen „Sozialstaatsprinzip“ sowie „soziale Marktwirtschaft“ als Grund- und Aufbauwissen für das Modul „Rechtsordnung“ des Orientierungskurses vor (vgl. BAMF 2005: 14f., 18f. u. 21f.). Auch in dem jüngst erschienenen Rahmencurriculum für Integrationskurse Deutsch als Zweitsprache werden die Themen „Arbeit“ und „Arbeitssuche“ sowie „Aus- und Weiterbildung“ als zentrale Handlungsfelder der Kommunikation aufgeführt (vgl. BAMF et al. 2008: 59ff.). Im Gegensatz zum Konzept für einen bundesweiten Integrationskurs werden diese Themen jedoch nicht bloß stichpunktartig benannt, sondern es werden nach dem Vorbild des Gemeinsamen Europäischen Referenzrahmens Lernziele in Form von („Can-do“-) Deskriptoren formuliert. Diese Deskriptoren beziehen sich auf Kompetenzen und Wissensbestände, die für die Kommunikation in den jeweiligen Handlungsfeldern als nötig erachtet werden, z.B. einen Urlaubsantrag stellen (vgl. BAMF et al. 2008: 62). Der Gemeinsame Europäische Referenzrahmen selbst, auf den sich ausnahmslos alle Lehrwerke für den Integrationskurs beziehen, teilt im Kapitel „Kontext der Sprachverwendung“ vier Kategorien von „Lebensbereichen bzw. Domänen“ ein, von denen eine auf den „Beruflichen Bereich“ entfällt (vgl. Europarat et al. 2001: 52f.). Dieser Bereich wird mit Hilfe unterschiedlicher Kategorien - allerdings nur stichwortartig - beschrieben: Orten wie Büros oder Fabriken, Institutionen wie Firmen oder Gewerkschaften, Personen wie Arbeitgeberinnen oder Arbeitnehmer, Objekten wie Maschinen oder Werkzeugen, Ereignissen wie Besprechungen oder Tarifverhandlungen, Handlungen wie Verwaltung oder Büroreinigung und Texten wie Geschäftsbriefen oder Handbüchern (vgl. Europarat et al. 2001: 54). Das Curriculum für einen bundesweiten Orientierungskurs tangiert das Thema Arbeit dagegen eher indirekt und peripher: So stellt etwa der Sozialstaat ein Schlüsselthema in Modul I, „Politik in der Demokratie“, dar; eines der Feinlernziele besteht hier in der Kenntnis des deutschen Sozialsystems, einer der Lerninhalte in der Arbeitslosenversicherung als Teil des Sozialversicherungssystems (vgl. BAMF 2007: 17f.). In Modul III, „Mensch und Gesellschaft“, werden im Rahmen

Vgl.: http://www.integration-in-deutschland.de/cln_101/nn_283532/SubSites/Integration/DE/03_ _Akteure/Integra-tionskurse/Paedagogisches/Lehrmittel/lehrmittel-node.html?__nnn=true; 30.07.2008. Eine detaillierte Darstellung der einzelnen Zulassungskriterien ist jedoch nicht veröffentlicht. 
des Schlüsselthemas „Erziehung und Bildung“ unter anderem Schule und Ausbildung, Erwachsenenbildung und lebenslanges Lernen thematisiert, die, insofern es sich um berufliche Aus- und Weiterbildung handelt, ebenfalls dem Thema Arbeit zugeordnet werden können (vgl. BAMF 2007: 27f.).

Die Bedeutung des Themas Arbeit in den Lehrwerken und in den Curricula des BAMF reflektiert den hohen Stellenwert, der ihm auch im Zuwanderungsgesetz zukommt. Dies zeigt sich bereits am Titel des ersten Artikels, der mehr als die Hälfte des Zuwanderungsgesetzes umfasst und ein eigenständiges Gesetz bildet: das Gesetz über den Aufenthalt, die Erwerbstätigkeit und die Integration von Ausländern im Bundesgebiet (Aufenthaltsgesetz). Einen entsprechenden Raum nimmt das Thema Arbeit bzw. Erwerbstätigkeit auch im Gesetzestext ein. Deutlich wird dies etwa anhand der Definition von Erwerbstätigkeit gleich zu Beginn des Gesetzes (vgl. AufenthG 2004: Kap. 1, $\int 2$, Abs. 2), aber auch anhand der Existenz eines eigenen Abschnitts zur Regelung der Erwerbstätigkeit (vgl. AufenthG 2004: Kap. 2, Abschnitt 4). Darüber hinaus spielt das Thema Arbeit in weiteren Abschnitten des Gesetzes eine Rolle, beispielsweise im Zusammenhang mit dem Aufenthaltstitel, der einen gesicherten Lebensunterhalt voraussetzt (vgl. AufenthG 2004: Kap. 2, Abschnitt 1, J 5).

Wie das Thema Arbeit in Lehrwerken für Integrationskurse diskursiv konstruiert wird, soll im zweiten Teil des Beitrags demonstriert werden. Zum Lehrwerkkorpus sei allerdings noch Folgendes angemerkt: Laut Neuner setzt sich ein Lehrwerk ,aus mehreren Lehrwerkteilen mit unterschiedlicher didaktischer Funktion“ zusammen und ist damit vom Lehrbuch zu unterscheiden, einem ,in sich abgeschlossene[n] Druckwerk mit fest umrissener didaktischer und methodischer Konzeption [...], in dem alle zum Lehren und Lernen benötigten Hilfsmittel [...] zwischen zwei Buchdeckeln enthalten sind“" (2003: 399). Gegenstand der Analyse sind entsprechend dieser Definition also nicht nur die Kursbücher der genannten Lehrwerke, sondern auch die Arbeitsbücher und Audio-CDs sowie die Lehrerhandreichungen. Andere Lehrwerkteile wie Übungshefte, Glossare, Kopiervorlagen und Online-Materialien werden allerdings nicht berücksichtigt, da sie einerseits lediglich den Status von fakultativen Zusatzmaterialien besitzen und da es andererseits forschungspraktische Gründe erforderten, den Umfang des Textkorpus zu begrenzen. Denn die Analyse mit Hilfe des gewählten Verfahrens erwies sich zwar als äußerst fruchtbar, aufgrund ihrer Kleinschrittigkeit aber auch - wie die Beispielanalyse zeigen wird - als äußerst aufwändig. Bei diesem Verfahren handelt es sich um die thematische Diskursanalyse.

\section{Zur Konstruktion des Themas Arbeit in Lehrwerken für Integrationskurse}

Im zweiten Teil des Beitrags soll die diskursive Konstruktion des Themas Arbeit in Lehrwerken für Integrationskurse anhand eines Beispieltextes analysiert, zuvor jedoch auf das Verfahren der thematischen Diskursanalyse eingegangen werden. Da die einzelnen Analyseschritte bereits an anderer Stelle erläutert wurden (vgl. Ucharim 2009), soll hier ein kurzer Überblick genügen. Der Schwerpunkt liegt vielmehr auf den diskurs- 
und erkenntnistheoretischen Grundlagen der Methode, die mit denen der Kulturstudien Deutsch als Fremdsprache konvergieren.

\subsection{Das Analyseverfahren: die thematische Diskursanalyse}

Die thematische Diskursanalyse ist von den Erziehungswissenschaftlern Thomas Höhne, Thomas Kunz und Frank-Olaf Radtke auf der Grundlage von Michel Foucaults Diskurstheorie entwickelt und erstmals zur Analyse von Schulbüchern eingesetzt worden. Untersucht wurde, wie Migrantinnen und Migranten in Schulbüchern für Sach- und Sozialkunde dargestellt werden. Dabei richtete sich das Erkenntnisinteresse nicht auf die Beurteilung der Lehrbücher hinsichtlich der „Wahrheit“, Ausgewogenheit oder „Objektivität“ ihrer Inhalte (vgl. Höhne et al. 1999: 38), sondern vielmehr auf die Struktur von Lehrbuchdiskursen, die sich einerseits, wie aus dem diskursanalytischen Ablaufschema hervorgeht, durch die Analyse sprachlicher Mittel erschließen lässt (vgl. Höhne et al. 2005: 27). Andererseits werden in einer Diskursanalyse immer auch Wissensbestände ermittelt (vgl. Höhne et al. 2005: 29), insofern Diskurse die „sprachliche Seite des Wissens“ (Höhne et al. 1999: 34) bilden. Wissen wird dabei als gesellschaftliches und hegemoniales Wissen verstanden, mit dessen Hilfe soziale Wirklichkeit konstruiert wird (vgl. Höhne et al. 1999: 34 u. 38). In die Lehrbücher findet es Eingang, nachdem es politisch legitimiert und als wissenswert beurteilt worden ist; gleichzeitig wird es aber auch von ihnen hervorgebracht und distribuiert (vgl. Höhne et al. 2005: 27).

Dass Höhne, Kunz und Radtke ihrer Methodologie den sozialen Konstruktivismus zugrundelegen, wird an dieser Stelle deutlich; wie die sozial-konstruktivistischen Ansätze berufen auch sie sich auf Berger und Luckmann (vgl. 1999: 34). Der Bezug zu den Kulturstudien Deutsch als Fremdsprache, die sich im gleichen erkenntnistheoretischen Rahmen bewegen, ist damit evident. Weiterhin teilen die thematische Diskursanalyse und die Kulturstudien die Präferenz rekonstruktiver Verfahren, die sich im Fall der Kulturstudien im Wesentlichen aus dem zugrunde gelegten Kulturbegriff ergibt. Kultur wird hier, wie im ersten Teil des Beitrags ausgeführt wurde, als Gesamtheit der kulturellen Deutungsmuster, der sprachlich-textuell verankerten Wissensbestände einer Kommunikationsgemeinschaft definiert (vgl. Altmayer 2006b: 51f.), als ,lebensweltliche[s] Hintergrundwissen [...], das wir in deutschsprachigen Texten und Diskursen ,immer schon' als selbstverständlich und allgemein bekannt voraussetzen“ (Altmayer 2005: 247). Sie lässt sich damit als ,sprachlich-diskursives Phänomen“ beschreiben und ,nur mittels rekonstruktiv-qualitativer Forschungsmethoden“" analysieren (Altmayer 2006a: 191). Dementsprechend verstehen sich die Kulturstudien vor allem als „Text- und Kommunikationswissenschaft, die nach dem in ,Texte' und Diskurse eingehenden, als selbstverständlich und allgemein bekannt geltenden kulturellen Hintergrundwissen fragt und dieses Hintergrundwissen in ihren Textanalysen rekonstruiert und bewusst macht" (Altmayer 2005: 247). Die Ermittlung von Wissensbeständen, die in Diskursen lediglich implizit vorliegen bzw. präsupponiert werden und daher der Rekonstruktion bedürfen, stellt also sowohl in den Kulturstudien als auch in der thematischen Diskursanalyse ein zentrales Anliegen dar.

In der thematischen Diskursanalyse richtet sich diese Rekonstruktionsarbeit zum einen auf die intradiskursiven Relationen sprachlicher Zeichen, die diskurskonstitutiven semantischen Elemente und ihre Verknüpfungen, zum anderen auf die interdiskursiven 
Relationen sprachlicher Zeichen, die implizit in einem Diskurs enthaltenen Wissensbestände, die vor allem mit Hilfe verschiedener text- und argumentationsanalytischer Verfahren offengelegt werden sollen (vgl. Höhne et al. 2005: 33 u. 37). Im Einzelnen kann das Ablaufschema der thematischen Diskursanalyse in Form einer Liste dargestellt werden (vgl. Höhne et al. 2005: 34f.):

1. Diskursform- bzw. Layoutanalyse:

Untersuchung der Plazierung, Markierung und Rahmung von Text- und Bilddokumenten

2. Diskursanalyse der Dokumente

a) Untersuchung der intradiskursiven Relationen der sprachlichen Zeichen -

Analyseinstrumente und Untersuchungsgegenstände:

- Delinearisierung

- Strukturalistische Operationen

- $\quad$ Eingangssequenzen

- Kohäsionsmittel (Rekurrenz, Phorik, Paraphrase, Parallelismus, Chiasmus, Ellipse, Pro-Form, Konnexion, Tempus und Deixis)

- $\quad$ Semantische Merkmale und Isotopien

- Prädikationen und Differenzen

- Modalitäten

b) Untersuchung der interdiskursiven Relationen der sprachlichen Zeichen Analyseinstrumente und Untersuchungsgegenstände:

- Untersuchung von Kohärenzen bzw. Präsuppositionen mit Hilfe der Argumentationsanalyse

- Denotationen und Konnotationen

- Topoi (Themenkomplexe) und Tropen (Metaphern, Metonymien, Synekdochen)

\subsection{Bildanalyse}

Das Ablaufschema der thematischen Diskursanalyse berücksichtigt also das Layout, die Text- und die Bildebene; somit erfasst es die unterschiedlichen Ebenen, auf denen ein Lehrbuch-Diskurs funktioniert (vgl. Höhne et al. 2005: 34) und trägt dem Charakter dieses Mediums als „komplexe[r] Montage aus Text-, Bild- und Graphikelementen“ (Höhne et al. 1999: 68) Rechnung. Das analytische Instrumentarium ist unterschiedlichen linguistischen Teildisziplinen, Ansätzen und Theorien, aber auch der Text- und Bild-Semiotik entnommen; seine schematische Darstellungsform ist weniger als Checkliste denn als Werkzeugkasten zu verstehen, auf den - wie es auch in dem folgenden Analysebeispiel geschieht - dokumentenspezifisch zurückgegriffen werden kann und soll (vgl. Höhne et al. 2005: 34f.). 


\section{3 „Eine Arbeit in Deutschland“ oder vom Juristen zum Taxifahrer: eine Beispielanalyse}

Anhand eines Analysebeispiels soll nun die Konstruktion des Wirklichkeitsausschnitts Arbeit aufgezeigt werden. Das Beispiel stammt aus dem Lehrwerk Pluspunkt Deutsch, das sich, wie aus dem Untertitel „Deutsch als Zweitsprache“ eindeutig hervorgeht, als Integrationskurs-Lehrwerk versteht. Aus der dritten Lektion des Bandes 2a, deren Titel „Mein Arbeitsplatz" explizit auf das Thema Arbeit verweist, wird ein Lesetext in Abschnitt A, der die Überschrift „Eine Arbeit in Deutschland“ trägt, behandelt (vgl., auch im Folgenden Pluspunkt Deutsch 2a 2003: 34). Der Lesetext ist Bestandteil der ersten Aufgabe des Abschnitts und setzt sich aus vier eigenständigen kurzen Texten zusammen, von denen aber im Rahmen des Beitrags nur einer analysiert werden kann. Dementsprechend entfallen die Erläuterungen zu den strukturellen Gemeinsamkeiten zwischen den vier Texten. Im Gegenzug erfolgt eine ausführliche Analyse des Textdokuments, wobei die jeweils verwendeten Instrumente an den betreffenden Stellen benannt werden.

Diskursformanalyse: Bei der Betrachtung von Seite 34 fallen zunächst die drei kurzen Lesetexe ins Auge, neben denen jeweils ein Foto zu sehen ist. Obwohl sich der vierte Text auf der folgenden Seite befindet und alle Texte in verschiedenen Farben unterlegt sind, werden die Dokumente aufgrund von Regelmäßigkeiten in der Anordnung als zusammengehörig wahrgenommen: So ist beim ersten und dritten Text das Foto rechts und beim zweiten und vierten das Foto links vom Text plaziert. Zudem sind alle Dokumente leicht schräg gestellt, so dass sie einander überschneiden. Besonders markant stellen sich der Titel der Lektion und der des Abschnitts dar: Beide weisen die Signalfarbe Rot und eine Schriftgröße von 16 bzw. 14 Punkten auf. Dass sie damit gegenüber der Aufgabenstellung und den Lesetexten, für die die Farben Blau bzw. Schwarz sowie jeweils eine Schriftgröße von 12 Punkten gewählt wurde, besonders hervorstechen, ist evident.

Bildanalyse: Die Fotos neben den Texten zeigen verschiedene Menschen bei unterschiedlichen Arbeiten; hier soll jedoch lediglich das Bild analysiert werden, das dem ausgewählten Text zugeordnet ist. Abgebildet ist ein Mann, der am Steuer eines Taxis sitzt und durch das geöffnete Wagenfenster mit einem weiteren Mann spricht, der ein Kunde oder ein Kollege sein kann, vielleicht auch ein Passant, der nach dem Weg fragt. Beide Männer sind gemäß einer stereotypen Ikonographie durch ihre Haut- und Haarfarbe als „nicht deutsch“ markiert, was mit der Prädikation des Protagonisten als Migrant irakischer Herkunft im Text korreliert. Dass einer der beiden Männer offensichtlich als Taxifahrer arbeitet, entspricht ebenfalls einem zentralen Inhalt des Textes. Das Bild verhält sich dem Text gegenüber damit redundant, d.h. es enthält keine anderen oder weiterführenden Aussagen und besitzt eine ausschließlich illustrative Funktion.

Diskursanalyse der Dokumente (intra- und interdiskursiv): Die Überschrift der Lektion „Mein Arbeitsplatz“ benennt, wie gesagt, explizit das Thema Arbeit und steuert damit die Erwartungshaltung der Rezipierenden bezüglich der folgenden Texte; sie wirkt demnach monosemierend. Das Lexem „Arbeitsplatz" sowie das Possessivpronomen in der ersten Person Singular verweisen in der Tat auf die Lesetexte, in denen ver- 
schiedene Personen in Ich-Form über ihren Arbeitsplatz sprechen. Zudem legt es das Possessivpronomen nahe, eine gewisse Identifikation der Sprechenden mit ihren jeweiligen Arbeitsplätzen anzunehmen. Im Gegensatz dazu fällt auf, dass die Überschrift des Abschnitts „Eine Arbeit in Deutschland“ das Possessivpronomen nicht mehr aufgreift. Auffällig ist das deshalb, weil die Überschrift des Abschnitts den Berichten der einzelnen Personen in den Lesetexten textlogisch näher steht als die Überschrift der Lektion, die sich auf alle Abschnitte bezieht. Wenn hier stattdessen ein indefiniter Artikel gewählt wird, entsteht der Eindruck, dass die Identifikation mit der eigenen Arbeit wieder zurückgenommen und an ihre Stelle eine Unbestimmtheit gesetzt wird, die angesichts der in den Texten geschilderten, teilweise mit einem geringen sozialen Prestige konnotierten Tätigkeiten durchaus als Beliebigkeit interpretiert werden kann. Die Lokalisierung der Arbeit ,in Deutschland“ deutet auf die Konstruktion einer migrantischen Perspektive hin, da dieser Ort für in der Bundesrepublik geborene und aufgewachsene Personen als selbstverständlich angenommen werden kann und daher keiner besonderen Erwähnung bedürfte. Indem diese migrantische Perspektive mit den in den Lesetexten genannten Berufen Sekretärin, Taxifahrer, Küchenhilfe und Krankenschwester verbunden wird, werden Migrantinnen und Migranten sowie - insofern die vorgestellten Personen potentiell als Identifikationsfiguren dienen - die Lernenden hinsichtlich beruflicher Tätigkeiten spezifisch positioniert.

Der ausgewählte Lesetext beinhaltet, wie im Rahmen der Bildanalyse erwähnt wurde, den Bericht eines Taxifahrers, der ebenso wie die anderen aus der Perspektive einer ersten Person Singular erzählt wird. Im ersten Satz, der Eingangssequenz, erfahren die Lernenden von dem sprechenden Ich Vor- und Nachnamen sowie Herkunftsstadt und -land - Angaben, aufgrund derer dieses Ich eine oberflächliche personale Identität gewinnt: Es handelt sich um Muhammed Mallallah aus Bagdad im Irak.

Der übrige Text thematisiert Muhammeds berufliche Tätigkeiten im Irak und in Deutschland. Schon im nächsten Satz - „In meiner Heimat war ich Jurist von Beruf.“ - werden die Themenkomplexe „Wohnort“ und „Berufstätigkeit“ eingeführt, die sich durch den gesamten Text ziehen. Das Tempus Präteritum weist darauf hin, dass der genannte Aufenthaltsort und der genannte Beruf nicht mehr dem gegenwärtigen Stand entsprechen, dass Muhammed also weder in seiner „Heimat“ lebt noch als Jurist arbeitet. Da dieser Satz unmittelbar an die Eingangssequenz anschließt, kann die „Heimat“ mit dem Herkunftsort Bagdad im Irak identifiziert werden. Es liegt hier also eine Beziehung der Koreferenz vor, eine Unterkategorie der Rekurrenz, die erst durch den Text hergestellt wird. Beide Themenkomplexe werden im Folgenden parallel weitergeführt: „Diesen Beruf kann ich hier nicht ausüben." Sowohl das anaphorisch verwendete Demonstrativpronomen als auch der Oberbegriff „Beruf“, der wiederum eine Unterkategorie der Rekurrenz, eine Substitution, darstellt, beziehen sich auf „Jurist“. Die Lokaldeixis „hier“ ist als Gegensatz zur Heimat zu verstehen; das Tempus Präsens weist darauf hin, dass es sich um den gegenwärtigen Aufenthaltsort handelt. Dieser Ort ist, wie dem weiteren Text entnommen werden kann, Deutschland bzw. Hamburg, und er ist nicht identisch mit der „Heimat“, mit der bereits das Herkunftsland Irak identifiziert 
wurde. Es wird also latent eine Differenz zwischen der „Heimat“ und dem „hier“ konstruiert, durch die der jetzige Lebensort Deutschland für den Migranten im Umkehrschluss zur „Fremde“ und er selbst implizit als „Fremder“ prädiziert wird.

Im Hinblick auf die Berufstätigkeit bestätigt sich die Vermutung aus dem ersten Satz: Muhammed arbeitet nicht als Jurist bzw. er kann es nicht. Das verneinte Modalverb bringt hier eine Modalität der Restriktion zum Ausdruck, die erst nachträglich erläutert wird: „Das deutsche Recht ist ganz anders und ich will nicht mehr neu studieren. “ Zwar ist dieser Satz asyndetisch angeschlossen, kann bzw. muss aber durch einen kausalen Konnektor wie „denn“ ergänzt werden, da ein Grund für die vorangehende Aussage erwartet werden kann. Dieser Grund besteht darin, dass das „Recht“", das durch die explizite Prädikation „deutsch“ näher bestimmt wird, „ganz anders“ ist. Hier liegt ein Vergleich vor, aber da der zweite Teil dieses Vergleichs ellidiert ist, muss er aus dem Kontext erschlossen werden. Vor dem Hintergrund, dass Muhammed im Irak Jurist war, wäre dann die Ergänzung „als das irakische Recht“ einzusetzen. Die Differenz zwischen „Heimat" und „Fremde“ wird damit wieder aufgenommen und durch die Gradpartikel „ganz", die die Unterschiedlichkeit als Hauptmerkmal von deutschem und irakischem Recht hervorhebt, zusätzlich unterstrichen. Ebenfalls wieder aufgenommen werden in diesem Satz die Themenkomplexe „Berufstätigkeit“ und „Wohnort“, auf den das Adjektiv „deutsch“ einen ersten konkreten Hinweis gibt. Im zweiten der beiden Hauptsätze wird die Begründung fortgesetzt. Beide Hauptsätze sind auf den ersten Blick zusammenhanglos durch den Konnektor „und“ verbunden. Der Zusammenhang lässt sich aber durch eine Argumentationsanalyse herstellen. Der erste Hauptsatz liefert dabei das Datum und der zweite die Konklusion. Die Schlussregel, die das Datum „Das deutsche Recht ist anders als das irakische.“ mit der Konklusion „Ich will nicht mehr neu studieren.“ verbindet, müsste lauten: „Irakische Juristen müssen sich das deutsche Recht in einem neuen (!) Studium aneignen." Die Argumentationsanalyse gibt also Auskunft über die Bedingungen, unter denen Muhammed in seinem Beruf arbeiten könnte. Auffällig ist in diesem Zusammenhang das Modalverb „wollen“: Es impliziert, dass die Entscheidung gegen das Studium eine freie Willensentscheidung gewesen sei. Die restriktive Praxis der Anerkennung von nicht in der Bundesrepublik erworbenen Studien- und Berufsabschlüssen wird dagegen nicht thematisiert.

Die Konsequenzen dieser Entscheidung werden im folgenden Satz umschrieben: „Deshalb war es zuerst schwierig für mich.“ Der Konnektor „deshalb“ paraphrasiert die vorangehenden Begründungen. Unklar ist aber, was genau mit der Prädikation „schwierig“ belegt wird und warum. Ersteres lässt sich aus dem Kontext der Lektion ermitteln: Mit der Pro-Form „es“ ist wohl die Aufnahme einer Arbeit gemeint. Der Grund für die Schwierigkeiten muss hingegen wiederum mit Hilfe einer Argumentationsanalyse und vor dem Hintergrund des vorangehenden Satzes erschlossen werden: Das Datum wäre demnach „Ich will nicht neu studieren.“, die Konklusion „Deshalb war es zuerst schwierig für mich.“ Eine Verbindung würde folgende Schlussregel herstellen: „Wer nichts Neues lernen will, hat Schwierigkeiten, eine Arbeit zu finden." Mit anderen Worten: Nicht die restriktive Anerkennungspraxis von nicht deutschen Berufsabschlüssen 
ist für Muhammeds Schwierigkeiten verantwortlich, sondern seine Entscheidung, nicht mehr zu studieren - also letztlich er selbst.

Dass diese schwierige Zeit immerhin der Vergangenheit angehört, deuten das Tempus Präteritum und die Temporaldeixis „,zuerst“ sowie - komplementär dazu - das Tempus Präsens und die Temporaldeixis ,jetzt“ im folgenden Satz an. Auch der adversative Konnektor „doch“, der den Satz einleitet, unterstützt diese Deutung, indem er auf eine Wende hinweist. Da die frühere Situation mit Hilfe einer expliziten Prädikation als „schwierig“ geschildert wird, kann diese Wende, so der Umkehrschluss, nur eine Wende zum Besseren, eine Lösung der Schwierigkeiten sein. Diese Lösung besteht in einer beruflichen Neuorientierung: „Doch dann habe ich einen Taxikurs besucht und jetzt fahre ich Taxi." Die Wende vom Juristen zum Taxifahrer bedeutet einen sozialen Abstieg, denn der erste Beruf ist mit einem wesentlich höheren Sozialprestige konnotiert als der zweite. ${ }^{6}$ Der Statusverlust wird jedoch nicht explizit thematisiert, im Gegenteil: Durch die implizite Prädikation der neuen Tätigkeit als Wende zum Besseren und Lösung werden die beiden Berufe äquivalent gesetzt und der soziale Abstieg damit positiv umgedeutet. Die positive Wertung wird im anschließenden Satz implizit fortgeführt: „Das Taxi gehört mir und ich bin mein eigener Chef.“ Indem Muhammed das Prädikat „eigener Chef“ beigelegt wird, wird sein Status als Selbständiger mit Unabhängigkeit, also wiederum positiv konnotiert. Dethematisiert wird jedoch, dass die prekäre Selbständigkeit von Taxifahrerinnen und Taxifahrern mit Unabhängigkeit nichts zu tun hat, sondern eher mit dem Gegenteil. Die Anwendung des Konzepts der semantischen Merkmale ergibt, dass diese scheinbare Unabhängigkeit mit der ebenso scheinbaren „freiwilligen Entscheidung“ gegen das Studium korreliert. Vor dem Hintergrund der vorangehenden positiven Wertungen lassen sich auch die Kenntnisse, die im Zusammenhang mit der neuen Tätigkeit erworben werden, als Erfolg konnotieren: „Hamburg kenne ich heute besser als die meisten Deutschen.“ Dass mit der expliziten Prädikation „besser“ ein Vergleich zugunsten Muhammeds vorliegt, ist offensichtlich. Indem aber die Eigenschaft „deutsch“ ausschließlich einer der beiden Vergleichskomponenten zukommt, wird wiederum eine Differenz hergestellt, die mit der impliziten Prädikation Muhammeds als „Fremdem“ einhergeht und gleichzeitig die Voraussetzung für die Wertung der neuen Ortskenntnisse als Erfolg schafft: „Der Iraki, der Fremde, kennt eine Stadt in der Fremde besser als die Deutschen, die Einheimischen." Aber da gute Ortskenntnisse für einen Taxifahrer nichts Außergewöhnliches, sondern vielmehr Bedingung für das Ausüben dieser Tätigkeit sind, erscheint der besondere Wert dieses Wissens doch recht zweifelhaft. Als Kompensation für das prestigeträchtige Wissen eines Juristen und den damit einhergehenden Sozialstatus taugt es jedenfalls ebenso wenig wie die fragwürdige Selbständigkeit.

Der letzte Satz paraphrasiert die Kernaussage des gesamten Textes, die letztlich die Möglichkeit von persönlichem Glück unabhängig von äußeren Bedingungen suggeriert: „Das Leben ist natürlich auch in Deutschland nicht immer einfach, aber ich bin zufrieden." Da Muhammed ebenso wie die Lernenden in den Integrationskursen einen Mi-

6 Dies ist umso mehr der Fall, als es sich bei dem Beruf des Taxifahrers nicht um einen Ausbildungsberuf im engeren Sinn handelt; nötig sind lediglich ein Führerschein und eine Schulung. 
grationshintergrund besitzt, dient er potentiell als Identifikationsfigur. Aufgrund dieser Funktion wird auch seine berufliche Laufbahn in Deutschland den Lernenden implizit als Modell präsentiert, so dass der Text als Aufforderung an die Lernenden gelesen werden kann, trotz Schwierigkeiten mit ihrem Leben in Deutschland „zufrieden“ zu sein und gegebenenfalls den eigenen sozialen Abstieg positiv umzudeuten. Die zu dem Lesetext gehörige Aufgabenstellung zielt ausschließlich auf das Verständnis der Textoberfläche; eine Aufforderung zu einer echten Auseinandersetzung mit der Aussage gibt es nicht.?

\section{Schlussbemerkung}

Von der Analyse eines einzigen Textdokuments kann selbstverständlich nicht auf die Konstruktion des Themas Arbeit in allen Lehrwerken für Integrationskurse geschlossen werden. Ein Gesamtbild ergibt sich erst aus dem Vergleich mit weiteren Texten. Allerdings lässt sich hinsichtlich der beruflichen Positionierung von Migrantinnen und Migranten in Integrationskurs-Lehrwerken bislang ein relativ homogenes Bild konstatieren, für das der hier analysierte Text als exemplarisch gelten kann.

\section{Literatur}

Altmayer, Claus (2005): Landeskunde - eine (auch) empirische Wissenschaft? Konzeptionelle und methodologische Überlegungen zur empirischen Erforschung kultureller Lernprozesse. In: Hahn, Angela; Klippel, Friederike (Hrsg.) (2005): Sprachen schaffen Chancen. Dokumentation zum 21. Kongress für Fremdsprachenforschung der DGFF, München Oktober 2005. München: Oldenbourg, 243-265.

Altmayer, Claus (2006a): Landeskunde als Kulturwissenschaft. Ein Forschungsprogramm. In: Jahrbuch Deutsch als Fremdsprache 32, 181-199.

Altmayer, Claus (2006b): „Kulturelle Deutungsmuster“ als Lerngegenstand. Zur kulturwissenschaftlichen Transformation der „Landeskunde“. In: Fremdsprachen Lebren und Lernen 35, 44-59.

Arnsdorf, Dieter et al. (2003): Mit uns leben. Kursbuch. Bd. 1. Stuttgart: Klett.

Arnsdorf, Dieter et al. (2004): Mit uns leben. Kursbuch. Bd. 2. Stuttgart: Klett.

Arnsdorf, Dieter et al. (2005): Mit uns leben. Kursbuch. Bd. 3. Stuttgart: Klett.

Bovermann, Monika et al. (2004): Schritte. Deutsch als Fremdsprache. Kurs- und Arbeitsbuch. $B d$. 2. Ismaning: Hueber.

Bovermann, Monika et al. (2004): Schritte. Deutsch als Fremdsprache. Kurs- und Arbeitsbuch. $B d$. 3. Ismaning: Hueber.

Bovermann, Monika et al. (2006): Schritte. Deutsch als Fremdsprache. Kurs- und Arbeitsbuch. $B d$. 5. Ismaning: Hueber.

Bundesamt für Migration und Flüchtlinge (Hrsg.) (2005): Konzept für einen bundesweiten Integrationskurs. http://www.bamf.de/cln_101/nn_441592/SharedDocs/Anlagen/

Die Aufgabenstellungen lauten im Einzelnen: „a) Lesen Sie die Texte.“ und „b) Machen Sie eine Tabelle in Ihrem Heft und ergänzen Sie.“ Die Tabelle enthält die Rubriken „Woher?“, „Beruf früher“" „Beruf jetzt“, „Vorteile“ und - immerhin - „Nachteile“ (Pluspunkt Deutsch 2 a 2003: 34f.). 
DE/Integration/Publikationen/Integrationskurse/integrationskurskonzept-dtbroschuere-publikation, templateId $=$ raw,property $=$ publicationFile.pdf $/$ integrationskurskonzept-dt-broschuere-publikation.pdf (30.07.2008).

Bundesamt für Migration und Flüchtlinge (Hrsg.) (2007): Curriculum für einen bundesweiten Orientierungskurs. http://www.integration-in-deutschland.de/cln_092/nn_283556/ SharedDocs/Anlagen/DE/Integration/Downloads/Integrationskurse/Lehrkraefte/curriculum-orientierungskurs-pdf,templateId=raw,property $=$ publicationFile . pdf/curriculum-orientierungs-kurs-pdf.pdf (30.07.2008).

Bundesamt für Migration und Flüchtlinge (2008): Das Integrationsportal. http://www. integration-in-deutschland.de (30.07.2008).

Bundesamt für Migration und Flüchtlinge, Bundesministerium des Innern; Goethe Institut (Hg.) (2008): Rahmencurriculum für Integrationskurse Deutsch als Zweitsprache. http: / / www.integration-in-deutschland.de/cln_092/nn_283556/SharedDocs/Anlagen/ DE/Inte-gration/Downloads/Integrationskurse/Lehrkraefte/rahmencurriculumintegrationskurs, templateId = raw,property $=$ publicationFile.pdf $/$ rahmencurriculumintegrationskurs.pdf (30.07.2008).

Bundesregierung; Bundesministerium des Innern (2004): Verordnung über die Durchführung von Integrationskursen für Ausländer und Spätaussiedler. Vom 13. Dezember 2004. In: BGBl I 2004, 3370.

Bundestag; Bundesrat (2004): Gesetzü̈ber den Aufenthalt, die Erwerbstätigkeit und die Integration von Ausländern im Bundesgebiet [= Artikel 1 des Gesetzes zur Steuerung und Begrenzung der Zuwanderung und zur Regelung des Aufenthalts und der Integration von Unionsbürgern und Ausländern (Zuwanderungsgesetz)]. Vom 30. Juli 2004. In: BGBl I 2004, 1950.

Feil, Robert; Hesse, Wolfgang (2006): Miteinander leben. Unterrichtsmaterial für Sprach- und Orientierungskurse. München: Iudicium.

Flick, Uwe (2005): Wissenschaftstheorie und das Verhältnis von qualitativer und quantitativer Forschung. In: Mikos, Lothar; Wegener, Claudia (Hrsg.) (2005): Qualitative Medienforschung. Ein Handbuch. Konstanz: UVK, 20-28.

Gaidosch, Ulrike et al. (2006): Zur Orientierung. Basiswissen Deutschland. 2. Aufl. Ismaning: Hueber.

Höhne, Thomas; Kunz, Thomas; Radtke, Frank-Olaf (1999): Zwischenbericht: Bilder von Fremden. Formen der Migrantendarstellung als der ,anderen Kultur" in deutschen Schulbüchern von 1981-1997. Frankfurt a.M.: Johann-Wolfgang-Goethe-Universität.

Höhne, Thomas; Kunz, Thomas; Radtke, Frank-Olaf (2005): Bilder von Fremden. Was unsere Kinder aus Schulbüchern über Migranten lernen sollen. Frankfurt a.M.: Johann-Wolfgang-Goethe-Universität.

Kaufmann, Susan et al. (2005): Orientierungskurs - Geschichte, Institutionen, Leben in Deutschland. Berlin et al.: Langenscheidt.

Keller, Reiner (2004): Diskursforschung. Eine Einführung für SozialwissenschaftlerInnen. 2. Aufl. Wiesbaden: Verlag für Sozialwissenschaften.

Kilimann, Angela et al. (2005): 30 Stunden Deutschland. Stuttgart: Klett. 
Krüger, Georg et al. (2003): Pluspunkt Deutsch 1a. Der Integrationskurs Deutsch als Zweitsprache. Kursbuch. Berlin: Cornelsen.

Krüger, Georg et al. (2003): Pluspunkt Deutsch 2a. Der Integrationskurs Deutsch als Zweitsprache. Kursbuch. Berlin: Cornelsen.

Krüger, Georg et al. (2004): Pluspunkt Deutsch 2b. Der Integrationskurs Deutsch als Zweitsprache. Kursbuch. Berlin: Cornelsen.

Krüger, Georg et al. (2005): Pluspunkt Deutsch 3. Der Integrationskurs Deutsch als Zweitsprache. Kursbuch. Berlin: Cornelsen.

Lemcke, Christiane et al. (2002): Berliner Platz: Deutsch im Alltag für Erwachsene. Lehr- und Arbeitsbuch. Bd. 1. Berlin et al.: Langenscheidt.

Lemcke, Christiane et al. (2003): Berliner Plat:: Deutsch im Alltag für Erwachsene. Lehr- und Arbeitsbuch. Bd. 2. Berlin et al.: Langenscheidt.

Lemcke, Christiane et al. (2004): Berliner Platz: Deutsch im Alltag für Erwachsene. Lehr- und Arbeitsbuch. Bd. 3. Zertifikatsband. Berlin et al.: Langenscheidt.

Neuner, Gerhard (1988): Fremdsprachlicher Text und universelle Lebenserfahrungen. Aspekte einer themenorientierten fremdsprachlichen Textdidaktik. In: Neuner, Gerhard (Hrsg.): Kulturkontraste im DaF-Unterricht. 2. Aufl. München: Iudicium, 11-32.

Neuner, Gerhard (2003): Lehrwerke. In: Bausch, Karl-Richard; Christ, Herbert; Krumm, Hans-Jürgen (Hrsg.): Handbuch Fremdsprachenunterricht. 4. Aufl. Tübingen et al.: Francke, 399-402.

Rat für kulturelle Zusammenarbeit beim Europarat; Goethe-Institut Inter Nationes (Hrsg.) (2001): Der gemeinsame europäische Referenzrabmen für Sprachen: lernen, lebren und beurteilen. Berlin et al.: Langenscheidt.

Rusch, Gebhard (1998): Konstruktivismus, radikaler. In: Nünning, Ansgar (Hrsg.): Metzler-Lexikon Literatur- und Kulturtheorie: Ansätze - Personen - Grundbegriffe. Stuttgart et al.: Metzler, 280-282.

Schote, Joachim et al. (2006): Pluspunkt Deutsch. Der Orientierungskurs Deutsch als Zweitsprache. Berlin: Cornelsen.

Steinke, Ines (2007): Gütekriterien qualitativer Forschung. In: Flick, Uwe; Kardoff, Ernst von; Steinke, Ines (Hrsg.): Qualitative Forschung. Ein Handbuch. 5. Aufl. Reinbek: Rowohlt, 319-331.

Teske, Doris (2002): Cultural Studies: GB. Berlin: Cornelsen.

Ucharim, Anja (2009): Die traditionelle Lehrwerkanalyse und die Diskursanalyse - Zwei Methoden zur inhaltlichen Analyse von Lehrwerken für Integrationskurse. In: Peuschel, Kristina, Pietzuch, Jan-Paul (Hrsg.): Kaleidoskop der jungen DaF-/DaZ-Forschung. Dokumentation zur zweiten Nachwuchstagung des Fachverbandes Deutsch als Fremdsprache, 29. und 30. Mai 2007 am Herder-Institut der Universität Leipzig. Materialien Deutsch als Fremdsprache Bd. 80, Göttingen: Universitätsverlag, 149-168. 
Christoph Chlosta, Matthias Jung (Hrsg.) (2010): DaF intergriert: Literatur - Medien - Ausbildung. Tagungsband der 36. Jabrestagung des Fachverbandes Deutsch als Fremdsprache 2008. Göttingen: Universitätsverlag, 351-362.

\section{Magdalena Michalak (Lüneburg)}

\section{„Deutsch kann ich nur mit einem Lehrbuch lernen.“ Wege zum informellen Spracherwerb}

\section{Einleitung}

Eine Sprache ausreichend zu beherrschen bedeutet im weiteren Sinne sich zu verständigen, die Sprache im Mündlichen und im Schriftlichen angemessen anwenden zu können. Dies bedeutet, dass man bestimmte sprachliche Kompetenzen erworben hat: ein Potenzial an Fähigkeiten und Fertigkeiten im Bereich Hörverstehen, Sprechen, Leseverstehen und Schreiben. Darunter fällt alles, was Menschen dazu befähigt, an der Schriftund Sprachkultur teilzuhaben. „Sprachbeherrschung“ meint unter diesem Aspekt die Fähigkeit, das Fernsehprogramm zu studieren, mit den Nachbarn zu sprechen, Tabellen und Fahrpläne zu entschlüsseln, ein Lexikon zu benutzen, einen Brief zu schreiben, Gedichte zu lesen - im Allgemeinen: jede (schrift-)sprachliche Kompetenz im Alltag, in der Schule und im Beruf. Im Laufe der Zeit werden aber Sprache und Schrift nicht allein als Mittel der Kommunikation, sondern vor allem als ein Medium des Lernens eingesetzt. So betrachtet ist Sprache überall vorhanden. Literale Erfahrungen sind hier für die Lerner sehr hilfreich: Sie ermöglichen nicht nur sich das Wissen anzueignen und die Welt besser zu verstehen, sondern auch Zusammenhänge und Verbindungen herzustellen, Textkompetenz zu erwerben, den Wortschatz zu erweitern sowie die Sprache und Ausdrucksfähigkeiten insgesamt weiter zu entwickeln. Der natürliche Erwerb solcher Kompetenzen - sowohl in der Erst- als auch in der Zweitsprache - vollzieht sich immer in sozialen Kontexten, in denen sich der Lerner bewegt: einerseits institutionell im Kindergarten, in der Schule oder in einem Deutschkurs, andererseits informell - in der 
sozialen Alltagspraxis, auch und vor allem in den Familien, unter Freunden, Bekannten oder Nachbarn. Im sozialen Umfeld sind es vor allem die informellen Lernprozesse im alltäglichen Leben, welche die Kompetenzen des Individuums herausfordern und erweitern. Nach Expertenschätzungen findet nur etwa 30\% des Lernens in klassischen Bildungsinstitutionen statt (vgl. Cross 2003). Zu den Formen des informellen Lernens zählen laut Dohmen Erfahrungslernen, implizites Lernen, Alltagslernen, selbstgesteuertes Lernen und Lernen am Arbeitsplatz, die sich jedoch gegenseitig überschneiden (s. Dohmen 2001). Das informelle Lernen beruht im Wesentlichen auf der eigenen, nicht von anderen angeleiteten Verarbeitung von Erfahrungen (vgl. Watkins; Marsick 1992). Wie das formale Lernen auf einen anleitenden Lehrer bezogen ist, so hängt das informelle Lernen mit einer lernanregenden und lernunterstützenden Umwelt zusammen.

Dies bezieht sich auch auf den Zweitspracherwerb: Der ungesteuerte Spracherwerb - als implizites, selbstgesteuertes Alltagslernen - ist nicht mehr eng und dominant auf eine persönliche Lehrautorität, sondern auch auf eine weitere Umwelt mit vielfältigen Lernanregungen, Lernherausforderungen und Lernhilfen bezogen. D.h. Lernen im informellen Kontext ist autonom, selbstgesteuert, verläuft aber in sozialen Kontexten. Der Lerner muss dennoch den Prozess wahrnehmen, selbst z.B. über die Phänomene der Sprache reflektieren und sich dessen bewusst sein, dass er Sprache als Werkzeug bei der Ausübung beinahe jeder Tätigkeit anwendet (vgl. Edmondson; House 1997).

Im Alltag sind es in erster Linie die Eltern, die den Lernprozess - hier den Sprachund Schrifterwerb - stark beeinflussen. Die Eltern prägen ihre Kinder dadurch, dass sie ihnen bestimmte Regeln und Normen, Traditionen und Rituale, Einstellungen und Erwartungen vermitteln (vgl. Trommsdorff 1989: 101f.). Ein Problem ist die Tatsache, dass Erwachsene schon über relativ verfestigte Lerngewohnheiten verfügen, die sie auch an ihre Kinder weitergeben. Die Eltern als aktiv Handelnde im Spracherwerbsprozess der Kinder sind für sie die ersten Ansprechpartner, die für ihre akuten Lernbedürfnisse jeweils angemessene Lernhilfen - mit Anregungen, Informationen, Hinweisen - anbieten können und sie demzufolge effektiv fördern können. ${ }^{1}$ So können sie den Lernprozess der eigenen Kinder unterstützen und auch selbst bewusst die deutsche Sprache lernen und dadurch die familiale Sprachkultur fördern. Denn Lernstile entfalten sich im Erziehungsprozess des Elternhauses und werden zu Persönlichkeitseigenschaften. Ein Lernstil bezeichnet dabei ,intraindividuell relativ stabile, zumeist situations- und aufgabenspezifische Präferenzen (Dispositionen, Gewohnheiten) von Lernern sowohl bei der Verarbeitung von Informationen als auch bei der sozialen Interaktion. Der Terminus bezieht sich damit nicht nur auf in engerem Sinne kognitive, sondern auch auf motivationale und affektive Aspekte menschlichen Verhaltens und Handelns" (Grotjahn 2003: 326f). Diese Lerngewohnheiten hängen mit der Art und Weise zusammen, wie die Lerner bis dahin gelernt haben und welche Unterrichtsmethoden ihnen vertraut sind. Somit hat jeder Kursteilnehmer eine andere Lerngeschichte. Er kommt zu einem Integrationskurs mit unterschiedlichen Bedürfnissen und Erwartungen, die auf beiden

1 Untersuchungen zeigen, dass die Hauptinformanten für Strategien zum Erlernen einer Fremdsprache in erster Linie Klassenkameraden und die Familie sind (vgl. Rampillon 1991: 3). 
Seiten - Lehrer und Lerner - zu erfüllen sind (vgl. Roos 1996: 29). Vor allem diejenigen Migranten, die den schulischen Unterricht vor vielen Jahren genossen haben, bringen auch verschiedene Lernweisen mit. Lernen und die damit verbundenen Anstrengungen sind für sie ungewohnt geworden, was erneut Verunsicherungen verursachen kann (vgl. Rampillon 1991: 2f.). Die Kursteilnehmer sind auch durch ihren kulturellen Hintergrund geprägt und zeigen damit andere Einstellungen zum Lernen und andere Verhaltensweisen gegenüber dem Lehrer (vgl. Wagner; Schmidke 1983: 35f; Auernheimer 2003: 116).

Hinzu kommt die Tatsache, dass der Zweitspracherwerb nicht nur auf die Teilnahme an Integrationskursen reduziert werden darf: Es findet primär vor, neben und nach dem Deutschkurs statt. Das sprachliche Lernen setzt damit die Verankerung in einer alltagsweltlichen Lebenspraxis voraus. Wer die deutsche Sprache nur im Kurs - praktisch als eine Fremdsprache - lernt, ohne sie im Alltag zu gebrauchen und zu entwickeln, bei dem wird der Lernerfolg gering bleiben. Nach einem Integrationskurs kann man das Kursdeutsch bald wieder verlernen, falls es im Alltag in sozialen Kontakten nicht angewendet wird. Denn „jeder Spracherwerb ist Sprachvermittlung““ (Butzkamm 2002: 131). Das soziale Umfeld bietet eine Vielfalt von Sprachlernmöglichkeiten: Lernen findet somit nicht nur in Institutionen, sondern vielmehr als lebensbegleitendes oder besser lebensintegriertes Lernen im Alltag, am Arbeitsplatz, im Familienkreis oder in der Freizeit statt (Europäische Kommission 2001: 32f.). Ob das soziale Umfeld dennoch auch als Lernfeld gestaltet wird, Lernmöglichkeiten gesucht, wahrgenommen und realisiert werden, ist durch verschiedene Faktoren bedingt. Es hängt - so die Annahme - von der Anregung und Unterstützung des sozialen Umfeldes und von der Kompetenz, Motivation und Interessen des Individuums ab.

Es stellt sich daher die Frage, welche Einstellungen die Migranten zum eigenen Sprachelernen und zum Sprachelernen ihrer Kinder haben. Welche Erwartungen haben sie bezüglich der Fördermöglichkeiten - im Sinne des autonomen Lernens im informellen Umfeld - an die Lehrperson? Die Hauptthese dieses Beitrags lautet: Eines der wesentlichsten Probleme für Migranten besteht in der fehlenden Kenntnis darüber, wie man ungesteuert und autonom Deutsch lernen kann. Beleg dafür sind Unterrichtsbeobachtungen und Befragungen von Migranten in Integrationskursen, die im Rahmen einer qualitativen Untersuchung bei einem Träger in $\mathrm{Kiel}^{2}$ durchgeführt wurden.

\section{Forschungsdesign}

Von 2003 bis 2005 war ich als Kursleiterin in drei niedrigschwelligen Integrationskursen mit insgesamt 73 Kursteilnehmern tätig. Jeder Kurs beinhaltete jeweils 600 Stunden und dauerte je ca. ein Jahr. Die Tatsache, dass ich selbst als Kursleiterin mit den Lernern, also mitten im Unterrichtsgeschehen, gearbeitet habe, erwies sich als vorteilhaft für die Untersuchung. Dadurch konnte das Vertrauen der Lernenden schnell gewonnen werden. Für die Studie wurde daher die offene, teilnehmende, direkte Beobachtung ${ }^{3}$

Zentrale Bildungs- und Beratungsstelle für Migrantinnen und Migranten e.V. in Kiel.

3 Die Beobachtung dient als Verfahren zur zielorientierten Erfassung von sinnlich wahrnehmbaren Handlungen. Der Beobachter versucht seine Beobachtungen zu systematisieren und den Beobachtungsvorgang kritisch (hinsichtlich einer Verzerrung durch seine Perspektive) zu prüfen (vgl. Lamnek 2001a: 266). 
als Forschungsmethode ausgewählt, um die Sichtweise der Kursteilnehmenden auf ihr sprachliches Lernen zu untersuchen (vgl. Lamnek 2001a: 268f). Im Unterricht wurden - orientiert an den Lehrwerken - regelmäßig Situationen geschaffen, die eine Reflexion über den Lernprozess und das Gelernte ermöglichten. ${ }^{4}$ Einschätzungen der Beteiligten wurden über mündliche Befragungen erhoben: In dem angegebenen Zeitraum wurden neben den protokollierten Beobachtungen im Unterricht im Lernprozess auch Interviews mit einzelnen 22 Kursteilnehmern aus verschiedenen Ländern (Afghanistan, Algerien, Armenien, Ekuador, Ghana, Irak, Iran, Kasachstan, Kolumbien, Kroatien, Marokko, Thailand, Togo, Tschetschenien, Türkei, Ukraine und Vietnam) durchgeführt. Das Durchschnittsalter der Kursteilnehmer betrug 37 Jahre. Alle Befragten hatten Kinder im Vorschul- oder im Schulalter. Diese spezielle Teilnehmergruppe hatte in der Mehrheit wenig oder lange zurück liegende Lernerfahrung (vgl. dazu Rost-Roth 2005).

Das Ziel der Untersuchung war die Erfassung von Spezifka der Lernergruppe bezüglich ihrer Lernautonomie beim Spracherwerb unter Einbezug der Perspektive der Beteiligten. Dabei ist vor allem die individuelle Lernerperspektive hervorzuheben, die „als konstitutiv für die Analyse des Phänomens ZSE betrachtet werden muss“ (Ohm 2004: 48) und die auch in den Integrationskursen häufig übersehen wird (vgl. Wölbert 2001). Die Subjektivität des Lerners als Objekt ist zwar in diesem Kontext ersichtlich. Der Zweitspracherwerb im informellen Umfeld, d.h. in einer Sozialwelt verlangt jedoch im Sinne von Ohm „,nach einem explizit sozialwissenschaftlichen Zugang [...]“ (Ohm 2004: 48). Für die Befragungen wurde ein Leitfaden im Vorfeld entworfen. ${ }^{5}$ Dieser wurde in fünf Bereiche unterteilt, zu denen jeweils Fragestellungen entwickelt wurden. $\mathrm{Zu}$ Anfang wurden den Kursteilnehmern allgemeine Fragen zu ihrer persönlichen Situation gestellt, um ihre Lernmöglichkeiten besser einschätzen zu können. Der erste Bereich bezog sich darauf, wie Sprache erlernt wird. Die Kursteilnehmer wurden animiert, darüber zu erzählen, in welchen Situationen sie Deutsch lernen und welche Inhalte sie als Lerner für relevant halten. Analysiert wurden Lernvorstellungen der Migranten über den Spracherwerb, ihre Erwartungen und angewandte Strategien. Dabei soll nicht nur die aktuelle Lebenssituation, sondern auch - zumindest retrospektiv - die Bildungsbiografie bzw. schulische Erfahrungen berücksichtigt werden. Die Untersuchung des Lernortes $^{6}$ wurde mit einbezogen, um das Lernverhalten der Lerner im häuslichen Umfeld zu erforschen. Der nächste Bereich betraf den Umgang mit der Schrift und Lesepraktiken der Lerner. Des Weiteren wurde die Rollenverteilung zwischen dem Lehrer und dem Lerner angesprochen und explizit das Verhältnis von Fremd- bzw. Selbststeuerung im Unterricht betrachtet. Durch die Unterrichtsbeobachtungen konnte die bereits be-

4 In den Kursen wurde mit folgenden Lehrwerken gearbeitet: Lemcke, Ch.; Rohrmann, L.; Scherling, T.: Berliner Platz (3. Bd.). Langenscheidt 2002; Bovermann, M. et al.: Schritte 1-2. Hueber Verlag 2003.

5 So konnten die Fragen verändert und in ihrer Reihenfolge flexibel gestaltet werden (vgl. Lamnek 2001b: 287). Es wurden teils offene, teils implizit geschlossene Fragen gestellt. Offene Fragen haben den Vorteil, dass sie einer alltäglichen Gesprächssituation ähneln, was den Migranten die Interviewsituation erleichterte. Zusätzlich erfährt man durch offene Fragen mehr Details von dem Befragten, welche man der Forschungsfrage entsprechend vertiefen kann (vgl. Lamnek 2005: 340f).

6 Der Lernort nimmt insofern Einfluss auf die Lernautonomie, als er eigenständiges Problemlösen ermöglichen kann. 
stehende Lernerautonomie der Kursteilnehmer erfasst werden, wodurch Rückschlüsse auf den Ursprung des autonomen Handelns möglich waren. Zusätzlich wurden die bevorzugten Arbeitsformen beim Sprachelernen und Benutzung von Lernhilfen untersucht. Dies zielte auf selbstgesteuerte und fremdgesteuerte Unterrichtssituationen im Vergleich ab und darauf, wie sich die Kursteilnehmer zu ihnen verhalten.

\section{Ergebnisse der Untersuchung in Integrationskursen}

Durch die Studie konnte ermittelt werden, dass für die Mehrheit der Erwachsenen der unbewusste und selbstgesteuerte Spracherwerb im Lebenszusammenhang nicht als „richtiges Lernen“ angesehen wird: Deutsch wird ausschließlich mit Hilfe eines Lehrwerks gelernt. Gespräche auf Deutsch im Unterricht oder auch im Alltag dienen dagegen der Unterhaltung. Zu Hause die Sprache zu lernen heißt an einem Tisch zu sitzen, Hausaufgaben zu machen, Vokabeln auswendig zu pauken. Die Befragten haben das Sprachelernen hauptsächlich mit Anstrengung, Mühe und Verzicht verbunden. Die Migranten haben selbst zum Teil in einem sehr verschulten System gelernt und sind an das freie Zeit- und Arbeitsmanagement nicht gewöhnt. Die Tatsache, dass sie sich ausschließlich auf den Lehrstoff im Deutschkurs beschränken, lediglich die nötigen Hausaufgaben machen und nur den Ratschlägen der Dozenten folgen, bestätigt die Schwierigkeiten beim autonomen Lernen. Dabei werden Übungen mit vorgegebnen Lösungen bevorzugt, denn dadurch kann das erwünschte Ergebnis erreicht werden. Eine Kursteilnehmerin erklärte: „Es muss richtig sein, sonst ist der Lehrer nicht zufrieden.“

Das selbständige Lernen im informellen Kontext fällt den erwachsenen Lernern schwer, denn sie kennen den Unterricht als eine traditionelle Unterrichtsform, die sich durch Instruktion, streng vorgegebene und vorbereitete Inhalte, durch Progression und strenge Kontrolle charakterisieren. Alle Kursteilnehmer gaben zu, dass sie nie gelernt haben, wie sie lernen sollen. Sie wurden zu keinem Zeitpunkt in den Wissensvermittlungsprozess eingebunden und der eigentliche Lernprozess wurde kaum reflektiert, geschweige denn gefördert. Sie wissen nicht, wie sie den Spracherwerbsprozess selber steuern können. Sie sind Eigenwahl, der Eigenverantwortung, der Selbstkontrolle, des explorativen und problemlösenden Lernens nicht gewöhnt. Aus diesen Gründen können die Lernerorientierung und das autonome Lernen zu Unsicherheit und Unbeholfenheit führen. Die Lerner nehmen das Verfahren nicht ernst sondern als reine Spielerei auf. Daher wundert auch nicht die Einstellung, dass ihre Kinder in der deutschen Schule nicht lernen, denn sie bekommen kaum Hausaufgaben. Eine Kursteilnehmerin türkischer Herkunft kommentierte: „Im Kindergarten spielen die Kinder, in der Schule sollen sie lernen. Was machen meine Kinder hier in der Schule? Sie lernen nicht! Nur spielen!“

Interessant ist in diesem Kontext die Betrachtung der Klassenraumkultur. Das kulturspezifische Verständnis von Rollenerwartungen hat dabei große Relevanz. Hier spiegeln sich äußerst unterschiedliche Annahmen darüber wider, was Lehrer und was Lernende zu tun haben, und in welcher Weise sie die Handlungen des anderen im Lernprozess verstehen. Der Lehrer gilt als moralische Person, die dazu noch Wissen vermitteln kann 
(vgl. dazu Gotows 1981: 74). Die Lehrperson wird als ein Vorbild in jeder Hinsicht (auch in Bezug auf das Äußere) angesehen und erfreut sich starker Autorität. Was die Lehrkraft sagt und lehrt ist nicht anzuzweifeln. Die Befragungen haben auch ergeben, dass der Lehrer und der Schüler in diesem Lernsystem einander vertrauen und wissen, was sie voneinander zu erwarten haben. Der Glaube der Beteiligten an die Effektivität lässt den Lernprozess in der von allen erwarteten Art und Weise funktionieren. Die Kursteilnehmer wiesen weiterhin ein großes Bedürfnis nach Sicherheit auf: Fast 80\% der Lerner meinten, sie würden mit der Lenkung durch den Lehrer ein korrekteres Ergebnis erhalten. Ein armenischer Kursteilnehmer bemerkte dazu: „Der Lehrer hat doch eine Ausbildung. Er weiß am besten, was, wie und wann ich lernen soll.“ Im Gegensatz dazu verstehen deutsche Lehrer eindeutig ihre Beziehung zu den Lernern institutionenspezifisch und formal, „nehmen sich und die Schüler in der je spezifischen Rolle als Lehrer und Schüler wahr [...]“ (Auerheimer 2003: 117). Sowohl die Lehrkräfte als auch die Schüler in vielen deutschen Schulen scheinen sich über das Unterrichtsgeschehen im Unklaren zu sein. Migranten sind sich daher nicht sicher, was von den Lernern, auch von ihren Kindern als Schülern erwartet wird. Aus diesem Grund wird das Geschehen häufig weder als Unterricht noch als ein Lernprozess anerkannt.

$\mathrm{Zu}$ den meist ausgeprägten Lerneigenschaften gehört die Art der Aneignung von Kenntnissen und zwar das unreflektierte Auswendiglernen des Lernstoffes, das Pauken von Vokabeln. Lerninhalte und der Kontext werden hierbei oft nicht beachtet. Neue Wörter werden abgeschrieben und auswendig gelernt. Die Tendenz zur Selbständigkeit zeigt sich jedoch im Aufschreiben der Vokabeln in der Form, wie sie im Text vorkommen anstelle des Abschreibens nach einem alphabetischen Glossar. Die neuen Wörter werden fast immer mit der Übersetzung in der Erstsprache notiert. Die Kursteilnehmer bestätigten, dass sie zum besseren Behalten des Vokabulars und der Regeln eine visuelle Hilfe brauchen. Für das Durchlesen des Stoffes der letzten Stunde bleibt den Kursteilnehmern oft nicht genug Zeit übrig. In der Anfangsphase der Kurse waren die Lerner an Fragen, die sich nicht auf die Inhalte aus dem Unterricht bezogen, wie z.B. Wetter, Erlebnisse aus dem Vortag oder eigene Essgewohnheiten, nicht gewohnt. Sie haben zwar zu Hause fleißig gelernt, aber nur die Inhalte, die im Deutschkurs behandelt wurden. Die meisten Befragten gehen beim Sprachelernen auch benennend vor: Sie nennen die Gegenstände, wiederholen diese oder lernen sie auswendig. Dadurch eignen sie sich nur Nomen an. Für die Beschreibung einer Handlung, einer Tätigkeit fehlt es ihnen dann an Wortschatzkenntnissen. Hinzu kommt, dass die Kursteilnehmer dazu neigen, deklaratives Wissen zu erwerben, anstatt nach Lösungen zu suchen. Im Mittelpunkt steht das Faktenwissen, nicht das Handelswissen oder der Erwerb von Kompetenzen (vgl. dazu Grotjahn 1997): Die Befragten sprechen nur dann vom Sprachelernen, wenn „Fakten“ oder „Lernstoff“ aufgenommen werden. Eine Lernende aus Kroatien erklärte: „Also hier, im Deutschkurs sagen wir, wo und wie man sucht Informationen. In meiner Heimat viel wichtiger ist, was der Schüler hat gelernt.“

Im Unterricht wird oft an Texten gearbeitet. Dabei tendieren die meisten Migranten dazu, einen Text Wort für Wort zu erarbeiten. Sie fühlen sich ausgesprochen unbehag- 
lich, wenn sie, ausgehend von einem Globalverständnis, nicht alle unbekannten Wörter nachschlagen oder bei dem Lehrer erfragen können. Sie neigen zum totalen Lese- und Hörverstehen, bei dem die Konzentration weniger auf dem oft banalen Inhalt liegt, sondern mehr auf den sprachlichen Problemen. Die Übersetzungstechniken nehmen einen großen Anteil ein: Die Tendenz ist jeden Text wortwörtlich verstehen zu wollen und bei jedem unverstandenen Wort, jeder grammatischen Schwierigkeit stecken zu bleiben. Denn die Sprache zu können bedeutet für die Mehrheit der Befragten alle Wörter zu verstehen und fast alle Regeln zu kennen. Auf diese Weise werden Gewohnheiten geschaffen, die dem sinnentnehmenden Hören und Lesen erheblich im Wege stehen. Dabei verlangen die Kursteilnehmer immer mehr Grammatik im Unterricht, denn das wird als das Fundament der Sprache verstanden. Ein Teilnehmer aus Armenien stellte fest: „Weißt du die Regel nicht, so kannst du die Sprache nicht.“ Das wird übrigens auch von der Lehrkraft erwartet. Dies ist vermutlich auch auf die Lernerfahrungen der Kursteilnehmer mit einem Grammatik- und Übersetzungsunterricht und dem rein deduktiven Sprachlernprozess über die Grammatik zurückzuführen. Im Fremdsprachenunterricht in der Heimat - die meisten haben Englisch in der Schule gelernt - haben sie vorwiegend grammatische Regeln studiert und Texte gelesen bzw. übersetzt; Interaktion und Sprechen waren fast völlig ausgeklammert. Die Folge: vergleichsweise geringes Hörverständnis und große Schwierigkeiten beim Sprechen, bei relativ guten grammatischen Kenntnissen. Vermittelt man nur das explizite Sprachwissen, das Kennen der Sprache, so fehlt den Lernern oft die Fähigkeit, die erworbenen Regeln automatisch in der Sprachpraxis anzuwenden. Die Regularitäten der Sprache kann man unproblematisch lehren, aber erst in der richtigen Anwendung dieses Wissens kann sich ein Können herausbilden (vgl. Ossner 2006: 35). Daher lassen sich die dafür erforderlichen Kompetenzen nicht direkt vermitteln, ,,sondern sind das Ergebnis individueller Anstrengung und dabei gewonnener Erfahrung" (s. ebd.: 34).

Auch zu ihren Lesepraktiken und Medienbenutzung beim Sprachelernen wurden die Kursteilnehmer befragt, so dass der Lernprozess im Kurs auf ihre Bedürfnisse abgestimmt werden konnte. Dabei wurde festgestellt, dass Formen von Schriftsprachgebrauch für Individuen zwischen Gesellschaften unterschiedliche Bedeutungen haben. Nur zwei ehemalige Russischlehrerinnen gaben zu, oft und gerne literarische Texte zu lesen. Es könnte für manche erstaunlich sein, dass die anderen Migranten bis auf die Bibel, den Koran oder eventuell Kochbücher gar keine Schriften zu Hause stehen haben. Das impliziert aber nicht, dass sie gar nicht lesen. Sie bevorzugen eben andere Textsorten sowie das Lesen zu anderen Zwecken. Die befragten Migranten greifen nach Texten zu religiösen Zwecken, um zu lesen und auch gleichzeitig zu lernen. Dies wird auch gezielt auf Deutsch gemacht, wie ein Kursteilnehmer aus Togo erläuterte: „Einmal in der Woche gibt es Kaffee in Gemeinde. Ich gehe dort. Wir lesen dann die Bibel zusammen. Ich verstehe nicht alles, aber alte Frauen, deutsch mir helfen.“ Gelesen werden auch Lesetexte für den Deutschunterricht, meistens im Rahmen von Hausaufgaben. Die männlichen Kursteilnehmer suchen auch gezielt nach bestimmten Informationen im Internet. Jedoch am Computer Sitzen wird im Allgemeinen nur als 
Spielen oder Vergnügen angesehen, nicht als eine Lernform. Bei vielen Migranten läuft zu Hause immer das Radio oder der Fernseher. Zum Teil wissen sie aber nicht, was sie am Tag davor gehört oder gesehen haben. Die Frauen haben dabei die Vorliebe für Fernsehserien, die männlichen Kursteilnehmer bevorzugen Nachrichten und informative Programme. Dennoch ist den Lernern größtenteils nicht bewusst, dass sie dabei ihre sprachlichen Kompetenzen erweitern können: Das Radiohören oder Fernsehen werden nicht gezielt eingesetzt, um neues Sprachwissen zu erlangen. Interessant ist, dass die meisten Migranten zwar Bücher nicht als ihre Lieblingslektüre erwähnen, aber dafür regelmäßig Zeitungen oder Zeitschriften lesen. Dazu ein Kommentar von einem irakischen Kursteilnehmer: „Wozu soll ich Romane lesen? Bessere Geschichten kann ich von mein Nachbar hören. Oder einige Programme im Fernsehen sehen. Mich interessieren nur konkret Informationen." Und hier liegt m. E. das Potenzial auch für den informellen Spracherwerb: Man muss den Lernern bewusst machen, dass man erstens durch das Lesen auch die Sprache lernt. Zweitens sollen sie dazu angeregt werden, die sie interessierten Sachtexte (Sportberichte, Nachrichten, Anzeigen etc.) auch im informellen Umfeld zu lesen.

Einige Kulturen legen sehr großen Wert auf gegenseitige Unterstützung und Zusammenarbeit und begegnen dem Wettbewerb als einem Motivationsfaktor für das Lernen eher mit Misstrauen. Manche Kursteilnehmer bevorzugen den Frontalunterricht und äußerten ihre Abneigung zu Gruppenarbeit: „In der Gruppe komme ich fast nie zu Wort und ich habe Angst zum Sprechen" (Teilnehmer aus Algerien). Ein anderer Lerner aus dem Irak: „Es ist manchmal schwierig Leute aus anderen Ländern verstehen. Was kann ich dann von ihnen lernen?" Die Beobachtungen ergaben, dass Migranten aus Südamerika und aus Afrika die aktive Beteiligung und Interaktion dem passiven Zuhören vorzogen. Für die Lerner aus dem asiatischen Kulturkreis waren Bescheidenheit und Respekt vor den Älteren und vor den Lehrern sehr wichtig. Schüchternheit und Zurückhaltung war unter den slawischen Kursteilnehmern zu bemerken. Es kam im Unterricht oft vor, dass z.B. Lerner russischer Herkunft erst dann das Wort ergriffen haben, wenn sie sich einen grammatikalisch korrekten Satz überlegt hatten. Diese durch den schulischen Unterricht geprägte Einstellung und Angst vor eventuellen Fehlern beim Sprechen können den Sprachlernprozess hemmen. Hinzu kommen Denkgewohnheiten und negative Selbsteinschätzung - typisch für einen umfeldsensibleren Lernstil. Feldabhängige Lerner orientieren sich stärker an Modellen und Vorgaben, sind empathischer und entwickeln ein niedriges Selbstwertgefühl, wenn sie mit divergierenden Erwatungen konfrontiert werden (vgl. Apeltauer 1987: 11f.). Eine ukrainische Kursteilnehmerin meinte: „Ich dachte immer, alle Leute achten nur auf meine Fehler. Bei fremde Leute spreche ich nicht viel, weil ich glaube, sie lachen mich aus." Scheu vor persönlicher Meinungsäußerung vor dem Auditorium trägt dazu bei, dass die Lernenden - diese Anmerkung bezieht sich nur auf Frauen - auf Fragen nicht spontan antworten, sondern eher Rückfragen bei Mitlernern stellen. Für derartige kulturspezifische Differenzen muss jeder Lehrer sensibel sein. 
Die Konklusion der Forschung ist, dass der größte Teil der Befragten das Lernen im Unterricht, gesteuert von dem Lehrer, für die beste Möglichkeit des Lernens hält. Sie kennen aber keine anderen Lernvarianten. Anschließend stellt sich die Frage, wie Erwachsene mit Migrationshintergrund gefördert werden können, damit sie durch die Anregung zum Sprachlernen im informellen Umfeld, d.h. auch außerhalb der Integrationskurse, ihre Deutschkenntnisse vertiefen können. Welche didaktisch-methodischen Konsequenzen ergeben sich aus dieser Untersuchung für den DaZ-Unterricht mit Erwachsenen?

\section{Verknüpfung von Spracherwerb in Integrationskursen und im Alltag}

Zur Erfüllung dieser Aufgaben ist eine Veränderung der Lehrerrolle in Integrationskursen notwendig. Der Erwerb des Deutschen als Zweitsprache erfolgt weniger über den Weg der Belehrung in formalisierten Strukturen, sondern über selbstgesteuertes Lernen in informellen Lernarrangements. Das Wissen über kulturelle Lernverfahren und assoziierte Kompetenzen sowie Ressourcen der DaZ-Lerner kann und sollte in der Entwicklung kulturrelevanter Curricula und in der Unterrichtsvorbereitung berücksichtigt werden. Aus der Lernumwelt kommen immer wieder neue Herausforderungen zum Sprachelernen, aber es kommen insgesamt - im Vergleich zur schulischen Lernumwelt - noch zu wenige Lernhilfen. Erfolgreiches informelles Lernen hängt aber - laut Watkins und Marsick - nicht nur von der Qualität der zugrundeliegenden Aktivität, Reflexion und Kreativität der Lernenden, sondern auch vom Anregungs- und Unterstützungspotential ihrer Umwelt ab.

Diese Umwelt wird hier als eine Lehrperson definiert, die Migranten als Lernberater beim Sprachelernen unterstützt und sie zum eigenverantwortlichen Lernen animiert. Der Lehrer soll die Lerner - sowohl die Eltern als auch die Kinder - auf die Möglichkeiten und das Potenzial des ungesteuerten Spracherwerbs im informellen Kontext hinweisen. Sie müssen zum autonomen Lernen hingeführt und angeleitet werden. Die Verfahren müssen davor besprochen und ausprobiert werden, wobei der Lehrer die DaZ-Lerner als Moderator unterstützen und ihnen helfen muss. So auch mein Beispiel: Nach einem gewissen Training haben die Kursteilnehmer selbst entdeckt, dass sie durch das Studieren von Plakaten oder Überschriften im Bus, durch das Lesen der Werbung und Anzeigen oder durch das Anschauen von Lieblingsserien auch Deutsch lernen können.

Nur der Lerner kann erfolgreich lernen. Der Zweitsprachelerner muss wahrnehmen, dass er selbst für seinen Spracherwerb verantwortlich ist. Das Lernen ist dann besonders wirksam, wenn er selber aktiv an dem Lernprozess teilnimmt. Dafür muss er in erster Linie über den Spracherwerb und den eigenen Lernprozess reflektieren. Autonom lernt nur, wer offen und neugierig ist, wer Fragen hat, wer über das Erfahrene nachdenkt. Als Lerner muss man die Notwendigkeit der ständigen Übung akzeptieren und die Möglichkeiten nutzen, die Zielsprache funktional in verschiedenen Kommunikationssituationen einzusetzen (vgl. Ender 2007). Und dafür braucht man Anstöße von 
außen, z.B. im Unterricht. Bildung ist oft gerade dort drin, wo nicht Bildung draufsteht: Der Lerner muss sich dessen bewusst sein, dass er Sprache überall, in jedem Kontext, lernen kann. Er muss sich überlegen, was Sprachelernen bedeutet und dadurch über den eigenen Spracherwerb reflektieren. Ausschließlich grammatische Regeln zu lesen oder Vokabeln auswendig zu lernen ist nicht effektiv genug. Die Empfehlung ist, Phänomene des Deutschen zu entdecken und bewusst über die Regelmäßigkeiten auch im Alltag nachzudenken. Das Lernen von neueren sprachlichen Elementen sowie die Vernetzung und Integration sprachlichen Wissens, das mit Awareness begleitet wird, laufen schneller und effizienter ab (vgl. Edmondson 2002: 60). Anregungen dazu kann man „draußen“ beim Vorbeigehen an Läden, an einer Haltestelle oder im Wartezimmer beim Arzt bekommen. In diesem Kontext ist zu beachten, dass jeder Lehrer in Integrationskursen auf außerschulische Lernmöglichkeiten hinweisen oder diese in den Unterricht integrieren soll. Denn ein Integrationskurs dauert nur 600 Stunden, und danach können die Kursteilnehmer ihre sprachlichen Kompetenzen nur selbständig erweitern. Für den Lehrer heißt es, dass er im Integrationskurs auch Unterrichtsphasen einplanen soll, in denen die Kursteilnehmer über ihre individuellen Lernerfahrungen sprechen, ihr Wissen über das Sprachenlernen erweitern und eventuell modifizieren.

Lernen ist eingebunden in die Kultur der Lernenden und ihre Erfahrungen mit der Welt wie auch mit sich selbst als Individuum und sozialem Wesen in dieser Welt. Durch Reflexion über eigene Lerngewohnheiten und den Austausch über Lerntechniken kann eine Veränderung des Lernverhaltens bei Migranten angeregt werden. Eine bewusste und selbstkritische Einstellung zum eigenen Lernprozess, seine Überwachung und die kontinuierliche Beobachtung einzelner Lernschritte sind eine wichtige Voraussetzung für den Lernerfolg (vgl. Bimmel; Rampillon 2003: 22f.). Dabei sind jedoch die Vorlieben der Lerner zu beachten: Lesen ist z.B. nicht gleich Lesen. Wer keine literarischen Werke mag, kann genauso gut Sachtexte lesen und somit seine Deutschkenntnisse vertiefen.

Mit der Lernerorientierung und dem autonomen Lernen ist die Konzeption der Lernstrategien eng verbunden. Lerntechniken sind für den Lernenden Werkzeuge, die ihm helfen, den komplexen Spracherwerbsprozess in den Griff zu bekommen und den individuellen Lernprozess effizienter zu gestalten. Lern- und Arbeitsstrategien müssen aber vermittelt werden. Sie können mehr oder weniger bewusst bzw. unbewusst eingesetzt werden, und sie können sich von bewussten in automatisierte Verhaltensweisen wandeln. Für den Zweitsprachelerner ist es anfangs sinnvoll, bestimmte Strategien ganz bewusst anzuwenden, damit sie gelernt werden und deren Einsatz als sinnvoll verstanden wird. Die Herausbildung von direkt abrufbaren Verarbeitungsstrategien kann anschließend erst durch wiederholte Anwendung erreicht werden. So kann der Lehrer bestimmte Rituale im Unterricht entwickeln: z.B. regelmäßige Wörterbücherbenutzung, Nachschlagen in Lexika oder Anwendung von eigener Merkheften, um damit die Migranten an eine Art des eigenverantwortlichen Lernens zu gewöhnen. Es liegen Erfahrungen und Erkenntnisse vor, die die Lernenden und die Lehrenden kennen und sich im gegebenen Fall zu Nutze machen sollten. Dazu ist es aber notwendig, dass im Rahmen von Integrationskursen diese Erfahrungen und Einsichten diskutiert werden. Die 
Effizienz eines bestimmten Lernstils hängt lediglich von der Übereinstimmung zwischen Instruktionsmethode und Lernstil ab (vgl. Riemer 1997: 66f.). Schließlich muss jeder Lerner die für ihn günstigsten Lern- und Arbeitsstrategien selbst auswählen und diese in einer ihm nützlich erscheinenden Kombination einsetzen.

Die Professionalität der Lehrkräfte muss nach solchem Lernverständnis weiter gefasst werden: Systematische Anleitung und individuelle Beratung gehören zusammen. Eine zentrale Kompetenz für professionelle Unterstützungen des informellen Lernens ist die didaktische Sensibilität, Phantasie und Kreativität, um die Lernbedürfnisse und Lerninteressen der Migranten in ihrem Alltag aufzuspüren und sie dann zum autonomen Lernen anzuregen.

\section{Literatur}

Apeltauer, E. (1987): Einführung in den gesteuerten Zweitspracherwerb. In: Ders. (Hrsg.): Gesteuerter Zweitspracherwerb. Voraussetzungen und Konsequenzen für den Unterricht. Max Hueber, 9-50.

Auernheimer, G. (2003): Einführung in die Interkulturelle Pädagogik. Darmstadt: Wissenschaftliche Buchgesellschaft.

Bimmel, P.; Rampillon, U. (2003): Lernerautonomie und Lernstrategien. Fernstudieneinheit 23. Berlin: Langenscheidt.

Butzkamm, W. (2002): Psycholinguistik des Fremdsprachenunterrichts. Tübingen: Francke.

Cross, J. (2003): Informal Learning - the other 80\%. Internet Time Group, http:// www.internettime.com/Learning/The \%20Other\%2080\%25.htm.

Dohmen G. (2001): Das informelle Lernen - Die internationale Erschließung einer bisher vernachlässigten Grundform menschlichen Lernens für das lebenslange Lernen aller. http:/ / www.bmbf. $\mathrm{de} / \mathrm{pub} / \mathrm{das}$ informelle_lernen.pdf.

Edmondson, W. (2002): Wissen, Können, Lernen - kognitive Verarbeitung und Grammatikentwicklung. In: Börner, W.; Vogel, K. (Hrsg.): Grammatik und Fremdsprachenerwerb. Tübingen: Gunter Narr, 51-70

Edmondson, W.; House, J. (1997): Zur Einführung in den Themenschwerpunkt. Language Awerness. In: Fremdsprachen Lehren und Lernen (FLuL) 26, 3-8.

Ender, A. (2007): Wortschatzerwerb und Strategieneinsatz bei mehrsprachigen Lernenden. Baltmannsweiler: Schneider Verlag Hohengehren.

Europäische Kommission (2001): Mitteilung der Kommission: Einen europäischen Raum des Lebenslangen Lernens schaffen. Brüssel.

Gotowos, A. (1981): Was macht die Gastarbeiterkinder zu Ausländern? In: Essinger, H.; Hellmich, A.; Hoff, G. (Hrsg.): Ausländerkinder im Konflikt. Königstein: Athenäum, 72-74.

Grotjahn, R. (1997): Strategiewissen und Strategiegebrauch. Das Informationsverarbeitungsparadigma als Metatheorie der L2-Strategieforschung. In: Rampillon, U.; Zimmermann, G. (Hrsg.): Strategien und Techniken beim Erwerb fremder Sprachen. Ismaning: Hueber, 33-74. 
Grotjahn, R. (2003): Lernstile/Lernertypen. In: Bausch, K.-R.; Christ, H.; Krumm, H.-J. 2003: Handbuch Fremdsprachenunterricht. Tübingen: Francke, 326-331

Lamnek, S. (2001a): Beobachtung. In: Hug, Theo (Hrsg.): Wie kommt Wissenschaft zu Wissen: Einführung in die Forschungsmethodik und Forschungspraxis. Band 2. Baltmannsweiler: Schneider Verlag Hohengehren, 265-281.

Lamnek, S. (2001b): Befragung. In: Hug, Theo (Hrsg.): Wie kommt Wissenschaft zu Wissen? Einführung in die Forschungsmethodik und Forschungspraxis. Band 2. Baltmannsweiler: Schneider Verlag Hohengehren, 282-302.

Lamnek, S.: (2005): Qualitative Sozialforschung. Lehrbuch. Basel: Beltz.

Ohm, U. (2004): Zum Zweitsprachenerwerb von wirklichen Menschen im richtigen Lernen. In: Deutsch als Zweitsprache 4, 47-64.

Ossner, J. (2006): Sprachdidaktik Deutsch. Eine Einführung. Paderborn: Schöningh.

Rampillon, U. (1991): Fremdsprachen lernen - gewusst wie. Überlegungen zum Verständnis und zur Vermittlung von Lernstrategien und Lerntechniken. In: Der fremdsprachliche Unterricht 2, 2-9.

Riemer, C. (1997): Individuelle Unterschiede im Fremdsprachenerwerb. Eine Longtudinalstudie über die Wechselwirksamkeit ausgewählter Einflussfaktoren. Baltmannsweiler: Schneider Verlag Hohengehren.

Roos, J. (1996): Selbststudium und Klassenunterricht. Vermittlung von Lern- und Arbeitstechniken. In: Materialien Deutsch als Fremdsprache 42, 29-33.

Rost-Roth, M. (2005): „Mütterkurse“: Förderung pragmatischer Kompetenzen in Deutschkursen für Frauen mit Migrationshintergund. Lernvoraussetzungen und Kommunikationsbedürfnisse. In: Materialien Deutsch als Fremdsprache 74, 129-154.

Trommsdorff, G. (1989): Sozialisation und Werthaltungen im Kulturvergleich. In: Trommsdorff, Gisela et al. (Hrsg.): Sozialisation im Kulturvergleich. Stuttgart: Ferdinand Enke, 97-121.

Wagner, E.; Schmidke, H.P. (1983): Ausländische Schüler - Konflikte, Störungen und soziales Lernen. Tübingen: Institut für Fernstudien.

Watkins, K.; Marsick, V. (1992): Towards a theory of informal and incidental learning. In: International Journal of Lifelong Education 4/11, 287-300.

Wölbert, G. (2001): „Warum können die nicht besser Deutsch?“ Zweitspracherwerb und Integration aus der Deutschkurs-Praxis gesehen. In: Deutsch als Zweitsprache Extraheft, 40-45. 
Christoph Chlosta, Matthias Jung (Hrsg.) (2010):

DaF intergriert: Literatur - Medien - Ausbildung. Tagungsband der

36. Jahrestagung des Fachverbandes Deutsch als Fremdsprache 2008.

Göttingen: Universitätsverlag, 363-368.

\section{Petra Szablewski-Çavuş (Hamburg)}

\section{Qualität im berufsbezogenen Deutsch als Zweitsprache-Unterricht. Kriterien und Umsetzungsstrategien}

\section{Einleitung}

Deutsch in beruflicher Bildung und am Arbeitsplatz bildet für die Mehrheit der hier lebenden Migrantinnen und Migranten nach wie vor eine schwer zu überwindende Hürde beim Einstieg in den Arbeitsmarkt und der Teilnahme an beruflicher Qualifizierung. Veränderungen in der Arbeitsorganisation haben ständig steigende Anforderungen in Bezug auf zweitsprachliche kommunikative Kompetenzen am Arbeitsplatz zur Folge. Die Vermittlung von berufsbezogenem Deutsch und einer angemessenen zweitsprachlichen Kompetenz am Arbeitsplatz ist daher über den rein fachsprachlichen Deutschunterricht hinaus zu einem wichtigen Bestandteil in der beruflichen Bildung und Weiterbildung mit Migrant/innen geworden. Heterogene Zielvorgaben erschweren jedoch die Konzept- und Materialerstellung. Darüber hinaus erfordern unterschiedliche Berufsfelder und Arbeitsbereiche weitere Differenzierungen.

Das Konzept des berufsbezogenen Deutsch-als-Zweitsprache (DaZ)-Unterrichts, das hier zugrunde gelegt wird, greift die besonderen Anforderungen der beruflichen Weiterbildung insbesondere im Hinblick auf die Verbesserung der Kommunikation in und für Betriebe auf, die sich aus den Veränderungen der Arbeitsabläufe ergeben. Für einen qualitativ angemessenen Unterricht sind nicht nur neue Methoden umzusetzen, erforderlich ist insbesondere auch ein Perspektivenwechsel: 
Die Verantwortung für die Verbesserung der betrieblichen Kommunikation kann nicht allein den betroffenen Migranten und Migrantinnen übertragen werden; vielmehr tragen alle Akteure der Arbeitsmarktpolitik und der beruflichen Weiterbildung ihren Teil der Verantwortung in diesem Prozess und sie sind bei der Entwicklung und Umsetzung des Konzepts - mit ihren jeweiligen besonderen Expertisen - einzubeziehen:

- Arbeitgeber/innen sind gefordert, in die Qualifikation aller Beschäftigten (also auch in die, die auf prekären Arbeitsplätzen arbeiten und die über einen Migrationshintergrund verfügen) zu investieren und Qualifizierungsmaßnahmen zur Entwicklung kommunikativer Fertigkeiten (z.T.) in bezahlter Arbeitszeit durchzuführen.

- Die Öffentliche Hand ist gefordert, Anreize und Unterstützung - auch finanzieller Art - für Weiterbildungseinrichtungen und ggf. auch für Unternehmen zu bieten, um Impulse für die Entwicklung entsprechender Konzepte und Weiterbildungsangebote zu geben und um dazu beizutragen, dass solche Angebote entwickelt werden, die den Anforderungen und Voraussetzungen der Lernenden und denen der Arbeitswelt entsprechen. Ausdrücklich gefordert ist die Öffentliche Hand bezüglich der Migrantinnen und Migranten, die (noch) nicht oder nicht mehr arbeiten und die auf die Integration in den deutschen Arbeitsmarkt vorbereitet werden müssen.

- Betriebsräte und Gewerkschaften sind gefordert, das Augenmerk von Arbeitgeber/ innen und Kolleg/innen verstärkt auf die kommunikativen Abläufe im Betrieb zu richten, insbesondere im Hinblick auf die Teilhabe von Migranten und Migrantinnen, und z.B. gezielt die Durchführung von Schulungsangeboten anzuregen, die dazu beitragen können, dass Migrantinnen und Migranten sich aktiver an der betrieblichen und berufsfachlichen Kommunikation beteiligen können.

- Die betroffenen Arbeitnehmer/innen sind gefordert, sich auf neue Lernprozesse einzulassen und selbst in ihre Weiterbildung zu investieren (z.B. Lernanstrengungen und Zeit).

Um diesen Anforderungen gerecht zu werden, müssen alle Akteure bereit und fähig sein, sich mit den jeweils anderen Perspektiven fundiert auseinanderzusetzen, d.h. sie müssen auch eine gemeinsame Diskussionsbasis finden. Genau hierzu wollen die „Qualitätskriterien zum berufsbezogenen Deutschunterricht" beitragen, sie sollen eine Grundlage bieten, um allen Akteuren Kriterien - und eine Struktur für diese Kriterien - an die Hand zu geben, mit denen sie - jeder mit seinen jeweiligen konkreten Teilzielen - sich darüber verständigen können, was sie gemeinsam erreichen wollen, was dazu erforderlich ist und wie die Umsetzung gestaltet werden kann/muss.

Die Qualitätskriterien wurden vom Facharbeitskreis „Berufsbezogenes Deutsch“1 erarbeitet und richten sich in erster Linie

\footnotetext{
Der Facharbeitskreis „Berufsbezogenes Deutsch“ im bundesweiten Informations- und Beratungsnetzwerk „Integration durch Qualifizierung (IQ)“ wird durch das Bundesministerium für Arbeit und Soziales und die Bundesagentur für Arbeit gefördert. Koordiniert wird der Facharbeitskreis im Rahmen des Kompetenzzentrums NOBI - Norddeutsches Netzwerk zur beruflichen Integration von Migrantinnen und Migranten - von der Koordinierungsstelle „Berufsbezogenes Deutsch“ bei der passage gGmbH in Hamburg.
} 
- an die Organe der Öffentlichen Hand als Entscheidungshilfe bei der Förderung von Kursen im Rahmen von „Sprache und Beruf“,

- an Weiterbildungsträger und Betriebe, die Konzepte zum berufsbezogenen Deutschunterricht entwickeln und umsetzen,

- an die Fachöffentlichkeit als Grundlage für den (praktischen und theoretischen) Diskurs, welche Faktoren auf die Qualität von berufsbezogenem Deutschunterricht einwirken.

Hervorzuheben ist, dass der Facharbeitskreis für die Qualitätskriterien als Leitlinien übergeordnete Ziele für den Unterricht und für die Umsetzung dieser Ziele definierte:

- Der Unterricht soll zur Stärkung des Bewusstseins über eigene berufliche Kompetenzen (Empowerment) der Lernenden beitragen; dies erfordert, dass die bereits erbrachten Lebensleistungen der Teilnehmer/innen Anerkennung finden und in den Lernprozess eingebunden werden, dass also die „gesamte“ Person in das Unterrichtsgeschehen einbezogen ist. Von einem ganzheitlichen Ansatz auszugehen bedeutet konkret, dass nicht „,nur“ die offensichtlich am Arbeitsmarkt verwertbaren Kompetenzen und Schwierigkeiten aufgegriffen werden, sondern auch die Fähigkeiten, deren Verwertbarkeit für den Arbeitsmarkt (noch) nicht genutzt wurden (z.B. Mehrsprachigkeit oder die bereits erworbene Kompetenz im Umgang mit verschiedenen Kulturen). Des Weiteren beinhaltet Empowerment auch explizit die Reflexion über die eigenen Stärken und Fähigkeiten. Der Unterricht ist insofern auch explizit als Bestandteil einer begleitenden Beratung (Coaching) und Kompetenzfeststellung (Profiling) zur Qualifizierung sowie der Stellensuche vor dem Hintergrund der eigenen Fähigkeiten auszugestalten.

- Ein wesentliches Ziel des Unterrichts ist in der Stärkung bzw. Entwicklung der Fähigkeiten zum eigenständigen Lernen zu setzen. Hierfür sind z.B. im Unterricht Lern- und Kommunikationsstrategien zu erarbeiten, um auch außerhalb des Unterrichts die deutschsprachlichen kommunikativen Fertigkeiten weiterhin zu verbessern. Des Weiteren impliziert dieses Ziel die Vermittlung von a) Faktenwissen (z.B. über Formen der Arbeitsorganisation, über den Stellenwert von Verträgen, über den Aufbau von fachlichen und arbeitsplatzbezogenen Texten).

b) Recherchetechniken/Informationsstrategien: Wo kann ich mir welche Informationen holen? Wen kann ich befragen? Welche Hinweise helfen mir weiter?

c) Diskursstrategien: Was kann ich machen, wenn ich etwas nicht verstehe (Texte, Formulare, Anträge etc.)?

- Der „,berufsbezogene Deutschunterricht“ ist daraufhin auszurichten, dass die kommunikativen Anforderungen im Arbeitsleben (deutsch-)sprachlich besser bewältigt werden. Vor allem aus diesem Grunde ist es wichtig, die fachlichen und sprachlichen Anteile der beruflichen Kommunikation im Unterricht miteinander zu verzahnen: Berufsbezogene Deutschkurse sind immer auch mit fachlicher Qualifizierung/mit der Vermittlung von fachlichen Inhalten verbunden. 
Ziel der Qualitätskriterien ist es, die Anforderungen, die an den berufsbezogenen Deutschunterricht aus fachlich/pädagogischer Sicht bestehen, strukturiert und detailliert vorzustellen. Die Kriterien bieten also keine Auflistung von Standards und auch keine Handlungsempfehlungen. Sie unterstützen aber mittelbar die Qualität der Konzepte und können und sollen dazu dienen, die Umsetzung von konkreten Unterrichtsangeboten zum berufsbezogenen Deutschunterricht den jeweiligen realen Zielen zweckentsprechend und qualitativ hochwertig zu planen, umzusetzen und zu evaluieren.

Berücksichtigt wird dabei, dass dem ,berufsbezogenen Deutschunterricht ${ }^{\text {“ }}$ in der Praxis faktisch sehr unterschiedliche Konzepte zugeordnet werden, z.B.:

- Kursangebote für arbeitslose und/oder arbeitssuchende Migrant/innen, die (noch) nicht über Berufs- oder Arbeitserfahrungen verfügen,

- Kursangebote für Arbeitslose oder Arbeitssuchende, die über Berufs- oder Arbeitserfahrungen in bestimmten Branchen bzw. Berufsbereichen oder über entsprechende Berufsqualifikationen verfügen,

- Kursangebote als „,innerbetriebliche Weiterbildung“ für Beschäftigte eines Betriebes,

- Kursangebote zur Vorbereitung auf eine Teilnahme an beruflichen Qualifizierungsmaßnahmen,

- Kursangebote, die parallel zu konkreten Qualifizierungsmaßnahmen und/oder Berufspraktika durchgeführt werden: Die „eigentlichen“ Qualifizierungsmaßnahmen richten sich meist unspezifisch sowohl an Deutsch-Muttersprachler/innen als auch an Migrant/innen.

Die Qualitätskriterien bieten eine systematische Hilfe, um die jeweiligen Anforderungen der verschiedenen Konzepte zielgerecht einzuschätzen. Voraussetzung hierbei ist, dass alle aufgeführten Kriterien zum berufsbezogenen Deutschunterricht bei den Planungen berücksichtigt werden. Allerdings können sich - aufgrund der Unterschiedlichkeit der Konzepte im Detail - auch verschiedene Folgerungen für die Umsetzung und vor allem auch hinsichtlich der Bedeutung der einzelnen Kriterien mit Blick auf die Zielsetzungen ergeben.

Im Einzelnen sind für die Planung, für die Begutachtung und für die Evaluation von Kurs- und Maßnahmekonzepten die Anforderungen für das konkrete Konzept näher einzuschätzen und zu begründen. Dabei greifen die Qualitätskriterien folgende Fragen detailliert auf:

\section{Zielsetzungen des berufsbezogenen Deutschunterrichts}

Beschrieben und begründet werden soll in erster Linie, welche übergeordneten Ziele das Konzept verfolgt und welche Schwerpunkte hier gesetzt werden. Zu begründen ist ggf. auch, warum für die konkrete Angebotsplanung einzelne Zielsetzungen, wie sie in den Qualitätskriterien genannt werden, nicht verfolgt werden und wie sich diese Entscheidung begründet. Des Weiteren können auch Zielsetzungen ergänzt werden, die in den Qualitätskriterien nicht genannt werden; was aber ebenfalls zu begründen ist. 


\section{Angebotsplanung/Konzeptentwicklung}

Die Planung und Umsetzung von konkreten Kursangeboten mit den jeweils unterschiedlichen Feinzielen erfordert im Vorfeld eine Recherche

- der Nachfrage nach entsprechenden Kursangeboten von Migranten und/oder Migrantinnen - u.a. mit Blick auf die eventuell anfallenden Kosten für den Besuch des Kurses,

- des Bedarfs für ein entsprechendes Kursangebot seitens öffentlicher oder privater Geldgeber.

Im Vorfeld der Angebotsplanung und während der Durchführung der Angebote ist eine Auswahl der Institutionen zu treffen und zu begründen, mit denen schwerpunktmäßig kooperiert werden muss. Erste Verabredungen zur Art der Kooperation sind zu schließen.

Grundsätzlich ist beim berufsorientierten Deutschunterricht eine Verbindung der sprachlichen Qualifizierung mit Praxisanteilen herzustellen. Für die jeweiligen konkreten Angebotsplanungen ist darzustellen und aus den Zielen zu begründen, welche gemeinsame Praxis hergestellt werden soll.

Bei der Angebotsplanung ist darzustellen und zu begründen, ob und ggf. in welchem Umfang Aktivitäten für die Teilnehmergewinnung eingeplant werden. Grundsätzlich ist zu beachten, dass - im Sinne eines erwachsenengerechten Lernens - die freiwillige Teilnahme eine Grundbedingung für erfolgreiches Lernen ist. Bei Zuweisungen der Teilnehmer/innen aufgrund rechtlicher Bestimmungen ist besonders darauf hinzuwirken und in der Angebotsplanung darzustellen, wie eine positive Annahme des Qualifizierungsangebots zumindest im Verlauf der Teilnahme gefördert wird.

Eine Evaluation des Angebots ist als wichtiger Bestandteil in die Konzeptentwicklung einzubeziehen. Bei der Angebotsentwicklung ist zu beschreiben und zu begründen, für welche der drei beteiligten Interessengruppen (Lernende, Weiterbildungsträger, Förderer) Evaluationen mit welchen Instrumenten und zu welchen Zeitpunkten durchgeführt werden und wie die Ergebnisse in zukünftige Angebote einfließen werden.

\section{Fachliche und formale Planung}

Die fachlich/inhaltlichen und formalen Strategien für die konkreten Kursangebote sind auf der Grundlage der ausformulierten Zielsetzungen und Angebotsplanung/Konzeptentwicklung und unter Zuhilfenahme der folgenden Kapitel in den Qualitätskriterien

- Didaktik/Methodik,

- Inhalte des berufsbezogenen Deutschunterrichts,

- Lehrmaterialien für den berufsbezogenen Deutschunterricht,

- Institutionelle Rahmenbedingungen,

zu präzisieren. Auch hier ist ggf. zu begründen, warum für das konkrete Angebot einzelne Grundüberlegungen, wie sie in den Qualitätskriterien genannt werden, vernachlässigbar sind und/oder warum welche ergänzenden Ansätze verfolgt werden. 
Die Qualitätskriterien liegen als gedruckte Boschüre vor:

Facharbeitskreis Berufsbezogenes Deutsch: Integration - Sprache - Arbeit. Qualitätskriterien für den berufsbezogenen Unterricht Deutsch als Zweitsprache und sind zu beziehen bei:

Koordinierungsstelle Deutsch am Arbeitsplatz, passage gGmbH, Migration und Internationale Zusammenarbeit, Nagelsweg 14, 20097 Hamburg oder unter

dialog@deutsch-am-arbeitsplatz.de;

und stehen als Download zur Verfügung unter

http://www.deutsch-am-arbeitsplatz.de/produkte.html. 
Christoph Chlosta, Matthias Jung (Hrsg.) (2010): DaF intergriert: Literatur - Medien - Ausbildung. Tagungsband der 36. Jahrestagung des Fachverbandes Deutsch als Fremdsprache 2008. Göttingen: Universitätsverlag, 369-377.

\section{Andrea Daase (Herford)}

\section{Integrationskurse - Was kommt danach?}

\section{Einleitung}

„Was kommt nach den Integrationskursen?“ - eine Fragestellung, die schon mit dem Titel über den Themenschwerpunkt hinausgeht. Wie komme ich auf diese Frage? Muss denn etwas danach kommen? Der Integrationskurs dient doch schließlich dem Erwerb ausreichender Deutschkenntnisse sowie der Vermittlung von Alltagswissen, Kenntnissen der Rechtsordnung, der Kultur, der Geschichte in Deutschland und vielem mehr. Was ausreichende Kenntnisse der deutschen Sprache sind, verrät uns das Zuwanderungsgesetz auch, denn die Überprüfung der ausreichendenden Deutschkenntnisse geschieht mit der Prüfung Zertifikat Deutsch auf dem Niveau B1 des Gemeinsamen Europäischen Referenzrahmen für Sprache (GER).

Allerdings stand schon 2005 in einem Papier der Bundesregierung, dass die Integrationskurse ein „Grundbaustein der Integration in Deutschland“" seien und Hans Barkowski sagte auf der FaDaF-Tagung Integrationskurse im November 2007 in Berlin: „Integrationskurse sind nicht mehr als eine Erstversorgung. [...] Integration ist auch mit 900 Stunden nicht zu haben“.

Weder einen Grundbaustein noch eine Erstversorgung kann man mit ,,ausreichend“ beschreiben. Wer hört beim Hausbau schon mit dem Grundstein auf? Uns allen ist klar, dass die Integrationskurse alleine noch keine Integration bewirken, dass es keinen direkten Weg vom Deutschkurs zur Integration der Zuwanderer in unsere Gesellschaft gibt, wie Hans-Jürgen Krumm es formulierte, auch wenn eine Grafik aus der Anfangszeit der Integrationskurse dies gerne suggerieren möchte (Abb. 1). 


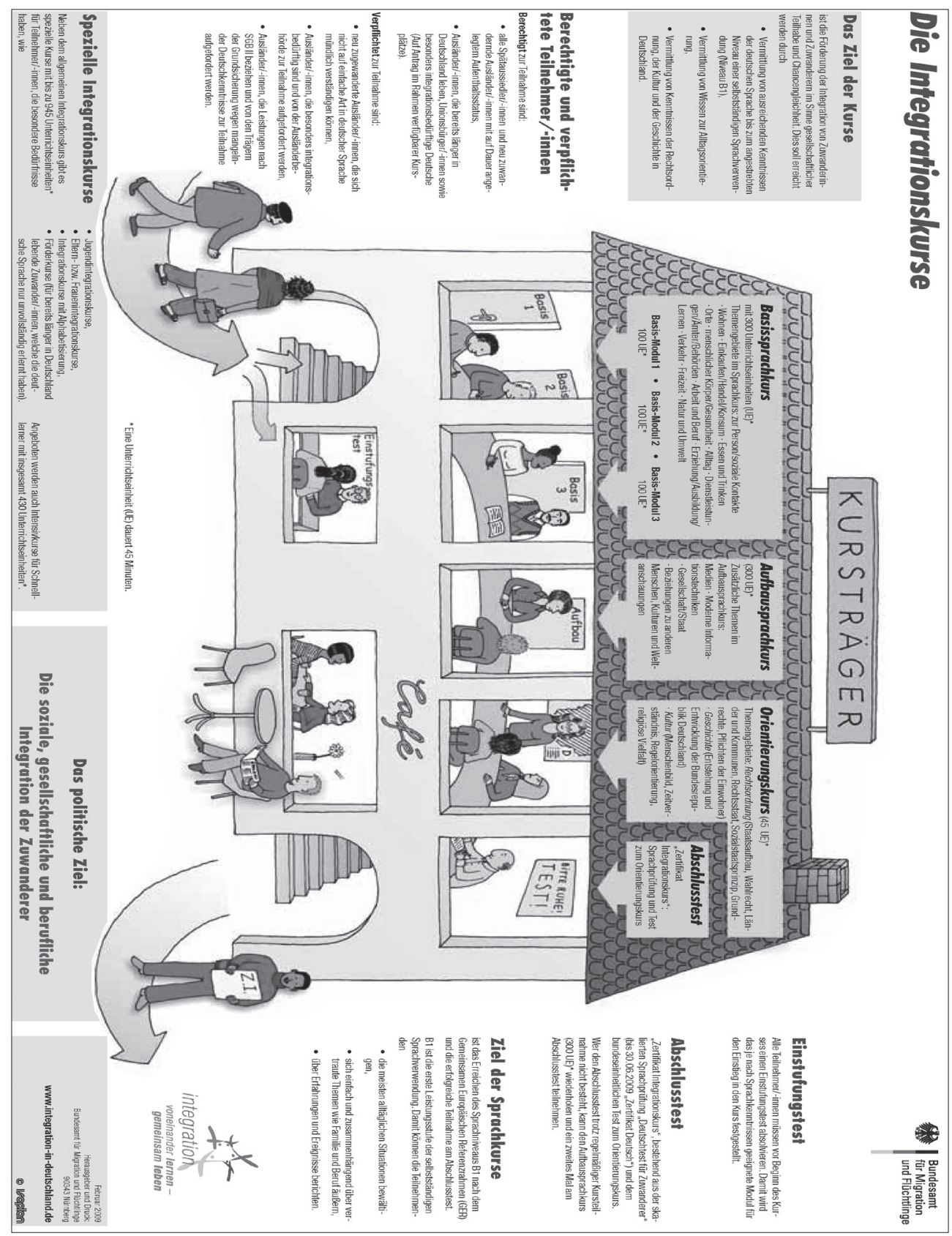

Abb. 1: Grafik zum Integrationskurs; Quelle: http://www.integration-in-deutschland.de/ cln_101/SharedDocs/Anlagen/DE/Integration/Downloads/Integrationskurse/Lehrkraefte/ grafik-zum-integrationskurs-pdf_IP,templateId=raw,property=publicationFile.pdf $/$ grafikzum-integrationskurs-pdf_IP.pdf 
Die ZuwanderInnen steigen in die Integrationskurse ein, durchlaufen diese und am Ende, nach der erfolgreichen Ablegung der B1-Prüfung steht die soziale und berufliche Integration der Zuwanderer - so verheißt die Grafik. Die Realität sieht - wie wir alle wissen - allerdings anders aus.

\section{Deutschkenntnisse alleine bewirken noch keine Integration}

Für eine erfolgreiche Integration von Migrantinnen und Migranten sind Deutschkenntnisse eine wichtige Voraussetzung; allerdings kann Integration nicht auf den Spracherwerb verkürzt werden: „Deutschkenntnisse sind kein „Synonym“ für Integration, sondern nur Teil der Integration und manchmal nicht einmal der wichtigste" (Clalüna 2008).

Verfolgt man allerdings das Thema Integration in den Medien, so erscheint das Erlernen der deutschen Sprache als Allheilmittel, nicht selten wird Integration mit dem Deutschwerb gleichgesetzt. Dass beide Seiten - Zugewanderte sowie die Aufnahmegesellschaft - weitaus mehr investieren und beitragen müssen, bleibt häufig außer Acht: „Integration gelingt nur, wenn neben die Sprachförderung auch eine gleichrangige Förderung der sozialen und beruflichen Eingliederung tritt und MigrantInnen von Anfang an Gelegenheit zur Teilhabe an der Gesellschaft des Aufnahmelandes erhalten“" (Trinationales ExpertInnenforum Sprache und Integration 2006). Dies setzt natürlich die Bereitschaft der Aufnahmegesellschaft dazu voraus. Insbesondere für eine Integration in den Arbeitsmarkt reichen Angebote zur Förderung der Kenntnisse in der Zweitsprache Deutsch nicht aus, zumal wenn sie nur bis zum Niveau B1 führen.

\section{Deutschkenntnisse für den Arbeitsmarkt}

Zu Beginn der Migration nach Deutschland wurden überwiegend Arbeitskräfte für Stellen gesucht, für die keine deutschsprachliche Qualifizierung (und häufig auch keine fachliche) gefordert wurden. Heute hingegen finden sich in Stellenanzeigen auch zu „einfachen“ Tätigkeiten die deutlich ausgesprochene und oft alleinig aufgeführte Zugangsqualifikation „Beherrschen der deutschen Sprache“, meistens mit dem Zusatz „,in Wort und Schrift“. Ein Arbeitsplatzangebot für Menschen ohne bzw. mit geringen Deutschkenntnissen ist heutzutage kaum noch vorhanden.

Veränderungen in der Arbeitsorganisation erhöhen die Anforderungen an die kommunikativen Fähigkeiten und damit an die Deutschkenntnisse - und dies gilt bei weitem nicht nur für die Managerebene: „Die veränderten Anforderungen an Kommunikation greifen heute fast auf jedes Berufsbild, auf jeden Arbeitsplatz über und sie wirken sich nicht zuletzt auch auf den Bedarf an Fort- und Weiterbildung aus." (Szablewski-Çavuş 2008: 38). In nahezu jedem Beruf, auf jedem Arbeitsplatz ist es heutzutage unausweichlich, sich mitteilen und verhandeln zu können. Untersuchungen haben gezeigt, „dass neben Allgemein- und Fachsprache eine Art Arbeitssprache beschrieben sowie gelehrt und gelernt werden kann, die sowohl branchen- und betriebsspezifische Aspekte hat als auch übergreifende gemeinsame Charakteristika“" (Grünhage-Monetti; Klepp 2004: 17). 
Die Integrationskurse können diesen Bedarf an berufs-, arbeits-, ausbildungs- und qualifizierungsspezifischer Kommunikation nicht decken. Ihr Ziel, das Bestehen der Abschlussprüfung auf dem Niveau B1, erreichen zum einen bei weitem nicht alle Teilnehmenden - und daran ändert auch die Möglichkeit der Wiederholung der 300 Stunden Aufbaukurs nicht viel -, andererseits reicht es auch für die kommunikativen Anforderungen vieler Arbeitsplätze nicht aus. Viel wichtiger aber ist, dass die Integrationskurse reine Deutsch-Sprachkurse sind, die sich gegen Ende stark auf die Prüfungsvorbereitung konzentrieren. Zeit, um sich mit berufsspezifischen Inhalten, arbeitsmarktlichen Anforderungen, Kommunikationsstrategien (um nur einige wichtige Elemente berufsbezogenen Deutschs zu nennen) zu beschäftigen, bleibt kaum.

Es ist aber erwiesen, dass es weit mehr braucht als die Förderung der Kenntnisse in der Zweitsprache Deutsch, um die Chancen für Menschen mit Migrationshintergrund auf dem und für den Arbeitsmarkt in Deutschland zu erhöhen. Hier sind spezielle Angebote, zugeschnitten auf die unterschiedlichen Zielgruppen, mit einem klaren Arbeitsmarktbezug notwendig - wie sie z.B. im Kreis Herford seit vielen Jahren durchgeführt werden. Solche Angebote gibt es (noch - dazu später mehr) bundesweit an vielen Orten, das Rad wurde im Kreis Herford nicht neu erfunden. Dennoch ist das im Folgenden beschriebene Projekt insofern herausragend, als eine Koordinierungsstelle für die Förderung von arbeitsmarkbezogenen Deutschkenntnissen für Personen im SGB II eingerichtet und über die letzten sechs Jahre hinweg an einem einzigartigen Netzwerk gearbeitet sowie in diesem die berufsbezogene Deutschförderung fortwährend weiterentwickelt wurde.

\section{Praxisbeispiel Kreis Herford}

\subsection{Fallmanagement Arbeit \& Sprache}

In Anlehnung an die Entwicklungen in der Arbeitsmarktpolitik wurde im Kreis Herford das „Fallmanagement Arbeit \& Sprache“ als der Dreh- und Angelpunkt sowie Überbau eines umfassenden modularen Gesamtansatzes zur arbeitsmarktbezogenen Deutschförderung bzw. sprachlich unterstützten Arbeitsmarktintegration für Personen im Bezug von Arbeitslosengeld II entwickelt. Die Stelle fungiert als Koordinierungsstelle eines engen Netzwerkes und verbindet das Instrument Case Management innovativ mit der Förderung in der Zweitsprache Deutsch und der Arbeitsmarktintegration.

Das bis Ende 2008 noch durch den Europäischen Sozialfonds (ESF) kofinanzierte Projekt „Fallmanagement Arbeit \& Sprache“ besteht seit 2003, zu Beginn firmierte es noch unter anderem Namen. Außer 2007 lief es immer über Mittel des ESF und des Landes Nordrhein-Westfalen, im Jahr 2007 wurde es komplett aus Mitteln der ARGE (Arbeitsgemeinschaft für Arbeit) Herford finanziert, was den Stellenwert dieses Projektes innerhalb der ARGE verdeutlicht. Die Grundidee war von Anfang an, sinnvolle, lern- und arbeitsfähige Gruppen für die Deutschförderkurse zusammenzustellen und so teilnehmer- und bedarfsorientierte Angebote machen zu können. Das Projekt und die Kurse selbst wurden in den letzten Jahren permanent weiterentwickelt, verbessert und ausgeweitet. 
Die FallmanagerInnen und ArbeitsvermittlerInnen der ARGE nennen dem „Fallmanagement Arbeit \& Sprache“ alle Personen, von denen sie glauben, dass die Deutschkenntnisse noch nicht ausreichen, um eine ihren Qualifikationen und Fähigkeiten entsprechende Arbeit oder eine Ausbildung in Deutschland aufnehmen zu können. Die Kundinnen und Kunden werden dann zentral hinsichtlich ihrer Deutschkenntnisse, aber auch ihres Bildungshintergrundes, Berufswünschen etc. getestet (Gespräch und schriftlicher Test). Ebenso wird geprüft, ob sie für einen Integrationskurs in Frage kommen bzw. die Berechtigung oder Verpflichtung dafür haben. Auf der Grundlage des Gespräches sowie des schriftlichen Tests erfolgt die Einstufung in einen der Kurse.

Es gibt eine enge Zusammenarbeit zwischen dem Fallmanagement Arbeit \& Sprache, den Deutschförderungs- und Weiterbildungsträgern, den regional tätigen Beratungsstellen sowie den BeraterInnen der ARGE Herford. Dies ermöglicht eine teilnehmerorientierte Förderung und im Einzelfall schnelle und individuelle Entscheidungen. So kann es zum Beispiel vorkommen, dass bei bestimmten Anliegen oder Problemen der Berater der ARGE zum Kunden in den Deutschkurs kommt, um dort ein Gespräch, ggf. auch zusammen mit der Lehrkraft, zu führen, oder die sozialpädagogische Begleitung kommt in die ARGE, um mit dem Berater und dem jeweiligen Kunden gemeinsam zu überlegen, wie es beruflich weitergehen kann.

\subsection{Differenziertes Kurssystem}

Die Deutschkurse mit Arbeitsmarktbezug dauern zwischen sechs und zehn Monaten, schließen ein Praktikum auf dem ersten Arbeitsmarkt und z.T. eine berufsspezifische fachpraktische Qualifizierung sowie eine sozialpädagogische Begleitung mit ein und werden in Gruppen von zwölf Personen durchgeführt. Ziel ist immer die Stärkung der Qualifizierungs- und Beschäftigungsfähigkeit (unterstützt durch spezifische Kursinhalte, Abbau von Vermittlungshindernissen, Hilfe bei der Anerkennung von Abschlüssen und aktuellen Bewerbungen) verbunden mit der Stärkung und Erweiterung der kommunikativen Handlungsfähigkeit der Teilnehmenden in der Zweitsprache Deutsch.

Unterschieden werden die beiden Kursarten „Arbeit \& Sprache“ und „Arbeitsmarktorientierte Deutschkurse“. Erstere sind auf ein bestimmtes Berufsfeld ausgerichtet und schließen eine fachpraktische Qualifizierung mit ein, letztere sind berufsfeldübergreifend. Weitere Module neben der allgemeinen und berufsbezogenen Deutschförderung und der fachpraktischen Qualifizierung sind z.B. Bewerbungstraining, PC-Training, das Praktikum mit Vor- und Nachbereitung, Kompetenzcheck, Berufswegeplanung etc.

Wichtig ist, dass die einzelnen Module der Kurse nicht getrennt voneinander laufen, sondern eng miteinander verzahnt sind. So findet z.B. ein Teil des Unterrichts als Teamteaching statt: die Sprachlehrkraft ist z.B. auch immer wieder in der Werkstatt mit anwesend oder die sozialpädagogische Begleitung im Deutschunterricht. Ein erheblicher Teil des Unterrichts findet in Projektform statt. Es gibt Exkursionen, Betriebsbesuche und es werden auch immer wieder externe ReferentInnen in die Kurse eingeladen.

Hinzugefügt werden muss, dass nicht alle Personen zwangsläufig erst einen Integrationskurs und dann einen arbeitsmarktbezogenen Kurs durchlaufen. Die Entscheidung 
erfolgt immer im Einzelfall und vor allem unter Berücksichtigung der Wünsche der KundInnen. So gibt es zum Beispiel Personen, die ihre Deutschkenntnisse ungesteuert erworben haben, aber immer das Gefühl haben „falsch“ zu sprechen und unbedingt noch einmal die Grammatik ,,richtig“ lernen wollen oder für die z.B. die B1-Prüfung aus persönlichen oder aufenthaltsrechtlichen Gründen sehr wichtig ist. Diese Personen besuchen dann in der Regel erst einmal einen Integrationskurs.

Andere, die evtl. genauso gut oder schlecht sprechen, möchten eigentlich viel lieber arbeiten und nicht unbedingt an einem Deutschkurs teilnehmen. Mit einem Kurs, der eine fachpraktische Qualifizierung und ein Praktikum beinhaltet, können sie sich viel eher anfreunden als mit einem reinen Deutschkurs.

\subsection{Rahmencurriculum als Grundlage}

Seit März 2008 gibt es ein Rahmencurriculum, das die Inhalte und Ziele für alle Kurse festschreibt und die Grundlage der im Kreis Herford im Rahmen des SGB II organisierten Angebote ist, die die Förderung von Deutsch als Zweitsprache mit einem Arbeitsmarktbezug verbinden.

Es basiert auf neuesten Arbeiten und Entwicklungen in den Bezugswissenschaften sowie praktischen Arbeiten zum Thema, wie zum Beispiel der Arbeit der „Koordinierungsstelle Deutsch am Arbeitsplatz“ oder dem Rahmenkonzept „Arbeitsmarktorientierte Deutschförderung“ aus der Schweiz. Der Curriculumsbegriff, der ihm zugrunde liegt, ist ein weiter, das heißt, es wird beschrieben, wie, was und wozu gelehrt wird - und wer die handelnden Personen, also die Lernenden und Lehrenden sind. Es ist stark beeinflusst von der funktionalen Curriculumsdiskussion sowie von pragmatischen Überlegungen und orientiert sich an den Bedürfnissen der Lernenden. Es erhebt keinen Anspruch auf Vollständigkeit, sondern soll als ein offenes und lernendes Instrument verstanden werden.

Das Curriculum folgt den pädagogischen Vorgaben Teilnehmerorientierung, Handlungsorientierung und Bedarfsorientierung. Es geht von einer heterogenen Zielgruppe hinsichtlich mehrerer Merkmale aus, die bei der Unterrichtsplanung und -gestaltung zu berücksichtigen sind. Grundlage der Ziele und somit der Gestaltung des Unterrichts sind zum einen der Sprachbedarf im Alltag der Lernenden, insbesondere aber bei Stellensuche und im Berufs-, Ausbildungs- und Qualifizierungsalltag, zum andern das subjektive Sprachverwendungsbedürfnis der Teilnehmenden. Es muss immer wieder überprüft werden, was die Gruppe, was der/die Einzelne lernen möchte, leisten und erreichen kann, um dann eine bedarfsorientierte und möglichst passgenaue Förderung gewährleisten zu können

Auch mit diesem Rahmencurriculum und dem Schwerpunkt auf qualitativ hochwertiger Arbeit im Bereich der arbeitsmarktbezogenen Sprachförderung Deutsch als Zweitsprache ist der Kreis Herford sicher bundesweit einer der Vorreiter. 


\subsection{Fortbildungen für Lehrkräfte}

Das lebenslange Lernen, Fort- und Weiterbildung ist nicht nur für unsere Kundinnen und Kunden, sondern auch für die in diesem Projekt tätigen Mitarbeiter-/innen von immenser Wichtigkeit. Hierfür wird gemeinsam mit einigen Sprachschulen aus Bielefeld ein Fortbildungsprogramm mit passgenauen Workshops organisiert. Zum einen werden einschlägige Referentinnen und Referenten bzw. Trainer-/innen zu den von den Kursleitenden gewünschten Themen bzw. in der Arbeit auftauchenden Problemen eingeladen, zum anderen wird durch einen engen Austausch und Kooperation mit den umliegenden Kreisen und Städten das Angebot an Fortbildung und Austausch vergrößert und der regionalen fachlichen Erfahrungs- und Ideenaustausch verstärkt, nicht zuletzt um einen Transfer bewährter und erfolgreicher Konzepte zu ermöglichen sowie die Kommunikation und Vernetzung von Expertinnen und Experten auf eine größere Plattform zu stellen.

\section{4 Änderungen von Seiten des BMAS}

Am 11. April 2008 erschien die sogenannte Arbeitshilfe SWL im SGB II (das Sozialgesetzbuch II regelt den Hilfebezug für Personen, die Arbeitslosengeld II erhalten) des BMAS (Bundesministerium für Arbeit und Soziales). SWL steht für „sonstige weitere Leistungen“, ein Instrument im SGB II, über das im Kreis Herford und an vielen anderen Stellen im Bundesgebiet bisher die (berufsbezogene) Deutschförderung finanziert wurde. In dieser Arbeitshilfe steht zum einen, dass es sich bei diesem Instrument um eine Einzelfallförderung handelt und Projektförderung damit ausscheidet. Noch entscheidender aber ist für uns (und für viele andere auch), dass ab sofort jede Förderung der Zweitsprache Deutsch ausschließlich über das BAMF (Bundesamt für Migration und Flüchtlinge) läuft. Bezüglich der berufsbezogenen Sprachförderung wurde auf die ESFBAMF-Kurse verwiesen, die fortan verwendet werden sollten. Hierzu ist allerdings anzumerken, dass es diese Förderung bei Erscheinen der Arbeitshilfe noch gar nicht gab. Das bundesweite Ausschreibungsverfahren, bzw. die erste Phase zur Trägerauswahl, ist mittlerweile abgeschlossen. In einer zweiten Phase können konkrete Kurse beantragt werden, die voraussichtlich im ersten Quartal 2009 starten werden.

Diese Entscheidung sowie die beschriebenen Begleitumstände bedeutet eine Förderpause in diesem Arbeitsbereich von fast einem Jahr. Was dies für Projekte wie dem unseren sowie die in diesem Bereich tätigen Träger bedeutet, muss nicht weiter ausgeführt werden. Vor allem aber für die Teilnehmenden in Integrationskursen bedeutet dies, dass sie nach 600 oder 900 Stunden reiner Deutschförderung in den Integrationskursen keine Anschlussförderung erhalten. Im schlimmsten Fall, wenn noch keine persönlichen Kontakte zur Aufnahmegesellschaft bestehen, wie dies ja leider häufig der Fall ist, werden die bis dahin erworbenen Deutschkenntnisse wieder vergessen, weil die Anwendung, die Sprachpraxis fehlt.

Wenn 2009 die ESF-BAMF-Kurse dann bundesweit eingeführt werden, müssen zuvor zerschlagene Strukturen und Netzwerke wieder belebt werden, was sicher nicht immer möglich sein wird. Personen im Bezug von Arbeitslosengeld II, denen in diesem Jahr leider noch gesagt werden muss, dass es keine weitere Förderung für sie gibt, obwohl sie gerne weiterlernen möchten, werden dann wieder sozusagen ,aus der Versenkung ge- 
holt" - und wahrscheinlich zu einem berufsbezogenen Deutschkurs verpflichtet. - Die Frage, was daran politisch und didaktisch sinnvoll ist, ob der FaDaF Stellung beziehen kann und möchte oder das BAMF vielleicht einen Ausweg weiß - diese und weitere Fragen wurden auf der FaDaF-Tagung zumindest ansatzweise diskutiert.

\section{Aussicht}

Auf einer Fachtagung Deutsch als Fremdsprache bzw. im Tagungsband fällt ein solcher Beitrag sicher etwas aus dem Rahmen, ist er doch zum einen sehr praktisch, zum andern aber auch politisch motiviert. Doch die Fachwelt im Bereich Deutsch als Fremd- und Zweitsprache darf die Augen nicht vor solchen Entwicklungen, Ereignissen und Entscheidungen verschließen, tangieren sie doch direkt und indirekt das fachliche Arbeiten: „Das Fach DaZ steht wie kein anderes Sprachfach in einer Spannung zwischen fachlichen Positionen und politischen Entscheidungen." (Clalüna 2008).

Der Bereich Deutsch als Zweitsprache bekommt auf der FaDaF-Tagung einen immer größeren Stellenwert - in Zukunft ja vielleicht mit einem eigenen Themenschwerpunkt, der nicht auf die Integrationskurse beschränkt bleibt, oder mit einer eigenen Fachtagung, auf der Expertinnen und Experten (damit meine ich genauso jene aus der Wissenschaft wie jene aus der Praxis) neben fachlichen Diskussionen auch Stellung beziehen zu dem, was von politischer und verwaltungstechnischer Seite entschieden wird. Denn solche Entscheidungen sind selten fachlich motiviert und bedürfen m.E. klarer Statements aus der Fachwelt. Zu oft schon sind sie weitgehend unkommentiert hingenommen worden, Leidtragende waren immer die Lernenden und Lehrenden. Leidet aber aufgrund ungünstiger Rahmenbedingungen sowie Fehlentscheidungen die Qualität unserer Arbeit, werden für das schlechte Ergebnis die Lernenden und Lehrenden verantwortlich gemacht bzw. gerät der gesamte Bereich in die Kritik bei Politik, Verwaltung und in der Gesellschaft. An dieser Stelle müsste es auch im Interesse des Fachverbandes sein, die Verhältnisse gerade zu rücken.

\section{Literatur}

Bundesagentur für Arbeit (2007): Leistungen an erwerbsfähige Hilfebedürftige nach dem SGB II. Hinweise zu $\int 16$ Abs. 2 Satz 1 SGB II. Sonstige weitere Leistungen (SWL). Stand April 2008.

Bundesregierung (2005): Integrationsaktivitäten des Bundes. Bestandsaufnahme im Rahmen der Interministeriellen Arbeitsgruppe Integration. Stand 04.08.2005, http://www.bamf.de/ template/integration/anlagen/integrationsprogramm/integrationsaktivitaeten_ des_bundes.pdf (16.09.2005).

Bundesregierung (2007): Erste Verordnung zur Änderung der Integrationskursverordnung vom 05. Dezember 2007. http://www.bamf.de/template/integration/anlagen/integrationskurs/grundlagen/integrationskursverordnung.pdf (22.05.2008).

Clalüna, Monika (2008): Das Fach „Deutsch als Zweitsprache“ zwischen politischen Forderungen und fachlichen Positionen. http://www.isabern.ch/upload/pdf/Referat_Claluena.pdf (16.11.2008). 
Daase, Andrea (2008): Rahmencurriculum für die Arbeitsmark.torientierte Deutschförderung für Personen mit Migrationshintergrund im Rabmen des SGB II im Kreis Herford. http:/ / www. fallmanagement-arbeit-und-sprache.de/downloads/rahmencurriculumchancemaerz2007.pdf (16.11.2008).

Deeke, Axel (2007): „Sprachförderung allein greift häufig zu kurz." IAB-Kurzbericht, Nr. 3, 31.01.2007.

Grünhage-Monetti, Matilde; Klepp, Andreas (2004): Zweitsprache am Arbeitsplatz als Herausforderung für Integration und Partizipation. Europäische Perspektiven. In: Deutsch als Zweitsprache 1. Baltmannsweiler, 15-20.

Isoplan: AiD. Integration in Deutschland: Grafische Übersicht zum Integrationskurs. http://www. integration-in-deutschland.de/cln_101/nn_283828/SharedDocs/Anlagen/DE/Integration/Downloads/Integrationskurse/Kurstraeger/Sonstiges/grafische-uebersicht-integratio nskurs,templateId=raw,property=publicationFile.pdf/grafische-uebersicht-integrationskurs. $\operatorname{pdf}(30.11 .2008)$.

Krumm, Hans-Jürgen (2003): Integration durch Deutschlernen - ein falsches Versprechen? Vortrag auf der Tagung „LernRaum Wien“ am 24.10.2003, http:/ / www.sprachenrechte. at/cgi-bin/TCgi.cgi? target=home\&P_Txt=38 (16.11.2008).

Szablewski-Çavuş, Petra (2008): Deutsch als Zweitsprache: eine Schnittmenge der beruflichen Bildung. In: ÖDaF-Mitteilungen 1/2008, Berufssprache Fachsprache Unterrichtssprache Deutsch. Vermittlung von sprachlichen Fertigkeiten und kommunikativer Kompetenz, Wien, 37-46.

Szablewski-Çavuş, Petra (2005): Das Konzept „Deutsch am Arbeitsplatz". http://www. deutsch-am-arbeitsplatz.de (16.11.2008)

Trinationales ExpertInnenforum Sprache und Integration (2006): Spracherwerb fördern - Menschenrechte verwirklichen. Integration gelingt nicht mit Zwang und Sanktionen. Abschlusserklärung April 2006, http://www.dieuniversitaet-online.at/pdf/2006/TRI_Abschlusserklaerung.pdf (16.11.2008). 

Christoph Chlosta, Matthias Jung (Hrsg.) (2010):

DaF intergriert: Literatur - Medien - Ausbildung. Tagungsband der

32. Jahrestagung des Fachverbandes Deutsch als Fremdsprache 2008.

Göttingen: Universitätsverlag, 379-386.

\section{Silke Ghobeyshi (Ankara, Türkei)}

\section{SprachBarriere. \\ Eine Untersuchung unter Teilnehmern der Sprachprüfung nach $\ 30$, Abs. I, Nr. 2 AufenthaltG.}

\section{Einleitung}

„Nach der grundlegenden Reform des Aufenthaltsgesetzes müssen ausländische Ehepartner, die nach Deutschland ziehen möchten, schon bei der Beantragung des Visums im Heimatland einfache Deutschkenntnisse nachweisen. Der Grund: Sie sollen sich in Deutschland von Anfang an zumindest auf einfache Art auf Deutsch verständigen und am gesellschaftlichen Leben teilnehmen können. So soll nachziehenden Ehegatten der Einstieg in den Integrationskurs und damit auch die Integration in die deutsche Gesellschaft erleichtert werden. Ihre Startchancen werden dadurch verbessert.“ (Merkblatt zum Nachweis einfacher Deutschkenntnisse beim Ehegattennachzug der Deutschen Botschaft Ankara; Stand: Februar 2008)

Der zu Grunde liegende Paragraph \30, Abs. I, Nr. 2 des deutschen Aufenthaltsrechtes wurde in Deutschland lange und heftig diskutiert und hat die deutsch-türkischen Beziehungen belastet, unter anderem war die Gesetzesänderung der Grund für den Boykott türkischer Verbände bei dem von Angela Merkel initiierten so genannten „Deutschen Integrationsgipfel“ im Juli 2007. Insbesondere die Tatsache, dass Ehegatten von Ausländern mit der Staatsangehörigkeit von Australien, Israel, Japan, Kanada, Republik Korea, Neuseeland und den Vereinigten Staaten von dem Gesetz ausgenommen sind, wurde auf türkischer Seite als diskriminierend empfunden, was streckenweise zu Verzerrungen in der Debatte geführt hat. So wurde gerne übersehen, dass für die genannten Länder 
generell keine Visumspflicht für Deutschland besteht. Der Höhepunkt der Auseinandersetzung war die Darstellung Angela Merkels mit Hakenkreuz-Binde, eindeutigem Oberlippenbart und dem Schriftzug „Türken raus“ in der islamistischen türkischen Tageszeitung „Anadolu'da Vakit“ vom 2.9.2007 (einen Tag nach der Gesetzesunterzeichnung), die wiederum zu einer Protestnote von deutscher Seite geführt hat.

Im folgenden Beitrag soll dargestellt werden, wie die Sprachprüfungen zum Nachweis einfacher Sprachkenntnisse in Ankara durchgeführt und angenommen wurden - nachdem sich die politischen Wogen geglättet hatten.

\section{Die Sprachprüfung}

Den Nachweis einfacher Deutschkenntnisse erbringt man in der Türkei durch die Teilnahme an einer „Start Deutsch 1“-Prüfung, die von den drei Goethe-Instituten (GI) in Ankara, Istanbul und Izmir abgenommen wird. Je nach Wohnort wird man einem der drei Institute zugeteilt, Ankara hat die meisten Prüflinge (60 pro Tag, 300 pro Woche) und das GI Ankara musste für die Durchführung der „Start 1-Sprachprüfung“, die intern „Brautprüfung“ genannt wird, ein eigenes Prüfungszentrum einrichten, d.h. zusätzliche Räume anmieten.

Die „Start Deutsch 1“-Prüfung setzt Sprachkenntnisse auf der ersten Kompetenzstufe A1 des Europäischen Referenzrahmens voraus. Zur Erreichung dieser Stufe benötigt man - abhängig von Vorkenntnissen und Lernvoraussetzungen - 85 bis 170 Unterrichtseinheiten à 45 Minuten. Die Teilnahme an der Prüfung ist nicht an den Besuch eines Sprachkurses gebunden.

Die schriftlichen Prüfung (Dauer: ca. 65 Minuten) besteht aus den Teilprüfungen Hören, Lesen und Schreiben. Im Hören-Teil werden kurze Texte (Alltagsgespräche, öffentliche Durchsagen, private und öffentliche Telefonansagen) vorgespielt, die Prüfungsteilnehmer sollen daraus relevante Informationen entnehmen. Im Lesen-Teil werden kurze Texte gelesen (Notizen, Kleinanzeigen, Hinweisschilder, Aushänge) und wiederum relevante Informationen herausgesucht. Im Schreiben-Teil werden fehlende Daten in einem Formular ergänzt und eine kurze persönliche Mitteilung (Brief, E-Mail) nach Vorgabe von Leitpunkten geschrieben. Dazu an dieser Stelle ein Beispiel aus dem Übungssatz 02 von ,Start Deutsch 1“:

„Sie haben seit langem für Samstagnachmittag einen Termin mit Ihrem Nachbarn Christian. In Ihrer Firma gibt es aber ein Problem und Sie müssen auch am Samstag bis zum Abend arbeiten. Legen Sie ihm einen Zettel am Samstagmorgen unter die Tür und schreiben Sie:

- Entschuldigung und Erklärung

- Neuer Termin: Sonntagabend?

- Zusammen essen?

Schreiben Sie zu jedem Punkt ein bis zwei Sätze auf den Antwortbogen (ca. 30 Wörter). Vergessen Sie nicht den passenden Anfang und Gruß am Schluss.“ 
Die mündliche Gruppenprüfung (Dauer: ca. 15 Minuten) besteht aus drei Teilen, der persönlichen Vorstellung, dem Erfragen und Geben von Informationen und dem ÄuBern von und reagieren auf Bitten. Inwieweit die Prüfungsfragen der Lebenswirklichkeit der Probanden entsprechen, kann an dieser Stelle nicht diskutiert werden.

Für die Teilnahme an der Prüfung müssen die Teilnehmer eine Gebühr von derzeit 120 YTL (ca. 60 Euro) entrichten. Ein entsprechender Vorbereitungskurs mit einem Umfang von 180 UE würde beim GI Ankara 1.100 Y'TL (ca. 550 Euro) kosten; zum Zeitpunkt der Untersuchung fanden am GI Ankara drei solcher „Brautkurse“ mit jeweils 18 Teilnehmern statt.

\section{Die Untersuchung}

Die Untersuchung wurde in der 16. und 17. Kalenderwoche 2008 im Prüfungszentrum des GI Ankara auf der Grundlage von Fragebögen durchgeführt. ${ }^{1}$ Untersuchungssprache war Türkisch, jeder Fragebogen beinhaltete insgesamt 60 Fragen zur Person, zum Schulbesuch, zu Sprachlernerfahrungen, zu Einstellungen zu und Erfahrungen mit der Deutsch „Start 1“-Prüfung u.a. Anonymität wurde zugesichert. Die Fragebögen wurden von der Verfasserin erstellt und von Mitarbeitern des GI Ankara nach Ablegen der Prüfung ausgeteilt, zu einem Zeitpunkt, als die Prüflinge nicht mehr dem unmittelbaren Prüfungsdruck ausgesetzt waren und sich in einer Phase längeren Wartens auf das Prüfungsergebnis (das noch am selben Tag mitgeteilt wird) befinden.

Insgesamt wurden 307 Fragebögen ausgeteilt und eingesammelt, aus Gründen, die die Verfasserin zu verantworten hat, wurden für die Auswertung jedoch nur 150 zufällig ausgesuchte Fragebögen herangezogen. Ausgewertet wurde mit dem Statistik-Programm „GrafStat“, bei 150 mal 60 Fragen handelt es sich hier um 9.000 Einzeleingaben.

Die Idee der Untersuchung war es, mit Hilfe der Daten den sprachlerntheoretischen Ansatz zu untermauern, dass heranwachsende und erwachsene Lerner Schwierigkeiten mit dem Sprachenlernen haben, wenn keinerlei intrinsische Motivation messbar ist. Die Ergebnisse sind jedoch vollkommen anders ausgefallen als erwartet und ich stehe nun vor einem Datensatz, den ich nie haben wollte.

\section{Die Ergebnisse}

\subsection{Angaben zur Person}

84\% der Probanden sind verheiratet, 9,3\% verlobt, 6,7\% ledig. 88\% haben keine Kinder, 11\% haben mindestens ein Kind (keine Angabe: 1\%). Die Mehrheit der Probanden ist jung: 18,7\% sind 26-30 Jahre alt, 38\% - und damit die größte Gruppe - sind 21-25 Jahre alt und 26\% sind unter 21 Jahre alt. Der etwas spöttische Name „Brautprüfung“ ist nicht ganz berechtigt, denn immerhin 31,3\% der Prüflinge sind männlich. Das GI Ankara spricht diesbezüglich in öffentlichen Stellungnahmen von 30-40\%. Interessant ist hier die Korrelation zwischen Alter und Geschlecht: von den unter 21-Jährigen sind 6 männ-

1 Für die Möglichkeit der Erhebung und die produktive Zusammenarbeit danke ich dem derzeitigen Leiter der Sprachabteilung des GI Ankara, Herrn Günter Neuhaus. 
lichen und 33 weiblichen Geschlechts, in der Altersgruppe der 21 bis 25-Jährigen befinden sich 23 Männer und 34 Frauen (absolute Nennungen).

Die Herkunft der Prüfungsteilnehmer am GI Ankara ist zu großen Teilen der Südosten der Türkei sowie die Schwarzmeerstädte Trabzon, Samsun und Zonguldak. Weniger oft vertreten war die Gegend um die Städte Sivas, Erzurum, Diyarbakir. Diese Beobachtung führte zu der Arbeitshypothese, dass Menschen, die aus diesen bildungsstrukturell weniger erschlossenen Gebieten mit hoher Analphabetenquote stammen, von vornherein von der Prüfung ausgeschlossen und damit tatsächlich diskriminiert werden. Laut mündlichen Angaben der Deutschen Botschaft Ankara trifft dies jedoch nicht zu: gemäß den Statistiken der Visastelle werden aus den Städten Erzurum und Diyarbakir ohnehin vergleichsweise wenig Anträge auf ein Visum gestellt, eine Veränderung zu der Antragsquote vor der Gesetzesänderung soll hier nicht feststellbar gewesen sein. Die Verfasserin hatte aus juristischen und zeitlichen Gründen leider keine Möglichkeit, die Richtigkeit dieser Aussage zu überprüfen.

Genannt werden im Folgenden die Herkunftsstädte mit einer absoluten Nennung ab 5: Şanliurfa (5), Adana (5), Karaman (5), Kahramanmaraş (5), Mersin (6), Ankara (10), Trabzon (7), Aksaray (17), Konya (17) und, als Spitzenreiter, die aufstrebende Stadt im Grenzgebiet zu Syrien, Gaziantep (22).

\subsection{Angaben zu Ausbildung und Beruf}

Zu den Annahmen, die sich im Laufe der Auswertung als völlig falsch erwiesen haben, gehört das Bild von dem ungebildeten Mädchen vom Lande, das kaum lesen und schreiben kann und früh heiratet bzw. von den Eltern verheiratet wird. Zwar können und sollen zum letzteren Aspekt keine näheren Aussagen getroffen werden, zweifelsfrei festgestellt wurde jedoch: ungebildet sind die Prüfungsteilnehmer mehrheitlich nicht. Nur 20\% haben lediglich die (bis 1997 gültige) Schulpflicht von fünf Jahren hinter sich, 26\% haben die Mittelschule von acht Jahren besucht und knapp 45\% haben das türkische Gymnasium (Lise) mit elf Jahren und mehr Schulzeit absolviert und das entsprechende Abgangszeugnis. Die Mehrheit der Frauen hat mindestens die Mittelschule absolviert, 40\% von ihnen haben einen Gymnasialabschluss.

Das Abgangszeugnis des Gymnasiums (Lise Diplomasi) berechtigt in der Türkei nicht zur Aufnahme eines Hochschulstudiums. Hierzu muss man sich einer Zentralen Universitätsaufnahmeprüfung unterziehen, die einer sehr kosten- und zeitintensiven Vorbereitung bedarf. Nur knapp 11\% der Probanden gab an, über eine Hochschulbildung zu verfügen.

Der am meisten genannte Beruf war mit 56\% Hausfrau, insgesamt gaben 81,5\% der Frauen die türkische Entsprechung „ev hanım“ an. 34\% der Teilnehmer gaben an berufstätig zu sein, davon waren 80,8\% Männer und 12,6\% Frauen. Als arbeitslos stuften sich 6,4\% der Männer und 3,9\% der Frauen ein. Eine Überprüfung der Korrelation zwischen Beruf und Schulabschluss bestätigte, dass der Abschluss wohl eine Auswirkung auf die Berufstätigkeit hat (die absolute Mehrheit der Berufstätigen hat 
einen Gymnasialabschluss) nicht aber auf die Tätigkeit als Hausfrau. Will sagen: Frauen werden unabhängig vom Schulabschluss mehrheitlich Hausfrau.

\subsection{Angaben zu Erst- und Fremdsprachen}

94,6\% der Teilnehmer gab Türkisch als Muttersprache an, lediglich 4,7\% Kurdisch und nur $0,7 \%$ Arabisch. Sieht man sich die geografische Verteilung der Probanden an, so ist dieses Ergebnis kaum nachvollziehbar, eher scheint es so zu sein, dass es in der Türkei neben einer ausgeprägten Vaterlands- auch eine umfassende Muttersprachensemantik gibt. Ein Indiz für die Richtigkeit dieser Vermutung ist die Tatsache, dass mir in der Entstehungsphase des Fragebogens von sämtlichen türkischen Kollegen abgeraten wurde, die Antworten „Kurdisch“ oder „Arabisch“ als Antworten vorzugeben; Antworten dieser Art wurden folgerichtig immer handschriftlich unter , andere“ eingetragen.

Das Antwortverhalten auf die Frage nach dem Beherrschen von Fremdsprachen zeigt demgegenüber einen hohen Grad an Ehrlichkeit: Obwohl die Mehrheit in Mittelschule und Gymnasium Englischunterricht hatte, gaben nur 19,3\% an, Englisch zu können. 48\% machten vorsichtshalber gar keine Angabe, interessant sind die 31,3\%, die unter ,andere“ handschriftlich „Deutsch“ eintrugen. Auf die A1-Kenntnisse in Deutsch scheinen viele demnach richtig stolz zu sein.

\subsection{Angaben zur Prüfung und zur Prüfungsvorbereitung}

59\% der Prüfungsteilnehmer legten die Prüfung zu ersten Mal ab, 28\% zum zweiten Mal, jeweils 5\% zum dritten bzw. vierten Mal (keine Angabe: 3\%). Die Prüfung kann theoretisch beliebig oft wiederholt werden.

$38 \%$ gaben an, über die Prüfungsinhalte sehr gut informiert gewesen zu sein, $36 \%$ waren ihren Angaben zufolge gut informiert. Jeweils 7\% meinten, sie seine schlecht bzw. sehr schlecht informiert gewesen (weiß nicht: 8\%, keine Angabe: 4\%).

Auf die Frage nach der Bewertung der Prüfung antworteten 27,6\% ,sehr schwer“" 35,3\% „schwer“, 21,1\% „weiß nicht“ und jeweils 2\% „leicht“ und „sehr leicht“ (keine Angabe: $2 \%$.

Interessant sind die Antworten auf die Frage nach der Prüfungsvorbereitung: 87\% haben (mehrheitlich an einer Sprachschule in ihrer Heimatstadt) einen Vorbereitungskurs besucht, nur 11\% nicht (keine Angabe: 2\%). 7\% gaben an, sich ausschließlich mit Hilfe des Internets auf die Prüfung vorbereitet zu haben; die Übungssätze sind im Netz - unter anderem auf den Seiten des GI Ankara - frei verfügbar.

Knapp 60\% derjenigen, die einen Vorbereitungskurs besucht haben, fanden diesen Kurs „sehr gut“ oder „gut“, demgegenüber stehen zusammen 8\%, die den Kurs „schlecht“ oder ,sehr schlecht“ fanden. Dementsprechend hat der Kurs 59\% der Teilnehmer Spaß gemacht, 22\% offenbar nicht (weiß nicht: 12\%, keine Angabe: 7\%). 


\subsection{Einstellungen zum Gesetz, zur Prüfung und zum Sprachenlernen}

Nach den eingangs dargestellten politischen und gesellschaftlichen Diskussionen um das Gesetz zu Nachweis einfacher Deutschkenntnisse gibt es kein anderes Ergebnis, das so überraschend war wie dieses (vgl. Abb.1):

Fast 50\% der Teilnehmer finden das Gesetz, um das so viel Wirbel gemacht wurde, demnach gut oder sogar sehr gut im Vergleich zu knapp über 30\%, die es schlecht oder sehr schlecht finden. Eine weitere Grafik (vgl. Abb. 2) macht deutlich, wer hinter diesem Antwortverhalten steht: 19,4\% der Frauen finden das Gesetz sehr gut und 37,9\% finden es gut. 14,9\% der Männer finden das Gesetz schlecht und 31,9\% der Männer gar sehr schlecht. Es gibt in diesem Punkt meiner Einschätzung nach wenig Deutungsspielraum: Die jungen Frauen, die mehrheitlich gut bis sehr gut ausgebildet sind und nun (mehrheitlich ohne Kinder!) im Hause der Eltern oder Schwiegereltern Hausarbeiten verrichten und auf ihre Ausreise nach Deutschland warten, wollen lernen und wollen Deutsch lernen. Folgende Kontrollfragen bestätigen die sich hier aufzeigende Tendenz:

- „Finden Sie, dass Deutsch eine schöne Sprache ist?": ja: 70\%, nein: 6\%, weiß nicht: 13\%, (keine Angabe: 11\%).

- „Es ist schwierig in einem Land zu leben, ohne die Sprache des Landes zu sprechen": ich stimme $z_{u}=68 \%$, ich stimme nicht $z^{u}=29 \%$ (keine Angabe: 3\%).

- „Ich kann auch in Deutschland leben ohne Deutsch zu sprechen“: ich stimme ₹u= 33\%, ich stimme nicht zu $=64 \%$ (keine Angabe: 3\%).

- „Eine Fremdsprache zu lernen ist immer ein Vorteil“": ich stimme zu $=90 \%$, ich stimme nicht $2 u=7 \%$ (keine Angabe: 3\%).

- „Alle Menschen sollten die Sprache des Landes, in dem sie künftig leben werden, bereits vor der Ausreise erlernen“: ich stimme zu $=57 \%$, ich stimme nicht zu $=39 \%$ (keine Angabe: $4 \%$ ).

- „Dem türkischen Sprichwort: Eine Sprache $=$ ein Mensch, zwei Sprachen = zwei Menschen" stimmen 80\% zu, 16\% stimmen nicht zu (Keine Angabe: 4\%).

Trotz einzelner Widersprüche sind diese Angaben in ihrer Gesamtheit eindeutig: es gibt bei der Mehrheit der Befragten durchaus die Motivation Deutsch zu lernen, begründet in der Einsicht, dass dies eine persönliche Bereicherung darstellt und ihnen bei ihrem künftigen Aufenthalt in Deutschland nützlich sein wird. Die erwartete Protesthaltung und eine damit verbundene Lernverweigerung blieben jedenfalls mehrheitlich aus. 


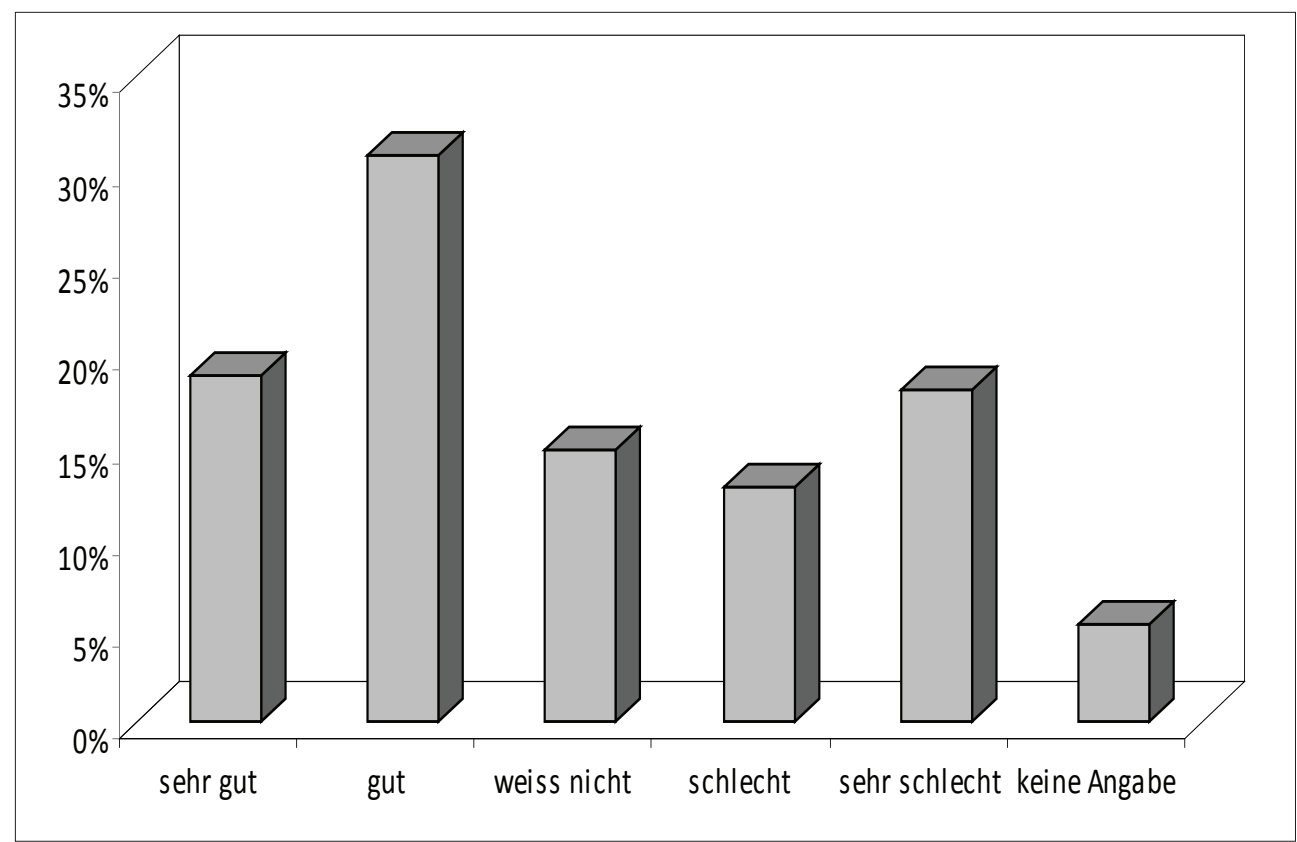

Abb. 1: Antwort auf die Frage: „Wie finden Sie das Gesetz zum Nachweis einfacher Deutschkenntnisse?"

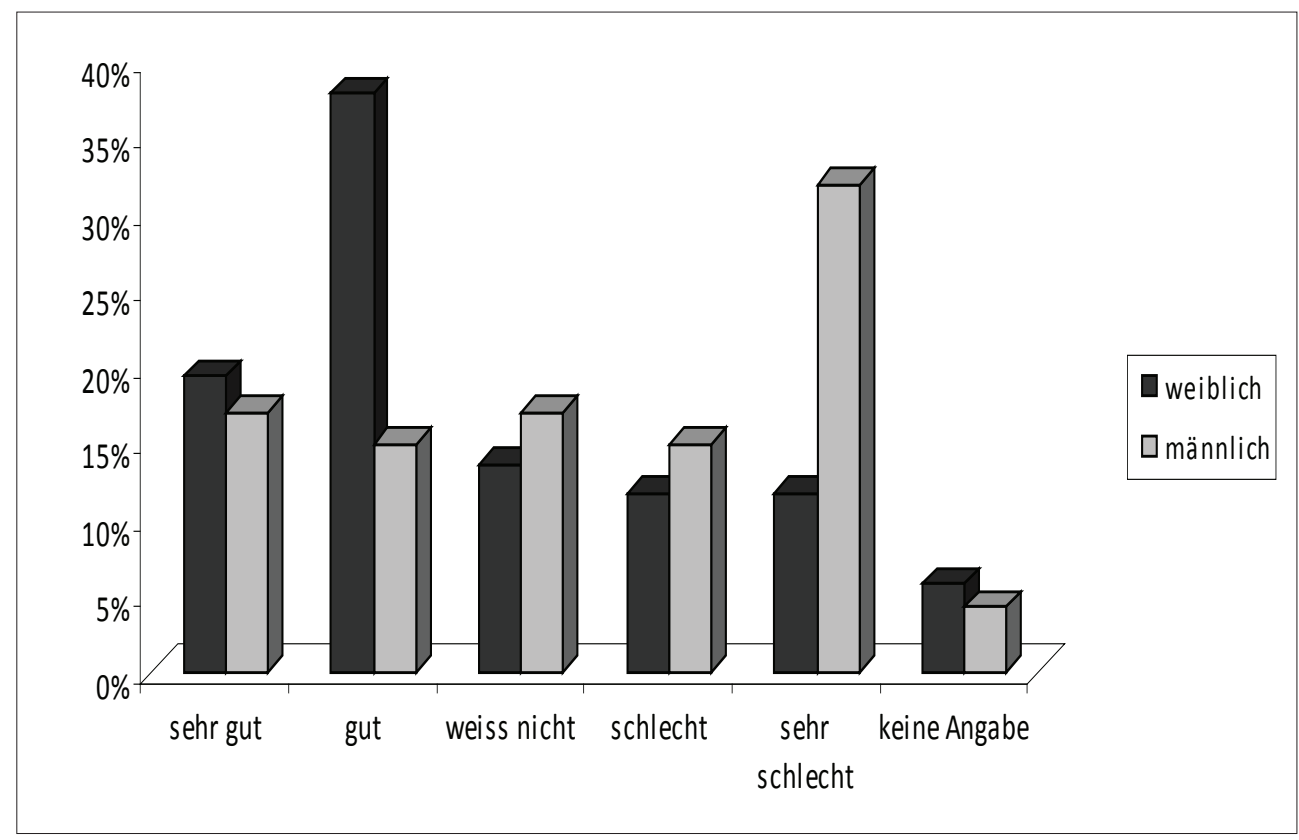

Abb. 2: Verhältnis Einstellung zum Gesetz nach Geschlecht 


\subsection{Angaben zur Funktionalität der erworbenen Deutschkenntnisse}

Noch deutlicher wird die generelle Akzeptanz der Notwendigkeit des Sprachenlernens bei den Antworten auf die Fragen, was denn mit den erworbenen Deutschkenntnissen erreicht werden soll. Zunächst konstatieren $82 \%$ der Befragten, dass das, was sie für die Prüfung gelernt haben, ihnen in Deutschland helfen wird, bei nur 2\%, die das Gegenteil behaupten (weiß nicht: 6\%, keine Angabe: 10\%). Ebenso 82\% geben an, dass sie in Deutschland auf jeden Fall weiter Deutsch lernen werden, nur 1\% nimmt davon Abstand (weiß nicht: 8\%, keine Angabe 9\%).

$79 \%$ der Probanden meinen, dass sie mit Deutschkenntnissen in Deutschland mehr Chancen haben, 10\% sehen ihre Chance demgegenüber sprachunabhängig (keine Angabe: $11 \%$ ).

Auf die Frage, was sie mit den erworbenen Sprachkenntnissen machen möchten, antworten 34,6\% ,weitere Deutschkenntnisse erwerben“, 13\% „Kontakt zu Deutschen finden“, 10\% einen Arbeitspaltz finden, 7\% „mein Leben in Deutschland eigenständig meistern“ (weitere vorgegebene Antwortmöglichkeiten, Mehrfachnennung möglich.)

\section{Schluss}

Mit dem hier zusammengefassten Beitrag liegen erstmals Umfrageergebnisse zu den „Prüfungen zum Nachweis einfacher Deutschkenntnisse“ vor. Ich stelle den Datensatz Interessierten gerne in seiner Gesamtheit für zusätzliche und/oder kontrollierende Auswertungen zur Verfügung. Lohnen würde sich sicherlich eine Überarbeitung mit SPSS.

Kritisch gesehen werden kann, dass ich die Ausgabe und das Einsammeln der Fragebögen zu keinem Zeitpunkt selbst kontrolliert habe und so keine genaueren Angaben zu den Erhebungsbedingungen machen kann. Auch diesbezüglich kann ich nur dazu einladen, die Untersuchung unter besseren Bedingungen als ich sie aufgrund eines unmittelbar bevorstehenden Standortwechsels hatte zu wiederholen.

Der ZEIT-Kolumnist Jörg Lau fasste seine, den hier dargestellten Ergebnissen ähnelnden Erfahrungen mit „Start 1“-Prüfungsteilnehmern und den dazu diametral entgegenstehenden (Re-)Aktionen der türkischen Verbände in Deutschland in einem Internet-Blog einmal sehr passend zusammen: „Manchmal sind die Repräsentierten klüger als ihre Repräsentanten." ${ }^{\text {2 }}$

2 http://blog.zeit.de/joerglau/2007/09/26/turken-lieben-neues-zuwanderungsrecht_784 


\section{Christian Krekeler \& Rolf Rodenbeck}

\section{Forum „Unterrichtspraxis“ - Bericht}

Im Forum Unterrichtspraxis steht der Austausch von neuen Modellen und Ideen für den Unterrichtim Fach Deutsch als Fremdspracheim Mittelpunkt. Gemäß dem Motto,,aus der Praxis fürdie Praxis"wurdeninden Beiträgen aktuelleEntwicklungen in den verschiedenen Tätigkeitsbereichen diskutiert, Kurskonzepte vorgestellt und Unterrichtsmaterialien und -ideen vorgestellt. Das breite Themenspektrum ist dabei Programm:

- Curriculumentwicklung in Finnland,

- Akademisches Schreiben für technische Disziplinen,

- Vermittlung von Lesestrategien durch die Arbeit mit Lückentexten,

- Kreatives Schreiben und darstellendes Spiel,

- Kreativ-biographisches Schreiben in der interkulturellen Bildung,

- Witze im Fremdsprachenunterricht,

- Regionalisierte Lehrmaterialien,

- Aussprachetraining mit rhythmischen Elementen,

- Projektarbeit im landeskundlichen Unterricht.

Rolf Rodenbeck von der Schwedischen Wirtschaftsuniversität Helsinki stellte in einem Praxisbericht ein innovatives Curriculum für Deutsch als Wirtschafts- und Geschäftssprache und den Prozess seiner Entstehung vor. Zum Erfolg trug wesentlich bei, dass das neue Curriculum in weiten Teilen auf der Basis eigener Forschungsergebnisse konzipiert wurde.

Olaf Lenders von der Hochschule Konstanz HTWG führte einen Workshop zum Verfassen akademischer Texte mit technischen Inhalten durch. Er stellte erprobte Übungen vor, welche Lerner dazu motivieren können, ihre Texte selbst zu erstellen, zu bewerten und zu überarbeiten.

Isolde Mozer von der Universität Frankfurt am Main unterbreitete einen Unterrichtsvorschlag zur Förderung des Leseverstehens. Wenn Lerner einen Lückentext erhalten, müssen vorausgehende und nachfolgende Informationen in der Textumgebung der Lücke beachtet, logische Strukturen analysiert und das Vorwissen der Lerner aktiviert werden. Lerner können Auslassungs-Texte auch selbst erstellen und ihrem Kurs präsentieren. Unterrichtspraktisch empfiehlt sich diese Methode vor allem als Einstiegseinheit zum Leseverstehen aufgrund ihrer inhaltlichen Variabilität, der studentischen Mitgestaltungsmöglichkeiten und ihrer Überschaubarkeit.

Lisanne Klein Gunnewiek von der Universität Marburg demonstrierte, wie die didaktischen Methoden Kreatives Schreiben und Darstellendes Spiel einen ganzheitlichen Sprachlernprozess begünstigen können. Dies wurde anhand der Erfahrungen aus einem Hochschulseminar erläutert, in dem Studierende Projekte zum Thema Kreatives Schreiben und Darstellendes Spiel in Schulen durchführten. 
Barbara Thums-Senft und Eva Finke aus Bonn boten einen weiteren Beitrag zur Kreativität im Fremdsprachenunterricht. Sie stellten ihre Methode des kreativen-biographischen Schreibens vor und zeigten an verschiedenen Beispielen - u.a. Gedichten aus ihrer Arbeit in Integrationskursen, wie sie beim kreativen Schreiben biographische Elemente der Lernenden in den Schreiblernprozess einbeziehen.

Stanka Murdsheva von der Technischen Universität Sofia thematisierte die Rolle von Witzen im Fremdsprachenunterricht. Sie zeigte, dass Witze in den einschlägigen Lehrwerken primär für den Spracherwerb verwendet werden. Sie plädierte dafür, Witze stärker für die Reflexion der eigenen und fremder Kulturen zu nutzen.

Larisa Klyushkina und Annegret Middeke von der Universität Göttingen stellten Lehrmaterialien bzw. -werke vor, welche Sprach- und Kulturkompetenzen für den Austausch zwischen Deutschland und Osteuropa vermitteln. Dabei steht der Vergleich zwischen Ausgangs- und Zielkultur im Mittelpunkt der Spracharbeit. Die Lehrwerke sind regionalisiert, das heißt, die jeweiligen Lehr- und Lerntraditionen werden berücksichtigt.

Andreas Fischer aus Eichstetten demonstrierte, wie sich rhythmische Elemente bei der Ausspracheschulung einsetzen lassen. Dazu wird zu Sprechstücken in Dialogform von den Lernern auf Kleininstrumenten eine rhythmische Begleitung gespielt. Durch Gestik und Emotion werden Theatertechniken eingesetzt, damit sich neben der authentischen Realisierung von Intonation, Rhythmus und Melodie auch Geläufigkeit einstellt.

Renata Rozalowska von der Universität Gdańsk stellte ein von ihr erprobtes Konzept zur Projektarbeit im landeskundlichen DaF-Unterricht vor. Studentische Lerner verfolgten dabei, wie polnische Zeitungen während der Projektphase über Österreich berichteten. Ziel war jedoch nicht nur, das Wissen über Österreich und seine Verbindungen zu Polen zu erweitern, sondern den zukünftigen Lehrkräften auch zu vermitteln, wie sie Projektarbeit in ihrer zukünftigen Tätigkeit einsetzen können.

Insgesamt vermittelten die Beiträge im Forum ein überaus facettenreiches Bild über neue Unterrichtsideen und -konzepte sowie innovative Methoden, die aus den verschiedenen Praxisfeldern im Bereich Deutsch als Fremdsprache bzw. Zweitsprache heraus entwickelt worden sind. 


\section{Rolf Rodenbeck (Helsinki, Finnland)}

\section{Deutsch als Wirtschafts- und Geschäftssprache: Lehrforschung und Curriculumentwicklung}

\section{Einführung}

An der Hanken School of Economics in Helsinki wurde in einem ca. zehnjährigen Projekt das deutsche Sprachcurriculum einer grundlegenden Revision unterzogen. Unter Einbeziehung aktueller Forschungsergebnisse der angewandten Sprachwissenschaften und der DaF-Didaktik sowie Finnland-spezifischer Bedarfsanalysen war es das Ziel, ein zeitgemäßes und konsistentes Deutschcurriculum für Studierende der Wirtschaftswissenschaften zu schaffen. Durch das Projekt wurde für die deutsche Sprachausbildung ein deutliches Profil erarbeitet, dessen Fokus auf fachkommunikativer Kompetenz und interkultureller Geschäftskommunikation liegt. Die am Zentrum für Sprachen und Wirtschaftskommunikation entwickelten Lehr- und Lernmaterialien wurden an den Gemeinsamen Europäischen Referenzrahmen für Sprachen (GER) angepasst. Dokumentiert wurde das gesamte Projekt in einer zweisprachigen Publikation (deutsch/ schwedisch), in der neben einer Skizzierung der Ausgangs- und Rahmenbedingungen wichtige Teilprojekte mit den in ihrem Rahmen durchgeführten Forschungsarbeiten beschrieben und das Verfahren der Evaluation und Qualitätssicherung des Curriculums vorgestellt werden (vgl. Breckle; Båsk; Rodenbeck 2006). 


\section{Sprachenstudium an der Hanken School of Economics}

Die 1909 gegründete Hanken School of Economics (Svenska handelshögskolan) in Helsinki mit einem Nebencampus in Vaasa zählt mit ca. 2.300 Studierenden, 114 Lehrenden und Forschenden sowie ca. 160 Doktoranden zu den kleineren Hochschulen Finnlands. Das Sprachenstudium ist obligatorischer Bestandteil des wirtschaftswissenschaftlichen Fachstudiengangs. Neben den beiden Landessprachen Finnisch und Schwedisch müssen dabei auch zwei Fremdsprachen studiert werden. Für den Abschluss „Ekonomie Kandidat“ (Bachelor) sind 24 Studienpunkte (SP) von insgesamt 180 erforderlich, aufgeteilt auf die beiden Landessprachen und zwei Fremdsprachen (Deutsch, Englisch, Französisch, Russisch, Spanisch). Für den Abschluss „Ekonomie Magister" (Master $=120$ SP) sind sechs Studienpunkte für das Sprachenstudium vorgesehen. Mit 26 Studienpunkten in einer Sprache erhält diese Nebenfachstatus.

Wenngleich Englisch als Wirtschafts- und Wissenschaftssprache unbestritten die Spitzenposition einnimmt, hat Deutsch seine Position als zweitwichtigste Fremdsprache und bedeutende Wirtschaftssprache immer behaupten können. Nach wie vor wählen 20 bis 25 Prozent aller Studierenden Deutsch als eine obligatorische Sprache. Ebenso groß ist der Anteil derer, die sich für ein Austauschstudium an einer deutschsprachigen Hochschule entscheiden (vgl. Båsk; Rodenbeck 2007: 4f.).

\section{Curriculumrevision 1995 bis 2005}

Die Globalisierung des Handels- und Wirtschaftsverkehrs und die sich gleichzeitig verändernden Kommunikationsformen mittels moderner Informationsmedien konfrontierten Wirtschaft und Unternehmen seit Ende der 1980er Jahre mit bis dahin unbekannten Anforderungen. Auch der wirtschaftssprachlich orientierte Fremdsprachenunterricht sah sich durch diese Veränderungen völlig neuen Bedingungen und Herausforderungen gegenübergestellt. Gewohnte und etablierte Inhalte, Vermittlungsmethoden und Medien entsprachen offensichtlich nicht mehr den Erfordernissen zeitgemäßen Unterrichts. Zeitgleich wurden im Zuge des sog. „Bolognaprozesses“ sämtliche Studienordnungen im Sinne einer gesamteuropäischen Vergleichbarkeit der Studienabschlüsse revidiert. Als dritte Komponente wurde der Gemeinsame Europäische Referenzrahmen für Sprachen (GER) zu einem allgemeinen Planungs- und Evaluationsinstrument.

Dieses veränderte Bedingungsgefüge war der Anlass für eine grundlegende Revision des Deutschcurriculums an der Hanken School of Economics. In den Jahren 1995 bis 2005 wurden sämtliche Einzelkurse des Gesamtcurriculums völlig neu gestaltet oder grundlegend überarbeitet. Es wurden kurstragende Lehrmaterialien entwickelt und als Curriculumbausteine aufeinander abgestimmt. Die medialen und kommunikativen Möglichkeiten moderner Informationstechnologie wurden dabei weitestgehend einbezogen. Dieses betrifft die Gestaltung der Kurse und Materialien in Form von Onlineoder sog. Blended Learning-Kursen wie auch die Formen der Kommunikation mit den Studierenden.

Alle KollegInnen der deutschen Sprachabteilung waren in diesen Prozess einbezogen. Darüber hinaus wurde mit interessierten KollegInnen anderer Hochschulen und 
Partnerorganisationen (Goethe-Institut, Deutsch-Finnische Handelskammer, Deutsche Botschaft Helsinki) kooperiert. Das Forschungsinteresse einzelner KollegInnen erwies sich als außerordentlich fruchtbar und hilfreich für diesen Prozess. So entstanden in dem Zeitraum u.a. eine Dissertation, zwei Lizentiatenarbeiten, ein kommerziell vertriebenes Online-Lehrprogramm sowie ein international vertriebenes Lehrbuch mit deutlichen Bezügen zu einzelnen Curriculumbausteinen (siehe Literaturverzeichnis). Besonders begünstigt wurde der Prozess auch durch vier „Generationen“ von DAAD-Lektoren, die für jeweils fünf Jahre eine Lektorenstelle am Institut innehatten.

\subsection{Curriculumentwicklung: Determinanten und Ziele}

Das revidierte deutsche Sprachencurriculum lässt sich im Wesentlichen durch vier Ziele bzw. Determinanten kennzeichnen (siehe Båsk; Rodenbeck 2007: 6):

- fachkommunikative Kompetenz als Leitziel,

- Integration von fachlichem und sprachlichem Lernen,

- Interkulturelle Kompetenz,

- Lernerstrategien und Lernerautonomie.

Es umfasst in seiner heutigen Ausprägung die Niveaustufen A1 bis C1 des GER (siehe Übersicht 1).

\section{Übersicht 1:}

Hanken School of Economics

Deutschcurriculum 2006/07 (nach: Båsk/Rodenbeck 2007: 12)

\begin{tabular}{|c|c|c|c|}
\hline Deutsch VI & Wirtschaftsdeutsch International (PWD-Vorber.) & $\mathrm{C} 1$ & 4 ECTS \\
\hline Deutsch VI & Unternehmenspräsentation und Verhandlung & $\mathrm{C} 1$ & 4 ECTS \\
\hline Deutsch VI & Deutsches Wirtschaftsrecht & $\mathrm{C} 1$ & 4 ECTS \\
\hline Deutsch VI & Vorbereitungskurs Auslandsstudium & $\mathrm{C} 1$ & 4 ECTS \\
\hline Deutsch VI & Aktuelle Themen & C 1 & 4 ECTS \\
\hline Deutsch V & Wirtschaftstexte: Terminologie und Strukturen & B2 & 4 ECTS \\
\hline Deutsch V & Interkulturelle Themen & B2 & 4 ECTS \\
\hline Deutsch IV & Mündliche Kommunikation & $\mathrm{B} 1 / 2$ & 4 ECTS \\
\hline Deutsch IV & Geschäftsbriefe & $\mathrm{B} 1 / 2$ & 4 ECTS \\
\hline Deutsch III & III-4 Basistexte Wirtschaft & B1 & 2 ECTS \\
\hline Deutsch III & III-3 Deutsch im Alltag & B1 & 2 ECTS \\
\hline Deutsch III & III-2 Politik und Gesellschaft D-A-CH & B1 & 1 ECTS \\
\hline Deutsch III & III-1 Grammatik & B1 & 1 ECTS \\
\hline Deutsch II & $\mathrm{B}$ - Land und Leute D-A-CH & A2 & 3 ECTS \\
\hline Deutsch II & A - Karriere D & A2 & 3 ECTS \\
\hline Deutsch I & Anfängerkurs & A1 & 6 ECTS \\
\hline
\end{tabular}


In Anlehnung an Baumann wird ,fachkommunikative Kompetenz“verstanden als „Fähigkeit der jeweiligen Lerner, [...] Fachtexte als interkulturell, sozial, situativ und funktional bestimmte, sachlogisch gegliederte, semantisch strukturierte, linear-sequentiell sowie hierarchisch organisierte sprachliche Einheiten zu produzieren bzw. zu rezipieren“ (Baumann 2000: 159). Diese Kompetenz wird durch das Lösen von Aufgaben und Übungssequenzen erworben, welche das Verstehen und Produzieren von - mündlichen wie schriftlichen - Fachtexten zum Lerngegenstand haben:

„Das Ziel dieser Ausbildung im Bedingungsgefüge des fachbezogenen Fremdsprachenunterrichts besteht darin, dem Lerner die kommunikativen Tätigkeiten des Fachtextproduzierens und Fachtextrezipierens auf der Grundlage textsortenbezogener Sprachfertigkeiten (Lesen, Hören, Sprechen, Schreiben, Übersetzen) zu vermitteln, um ihm dadurch die Entwicklung einer fachkommunikativen Kompetenz zu ermöglichen." (Baumann 2000: 158f.)

Die Integration von inhaltlichem und sprachlichem Lernen bildet heute ein zentrales Element des deutschen Sprachcurriculums: „Ökonomische, gesellschaftliche und kulturelle Lerninhalte werden mit dem Studium der deutschen Sprache in Form eines integrativen Fachsprachenunterrichts verknüpft" (Båsk; Rodenbeck 2007: 7). Der gesamte Lehr- und Lernprozess orientiert sich darüber hinaus an sprachlichen Verwendungssituationen, die dem Studien- und künftigen Berufsalltag der Studierenden entsprechen.

Interkulturelle Kompetenz als Ausgangs- und Bezugspunkt erfolgreicher internationaler Geschäftstätigkeit hat für das deutsche Sprachcurriculum einen zentralen Stellenwert. Die Entwicklung der „Fähigkeit und Fertigkeit von Fremdsprachenlernern [...], über Differenzen zwischen der eigenen und der Zielkultur zu wissen, diese in konkreten Situationen zu erkennen und Strategien zu entwickeln, einfühlsam auf die Gepflogenheiten der anderen Kultur einzugehen“" (Volkmann 2002: 12), gehört zu den Zielen aller Deutschkurse an der Hochschule.

Ein Fokus der Sprachlernforschung richtete sich zu Beginn der 1990er Jahre auf die Autonomie des individuellen Lernens im Sinne der Selbststeuerung von Lernprozessen und die Verwendung von Lernstrategien. Diese Entwicklung fiel nicht zufällig mit den technischen Möglichkeiten zusammen, welche die sog. neuen Medien mit Lernersoftware und interaktiven Lernerplattformen bieten, die dem Lerner deutlich erweiterte Möglichkeiten bieten, Zeitpunkt, Tempo und Ort seines Lernens zu beeinflussen. Bei der Entwicklung des neuen Curriculums hat die deutsche Abteilung ihr Kursangebot deutlich in diesem Sinne ausgerichtet: Zur Unterstützung oder Ergänzung der Lernmaterialien in Form von Kompendien gibt es zu vielen Kursen Online-Übungen, Hausaufgaben sowie Zusatzmaterialien, die kurszeit- und kursortunabhängig individuell bearbeitet und deren Lösungen i.d.R. selbstständig überprüft werden können.

\subsection{Curriculumentwicklung: Teilprojekte}

Im Folgenden sollen wichtige Teilprojekte skizziert werden. Die jeweils angegebenen Hinweise auf Publikationen der an der Curriculumentwicklung beteiligten LektorInnen bzw. Quellen ermöglichen bei Bedarf eine Vertiefung. 
- Fokus Leseverstehen: Entwicklung eines Lesekurses im Fach Deutsch als Fremdsprache

Kurs: Deutsch III - Basistext Wirtschaft

Literatur: Båsk 1996 und 2007

- Fokus Hörverstehen: Entwicklung eines Vorbereitungskurses für das Auslandsstudium

Kurs: Deutsch VI - Vorbereitungskurs Auslandsstudium

Literatur: Breckle 2007b; Schlabach 1997 und 2000

- Fokus Schriftlicher Ausdruck: Entwicklung eines Kurses zur deutschen Geschäftskorrespondenz

Kurs: Deutsch IV - Geschäftsbriefe

Literatur/Quelle: Båsk 2007b; Müntzel; Tiittula 1995, Müntzel; Steuer 2002

- Fokus Mündlicher Ausdruck: Entwicklung eines Kurses zur mündlichen Geschäftskommunikation

Kurs: Deutsch VI - Unternehmenspräsentation und Verhandlung

Literatur: Reuter; Rodenbeck 1992, Rodenbeck 1997

- Fokus Interkulturelle Kommunikation: Entwicklung eines Kurskonzepts

Kurs: Interkulturelle Themen

Literatur: Breckle 2000, 2005 und 2007a

- Fokus Integration von fachlichem und sprachlichem Lernen: Entwicklung eines Lehrwerks zum deutschen Wirtschaftsrechts

Kurs: Deutsch VI - Deutsches Wirtschaftsrecht

Literatur: Cebulla; Rodenbeck 2001 und Rodenbeck 2001

- Fokus Virtuelle Grammatik: Entwicklung eines Online-Programms zum Selbststudium

Kurs: Deutsch III - Grammatik

Quelle: http://donnerwetter.kielikeskus.helsinki.fi/DVG

\section{Evaluation und Qualitätssicherung}

Die oben skizzierten Curriculumbausteine und die ihnen zugrunde liegenden Lehrmaterialien wurden in z.T. mehrjährigen Prozessen im Unterricht erprobt und mehrfach revidiert. Darüber hinaus wurde ein Evaluationssystem aufgebaut, das zum einen der internen Kommunikation und zum anderen der Qualitätssicherung der einzelnen Kurse sowie des Curriculums insgesamt dient. Das System basiert auf qualitativen und quantitativen Kriterien. Dazu zählen u.a. die Transparenz der Kurse und des Curriculums für die Studierenden, die Messung ihrer Zufriedenheit durch systematische und regelmäßige Kursauswertungen sowie die Akzeptanz des Curriculums durch quantitative Auswertungen (interner Vergleich mit konkurrierenden Fremdsprachen an der Hochschule und im Periodenvergleich). Durch entsprechende Bedarfsanalysen wird darüber hinaus in unregelmäßigen Abständen der deutsche Fremdsprachenbedarf allgemein sowie in einzelnen Fertigkeitsbereichen ermittelt. Ein weiteres Evaluationsinstrument besteht darin, den objektiven Sprachstand der Studierenden zu ermitteln durch deren 
Teilnahme an externen Prüfungen wie TestDaF oder die Prüfung Wirtschaftsdeutsch International (siehe: Breckle 2007c).

\section{Schlussbemerkung}

Die Totalrevision des deutschen Sprachcurriculums an der Hanken School of Economics war ein kreativer Prozess, an dem alle KollegInnen der betreffenden Sprachabteilung beteiligt waren - inklusive vier Generationen von DAAD-LektorInnen.

Das Ergebnis, das natürlich zu Beginn des Gesamtprojektes nicht vorhersehbar war, erscheint in der Rückschau beeindruckend und kann sicherlich als beispielhaft für die Integration individueller Lehrforschungsprojekte in ein langfristiges Gesamtprojekt zur Curriculumentwicklung an Sprachzentren oder Sprachinstitutionen gelten. Die Erfolgsbedingungen der Arbeit lassen sich auf vier Ebenen charakterisieren:

- Interesse, Neugier, Spaß, Arbeitsbereitschaft, Beharrlichkeit,

- Ressourcen: personell, finanziell, arbeitsorganisatorisch,

- Zusammenarbeit mit internen und externen Kooperationspartnern bzw. in der Form von Netzwerken,

- $\quad$ und nicht zuletzt: Rückendeckung von Kollegen und Vorgesetzten, die interne und externe Kommunikation der Projekte sowie ihre Dokumentation.

Alle Bedingungen wurden während der Einzelprojekte erfüllt - nicht immer und nicht immer gleichzeitig und zufriedenstellend, aber doch in einem Maße, dass die jeweils individuellen und gemeinsamen Zielsetzungen nie utopisch erschienen.

\section{Literatur}

Baumann, Klaus-Dieter (2000): Die Entwicklung eines integrativen Fachsprachenunterrichts - eine aktuelle Herausforderung der Angewandten Linguistik. In: Baumann, Klaus-Dieter; Kalverkämper, Hartwig; Steinberg-Rahal, Kerstin (Hrsg.): Sprachen im Beruf. Stand - Probleme - Perspektiven. Tübingen: Narr, 149-173.

Båsk, Märta (1996): Några textuella faktorers inverkan på svenskspråkiga studerandes läsförståelse av tyska tidningstexter. Vaasa: Universität Vaasa (Lizentiatenarbeit).

Båsk, Märta (2007a): Basistexte Wirtschaft. In: Breckle, Margit; Båsk, Märta; Rodenbeck, Rolf (Hrsg.): Wirtschaftssprache Deutsch in Studium und Beruf. Curriculumentwicklung an der Schwedischen Wirtschaftsuniversität in Finnland. Ekonomisk tyska i studier och yrkesliv. Utveckling av ett kursprogram vid Svenska handelshögskolan. Helsinki: Svenska handelshögskolan, 19-24.

Båsk, Märta (2007b): Geschäftsbriefe. In: Breckle, Margit; Båsk, Märta; Rodenbeck, Rolf (Hrsg.): Wirtschaftssprache Deutsch in Studium und Beruf. Curriculumentwicklung an der Schwedischen Wirtschaftsuniversität in Finnland. Ekonomisk tyska $i$ studier och yrkesliv. Utveckling av ett kursprogram vid Svenska handelshögskolan. Helsinki: Svenska handelshögskolan, 25-31.

Båsk, Märta; Rodenbeck, Rolf (2007): Wirtschaftssprache Deutsch in Studium und Beruf: Profilierung des Deutschcurriculums an der Schwedischen Wirtschaftsuniversität in Finnland. In: Breckle, Margit; Båsk, Märta; Rodenbeck, Rolf (Hrsg.): 
Wirtschaftssprache Deutsch in Studium und Beruf. Curriculumentwicklung an der Schwedischen Wirtschaftsuniversität in Finnland. Ekonomisk tyska i studier och yrkesliv. Utveckling av ett kursprogram vid Svenska handelshögskolan. Helsinki: Svenska handelshögskolan, 1-18.

Breckle, Margit (2004): „In Schweden ist die Kommunikation weicher“. Zur deutsch-schwedischen Wirtschaftskommunikation unter besonderer Berücksichtigung der Imagearbeit. Göteborg: Universität Göteborg (Dissertation).

Breckle, Margit (2007a): Interkulturelle Themen. In: Breckle, M.; Båsk, M.; Rodenbeck, R. (Hrsg.): Wirtschaftssprache Deutsch in Studium und Beruf. Curriculumentwicklung an der Schwedischen Wirtschaftsuniversität in Finnland. Ekonomisk tyska i studier och yrkesliv. Utveckling av ett kursprogram vid Svenska handelshögskolan. Helsinki: Svenska handelshögskolan, 32-39.

Breckle, Margit (2007b): Vorbereitungskurs Auslandsstudium. In: Breckle, Margit; Båsk, Märta; Rodenbeck, Rolf (Hrsg.): Wirtschaftssprache Deutsch in Studium und Beruf. Curriculumentwicklung an der Schwedischen Wirtschaftsuniversität in Finnland. Ekonomisk tyska $i$ studier och yrkesliv. Utveckling av ett kursprogram vid Svenska handelshögskolan. Helsinki: Svenska handelshögskolan, 50-56.

Breckle, Margit (2007c): Wirtschaftssprache Deutsch in Studium und Beruf: Qualitätssicherung - Evaluation - Benchmarking. In: Breckle, Margit; Båsk, Märta; Rodenbeck, Rolf (Hrsg.): Wirtschaftssprache Deutsch in Studium und Beruf. Curriculumentwicklung an der Schwedischen Wirtschaftsuniversität in Finnland. Ekonomisk tyska i studier och yrkesliv. Utveckling av ett kursprogram vid Svenska handelshögskolan. Helsinki: Svenska handelshögskolan, 65-84.

Breckle, Margit; Båsk, Märta; Rodenbeck, Rolf (Hrsg.) (2007): Wirtschaftssprache Deutsch in Studium und Beruf. Curriculumentwicklung an der Schwedischen Wirtschaftsuniversität in Finnland. Ekonomisk tyska $i$ studier och yrkesliv. Utveckling av ett kursprogram vid Svenska handelshögskolan. Helsinki: Svenska handelshögskolan, vollständige Textversion als PDF-Datei abrufbar unter: http://dhanken.shh.fi/dspace/bitstre am/10227/256/1/63-978-951-555-957-9.pdf.

Cebulla, Mario; Rodenbeck, Rolf (2001): Deutsches Wirtschaftsrecht. Eine Einführung mit integriertem Fachsprachenkurs. München: Beck, Athen: Sakkoulas, Bern: Stämpfli.

Müntzel, Uta; Steuer, Outi (2002): Perfekte Geschäftskommunikation per Brief, Fax und EMail. Ein netzgestütztes Lern- und Trainingsprogramm (online). Das Programm ist mit persönlichem Passwort zugänglich: http://opit.wsoy.fi/LMS_newlogin.asp.

Müntzel, Uta; Tiittula, Liisa (1995): Saksan kieli suomalais-saksalaisessa kaupassa. Deutsch im finnisch-deutschen Handel. Eine Bedarfsanalyse. Helsingin kauppakorkeakoulun julkaisuja D-215. Helsinki: Wirtschaftsuniversität Helsinki.

Reuter, Ewald; Rodenbeck, Rolf (1992): Unternehmenspräsentationen. Ein videogestütətes Unterrichtsprogramm für den mündlichen Fachsprachenunterricht im Bereich „Wirtschaft". Materialien des Zentralen Spracheninstituts der Universität Jyväskylä n:o 83, Videofilm/ Übungsbuch/Lehrerhandbuch. Jyväskylä: Universität Jyväskylä.

Rodenbeck, Rolf (1997): Verhandlungssprache Deutsch - Ein praxisbezogenes Kursmodell aus der Arbeit mit schwedischen WirtschaftsstudentInnen. In: Wolff, Armin; Blei, Dagmar (Hrsg.): DaF für die Zukunft. Eine Zukunft für DaF! (Materialien Deutsch 
als Fremdsprache 44). Regensburg: Fachverband Deutsch als Fremdsprache, 207226.

Rodenbeck, Rolf (2001): Deutsches Wirtschaftsrecht - Eine fachliche und sprachliche Einführung. In: Wolff, Armin; Winters-Ohle, Elmar (Hrsg.): Wie schwer ist die deutsche Sprache wirklich? (Materialien Deutsch als Fremdsprache 58), 659-665.

Rodenbeck, Rolf (2007a): Mündliche Geschäftskommunikation: Unternehmenspräsentation und Verhandlung. In: Breckle, Margit; Båsk, Märta; Rodenbeck, Rolf (Hrsg.): Wirtschaftssprache Deutsch in Studium und Beruf. Curriculumentwicklung an der Schwedischen Wirtschaftsuniversität in Finnland. Ekonomisk tyska $i$ studier och yrkesliv. Utveckling av ett kursprogram vid Svenska handelshögskolan. Helsinki: Svenska handelshögskolan, 40-49.

Rodenbeck, Rolf (2007b): Deutsches Wirtschaftsrecht. In: Breckle, Margit; Båsk, Märta; Rodenbeck, Rolf (Hrsg.): Wirtschaftssprache Deutsch in Studium und Beruf. Curriculumentwicklung an der Schwedischen Wirtschaftsuniversität in Finnland. Ekonomisk tyska $i$ studier och yrkesliv. Utveckling av ett kursprogram vid Svenska handelshögskolan. Helsinki: Svenska handelshögskolan, 57-64.

Schlabach, Joachim (1997): Auslandsstudium in Deutschland und Österreicb: Erfahrungen von Studierenden der Schwedischen Wirtschaftsuniversität. Hankeiters erfarenheter av utbytesstudier i Tyskland och Österrike. Working Papers 348. Helsinki: Schwedische Wirtschaftsuniversität.

Schlabach, Joachim (2000): Deutschsprachige Wirtschaftsvorlesungen aus fremdsprachendidaktischer Sicht. Textlinguistische Beschreibungen als Basis für eine Schwierigkeitshypothese. Tampere: Universität Tampere (Lizentiatenarbeit).

Volkmann, Laurenz (2002): Aspekte und Dimensionen interkultureller Kompetenz. In: Volkmann, Laurenz; Stiersdorfer, Klaus; Gehring, Wolfgang (Hrsg.): Interkulturelle Kompeten: Tübingen: Narr, 11-47.

\section{Andere Quellen}

Virtuelle Grammatik: http://donnerwetter.kielikeskus.helsinki.fi/DVG 
Christoph Chlosta, Matthias Jung (Hrsg.) (2010): DaF intergriert: Literatur - Medien - Ausbildung. Tagungsband der 36. Jahrestagung des Fachverbandes Deutsch als Fremdsprache 2008. Göttingen: Universitätsverlag, 397-410.

Stanka Murdsheva (Sofia, Bulgarien)

\section{„Mit Witzen Deutsch lernen?“ - „Mach doch keine Witze!“ Humor im interkulturellen DaF-Unterricht aller sprachlichen Stufen}

\section{Einleitung}

Macht man Bestandsaufnahmen von DaF-Lehrwerken unterschiedlicher Autoren, so wird deutlich, dass der Witz in den gängig in der schulischen Praxis eingesetzten Lehrwerken für Muttersprachler bisher lediglich eine sehr untergeordnete und „bescheidene Rolle“ (Uhlrich 1980: 5) spielt. Dies ist umso erstaunlicher, als der Witz eine weit verbreitete Gattung und auch in unserer gegenwärtigen Gesellschaft äußerst lebendig und beliebt ist. Die Gründe für den Verzicht auf die Textsorte Witz dürften vielleicht in der intuitiv empfundenen geringen Seriosität, ja: Trivialität des Gegenstandes liegen, entspricht doch das Unterrichten mit Witzen - so wird das wahrscheinlich auch nur empfunden - nicht den akademischen Maßstäben von Fach und Lehrern.

Trotzdem ist gerade in jüngster Zeit die didaktische Bedeutung des Witzes entdeckt und der Witz als Unterrichtsgegenstand aufgewertet worden. Insbesondere im Bereich des Sprachunterrichts kann der Witz als sprachbedingtes Kulturprodukt den Lernenden mit den Finessen der Sprache und der Kultur vertraut machen und zur Herausbildung schriftlicher und mündlicher Kommunikationsfähigkeiten genutzt werden.

Aber wenn schon in muttersprachlichen didaktischen Konzepten die Verwendung von Witzen eindeutig unterrepäsentiertist, um wie viel mehr gilt dies für den fremdsprachlichen, in unserem Fall den DaF-Unterricht? Eine entsprechende Bestandsaufnahme derzeit gängiger Unterrichtslehrwerke zeigt dies ganz eindeutig als Desiderat auf. 
Erschwerend für die Einsetzbarkeit dürfte zu den oben genannten Gründen hier hinzukommen, dass eine fremdsprachliche Mindestkompetenz unabdingbar ist.

Wenn es aber zutrifft, dass der Witz, wie oben formuliert, einen spezifischen Zugang zur Fremdsprache und dem durch sie repräsentierten Kulturkreis darstellt, dürfte ein stärkerer Einsatz des Witzes im fremdsprachlichen Unterricht ein Gewinn sein.

In den nachfolgenden Ausführungen wird deshalb versucht, auf der Grundlage einer zusammenfassenden Definition des Witzes als einer „komisch“ wirkenden Aussage seine Funktion herauszuarbeiten sowie seine Struktur aufzuzeigen, um schließlich daraus die didaktische Relevanz des Witzes im fremdsprachlichen Unterricht des Deutschen abzuleiten.

In der Fachliteratur wird ,für eine unverkrampfte Einbeziehung humoristischen Materials“ (Hohenhaus 2000: 434) plädiert. Diese zeigen etwa Urios-Aparasi und Wagner (2008) für den DaF-Unterricht in den USA oder Hohenhaus für den DaF-Unterricht in Großbritannien auf. Hohenhaus beschreibt eine Reihe von Anwendungen aus dem Bereich der Phraseologie, der deutschen Dialekte, der Lexik und der Übersetzung. Humoristische Effekte ergeben sich durch Fehler insbesondere bei der wörtlichen Übertragung von der Muttersprache in die Fremdsprache oder umgekehrt. Behandelt werden nicht nur Beispiele in Texten, sondern auch Anspielungen in Cartoons, Graffiti und Überschriften. Äußerst komisch sind die Beispiele aus dem Bereich der Lexik. Es geht um die sogenannten „falschen Freunde“ und anschließend um die „Filserbriefe“. Überzeugend sind auch die Beispiele für die falschen Direktübertragungen von syntaktischen Strukturen der Ausgangssprache auf die Zielsprache oder für wörtliche Übertragungen von Phraseologismen in die Zielsprache. Weiterhin wird beschrieben, wie spielerische Elemente einbezogen werden, um idiomatisches Wissen zu erarbeiten oder zu festigen. Dabei wird einerseits auf die sogenannten universalen, andererseits die interkulturell differenten Tabu-Bereiche aufmerksam gemacht (z.B. Tod, Sex, Religion). Mit solchen Themen sollte man - darauf weist Hohenhaus ausdrücklich hin - äußerst behutsam umgehen.

Nützliche Empfehlungen und Vorschläge, wie man „mit Witzen Deutsch lernen“ kann, sind in dem gleichnamigen Band von Anne Spier enthalten. In der Sammlung von 520 thematisch geordneten und in Gruppen für Anfänger und Fortgeschrittene unterteilten Witzen für den Sprachunterricht Deutsch als Fremdsprache/Zweitsprache werden solche Witze nicht berücksichtigt, die sich über Minderheiten lustig machen oder zum Verständnis ein spezielles Fach- und Kulturwissen erfordern. Manchmal folgt auf die Witze eine kurze, aber ernsthafte Erläuterung durch die Autorin, warum und mit welchen Lernern Vorsicht geboten sei. Eine Empfehlung, derartige Witze, die ja bekanntlich Träger von Kulturen sind, als Anlass für interkulturelle Reflexionen zu nutzen, gibt es nicht. Die dort angeführten Witze sind geeignet für einen Einstieg in ein neues Thema, zum Erzählen Üben. Hier sind auch Ideen vorhanden, wie man mit Witzen arbeiten sollte, damit die Lerner sie verstehen. 
Sammlungen von Witzen oder Dossiers, thematisch gruppiert, finden sich auch online. ${ }^{1}$ Sehr wenig davon sind für den Sprachunterricht aufbereitet. Zum Thema „Witze zu Schule und Lernen“2 findet man z.B. zehn Witze vor, mit denen das Leseverstehen durch Zuordnungsübungen trainiert werden kann. Eine Textrekonstruktionsübung ist anhand von 18 männerfeindlichen Witzen ${ }^{3}$ vorhanden.

Überblickt und untersucht wurden auch gängige im Fremdsprachen-/DaF-Unterricht eingesetzte Unterrichtslehrwerke, in denen es Cartoons gibt. ${ }^{4}$ Sie werden meistens zum Einstieg ins Thema gewählt, wie in der Lektion „Kommunikation“ in „Sprachkurs Deutsch neu“ (Lektion 5: 228-229), in der vor allem die Formen des Verstehens und des Missverstehens analysiert werden. Im Lehrwerk „Auf neuen Wegen“ dienen Cartoons dem heiteren Beruferaten (Auf neuen Wegen: 72), in anderen Lehrbüchern der Veranschaulichung von Zitaten, Sprichwörtern, Texten (Berliner Platz 3: 135; Unterwegs, Materialienbuch: 19) oder zum Verfassen lustiger, ernsthafter oder spannender Geschichten (em-Brückenkurs, Kursbuch: 43, Arbeitsbuch: 44, 48-49). Zusammenfassend kann festgehalten werden, dass Cartoons und andere humoristische Unterrichtsmittel zum Veranschaulichen, zum Einstieg ins Thema, als Schreib- und/oder Sprechanlass verwendet werden und damit nur die Funktion eines „Vehikels“ haben (Hohenhaus 2000: 443). Ob sie als komisch oder nicht empfunden werden (und wenn ja/nein, warum), wird nicht thematisiert. Selbst bei Cartoons zum Thema Kommunikation oder Alltag der Deutschen wird das humoristische Bildmaterial nicht als Grundlage für eine inhaltliche Auseinandersetzung genutzt. So ist es nicht verwunderlich, dass die Untersuchung der Lehrwerke für Deutsch als Fremdsprache für alle Niveaustufen ergab, dass die Textsorte „Witz“ eine „Seltenheit“ darstellt. In „Hülle und Fülle“ findet man sie nur im „Delfin“-Lehrbuch (168-170) im Zusammenhang mit dem Thema Humor und Alltag, und zwar in den Bestandteilen Eintauchen, Lesen und Hören. Dort sind Witze zu finden, die Allgemeines zum Thema haben, z.B. ein Musikerwitz oder ein Polizistenwitz. Die Witztexte werden hier - wie andere authentische Texte - für das Training der verschiedenen Fertigkeiten wie Lese- und Hörkompetenzen verwendet. Die methodischdidaktische Aufbereitung der Witze in dem Buch lässt charakteristische Übungen zum Spracherwerb erkennen, wie z.B. Zuordnungs- oder Richtig-/Falsch-Übungen sowie Ergänzungsübungen. Die Beschäftigung mit dem Aufbau und den Inhalten der Witze ist ebensowenig vorgesehen wie individuelle und interkulturelle Reflexionen bezüglich möglicher Humorkonzepte in verschiedenen Kulturen. Lediglich im DaF-Lehrwerk

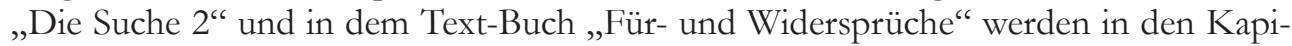
teln über kulturelle Begegnungen und Stereotype unter anderem auch ethnische Witze besprochen und dabei folgende Fragen diskutiert: „Mit welcher Absicht werden solche Witze erzählt?“ „Inwiefern kommt es darauf an, wer solche Witze erzählt?“ (Für- und Widersprüche: 18-24), „Verschiedene Nationen: Welche Stärken und Schwächen wer-

Z.B. http://www.deutsch-als-fremdsprache.de/infodienst (10.12.2009).

S. http://www.daf-portal.de/unterrichtsideen/index.php3?bereich=005 (10.12.2009).

S. http://vonrauch.de/daf/Textrekonstruktion/MaennerfeindlicheWitze.pdf (10.12.2009).

Siehe auch die Auflistung am Ende dieses Beitrags. 
den den einen und den anderen zugeschrieben?“, „In Ihrem Land: Über welche Nationalitäten/Gruppen erzählt man gerne Witze?“ (Die Suche 2: 148-149).

\section{Der Witz}

Will man als Lehrender Witze im DaF-Unterricht einsetzen, sollte man als erstes klären, was die Gattung der Witze bzw. den humoristischen Diskurs auszeichnet und worin die Ursachen für die besondere Wirkung des Witzes liegen. Diese Fragen stehen im Mittelpunkt, wenn es um den Witz als Untersuchungsgegenstand geht. Das Wissen über die Besonderheiten der Textsorte ist wichtig, wenn man die Witztexte für den Unterricht aufbereiten will.

Ein typisches Merkmal des Witzes, der einen kurzen, selbständigen, fiktionalen, komisch pointierten Prosatext (mündlich und/oder schriftlich) darstellt, ist seine komprimierte sprachliche Form mit intellektueller Zuspitzung. Da der Witz auf der Kunst des Andeutens basiert, ist - aufgrund eben dieser verschlüsselten, geheimen Vorgänge - für das Verstehen eine relativ hohe Anstrengung vonnöten. Beim Witzeverstehen werden beim Hörer/Leser ähnliche Motive, Erfahrungen und Wertungen vorausgesetzt. Der Witz umreißt eine bestimmte, dem Alltagsleben entnommene Situation (gesellschaftlich unerwünschte Gedanken denken und aussprechen; Ablehnung von Personen und Vorgängen direkt oder indirekt in einer verbindlichen und durch das gemeinsame Lachen verbindenden Form zu äußern) und hat folgende psychische und soziale Funktionen: Spannungsabbau, Angstüberwindung, Lustgewinn, „Veredlung“ des Schlechten sowie Gesellschaftskritik. Der Witz lässt folgenden Aufbau erkennen:

- Einleitung oder Einführung in die Ausgangssituation des Witzgeschehens (1)

- Überleitung von der Ausgangssituation zur Pointe (2)

- Pointe (3)

Beispiel: ${ }^{5}$

(1) Aus der geschlossenen Abteilung einer psychiatrischen Klinik sind während eines Brandes einige Patienten geflohen. Die Pfleger machen sich daran, sie wieder einzufangen.

(2) Als die nach einigen Stunden wieder zurück sind, fragt der Chefarzt den Pflegeleiter: "Sind alle zehn ausgebrochenen Patienten wieder da?““

(3) „Was, bloß zehn?“ meint der Pfleger verblüfft, „wir haben zwanzig mitgebracht!“

Ableiten lässt sich eine operationale Definition des Witzes als kurz gefasstes sprachliches Gebilde, das mittels verschiedenartiger Tricks Pointen erzeugt und damit den Hörer oder Leser zum Lachen bringt.

Meine didaktischen Überlegungen zum Witz im interkulturellen DaF-Unterricht gehen von der Leitfrage aus: In welcher Weise können die Rezeption und Analyse, unter Umständen auch die Produktion von Witzen im Unterricht dazu beitragen, bei den Lernern Kompetenzen zur Bewältigung von verschiedenen Lebenssituationen, aber auch von speziellen sprachlichen Kommunikationssituationen auszubilden? Im Fol-

\footnotetext{
5 Die nachfolgenden Witze stammen aus den im Verzeichnis angeführten Witzequellen.
} 
genden werden verschiedene, erprobte Vorschläge skizziert, wie man mit Witzen den Unterricht bereichern und in welcher Weise der Witz zur Aufwertung des Unterrichts beitragen kann.

\section{Sprachhandlungskompetenz: Der Witz als Unterrichts- gegenstand}

\section{1 Üben des Leseverstehens}

Funktioneller Sprachunterricht geht in der Regel nicht deduktiv, sondern induktiv vor, indem nicht aus dem Text herausgelöste isolierte Ausdrücke untersucht werden, sondern die sprachliche Erscheinung in ihrer Kontext- und Situationsabhängigkeit (Burger 1995: 33). Aus diesem Grunde kommt vor allem im Anfängerunterricht dem Leseverstehen eine besondere Bedeutung zu. So können bereits im Anfangsunterricht Lesetexte zur Anwendung kommen, die in Wortschatz und Grammatik über das hinausgehen, was die Schüler und Studenten bis dahin gelernt haben, unter der Bedingung, dass sie lediglich rezeptiv bearbeitet werden; dem Lerner wird somit ermöglicht, den aufgrund seines noch geringen Sprechvermögens vorgegebenen engen thematischen Rahmen punktuell zu überschreiten. Das Verdienst eines ausgiebigen Lesetrainings besteht darin, Techniken der Worterschließung zu schulen, was im Endeffekt dazu führen sollte, dass der Lerner weniger Zeit dazu benötigt, unbekannte Vokabeln zu identifizieren, da er gelernt hat, sie aus dem Kontext zu erschließen.

Unter Berücksichtigung dieser Faktoren bietet sich der Witz als Unterrichtsmaterial zum Training des Leseverstehens aus folgenden Gründen an: Lernende, deren Sprachkenntnisse noch begrenzt sind, neigen dazu, beim kontextuellen Erschließen nur den unmittelbaren Zusammenhang, also lediglich den jeweiligen Satz, in dem sich die unbekannte Vokabel befindet, zu berücksichtigen. Die Kürze und Geschlossenheit des Witzes, insbesondere seine Pointiertheit verpflichten dagegen den Lerner zur genauen Beachtung des vorgegebenen Wortlautes, und zur Erfassung des Gesamttextes, da die Pointe sonst nicht verstanden werden kann. Für das Erschließen der Pointe sind auch Satzmelodie und Satzakzent wichtig, die mit geübt werden.

Im Anfängerunterricht nehmen die Lerner häufig eine ablehnende Haltung gegenüber längeren Texten ein, die Erfahrung hat sicher jeder gemacht. So bietet sich der Witz als kurze, abgeschlossene Texteinheit eher an, die Lerner zur Wahrnehmung des Textes zu motivieren. Darüber hinaus fördert natürlich auch die Freude am Erkennen der Pointe das Interesse an dem Text.

Die konventionelle Methode, den Witztext im Unterricht zu präsentieren, besteht im Vorlesen bzw. dem gemeinsamen Lesen des Textes mit den Lernern. Daneben möchte ich noch eine weitere Variante der Witztextdarbietung anführen, die wie die beiden erstgenannten vorrangig der Entwicklung des Lesens und des Verstehens dienen soll: Der Witztext wird den Lernern in verkehrter Zeilenfolge dargeboten, so dass diese aufgefordert sind, durch Nummerierung der Zeilen den Witz in seiner richtigen Reihenfolge zusammenzusetzen. Dazu kann der Text beispielsweise zeilenweise zerschnitten und an die Lerner verteilt werden, die anschließend die 
richtige Anordnung der Zeilen vornehmen. Dabei ist es nicht immer nötig, jedes unbekannte Wort zu erläutern. Indem die Lerner versuchen, die richtige Reihenfolge der Textzeilen herauszufinden, gelingt es ihnen auch eher, unbekannte Begriffe aus dem Zusammenhang zu erschließen.

Der Spaß an solchen Übungen sowie die Freude über das gelungene Ergebnis werden die Kursteilnehmer zu weiteren Aktivitäten motivieren; der Fremdsprachenunterricht lässt sich somit abwechslungsreicher und emotionaler gestalten.

\subsection{Förderung der Erzählbereitschaft und -fähigkeit}

Rezeption und insbesondere die Produktion von Witzen im Rahmen des Fremdsprachenunterrichts können darüber hinaus zur Verbesserung der mündlichen Ausdrucksfähigkeit sowie zur Förderung der Gesprächsbereitschaft beitragen. Im Vordergrund steht hierbei die Anregung zur kreativen Äußerung, indem sich die Textproduktion nicht auf einfache Reproduktionen beschränkt, sondern indem der Lerner eigenständig mit der Sprache handelt. Dadurch wird auch die eintönige und ausdruckslose Unterrichtssprache vermieden und ein realitätsnaher Sprachgebrauch erreicht.

Im Folgenden möchte ich verschiedene Vorschläge präsentieren, wie man Witze als Impulse im Bereich mündlicher (zum Teil auch schriftlicher) Kommunikation einsetzen kann.

\section{(a) Spontanes Erzählen von Witzen}

Witze zu erzählen ist eine besonders beliebte Form des Erzählens; eine im Rahmen des Fremdsprachenunterrichts regelmäßig stattfindende „Witz-Viertelstunde“ wäre nicht nur zur Schaffung einer lockeren Atmosphäre geeignet, sondern könnte auch dazu beitragen, den Lerner zum häufigen und korrekten Sprechen zu bewegen. In Abhängigkeit von Alter und Sprachniveau der Schüler wären zwei Varianten des methodischen Vorgehens möglich:

Mündliches „Nacherzähblen“ von Witzen: Im Anfangsunterricht sind die Lerner noch nicht in der Lage, selbständig Witze in der Fremdsprache zu produzieren und frei zu gestalten, der Lehrer muss daher den Lernern geeignete Witze zur Verfügung stellen. Eine Unterrichtsstunde ließe sich dabei in der Form gestalten, dass der Lehrer den Lernern mehrere einfach gestaltete Witze vorliest, und die Kursteilnehmer im Anschluss daran die Witze nacherzählen lässt, die ihnen gefallen haben und die sie sich besonders gut einprägen konnten. Das mündliche Nacherzählen eines Witzes erfordert vom Lerner, einen Text von relativ strenger formaler Gebundenheit in eigener Weise zu interpretieren durch eine möglichst planvolle, auf Wirkung beim Zuhörer angelegte Gestaltung seines Vortrages. Durch das gleichzeitige Aufnehmen, Verarbeiten und Reproduzieren des Witzes werden bei den Lernern nicht nur Fertigkeiten zur mündlichen Textbildungskompetenz ausgebildet, sondern auch deren mündliche Rezeptionsfähigkeit geschult.

Selbstständige Produktion von Witzen: Im fortgeschrittenen Fremdsprachenunterricht könnten die Kursteilnehmer im Rahmen einer solchen regelmäßigen „Witz-Viertelstun$\mathrm{de}^{\text {“ }}$ ermutigt werden, selbstständig ihnen bereits bekannte Witze zu initiieren. Voraussetzung dazu wäre, dass die Lerner bereits über eine „Sammlung“ deutschsprachlicher 
Witze verfügen, die sie sich unter anderem durch das regelmäßige Lesen von Zeitschriften angeeignet haben. Solch eine Unterrichtseinheit lebt vom spontanen mündlichen Mitteilungsdrang der Lerner, wodurch eine lockere Erzählrunde geschaffen wird, innerhalb derer wiederum andere angesteckt werden, produktiv mitzumachen. Möglicherweise werden dabei auch gehemmte Studenten aus der Reserve gelockt. Das freie Erzählen von Witzen in einer fremden Sprache stellt, auch wenn die Kürze der Textsorte Witz die Aufgabe etwas erleichtert, für den Lerner eine besondere Anforderung dar: Während der Lerner zum freien Formulieren eines Witzes schon über besondere Ausdrucksfähigkeiten in der fremden Sprache verfügen muss, ist er zudem gehalten, unter Zuhilfenahme entsprechender para- und extraverbaler Gestaltungsmittel die Aufmerksamkeit des Zuhörers zu erwecken. Die unmittelbar wahrzunehmende Reaktion der Zuhörer ist eine natürliche Erfolgskontrolle für den Erzähler und ein Ansporn zu weiteren Versuchen; entsprechende Erfolgserlebnisse fördern die kommunikative Kompetenz auch bei nichterzählerischen Gesprächsformen, wie beispielsweise Beschreiben oder Berichten.

(b) Übersetzung von deutschen Witzen in die Fremdsprache

Eine andere Möglichkeit, Witze innerhalb des Fremdsprachenunterrichts zum Einsatz zu bringen, besteht darin, anstelle des freien Vortrages, Witze vorlesen zu lassen, die ursprünglich bulgarisch/muttersprachig waren, und durch eine Gruppenarbeit in die deutsche Sprache übertragen wurden. Wichtig ist, ein Angebot an bestimmten deutschen Witzen zur Verfügung zu stellen, die sich in eine andere Sprache übersetzen lassen, ohne dass die Wirkung der Pointe verloren geht. Die Umsetzung eines muttersprachlichen Witzes in die deutsche Sprache ist dabei nicht einfach mit einer bloßen Transkription gleichzusetzen, sondern verlangt vom „Übersetzer“ die Fähigkeit, ein bestimmtes Geschehen innerhalb eines vorgegebenen Erzählrahmens in sprachlich korrekter Form aufzuarbeiten und gleichzeitig situationsangemessen und adressatengerecht zu gestalten, so dass Pointe und Komik selbst in der fremden Sprache erhalten bleiben.

(c) Die Anwendung des Witzes im Grammatikunterricht

Grammatische Regeln und dazugehörige Mustersätze werden nur mit Mühe geübt, da sie in der Regel nicht nur zu abstrakt und trocken sind, sondern auch wenig motivierend und einprägsam. Der typische Grammatiksatz ist aus der Situation gerissen. Da in einer Lerngrammatik das grammatische Phänomen in einer sinnvollen sprachlichen Umgebung stehen sollte, könnte und sollte der Witz als Textbeispiel in die Grammatiken aufgenommen werden. Argumente dafür wären: Der Witz stellt eine vollständige kleine Situation dar, die zumeist an allgemeinmenschliche Erfahrungen anknüpft. Zudem umfasst er viele Stilebenen der lebendigen Schrift- und Umgangssprache. Durch die Anteilnahme des Lesers und sein „Aha-Erlebnis“ prägt sich die sprachliche Struktur solcher Texte besser ein. Witze mit guter Pointe sind eine intellektuelle Herausforderung, sie regen zum Nachdenken und wiederholtem Lesen an. 
Beispiele:

1. Die Ehefrau sagt zu ihrem Mann: „Du, ich finde es nicht gut, dass du immer sagst ,mein Haus', ,mein Auto'. Alles, was wir haben, gehört uns doch gemeinsam. Warum sagst du nicht ,unser Haus', ,unser Auto' - hörst du mir eigentlich zu, was suchst du denn im Kleiderschrank?“ „Unsere blaue Hose.“ (Possessivpronomen)

2. Ein Mann kommt in eine Tierhandlung und will einen Papagei kaufen. Er fragt: „Wie viel kostet dieser wunderschöne Papagei?“ Der Verkäufer antwortet: „Der ist nicht billig. Er spricht drei Sprachen. 2000 Euro müssen Sie schon bezahlen.“ Der Kunde sagt: „Das ist viel Geld. Was soll denn dieser zweifarbige Papagei gleich daneben kosten?" Verkäufer: , 3000 Euro.“ Mann: „, Und was muss ich für diesen grauen Papagei da links bezahlen?“ Verkäufer: „Der kostet 4000 Euro?“ Mann: „4000 Euro für einen so mickrigen Vogel! Was kann der denn?“ Verkäufer: „Was er kann, das weiß ich auch nicht so recht. Aber die anderen sagen ,Chef' zu ihm.“ (Modalverben)

\subsection{Sensibilisierung für Stereotype ${ }^{6}$}

Gute Erfahrung konnte ich mit dem Einsatz von Nationen- und Ethnowitzen in kulturheterogenen Lernergruppen machen, wo interkulturelles Lernen sozusagen selbstverständlich passiert. Interkulturalität ist Bestandteil des Geschehens im Unterricht, was auch Negatives bedeuten kann, denn es kann zu Konflikten kommen.

Bei aller Brisanz können ethnische Witze als sozial relevante und imagologisch aufschlussreiche Phänomene im Fremdsprachenunterricht zu interkulturellen Sensibilierungszwecken eingesetzt werden, denn sie

1. repräsentieren die Bilder in den Köpfen der Menschen,

2. sind als Textsorte weder sprach- noch kulturspezifisch,

3. sind Träger von ethnischen Stereotypen, so dass der Lerner sowohl über standardisierte Fremd- als auch Eigenbilder reflektieren kann,

4. sindbrauchbarelandeskundliche Textmaterialien, die als Quelle für Fremderfahrungen angesehen werden können,

5. können - neben der bereits beschriebenen Förderung der Kommunikationsfähigkeit - zum Einüben von Perspektivenwechsel dienen, was die Fähigkeit zum Fremdverstehen und zur Empathie einschließt (Hoffmann 2000: 86f.).

Im Unterricht, der interkulturelles Lernen mit Hilfe von ethnischen Witzen zum Ziel hat, sollten die Lernenden Wahrnehmungsfertigkeiten erwerben, sich der Existenz von Stereotypen und Vorurteilen bewusst werden, aber auch lernen, diese zu hinterfragen und zu widerlegen. Es sollten nicht nur die eigenen Heterostereotype bzw. Vorurteile der eigenen Gruppe gegenüber einer anderen thematisiert werden. Ein wichtiger Lernschritt stellt die Auseinandersetzung mit dem Blick der anderen auf die eigene Gruppe dar. Dies ist umso wichtiger, als durch die direkte Betroffenheit die Unhaltbarkeit von Stereotypen, die ja auf simplifizierender Generalisierung beruhen, gezeigt werden kann.

6 Zu Allgemeinstereotypen lässt sich eine Unmenge an Forschungsliteratur finden, zu Ethnostereotypen weniger. Meine Ausführungen basieren auf der Definition von Hoffmann (2000: 86f.). 
Die Lerner sind auch für Differenzen zwischen Selbstwahrnehmung und Selbstdarstellung für andere zu sensibilisieren.

Die konkrete Arbeit mit ethnischen Witzen, die bekanntlich auf Vorstellungsklischees der Wirklichkeit beruhen und nicht die Wirklichkeit selbst darstellen, könnte mit dem Ermitteln von stereotypen Vorstellungen von Deutschland und dem Heimatland beginnen, damit die Lerner sich bewusst werden, welche Auto- und Heterostereotype allgemein im Umlauf sind und welche sie selber haben. Gleichzeitig werden die Lerner mit dem Begriff „Stereotyp“ bekannt gemacht und allmählich befähigt, Stereotype einer kritischen und sachbezogenen Analyse zu unterziehen, um sich von klischeehaften Vorstellungen einer fremden Kultur zu befreien und die eigene Kultur besser verstehen zu können.

Methodisch lässt sich das Deutschlandbild z.B. mit Eigenschaftslisten schnell ermitteln, wobei die Lerner zur Kritik an den Listen angeleitet werden, damit sie erkennen, dass sie auf diese Weise nur Qualifizierungen erhalten, die der Mensch selbst erschaffen hat. Ein Aufsatz über ihr Deutschlandbild ergibt ein differenzierteres Bild, wobei gleichzeitig Deutsche (etwa über ein E-Mail-Tandem, wie es an der TU Sofia seit langem praktiziert wird, ${ }^{7}$ oder in Bulgarien lebende Deutsche oder Touristen) ein Selbstbild entwerfen könnte. Das Ziel ist, möglichst umfangreiche, aber auch qualitative Daten zu erheben, denn es sollten Gründe für bestimmte Einstellungen und Urteile ermittelt werden. So entstehen widersprüchliche und kontroverse Bilder und vielschichtige Urteile, für die die Lerner sensibilisiert werden.

In dieser Phase können Sachtexte über die Deutschlandbilder anderer Nationen gelesen und Fragen nach der „Gültigkeit“ der Äußerungen des Autors besprochen werden. Es können aber auch Fragebögen zu Fremd- und Selbstbildern entworfen werden. Im Fragebogen kann unter anderem weiter zwischen persönlichem und vermutetem Heterostereotyp differenziert werden. Hier ein Beispiel für einen solchen Fragebogen.

Angaben zum Befragten. Bitte angeben und oder ankreuzen.

1. Heimatland:

2. Geschlecht: w m

1. Wie sehen Sie selbst die Deutschen? Beschreiben Sie den typischen Deutschen. Wenn Ihnen das deutsche Wort nicht sofort einfällt, so können Sie auch das bulgarische Wort notieren.

2. Was meinen Sie, wie schätzen Ihre Landleute die Deutschen ein?

3. Was meinen Sie, wie schätzen die Deutschen Ihre Landsleute ein?

4. Wie sehen sich die Deutschen selbst? Wie könnte das deutsche Selbstbild konstituiert werden?

5. Welche Schwierigkeiten haben Deutsche in Ihrem Heimatland?

6. Auf welche Schwierigkeiten treffen

- Ihre Landsleute?

- treffen Sie in Deutschland?

S. http://www.tu-dresden.de/sulifg/daf/daflinks.htm oder auch http://www.slf.ruhr-uni-bochum.de/ etandem/etindex-de.html (10.12.2009). 
Zusammenfassend lässt sich noch einmal sagen: Ein wichtiges Lernziel ist die Bewusstmachung von tradierten Selbst- und Fremddarstellungen und ihr fraglicher Wahrheitsgehalt sowie die Sensibilisierung für und die Reflexion über Selbstbilder, Selbstdarstellungen und vermutete Fremdbilder. Diese Lernergebnisse lassen sich neben den unter 3.1 und 3.2 genannten Sprachhandlungskompetenzen nennen.

Bevor die konkrete Arbeit mit den Witzen beginnt, ist eine Auswahl der Witze zu treffen. Dabei wäre die Berücksichtigung folgender Kriterien nützlich:

1. Relevanz für die Lerner. Thematisiert der Witz Bereiche, die für die Lerner von Interesse sind und in denen sie ihre eigene Erfahrung, ihr Weltwissen mitbringen oder einbringen können?

2. Wie viel kulturspezifisches Wissen wird für das Verständnis des Witzes vorausgesetzt?

3. Ist der Witz repräsentativ für die Kultur/die Nationalität?

4. Wie ist die sprachliche Angemessenheit?

5. Wie ist die Ergiebigkeit des Textes für die Rezeption, z.B. seine Länge?

Bei ethnischen Witzen ist außerdem die Relevanz des Stereotypes in dem Witz für die Pointe zu überprüfen, d.h. welche Rolle ethnische Stereotype bei der Pointenkonstruktion spielen. ${ }^{8}$ Zwei Fälle sind möglich: 1. Das ethnische Stereotyp ist nicht konstitutiv. Es ist aus dem Witz erschließbar. 2. Das ethnische Stereotyp kann nicht erschlossen werden, sondern wird vom Leser als Wissen unterstellt. Das heißt auch, dass die Ethnie nicht ausgetauscht werden kann. Ein solches ethnisches Stereotyp ist pointenkonstruktiv.

Ethnische Witze arbeiten sowohl mit aus dem Witz erschließbaren (Fall 1) als auch mit als bekannt unterstellten Stereotypen (Fall 2). Für den Einsatz im Fremdsprachenunterricht ist zu überprüfen, ob der Witz sprachlich vorentlastet werden muss, was angesichts der für die Witze typischen Wortspiele oft der Fall ist.

Das folgende Beispiel soll die Relevanz des Stereotyps für die Pointe und das für das Verstehen notwendige „Vorwissen“ verdeutlichen. Der Witz als Text:

\section{Himmel und Hölle in Europa}

Himmel ist, wo die Engländer die Polizisten sind, wo die Deutschen die Mechaniker sind, wo die Franzosen die Köche sind, wo die Italiener die Liebhaber sind und wo die Schweizer alle organisieren.

Hölle ist, wo die Deutschen die Polizisten sind, wo die Franzosen Mechaniker sind, wo die Engländer die Köche sind, wo die Schweizer die Liebhaber sind und wo die Italiener alle organisieren.

8 In der Pointe werden zwei zunächst unabhängig voneinander scheinende Vorstellungsbereiche in überraschender und überzeugender Weise miteinander verknüpft. 
Über den Witz können die Lerner lachen, wenn sie die notwendige Stereotypenkenntnis mitbringen. Als Übung zur Reflexion hat sich folgende Umkehrübung bewährt:

In dem Witz über die Hölle und den Himmel in Europa wird die Hölle so dargestellt:

\section{Himmel und Hölle in Europa}

Hölle ist, wo die Deutschen die Polizisten sind, wo die Franzosen Mechaniker sind, wo die Engländer die Köche sind, wo die Schweizer die Liebhaber sind und wo die Italiener alle organisieren.

Wie sieht der Himmel aus? Ergänzen Sie:

Himmel ist, wo die ....................... die Polizisten sind, wo die ....................... die Mechaniker sind, wo die ....................... die Köche sind, wo die ........................ die Liebhaber sind

und wo die alle organisieren.

Ein weiteres Beispiel, in dem der Stereotyp für die Pointe sehr wichtig ist, basiert nicht auf Stereotypen von Nationen oder Ethnien, sondern von verschiedenen Städten bzw. ihrer Einwohner.

„Ein Wiesbadener, ein Nürnberger und ein Stuttgarter sind auf eine Party eingeladen. Der Wiesbadener bringt sechs Flaschen Wein mit, der Nürnberger sechs Flaschen Bier und der Stuttgarter sechs gute Freunde.“ Auch dieser Witz lässt sich durch Zuordnungen, Ergänzungen, Übertragungen auf die Heimatkultur (z.B. ein Sofioter, ein Plovdiver und ein Schumener) ,weiterspinnen“ und - wie von Hohenhaus gefordert - heitere Weise für die Arbeit mit der Stereotypenproblematik verwerten.

Für die Zwecke des interkulturellen Lernens mit ethnischen Witzen wären folgende Aufgabentypen angemessen:

1. Szenen erspielen: Der Witz wird dramatisierend nachgespielt. Es wird deutlich, wie die Lerner den Witz interpretieren, so kann man auch den kulturfremden Text den Lernern näher bringen. Die vom Witz vorgegebenen Beziehungskonflikte lassen sich im Unterricht in Form von Rollenspielen szenisch umsetzen und erörtern, so wird die Fähigkeit zur Perspektivendifferenz, Empathie und Perspektivenübernahme geübt.

- Ein Amerikaner, ein Engländer und ein Schweizer sitzen zusammen und prahlen mit nationalen Errungenschaften. Der Engländer sagt: „Wir bauen jetzt ein Unterseeboot, das kann ein Jahr unter Wasser bleiben, es fährt völlig lautlos und ist so schnell wie ein Flugzeug!“ „Und wir", erwidert der Amerikaner, „bauen jetzt einen Wolkenkratzer in Chicago, 600 Meter hoch und nur aus Glas - kein Stahl, kein Beton, ausschließlich Glas!“ Der Schweizer sagt, nachdem er lange nachgedacht hat: „So etwas Gewaltiges haben wir natürlich nicht. Aber bei uns am 
Vierwaldstätter See, da lebt ein Knecht, wenn der einen guten Tag sagt, können acht Raben nebeneinander auf ihm sitzen!" Nach einer langen Pause beginnt der Engländer wieder zu erzählen: „Also ...“

2. Hypothesenbildung: Bei längeren Witzen wird das Lesen unterbrochen und man lässt die Lerner vermuten, wie es weitergehen könnte; auch hier wird die Perspektivenübernahme geübt.

- Ein amerikanischer und ein deutscher Architekt wetten, wer schneller bauen könne. Nach einem Monat ...

3. Witze aus anderer Perspektive schreiben lassen, aus der Perspektive einer anderen Person. Beim Umschreiben in einen anderen (eigenkulturellen) Kontext wird das Bewusstwerden der eigenkulturellen Identität gefördert.

- Ein Amerikaner, ein Engländer, ein Franzose und ein Deutscher haben einen Schiffsuntergang überlebt und sind auf einer Insel gestrandet. Nach ein paar Mo-

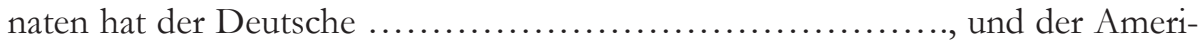
kaner

Oder

- Jede Nation sollte ein Buch über den Elefanten schreiben:

Frankreich: ...

England: ...

Wales: ...

Amerika: ...

Japan: ...

Griechenland: ...

...

4. Frei produktive Aufgabenstellungen bieten sich an, die auf dem Perspektivenwechsel beruhen, z.B. die Erstellung eines Umkehrtextes.

5. Die Teilnehmer können Texte und Rollenspiele entwerfen, denen eigene Erfahrungen auf Ferienreisen oder Auslandsaufenthalten zugrunde liegen - zu diskutieren wären dabei die Verbindlichkeit von Normen, wie z.B. generationsspezifische Normen, Geschlechterrollen.

\section{Plädoyer für mehr Witz(e) im Fremdsprachenunterricht}

Humoristisches Material, darunter Witze, können im Fremdsprachenunterricht vielfältiger verwendet werden als nur zu Spracherwerbszwecken. Vor allem Nationen- und Ethnowitze bieten sich für interkulturelle Sensibilisierungsübungen und Reflexionen über die verschiedensten Aspekte von Stereotypisierungen an. Durch die Beschäftigung mit den Ethnostereotypen in Nationen- und Ethnowitzen sollen die Lerner Wahrnehmungsfertigkeiten erwerben, mit denen sie sich der Existenz und Funktionen von Stereotypen bewusst werden, und kognitive Fähigkeiten, mit denen sie diese hinterfragen und auch widerlegen können. Einen wichtigen Lernschritt stellt dabei die Auseinan- 
dersetzung mit fremden Stereotypen und Vorurteilen gegenüber der eigenen Gruppe dar, weil durch die direkte Betroffenheit die Differenzen zwischen Fremd- und Selbstwahrnehmung am deutlichsten spürbar sind und die Fragwürdigkeit bzw. Unhaltbarkeit von stereotypen Äußerungen am deutlichsten werden. Wenn obendrein „Humor als pädagogisches Mittel hilft" (Urios-Aparisi; Wagner 2008: 244) und zu einer entspannteren Atmosphäre im Unterrichtsraum beiträgt, kann nur dafür plädiert werden, im Fremdsprachenunterricht etwas großzügiger damit umzugehen. Denn „[b]eim Lachen erhebt sich der Mensch über alle kulturellen Grenzen. Das Lachen ist Explosion, Entladung, Befreiung, es ist ganz Bauch als Gegenpol zum Kopf.“ (Hoffmann 2008: 212).

\section{Literatur}

Burger, Günther (1995): Mehr Lesen im Anfängerunterricht? In: Burger, Günther (Hrsg.): Fremdsprachenunterricht in der Erwachsenenbildung. Perspektiven und Alternativen für den Anfängerunterricht. Braunschweig: Westermann, 33-37.

Dimova, Ana (2008): Humor und Witz als Übersetzungsproblem. In: Hoffmann, Tina; Lercher, Marie-Christin; Middeke, Annegret; Tittel, Kathrin (Hrsg.): Humor. Grenzüberschreitende Spielarten eines kulturellen Phänomens. Göttingen: Universitätsverlag, 7-20.

E-Tandem Europa: http://www.slf.ruhr-uni-bochum.de/etandem/etindex-de.html (10.12.2009).

Hoffmann, Edgar (2000): Russland und der Westen in der Werbung. In: Rösch, Olga (Hrsg.): Stereotypisierung des Fremden. Auswirkungen in der Kommunikation. Berlin: News \& Media, 85-112.

Hoffmann, Tina (2008): Humor im Theater mit Fremdsprachenstudenten oder: Warum gerade Komödie? In: Hoffmann, Tina; Lercher, Marie-Christin; Middeke, Annegret; Tittel, Kathrin (Hrsg.): Humor. Grenzüberschreitende Spielarten eines kulturellen Phänomens. Göttingen: Universitätsverlag, 205-213.

Hohenhaus, Peter (2000): Zur Verwendung humoristischen Materials im DaF-Unterricht. In: Info DaF 4, 433-448.

Urios-Aparisi, Eduardo; Wagner, Manuela (2008): Eine empirische Untersuchung zum Einsatz von Humor im Fremdsprachenunterricht in den USA. In: Hoffmann, Tina; Lercher, Marie-Christin; Middeke, Annegret; Tittel, Kathrin (Hrsg.): Humor. Grenzü̈berschreitende Spielarten eines kulturellen Phänomens. Göttingen: Universitätsverlag, 233-250.

Ulrich, Winfried (1980): Der Witz, im Deutschunterricht. Braunschweig: Westermann.

Zeuner, Ulrich (1998): E-Mail-Projekt „Interkulturelle Bewusstheit“. Kursbuch, http:/ /www. tu-dresden.de/sulifg/daf/mailproj/inhalt.htm (10.12.2009).

\section{Gesichtete Lehrwerke}

Aufderstraße, Hartmut; Müller, Jutta; Storz, Thomas (2005): Delfin. Zweibändige Ausgabe. Lehrbuch Teil 1. Ismaning: Hueber.

Aufderstraße, Hartmut; Müller, Jutta; Storz, Thomas (2005): Delfin. Zweibändige Ausgabe. Arbeitsbuch Teil 1. Ismaning: Hueber.

Aufderstraße, Hartmut; Müller, Jutta; Storz, Thomas (2005): Delfin. Zweibändige Ausgabe. Lehrbuch Teil 2. Ismaning: Hueber. 
Aufderstraße, Hartmut; Müller, Jutta; Storz, Thomas (2005): Delfin. Zweibändige Ausgabe. Arbeitsbuch Teil 2. Ismaning: Hueber.

Bahlmann, Clemens; Breindl-Hiller, Eva; Dräxler, Hans D.; Ende, Karin; Storch, Günther (2004): Unterwegs. Materialienbuch. Berlin; München: Langenscheidt.

Eisman, Volker; Schneider, Peter; Altschüler, Ursula; Rothenhäusler, Rainer; Thurmair, Maria (1996): Die Suche 2. Berlin; München: Langenscheidt.

Häussermann, Ulrich; Dietrich, Georg; Günther, Chritiane (1989-1994): Sprachkurs Deutsch NEU. Band 1-6. Frankfurt a.M.: Sauerländer; Diesterweg.

Köker, Anne; Lemcke, Christiane; Rohrmann, Lutz; Rusch, Paul; Scherling, Theo; Sonntag, Ralf (2004): Berliner Platz 3. Berlin; München: Langenscheidt.

Orth-Chambah, Jutta unter Mitarbeit von Perlmann-Balme, Michaela; Schwalb, Susanne (2006): em-Brückenkurs. Arbeitsbuch. Ismaning: Hueber.

Perlmann-Balme, Michaela; Schwalb, Susanne; Weers, Dörte (2006): em-Brückenkurs. Kursbuch. Ismaning: Hueber.

Roche, Jorg; Webber, Mark J. (1994): Für- und Widersprüche: Ein integriertes Textbuch für Colleges und Universitäten. New Haven; London: Yale UP.

Willkop, Eva-Maria; Wiemer, Claudia; Müller-Küppers, Evelyn; Eggers, Dietrich; Zöllner, Inge (2007): Auf neuen Wegen. Deutsch als Fremdsprache für die Mittelstufe und Oberstufe. Ismaning: Hueber.

\section{Witzeverzeichnis}

1. Bettermann, Rainer (1996/1997): Typisch Deutsch? Seminarmaterial Wintersemester 1996/1997, Konzept-Literatur-Material, FSU Jena.

2. Howland, Chris; Lenz, Michael; Thoma, Dieter (1999): Ganz Deutschland lacht. 50 deutsche Jahre im Spiegel ibrer Witre. München: dtv.

3. Köhler, Peter (1993): Das Witzbuch. Stuttgart: Reclam.

4. Spier, Anne (2008): Mit Witzen Deutsch lernen. Eine Sammlung von 520 Witzen für den Sprachunterricht Deutsch als Fremdsprache/Zweitsprache. Berlin: Cornelsen Verlag Scriptor.

5. Zeuner, Ulrich (1998): E-Mail-Projekt Interkulturelle Bewusstheit. Kursbuch, http:// www.tu-dresden.de/sulifg/daf/mailproj/inhalt/htm (10.12.2009).

\section{Internetquellen (14.12.2009)}

1. www.daf-portal.de/unterrichtsideen

2. www.fischernetzz.de/island.htm

3. www.fun-mix.de/witze/nationen.htm

4. www.lachen24.de/witze

5. www.skandi-bg.com

6. www.teppich-pies.de/witze-2002

7. www.vonrauch.de 
Christoph Chlosta, Matthias Jung (Hrsg.) (2010):

DaF intergriert: Literatur - Medien - Ausbildung. Tagungsband der

36. Jahrestagung des Fachverbandes Deutsch als Fremdsprache 2008.

Göttingen: Universitätsverlag, 411-420.

\author{
Renata Rozalowska-Żądło (Gdańsk, Polen)
}

\title{
Projektarbeit im landeskundlichen Deutsch-als- Fremdsprache-Unterricht am Beispiel des Projekts „Österreich in Polen“
}

\section{Einführung}

Die Landeskunde der deutschsprachigen Länder spielt im Deutsch als FremdspracheUnterricht wegen ihres interdisziplinären Charakters eine wichtige Rolle. Sie bietet die Möglichkeit, verschiedene Themenbereiche anzusprechen und damit besser auf die persönlichen Interessen der Lernenden einzugehen.

In modernen Lehrprogrammen der Institutionen zur Deutschlehrerausbildung nimmt die Landeskunde einen wichtigen Platz ein. Zu solchen Programmen gehört auch das Curriculum für die Fremdsprachenlehrerkollegs in Polen, das im Jahre 1995 entwickelt wurde. Im Programm des Lehrerkollegs der Universität Gdańsk, das sich auf dieses Curriculum stützt, sind für die Landeskunde der deutschsprachigen Länder 90 Unterrichtsstunden vorgesehen, die sich zu gleichen Anteilen auf drei Semester verteilen. In diesem Fachbereich sind Fächer wie Geschichte, Landeskunde und Kulturkunde zusammengefasst. Die Inhalte beziehen sich auf den deutschsprachigen Raum mit seinen nationalen, regionalen und grenzübergreifenden Erscheinungen. Wegen der Vielfältigkeit und Unterschiedlichkeit dieses Raumes und der sich daraus ergebenden unendlichen Menge von Informationen wurde bewusst auf den Anspruch der Vollständigkeit verzichtet. Daher wird im Unterricht immer nur ein Ausschnitt der kulturellen Realität der Zielsprachenländer vermittelt, der jedoch die Lernenden zur 
weiteren selbstständigen Suche und ständigen Weiterbildung anspornen soll. Das Unterrichtsprogramm wird gemeinsam mit den Studierenden unter Berücksichtigung ihres Vorwissens und der persönlichen Interessen gestaltet. Der Landeskundeunterricht soll nicht nur Fach- sondern auch Sprach- und Handlungsunterricht sein, was bedeutet, dass die Informationsvermittlung in die sprachpraktische und methodisch-didaktische Ausbildung integriert wird (vgl. Stasiak 1995: 121-147).

Dies lässt sich sehr gut mit Hilfe von Unterrichtsprojekten verwirklichen. Im Folgenden wird der Verlauf eines Projekts beschrieben, das im Jahr 2006/2007 mit Studenten des dritten Semesters des Kollegs zur Ausbildung von Fremdsprachenlehrern der Universität Gdańsk durchgeführt wurde.

\section{Die Ausgangslage}

Das Fach Landeskunde wird im dritten Studiensemester angeboten und in den folgenden zwei Semestern fortgesetzt. Da in unserer Einrichtung das D-A-CH-Konzept verwirklicht wird, wurden den drei deutschsprachigen Ländern (Deutschland, Österreich und der Schweiz) im Rahmenprogramm jeweils 30 Stunden gewidmet.

Am Anfang des Semesters wird versucht, das Vorwissen der Studenten über diese Länder zu erfassen. Meistens geschieht dies auf Basis eines Fragebogens mit offenen Fragen zu geographischen Angaben, berühmten Persönlichkeiten, aktuellen Ereignissen und zur Geschichte.

An der Umfrage über Österreich von Oktober 2006 haben 42 Studenten des dritten Semesters teilgenommen, die Deutsch als Fremdsprache für das Lehramt studieren. $\mathrm{Zu}$ den einzelnen Bereichen wurden folgende Angaben gemacht (in den Klammern wird die Zahl der Studenten angegeben, die diese Fakten bzw. Persönlichkeiten genannt haben):

Geographische Angaben: ein Land in Mitteleuropa (alle), grenzt an Deutschland (alle), Alpen (alle), die Hauptstadt ist Wien (alle), Salzburg (6), die Donau (alle);

Berühmte Österreicher: Wolfgang Amadeus Mozart (alle), Johann Strauß (8), Adolf Hitler (2), Siegmund Freud (1), Arthur Schnitzler (1), Ludwig Wittgenstein (1), Sissi (1);

Wichtige historische Ereignisse: der Entsatz Wiens unter der Führung des polnischen Königs Jan III. Sobieski (1), die Teilungen Polens, an denen Österreich teilgenommen hat (3), die Union zwischen Österreich und Ungarn (1), der Anschluss Österreichs an das Dritte Reich (2)

Allgemeines bzw. Stereotypes: in Österreich spricht man Deutsch (alle), teuer (alle), viele Touristen (alle), Österreicher sind nett und freundlich (alle).

Es muss hervorgehoben werden, dass nur sieben Studenten in Österreich waren und einen unmittelbaren Kontakt zu Österreichern hatten. Die Aufenthalte beschränkten sich allerdings auf ein paar Stunden bzw. einen Tag in Wien auf der Durchreise nach Italien oder auf einen einwöchigen Skiurlaub in den österreichischen Alpen. Die Studenten behaupteten auch, dass in ihrem Schulunterricht keine Informationen über Österreich vermittelt wurden. Fakten aus der polnischen Geschichte wie: Jan III. Sobieski und der 
Entsatz Wiens, die Teilungen von Polen, an denen die österreichische Monarchie beteiligt war, wurden nur vereinzelt erwähnt. Das Gleiche gilt für den Anschluss Österreichs an das Dritte Reich, obwohl diese Inhalte zu dem polnischen Schullehrplan gehören und von den bisherigen Jahrgängen immer genannt wurden. Die Studenten konnten keine gegenwärtigen, politischen Ereignisse in Österreich nennen. Als Grund gaben sie an, dass die polnischen Medien über Österreich und Österreicher nicht berichten. Diese Feststellung gab den Anstoß, ein Projekt zum Thema „Österreich in Polen“ durchzuführen.

\section{Verlauf der Projektarbeit}

Im Folgenden werden die einzelnen Schritte des Projekts vorgestellt.

\subsection{Einführung in die Projektarbeit als Arbeitsform}

Es stellte sich heraus, dass keiner der 42 Studenten mit der spezifischen Arbeitsform der Projektarbeit Erfahrung hatte. Zuerst musste also erklärt werden, was eigentlich Projekte sind. Zu diesem Ziel wurden die Studenten gebeten, sich mit Fachliteratur zum Thema auseinanderzusetzen. Die Texte wurden dann im Unterricht besprochen. Es wurde u.a. geklärt aus welchen Phasen ein Unterrichtsprojekt bestehen sollte und nach welchen Kriterien es bewertet wird. Dabei wurde festgestellt, dass bei der Bewertung u.a. Faktoren wie die Selbstständigkeit, die Zusammenarbeit der Gruppenmitglieder, die Übereinstimmung des Projektinhalts mit den formulierten Zielen, die Strukturierung der Arbeit, die Form und der Inhalt der Präsentation der Ergebnisse berücksichtigt werden sollten (vgl. Mikina; Zając 2006: 60). Um eine möglichst genaue und objektive Bewertung sicherzustellen, wurden die Studenten aufgefordert, die einzelnen Schritte der Projektarbeit schriftlich zu dokumentieren.

\subsection{Einführungsrecherche}

Die Studenten untersuchten zwei Wochen lang den polnischen Zeitungsmarkt, um feststellen zu können, welche relevanten Zeitungen es überhaupt gibt, welche sie am meisten interessieren, und welche die meisten Informationen über Österreich enthielten. Sie kamen zum Schluss, dass sich zum Zweck der Projektarbeit am besten drei überregionale Tageszeitungen (Gazeta Wyborcza, Rzeczpospolita, Dziennik) und eine lokale Tageszeitung (Dziennik Bałtycki) eignen. Diese Zeitungen sollten drei Monate lang auf Informationen über Österreich untersucht werden.

\subsection{Gruppenbildung}

Jeder Student musste sich entscheiden, mit welcher Zeitung er sich beschäftigen wolle. Auf diese Weise bildeten sich die Kleingruppen, die aus fünf bzw. sechs Personen bestanden. 


\subsection{Festlegung von Zielen und Vorgehensweisen}

Das Hauptziel aller Gruppen war es, festzustellen, welches Bild von Österreich die ausgewählten Tageszeitungen vermitteln. In dieser Phase formulierten die Studenten gemeinsam konkrete Teilziele und erstellten unter Berücksichtigung der persönlichen Interessen und Betätigungswünsche einen Arbeitsplan. Es wurden auch Vorgehensweisen besprochen, mit denen die gestellten Aufgaben bewältigt werden können. Die Studenten bestimmten u.a., wer an welchen Tagen die Zeitung kauft, wer an welchen Tagen die Zeitung liest und Informationen über Österreich sammelt und wie die Arbeit aufgeteilt wird (wird z.B. nur eine Person an einem bestimmten Tag die ganze Zeitung lesen oder werden mehrere Personen für die einzelnen Teile z.B. Wirtschaft, Sport usw. zuständig sein?).

\subsection{Zwischenreflexion}

Ein Mal im Monat wurde während eines gemeinsamen Treffens bilanziert, inwiefern die gestellten Ziele erreicht werden konnten, ob diese sich geändert haben und welchen Veränderungen der Arbeitsplan gegebenenfalls unterzogen werden muss. Schon während des ersten Treffens stellte sich heraus, dass nicht alle Gruppenmitglieder zuverlässig waren und ihren Teil der Arbeit zufriedenstellend ausführten. Einige Studenten wollten zum Teil aus persönlichen und zum Teil aus organisatorischen Gründen die Gruppe wechseln.

\subsection{Sichtung des Materials}

Die Materialsammlung sollte nach Informationen, die für das Bild von Österreich relevant sind, und solchen, die sich am besten zur Gestaltung der vereinbarten Endprodukte des Projekts eignen, geordnet und ausgewertet werden. Inhaltlich wurde das gesammelte Material folgenden Bereichen zugeordnet: Politik, Wirtschaft, Kultur, Sport, Sensation, Praktisches und Tourismus.

\subsection{Präsentation der Ergebnisse}

Die Ergebnisse der Projektarbeit wurden während eines Treffens vorgestellt. Die meisten Gruppen erstellten Collagen und präsentierten deren Inhalte. Eine Gruppe entschied sich für eine Videoaufnahme und eine für eine Powerpoint Präsentation. Alle Gruppen sichteten das gesammelte Material nach den oben genannten inhaltlichen Kriterien. Zur Veranschaulichung seien hier einige ausgewählte Schlagzeilen aus den Collagen in einer freien Übersetzung ins Deutsche angeführt:

Politik: Wahlen 2006 in Österreich; David Irving - Holocaust Leugner entlassen;

Wirtschaft: 12\% der Arbeitskräfte in Österreich sind Ausländer aus Osteuropa; Raiffeisen

Bank kauft Anteile einer polnischen Bank BPH; In Österreich arbeiten. In Polen Steuer zahlen; Österreicher investieren in Malbork;

Kultur: Wien - eine makabre Stadt. Buchrezension; Eine schöne Stadt zum Sterben. Das Bestattungsmuseum in Wien; Explorer - Preis für Kurt Diemberger; Michael Glawogger 
und sein „Workingman’s Death. Helden der Arbeit“ ; Elfriede Jelinek - österreichische Nobelpreisträgerin; Wiener Aaron Quartet und der Sopranist Arno Raunig in Gdańsk;

Sport: Vierschanzen-Tournee. 13 Österreicher im Finale;

Sensation: Natascha Kampusch will das Haus ihres Entführers kaufen; Känguru auf österreichischen Autobahnen; Busunfall in der Nähe von Salzburg;

Praktisches: Geldstrafen für Weihnachtsdekorationen in den Autos; Westenpflicht für Autofahrer in Österreich;

Tourismus: Christkindlmarkt in Wien.

Aus der Recherche ergab sich, dass die politischen Informationen vor allem von den im Oktober in Österreich durchgeführten Wahlen und ihren Folgen bestimmt waren. Die Zeitungen berichteten über Wahlergebnisse, Probleme mit der Regierungsbildung, über die Bildung der großen Koalition und über die Proteste der österreichischen Studenten gegen das ausgehandelte Regierungsprogramm. Stichwortartig wurden die Studiengebühren, die Erhöhung der Benzinsteuern und die Kinderzulage erwähnt. Ein weiteres Thema, das diskutiert wurde, war die Entlassung des kontroversen Historikers David Irving, der zwar wegen der Holocaust-Leugnung zu drei Jahren Gefängnis verurteilt wurde, aber nur 13 Monate in einem österreichischen Gefängnis verbrachte.

Im Bereich „Wirtschaft" fanden sich Informationen, die sowohl unsere Region (Pommersche Wojewodschaft) betrafen als auch österreichische Lösungen von verschiedenen Problemen, mit denen auch Polen heutzutage kämpft. Die Studenten erfuhren u.a., dass eine österreichische Firma (VST Verbundschalungstechnik GmbH) in Malbork (eine kleine Stadt etwa 50 Kilometer von Gdańsk entfernt) eine Fabrik baut, wodurch etwa 250 bis 300 neue Arbeitsplätze geschaffen werden. Die polnischen Zeitungen berichteten auch darüber, dass Polen wirtschaftlich auf dem gleichen Stand wie Österreich vor zehn Jahren ist, über die in Österreich arbeitenden Ausländer, über die Arbeit, die sie am häufigsten verrichten, und über Steuervergünstigungen, welche die arbeitenden Studenten nützen können. Aus den Zeitungsberichten ging auch hervor, dass immer mehr österreichische Firmen in Polen investieren (Bank Austria Creditanstalt, Telekom Austria).

Der bekannte polnische Skispringer Adam Małysz und sein österreichischer Rivale Gregor Schlierenzauer haben auch Schlagzeilen gemacht. Es wurde über den Wettkampf im Skispringen im Rahmen von verschiedenen Veranstaltungen (VierschanzenTournee, Weltmeisterschaften usw.) berichtet.

Im Bereich Kultur wurden unterschiedliche Personen und Ereignisse thematisiert: die Schriftstellerin Elfriede Jelinek als österreichische Nobelpreisträgerin im Jahr 2004, die spektakuläre Aktion „House attack“ von Erwin Wurm, Michael Glawogger mit seinem kontroversen und erschütternden Film „Workingman’s Death. Helden der Arbeit" und eine Rezension des Buches von Gerhard Roth „Eine Reise in das Innere von Wien“, das ins Polnische übersetzt und 2006 in Polen herausgegeben wurde. Es gab auch Informationen über kulturelle Veranstaltungen in unserer Stadt Gdańsk, bei denen 
österreichische Künstler aufgetreten sind. So erfuhren die Studenten einiges über das Wiener Aaron Quartet und über den Sopranisten Arno Raunig.

Relativ viele Informationen befanden sich im Teil „Sensation“. Das weltweite Medienecho auf das plötzliche Auftauchen der im Jahre 1998 entführten Natascha Kampusch war auch in Polen zu vernehmen. Ziemlich lange für Aufregung sorgte ein aus einem Gehege entlaufenes Känguru, das auf einer Tiroler Autobahn gesichtet wurde. Außerdem wurden auch diverse Tragödien wie Busunfälle auf den österreichischen Autobahnen, der Absturz eines in Österreich registrierten Flugzeugs über der Ostsee angesprochen. Unter Nachrichten dieser Art waren auch wahre Kuriositäten zu finden wie z.B. ein Bauarbeiter, der mit einem Nagel im Gehirn ins Krankenhaus gebracht wurde und überlebte.

Einige Informationen konnten von den Studenten nicht eindeutig zugeordnet werden. Dabei handelte es sich u.a. um das Bestattungsmuseum in Wien und den Christkindlmarkt.

\subsection{Gesamtevaluation}

In Bezug auf das Ziel des Projekts kamen die Studenten zu der Schlussfolgerung, dass das Bild von Österreich, das zum Zeitpunkt der Projektarbeit in den ausgewählten polnischen Zeitungen vermittelt wurde, positiv war. Ihnen war aber bewusst, dass dieses Bild keineswegs vollständig und konstant sein kann, weil es vor allem durch aktuelle Ereignisse des untersuchten Zeitraums und die eher subjektive Themenwahl geprägt ist. Es wurde hervorgehoben, dass es sich um die Außensicht auf Österreich handelt. Die Ergebnisse der Recherche wurden folgendermaßen verallgemeinert:

Österreich ist ein Land, in dem zwei politische Parteien (Sozialdemokratische Partei Österreichs - SPÖ und Österreichische Volkspartei - ÖVP) mit zum Teil unterschiedlichen Programmen im Stande waren, sich zu einigen und eine Regierungskoalition zu bilden. Dort leben und arbeiten viele Ausländer. Österreich ist wirtschaftlich gut entwickelt und investiert in den ehemaligen Ostblockländern, u.a. auch in Polen. In Österreich legt man einen großen Wert auf Sportarten wie Skispringen. Es gibt zeitgenössische österreichische Künstler, die weltbekannt sind.

In dieser Phase wurde die Frage diskutiert, inwiefern die Recherche für die Teilnehmer aufschlussreich war. Es zeigte sich, dass die Studenten mit Hilfe des Projektes

- ihren Wortschatz zu bestimmten Themenfeldern (Politik, Wirtschaft, Kunst, Rechtssprache) erweiterten. Sie haben zwar die Texte auf Polnisch gelesen, mussten aber darüber auf Deutsch berichten.

- ihr Wissen über Österreich bereicherten. Sie lernten u.a. die österreichischen Parteien und ihre Programme kennen und machten sich mit Hilfe von verschiedenen Internetquellen ein relativ genaues Bild über die politische Landschaft Österreichs im Herbst 2006. Sie erfuhren über die Schriftstellerin Elfriede Jelinek und beschlossen, einige ihrer Bücher zu lesen und den Film „Die Klavierspielerin“ zu sehen.

- ihr Allgemeinwissen bereicherten. Viele von ihnen kannten z.B. den Begriff „Holocaust-Lüge“ bzw. „Auschwitz-Lüge“ nicht, obwohl er auch im Polnischen als 
„kłamstwo oświęcimskie“ bekannt ist. Die Nachricht über den Holocaust-Leugner David Irving hat sie angespornt, nach weiteren Artikeln zu diesem Thema zu suchen und über ähnliche Vorfälle in Polen zu diskutieren.

- über die aktuellen politischen Ereignisse in Polen nachdachten. Einen Anlass, über die aktuelle politische Lage in Polen zu sprechen, boten z.B. die Wahlergebnisse in Österreich.

- praktische Informationen gewannen, die sie später nutzen können. Zum Beispiel: Welche Bedingungen muss man erfüllen, um in Österreich zu studieren und als polnischer Student dort auch arbeiten zu dürfen?

- neue Unterrichtsideen für ihren eignen Unterricht fanden und zwar zu einem der Lieblingsthemen vieler Schüler: Weihnachten. Es zeigte sich, dass die im Internet zugänglichen Informationen über den Christkindlmarkt in Wien nach methodischdidaktischer Aufbereitung sehr gut im Deutschunterricht eingesetzt werden können.

- recherchieren lernten. Ihnen wurde bewusst, dass Informationen über die deutschsprachigen Länder praktisch überall vorhanden sind. Schließlich gibt es in vielen größeren und kleineren polnischen Städten Filialen von österreichischen Firmen. In polnischen Läden kann man österreichische Produkte kaufen, Reisebüros bieten verschiedene Prospekte über Österreich an, auch in kleineren Bibliotheken sind polnische Ausgaben von Jelinek zu finden usw. Die Studierenden stellten fest, dass sie diese Signale bislang nicht wahrgenommen haben.

- sich mit den Merkmalen, der Organisation und Durchführung des Projektunterrichts bekannt machten.

Es scheint also, dass alle Studenten von der Teilnahme am Projekt profitierten. Die Arbeit war u.a. deswegen erfolgreich, weil die Palette von Informationen über Österreich relativ breit war und jeder Teilnehmer für sich etwas Interessantes finden konnte. Die Möglichkeit, das persönliche Interesse zu entwickeln, ist eine der wichtigsten Voraussetzungen für eine gelungene Projektarbeit.

\section{Selbstständige Einzelarbeit im Anschluss an das durchgeführte Projekt}

Wie in der Einführung bereits erwähnt wurde, sollte der Landeskundeunterricht den Studierenden die Möglichkeiten zur weiteren selbstständigen Arbeit bieten, bei der auch sprachliche Fertigkeiten trainiert werden könnten. Aus diesem Grund wurden die Studierenden im Anschluss an das Projekt aufgefordert, die Arbeit an bestimmten Themen, die sich aus der Recherche ergaben, selbstständig fortzusetzen und die Ergebnisse schriftlich festzuhalten. Es wurden folgende Möglichkeiten vorgeschlagen:

Ein Referat: Der Umgang Österreichs mit der nationalsozialistischen Vergangenheit (in Anlehnung an die Verhaftung und Entlassung von David Irving).

Eine Stellungnahme: Die Holocaust-Leugner. Ihre Ziele und Motive. Beurteilen Sie die Argumentationsweise.

Ein Referat: Wahlkampagnen in Österreich und Polen. Ein Vergleich. 
Eine Filmkritik: Michael Haneke: „Die Klavierspielerin“.

Eine Buchrezension: Elfriede Jelinek: „Die Klavierspielerin“.

Eine Buchrezension: Gerhard Roth „Eine Reise in das Innere von Wien“.

Die meisten Studenten entschieden sich, die Wahlkampagnen in Polen und in Österreich zu vergleichen oder den Film „Die Klavierspielerin“ anzusehen und eine Kritik zu schreiben. Einige wenige bearbeiteten ausführlicher das Thema der Holocaust-Leugner. Nur eine Studentin beschloss das Buch von Gerhard Roth zu lesen, in der Hoffnung, dass es sich um einen außergewöhnlichen Reiseführer handelt. Die anderen vorgeschlagenen Themen haben kein Interesse geweckt.

\section{Methodisch-didaktische Reflexion}

Wie bereits erwähnt wurde, handelte es sich bei den Studenten um angehende Deutschlehrer, für die es die erste Begegnung mit dem Projektunterricht als Arbeitsform war. Es war also notwendig, den Verlauf des Projekts methodisch-didaktisch zu reflektieren, um den Studierenden zu verdeutlichen, welche Aspekte besonderer Aufmerksamkeit bedürfen. Es wurden u.a. folgende Fragen diskutiert: Welche Ziele wurden gesetzt? Auf welche Weise wurden sie erreicht? Welche positiven und negativen Erfahrungen waren mit dem Projekt verbunden? Was könnte verändert werden, um mögliche Fehler zu vermeiden?

Infolge der Diskussion formulierten die Studenten auch Problembereiche und wiesen auf Mängel hin, an deren Beseitigung in Zukunft gearbeitet werden muss. Es handelte sich dabei um

- die praktische Umsetzung der zugeteilten Aufgaben durch die einzelnen Gruppenmitglieder. Einige Studenten haben ihre Arbeit unzureichend verrichtet, ohne darauf zu achten, dass ihr unfaires Verhalten das Gesamtergebnis der Gruppenarbeit negativ beeinflussen kann. Die größten Schwierigkeiten bereitete ihnen die systematische Arbeit. Ihnen fehlte wahrscheinlich das Bewusstsein, dass alle Gruppenmitglieder gleichermaßen für den Erfolg oder Misserfolg des ganzen Unternehmens verantwortlich sind.

- die ziel- und zweckorientierte Sichtung und Auswertung des gesammelten Materials. Eine Gruppe konzentrierte sich vor allem auf die sensationsbedachten Nachrichten und Kuriositäten, die zwar tatsächlich in der Presse vorhanden waren, aber in Hinblick auf das Gesamtbild von Österreich ohne Bedeutung sind. In Zukunft sollte vielleicht in der Besprechung der Zwischenergebnisse mehr darauf geachtet werden, ob die Projektteilnehmer das gemeinsame Ziel nicht aus den Augen verloren haben. Nach Bedarf sollte die Lehrkraft in den Zwischenreflexionsphasen stärker steuern, wenn das Projekt eine unerwünschte Richtung einzuschlagen droht.

- die Form und die Weise der Präsentation. Fast alle Gruppen hatten Probleme, die Ergebnisse ihrer Arbeit schlüssig und interessant darzustellen, was den Gesamteindruck etwas beeinträchtigt hat. Den Projektteilnehmern muss bewusst gemacht wer- 
den, dass ihnen außer Collagen noch andere Präsentationsmöglichkeiten zur Verfügung stehen.

- kritische Auseinandersetzung mit den Arbeitsergebnissen. Die Studenten stellten so gut wie keine Fragen und wollten sich zur Arbeit der anderen Gruppen nicht äußern. Schon während der Besprechung der Zwischenergebnisse sollte daher kritisches Diskutieren trainiert werden mit dem Ziel, Kritikfähigkeit aufzubauen. Den Teilnehmern sollte auch bewusst gemacht werden, dass sich Kritik nicht gegen einzelne Personen oder die Gruppe richtet, sondern helfen soll, die gemeinsame Planung, Reflexion und Durchführung zu verbessern (vgl. Halcinova; Menzlova; Olejarova; Schneider 1998: 4).

- Probleme mit der Gesamtevaluation. Es wäre einfacher die Gesamtevaluation vorzunehmen, wenn den Studenten einheitliche Bewertungsbögen zur Verfügung stehen würden. Sie sollten detaillierte Fragen zu Selbstbewertung und zur Projektarbeit beinhalten. Die Bögen sollten zusammen mit den Studenten entwickelt werden. In der Fachliteratur sind mehrere Vorschläge zum Inhalt solcher Arbeitsblätter vorhanden (dazu u.a. Mikina; Zając 2006: 99-112; Horbowiec; Tymoszuk; Zaremba; Ziemba 2008: 1-10).

\section{Fazit}

In dem in der Einführung angesprochenen Landeskundecurriculum wurde festgelegt, welche Fähigkeiten die Studierenden während des Studiums am Lehrerkolleg erwerben sollen (Stasiak 1995: 126f.). Es wäre wünschenswert, dass sie lernen:

- den eigenen Unterricht gemeinsam mit dem Lehrer zu planen und entwicklungsfähige Themenkomplexe zu finden,

- komplexe Themen und Inhalte didaktisch zu reduzieren, d.h. sie dem Niveau einer bestimmten Lernergruppe anzupassen,

- landeskundliche Unterrichtsreihen und -sequenzen zu planen, durchzuführen und zu analysieren,

- aktuelle Entwicklungen und Erscheinungen in den deutschsprachigen Ländern wahrzunehmen und in den eigenen Unterricht einzubeziehen,

- Informationen und Materialien selbstständig zu beschaffen,

- projektorientiert zu arbeiten,

- Arbeitsergebnisse anhand geeigneter Kriterien zu überprüfen und zu bewerten.

Aus den bisherigen Ausführungen geht hervor, dass die in dem Beitrag präsentierte Projektarbeit die Studenten den oben formulierten Zielen ein gutes Stück näher brachte. Sie haben nicht nur ihr Wissen zu verschiedenen Themen bereichert und ihre Sprachfertigkeiten verbessert, sondern auch eine für sie neue Arbeitsweise kennen gelernt, erprobt und ihre eigenen Erfahrungen analysiert. Da es sich bei der Gruppe um angehende Deutschlehrer handelt, ist der letzte Punkt von großer Bedeutung. 


\section{Literatur}

Halcinova, Katarina; Menzlova, Beata; Olejarova, Alexandra; Schneider, Gunther (1998): Projektarbeit im Lehrwerk „Hallo, da bin ich!“ In: Primar 18, 4-8.

Horbowiec, Jolanta; Tymoszuk, Elżbieta; Zaremba, Elżbieta; Ziemba, Beata (2008): Ocenianie uczniów pracujacych metoda projektu. http://bslocka.scholaris.pl /Elektroniczny $\% 20$ przewodnik/Ocenianie $\% 20$ uczniow $\% 20$ pracujacych $\% 20$ metoda $\% 20$ projektu.doc, 1-10 (15.10.2008).

Mikina, Agnieszka; Zając, Bożena (2006): Jak wdrażać metode projektów? Kraków: Oficyna Wydawnicza Impuls.

Stasiak, Halina (wissenschaftliche Leitung) (1995): Curriculum für Fremdsprachenlehrerkollegs. Deutsch. Revidierte Erprobungsfassung. Warszawa: Ministerstwo Edukacji Narodowej. 


\section{Matthias Jung \& Annegret Middeke}

\section{Forum „Beruf und Qualifizierung““}

Das Forum „Beruf und Qualifizierung“ hat sich aus diversen Sonderveranstaltungen entwickelt, die - auf Wunsch der Mitglieder - der $\mathrm{FaDaF}$ bereits auf früheren Jahrestagungen zusätzlich zu den Themenschwerpunkten und dem Forum „Unterrichtspraxis“ angeboten hat. Dazu gehörten z.B. ein Workshop zum Berufsfeldbezug in den BA/ MA-Studiengängen DaF und DaZ oder eine Beratungsveranstaltung für Honorarlehrkräfte von Erwin Denzler, Dozent für Arbeits- und Sozialrecht (Fürth), die seitdem zu einem festen Bestandteil von FaDaF-Jahrestagungen geworden ist und dementsprechend auch in Düsseldorf auf dem Programm stand.

Auf der Düsseldorfer Jahrestagung wurde das Forum „Beruf und Qualifizierung“ zum ersten Mal als durchgehende Veranstaltung parallel zu den vier Themenschwerpunkten, dem Forum „Unterrichtspraxis“ und den Ausstellerpräsentationen angeboten. Eingeleitet wurde es mit einem Vortrag von Prof. Dr. Claudia Riemer (Bielefeld) aus dem Bereich akademische Qualifizierung, der sich primär an den wissenschaftlichen Nachwuchs im Fach DaF/DaZ richtete. "Themenfindung, Forschungsplanung und forschungsmethodische Unterscheidungen" standen im Mittelpunkt ihrer Betrachtung der zentralen Problemfelder empirischer Forschung.

Erwin Lüer (Düsseldorf), freiberuflicher DaF- und Kommunikationstrainer, referierte über „Erfahrungen, Strategien und Möglichkeiten“ selbstbestimmter, professioneller Freiberuflichkeit. Ausgehend davon, dass aufgrund des Mangels an festen Stellen für DaF-Lehrkräfte sehr viele von ihnen ungewollt als Freiberufler tätig und damit in besonders hohem Maße der Gefahr des Lohndumpings ausgesetzt sind, zeigte Lüer alternative Wege in verwandten Bereichen wie Kommunikationstraining oder Personalentwicklung auf, in denen qualifizierte DaF-Dozenten gesucht und bessere Honorare gezahlt werden.

Anschließend fand die bewährte Beratungsveranstaltung für selbständige Honorarlehrkräfte von Erwin Denzler statt. Es ging um das Thema Sozialversicherung, einem vielen Honorarlehrkräften allzu gut bekanntem Problem, sowie um Kranken- und Rentenversicherung, wobei im Anschluss an jeden Themenbereich offene Fragen mit dem Referenten diskutiert wurden. Auch wenn die persönliche Situation der einzelnen Honorarlehrkräfte - je nach Familienstand, Arbeitgeber, Freibeträgen, Ausnahmebeständen etc. - sehr unterschiedlich sind, konnte die Veranstaltung doch bei der Entwicklung individueller Strategien im Umgang mit Versicherungsträgern bzw. der Erwägung möglicher Alternativen bei Altersvorsorge und Krankenversicherung helfen.

Ein Gemeinschaftsvortrag des FaDaF-GATE -Konsortiums gewährte Einblicke in den Bereich „Bildungsmarketing für DaF-Kurse im Ausland“. Seit 2005 ist der FaDaF über ein Konsortium von überwiegend universitätsnahen Sprachkursanbietern im Rahmen der GATE-Hochschulmarketinginitiative des DAAD auf bis zu sechs Hoch- 
schulmessen im Ausland vertreten und wirbt für das Deutschlernen in Deutschland bei FaDaF-Mitgliedsinstituten zum Zwecke der Studienvorbereitung. Mitglieder des Konsortiums berichteten über Messe-Erfahrungen von Sibirien bis Chile und von der Türkei bis Indien und China. Eine wichtige Beobachtung war, so die Referenten, dass die Interessen und Entscheidungskriterien der Studienbewerber bzw. die Situation des Deutschlernens sich nicht nur von Land zu Land deutlich unterscheiden, sondern auch von dem Bild stark abweichen, das man gewinnt, wenn man Teilnehmer nur im Inland rekrutiert. Eine andere, dass die Bedeutung des eigenen Messe-Auftritts unter einem Qualitätssiegel und im Verbund für Kursinteressenten ein wesentliches Argument darstellt, da einer seriösen „Marke“ vertraut wird.

Den Abschluss bildete, moderiert von Matthias Jung (Düsseldorf), eine Diskussionsrunde zum Thema „Arbeitsmarkt für DaF-Lehrkräfte“ aus der Sicht von Kursanbietern. Angesichts des unübersichtlichen, uneinheitlichen Arbeitsmarktes für DaF-Lehrkräfte, der darüber hinaus in vielen Bereichen durch sinkende Honorare und allgemein hohen Konkurrenzdruck unter den Lehrkräften und Kursanbietern geprägt ist, stellten Vertreter von FaDaF-Mitgliedsinstituten ihre Erwartungen an den DaF-Markt und ihre Anforderungen an DaF-Dozenten dar, tauschten Erfahrungen aus und berichteten aber auch von Berufswegen, die zu Festanstellungen führen (können).

Im Band ist nur der Beitrag von Claudia Riemer abgedruckt, weil die anderen Veranstaltungen eher Beratungs- und Diskussionscharakter hatten. Hinzu kommt ein Beitrag von Matthias Jung, der auf einen Vortrag im Themenschwerpunkt 3: „Lehreraus- und -fortbildung" zurückgeht und auf die letztgenannte Problematik eingeht. Empfehlen möchten wir außerdem das „Handbuch zur Sozialversicherung für freiberufliche Dozenten" von Erwin Denzler, ein sorgfältig recherchierter Ratgeber, der sich zwar in erster Linie an Dozenten richtet, aber ebenso für andere „selbständige Lehrer“ im Sinne der Rentenversicherung gilt. ${ }^{1}$

\footnotetext{
1 S. http://www.erwin-denzler.de/sv-dozenten/ (15.10.2009).
} 
Christoph Chlosta, Matthias Jung (Hrsg.) (2010): DaF intergriert: Literatur - Medien - Ausbildung. Tagungsband der 36. Jahrestagung des Fachverbandes Deutsch als Fremdsprache 2008. Göttingen: Universitätsverlag, 423-434.

\section{Claudia Riemer (Bielefeld)}

\section{Erste Schritte empirischer Forschung: Themenfindung, Forschungsplanung, forschungsmethodische Entscheidungen}

\section{Vorbemerkung}

Dieser Beitrag richtet sich an diejenigen, die (noch) wenig Erfahrung in der Durchführung empirischer Forschungsprojekte (insbesondere im Bereich des Lehrens und Lernens von Fremdsprachen) haben. Er will in erster Linie strategische Vorgehensweisen vorschlagen und auf häufige Fehlerquellen hinweisen. Er kann auf keine Weise eine grundlegende Einführung in die Forschungsmethodologie und Forschungsmethoden ersetzen. Die am Ende angebotene Auswahlbibliographie soll eine Hilfestellung bei der Auswahl geeigneter Fachlektüre anbieten.

Wer ein empirisches Forschungsprojekt plant, sollte sich zunächst kritisch mit den eigenen Ressourcen auseinandersetzen. Auch unerfahrene ForscherInnen können an vorhandene Kenntnisse anknüpfen, die als Grundlage bei der Findung von Forschungsinteressen dienen können. Ein erster Schritt sollte daher die Reflexion hinsichtlich vorhandener oder fehlender Kompetenzen sein, unter anderem in Bezug auf:

- fachwissenschaftliche Kenntnisse, z.B. zu Einflussfaktoren des Fremdsprachenerwerbs, zur linguistischen Analyse lernersprachlicher Fehler;

- fachdidaktiktische Kenntnisse, z.B. zum Bedingungsgefüge des Fremdsprachenunterrichts, zu Aufgaben- und Übungstypen, zu Sozialformen, zu Verfahren der Fehlerkorrektur; 
- eigene Sprachlehr- und Sprachlernerfahrungen, bei denen bestimmte „Problembereiche" festgestellt wurden, denen man vielleicht nachgehen möchte;

- forschungsmethodische Kenntnisse und Erfahrungen.

Der letzte Kenntnisbereich ist häufig der, der am wenigsten ausgebildet ist, was v.a. am Zuschnitt der akademischen Ausbildung im Bereich DaF und der Fremdsprachenforschung liegt, bei der mit wenigen Ausnahmen keine grundlegenden Lehrangebote im Bereich der empirischen Forschungsmethodologie angeboten werden. Vieles muss daher im Selbststudium mühsam erarbeitet werden. Forschungsmethodische Kenntnisse sind vonnöten mit folgenden Ausdifferenzierungen:

- forschungsmethodologische Grundlagen (z.B. Kenntnis der Paradigmen quantitativer und qualitativer Forschung, Gütekriterien, Triangulation, Menschenbildannahmen, Zusammenstellung von Stichproben);

- Methoden der Datenerhebung (z.B. Interview, Fragebogen, Gruppendiskussion, Test, Introspektion);

- Methoden der Datenaufbereitung (z.B. Quantifizierungsverfahren, Transkriptionsverfahren);

- Methoden der Datenanalyse und Dateninterpretation (z.B. statistische Datenanalyse, qualitative Inhaltsanalyse, Diskursanalyse).

Um begründete Entscheidungen für ein Forschungsdesign treffen zu können, ist ein Zugang zu sowohl quantitativen als auch qualitativen Forschungsansätzen unverzichtbar. Vor allem ist ein Bewusstsein darüber relevant, dass die Entscheidung für ein qualitatives oder quantitatives Design sämtliche Ebenen - von der Festlegung der Fragestellung über die Festlegung geeigneter Erhebungsmethoden bis zur Analyse der Daten und der davon ableitbaren Schlussfolgerungen - betrifft (vgl. Abb. 1).

\section{Planung einer empirischen Untersuchung - ein Vorschlag}

Die im Folgenden vorgeschlagenen Handlungsschritte stellen eine (erprobte) Möglichkeit dar, ein Forschungsprojekt zu initialisieren, bei dem empirische Daten erhoben und ausgewertet werden sollen.

\subsection{Allgemeines Erkenntnisinteresse und Ziele formulieren}

Am Anfang sollte die Sammlung und Reflexion allgemeiner Ziele der eigenen Forschung stehen. Es geht hier (noch) nicht um die Festlegung einer Fragestellung, sondern zunächst einmal darum, die eigenen Interessen in den Fokus zu rücken. Dieser Schritt ist besonders wichtig, um (später) ein Thema festzulegen, das den Forschenden wirklich interessiert. Dies klingt trivial, ist es aber nicht: Empirische Forschung kann höchst aufreibend sein - wenn man ein Thema verfolgt, das einem wirklich am Herzen liegt, wird man eher imstande sein, auch schwierige Phasen zu überstehen! 


\section{Studien, Datenerhebung, -aufbereitung und -analyse auf einer Skala von QUANTITATIV bis QUALITATIV}

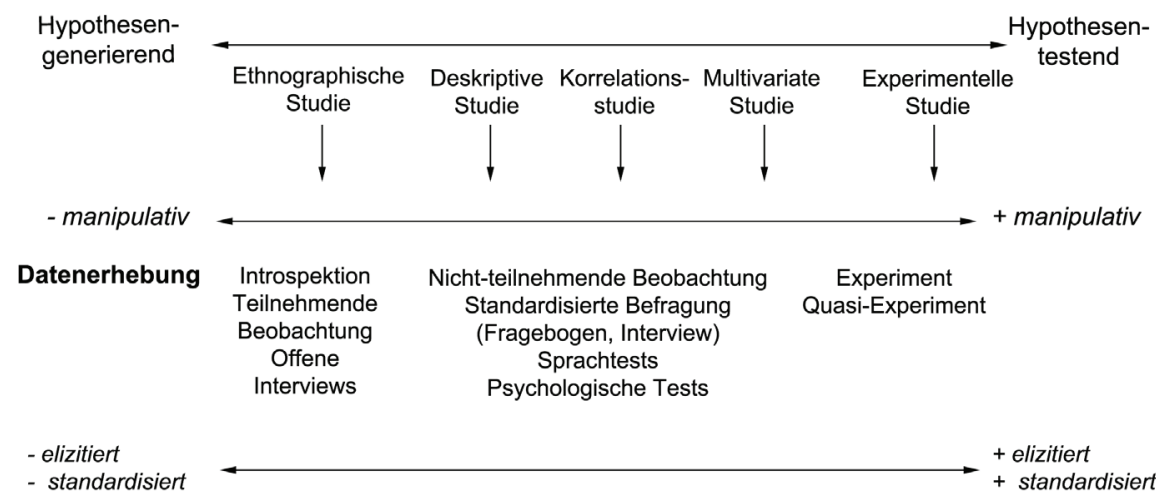

Datenaufbereitung Transkription Protokoll

Datenanalyse

subjektiv

Hermeneutik
Deskriptive Statistik:

zentrale

Tendenzen

Variabilität
Quantifizierung

Inferentielle Multivariate

Statistik:

Korrelation

Statistik: Multiple

Regression

Diskriminationsanalyse

Faktoranalyse LISREL
Quantifizierung

Inferentielle/

multivariate

Statistik:

t-Test

Varianz-

analyse

LISREL

elizitiert

standardisiert

objektiv

Abb. 1 
Möglichkeiten zur Findung von Ausgangspunkten von Forschungsprojekten und zum Finden allgemeiner Erkenntnisinteressen können sein:

- Anknüpfen an eigene (Lern-)Erfahrungen;

- Anknüpfen an Lehrerfahrungen und Lehrerbedürfnissen;

- Impulsen anderer Forschungen folgen (z.B. dem nachgehen, was häufig am Ende von publizierten empirischen Studien steht);

- vorhandenes Wissen über einen Gegenstandsbereich (das man z.B. aus der Fachliteratur bezogen hat) vertiefen wollen;

- neue Erkenntnisse gewinnen, bestehende Erkenntnisse überprüfen wollen (für die Theorie, für die Praxis).

Die folgenden Strategien haben sich in dieser Phase als hilfreich erwiesen. Die beiden ersten Strategien sollten in der ersten Phase aufgenommen, aber in allen Folgephasen beibehalten werden:

- ein Journal/Forschungstagebuch führen. In ein eigenes Heft, das ständig mitgeführt werden sollte, werden (zunächst) allgemeine und (zunehmend) spezifische Überlegungen eingetragen und u.a. Techniken des schriftlichen Nachdenkens, auch zur Gedankenklärung, angewandt. Erste Entscheidungen, aber auch Unsicherheiten und Alternativen werden festgehalten;

- Beratungsgespräche führen, die dabei helfen abzuklären, ob man einem (für den Rahmen der angestrebten Arbeit) geeigneten Thema auf der Spur ist, und sich Literaturtipps geben lassen;

- Partner finden. Wer eine Examensarbeit schreibt oder eine Promotion anstrebt, ist (meistens) nicht allein. Auch wenn man vielleicht nicht den gesamten Forschungsprozess gemeinsam gestalten kann (und will), so ist ein gleichgesinnter kritischer Mitdenker, der ebenfalls ein empirisches Projekt plant, ein ausgezeichnetes Korrektiv;

- nicht nur in dieser Phase, aber bereits in dieser sollte man damit beginnen, empirische Forschungsliteratur zu lesen, die zum betreffenden Themenbereich publiziert wurde;

- einen Forschungsbericht über diese publizierten Arbeiten (anfangen zu) schreiben: Für die Arbeit später muss sowieso ein solcher geschrieben werden, also so früh wie möglich die Lektüre verschriften, um später nicht alles doppelt und dreifach machen zu müssen. Die Schriftform hilft bei der Feststellung von allgemeinen Tendenzen und evtl. offenen oder widersprüchlichen Befunden, denen nachzugehen es lohnt.

\subsection{Exakte Forschungsfrage formulieren}

In dieser Phase steht die genaue Auswahl und Spezifizierung des Erkenntnisinteresses und des Untersuchungsgegenstandes im Zentrum. Hier geht es also darum, Entscheidungen darüber zu treffen, was eigentlich genau untersucht werden soll - und was nicht! Außerdem beginnt das Nachdenken darüber, welches Forschungsdesign (eher quanti oder eher quali?) geeignet ist. Folgende Strategien können hierbei helfen: 
- Reichweite des Erkenntnisinteresses einschränken, aber: Interesse nicht aus den Augen verlieren (man sollte nicht plötzlich einen vermeintlich leichter untersuchbaren Nebenaspekt ins Zentrum stellen, der einen eigentlich gar nicht mehr interessiert, vgl. oben);

- realistisch bleiben (nicht nur in dieser Phase!);

- forschungsmethodologische Fachliteratur konsultieren;

- publizierte empirische Studien aus dem Forschungsfeld mit einer Checkliste lesen. Dieses Lesen empirischer Arbeiten sollte sehr zielgerichtet sein, d.h., es sollte sich dabei um Studien handeln, die den eigenen Untersuchungsgegenstand betreffen, damit man deren Vorgehensweisen und Entscheidungen in Bezug auf das eigene Erkenntnisinteresse reflektieren kann. Die von mir hierfür eingesetzte Checkliste ist in Abbildung $2 \mathrm{zu}$ finden.

\subsection{Operationalisierbare Definitionen von Konstrukten finden: erster Entwurf eines Forschungsdesigns}

Nachdem die Forschungsfrage genau festgelegt wurde, geht es in diesem Schritt nun um die exakte Festlegung, wie der gewählte Gegenstand untersucht werden soll. Hierfür müssen zunächst möglichst genaue Definitionen der fokussierten Konstrukte, die z.B. als Variablen vorliegen, gefunden werden. Und die Konstrukte müssen operationalisierbar sind, d.h., sie müssen beobachtbar, identifizierbar, evtl. sogar exakt messbar und damit kontrollierbar sein. Auch in einer eher offenen qualitativen Studie muss klar festgelegt sein, wie der Untersuchungsgegenstand operationalisiert wird!

Es sind dann geeignete Datenerhebungsverfahren festzulegen; evtl. müssen für die Datenerhebung sogar eigene Instrumente (z.B. Fragebogen, Beobachtungsbogen, Interviewleitfäden) entwickelt werden. Bei der Erwägung von Datenerhebungsverfahren ist sofort auch an die Konsequenzen für die Datenaufbereitung und die Datenanalyse zu denken. So muss z.B. an die Notwendigkeit von Transkriptionen mündlicher Daten gedacht werden oder an die Möglichkeiten und zu erfüllende Voraussetzungen, wie erhobene Daten quantifizierbar und damit einer statistischen Auswertung zugänglich gemacht werden können. Und - und auch hierüber sollte man unbedingt in dieser Phase bereits gründlich nachdenken! - damit verbunden sind Fragen danach, wie die erhobenen Daten später ausgewertet werden können und sollen, um gemäß der Forschungsfrage zu relevanten Antworten kommen zu können. Ein häufiger Fehler ist, dass Verfahren der Datenauswertung erst zu spät erwogen werden, nämlich wenn die Daten bereits vorliegen und man die Datenerhebung gar nicht mehr beeinflussen kann. Man stellt dann vielleicht zu spät fest, dass man z.B. zu wenige Items vorgesehen hat, um die Reliabilität der Daten, die eine spezifische Variable betreffen, überprüfen zu können.

Ziel dieser Phase ist es, die Konsistenz der Untersuchung sicherzustellen. Am Ende der Phase steht das vorläufige Forschungsdesign mit ausgewählten Datenerhebungs-, -aufbereitungs- und -analyseverfahren (vorläufig) fest. 


\section{Checkliste zur kritischen Lektüre empirischer Studien}

Lesen Sie eine publizierte empirische Studie, die den Sie interessierenden Aspekt des Fremdsprachenlernens untersucht; solche Studien finden Sie z.B. in Fachzeitschriften wie Language Learning, Modern Language Review, Studies in Second Language Acquisition, Language Teaching Research, Zeitschrift für Fremdsprachenforschung.

Bearbeiten Sie dann folgende Checkliste:

1. 1.1 Erkenntnisinteresse/Fragestellung/Forschungshypothesen der Studie?

1.2 Untersuchungsgegenstand/Untersuchungsvariablen?
1.3 Sind die Angaben
a) nachvollziehbar?
b) ausreichend?

2. 2.1 Probanden/Untersuchungsteilnehmer (Anzahl, weitere Informationen)?
2.2 Sind die Angaben
a) nachvollziehbar?
b) ausreichend?

3. 3.1 Welche Methoden der Datenerhebung?
3.2 Sind die Angaben
a) nachvollziehbar?
b) ausreichend?

4. 4.1 Welche Methoden der Datenaufbereitung?
4.2 Sind die Angaben
a) nachvollziehbar?
b) ausreichend?

5. 5.1 Welche Methoden der Datenanalyse?
5.2 Sind die Angaben
a) nachvollziehbar?
b) ausreichend?

6. Verfolgt die Studie eher einen qualitativen oder quantitativen Forschungsansatz?

7. Wird die eingangs gestellte Forschungsfrage beantwortet?

8. Sind die Interpretationen, Schlussfolgerungen nachvollziehbar, glaubwürdig?

9. Sind Daten/Instrumentarien ausreichend dokumentiert?

10. Ist die Studie replizierbar?

11. Ist der gewählte Forschungsansatz dem Erkenntnisinteresse und Untersuchungsgegenstand angemessen?

12. Haben Sie alternative Ideen, wie man die Fragestellung untersuchen könnte? 
Folgende Strategien können in dieser Phase helfen:

- Orientierung an vorhandener Forschungsliteratur und forschungsmethodologischer Fachliteratur, auch und insbesondere zu einzelnen Verfahren der Datenerhebung, Datenaufbereitung und Datenanalyse (hierfür sollte auch die in den Sozialwissenschaften, der Erziehungswissenschaft und der Psychologie vorhandene Fachliteratur zu empirischen Forschungsmethoden intensiv konsultiert werden);

- externe Beratung zu Methoden und damit verbundenen Möglichkeiten und Problembereichen wahrnehmen, zu denen es im eigenen Fachbereich keine Angebote gibt (z.B. zur Statistik), Kennenlernen von softwaregestützten Transkriptionsverfahren (z.B. EXMARaLDA), Besuch von Methodenworkshops zur Datenanalyse (z.B. statistische Datenauswertung mit SPSS, qualitative Datenanalyse mit atlas.ti oder MAXQDA).

\subsection{Realisierbarkeit einschätzen}

In dieser Phase sollte man erst einmal „einen Gang zurückschalten“. Bevor man sich in die Erhebung von Daten stürzt, sollte genau erwogen werden, ob das geplante Design in seinen vorgesehenen Facetten und in angemessener Qualität auch wirklich zu realisieren ist. Folgende Schritte sollten vorgesehen werden:

- Zeitfaktor einschätzen (insbesondere, aber nicht nur für die Phase der Datenerhebung und -aufbereitung; wie viele Stunden wird z.B. die Transkription von Daten in Anspruch nehmen?);

- Pilotierung neu erstellter Datenerhebungsinstrumente mit einer geeigneten Versuchsgruppe (unverzichtbar!);

- Zugang zu geeigneten Untersuchungsteilnehmern herstellen, Notwendigkeit von Genehmigungen eruieren (von Behörden, Ämtern, Eltern, Untersuchungsteilnehmern; insbesondere im vorschulischen und schulischen Kontext): erstes Betreten des Felds und Herstellung von (für beide Seiten vertrauensvollen) Kontakten;

- Forschungsethik beachten (auch: Datenschutz);

- Notwendigkeiten der technischen Ausstattung, Verfügbarkeit von Geräten, Qualität der Geräte;

- Kosten (z.B. für Geräteausleihe, Datenträger, Bezahlung/Belohnung der Untersuchungsteilnehmer, Beschäftigung von Hilfskräften).

Hierfür können u.a. folgende Strategien eingesetzt werden:

- Erstellung eines detaillierten Zeitplans (notwendiges Volumen für Datenerhebung, Datenaufbereitung, Datenanalyse, Schreiben der Arbeit inkl. weiterer notwendiger Recherchen, Einplanen ausreichender Reserven);

- Ausprobieren der ausgewählten Erhebungs-, aber auch der Aufbereitungs- und Analyseverfahren;

- Vorgespräche mit möglichen Untersuchungsteilnehmern, Institutionen führen und dabei mögliche Termine austauschen (sehr wichtig!); 
- Möglichkeiten der Forschungsförderung an der eigenen Institution recherchieren (z.B. Empfehlungsschreiben für Behörden, finanzielle Unterstützung (selten!), Unterstützung durch technische Ausstattung und technischen Support.

\subsection{Revisionsphase}

In dieser Phase steht die Überarbeitung des Forschungsdesigns im Zentrum. Die Forschungsfrage sollte prinzipiell überdacht und ggfs. angepasst werden; das Forschungsdesign inkl. der vorgesehenen Methoden sollte noch einmal äußert kritisch reflektiert und angepasst werden mit dem Ziel, späteren „Datenmüll“, also erstens unbrauchbare und zweitens sicherlich interessante, aber nicht unbedingt notwendige Daten zu vermeiden. Wer ein Mehr-Methoden-Design mit triangulativen Elementen gewählt hat, sollte sich z.B. fragen, ob die Vorteile einer multiplen Operationalisierung den erhöhten Aufwand rechtfertigen und ob die unterschiedlichen Daten tatsächlich sinnvoll miteinander in Beziehung zu setzen sind.

Am Ende dieser Phase steht die Entscheidung für ein Forschungsdesign: Hier sollte nun exakt festgelegt werden, ob man eine qualitative oder quantitative oder gemischte Studie durchführen möchte, ob und welche Mehr-Methoden- oder Ein-Methoden-Verfahren gewählt werden, ob ein Längsschnitt oder Querschnitt angelegt wird, ob eine Replikationsstudie, Pilotstudie, Fallstudie etc. angestrebt wird.

Ein Hinweis: Wenn zumindest die wichtigsten Reflexionen und Entscheidungen im Forschungstagebuch dokumentiert werden, wird vieles davon für die späteren Ausarbeitungen in der Arbeit verwendbar sein und die Transparenz der eigenen Studie für die Rezipienten der Forschung erhöhen.

\subsection{Datenerhebung planen und starten}

Und erst jetzt ist es so weit: Die Datenerhebung kann gestartet werden. Notwendige Schritte dabei sind:

- Untersuchungsteilnehmer kontaktieren und feste Termine vereinbaren;

- Umgang mit technischen Geräten üben; der Umgang mit Aufnahmegeräten, Mikrofonen, Kameras etc. will geübt sein, um spätere Pannen möglichst zu vermeiden;

- Ersatzlösungen zur Hand haben, Geräte können immer einmal defekt sein (Ersatzgeräte vorrätig haben); Aufnahmen können bei der Bearbeitung versehentlich beschädigt werden (mehrere Sicherungsdateien vorsehen).

\section{Zum Abschluss}

Der weitere Forschungsprozess selbst lässt sich nicht immer genau planen, nicht alles ist durch sorgfältige Reflexion und Vorbereitung vorauszusehen: „Pannen“ jeder Art - sei es das „Vergessen“ von Nachfragen oder Einfließen suggestiver Momente im Interview, sei es eine erst spät bemerkte Inkonsistenz in einem Fragebogen, sei es der plötzliche Ausstieg von Untersuchungsteilnehmern - sind keine Ausnahme! Die Planung eines Forschungsprojekts lässt sich noch recht linear beschreiben, so wie ich dies in den vorangegangenen Abschnitten versucht habe. Nichtsdestotrotz sind getroffene 
Entscheidungen auf der Basis der dann gesammelten Erfahrungen im Feld und der dabei gewonnen Daten weiter zu hinterfragen - denn was nützen die schönsten Daten, wenn sie trotz aller Umsicht keinen sinnvollen Beitrag für die Forschungsfrage liefern können (dies dürfte eher in hypothesengenerierender denn in hypothesentestender Forschung auftreten).

Aber alle möglicherweise später notwendig werdenden Veränderungen und Anpassungen des Forschungsdesigns werden umso leichter vorzunehmen und zu bewältigen sein, je durchdachter das anfängliche Unternehmen war.

\section{Auswahlbibliographie}

\section{Handbücher - Einführungen - Sammelbände zu Forschungsmethodologie und Forschungsmethoden (Auswahl)}

Aguado, Karin (Hrsg.) (2000): Zur Methodologie in der empirischen Fremdsprachenforschung. Baltmannsweiler: Schneider Verlag Hohengehren.

Albert, Ruth; Koster, Cor J. (2002): Empirie in Linguistik und Sprachlehrforschung. Ein methodologisches Arbeitsbuch. Tübingen: Narr.

Altrichter, Herbert; Posch, Peter ( $\left.{ }^{4} 2007\right)$ : Lehrerinnen und Lebrer erforschen ibren Unterricht. Eine Einführung in die Methoden der Aktionsforschung. Bad Heilbrunn: Julius Klinkhardt.

Backhaus, Klaus; Erichson, Bernd; Plinke, Wulff; Weiber, Rolf ( $\left.{ }^{11} 2006\right)$ : Multivariate Analysemethoden. Eine anwendungsorientierte Einführung. Berlin et al.: Springer.

Bortz, Jürgen (1984): Lehrbuch der empirischen Forschung für Sozialwissenschaftler. Berlin et al.: Springer.

Bortz, Jürgen ('2005): Statistik für Human- und Sozialwissenschaftler. Heidelberg: Springer.

Brown, James D. (1988): Understanding Research in Second Language Learning. A Teacher's Guide to Statistics and Research Design. Cambridge et al.: Cambridge University Press.

Brown, James D.; Rodgers, Theodore S. (2002): Doing Second Language Research. Oxford: Oxford University Press.

Dittmar, Norbert (2004): Transkription. Ein Leiffaden mit Aufgaben für Studenten, Forscher und Laien. Wiesbaden: VS Verlag für Sozialwissenschaften.

Dörnyei, Zoltan (2003): Questionnaires in Second Language Research. Construction, Administration, and Processing. Mahwah, NJ; London: Lawrence Erlbaum.

Dörnyei, Zoltan (2007): Research Methods in Applied Linguistics. Oxford: Oxford University Press.

Duff, Patricia A. (2008): Case Study Research in Applied Linguistics. New York; London: Lawrence Erlbaum.

Ellis, Rod; Barkhuizen, Gary (2005): Analysing Learner Language. Oxford: Oxford University Press.

Flick, Uwe (2004): Triangulation. Eine Einführung. Wiesbaden: VS Verlag für Sozialwissenschaften.

Flick, Uwe (2007): Qualitative Sozialforschung: eine Einführung. Reinbek bei Hamburg: Rowohlt (Rowohlts Enzyklopädie, Taschenbuch). 
Flick, Uwe; v. Kardorff, Ernst; Steinke, Ines (2000) (Hrsg.): Qualitative Forschung. Ein Handbuch. Reinbek bei Hamburg: Rowohlt (Rowohlts Enzyklopädie, Taschenbuch).

Gass, Susan M.; Mackey, Alison (2007): Data Elicitation for Second and Foreign Language Research. Mahwah, NJ; London: Lawrence Erlbaum.

Glaser, Barney G.; Strauss, Anselm L. (1998): Grounded Theory. Strategien qualitativer Forschung. Bern et al.: Hans Huber.

Hatch, Evelyn; Lazaraton, Anne (1991): The Research Manual. Design and Statistics for Applied Linguistics. New York: Newbury House.

Helfferich, Cornelia (2004): Die Qualität qualitativer Daten. Manual für die Durchführung qualitativer Interviews. Wiesbaden: VS Verlag für Sozialwissenschaften.

Huber, Günter; Mandl, Heinz (1982) (Hrsg.): Verbale Daten. Eine Einführung in die Grundlagen und Methoden der Erhebung und Auswertung. Weinheim; Basel: Belz.

Johnson, Donna M. (1992): Approaches to Research in Second Language Learning. New York; London: Guilford.

Kelle, Udo (1994): Empirisch begründete Theoriebildung. Zur Logik und Methodologie interpretativer Sozialforschung. Weinheim: Deutscher Studien Verlag.

Kromrey, Helmut ( $\left.{ }^{10} 2002\right)$ : Empirische Sozialforschung. Opladen: Leske + Budrich.

Lamnek, Siegfried (31995): Qualitative Sozialforschung. Bd. 1 Methodologie; Bd. 2 Methoden und Techniken. Weinheim: Beltz PsychologieVerlagsUnion.

Mackey, Alison; Gass, Susan M. (2005): Second Language Research. Methodology and Design. Mahwah, NJ; London: Lawrence Erlbaum.

Mayring, Philipp ( ${ }^{3}$ 1996): Einführung in die qualitative Sozialforschung. Weinheim: Beltz PsychologieVerlagsUnion.

Mayring, Philipp (72000): Qualitative Inhaltsanalyse. Grundlagen und Techniken. Weinheim: Deutscher Studien Verlag.

McDonough, Jo; McDonough, Steven (1997): Research Methods for English Language Teachers. London et al.: Armold.

McKay, Sandra L. (2006): Researching Second Language Classrooms. Mahwah, NJ; London: Lawrence Erlbaum.

Müller-Hartmann, Andreas; Schocker-v. Ditfurth, Marita (2001) (Hrsg): Qualitative Forschung im Bereich Fremdsprachen lehren und lernen. Tübingen: Narr.

Perry, Fred L. (2005): Research in Applied Linguistics. Becoming a Discerning Consumer. Mahwah, NJ; London: Lawrence Erlbaum.

Reicherts, Jo (2003): Die Abduktion in der qualitativen Sozialforschung. Opladen: Leske + Budrich.

Richards, Keith (2003): Qualitative Inquiry in TESOL. Basingstoke; New York: Palgrave Macmillan.

Schachter, Jacquelyn; Gass, Susan M. (Hrsg.) (1996): Second Language Classroom Research. Issues and Opportunities. Mahwah, NJ; London: Lawrence Erlbaum.

Seipel, Christian; Rieker, Peter (2003): Integrative Sozialforschung. Konzepte und Methoden der qualitativen und quantitativen Forschung. Weinheim; München: Juventa. 
Seliger, Herbert; Shohamy, Elana (1989): Second Language Research Methods. Oxford: Oxford University Press.

Silverman, David (1993): Interpreting Qualitative Data. Methods for Analyzing Talk, Text and Interaction. London et al.: Sage.

Steinke, Ines (1999): Kriterien qualitativer Forschung. Ansätze zur Bewertung qualitativ-empirischer Sozialforschung. Einheim; München: Juventa.

Strauss, Anselm; Corbin, Juliet (1996): Grounded Theory: Grundlagen qualitativer Sozialforschung. Weinheim: Beltz PsychologieVerlagsUnion.

Strübing, Jörg (2004): Grounded Theory. Zur sozialtheoretischen und epistemologischen Fundierung des Verfabrens der empirisch begründeten Theoriebildung. Wiesbaden: VS Verlag für Sozialwissenschaften.

Vollmer, Helmut (Hrsg.) (2007): Synergieeffekte in der Fremdsprachenforschung. Empirische Zugänge, Probleme, Ergebnisse. Frankfürt a.M.: Peter Lang.

Wallace, Michael J. (1998): Action Research for Language Teachers. Cambridge: Cambridge University Press.

\section{Ausgewählte (deutschsprachige) Aufsätze zur Forschungsmethodologie in der Fremdsprachenforschung}

Aguado, Karin (2000): Empirische Fremdsprachenerwerbsforschung. Ein Plädoyer für mehr Transparenz. In: Aguado, Karin (Hrsg.): Zur Methodologie in der empirischen Fremdsprachenforschung. Baltmannsweiler: Schneider Verlag Hohengehren, 119-131.

Aguado, Karin (2004): Introspektive Verfahren in der empirischen Fremdsprachenerwerbsforschung: Methodisch-methodologische Überlegungen und Vorschläge. Fremdsprachen und Hochschulen 71, 24-38.

Aguado, Karin; Riemer, Claudia (2000): Empirische Forschung: aus der Praxis für die Praxis? In: Wolff, Armin; Tanzer, Harald (Hrsg.): Sprache - Kultur - Politik. Regensburg: Fachverband Deutsch als Fremdsprache (= Materialien Deutsch als Fremdsprache 53), 153-165.

Arbeitsgruppe Fremdsprachenerwerb Bielefeld (Heidecker, Berit; Henrici, Gert; Niedergesähs, Karin; Olfe, Karl-Wilhelm; Riemer, Claudia; Yu, Su-Yon) (1996): Fremdsprachenerwerbsspezifische Forschung. Aber wie? Theoretische und methodologische Überlegungen. Teil I in Deutsch als Fremdsprache 33, 144-155; Teil II in Deutsch als Fremdsprache 33, 200-210.

Caspari, Daniela; Helbig, Beate; Schmelter, Lars ( $\left.{ }^{4} 2003\right)$ : Forschungsmethoden: Explorativ-interpretatives Forschen. In: Bausch, Karl-Richard; Christ, Herbert; Krumm, Hans-Jürgen (Hrsg.): Handbuch Fremdsprachenunterricht. Tübingen; Basel: Francke, 499-505.

Grotjahn, Rüdiger (1987): On the methodological basis of introspective methods. In: Faerch, Claus; Kasper, Gabriele (Hrsg.): Introspection in Second Language Research. Clevedon: Multilingual Matters, 54-81.

Grotjahn, Rüdiger (1993): Qualitative vs. quantitative Fremdsprachenforschung. Eine klärungsbedürftige und unfruchtbare Dichotomie. In: Timm, Johannes-Peter; Voll- 
mer, Helmut J. (Hrsg.): Kontroversen in der Fremdsprachenforschung. Bochum: Brockmeyer, 223-248.

Grotjahn, Rüdiger (1999): Thesen zur empirischen Forschungsmethodologie. Zeitschrift für Fremdsprachenforschung 10/1, 133-158.

Grotjahn, Rüdiger (2003): „Empirie in Linguistik und Sprachlehrforschung“. Kritische Bemerkungen zu einem „methodologischen Arbeitsbuch“. Zeitschrift für Fremdsprachenforschung 14/1, 169-186.

Grotjahn, Rüdiger $\left({ }^{4} 2003\right)$ : Konzepte für die Erforschung des Lehrens und Lernens fremder Sprachen: Forschungsmethodologischer Überblick. In: Bausch, KarlRichard; Christ, Herbert; Krumm, Hans-Jürgen (Hrsg.): Handbuch Fremdsprachenunterricht. Tübingen; Basel: Francke, 493-499.

Grotjahn, Rüdiger (2005): Subjektmodelle: Implikationen für die Theoriebildung und Forschungsmethodologie der Sprachlehr- und Sprachlernforschung. Zeitschrift für Fremdsprachenforschung 16/1, 23-56.

Grotjahn, Rüdiger (2006): Zur Methodologie der Fremdsprachenerwerbsforschung. In: Scherfer, Peter; Wolff, Dieter (Hrsg.): Vom Lehren und Lernen fremder Sprachen: Eine vorläufige Bestandsaufnabme. Frankfurt a.M. et al.: Peter Lang, 247-270.

Riemer, Claudia; Aguado, Karin (2001): Triangulation: Chancen und Grenzen mehrmethodischer empirischer Forschung. In: Aguado, Karin; Riemer, Claudia (Hrsg.): Wege und Ziele. Zur Theorie, Empirie und Praxis des Deutschen als Fremdsprache (und anderer Fremdsprachen). Festschrift für Gert Henrici zum 60. Geburtstag. Baltmannsweiler: Schneider Verlag Hohengehren, 245-257.

Riemer, Claudia (2002): Für und über die eigene Unterrichtspraxis forschen: Anregungen zur Lehrerhandlungsforschung. In: Schreiber, Rüdiger (Hrsg.): Deutsch als Fremdsprache am Studienkolleg. Unterrichtspraxis, Tests, Evaluation. Regensburg: Fachverband Deutsch als Fremdsprache (= Materialien Deutsch als Fremdsprache 63), 129143.

Riemer, Claudia (2005): Nie zu früh und immer zu wenig: Forschung im und für den Fremdsprachenunterricht. In: Burwitz-Melzer, Eva; Solmecke, Gert (Hrsg.): Niemals zu früh und selten zu spät: Fremdsprachenunterricht in Schule und Erwachsenenbildung. Berlin: Cornelsen, 85-93.

Riemer, Claudia (2006): Entwicklungen in der qualitativen Fremdsprachenforschung: Quantifizierung als Chance oder Problem? In: Timm, Johannes-Peter (Hrsg.): Fremdsprachenlernen und Fremdsprachenforschung: Kompetenzen, Standards, Aufgaben, Evaluation. Tübingen: Narr, 451-464.

Riemer, Claudia (2007): DaF/DaZ und empirische Forschung: wechselnde Herausforderungen. Info DaF 34/5, 445-459.

Wichtiges Forum für qualitative Forschung (inkl. Fachzeitschrift und NetzWerkstatt für ExamenskandidatInnen und DoktorandInnen):

http://www.qualitative-research.net 
Christoph Chlosta, Matthias Jung (Hrsg.) (2010):

DaF intergriert: Literatur - Medien - Ausbildung. Tagungsband der

36. Jahrestagung des Fachverbandes Deutsch als Fremdsprache 2008.

Göttingen: Universitätsverlag, 435-445.

\section{Matthias Jung (Düsseldorf)}

\section{DaF-Ausbildung am Arbeitsmarkt vorbei? Bestandsaufnahme und Vorschläge}

\section{Der DaF-Arbeitsmarkt: Honorarkräfte und Angestellte}

Im Unterschied zum Studium in den Fremdsprachenphilologien oder der muttersprachlichen Germanistik ist DaF/DaZ kein Schulfach, so dass bisher in allen Bundesländern der Weg in den Schuldienst verbaut ist, es sei denn die Bewerber hätten das Studium zusätzlich zu einem klassischen Lehramtsstudium mit zwei traditionellen Schulfächern gemacht. Ähnlich sieht es im Ausland aus, wo ebenfalls besondere Zugangsbedingungen qualifikationsbezogener wie administrativer Art (z.B. Staatsbürgerschaft oder perfekte Kenntnisse der Landessprache) für den Schuldienst gelten, die für einen deutschen Muttersprachler in aller Regel nicht ohne hohen Zusatzaufwand erworben werden können. Somit bleiben für in Deutschland ausgebildete DaF-/DaZ-Absolventen mit dem Berufswunsch bzw. dem Profil ,Lehrer‘ eigentlich nur Hochschulen, Institutionen der Erwachsenenbildung sowie Unternehmen als potenzielle Arbeitgeber übrig.

Aber auch hier hat sich das Angebot an angemessenen Stellen trotz unzweifelhaft wachsender Nachfrage, etwa durch die quantitativ ausgeweiteten Fördermaßnahmen im Integrationskursbereich, weiter verknappt. Das liegt vor allem an der finanziell beschämend schlechten und mit ständigen administrativen Unwägbarkeiten verknüpften Förderung von Integrationskursen bzw. an dem generellen Trend zum Ersatz von angestellten Kräften durch Honorarlehrer, die zudem zumindest im halbstaatlichen Integrationskursbereich, was die Stundensätze angeht, eine erschreckende Nivellierung nach unten erfahren haben. Dieser Trend lässt sich seit vielen Jahren in allen Bereichen 
beobachten, sei es in Hochschulen, Institutionen wie Volkshochschulen oder den Goethe-Instituten, in Firmenkursen oder bei privatrechtlichen Trägern unterschiedlichster Natur (oft gemeinnützig, eher in der Minderheit gewinnorientiert), an denen vermutlich sogar das Gros der in Deutschland erteilten DaF/DaZ-Stunden geleistet wird. Für die gemeinnützigen Anbieter seien beispielsweise überregionale Gruppierungen wie der Internationale Bund (IB), die Carl-Duisberg-Centren (CDC), universitäre Ausgründungen (z.B. IIKs in Bayreuth, Düsseldorf, Göttingen und anderswo), kirchliche und gewerkschaftliche Träger genannt. Für die gewinnorientierten Anbieter mögen Namen wie Inlingua, Berlitz, die Euro-Schulen oder die Benedict-School-Gruppe stehen (vgl. Jung 2010).

Es ist hier nicht der Ort, die Gründe oder das Für und Wider dieser Entwicklungen ausführlich zu diskutieren. Hier muss es ausreichen, darauf hinzuweisen, dass sie mit Marktmechanismen (z.B. Preis- und Konkurrenzdruck) und dem im Unterschied zum staatlichen Schulwesen fehlenden verpflichtenden Charakter, geringer Regulierung und bestenfalls partieller, aber immer volatiler Förderung zu tun haben, woraus eine geringe Planbarkeit und große finanzielle Risiken für Anbieter wie Lehrkräfte resultieren. Fakt ist offensichtlich, dass prinzipiell reine $\mathrm{DaF}$-/DaZ-Lehrerstellen kaum in großem Umfang existiert haben, ihre Zahl seit Jahren kontinuierlich zurückgeht oder DaF/DaZAbsolventen zu nicht ausbildungsadäquaten Bedingungen hinsichtlich Bezahlung und Befristung als Lehrer arbeiten. Darüber hinaus müssen sich diese Hochschulabsolventen dem Konkurrenzdruck von DaF-Lehrern stellen, die in Kurzschulungsmaßnahmen die Berechtigung für das Erteilen von Integrationskursen erworben haben. Doch selbst das muss als Fortschritt gesehen werden, da bis vor kurzem nicht einmal dieser Nachweis verlangt wurde. Außerhalb des Schuldienstes kann sich jeder als „Lehrer“ (auf dem „freien“ Bildungsmarkt zunehmend als „Trainer" bezeichnet) zur Vermittlung beliebiger Qualifikationen betätigen, wobei in der Fremdsprachenvermittlung oft die einzige Qualifikation darin besteht, native speaker zu sein. Zu den so theoretisch 80 Millionen potenziellen Konkurrenten allein in Deutschland kommt eine nicht unbeträchtliche Anzahl ausländischer Germanistinnen und Germanisten, die in Deutschland in ihrem Qualifikationsfeld arbeiten möchten und den Mangel an inländischen Qualifikationen bzw. ihre insbesondere in der Aussprache sinnfällige Nicht-Muttersprachlichkeit durch Honorarabschläge kompensieren, was die Honorarsätze zusätzlich nach unten zieht. Charakteristisch ist weiterhin, dass viele $\mathrm{DaF}$-/DaZ-Honorarkräfte nebenberuflich arbeiten, d.h. grundsätzlich finanziell anders abgesichert sind und deshalb Stundensätze akzeptieren, die Vollberufler ablehnen müssten.

Es überrascht daher wenig, dass viele DaF-Absolventen in der Arbeitslosigkeit oder als Honorarkräfte im Prekariat landen bzw. ausbildungsfremd unterkommen. Das seit einigen Jahren gestiegene Interesse an der sprachlichen Integration von Migranten hat nichts an dieser Situation geändert - im Gegenteil! Zum einen werden - anders als es scheinen mag - keineswegs so viel mehr Lerner gefördert als früher, denn im Wesentlichen wurde nur die Förderung anders, vor allem zentralisierter und möglicherweise 
teurer organisiert, zum andern hat diese Zentralisierung zu einer deutlichen Nivellierung nach unten bei der Bezahlung geführt.

Aktuell scheint es so, dass feste, unbefristete und ausbildungsgemäß auf MA-Niveau bezahlte DaF-Stellen bei den genannten Trägern primär mit Organisations- und Leitungsaufgaben verknüpft sind, d.h. gesucht wird zunächst nicht der gute DaF-Lehrer, sondern eher der gute Organisator. Nun könnte man denken, dass eine gute Lehrerausbildung automatisch auch die optimale Qualifikation für diese Art von pädagogischen Leitungsstellen, die meist auch weiterhin ein gewisses Stundendeputat beinhalten, bedeutet. Es käme dann nur noch auf gewisse Persönlichkeitsmerkmale und „Organisationstalent" an, die sich in einem Studium nur begrenzt vermitteln lassen bzw. nicht fachspezifisch sind. Auch wenn es hier offensichtlich um die sogenannten „Schlüsselqualifikationen“"geht, lässt sich doch festhalten, dass diese zumindest für den Bildungsoder sogar Sprachenbereich sehr viel genauer und komplexer spezifiziert werden können.

Zunächst einmal geht es um mehr als nur gute Organisation und einen ,absoluten“ oder gar wissenschaftlichen Qualitätsbegriff. Gebraucht und nachgefragt werden nicht die besten Pädagogen, sondern „Kurs-“ oder „Trainingsmanager“" (so heißt dieses Berufsbild im angloamerikanischen Sprachraum oder bei großen Firmen). Das Wort „Manager“ ist hier nicht nur ein modischer Anglizismus, sondern beinhaltet eine Fokusverschiebung: Die gesuchte Funktion schließt vor allem auch die wirtschaftliche und personelle Perspektive bzw. Verantwortung ein. Notwendig sind etwa das Verständnis und der operationalisierte Umgang mit betriebswirtschaftlichen Konzepten aus der Finanzbuchhaltung (z.B. Bilanz, Gewinn- und Verlustrechnung, Forderungen, Verbindlichkeiten, Rückstellungen, Vorsteuer), aus der Kostenrechnung (z.B. Fixkosten, Deckungsbeiträge, Kostenstellen, Rendite), aus dem Qualitätsmanagement (ISO-Zertifizierungen, „Total Quality“, Qualitätssicherung), aus dem Personalwesen (Vertragsformen wie Dienst- oder Werkvertrag, Mitarbeiterformen wie Angestellte, Teilzeitkräfte, Honorarkräfte, geringfügig Beschäftigte, studentische Hilfskräfte, Tarifrecht) und vor allem aus der Personalführung bzw. dem Feld kommunikativer Fertigkeiten (z.B. Führungsstile, Personalentwicklung, Mitarbeitergespräche und Verhandlungen), denen angesichts der schwierigen wirtschaftlichen Lage vieler freiberuflicher oder angestellter Dozenten besondere Bedeutung zukommt.

Erfahrungsgemäß - und ich beziehe mich hier sowohl auf eigene Erfahrungen als Geschäftsführer des IIK Düsseldorf e.V. (www.iik-duesseldorf.de) als auch auf Erfahrungen anderer Leiter, wie sie sich im $\mathrm{FaDaF}$-Arbeitskreis „Wirtschaften mit DaF“ austauschen - ist es bei überdurchschnittlicher Bezahlung, speziell in den Ballungszentren leicht, gute DaF-Lehrer zu finden. Gute Kursmanager sind dagegen rar und - soweit sie aus dem eigenen Dozentenpool rekrutiert werden - fallen die entsprechenden „Talente“, die das Unterrichten nicht nur als pädagogisch optimierbaren Faktorenkomplex sehen, sondern als didaktisches Handeln in einem wirtschaftlichen Kontext verstehen und denken, innerhalb der Menge der rein pädagogisch interessierten Kursleiter schnell auf. 
Dieses Bewusstsein und Interesse sind nicht jedermanns Sache, viele Lehrer gehen auf Dauer ganz im Unterrichten auf, aber stellen auch keine angeborene „Berufung“ dar. Es ist eine Haltung, die man in Grenzen auch in der Ausbildung erwerben und mit Fach- und Konzeptwissen anreichern kann oder über die man sich zumindest klar werden sollte, um entscheiden zu können, ob man diese Richtung persönlich verfolgen möchte. Eine entsprechende Ausbildung würde über den DaF-Kontext hinaus zu einer allgemeinen Leitungsfunktion im Sprachenbereich bei allen Institutionen und Anbietern, speziell der kostenpflichtigen Erwachsenenbildung, qualifizieren.

Versuchen wir einmal abzuschätzen, wie viele derartige Stellen es für Kursmanager zumindest im DaF-/DaZ-Bereich überhaupt gibt. Naturgemäß ist eine solche Abschätzung wegen der unklaren Abgrenzung des Berufsbildes zu Bezeichnungen wie „Pädagogischer Mitarbeiter“ oder „Leiter DaF-Kurse“ schwierig. Hinzu kommt die Intransparenz des Bildungsmarktes allgemein, sobald es um die Erwachsenenbildung mit ihrer Vielzahl von gewinnorientierten und gemeinnützigen Trägern geht. Nennen wir dennoch ein paar Zahlen: Laut Bundesamt für Migration und Flüchtlinge gibt es rund 1.800 registrierte Träger für Integrationskurse, davon ein Großteil der 960 Volkshochschulen. ${ }^{1}$ Der Fachverband Deutsch als Fremdsprache zählt unter seinen Mitgliedern 101 außeruniversitäre DaF-Institutionen und 96 DaF-Studiengänge bzw. -Lehrgebiete, Sprachenzentren o.ä. an Hochschulen (interne Angaben, Stand 30.11.2010). Von diesen knapp 200 Institutionen sind ca. 50 auch Integrationskursträger. In der Anbieterdatenbank auf www.fadaf.de haben sich 414 DaF-Anbieter registriert (Abfrage vom 30.11.2010; darunter ebenfalls viele Hochschulkurse und Integrationskursträger). Bleibt die Frage, wie viele Institutionen noch nicht in der größten Zahl von 1.800 Integrationskursträgern plus ca. 100 universitären DaF-Lehrgebieten erfasst sind. Hier ist sicherlich mit einer erheblichen Dunkelziffer zu rechnen (z.B. Goethe-Institute und Volkshochschulen oder Ketten wie die Euro-Schulen, Carl-Duisberg-Centren, IIKs, Berlitz-Schulen, die keine Integrationskurse anbieten, sowie hauptberufliche Training-Manager in Firmen und Instituten, die nur für Firmen arbeiten. Gerade diese Gruppe ist gar nicht erfasst und ihre Zahl nur ganz schwer zu schätzen).

Hinzu kommen entsprechende Stellen im deutschsprachigen Ausland bzw. im nichtdeutschsprachigen Ausland, die auf einem vergleichbaren Gehaltsniveau liegen. Andererseits sind auch viele der genannten 1.800 Integrationskursträger zu klein, um einen angestellten DaF-Kursmanager zu beschäftigen, oder in Wirklichkeit gar nicht mehr aktiv, sondern nur noch Karteileichen. Auf der Basis der genannten Zahlen erscheinen mir deshalb folgende Schätzungen realistisch: Um die 1.000 Stellen mit großer wirtschaftlicher Verantwortung und ca. 1.000 weitere Stellen mit geringerer wirtschaftlicher oder personeller Verantwortung (bis hin zum pädagogischen Leiter DaF/DaZ als Mitarbeiter eines universitären Sprachenzentrumsgeschäftsführers, der nur indirekt ökonomischen Einfluss hätte). Nicht in dieser Schätzung inbegriffen sind dabei Stellen als

Stand 30.11.2010 laut www.bamf.de/nn_443130/DE/Integration/Integrationskurse/integrationskurse-node.html bzw. www.dvv-vhs.de/die-vhs/vhsinzahlen/ 
Kursmanager Fremdsprachen allgemein mit mehr oder weniger starken DaF-Anteilen, wobei Englisch insgesamt meist überwiegen würde.

Noch nicht berücksichtigt ist in dieser Diskussion, dass auch Freiberufler, soweit sie ansonsten ausschließlich als Trainer ohne übergreifende Organisationsverantwortung arbeiten, gewisse Managementfertigkeiten gut gebrauchen können, da sie, um gerade nicht im Prekariat zu landen, in der Lage sein müssen, ihren Arbeitskrafteinsatz ökonomisch zu beurteilen und sich selbst vermarkten zu können, d.h. sozusagen ihr eigener Manager sind. Das gilt umso mehr, wenn sie als Firmentrainer unterwegs sind bzw. weitere Kurstypen - z.B. Kommunikationstrainings - in ihrem „Trainer-Portfolio“ haben. Hier gilt es nicht zuletzt, einen Blick auf den Markt für freie Trainer allgemein zu werfen. Es gibt zum Teil sehr erfolgreiche und finanziell gut gestellte freiberufliche Trainer, auch wenn sich charakteristischerweise die Honorare von Fremdsprachentrainern bei weitem nicht mit denen vom Kommunikations- und Managementtrainern messen können und die DaF-Honorare in Deutschland hier noch mal niedriger als bei Trainern für andere Fremdsprachen liegen. ${ }^{2}$ Schon die Zahl der derzeit lieferbaren Titel zum „Selbstmarketing für Trainer“ (etwa Häuser 2003, Lutzer 2005, Bernecker; Gierke; Hahn 2010, um nur die drei laut Amazon derzeit verkaufsstärksten Titel in diesem Segment zu nennen) ist hier bezeichnend. Rund 30 einschlägige Ratgebertitel zeigen, dass es hier ein offensichtliches Qualifizierungsdefizit gibt.

\section{Das Berufsbild,Kursmanager' in DaF-/DaZ-Studiengängen}

Unterstellen wir einmal, dass das oben skizzierte Berufsbild tatsächlich ein bisher in der Hochschulausbildung unterschätztes Potenzial für die qualifikationsangemessene Beschäftigung von DaF/DaZ-Absolventen hat. Dann ist zu fragen, (a) inwiefern die bisherigen Hochschulcurricula dennoch dieses Feld abdecken und (b) wie bei dieser Analyse sichtbar werdende Defizite behoben bzw., allgemeiner formuliert, wie die existierenden Ausbildungsangebote in dieser Hinsicht stärker profiliert werden können.

An sich bietet die mittlerweile grundsätzlich erfolgte Umstellung auf BA/MA und der damit oft verknüpfte Anspruch größerer Praxisnähe (vgl. Casper-Hehne; Koreik; Middeke 2006) die Chance, auf besser auf derartige Gegebenheiten vorzubereiten. Dennoch bleibt das implizite Berufsbild der DaF-/DaZ-Studiengänge der Lehrer oder Forscher: Betrachten wir die Studiengangscurricula, soweit sie online veröffentlicht sind, ${ }^{3}$ dann zeigt sich, dass Inhalte weiterhin exklusiv Linguistik, Didaktik und Literaturwissenschaft für $\mathrm{DaF}$ umfassen. Die curricularen Veränderungen der letzten Jahre spiegeln Neuerungen der Bezugswissenschaften wider: z.B. mehr Kulturwissenschaften/Interkulturelle Kommunikation oder mehr Mediendidaktik/Sprachtechnologie. Betriebswirtschaftliche Inhalte oder bessere Management-Kompetenzen kommen in den Stundenplänen höchstens als fakultative Elemente vor, d.h. in frei wählbaren

Laut einer BAMF-Studie verdienen Integrationskurslehrer 18,35 EUR brutto pro Stunde, Lehrer im staatlichen Schuldienst 71\% mehr (BAMF 2010).

3 Mein besonderer Dank gilt hier Lena Busch, die eine entsprechende Auswertung von Studiengängen und Zusatzqualifikationen DaF/DaZ in Deutschland erstellt hat (Stand: 30.11.2009), einen schnellen Überblick über DaF-/DaZ-Studiengänge bietet auch das DaF-Wiki (2007ff.) auf www.fadaf.de. 
Veranstaltungen zum Erwerb von Schlüsselqualifikationen, wie sie mittlerweile wohl jede Hochschule ihren Studierenden fächerübergreifend anbietet.

Betrachten wir ein paar Beispiele genauer ${ }^{4}$ V Vereinzelt tauchen in $\mathrm{DaF}$-/DaZ-bezogenen Studiengängen wirtschaftsbezogene Inhalte explizit auf: Im Zusatzstudium „Interkulturelle Pädagogik/Deutsch als Zweitsprache an der Universität Köln werden auch wirtschaftliche Aspekte der Migration behandelt. Relevanter für das Berufsbild „Kursmanager" erscheinen auf den ersten Blick Inhalte wie interkulturelle Wirtschaftskommunikation. In Trier im BA-Nebenfach DaF etwa gibt es in dem Modul „Lehren und Lernen im Kontext von Mehrsprachigkeit“ den Inhalt „Wirtschafts- und Wissenschaftskommunikation“. Gewichtiger ist der wirtschaftliche Aspekt in Studienangeboten, die von vorneherein interdisziplinär ausgerichtet sind, wie z.B. das BA-Ergänzungsfach „Interkulturelle Wirtschaftskommunikation“ an der Universität Jena. Allerdings sind hier die genannten betriebswirtschaftlichen Inhalte auf eine ganz andere Berufspraxis, nämlich die des Interkulturellen Managements fokussiert. Studienrichtungen oder Wahlpflichtmodule wie „Interkulturelle Wirtschaftskommunikation“ betonen zwar die Verbindung mit der Wirtschaft, aber sehen sie vor allem als ein weiteres Berufsfeld, über das es wissenschaftliche Erkenntnisse zu vermitteln gilt.

Auch über Praktika kann man natürlich in die Wirtschaft hineinschnuppern. Zum Beispiel waren Betriebspraktika in München auch in dem mittlerweile durch BA/MAStudiengänge ersetzten Magisterstudiengang ausdrücklich zugelassen, wenn es sich um durch Mehrsprachigkeit geprägte Unternehmen handelte. Hinzu kommen meist optionale Lehrveranstaltungen zu Themen wie „Wirtschaftsdeutsch“ als Beispiel für Fachsprachendidaktik (Universität Marburg) oder ,Wirtschaftspädagogik“ (extern wählbares Modul im Master DaF in Mainz), die einen Bezug zum Wirtschaften haben.

Derartige für DaF/DaZ-Studierende im Rahmen ihres Studiums mögliche Ausflüge in die Wirtschaft bleiben aber individuell-zufällig und sind von einer additiven Konzeption geprägt statt sich zu einem konkreten Berufsbild zu integrieren. Die Relevanz des von einem Dozenten aus der Allgemeinen Betriebswirtschaft vermittelten Wissens dürfte allgemein für die konkreten Berufsbilder von DaF/DaZ-Studierenden gering und in ihrer Bedeutung für das Berufsbild „Training-Manager“ wenig einsichtig sein. Bei einer integrierten Konzeption würden die betriebswirtschaftlichen Kenntnisse an dagegen einem Fundus von Aufgaben, Praxisbeispielen und Fallstudien vermittelt, die sich konkret auf die Praxis des genannten Stellenprofils beziehen.

Um dies mit einem einfachen, bewusst besonders ökonomisch-profanen Praxisbeispiel zu illustrieren, betrachten wir einmal die Frage, wann ein „pädagogischer Manager“" einen Kurs absagen wird: Üblich, speziell in öffentlichen Institutionen, ist, dass es eine festgelegte Mindestteilnehmerzahl und einen bestimmten Zeitpunkt vor Kursbeginn gibt, zu dem die Entscheidung über die Kursabsage oder -durchführung quasi automatisch fällt. Das ist unter ökonomischen Gesichtspunkten suboptimal, weil viel zu unflexibel. Möglicherweise muss sich ein neues Angebot erst etablieren, läuft also erst

4 www2.uni-jena.de/philosophie/iwk/download/modulkatalog_bachelor_iwk_ws1011 neu.pdf (10.11.2010). 
ab der nächsten Durchführung rentabel, war der Absagezeitpunkt aus organisatorischer Bequemlichkeit zu früh angesetzt oder hat die Kursabsage negative Folgeeffekte, die einen größeren wirtschaftlichen Schaden bedeuten, als es die nicht ganz rentable Kursdurchführung (etwa bei Kurssystemen mit garantierten Niveaustufen) bedeutet hätte, weil hierdurch Kursteilnehmer langfristig verloren gehen. Oder - und hier wird es schon ziemlich technisch - ist es wirtschaftlicher, einen kleinen sogenannten Deckungsbeitrag zu erwirtschaften als keinen? Beruht die angestellte Kostenrechnung vielleicht auf falschen Annahmen, z.B. weil sich der Personalaufwand geändert hat?

Gefragt ist daher nicht nur das Verständnis für die „offensichtliche“ Rentabilitätsberechnung eines Kurses auf der Basis der direkten Kosten in der einfachsten Form (Kursgebühren x Teilnehmerzahl ./. Lehrerkosten). Das wird schon beim Berechnen der Kosten pro Unterrichtsstunde bei einem angestellten Lehrer ziemlich kompliziert und steigert sich in seiner Komplexität noch, wenn die Kosten für fest angemietete Unterrichtsräume einberechnet werden müssen, was nur auf der Basis bestimmter Annahmen, etwa zur Auslastung der Räume, möglich ist. Hinzu kommen aber vor allem weitere Fixkosten, als Sekretariats-, Buchhaltungs-, Marketing-, Geschäftsführungskosten und Abschreibungen auf Geräte und Mobiliar, um einmal nur die größten Posten zu nennen, die ebenfalls mit den Kursgebühren anteilig erwirtschaftet werden müssen.

Diese können nur nach bestimmten Schlüsseln auf die einzelne Unterrichtsstunde oder Kurse verteilt werden. Entscheidend ist hier nicht die verwendete Formel. Sie muss letztlich von der Buchhaltung bzw. Geschäftsführung vorgegeben werden. Sie stellt aber keine objektive Berechnung, sondern eine annahmenbasierte Modellierung dar, deren Zustandekommen und Implikationen es zu verstehen, mit zu gestalten und bei den Entscheidungen als Kursmanager über Einrichtung und Absage von bewährten bzw. neu eingerichteten Kursangeboten zu berücksichtigen gilt. Auch ist es keineswegs so, dass als Resultat einer solchen Berechnung ein Kurs mit mathematischer Präzision abgesagt werden kann: Dies bleibt, vor allem wenn sich Teilnehmer individuell anmelden können, eine unternehmerische, marktbasierte und damit risikobehaftete „Investitionsentscheidung“, was den Zeitpunkt und die langfristige Perspektive angeht.

Nur ein Kursmanager, der das Wissen über derartige Zusammenhänge hat, sie in der Praxis erkennt und als Steuerungsgrößen begreift, kann mehr als ein fremdbestimmter pädagogischer „Erfüllungsgehilfe“ des Managements sein. Er wird gegenüber dem didaktisch und wissenschaftlich bestens ausgebildeten DaF-/DaZ-Lehrer bei der Besetzung einer Leitungsstelle immer vorgezogen, vorausgesetzt, er verfügt auch über die notwendigen persönlichen Führungsfertigkeiten, die den zweiten großen Defizitbereich existierender DaF-/DaZ-Studiengänge als Ausbildung für das Profil „Kursmanager“ darstellen, was ich aber hier nicht weiter ausführen möchte, da mir dieser Aspekt leicht vorstellbar erscheint.

Ein weiteres Beispiel sei hier aus dem m.W. der ganz aus dem Fokus der DaF-/ DaZ-Studiengänge geratene Bereich der Firmenkurse genannt. Für Firmenkurse, die typischerweise „,inhouse“ im Unternehmen als Element der „Personalenwicklung“, von der Abteilung „Human Ressources“ beauftragt, durchgeführt werden, hat das Konzept 
des „Return on Investment“ - mittlerweile auch auf den Weiterbildungssektor adaptiert als „Return on Education (RoE)“ - größte Bedeutung. Gemeint ist damit die Frage, inwiefern ein in die „Personalentwicklung“ investierter Euro den Firmengewinn um mehr als einen Euro verbessert und damit als Weiterbildungsrendite materialisiert. Sicherlich wird ein derartiger Effekt gerade bei Softskills weniger plausibel nachzuweisen sein als etwa bei Investitionen in neue Maschinen. Die Zusammenhänge sind sehr viel komplexer und widersprüchlicher, bedenkt man etwa, dass selbst ein fachlich schlechtes oder irrelevantes Training positive Motivationseffekte haben kann („Ich bin meinem Unternehmen etwas wert"), die dann zu einer Steigerung der Produktivität des betreffenden Mitarbeiters führen.

Heruntergebrochen auf die Ebene von Fremdsprachentrainings geht es dann darum, bedarfsgerechte Schulungsmaßnahmen möglichst ökonomisch zu konzipieren und den jeweiligen Entscheidern in Unternehmen, die meist keine Fremdsprachendidaktiker sind, nicht zuletzt unter dem Aspekt des RoE kommunizieren zu können. Der „Training Manager“ muss plausibel machen können, welche real am Arbeitsplatz vorkommenden Situationen, die „Trainees“ nach dem Training so viel besser bewältigen können, dass dadurch Betriebsabläufe effizienter werden bzw. der Umsatz steigt. Dabei hilft z.B. der bedarfsorientierte Ansatz des Europäischen Referenzrahmens für Sprachen (GER) mit seinen „Kann-Bestimmungen“, die zudem den Vorteil haben, nicht im Didaktikjargon formuliert und damit auch fachlichen Laien gut vermittelbar zu sein (vgl. Jung 2007 und Jung; Eilert-Ebke 2007).

\section{Fazit und Perspektiven}

Dieses letzte Beispiel zeigt aus meiner Sicht sehr schön das Ineinandergreifen von fachdidaktischen und betriebswirtschaftlichen Konzepten. Leider aber werden solche Beispiele aus der Praxis eines im Feld der Firmenkurse arbeitenden Trainingsmanagers $\mathrm{m}$.W. nirgendwo in die $\mathrm{DaF}$-/DaZ-Ausbildung einbezogen. Das ist umso bedauerlicher, als auch die vielen freiberuflichen Fremdsprachentrainer, sofern sie für die Wirtschaft arbeiten, wo die höheren Honorare gezahlt werden, derartige Kompetenzen gut gebrauchen können, selbst wenn sie Einzelkämpfer sind. Das dürfte u.a. daran liegen, dass das konkret ,,bedarfsgerechte“ Vermitteln von Fremdsprachen gegenüber der Zielvorstellung des „allgemeinbildenden“ Fremdsprachenunterrichts in Hochschulstudiengängen naturgemäß zurücktritt. Denn selbst der Fachfremdsprachenunterricht bleibt in seiner Hauptstoßrichtung allgemeinbildend, wenn er primär einen situationsübergreifenden Fremdspracherwerb fördert, auch wenn die exemplarischen Inhalte (z.B. Texte, Vokabular, Grammatik), mit denen dies geschieht, typisch für ein bestimmtes kommunikatives Feld sind. Insofern lassen sich sehr wohl ,,allgemeinbildende“ und ,bedarfsgesteuerte" Berufsfeldtrainings unterscheiden (vgl. Jung 2007).

An diesem letzten Beispiel wird hoffentlich auch deutlich, dass mit „Praxisbezug“ gerade nicht das „Einknicken“ vor dem ökonomischen Druck der Praxis und der individuellen Lebensumstände im Sinne des Herunterschraubens von Qualitätsansprüchen gemeint ist. Im Gegenteil, der Fokus auf bisher vernachlässigte, aber sehr relevante 
berufliche Gegebenheiten von angestellten und freiberuflichen DaF-Kräften und das Entwickeln und Kommunizieren adäquater Konzepte bei gleichzeitiger Aufrechterhaltung hoher fachlicher Ansprüche stellen eine besondere Herausforderung dar und heben in der Praxis die Standards der Vermittlung fremdsprachlicher Kompetenzen. So wie der Unterrichtsentwurf einer Lehrprobe niemals „realistisch“ in dem Sinne ist, dass ein Lehrer später im Beruf jede Stunde genau so detailliert vorbereiten kann, gilt dies auch für entsprechend sorgfältig konzipierte Trainings. Mit der idealisierten Konzeption perfekt bedarfsgerechter und ökonomisch geplanter Trainings würden aber doch Fertigkeiten vermittelt, die in der Praxis der Auftragskursplanung (als Gegensatz zur „offenen Kursplanung“ für Teilnehmer, die einen ganz unterschiedlichen institutionellen Hintergrund haben und individuell Gebühren zahlen) dringend benötigt werden, gerade dann wenn man an einer Qualitätsverbesserung interessiert ist, zumal nicht nur Firmen, sondern auch verschiedene öffentliche Institutionen derartige Trainings regelmäßig „einkaufen“.

Um nicht falsch verstanden zu werden: Ich wende mich keineswegs gegen die Relevanz von DaF-/DaZ-Inhalten. Gut ausgebildete und erfolgreiche Fremdsprachendidaktiker bzw. -lehrer sind in der Regel wunderbare Kommunikatoren, besitzen viel interkulturelle Offenheit, Sensibilität und Erfahrung, was unabdingbare Voraussetzungen für qualitativ hochwertige Kursangebote sind, und ihnen nicht zuletzt die notwendige Autorität und fachliche Anerkennung bei den Kursleitern sichert. Es gibt allerdings auch eine typische Lehrertendenz zum inneren Rückzug auf eine Welt, die durch die vier Wände des Klassenraums begrenzt wird und in der man in seiner Stellung und Selbstwertgefühl unangefochten ist. Gerade dadurch, dass man sich nicht mit den ökonomischen Rahmenbedingungen des Lehrerberufs auseinandersetzt, hier nicht schon in der Ausbildung sensibilisiert wurde bzw. über nachweisbare Kompetenzen verfügt, überlässt man fachfremden Managern das Feld, wo doch eigentlich die Kombination von Expertise in Fremdsprachenfragen und im betriebswirtschaftlichen Management gefragt sind. Solche Bedarfe an fachlicher Doppelqualifizierung von Managern gibt es natürlich in fast allen Wirtschaftsbereichen, am deutlichsten vielleicht in den stark technisch definierten Branchen, wodurch beispielsweise hybride Studiengänge wie „Wirtschaftsingenieur" entstanden sind. Die Äquivalente im Bildungsbereich sind berufsbegleitende oder unmittelbar auf einen BA aufbauende Studiengänge „Bildungsmanagement" o.ä.

Wie ist nun das Berufsbild „Sprachkursmanager“ oder „Bildungsmanager Fremdsprachen und Kommunikation" in die Curricula entsprechender DaF-/DaZ-Studiengänge integrierbar, akzeptiert man einmal die These, dass das bisher nicht der Fall ist, es aber erwünscht wird? Zunächst stellt sich die Frage, ob nicht die vorhandenen Angebote, seien es „Zusatzqualifikationen“ oder die genannten Master „Bildungsmanagement", diesen Bedarf abdecken können. Natürlich wäre so eine Kombination ideal, allerdings wäre es für das Bild von DaF-/DaZ-Studiengängen fatal zu sagen: „,Ja wir bilden für ein Berufsbild DaF-/DaZ-Lehrer aus, wenn Ihr aber nicht, wie ein Großteil dieser Lehrer ins freiberufliche Prekariat abrutschen wollt, müsst Ihr Euch selber fort- 
bilden bzw. neben dem DaF-Master einen Zusatzmaster machen“, zumal dann, wenn man in eine solche wirtschaftliche schwierige und persönlich unbefriedigende Situation geraten ist, Geld und Zeit für eine entsprechende Ausbildung - gerade Weiterbildungsmaster sind oft kostenpflichtig - fehlen.

Auch einmalige oder fakultative Veranstaltungen in Richtung „Berufsfelderkundung“ sind zu wenig. Benötigt wird, um das notwendige Bewusstsein und praxisrelevante Managementkompetenzen vermitteln zu können, ein fester Anteil „DaF-Kursmanager/ -Firmentrainer" in den Curricula entsprechender Studiengängen, sei es wahlweise als Schwerpunktbildung oder obligatorisch für alle. Denkbar sind auch fächerübergreifende Veranstaltungen mit allen Philologien, da sich, wie gesagt, bei einer Erweiterung des Berufsbildes auf „Kursmanager Fremdsprachen“ die meisten Optionen für die späteren Absolventen ergeben. Die ausbildenden DaF-/DaZ-Institutionen müssen ein ureigenes Interesse daran haben, ihren Studierenden möglichst viele, ihrer Qualifikation angemessene berufliche Möglichkeiten zu eröffnen.

\section{Literatur}

BAMF (2009): Ramboll-Kurzgutachten zum Finanzierungssystem der Integrationskurse. http:/ / www.integration-in-deutschland.de/SharedDocs/Anlagen/DE/Integration/ Downloads/Integrationskurse/Kurstraeger/Sonstiges/ramboll-finanzierungsgutachten-2009.html (30.01.2010).

Bernecker, Michael; Gierke, Christiane; Hahn, Thorsten (2010): Akquise für Trainer, Berater, Coachs: Verkaufstechniken, Marketing und PR für mehr Geschäftserfolg in der Weiterbildung. 5. Auflage. Offenbach: Gabal.

Casper-Hehne, Hiltraud; Koreik, Uwe; Middeke, Annegret (Hrsg.) (2006): Die Neustrukturierung von Studiengängen „Deutsch als Fremdsprache“. Probleme und Perspektiven. Göttingen: Universitätsverlag.

DaF-Wiki (2007ff.). Topographie der DaF- und Germanistikstudiengänge im europäischen Hochschulraum. http:/ / www.fadaf.de/wiki (01.08.2010).

Große, Annika; Middeke, Annegret (2009): Die DaF-Wikis als Informations- und Verbreitungsmedium. In: Casper-Hehne, Hiltraud; Middeke, Annegret (Hrsg.): Sprachpraxis der DaF- und Germanistikstudiengänge im europäischen Hochschulraum. Göttingen: Universitätsverlag, 229-234.

Jung, Matthias; Wicke, Rainer; Krumm, Hans-Jürgen (2010): Institutionen und Verbände für Deutsch als Fremd- und Zweitsprache in Deutschland. In: Krumm, Hans Jürgen et al. (Hrsg.): Deutsch als Fremdsprache. Ein internationales Handbuch. Berlin: de Gruyter, 144-153.

Krumm, Hans Jürgen et al. (Hrsg.) (2010): Deutsch als Fremdsprache. Ein internationales Handbuch. Berlin: de Gruyter.

Häuser, Jutta (2003): Marketing für Trainer. Kein Profi(t) ohne Profil. Bonn: Managerseminare.

Jung, Matthias (2006): Vom Wissenschaftler zum Bildungsmanager oder: Die allmähliche und notwendige Veränderung des Bewusstseins beim Wirtschaften. In: Bar- 
kowski, Hans; Wolff, Armin (Hrsg.): Umbrüche. Vorträge der Jahrestagung Deutsch als Fremdsprache 2005. Regensburg: Fachverband Deutsch als Fremdsprache, 445-453.

Jung, Matthias; Schwarzer, Christine (2006): Universitätsnah wirtschaften - Das Institut für Internationale Kommunikation in Zusammenarbeit mit der Heinrich-HeineUniversität Düsseldorf e.V. In: Jahrbuch der Heinrich-Heine-Universität 2005/2006. Düsseldorf, 573-588.

Jung, Matthias (2007): Firmentraining: Trends, Erfahrungen, Tipps aus der Wirtschaft. In: Kiefer, Karl-Hubert et al. (Hrsg.): Wirtschaftsdeutsch vernetzt. München: Iudicium, 37-50.

Jung, Matthias; Eilert-Ebke, Gabriele (2007): Vom Sprachlehrer zum Firmentrainer ein Weiterbildungskonzept. In: Kiefer, Karl-Hubert et al. (Hrsg.): Wirtschaftsdeutsch vernetzt. München: Iudicium, 51-66.

Kiefer, Karl-Hubert et al. (Hrsg.) (2007): Wirtschaftsdeutsch vernetzt. München: Iudicium.

Lutzer, Birgit (2005): Marketing-Instrumente für Trainer: Die Klaviatur richtig beherrschen. Bonn: Managerseminare. 
Früher deckte „Deutsch als Fremdsprache (DaF)“ Forschung und Lehre des Faches überwiegend ab, durch die neu entstandene öffentliche Aufmerksamkeit für die sprachlichen Aspekte der Einwanderung ist mittlerweile Deutsch als Zweitsprache als gleichberechtigte Säule hinzugekommen. "DaF integriert" meint aber nicht nur das Zusammenwachsen beider Perspektiven der Deutschvermittlung, sondern auch die enge Verbindung unterschiedlicher Ansätze in Forschung und Lehre innerhalb der vier Themenschwerpunkte und der zwei Foren, die auf der 36. Jahrestagung des Fachverbandes Deutsch als Fremdsprache (FaDaF) vertreten waren. So gehen insgesamt knapp 40 ausgewählte Tagungsbeiträge unter den Blickwinkeln der Forschung, des Unterrichts oder der institutionellen Rahmenbedingungen auf die Themen - Literatur, Film, Theater • mediengestütztes Lernen - Lehreraus- und -fortbildung • Integrationskurse ein, während das thematisch - offene Unterrichtsforum und das - Forum Beruf DaF-/DaZ-Kräfte unmittelbar für die Berufspraxis besser qualifizieren wollen. Dadurch entsteht ein für die aktuelle Diskussion unverzichtbarer Querschnitt des Faches DaF/DaZ in seinen vielfältigen Konturen und neuen Entwịcklungen.

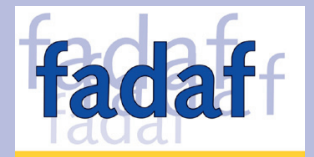

fadaf.de

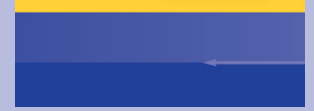

